\title{
Organic Marine Geochemistry
}

In Organic Marine Geochemistry; Sohn, M.;

ACS Symposium Series; American Chemical Society: Washington, DC, 1986. 
In Organic Marine Geochemistry; Sohn, M.;

ACS Symposium Series; American Chemical Society: Washington, DC, 1986. 

ACS SYMPOSIUM SERIES $\mathbf{3 0 5}$

\title{
Organic Marine Geochemistry
}

\author{
Mary L. Sohn, EDITOR
}

Florida Institute of Technology

Developed from a symposium sponsored by the Division of Geochemistry

at the 189th Meeting

of the American Chemical Society,

Miami Beach, Florida,

April 28-May 3, 1985

American Chemical Society, Washington, DC 1986 


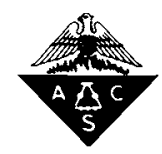

\section{Library of Congress Cataloging-in-Publication Data}

Organic marine geochemistry.

(ACS symposium series; 305 )

"Developed from a symposium sponsored by the Division of Geochemistry at the 189th Meeting of the American Chemical Society, Miami Beach, Florida, April 28-May 3, 1985."

Includes bibliographies and index.

1. Organic geochemistry-Congresses. 2. Marine sediments-Congresses. 3. Estuarine sedimentsCongresses.

I. Sohn, Mary L., $1952-$ il. American Chemical Society. Division of Geochemistry. III. American Chemical Society. Meeting (189th: 1985: Miami Beach, Fla.) IV. Series.

$\begin{array}{llll}\text { QA516.5.07235 } & 1986 & 551.46^{\prime} 083 & 86-3429\end{array}$

ISBN 0-8412-0965-0

\section{Copyright $\odot 1986$}

American Chemical Society

All Rights Reserved. The appearance of the code at the bottom of the first page of each chapter in this volume indicates the copyright owner's consent that reprographic copies of the chapter may be made for personal or internal use or for the personal or internal use of specific clients. This consent is given on the condition, however, that the copier pay the stated per copy fee through the Copyright Clearance Center, Inc., 27 Congress Street, Salem, MA 01970, for copying beyond that permitted by Sections 107 or 108 of the U.S. Copyright Law. This consent does not extend to copying or transmission by any means-graphic or electronic - for any other purpose, such as for general distribution, for advertising or promotional purposes, for creating a new collective work, for resale, or for information storage and retrieval systems. The copying fee for each chapter is indicated in the code at the bottom of the first page of the chapter.

The citation of trade names and/or names of manufacturers in this publication is not to be construed as an endorsement or as approval by ACS of the commercial products or services referenced herein; nor should the mere reference herein to any drawing, specification, chemical process, or other data be regarded as a license or as a conveyance of any right or permission, to the holder, reader, or any other person or corporation, to manufacture, reproduce, use, or sell any patented invention or copyrighted work that may in any way be related thereto. Registered names, trademarks, etc., used in this publication, even without specific indication thereof, are not to be considered unprotected by law.

PRINTED IN THE UNITED STATES OF AMERICA

\section{American Chemical Society. Library 115516 th St., N.W. Washington, D.C. 20036}




\title{
ACS Symposium Series \\ M. Joan Comstock, Series Editor
}

\author{
Advisory Board
}

Harvey W. Blanch

University of California-Berkeley

Alan Elzerman

Clemson University

John W. Finley

Nabisco Brands, Inc.

Marye Anne Fox

The University of Texas-Austin

Martin L. Gorbaty

Exxon Research and Engineering Co.

Roland F. Hirsch

U.S. Department of Energy

Rudolph J. Marcus

Consultant. Computers \&

Chemistry Research

Vincent D. McGinniss

Battelle Columbus Laboratories
Donald E. Moreland

USDA, Agricultural Research Service

W. H. Norton

J. T. Baker Chemical Company

James C. Randall

Exxon Chemical Company

W. D. Shults

Oak Ridge National Laboratory

Geoffrey K. Smith

Rohm \& Haas Co.

Charles S.Tuesday

General Motors Research Laboratory

Douglas B. Walters

National Institute of

Environmental Health

C. Grant Willson

IBM Research Department 


\section{FOREWORD}

The ACS Symposium SeRIES was founded in 1974 to provide a medium for publishing symposia quickly in book form. The format of the Series parallels that of the continuing ADVANCES IN CHEMISTRY SERIES except that, in order to save time, the papers are not typeset but are reproduced as they are submitted by the authors in camera-ready form. Papers are reviewed under the supervision of the Editors with the assistance of the Series Advisory Board and are selected to maintain the integrity of the symposia; however, verbatim reproductions of previously published papers are not accepted. Both reviews and reports of research are acceptable, because symposia may embrace both types of presentation. 


\section{PREFACE}

\section{B}

OTH ORGANIC AND INORGANIC AREAS of water-column and sediment geochemistry have recently served as the focus of much research. This book deals with major advances in organic marine and estuarine geochemistry, as well as the effects of organic substances on the speciation and distribution of inorganic and organometallic substances. The organization of this book is such that it should prove useful not only as a collection of related research articles, but also as a reference and a text suitable for graduate and advanced undergraduate courses in organic marine geochemistry.

The authors of the chapters include internationally acclaimed experts in their respective areas of specialization. Basic geochemical topics such as structures are included as well as diagenesis of organic natural products. Also discussed are anthropogenic pollutant substances in the marine environment and the effect of diagenesis and cycling on the distribution and fate of both toxic and nontoxic substances. I hope the combination of review and application chapters has produced a book that will be useful to many people in diverse fields.

Without the enthusiasm and cooperation of the exceptional authors and the encouragement of the former chairmen of the Geochemistry Division (F. Miknis, T. Weismann, and G. Helz), this book never would have materialized. In addition, I would like to thank my husband, Rolf, for assisting in the drafting of tables and figures and for helping with the organization of the book. I am also indebted to the Geochemistry Division for its support in sponsoring the symposium from which this book was developed and to The Petroleum Research Fund, administered by the American Chemical Society, for partial support of the symposium.

\section{MARY L. SOHN}

Florida Institute of Technology

Melbourne, FL 32901

May 14, 1985 


\title{
Organic Marine Geochemistry
}

\section{An Overview}

\author{
Mary L. Sohn
}

Department of Chemistry, Florida Institute of Technology, Melbourne, FL 32901

The use of modern hyphenated methods such as GC-MS have proven invaluable to the task of assigning specific sources to specific organic compounds isolated from marine sediments, suspended particulate matter, interstitial water and seawater. Early chapters of this volume discuss the correlation of various classes of compounds isolated largely from marine and brackish sediments with sources consisting of terrigenous plants, bacteria, phytoplankton, zooplankton and nonbiological components such as anthropogenic input, petroleum seepage, and the weathering of "mineral" deposits.

\section{Biomarkers}

A biological marker (or "biomarker") may be defined as "a compound the structure of which can be interpreted in terms of a previous biological origin." Since the isolation and identification of metalloporphyrins in bitumens by Treibs (2) in the $1930^{\prime}$ 's and their correlation with tetrapyrroles of chlorophylls, implying a biological origin for petroleum, an enormous amount of progress has been accomplished in this area of research.

In order to be a useful biomarker, a compound must retain enough of its original structure to be identified as a modified version of the original biological parent compound. The retention of the carbon backbone of biologically generated alcohols, in alkanes isolated from sediments and petroleum fractions, includes the classic cases of pristane and phytane as diagenetic products of phytol (the alcohol which esterifies the carboylic acid group in chlorophyl1-a) and 5 ,-cholestane from cholesterol. Other examples of the usefulness of alkanes as biomarkers include correlations of various n-alkanes to bacterial populations (3), and the association of $\mathrm{C}_{30}$-steranes with marine versus nonmarine input (originally as $\mathrm{C}_{30}$-sterols) (4).

Another factor commonly used as a source indicator with respect to alkanes is the carbon number distribution.

Briefly, n-alkane distributions with carbon number maxima in the 17-21 range $\left(\mathrm{C}_{17}-\mathrm{C}_{21}\right.$ ) originate largely from aquatic algal

sources, while maxima characterized by higher carbon numbers are

0097-6156/86/0305-0001\$06.00/0

() 1986 American Chemical Society 
indicative of higher plant input (leaf waxes of terrestrial plants ) $(1, \underline{5})$. In addition, $C_{23}-C_{33}$ n-alkanes with a predominance of an odd number of carbons to an even number of carbons (OEP) is also indicative of terrestrial higher plant input $(1,6-9)$ although loss of odd numbered carbon predominance can occur with maturity $(5)$. Thus, although petroleum is believed to be of biological origin, petroleum input is characterized by a lack of odd to even predominance (O.E.P. = 1.0). The isotopic composition of alkanes and of other classes of compounds can also be used as a general source input indicator. Isotopic fractionation resulting from the metabolic pathways involved in the synthesis of biologically produced compounds, when preserved in a diagenetic product, is frequently used to differentiate between terrestrial and aquatic sources. Hydrogen and carbon isotopic compositions of biogenic methanes from shallow aquatic environments is discussed in a later chapter of this volume (R. A. Burke and W. M. Sackett). The applicability of carbon isotopic data to tracing the source of deep-sea Mesozoic sediments is discussed by R.M. Joyce and E. S. Van vleet.

Many other classes of lipids besides alkanes have proven to be valuable biomarkers, including fatty acids, sterols, amino acids, polysaccharides, glycerols, wax esters, porphyrins and many isoprenoids. The greater the extent of alteration of a compound by diagenetic processes, the harder it is to correlate the product to the biological precursor. However, the successive changes undergone by the precursor molecule can sometimes be deduced from the structure of the product. In these cases the "biomarker" is also a geochemical marker and may be referred to as a biogeochemical indicator. For example, stenol to stanol ratios can be used as an indicator of sediment oxicity. High stenol/stanol ratios are indicative of oxidizing rather than reducing environments $(1,20)$. Perylene provides an interesting example of a PAH of disputed origin, which may prove to be a reliable indicator of syn-and post-depositional anoxia when present in greater than trace amounts (11). Indicators of the biogeochemistry of chlorophyll and the temperature dependence of chlorophyll diagenes is is reviewed in the chapter by J.W. Louda and E. W. Baker. Other chapters in this volume concerned with source input markers and geochemical indicators include those by S.C. Brassell and G. Eglinton, J.W. de Leeuw, J. Whelan et al., J.J. Boon et al., R.M. Joyce and E. S. Van Vleet.

\section{Humic Substances}

Compared to the well defined structures and interrelationships of the discrete molecular biomarkers and geochemical indicators discussed above, relatively little is known about marine humic substances. Whether the major source of input to dissolved and sedimentary marine humic substances is of terrigenous or marine origin is still occasionally debated in the literature, although most interpretations point towards marine planktonic sources (12-14), based most convincingly on isotopic ratios, GC-MS, ${ }_{H}$ and ${ }_{C}$ NMR and infrared spectra (15-17). Stuermer et al (12) propose a combination of ${ }^{13} \mathrm{C}$ and $\mathrm{H} / \mathrm{C}$ ratios as a 
source input indicator of terrestrial versus marine derived humic substances.

One of the most useful tools for determining input sources, functional group content and diagenetic relationships between humif fractions has proven to be ${ }^{13} \mathrm{C}$ NMR. The early applications of ${ }^{13} \mathrm{C}$ MMR to humic substances were done by solution NMR and were thus limited to base soluble humic and fulyic acids $(16,18,19)$. The subsequent application of solid-state ${ }^{13}$ C NMR to humic samples has allowed for direct comparisons between soluble and insoluble fractions as well as between humic substances from diverse environments. ${ }^{2} \mathrm{C}$ NMR analysis of solid samples is made possible by the use of cross polarization and magic angle spinning (CP/MAS). Cross polarization is a sensitivity enhancing technique in which the application of radio frequency pulses at the resonance frequencies of $\mathrm{H}$ and ${ }^{1} \mathrm{C}$ establishes contact between the two populations allowing for cross polanization (i.e. transfer of magnetization) from a large ${ }_{H}$ population to a minute ${ }^{3} \mathrm{C}$ population. Magic angle spinning (spinning the sample at several $\mathrm{kHz}$ at an angle of $54.7^{\circ}$ relative to the externally applied magnetic field) minimizes line broadening due to chemical shift anisotropy $(20-21)$ The combination of these techniques with high power decoupling and fourier transform analysis has yielded high resolution spectra which can provide reliable estimates of various carbon types, $(21-24)$.

The important question of the reliability of quantification of solid state ${ }^{13} \mathrm{C}$ NMR results can be answered in part by relaxation studies and the measurement of relaxation constants $(25-27)$ and is discussed in greater detail by M.A. Wilson and A.H. Gillam in a later chapter of this volume. Quantification of the aromatic content ( $f_{a}$ ) of marine humic and fulvic acids by CP/MAS ${ }^{13} \mathrm{C}$ NMR has demonstrated that these substances have low aromaticities relative to terrestrial counterparts $(16,28)$. The low aromatic (high aliphatic) content of marine humic substances is a result of their in situ production. Higher plants associated with terrestrial environments contribute lignin to soil humic substances. The lack of lignin in marine plants results in a low aromaticity of marine humic substances although coastal sediments may contain high levels of vascular plant residues (29). Lignin is an aromatic based natural polymer characterized by methoxyl group substitutions on the benezene ring structure. These lignin-aspociated methoxyl groups typically produce a distinctive ${ }^{13} \mathrm{C}$ MMR peak which is normally interpreted as a source marker for terrestrial input. However, as discussed in the chapter by M.A. Wilson and A.H. Gillam, contributions from other carbon types (possibly amino acid carbon) may contribute to this signal. The relatively new technique of dipolar dephasing is capable of distinguishing between terrestrial lignin methoxyl signals and other protonated carbons which may resonate in the methoxyl region of the spectrum. Dipolar dephasing takes advantage of different relaxation rates of various types of carbon and utilizes this phenomenon to distinquish between protonated and nonprotonated carbon (26). The utilization of dipolar dephasing in studying the diagenetic changes undergone by organic matter in marine sediments is discussed in a chapter by W.T. Cooper et al.. 
Recent advances in the structural interrelationships among humic substances of marine and estuarine sedimentary origin is discussed in the chapter by P.G. Hatcher and W.H. Orem.

\section{Organic Pollutants in the Marine Environment}

The biogeochemistry of organic pollutants in marine systems is of enormous economic and environmental impact. The environmental behavior of polychlorinated biphenyls ( $P C C^{\prime} s$ ) has been studied rather extensively because of their detrimental effects on human health and on living marine resources (30-32). As discussed in the chapters by J.W. Farrington et al., due to recent advances in gas capillary chromotographic methods, it is now possible to study the biogeochemistry of individual PCB's rather than that of combined industrial mixtures of $\mathrm{PCB}^{\prime} \mathrm{s}(33-36)$. In order to realistically assess the risks to animal health, it is important to be able to work with individual PCB levels rather than with unresolved mixtures because individual PCB's can vary greatly in terms of toxicity (37).

The contamination of coastal marine environments by anthropogenic hydrocarbon input is also a matter of urgent concern with respect to human health and preservation of natural resources. Hydrocarbon contamination by oil spills can often be traced to sources by fingerprinting techniques. An excellent review of current developments in this field is presented by E.S. Van Vleet (38) including discussions on computer interfaced total fluorescence, transmission infrared spectroscopy, GC and GC-MS, trace metal analysis etc.. The correlation of hydrocarbons with petroleum sources is frequently hindered by differential weathering. For a detailed discussion on the weathering of petroleum in the marine environment, the reader is referred to a current literature review (39). In this volume, the fingerprinting of hydrocarbon contamination from specific land use activities, supported by GC-MS analysis of polynuclear aromatic compounds (PNA) are discussed by R.H. Pierce et al, and by E.B. Overton et al., while fingerprinting of hydrocarbon contamination from carbonied coal products (creosote and coal tar) is described by T.L. Wade et al..

\section{Volatile Organic Substances}

The decomposition of complex organic substances by microbial marine populations results in the in situ production of biogenic methane, which is found in trace amounts in all fresh and salt waters. The relative importance of acetate assimilation and $\mathrm{CO}_{2}$ reduction as primary methanogenic pathways is discussed in the chapter by R.A. Burke and W.M. Sackett. In the past, these pathways were studied by the use of ${ }^{14} \mathrm{C}$ labelled substrates. However, the authors demonstrate the advantages of using stable hydrogen and carbon isotopic compositions of biogenic methanes to evaluate the relative contributions from these two pathways. Seasonal distributions of methane are discussed in the chapter by J.D. Cline et al...

Volatile halogenated methanes are also produced in situ in the marine environment and have been found to be associated with marine macroalge $(40)$. The release of these halogenated methanes 
into coastal seawater has also been demonstrated $(41-43)$ and is of environmental concern. A seasonal study of the release of polybromomethanes is described in the chapter by P.M. Gschwend and J.K. MacFarlane.

\section{Organic - Inorganic Interactions}

The major influence of organic marine substances on the partitioning and speciation of inorganic and organometallic substances is discussed in the closing chapters of this volume. Complexation, adsorption and/or reduction of ions and compounds by organic matter in marine and brackish systems greatly affect the cycling and bioavailability of many potential nutrients and toxic substances.

The complexation of metal ions by humic substances is a well documented phenomenon $(44-51)$. Due to the ubiquitous nature of these naturally occurring ligands, humic substances play an important role in determining the partitioning of metal ions and other substances in both terrestrial and aquatic environments $(52-56)$. In order to predict or model the partitioning of a particular metal ion in a given environment, it is essential to be able to evaluate the magnitude of the interaction between the pertinent components of the environment (the substrates) and the metal ion. When dealing with the various solid phases which may be present, adsorption of the ion onto each phase (clay, sand, silt, hydrous metal oxides, humus) can be studied via the evaluation of adsorption isotherms (56). In the solution phase, complexation is an important process which competes with ion-pair formation and subsequent precipitation. The strength of the complexation reaction can be measured by evaluation of a conditional formation constant. (57-59, 46).

Adsorption of dissolved substances onto suspended matter is a primary process in the removal of dissolved substance from the water column and subsequent concentration in sediments. The major role played by adsorbed organic coatings on particulate matter is well known $(60,61)$. The processes of complexation and adsorption in marine systems and their effects on the speciation of various ions and compounds are discussed in the closing chapters.

\section{Literature Cited}

1. Eglinton, G. In "Advances in Organic Geochemistry 1968"; Schenck, P.A.; Havenaar, I., Eds.; Pergamon Press: Oxford, 1968 pp. 1-24.

2. Treibs, A. Angew. Chimie 1936, 49, 682-686.

3. Volkman, J.K.; Farrington, J.W.; Gagosian, R.B.; Wakeham, S.G. In "Advances in Organic Geochemistry 1981"; Bjoroy, M., Ed.; John Wiley \& Sons Limited: 1982, pp. 228-240.

4. Moldowan, J.M. Geochim. Cosmochim. Acta 1984, 48, 2767-2768.

5. Baker, E.W.; Louda, J.W. In "Advances in Organic Geochemistry 1981; Bjoroy, M., Ed.; John Wiley \& Sons Limited: 1982 pp 295-319. 
6. Eglinton, G.; Hamilton, R.J. Science 1967, 156, 1322-1335.

7. Leenheer, M.J.; Flessland, K.D.; Meyers, P.A. Org. Geochem. 1984, 7, 141-150.

8. Brasse11, S.C.; Comet, P.A.; Eglinton, G.; Isaacson, P.J.; McEvoy, J.; Maxwe11, J.R.; Thomson, I.D.;

Tibbetts, P.J.C.; Volkman, J.K. In "Advances in Organic Geochemistry 1981; Bjoroy, M., Ed.; John Wiley \& Sons Limited: pp. 375-391.

9. Simoneit, B.R.T. In "Chemical Oceanography" Riley, J.P.; Chester, P., Eds.; Academic Press: New York, 1978; Vol. 7, pp. 233-311.

10. Gagosian, R. B.; Smith, S.0.; Lee, C.; Farrington, J.W.; Frew, N.M. In "Advances in Organic Geochemistry 1979" Douglas, A.G.; Maxwe11, J.R., Eds.; Pergamon Press:, 1980 ; pp.407-419.

11. Louda, J.W.; Baker, E.W. Geochim. Cosmochim Acta 1984, 48, 1043-1058.

12. Stuermer, D.H.; Peters, K.E.; Kaplan, I.R. Geochim. Cosmochim. Acta 1978, 42, 989-997.

13. Nissenbaum, A.; Kaplan, I.R. Limol. Oceanogr. 1972, 17, 570-582.

14. Stuermen, D.H.; Harvey, G.R. Nature, 1974, 250, 480-481.

15. Stuermer, D.H.; Payne, J.R. Geochim. Cosmochim Acta $1976,40,1109-1114$.

16. Hatcher, P.G.; Rowan, R.; Mattingly, M.A. Org. Geochem $1980,2,77-85$.

17. Gillam, A.H.; Wilson, M.A. Org. Geochem. 1985, 8, 15-25.

18. Vila, F.J.G.; Lentz, H.; Ludemann, H.D. Biochem. Biophys. Res. Commun. 1976, 672, 1063-1069.

19. Wilson, M.A.; Goh, K.M., J. Soil Sci 1977, 28, 645-652.

20. Andrew, E.R. In "Progress in NMR Spectroscopy", Emsley, J.W.; Feeney, J.; Sutcliffe, L.H., Eds.; Pergamon, 1972; Vol. 8, pp. 1-39.

21. Bartuska, V.J.; Maciel, G.E.; Schaefer, J.; Stejskal, E.0. Fue1 1977, 56, 354-358.

22. Hatcher, P.G.; VanderHart, D.L.; Ear1, W.L. Org. Geochem $1980,2,87-92$.

23. Miknis, F.P.; Netze1, D.A.; Smith, J.W.; Mast, M.A.; Maciel, G.E. Geochim. Cosmochim. Acta 1982, 46, 977-984.

24. Resing, H.A.; Garroway, A.N.; Hazlett, R.N. Fuel, 1978, $57,450-454$.

25. Yoshida, T.; Maekawa, Y.; Fujito, T. Anal. Chem. 1983, $55,388-390$.

26. Wilson, M.A.; Pugmire, R.J.; Grant, D.M. Org. Geochem. $1983,5,121-129$.

27. Wilson, M.A.; Vassallo, A.M. Org. Geochem. 1985, 8, 299-312.

28. Hatcher, P.G.; Breger, I.A.; Mattingly, M.A. Nature $1980,285,560562$.

29. Erte1, J.R.; Hedges, J.I. Geochim. Cosmochim. Acta 1984, 48, 2065-2074.

30. Miller, S. Environ. Sci. Technol 1982, 16, 98A-99A.

31. Bopp, R.F.; Simpson, H.J.; Olsen, C.R.; Kostyk, N. Environ. Sci. Techno1. 1981, 15, 210-216. 
32. Pierce, R.H.; Olney, C.E.; Felbeck, G.T. Geochim. Cosmochim. Acta 1974, 38, 1061-1073.

33. Ballschmiter, K.; Zell, M. Frezenius Z. Anal. Chem. $1980,302,20-31$.

34. Duinker, J.C.; Hillebrand, M.T.J. Environ. Sci. Technol. $1983,17,449-456$

35. Mullin, M.D.; Pochini, C.M.; McCrindle, S.; Romkes, M.; Safe, S.H.; Safe, L.M. Environ. Sci. Technol. 1984, 18, 468-476.

36. Duinker, J.C.; Hillebrand, M.T.J.; Boon, J.P. Netherlands J. Sea. Res. 1983, 17, 19-38.

37. Kimbrough, R.D. "Halogenated Biphenyls, Terphenyls, Naphthalenes, Dibenzodixins and Related Products.

Elsevier/North Holland Biomedical Press: New York, 1980, $406 \mathrm{pp}$.

38. Van Vleet, E.S. Mar. Techn. Soc. J. 1984, 18, 11-23.

39. Payne, J.R.; McNabb, G.D., Jr. Mar. Techn. Soc. J. 1984, $18,11-23$.

40. Hewson, W.D.; Hager, L.P. J. Phycol 1980, 16, 340.

41. Gschwend, P.M.; MacFarlane, J.K.; Newman, K.A. Science $1985,227,1033$.

42. Dryssen, D.; Fogelquist, E. Oceanol. Acta 1981, 4, 313.

43. Lovelock, J.E.; Maggs, R.J.; Wade, R.J. Nature 1973, $256,193$.

44. Adhikari, M.; Hazra, G.C. J. Indian Chem. Soc. 1972, 49, 947-951.

45. Ardakani, M.; Stevenson, F.J. Soil Sci. Soc. Am. Proc. $1972,36,884-890$.

46. Gamble, D.S.; Schnitzer, M.; Hoffman, I. Can. Journ. Chem. 1970, 48, 3197-3204.

47. Gamble, D.S. Anal. Chem. 1980, 52, 1901-1908.

48. Mantoura, R.F.C.; Riley, J.P. Analyt. Chim. Acta 1975, 78, 193-200.

49. Mantoura, R.F.C.; Dickson, A.; Riley, J.P. Est. Coast. Mar. Sci. 1978, 6, 387-408.

50. Mills, G.L.; Hanosn, A.K. Jr.; Quinn, J.G.; Lammela, W.R.; Chasteen, N.D. Mar. Chem. 1982, 11, 355-377.

51. Piotrowicz, S.R.; Harvey, G.R.; Boran, D.A.; Weisel, C.P.; Springer-Young, M. Mar. Chem. 1984, 14, 333-346.

52. Nissenbaum, A.; Swaine, D.J. Geochim.Cosmochim. Acta. $1976,40,809$.

53. Rashid, M.A.; Leonard, J.D. Chem. Geol. 1973, 11, 89-97.

54. Theis, T.L.; Singer, P.C. In "Trace Metals and Metal-Organic Interactions in Natural Waters"; Singer, P.C., Ed.; Ann Arbor Science Publishers, 1973.

55. Wallace, G.T. Mar. Chem. 1982, 11, 379-394.

56. Davies-Colley, R.J.; Nelson, P.O.; Williamson, K.J. Environ. Sci. Technol. 1984, 18, 491-499.

57. Gamble, D.S.; Schnitzer, M.; Kerndorff, H. Geochim. Cosmochim. Acta 1983, 47, 1311-1323.

58. Clark, J.S.; Turner, R.C. Soil Sci. 1969, 107, 8-11.

59. Elgala, A., E1-Damaty, A.; Abel-Latif, I. Z. Pflanz.Rodenk. 1976, 3, 293-300. 
60. Davis, J.A.; Leckie, J.0. Environ. Sci. Technol. 1978, $12,1309-1315$.

61. Balistrieri, L.S.; Brewer, P.G.; Murray, J.W. Deep-Sea Res. 1981, 28A, 101-121.

RECEIVED December 10, 1985

In Organic Marine Geochemistry; Sohn, M.; ACS Symposium Series; American Chemical Society: Washington, DC, 1986. 


\title{
Molecular Geochemical Indicators in Sediments
}

\author{
S. C. Brassell and G. Eglinton
}

Organic Geochemistry Unit, School of Chemistry, University of Bristol, Bristol BS8 1TS,
United Kingdom

\begin{abstract}
sediments from contemporary aquatic environments contain a diversity of compounds that provide an assessment of the sources of their organic matter. These components include lipids with structural features that are indicative of their biological origins. Thus, specific diterpenoids and triterpenoids are markers for sediment contributions from terrigenous vegetation. similarly, among the numerous sterols recognised in sediments many are diagnostic of their algal origins, notably $4 \alpha$-methylsterols derived from dinoflagellates. Several lipid types characterise contributions from bacteria; for example, acyclic isoprenoid alkanes arising from methanogens. Illustrative examples of such diagnostic lipid distributions show the possibilities for differentiating between sediments receiving allochthonous terrigenous organic matter and those dominated by autochthonous algal and bacterial contributions. Within the hydrocarbon distributions, by contrast, several features can denote non-biological sources of organic components, such as the weathering of ancient sediments, oil seepage and oil spillage. A further development in environmental assessment using molecular indicators stems from the recent recognition that the unsaturation of specific lipids contributed to sediments by coccolithophorid algae provide a measure of water temperatures.
\end{abstract}

This paper concentrates on three aspects of the application of molecular organic geochemistry to the interpretation of the biological origins of sedimentary organic matter and the use of such information in the evaluation of depositional environments. First, the basis

0097-6156/86/0305-0010\$06.75/0

(c) 1986 American Chemical Society

In Organic Marine Geochemistry; Sohn, M.;

ACS Symposium Series; American Chemical Society: Washington, DC, 1986. 
for the assignment of specific compounds as diagnostic markers for the contributions of particular biota to sediments is considered and illustrative examples of such molecular indicators are given. Second, the sedimentary distributions of such components are discussed and the possibilities for their use in the qualitative assessment of contributions from different biological sources to sediments is addressed. Third, one group of lipids which occur widely in marine sediments, namely long-chain $\left(\mathrm{C}_{37}\right.$ to $C_{39}$ l alkenones, are considered in terms of their potential to provide an assessment of oceanic water temperatures in the shallow subsurface from the sedimentary molecular record.

The standard methodology used in investigations of the organic constituents of sediments typically involves their extraction, then fractionation according to polarity or compound class and finally their evaluation and identification by gas chromatography (gc) and computerised gas chromatography-mass spectrometry (gc-ms). Details of such procedures are not given here, but can be found in the references cited.

\section{Molecular Indicators in Sediments}

The development of molecular markers as indicators of biological contributions to sedimentary organic matter relies on the information from the lipid composition of appropriate organisms. Such information is often scant. Therefore, existing data is used to propose working hypotheses that can be modified or amended when additional information becomes available. The underlying rationale for this approach is the tacit assumption that the biochemical pathways of lipid biosynthesis in different organisms are not necessarily uniform at the present time, nor have they been over geological history. Rather, it seems that the lipid compositions of biota have been tailored throughout evolution to meet their environmental needs. Hence, the discrepancies and similarities between the lipids of different organisms can be used to assess their generic relationships leading to chemotaxonomy. such chemotaxonomic description of organisms using lipid components relies on the information obtained from the analysis of both laboratory cultures and natural populations of individual species. The assignment of a given compound recognised in sediments to a specific biological source is based on such classifications aided by information from environmental analyses, such as the investigation of sediments thought to receive dominant inputs from a particular species or class of organism.

Indeed, the verification of the biological source and significance of individual lipid components of geochemical interest is often best served by studies designed to evaluate their origins in a chosen environment.

In Organic Marine Geochemistry; Sohn, M.;

ACS Symposium Series; American Chemical Society: Washington, DC, 1986. 
For some years it has been held that dinoflagellates are the biological source of the 4 a-methylsterols that occur, frequently as abundant components, in marine sediments $(\underline{1}-3)$. Such assignments were initially based on the widespread literature concerning $4 \boldsymbol{\alpha}$-methylsterols in cultured dinoflagellates (4) and the abundance of these compounds in sediments known to receive major contributions from this class of algae. The distributions of $4 \boldsymbol{\alpha}$-methylsterols, and also $4 \boldsymbol{\alpha}$-methylstanones, observed in the bottom sediments of priest pot, a small lake in the English Lake District, were almost identical to those recognised in a bloom of the dinoflagellate Peridinium lomnicki collected from the overlying waters (5). This study demonstrated that $\underline{\text {. }}$ lomnicki is the source of the 4-methylsteroids in Priest pot sediments and, in more general terms, provided convincing evidence in support of the link between sedimentary $4 \alpha$-methylsteroids and their presumed biological source, dinoflagellate algae.

overall, there are clear indications that particular organic components may be specific to single or multiple biological sources or, alternatively, may be non-diagnostic of their biological origins. In simple terms an individual component, or the distribution of a specific compound class, may be representative of contributions to sedimentary lipids from either algal, terrigenous higher plant or bacterial sources. Not all components, however, can be placed into one of these three classes; for example, some occur in all three, some may only occur in animals, whereas the origins of others are unknown. In addition to considerations of their ultimate biological origins individual compounds in sediments can be either unaltered biosynthetic products or, alternatively, derivatives formed by diagenetic, catagenetic processes, which retain structural elements that attest to their original biological source. Most biological marker compounds occurring in sediments can be considered as markers of one of the following five groups:
(ii) non-diagnostic components
(i i i ) a lgae
(iv)
(v)
terrigenous higher plants
bacteria
'unknown'

Examples of individual components held to be representative of these five categories are shown in Figures 1-5. The majority are known lipid constituents of organisms, whereas others are either diagenetic products or of an as yet undefined origin. The compounds chosen provide an illustrative, rather than a comprehensive, indication of the range of structural types in each category. Most of them have been discussed elsewhere in a fuller review paper (6), together with other structurally similar examples. Also, the individual compounds and compound distributions biosynthesised by, and held to be diagnostic for, algal, terrigenous higher plant and

In Organic Marine Geochemistry; Sohn, M.;

ACS Symposium Series; American Chemical Society: Washington, DC, 1986. 
bacterial inputs to recent sediments are published elsewhere (3). Within categories (ii), (iii) and (iv) individual marker compounds can be uniquely representative of a particular species, genus or class of organism. Alternatively, they can be non-specific components which occur widely in different, but perhaps distantly related, families. Clearly, similarities in the lipid compositions of related species or genera may reflect their ancestral links, whereas differences may stem from the divergence of their biosynthetic pathways.

Non-diagnostic biological markers. The components considered to be non-diagnostic indicators (Figure l) are likely to be those that play a fundamental role in biosynthetic processes. For example, essential constituents of cell structures (e.g. membranes) or similar physiological units might be expected to be common to many different types of organism and therefore occur ubiquitously. Hexadecanoic acid, for example, is a typical constituent of the membranes of numerous land and aquatic plants, animals and bacteria. It may be present in the form of wax esters or triacylglycerols but is generally of little value in differentiating between contributions to sediments from its various sources. similarly squalene is the biosynthetic precursor of many triterpenoids and, thus, occurs widely in organisms. Cholesterol, like hexadecanoic acid, is a constituent of the cell membranes of many different families of organisms, with the notable exception of bacteria. It acts as a 'rigidifier' in cell membranes. It is a prominant sterol of many algae and land plants, and is often the only sterol component of copepods. Tocopherols are held to play an important role in photosynthetic processes. Hence, they are abundant in many photosynthetic organisms, including higher plants, algae and cyanobacteria (7), making them non-diagnostic markers of the sources of sēdimentary organic matter.

Algal indicators. Individual marker compounds indicative of sediment contributions from algae (Figure 2) may occur in both marine and lacustrine environments, although their source species will differ. Indeed, botryococcene is the only component shown which has yet to be recognised in both environmental regimes. Carotenoids are perhaps the most source specific lipid constituents of organisms. For example, diatoxanthin occurs only in diatoms and can therefore be regarded as a highly specific marker for their contributions to sediments. Its absence in a sediment, however, cannot be taken as evidence for the lack of diatom contributions to organic matter, due to its lability. Indeed, this lability makes carotenoids of limited use as markers of the sources of organic matter in most sedimentary environments, with the notably exception of relatively shallow water systems, such as post-glacial

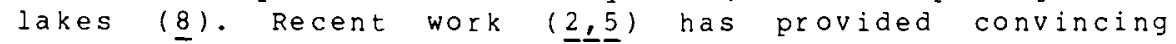

In Organic Marine Geochemistry; Sohn, M.;

ACS Symposium Series; American Chemical Society: Washington, DC, 1986. 

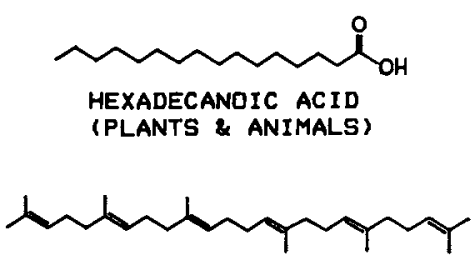

SOUALENE

(ALMOST UBIQUITOUS)
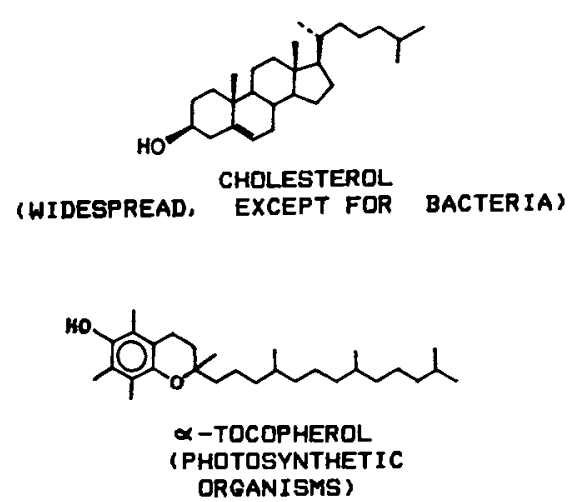

Figure 1. Compound structures, names and biological origins of examples of non-diagnostic indicators of the sources of sedimentary organic matter.

In Organic Marine Geochemistry; Sohn, M.;

ACS Symposium Series; American Chemical Society: Washington, DC, 1986. 

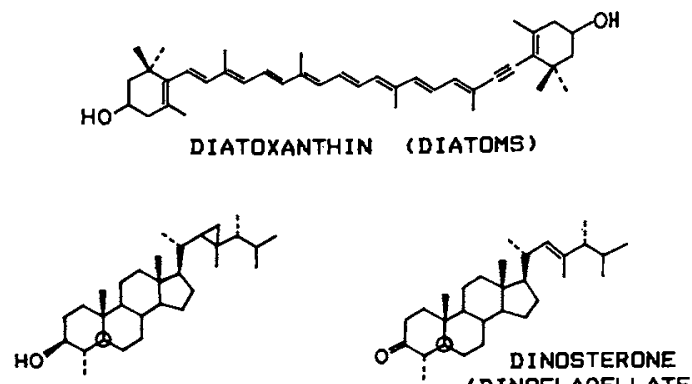

4-METHYLGORGOSTANOL (DINOFLAGELLATES)
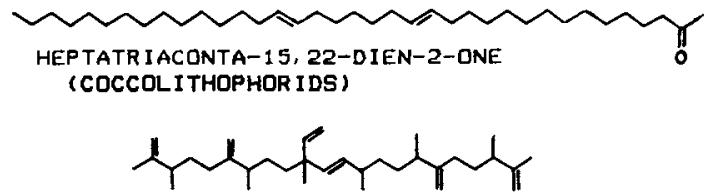

BOTRYOCOCCENE (GREEN ALGA)<smiles>CCC(C)CCC(CCC(C)C)C(C)CCCC(C)C</smiles>

$2,6,10-$ TR IMETHYL-7(3-METHYLBUTYL) DODECANE (GREEN ALGAE ?)

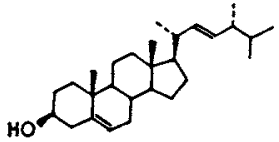

24-METHYLCHOLESTA5, 22-DIENOL (NON-SPECIFIC)

Figure 2. Compound structures, names and biological
origins of examples of indicators of algal contributions to sedimentary organic matter.

In Organic Marine Geochemistry; Sohn, M.; ACS Symposium Series; American Chemical Society: Washington, DC, 1986. 
evidence that the $4 \boldsymbol{\alpha}$-methylsteroids found in both marine and lacustrine sediments are derived from dinoflagellate algae. Hence, both $4 \alpha$-methylgorgostanol

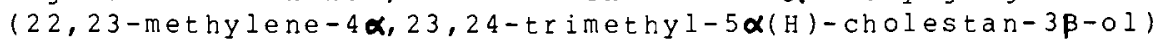
and

dinosterone

$(4 \alpha, 23,24 \mathrm{R}-t$ rimethyl-5 $\alpha(\mathrm{H})-\mathrm{cholest}-22 \mathrm{E}-\mathrm{en}-3-\mathrm{one})$ can be regarded as examples of steroidal compounds that are diagnostic of dinoflagellate contributions to sediments (e.g. 6). In addition, dinoflagellates are the only organisms in which these components have been recognised (4). Long-chain alkenones, such as héptatriaconta-15,22-dien-2-one, occur widely in both recent and ancient oceanic sediments ( 9 ) and are generally regarded as markers of inputs from prymnesiophyte algae, most notably coccolithophorids (9). Their recent recognition in lacustrine sediments (10) is consistent with an origin from such organisms. Botryococcene is the single marker compound included among these examples which has yet to be identified in sedimentary organic matter. However, its saturated analogue, botryococcane, and various homologues, have been identified in various petroleums and oil shales ( $11-1,12)$ where their structural specificity provides an unambiguous indication of

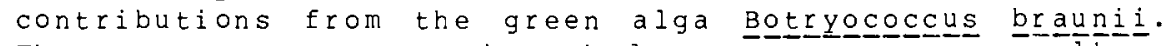
The branched alkane $2,6,10-t r i m e t h y l-7-(3-$ methylbutyl)dodecane has also been

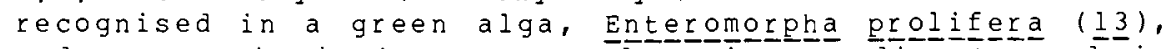
and occurs in both recent and ancient sediments and in petroleums (14). 24-Methylcholesta-5,22-dienol

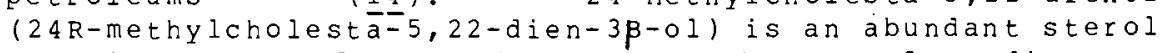
constituent of various species of diatoms, coccolithophorids and other algae (1 15$)$. Although its presence in several different algae precludes its use a specific marker for contributions from a single class of organism, this sterol is a general indicator of inputs from planktonic algae to sediments. The structures of many other 4-desmethylsterol constituents, differing most notably in their side chains, provide similar evidence of their derivation from an algal source.

Terrigenous indicators. Components derived from terrigenous sources (Figure 3 ) tend to be more prominant constituents of lacustrine, coastal or continental shelf sediments. Aeolian transportation of land-derived dusts, however, also results in significant inputs of such material in the open ocean $(16,17)$. Prominant among the components of aeolian dusts are the n-alkanes in the $\mathrm{C}_{25}$ to C 33 range derived from higher plant waxes (1 $\left.\frac{8}{2}\right)$. n-c 31 which it will commonly co-occur. Hence, the distribution pattern of these n-alkanes is more significant than the presence of any iñdividual member. Their persistance in the sediment record and in aeolian materials apparently stems from their resistance to microbial degradation. Many pentacyclic triterpenoids, namely components with

In Organic Marine Geochemistry; Sohn, M.;

ACS Symposium Series; American Chemical Society: Washington, DC, 1986. 


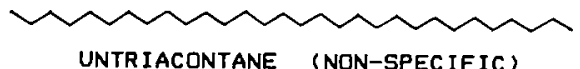

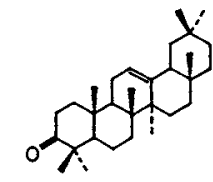

OLEAN-12-EN-3-DNE (NON-SPEC IFIC)

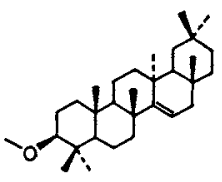

SAWAMI LLETIN (NON-SPEC IF IC)

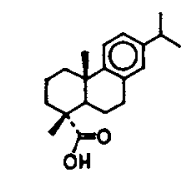

DEHYDROAB IET IC

AC ID

(CONIFERS)

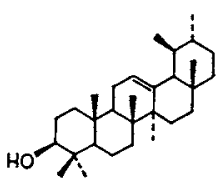

URS-12-EN-3-OL (NON-SPEC IF IC)

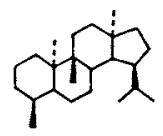

DE-A-LUPANE (NON-SPEC IFIC)<smiles>CC(C)c1cc2c(cc1O)[C@]1(C)CCCC(C)(C)C1CC2</smiles>

FERRUGINDL (CONIFERS)

Figure 3. Compound structures, names and biological origins of examples of indicators of terrigenous higher plant contributions to sedimentary organic matter.

In Organic Marine Geochemistry; Sohn, M.; ACS Symposium Series; American Chemical Society: Washington, DC, 1986. 
oleanane, ursane, taraxerane, lupane and friedelane skeletons, are characteristic of contributions to sediments from terrigenous higher plants. They generally occur as functionalised components in organisms, notably as alcohols, ketones, acids and esters, and are not specific to individual classes of biota. The most frequently encountered members in sediments are those with $\alpha$ - and $\beta$-amyrin skeletons (ursane and oleanane, respectively), notably the $\Delta^{1}$ alcohols and ketones (e.g. olean-12-en-3-one and urs-12-en-3B-ol). Sawamilletin (3B-methoxytaraxer-14-ene) appears to be one of the more refractory terrigenous triterpenoids, since it has been observed in certain sediments devoid of other triterpenoids of similar origins (19). one feature of general significance is that the presence of a functionality at $\mathrm{C}-3$ in such triterpenoids appears to make them succeptible to photochemical or microbial degradation, giving rise to ring-A opened carboxylic acids and, subsequently, to ring-A degraded triterpenoids (e.g. de-A lupane; 20). Both they and their intact precursors, tend to be especially abundant in deltaic sediments from tropical regions $(20,21)$. Diterpenoids, such as dehydroabietic acid and ferruginol (22,23) are marker components present in many species of terrigenous higher plants, but especially prevelant in conifers. Hence, they tend to be most abundant in sediments from temperature climes, especially those receiving inputs from extensively forested areas such as the Astoria Fan ( $2 \underline{2}$ ).

Bacterial indicators. Bacteria influence the composition of sedimentary organic matter in two ways: they degrade components derived from other organisms and they

contribute their own, often characteristic, biosynthetic products (Figure 4). It is the latter effect that is considered here. iso-Branched carboxylic acids have been long regarded as markers for contributions from bacteria to sediments (24), although they are of little use in distinguishing between inputs from different bacterial types. Perhaps the most source specific lipid components found in bacteria are the glycerol ether-linked acyclic isoprenoids that are characteristic of the cell membranes of archaebacteria (e.g. 25). Such components have been recognised among the polar lipids of sediments and petroleums (26). The neutral lipids of archaebacteria also contain a number of unique acyclic isoprenoid structures, such as $2,6,10,15,19$-pentamethyleicosane (27). The occurrence of this component and related isoprenoid alkanes in marine sediments is thought to reflect contributions from methanogens, since inputs from halophiles and thermoacidophiles in such environments is highly unlikely (28) . A number of C 30 pentacyclic triterpenes and triterpanes with 5-membered E-rings, including fern-9(11)-ene, neohop-13(18)-ene and hop-17(21)-ene, have been identified in an anaerobic photosynthetic bacterium (29). Their occurrence together

In Organic Marine Geochemistry; Sohn, M.;

ACS Symposium Series; American Chemical Society: Washington, DC, 1986. 
with other triterpenes in marine sediments has been taken to reflect bacterial contributions, although they are also found in ferns (28). In addition to the c 30 triterpenoids, a whole family $\overline{\mathrm{f}}$ extended $\left(>\mathrm{C}_{31}\right)$ hopanolds exist which are diagnostic bacterial compounds, since they play a role in the membrane structures of these primative organisms (30). Bacterial carotenoids, like those characteristic of a $\bar{g}$ ae, are highly specific. For example, spirilloxanthin is restricted to, and therefore a marker for, purple photosynthetic bacteria. It is perhaps noteworthy that all bacterial carotenoids, unlike those of higher organisms, possess identical functionalities and ring systems at either end of the polyisoprenoid chain. This inherent structural symmetry presumably reflects the simplicity of the biosynthetic pathways producing these compounds.

'Unknown' indicators. The precise biological origins of a significant number of components recognised in sedimentary organic matter is not known (Figure 5). All such 'unknown' compounds possess structures that retain obvious links to biosynthetic components, yet none has been identified in living organisms. In some cases it may be unclear whether the compound is a direct biosynthetic product or is generated by the diagenetic transformation of an unidentified precursor. Several 'unknown' indicators occur widely in geological materials; for example, the triterpane gammacerane has been recognised in numerous sediments and petroleums, yet its origin, whether diagenetic or biosynthetic, remains enigmatic. The only biological triterpenoid of related structure that might be a precursor is tetrahymenol (i.e. gammaceran-3 $\beta-01$ ), a component of the protozoan Tetrahymena ( 31 ). This triterpenol, however, has yet to be identified in any recent or ancient sediment; hence, this particular possible precursor/product relationship lacks appropriate supporting evidence in terms of the geological occurrence of the two compounds. A similar dichotomy exists with $28,30-b i s n o r h o p a n e$ (32, 33$)$; either it is a diagenetic product of some other hopanoid or it originates from an as yet unknown biological source. overall, a bacterial origin for 28,30-bisnorhopane seems most probable, given its hopanoid structure and its dominance of the hydrocarbon distributions in certain sediments ( 333 ). On the basis of their widespread occurrence in sediments and petroleums it has been proposed (34) that the tricyclic terpenoids related to tricyclohexaprane are derived from a probable bacterial membrane lipid, tricyclohexaprenol. This C 30 carbon skeleton, however, has yet to be identified in any organism and the link between tricyclic terpenoids and bacteria remains speculative, based solely on the geological evidence. The A-nor sterones found in many marine sediments ( 35 ) have not been reported in living organisms, although A-nor steranes do occur in sediments ( 36$)$. Sponges contain such altered steroidal

In Organic Marine Geochemistry; Sohn, M.;

ACS Symposium Series; American Chemical Society: Washington, DC, 1986. 

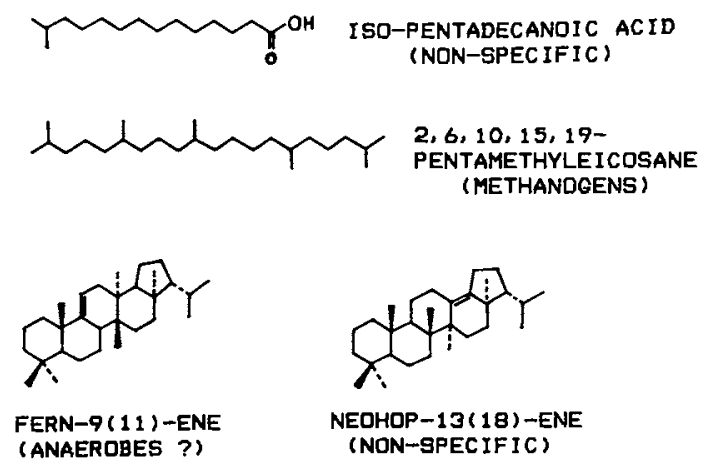

$$
\begin{aligned}
& \text { NEDHOP-13(18)-ENE } \\
& \text { (NON-GPEC IF IC) }
\end{aligned}
$$

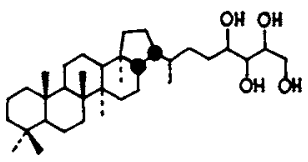

BACTER IOHOP ANETETRAOL (AEROBIC BACTERIA)

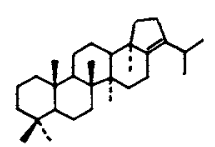

HDP-17(21)-ENE (ANAEROBES ?)

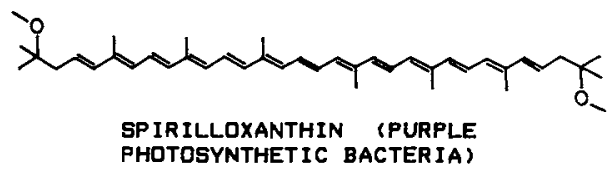

Figure 4. Compound structures, names and biological origins of examples of indicators of bacterial contributions to sedimentary organic matter.

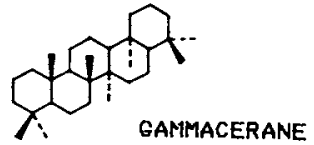

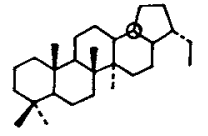

28, 30-BISNORHOPANE

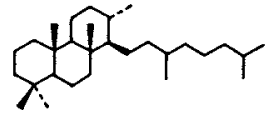

TRICYCLOHEXAPRANE

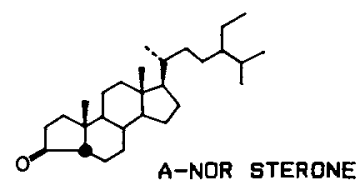

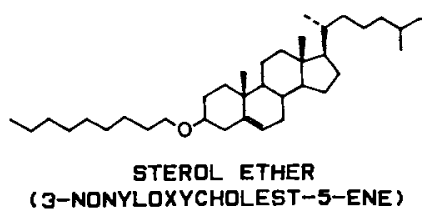

Figure 5. Compound structures and names of examples of sedimentary components derived from unidentified sources.

In Organic Marine Geochemistry; Sohn, M.;

ACS Symposium Series; American Chemical Society: Washington, DC, 1986. 
skeletons (37), but an origin from sponges cannot be verified solely on the evidence of the sedimentary occurrence of these compounds. Similarly, the source of sterol ethers is unclear. These compounds occur in diatomaceous oozes from many locations and ages (38, 19 ), but the dominance of $\mathrm{C}_{27}$ components among their ste $\bar{r}$ i $\bar{i}$ al moieties makes an origin from diatoms unlikely, since such a distribution would be atypical for these algae. It is also evident, however, that sterol ethers are not diagenetic products of steroids because the carbon number distributions of their steroidal moieties do not match those of other steroids in the same sediments. Also, there are few potential sources of $c_{9}$ to $c_{12}$ alkyl moieties required to form these ethers among sedimentary 1 ipids.

Compound Class Distributions in Biota. General considerations of the biological occurrence of individual components make it evident that particular skeletal types are restricted to specific classes of organism. For example, 4-methylsteroids appear to be resticted to dinoflagellates, whereas 4-desmethylsteroids are biosynthesized by a wide range of algae, including dinoflagellates, and higher plants. Similarly, among the pentacyclic triterpenoids hopanoids and fernenes are diagnostic of bacteria, whereas oleananoid and other related triterpenoids are specific markers for terrigenous higher plants. By contrast, the biological origin of gammacerane is unknown. These differences in the biological occurrence of pentacyclic triterpenoids is a clear manifestation of the divergence in the biosynthetic processes between such families of organisms.

Anthropogenic Hydrocarbon Indicators. All of the compounds cited above represent individual markers for different biological origins of sedimentary organic matter. Such compounds can become pollutants in sedimentary environments when they arise from, for example, high algal productivity induced by lake eutrophification caused by sewage and urban wastewater influxes. More generally anthropogenic influences on sedimentary organic matter stem from industrial effluents, such as chlorinated aromatic hydrocarbons (especially PCBs), and hydrocarbons derived from fossil fuels. In recent sedimentary environments the presence of an anactronous distribution of hydrocarbons, for example, thermally mature steranes (39), can indicate inputs of compounds from petroleum combustion and spillage. It is also possible, however, for such compounds to originate from the natural weathering of ancient sediments (39). A major diagnostic feature indicating petroleum contamination of sediments is the presence of an unresolved complex mixture of aliphatic hydrocarbons produced by the extensive biodegradation or weathering of crude oil (39). The use of such characteristics contrasts sharply with the principle of

In Organic Marine Geochemistry; Sohn, M.;

ACS Symposium Series; American Chemical Society: Washington, DC, 1986. 
utilizing individual marker compounds in the assessment of sediment inputs.

Relative Contributions from Different Biota to sediments. In the above discussions the occurrence of specific marker compounds or their distributions is shown to provide an indication of the biological or anthropogenic origins of sedimentary organic matter. This approach does not, however, permit the direct assessment of the relative proportions of contributions from different biological sources for various reasons. First, the marker compounds reflect only a small, and perhaps non-representative, portion of the total organic matter. Second, individual components undoubtedly differ significantly in their resistance to microbial degradation, both in the water column and in the sediment. Hence, their comparative abundances are influenced by the extent and nature of such alteration. Third, the concentrations of the diagnostic compounds for different classes of organisms can vary by orders of magnitude. In summary, the use of marker compounds for the absolute quantitative assessments of the various biological origins of sedimentary organic matter is problematic: however, comparative data can be obtained.

\section{Distributions of Marker Compounds in Marine sediments}

In the investigation of organic compounds in sediments the experimental procedures invariably include a separation scheme to divide and simplify total sediment extracts into suitable fractions of different polarity. Typically, this experimental procedure will yield a number of fractions containing principally hydrocarbon, ketone, carboxylic acid, alcohol or polar components. The reconstituted ion chromatograms (RIC) from gc-ms analysis of three such fractions are discussed herein to illustrate the observed distributions of marker compounds in marine sediments and discuss their inferred biological origins.

Hydrocarbon fraction. The aliphatic hydrocarbon distribution (Figure 6 ) of a sediment from the cariaco Trench (DSDP 15-147C-3-3) off venezuela contains two structural families of diagnostic compounds in addition to the steroids and triterpenoids in the polycyclic region. First, the n-alkane distribution is dominated by odd-numbered higher homologues (i.e. $C_{29}, C_{31}$ ) which are indicative of sediment contributions ${ }^{9}$ from terrigenous higher plants. At this site such components may originate from aeolian transported Saharan dust (16). Second, and more significantly, the distribution of hydrocarbons is dominated by various acyclic isoprenoids. Two of these components 2,6,10,15,19-pentamethyleicosane and lycopane (Peaks $E$ and $F$ in Figure 6) may be attributed to archaebacterial inputs, most probably from methanogens (2ㅇ), although the evidence for lycopane is

In Organic Marine Geochemistry; Sohn, M.;

ACS Symposium Series; American Chemical Society: Washington, DC, 1986. 


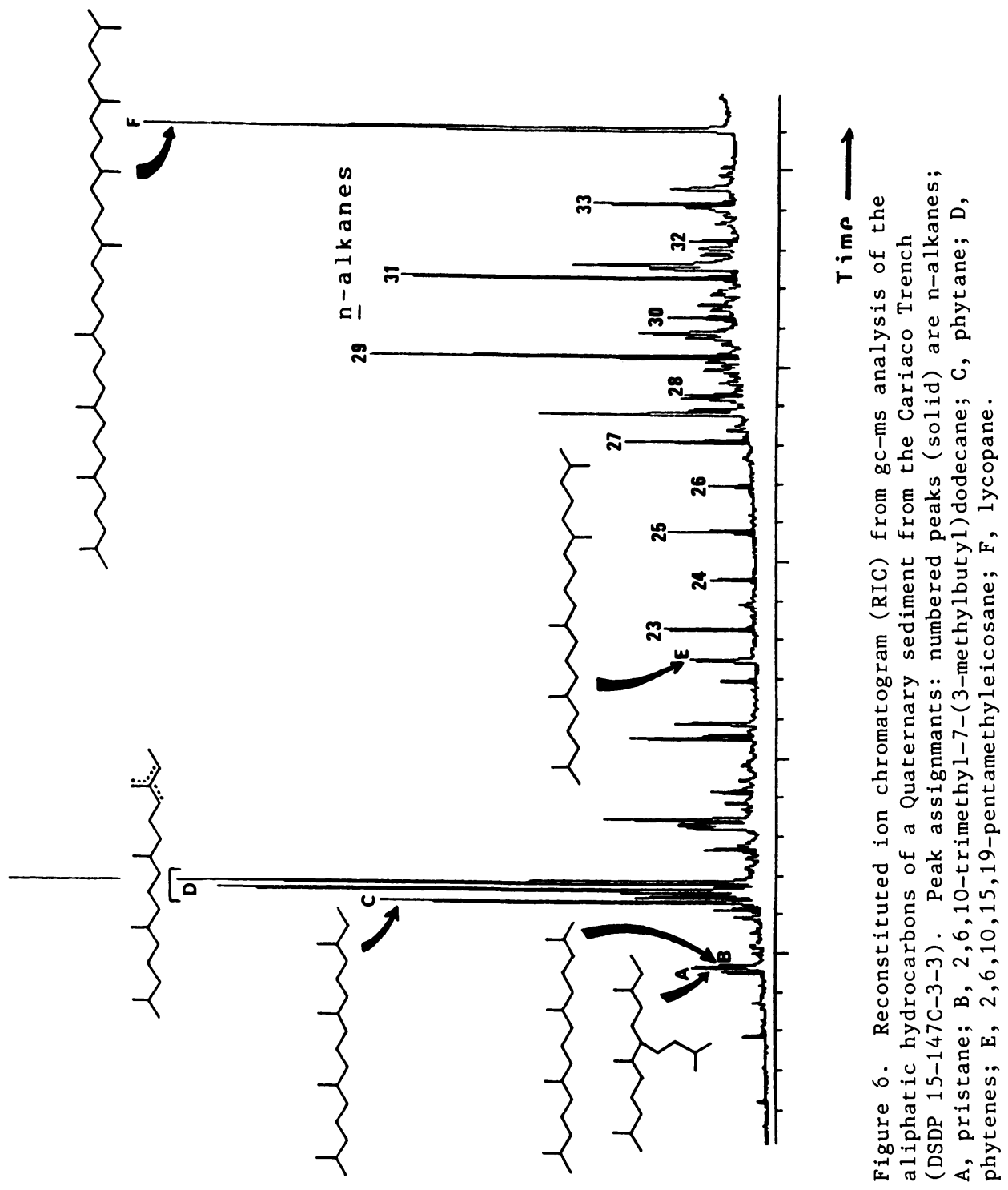

K 7 !suว น I

In Organic Marine Geochemistry; Sohn, M.; ACS Symposium Series; American Chemical Society: Washington, DC, 1986. 
circumstantial. Both phytane and the phytenes (Peaks C and D, respectively, in Figure 6) may also be of archaebacterial origin (27), or they may be products of phytol diagenesis (e.g. 4 I ). Pristane (Peak A in Figure 6) may be contributed by zooplankton or it may be formed diagenetically from phytol (e.g. 41 or tocopherols (7). In all cases it is an autochthonous component deriving from photosynthetic organisms or their predators. $2,6,10-$ Trimethyl-7-(3-methylbutyl)dodecane (Peak B in Figure 6) probably reflects contributions from green algae $(\underline{1} 3)$.

Ketone / Carboxylic Acid fraction. In the investigation of the lipid composition of a Pliocene ( $2 \mathrm{Ma}$ ) diatomaceous ooze from the walvis Ridge (DSDP 75-532-21-2) the total extract was methylated prior to compound class separation, thereby giving a fraction containing both ketones and carboxylic acid methyl esters (Eigure 7). The dominant components of this fraction were recognised by gc and gc-ms as $\mathrm{C}_{37}$ to $\mathrm{C}_{39}$ alkadienones and alkatrienones presumed to dérive from coccolithophorid algae (9). Other significant components of this fraction included a series of $\mathrm{C}_{22}$ to $\mathrm{C}_{30}$ n-alkanoic acids, which are indicative of inputs from terrigenous higher plants (18). $17 \beta(H), 21 \beta(H)-B i s h o m o h o p a n o i c$ acid (Peak A in Eigure-7) may be taken as a marker for bacterial contributions to the sedimentary organic matter since it is the expected major oxidation product of bacteriohopanetetraol. This fraction also contains tocopherols ( $\alpha-, \boldsymbol{\gamma}^{-}$and $\mathbf{6 - ;}$ Figure 7) which are non-diagnostic components that may originate from any photosynthetic organism. Typically, therefore, they will be of mixed origins from terrigenous higher plants, algae and bacteria.

Alcohol fraction. Sterols are a major class of compound in immature and unconsolidated sediments. In most open marine environments they are presumed to principally derive from marine algal sources ( 3,152$)$. Contributions from terrigenous higher plants may a lso be evident where the sediments are, in part land-derived, such as in coastal locations $(15,42)$. The major component in the sterol composition of a sediment from the cariaco Trench (DSDP 15-147B-4-2; analysed as TMS ethers; Figure 8; Table I) is

dinosterol

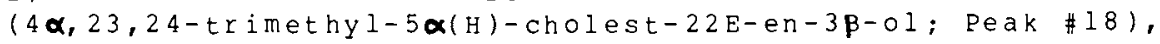
a well-established marker for dinoflagellate algae $(1-3,-5)$. Other $4 \alpha$-methylsterols (Peaks 15 and $19-21$ in Figure 8) similarly provide evidence of dinoflagellate inputs to the sediment. None of the other sterols can be linked directly to a specific source, but all may be attributed to a variety of planktonic algal sources, such as diatoms, dinoflagellates and coccolithophorids. One noteworthy feature of this sterol distribytion is the high proportion of $5 \boldsymbol{\alpha}(\mathrm{H})-\mathrm{stanols}$ relative to $\Delta^{5}-5$ terols. It may arise from preferential degradation of $\Delta^{5}$-stenols (4 3 ).

In Organic Marine Geochemistry; Sohn, M.;

ACS Symposium Series; American Chemical Society: Washington, DC, 1986. 


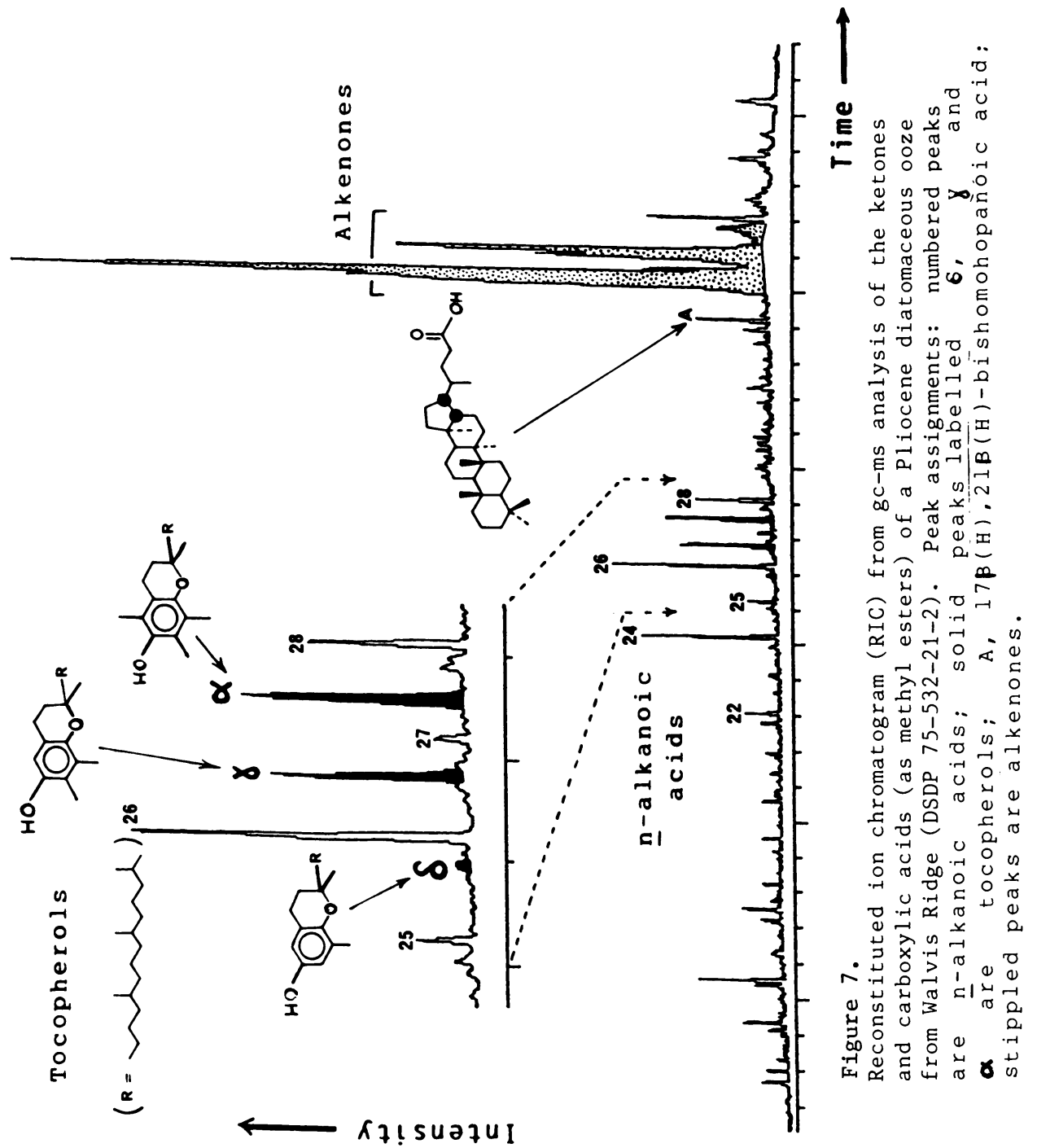

In Organic Marine Geochemistry; Sohn, M.;

ACS Symposium Series; American Chemical Society: Washington, DC, 1986. 


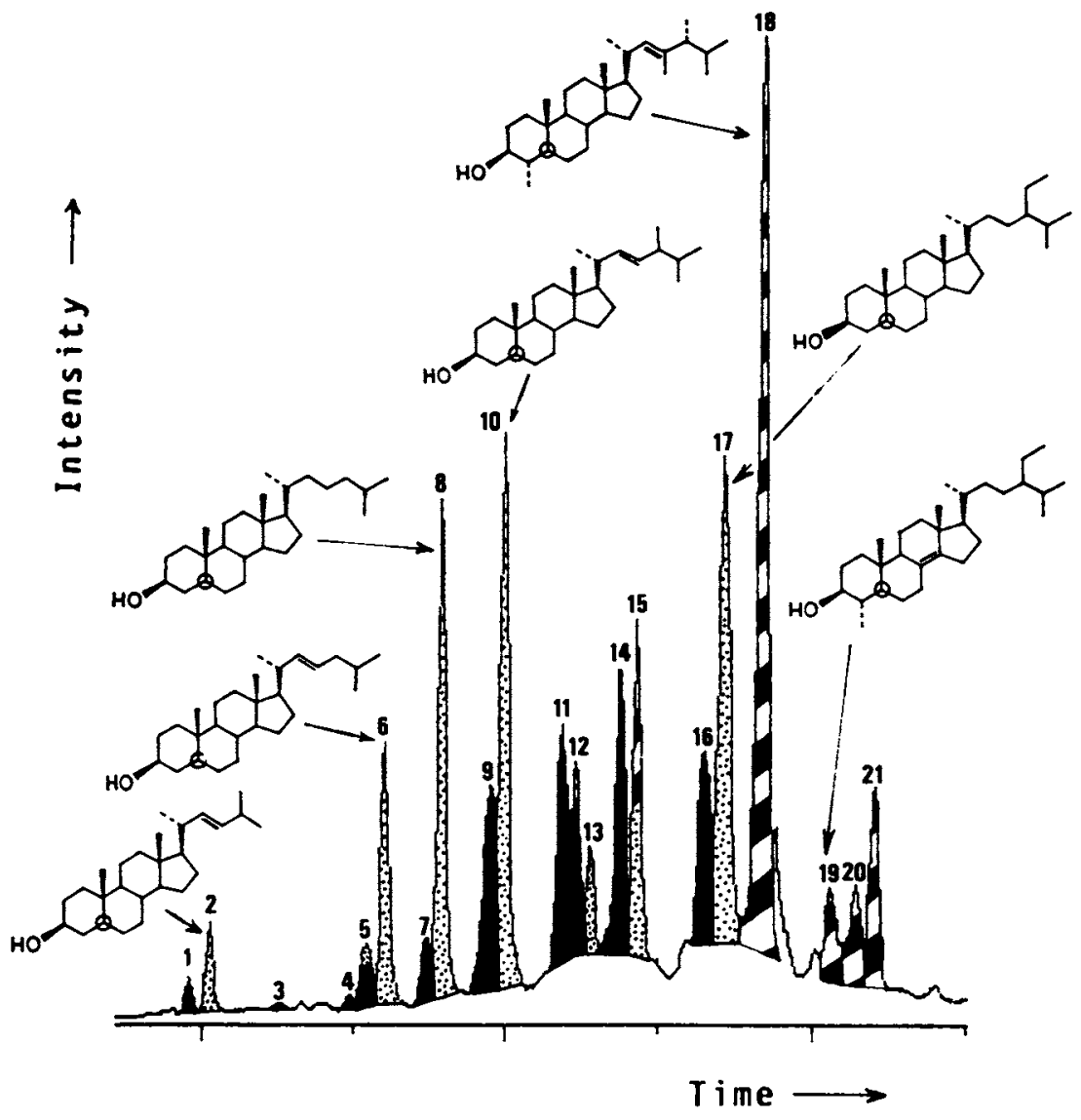

Figure 8. Reconstituted ion chromatogram (RIC) from gc-ms analysis of the sterols (as TMS ethers) of a Quaternary sediment from the Cariaco Trench (DSDP 15-147B-4-2). Peak assignments are given in Table I. solid, stippled and hatched peaks are $\Delta$-stenols, $5 \boldsymbol{\alpha}(\mathrm{H})-\mathrm{stanols}$ and $4 \boldsymbol{\alpha}$-methylstanols, respectively.

In Organic Marine Geochemistry; Sohn, M.; ACS Symposium Series; American Chemical Society: Washington, DC, 1986. 
Table I. Peak Assignments of sterols in Figure 8 .

\begin{tabular}{|c|c|}
\hline Peak ${ }^{a}$ & Assignment ${ }^{b}$ \\
\hline 1 & $24-$ norcholesta $-5,22 \mathrm{E}-\mathrm{d}$ ien- $3 \beta-01$ \\
\hline 2 & $24-$ nor $-5 \alpha(H)-c h o l e s t-22 E-e n-3 \beta-o 1$ \\
\hline 3 & $24-$ nor $-5 \alpha(\mathrm{H})-\mathrm{cholestan}-3 \beta-$ ol \\
\hline 4 & 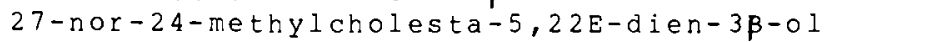 \\
\hline 5 & $\begin{array}{l}27 \text {-nor }-24-\text { methyl-5 } \alpha(\mathrm{H})-\mathrm{cholest}-22 \mathrm{E}-\mathrm{en}-3 \beta-01 \\
\text { cholesta-5, } 22 \mathrm{E}-\mathrm{dien}-3 \beta-01\end{array}$ \\
\hline 6 & $5 \alpha(\mathrm{H})-\mathrm{cholest}-22 \mathrm{E}-\mathrm{en}-3 \mathrm{~B}-01$ \\
\hline 7 & Cholest $-5-e n-3 \beta-o l$ \\
\hline 8 & $5 \alpha(\mathrm{H})-\mathrm{cholestan}-3 \beta-01$ \\
\hline 9 & 24 -methylcholest-5,22E-dien-3B-ol \\
\hline 10 & $24-$ methyl- $5 \alpha(H)-$ cholest- $22 \mathrm{E}-\mathrm{en}-3 \beta-o l$ \\
\hline 11 & $24-$ methylenecholest $-5-$ en $-3 \beta-01$ \\
\hline 12 & $\begin{array}{l}24 \text {-methylene-5 } \alpha(\mathrm{H})-\mathrm{cholestan}-3 \beta-01 \\
24 \text {-methylcholest }-5-e n-3 \beta-01\end{array}$ \\
\hline 13 & $24-$ methyl- $5 \alpha(\mathrm{H})-$ cholestan $-3 \beta-01$ \\
\hline 14 & $23,24-d i$ methylcholesta-5,22E-dien-3B-ol \\
\hline 15 & 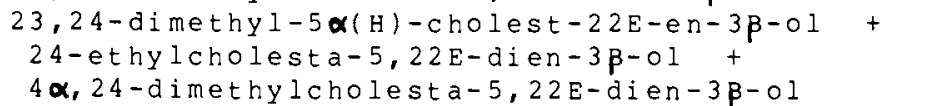 \\
\hline 16 & $24-e t h y l c h o l e s t-5-e n-3 \beta-01$ \\
\hline 17 & $24-e t h y l-5 \alpha(\mathrm{H})-\mathrm{cholestan}-3 \beta-01$ \\
\hline 18 & $4 \boldsymbol{\alpha}, 23,24-t$ rimethyl-5 $\alpha(\mathrm{H})-\mathrm{cholest}-22 \mathrm{E}-\mathrm{en}-3 \boldsymbol{\beta}-\mathrm{ol}$ \\
\hline 19 & $24-$ ethyl $-4 \alpha-$ methyl $-5 \alpha($ H) - cholest $-8(14)-e n-3 \beta-01$ \\
\hline 20 & $4 \alpha, 23 \mathrm{~s}, 24 \mathrm{R}-\mathrm{trimethyl}-5 \alpha(\mathrm{H})-\mathrm{cholestan}-3 \beta-01$ \\
\hline 21 & $4 \boldsymbol{\alpha}, 23 \mathrm{R}, 24 \mathrm{R}-\mathrm{trimethyl}-5 \boldsymbol{\alpha}(\mathrm{H})-\mathrm{cholestan}-3 \boldsymbol{\beta}-\mathrm{ol}$ \\
\hline
\end{tabular}

Number of peak in Figure 8 , where analysed as TMS ethers.

b

Sterol assignments are based on individual gc retention behaviour and mass spectra by comparison with reference or literature standards (e.g. 2 ) or by spectral interpretation.

In Organic Marine Geochemistry; Sohn, M.;

ACS Symposium Series; American Chemical Society: Washington, DC, 1986. 
or, alternatively, it may reflect the high proportion of sterols derived from dinoflagellate sources, since these organisms can be major sources of $5 \alpha(H)-s t a n o l s ~(\underline{5})$.

\section{Long-chain Alkenones - climatic Indicators?}

Following the recognition of series of $\mathrm{C}_{37}$ to $\mathrm{C}_{39}$
alkenones in the coccolithophorid Emiliania huxleyi and in sediments from the Japan Trench and e 1 sewhere $\left(4-\frac{1}{4}-\frac{1}{4}\right)$, the same series of components, but with a markediy greater dominance of the alkadienones, was identified in sediments from the Middle America Trench (46). From these data it seemed plausible that the difference in the unsaturateion of these components might be a reflection of the water temperatures of their environment (47). The ability to vary their lipid unsaturation with growth temperature is a well known characteristic of algae and bacteria which is designed to maintain their membrane fluidity. Thus, it seemed plausible that the changes in the unsaturation of long-chain alkenones might also be temperature dependent. subsequent studies of a wide variety of quaternary sediments from locations of different latitude and water temperature have confirmed this general observation ( 48 ). Further evaluation of this molecular tool. for climatic assessment has been directed towards its comparison with an established measure of palaeoclimatic fluctuations, namely $\boldsymbol{s}^{18}$ o values for foraminifera $(48)$. In a study of sediments from the kane Gap region in the eastern equatorial atlantic the unsaturation of $C_{3}$ alkenones (b in Figure 9) shows a variability which broadly corresponds to the glacial/ interglacial cycles assessed from $6{ }^{18}$ of planktonic foraminifera (Figure 9). In particular the lower values for the $c_{3}$ alkenone unsaturation index $\left(\mathrm{U}_{37}\right)$ correspond to the glacial maxima, most markedly in the 37 upper section of the core. The n-alkane concentrations in the core (c in Figure $\overline{9}$ ) vary independently of the alkenone unsaturation index, suggesting that they are influenced by factors other than water temperatures. Indeed, since their distributions are typical of those characteristic of higher plants (18), it is probable that they reflect the input of terrigenous organic matter, perhaps as an aeolian input (16). Both of the molecular trends ( $b$ and $c$ in Figure 9) show little relationship to the carbonate content of the sediments, which also shows downhole fluctuations (a in Figure 9). These data, discussed in detail elsewhere ( $48, \underline{8}, \underline{4})$, demonstrate that molecular geochemical information can play an important role in the assessment of the climatic record in sediments.

\section{Conclusions}

The structural specificity of organic compounds in different organisms enables their occurrence and distributions to be used in the assessment of the

In Organic Marine Geochemistry; Sohn, M.;

ACS Symposium Series; American Chemical Society: Washington, DC, 1986. 


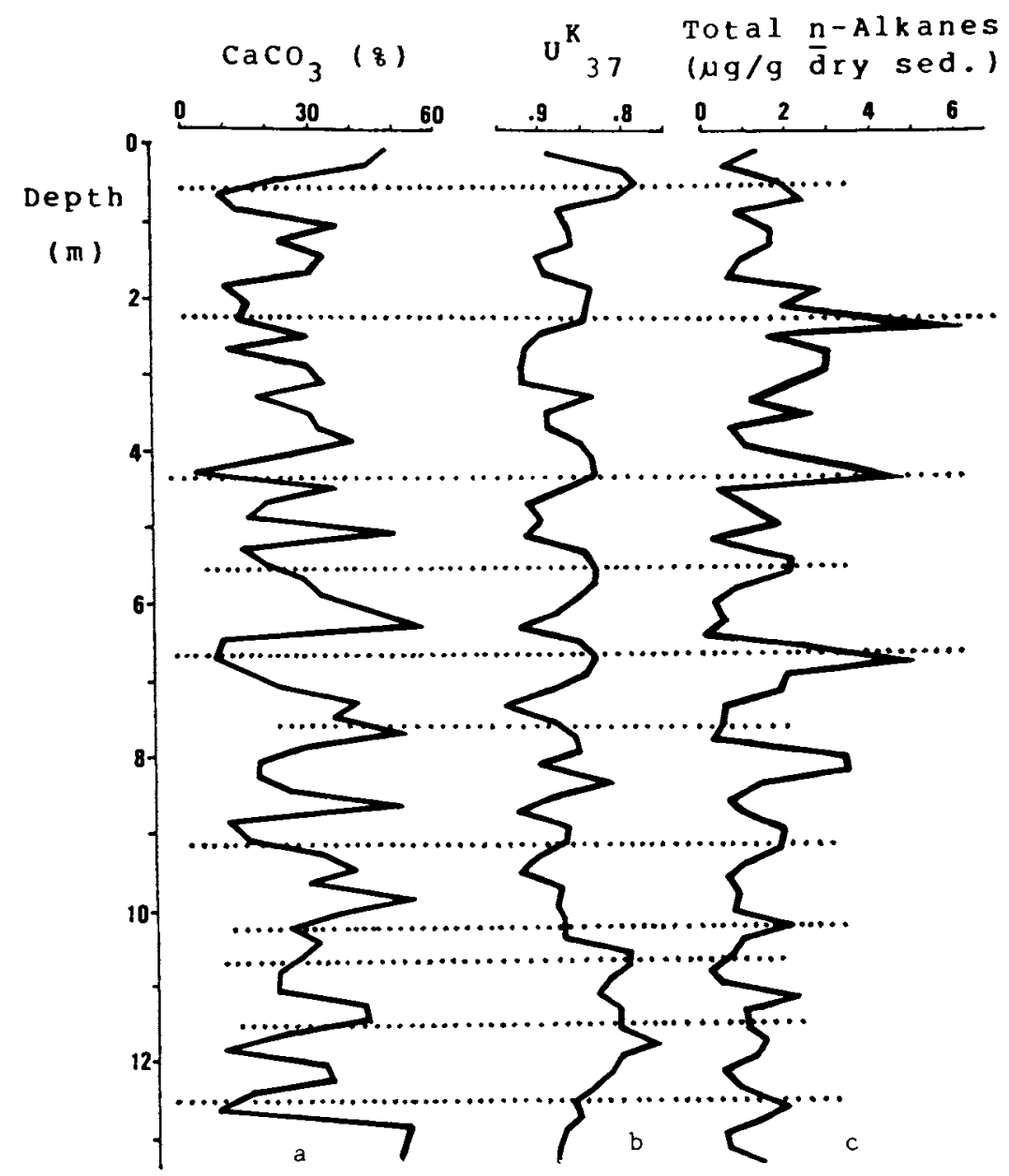

Figure 9. Downhole plots in a $13 \mathrm{~m}$ gravity core from the kane Gap region (Ml64l5-2) of: a, cakbonate contents; b, alkenone unsaturation ( ${ }_{37}{ }_{37}=$

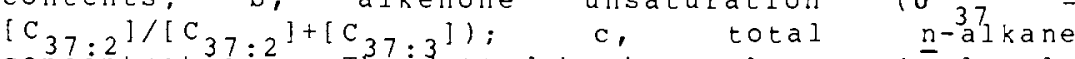
concéntrations. The dotted horizons denote the levels corresponding to glacial maxima, as indicated by preliminary $S^{18} 0$ data on foraminiferal carbonate (cf. $\underline{4}-\underline{4}, \underline{9})$. 
biological origins of sedimentary organic mater. In particular, such information can distinguish contributions from algae, terrigenous higher plants and bacteria. It also appears that the unsaturation of alkenones provides a molecular measure of palaeoclimate insofar as it records water palaeotemperatures. overall, organic molecules in sediments are both sensitive and unique indicators of depositional palaeoenvironments, often recording information that is not accessible by other techniques.

\section{Acknowledgments}

We thank Dr. Ian Marlowe for his invaluable efforts and contributions to the study of the kane Gap core. We are grateful to Drs. M. Sarnthein and U. Pflaumann for the preliminary, information on the glacial maxima inferred from the 6 values of foraminiferal carbonate. We acknowledge financial support from the N.E.R.C. (GR3/2951 and GR3/3758) for gc-ms facilities and from the Royal society for a V.G. Minichrom gc data system.

\section{Literature cited}

1. Boon, J. J.; Rijpstra, W. I. C.; de Lange, F.; de Leeuw, J. W. ; Yoshioka, M.; Shimizu, Y. NㅡㅡㅡㅡㅡㅡㄹㅡLond. $1979,277,125$.

2. de-Leeuw, J. W.; Rijpstra, W. I. C.; Schenck, P. A.; volkman, J. K. Geochim. Cosmochim. Acta 1983, 47, 455 .

3. Brassell, S. C.; Eglinton, G. In "Coastal Upwelling: Its Sediment Record"; Suess, E.; Thiede, J., Eds.; Plenum: New York, 1983 ; Part A, p. 545.

4. Withers, N. In "Marine Natural Products"; Scheuer, P. J., Ed.; ACademic: New York, 1983; Vol. 5, p.87.

5. Robinson, N.; Eglinton, G.; Brassell, S. C.; Cranwell, P. A. Nature, Lond. 1984, 308, 439.

6. Brassell, S. C.; Eglinton, G.; Maxwell, J. R. Bi occhem.-Soc. Trans. $1983,11,575$.

7. Goossens, H.; de-ieeuw, J. W.; Schenck, P. A.; Brassell, S. C. Natures, Lond. $1984,312,440$.

8. Züllig, H. Schwe

9. Marlowe, I. T.; Brassell, S. C.; Eglinton, G; Green, $\mathrm{J}$. C. In "Advances in Organic Geochemistry 1983"; Schenck, P. A.; de Leeuw, J. W. ; Lijmbach, G. W. M., Eds.; Org. Geochem. $1984,6,135$.

10. Cranwell, P. A. Géochim. Cosmochim. Acta 1985,49 , 1545 .

11. Moldowan, J. M. ; Seifert, W. K. J. Chem. Soc.. Chem. Commun. 1980, 912 .

12. Brassell, S. C.; Eglinton, G.; Fu Jiamo In "Advances in organic Geochemistry 12 "; Leythaeuser, D.; Rullkotter, J., Eds.; Pergamon, oxford, in press.

13. Rowland, S. J.; Yon, D. A.; Lewis, C. A.; Maxwell, J. R. Org. Geochem. 1985, 8, 207.

14. Yon, D. A.; Ryback, G.; Maxwell, J. R. Tetrahedron Letㅡㄴ. $1982,23,2143$.

In Organic Marine Geochemistry; Sohn, M.;

ACS Symposium Series; American Chemical Society: Washington, DC, 1986. 
15. Gagosian, R. B.: Nigrelli, G. E.; Volkman, J. K. In "Coastal Upwelling: Its sediment Record"; Suess, E.; Thiede, J., Eds.; Plenum, New York, 1983; Part A, p. 241 .

16. Simoneit, B. R. T.; Eglinton, G. In "Advances in organic Geochemistry $1975^{\prime \prime}$ Campos, R; Goni, J., Eds.: Enadimsa, Madrid, $1977 ;$ p. 415.

17. Schneider, J. K.; Gagosian, R.B.; Cochran, J. K.; Trull, T. W. Nature, Lond., 1983, 304, 429.

18. Eglinton, G. : Hamilton, R. J.: Science, 1967, 156 , 1322 .

19. Brassel1, S. C., unpublished data.

20. Corbet, B.; Albrecht, P.; Ourisson, G. J.-Am. Chem. Soc. $1980,102,1171$.

21. Hoffmann, C. F.; Mackenzie, A. S.; Lewis, C. A.; Maxwell, J. R.; Oudin, J. L.; Durand, B.; Vandenbroucke, M. Chem. Geol. 1984, 42, 1 .

22. Simoneit, B. R. T. Geochim. Cosmochim. Acta 1977 , 41,463 .

23. Brassell, S. C. ; Eglinton, G.; Howell, V. J. In "Marine Petroleum Source Rocks"; Brooks, J.; Fleet, A.J., Eds.; Blackwells, oxford, in press.

24. Cranwel1, P. A. Chem. Geol. 1973, 11, 307.

25. Holzer, G. Colorado sch. Mines_quat. $1983,9$.

26. Chappe, B.; Albrecht, P.; Michaelis, W. Science $1982,217,65$.

27. Holzer, G.: oró, J.; Tornabene, T. G. J._Chromatog. $1979,186,795$.

28. Brassell, S. C.; Wardroper, A. M. K.; Thomson, I. D. : Maxwel1, J. R.; Eglinton, G. Nature, Lond. 1981 , 290,693 .

29. Howard, D. L.; Simoneit, B. R. T.; Chapman, D. J. Arch. Microbiol. 137,200 .

30. Ourisson, G.; Albrecht, P.; Rohmer, M. Pure Appli. Chemem. $1979,51,709$.

31. Tsuda, Y.; Morimoto, A.; Sano, T.; Inubishi, Y.; Mallory, F. B.; Gordon, J. T. Tetrahedron Lett. 1965,1427 .

32. Seifert, W. K.: Moldowan, J. M.; Smith, G. W.; Whitehead, E. V. Nature, Lond. 1978, 271, 456.

33. Katz, B. J.: Elrod, L.W. Geochim. Cosmochim. Acta $1983,47,389$.

34. Ourisson, G.; Albrecht, P.; Rohmer, M. Trends Biochem. Sci. $1982,7,236$.

35. MCEvoy, J.; Maxwell, J. R.; Brassell, S. C. unpublished data.

36. van Grass, G.; de Lange, J.; de Leeuw, J. W.; Schenck, P.A. Nature, Lond. 1982, 296, 59.

37. Minale, L. ; Sodano, G. J Chem. Soc._Perkin I 1974 , 2380 .

38. Boon, J. J.; de Leeuw, J.W. Mar. Chem. 1979, 7, 117 .

39. Brassell, S. C.; Eglinton, G. In "Analytical Techniques in Environmental Chemistry"; Albaiges, J., Ed.: Pergamon, oxford, 1980; p. 1 . 
40. Rowland, S. J.; Maxwell, J. R. Geochim. Cosmochim. Act ta $1984,48,617$.

41. Didyk, B. M.; Simoneit, B. R. T.; Brassell, S. C.; Eglinton, G. Nature, Lond. 1978, 272, 216.

42. Huang, W. Y. : Meinschein, W. G. Geochim._Cosmochim. Acta $1976,40,323$.

43. Nishimura, M. Geochim. Cosmochim. Acta 1978, 42, 349 .

44. Volkman, J. K.; Eglinton, G.; Corner, E.D.S.; Sargent, J. In "Advances in Organic Geochemistry 1979 "; Douglas, A. G., Maxwell, J. R., Eds.; Pergamon, Oxford, 1980 ; p. 219.

45. de Leeuw, J. W.; van der Meer, F. W.; Rijpstra, w. I. C.; Schenck, P. A. In "Advances in organic Geochemistry 1979"; Douglas, A. G.; Maxwell, J. R., Eds.; Pergamon, Oxford, $1980 ;$ p. 211.

46. Brassell, S. C.; Eglinton, G.; Maxwell, J. R. In "Initial Reports of the Deep Sea Drilling project"; U.S. Government Printing office, Washington, D.C., 1981 ; Vol. LXVI, p. 557 .

47. Brassell, S. C.; Eglinton, G. In "Heterotrophic Activity in the Sea"; Hobbie, J.; Williams, P. J. leB., Eds.; Plenum, New York, $1984 ;$ p. 481 .

48. Brassell, S. C.; Eglinton, G.; Marlowe, I. T.;

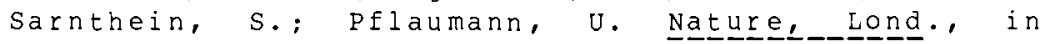
press.

49. Brassell, S. C.; Brereton, R. G.; Eglinton, G.; Grimalt, J.; Liebezeit, G.; Pflaumann, U.; Sarnthein, M. In "Advances in Organic Geochemistry 12 "; Leythaeuser, D; Rullkötter, J., Eds.; Pergamon, oxford, in press.

RECEIVED October 31, 1985

In Organic Marine Geochemistry; Sohn, M.;

ACS Symposium Series; American Chemical Society: Washington, DC, 1986. 


\title{
Sedimentary Lipids and Polysaccharides
}

\section{As Indicators for Sources of Input, Microbial Activity, and Short-Term Diagenesis}

\section{J. W. de Leeuw}

\section{Department of Chemistry and Chemical Engineering, Delft University of Technology, De Vries van Heystplantsoen 2, 2628 RZ Delft, The Netherlands}

\begin{abstract}
Organic compounds present in recent marine sediments reflect the biochemical composition of the overlying water column as well as the in situ benthic activity. Suites of sedimentary compounds are also considered as starting compounds in chemical diagenetic pathways. Samples from several locations have been analyzed (e.g. the Namibian Shelf (S.W.-Africa), the Black Sea, Solar Lake (N. Sinai) and the Gavish Sabkha (S. Sinai)). Selected groups of sedimentary compounds such as sterols, 4-methylsterols, hydroxy fatty acids, carotenoids, long chain unsaturated methy $1-$ and ethylketones, sterolethers, long chain 1,15-diols and 15-keto-monools, tocopherols, thiophenes and polysaccharides are discussed. These compounds have been selected in such a way that attention can be paid to the origin of sedimentary compounds, how they reflect the composition of the living communities in the overlying water column and the sediment itself, to symbiotic relationships, to microbial activity and to early diagenetic processes.
\end{abstract}

One of the ultimate goals in organic geochemistry is the detailed reconstruction of the environment of deposition using organic matter characteristics. Organic molecules isolated from sediment samples and subsequently identified carry information about their biological origin or about the state of diagenesis of the sediment or both. Therefore scientists working in the molecular organic geochemistry field have used and still use terms like biomarkers, chemical fossils, biological markers, geochemical fossils, guide molecules, biotracers, etc. to indicate the information content of individual organic compounds or suites of sedimentary organic compounds. Due to recent developments in the organic geochemistry of recent sediments in particular, these terms can be rather confusing and it is no longer clear what kind of information content of the organic molecules is being referred to. Therefore it is necessary to reevaluate the "marker concept" in organic geochemistry.

0097-6156/86/0305-0033\$08.25/0

() 1986 American Chemical Society 
Figure 1 schematically shows an approach by which sedimentary organic molecules are considered as information carriers, how the various kinds of information contents can be discriminated and how the assembled information is evaluated. The different ways by which the information content is expressed are shortly discussed hereafter.

Structures. Structural features such as the skeleton, the stereochemical configuration and the nature of functional groups of individual compounds can be highly informative. If the structures encountered are identical or reflect an origin from naturally occurring compounds, the degree of information is determined by the uniqueness of the occurrence in the natural environment which in its turn is determined by the uniqueness of the biosynthetic machinery of a certain group of organisms. We11-known examples are the extended hopanoids (1), dinosterol (2) and the very long unsaturated ketones (3). Sometimes the structures of the sedimentary organic molecules as such do not occur in the biosphere but are (based on specific structural features) easily traced back to natural precursors which are not entirely unique for certain groups of organisms. In this case the structural information can be used to unravel diagenetic pathways and to determine the degree of diagenesis of the sediment under study. Examples hereof are steroid hydrocarbons such as sterenes, diasterenes, spirosterenes, steranes, diasteranes and aromatized steroids which all reflect specific biochemical and chemical transformations of the originally present sterols (4). If the structural features still reflect structures of unique natural compounds, then they contain both information about their specific natural origin and diagenetical pathways. Examples hereof are the extended hopanes, 4methyldiasterenes, steranes and certain diterpenes (5).

Distribution patterns. A distribution pattern of a certain class of compounds can be highly informative in several aspects, while the individual components do not have any information content. The most common example to illustrate this type of information content are nalkane patterns observed in sediment extracts and oils. If the envelope of n-alkanes maximizes in the $\mathrm{C}_{27}-\mathrm{C}_{31}$ range and there is a strong odd even predominance, an origin from higher plant waxes is assumed. Based on exactly the same distribution pattern one also can conclude that the sediment has not undergone severe diagenesis. If the $n$-alkane patterns are smooth without any odd over even predominance only some general conclusions can be made about the degree of maturation. An even over odd predominance of $n$-alkanes can occur in sediments or oils which originate from hypersaline depositional environments (6)

Mode of occurrence. It is only in recent years that in some organic geochemical investigations attention has been paid to the fact that organic molecules in sediments (especially in recent sediments) occur in different modes (e.g. $\underline{7}, \underline{8}$ ). Since molecules in organisms are present as such or as parts of larger structural entities it is again the uniqueness of the biosynthetic machinery in specific groups of organisms which determines the various modes by which the molecules are present in the cells. To benefit from this potential source of information present in living systems sequential or specific procedures to isolate suites of organic molecules from sediment 
samples are required. Even when the molecules as such or the distribution patterns of certain classes of compounds do not yield much information, their mode of occurrence might be highly

informative. Straight chain fatty acids, for example, do not carry much information. If, however, it is analyzed which fatty acids occur free, which are esterified, or which are amide bound, we can obtain a lot of information from these compounds in terms of their biological origin and/or of early stage diagenetical pathways. This kind of information has been used to trace back the origin of alcohols and sterols in several sediments (7).

Total profiles. By analysis of total extracts, total hydrolyzates or total pyrolysis products, etc. without any preseparation, one can obtain so called total profiles. When gas chromatography or gas chromatography-mass spectrometry are applied for these kinds of analyses, we can study total profiles of lipid compounds which are amenable by GC. However, monitoring fractions of sedimentary organic matter can also be performed by IR, NMR, UV-VIS and other spectroscopic techniques. In this paper we will limit ourselves to GC and GC-MS profiles of lipid fractions obtained from sediments. The profiles might be considered as bird's eye views of the sedimentary organic matter. One can compare relative concentrations of individual compounds or classes of compounds directly, and by using the above mentioned information contents characterize the origin and/or diagenesis of the sediment in terms of relative contributions from different groups of organisms such as higher plants vs. dinoflagellates vs. coccolithophores vs. bacteria. Furthermore, if one observes in these total profiles similar or even identical distribution patterns of different classes of compounds, a correlation between these compound classes must exist, due to either the occurrence of similar patterns in certain groups of organisms or due to distinct diagenetic pathways by which one class of compounds is transformed to another compound class without affecting the distribution patterns. In this way individual molecules or distribution patterns which do not contain much information as such are becoming information carriers of some importance. No examples of this line of information are reported in the literature.

In this paper a number of examples will be given to illustrate the above mentioned concept. For that purpose first a critical evaluation of a selected part of our work in Delft from the last five or six years is presented. Subsequently the results of some ongoing research will be discussed to further illustrate the application of organic molecule information expressed in modes of occurrence and as total profiles of organic compounds from sediments. Finally the finding of new organic sulphur compounds and their possible significances are reported. In this report, mainly data from recent and subrecent sediments are discussed. Although some attention will be given to carbohydrates, the majority of the organic molecules considered here are lipids. It should be noted that this paper is not at all meant to give a complete review of organic information carriers in sediments; the investigations discussed are selected from our work at Delft to illustrate the above mentioned concept. 
Results and Discussion

Table I summarizes some of the sediments of which samples have been analyzed or are being analyzed in our group. Results obtained from extracts of these sediment samples are discussed in this paper.

Table I. Sediments Investigated

\begin{tabular}{lll}
\hline Sample & Age & Location \\
\hline 1. Solar Lake & $0-2500 \mathrm{yr}$. BP & North Sinai \\
2. Gavish Sabkha & very recent & South Sinai \\
3. Sarsina & $6 \times 10^{6} \mathrm{yr}$. & North Apennines \\
4. Sapropel S & $225 \times 10^{3} \mathrm{yr}$. & Eastern Mediterranean \\
5. Black Sea Unit 1 & $0-3000 \mathrm{yr} . \mathrm{BP}$ & Black Sea \\
6. Black Sea Unit 2 & $3000-7000 \mathrm{yr}$. BP & Black Sea \\
7. Livello Bonare11i & Cretaceous & Central Apennines \\
8. Sapropels & Very recent & Mediterranean \\
9. DSDP 362 & P1eistocene/Miocene & Walvis Ridge \\
10. Namibian She1f & I000-2500 yr. BP & off S.W.-Africa \\
11. Roze1 Point Oil & Miocene & Utah \\
12. Wadden Sea & Very recent & The Netherlands \\
\hline
\end{tabular}

Figure 2 shows their geographical position, except for the Rozel Point oil which comes from the Uinta basin in Utah, USA, and the mud samples from the Dutch Wadden Sea. The occurrence and possible significance of several suites of organic compounds isolated from a number of recent sediments have been reported by us over the last years. Firstly, results of this work will be critically evaluated and secondly, a few new compounds series and analytical approaches are discussed.

Midchain ketones and sterol ethers. Figure 3 shows the upper part of a Total Ion Current (TIC) trace obtained from a TLC fraction of an extract of the Namibian Shelf diatomaceous ooze. Long midchain ketones and sterolethers together with a series of wax esters were shown to be present in this fraction (9). The sterolethers are composed of common $\Delta^{5}$-sterol moieties and $C_{8}$ and $C_{9}$ alkylmoieties(I).

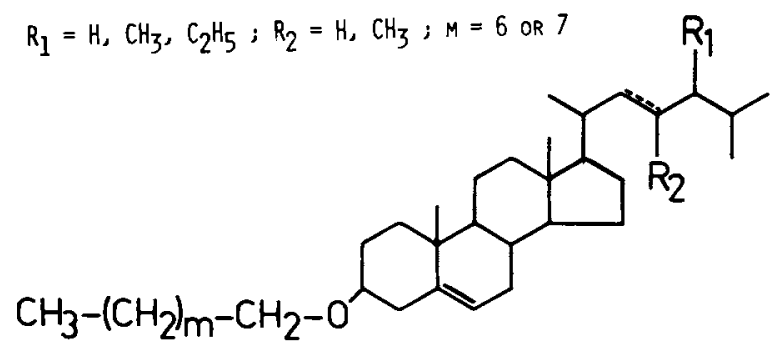

Although these compounds are encountered in several other sediments (10), their unique structural information cannot be validated since these compounds are not (yet) discovered by the natural product chemists in living systems. The reported occurrence of cholesteryl 


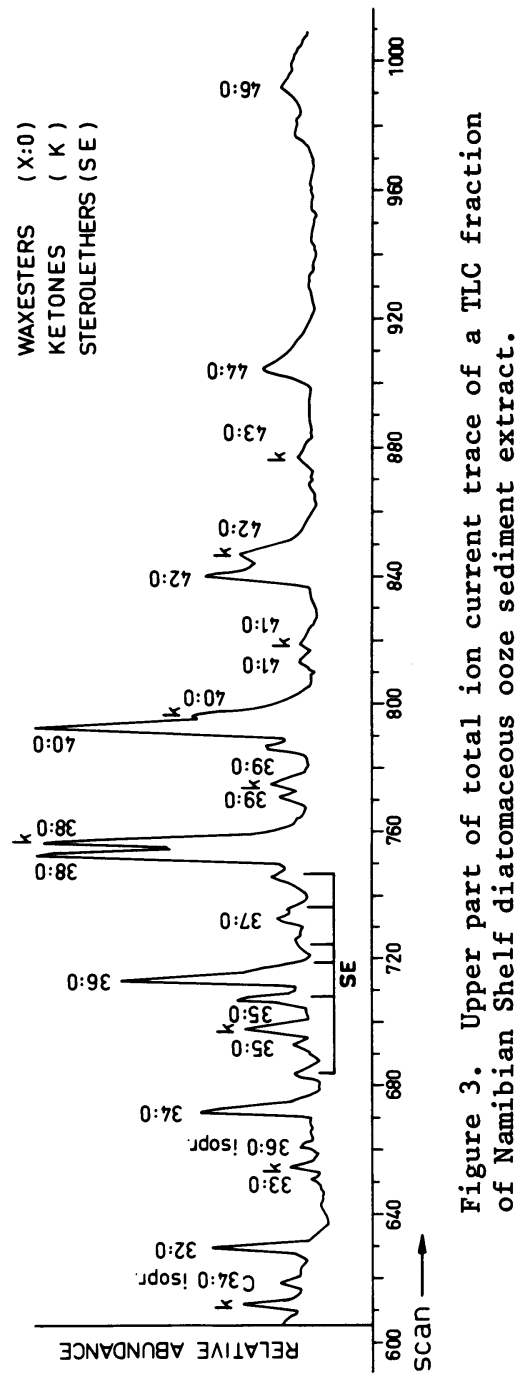

In Organic Marine Geochemistry; Sohn, M.; ACS Symposium Series; American Chemical Society: Washington, DC, 1986. 


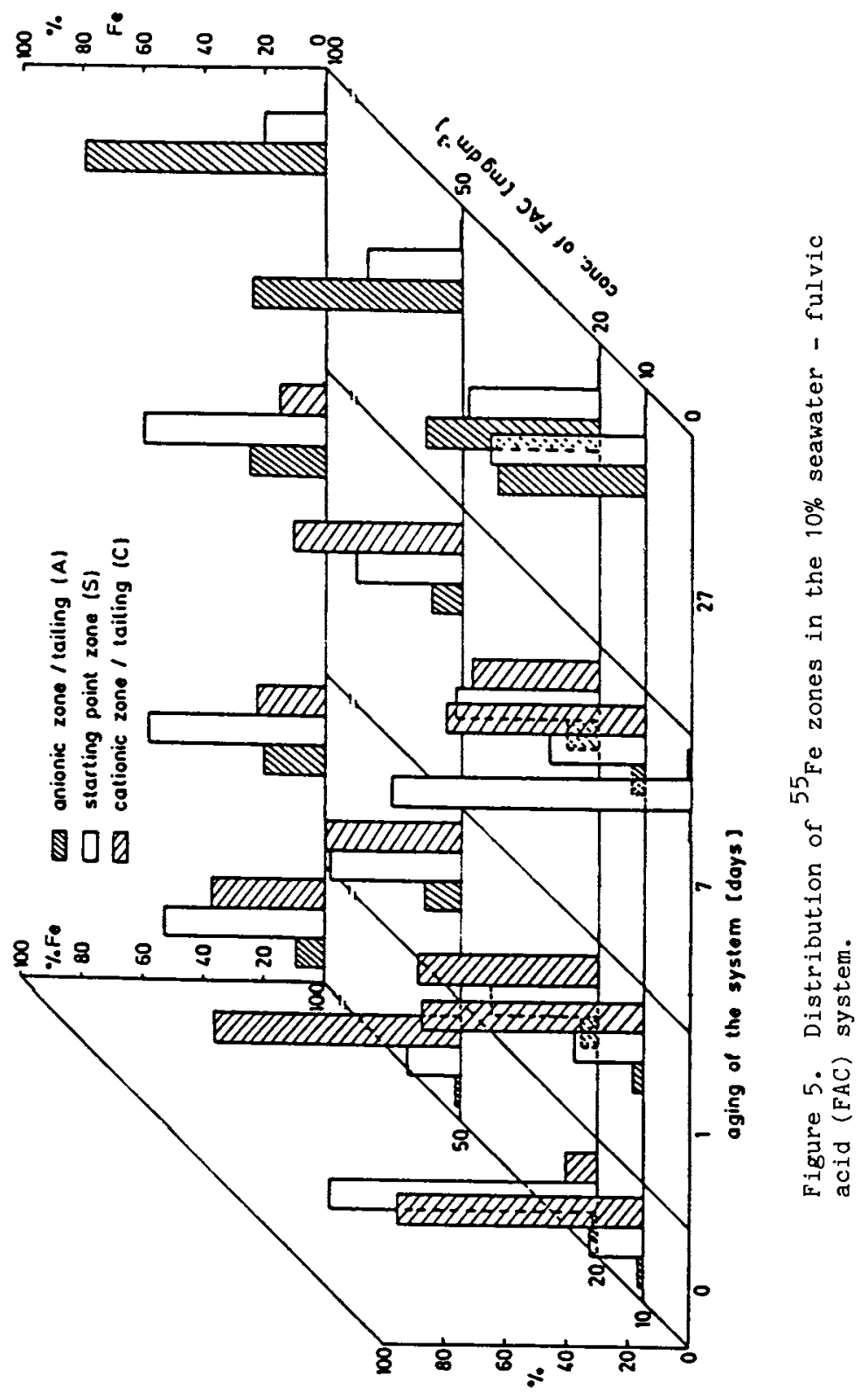

In Organic Marine Geochemistry; Sohn, M.;

ACS Symposium Series; American Chemical Society: Washington, DC, 1986. 
hexadecyl ether in bovine cardiac muscle (11) indicates that sterolethers as such occur in nature. Long-chain ketones as such are known to occur in plant waxes (12). In plants they are biosynthesized via the corresponding hydrocarbons and the distribution patterns of the hydrocarbons and mid-chain ketones in plants are therefore very similar and are characterized by a strong odd over even predominance. The mid-chain ketones present in this sediment extract do not at all reflect the hydrocarbon pattern and do have a strong even over odd predominance (II).

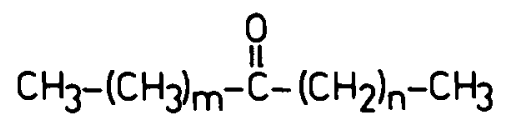

$|M-N| \leqslant 2 ; C_{31}-C_{43} ; C_{38,40,42}$

Thus a plant cuticle origin is highly unlikely. Their distribution pattern to some extent mimics the wax ester pattern, which might indicate a common biological origin of these compound classes. A diagenetical relationship seems less likely. Since in the Namibian Shelf sediment sample investigated virtually no organic compounds are encountered which are derived from terrestrial organisms, both the sterolethers and the long mid chain ketones probably originate from a group of marine organisms. At this moment nothing is known or can be said about the geological fate of these compounds.

Alkan-1,15-diols and alkan-15-one-1-ols. The occurrence of long chain 1,15-diols (III) and alkan-15-one-1-ols (IV) have been reported in the sterol and stanol fractions of Black Sea Unit I and Unit II sediment extracts for the first time (13).

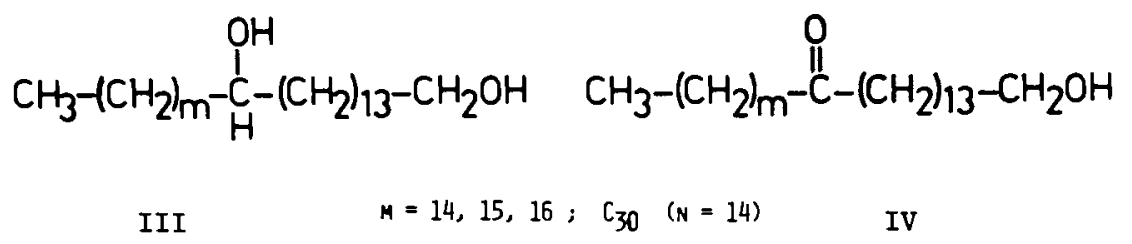

The upper part of two GC-traces are shown in Figure 4. Although these and similar compounds have been reported to occur in other sediments ever since (14), as yet nothing can be said firmly about their biological origin. The identical distribution patterns of the diols and keto-ols point to a tight biochemical relationship in the source organisms whatever they are, although in this case a diagenetical relationship via a partial reduction or oxidation cannot fully be excluded.

Although it is very likely that due to their specific structures and typical distribution patterns the mid-chain ketones, the sterolethers and the long chain 1,15-diols and keto-ols have a high information content and occur as such in living species, we are completely unable to use this information at this moment since we do not know what organisms they reflect and what the geological fate of these compounds is. 

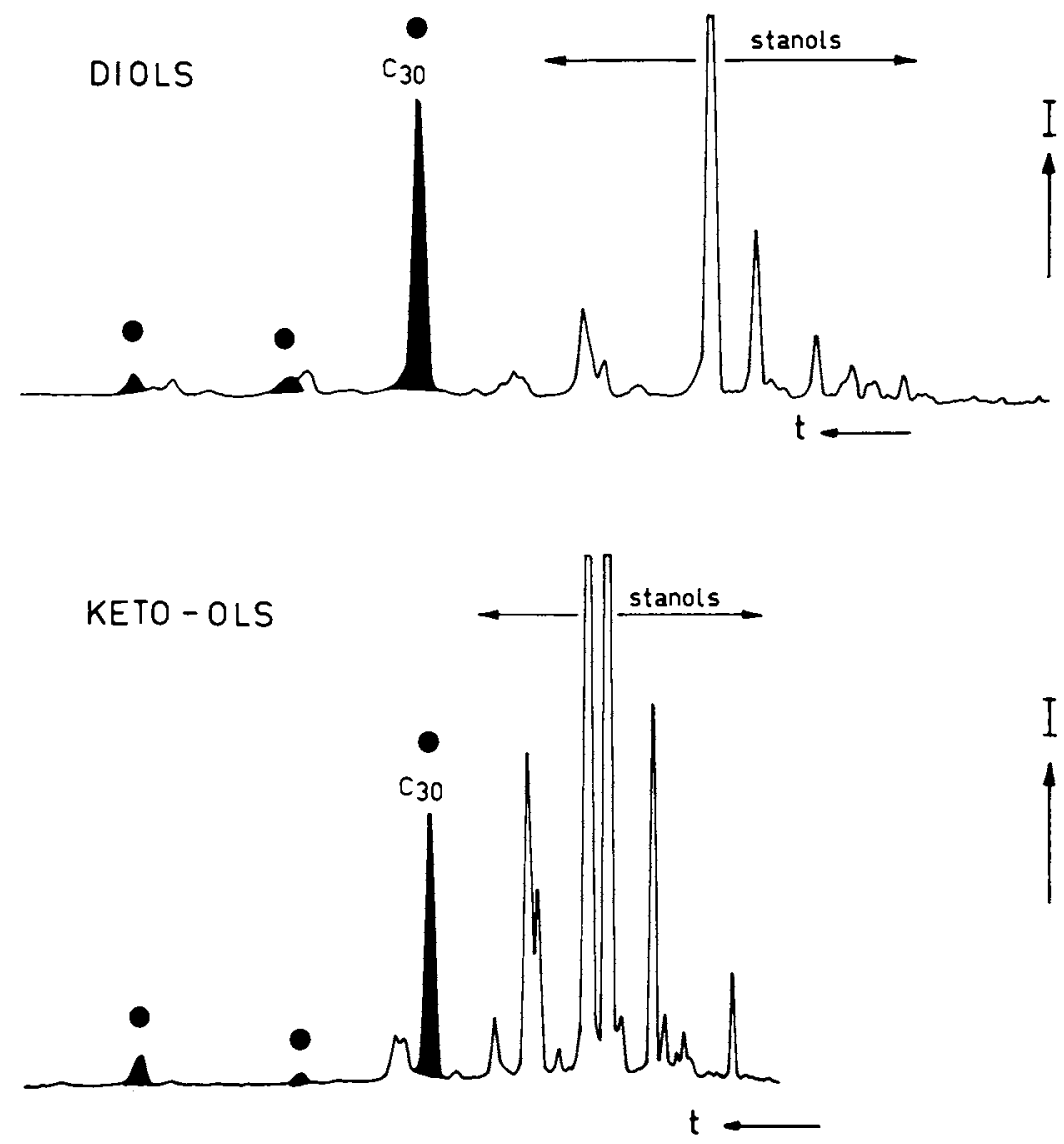

Figure 4. Upper part of GC-traces obtained for two sterol fractions isolated from Black Sea sediment extracts.

In Organic Marine Geochemistry; Sohn, M.; ACS Symposium Series; American Chemical Society: Washington, DC, 1986. 
Alky1- and alken-1-eny1-diacylglycerides. Alky1- and alken-1-eny1diacylglycerides (V, VI) were encountered in both the tissues of the lugworm Arenicola marina and in the intertidal flat sediment of the Wadden Sea (The Netherlands) where these lugworms live (15).<smiles>[R]C(=O)OC[C@H](COC)OC([R])=O</smiles>
$\mathrm{V}$

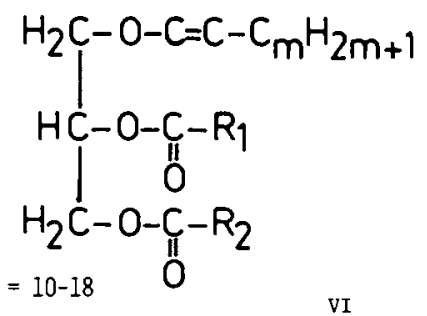

Figure 5 shows the GC-trace of a TLC fraction corresponding with the alkyldiacylglycerides separated from a total extract from the intertidal mud sediment. After TLC-separation the appropriate fraction was hydrolysed and subsequently silylated before GC and GC-MS analysis (15). The relative high abundance of iso-, anteiso and mid chain-methy 1 branched structures in the ether moieties supports a bacterial origin. Whether bacteria biosynthesize these compounds themselves or whether bacterially produced fatty acids are incorporated by other organisms higher up in the food chain, cannot be concluded at this moment. The geological fate of these compounds is as yet completely unknown, although it might be speculated that part of the alkyl moieties released from more ancient sediments after $\mathrm{BBr}_{3}$ treatment originate from these alkylglycerides (16).

Very long chain di- and tri-unsaturated methy 1 and ethyl ketones. The very long polyunsaturated methyl and ethylketones (VII) were first encountered in high concentrations in extracts of Walvis Ridge sediments $(17)$.

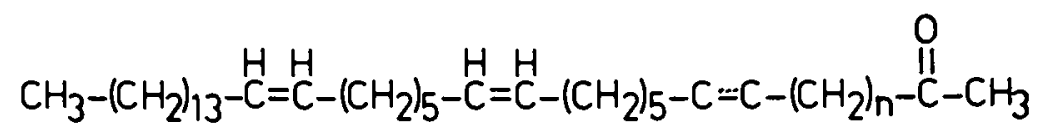

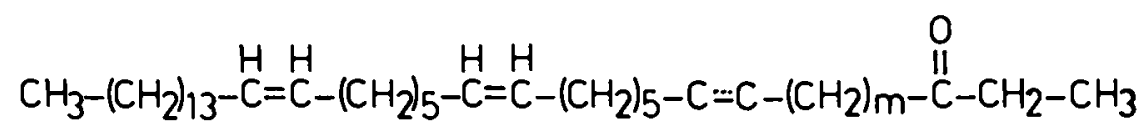

$N=6,7 ; M=5,6$

VII

Later on, their complete structural identification followed (3). Ever since, they have been encountered in many sediment extracts, sometimes together with smaller amounts of the corresponding hydrocarbons and fatty acids (18). By mere luck, these compounds were also 


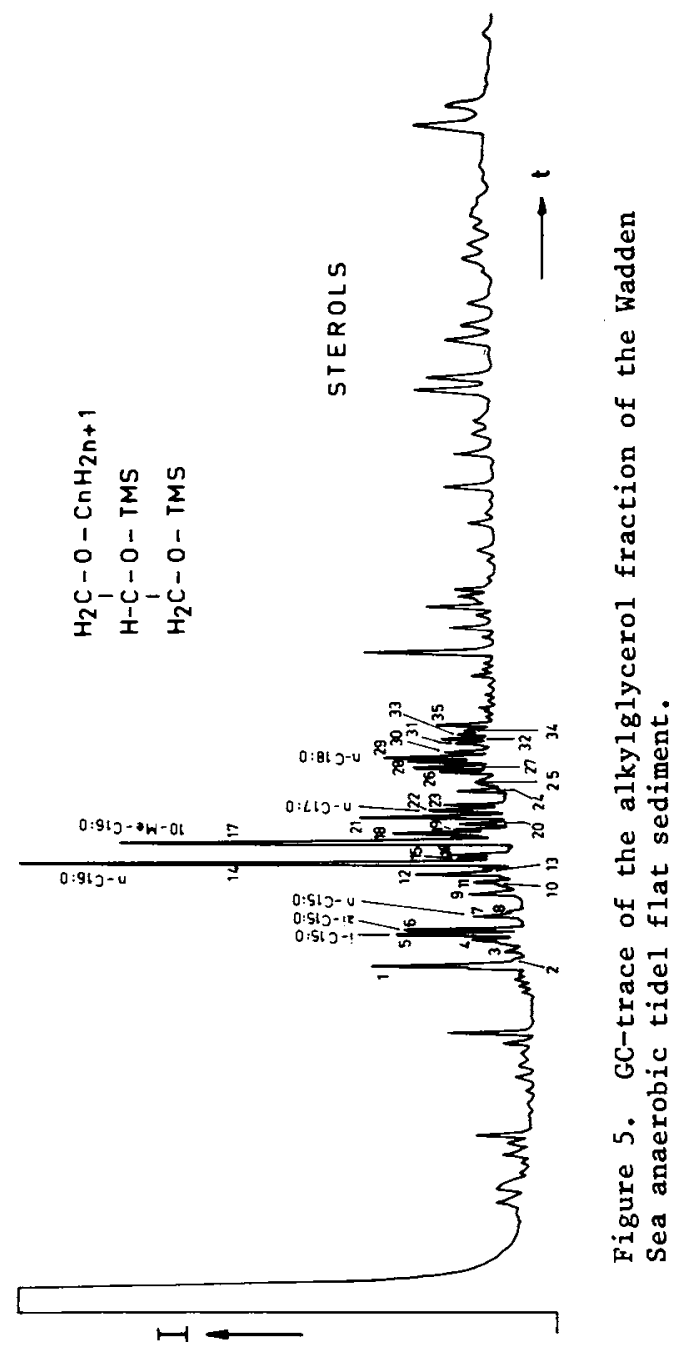

In Organic Marine Geochemistry; Sohn, M.;

ACS Symposium Series; American Chemical Society: Washington, DC, 1986. 
encountered in the widespread coccolithophore Emiliania huxleyi (19). Therefore, these very long chain ketones in sediments were thought to reveal the presence of coccolithophores in the original environment of deposition. When sediments are deposited underneath the calcium compensation depth (CCD) these molecules are then the only entities in the sediment informing us about the original presence of coccolithophores. However, a problem arises about the origin of these compounds since Emiliania huxleyi species first appeared in the fossil record about 250,000 years ago and many sediments which contain these ketones are much older. Recent findings (20) show that these ketones also occur in species of the Isochrysidales, indicating that they are not strictly limited to the true coccolithophorids. Although we at least have some useful ideas now where these sedimentary compounds come from, nothing at all is known about their geological fate.

Methoxy sugars, deoxy sugars and heptoses. Recently we have investigated the occurrence of polysaccharides in a number of recent sediments $(21,22)$. By using the procedure schematically indicated in the upper part of Figure 6, GC and GC-MS traces are obtained which reveal peaks corresponding to alditolacetates obtained from polysaccharides. The GC trace obtained from the deepest sample from a Solar Lake core (Figure 6) exhibits a number of major peaks derived from very common sugars which as far as their structures are concerned are not very informative. The smaller peaks, however, reveal the presence of various methoxy- and deoxy sugars (VIII and IX), which are thought to originate mainly from bacterially produced polysaccharides.<smiles>COC1COC(CO)C(O)C1O</smiles>

3-0-ME-ARA (24) VIII

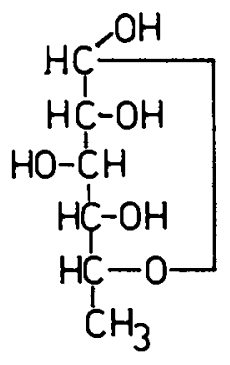

6-DEOXY-GLU (26)

IX<smiles>COC1C(O)C(C(O)CO)OCC1C(O)CO</smiles>

3-0-Me-Heptose $(60)$

$\mathrm{X}$

The heptoses (X) in the upper part of the trace (after "IS") reveal the presence of heptoses which probably indicate an origin from lipopolysaccharides (LPS) occurring in gram-negative bacteria. This possible origin from LPS is supported further by other experiments (see hereafter). Almost nothing is known about the geological fate of these specific sugars or about the polysaccharides in general. This is remarkable since polysaccharides seem to make up a major part of the organic matter in recent sediments (23). The examples given above for the alkylglycerides, the long chain unsaturated ketones and the specific sugar components show that in these cases relatively firm conclusions can be made about their biological origin, but as yet nothing is known about their geological fate. 


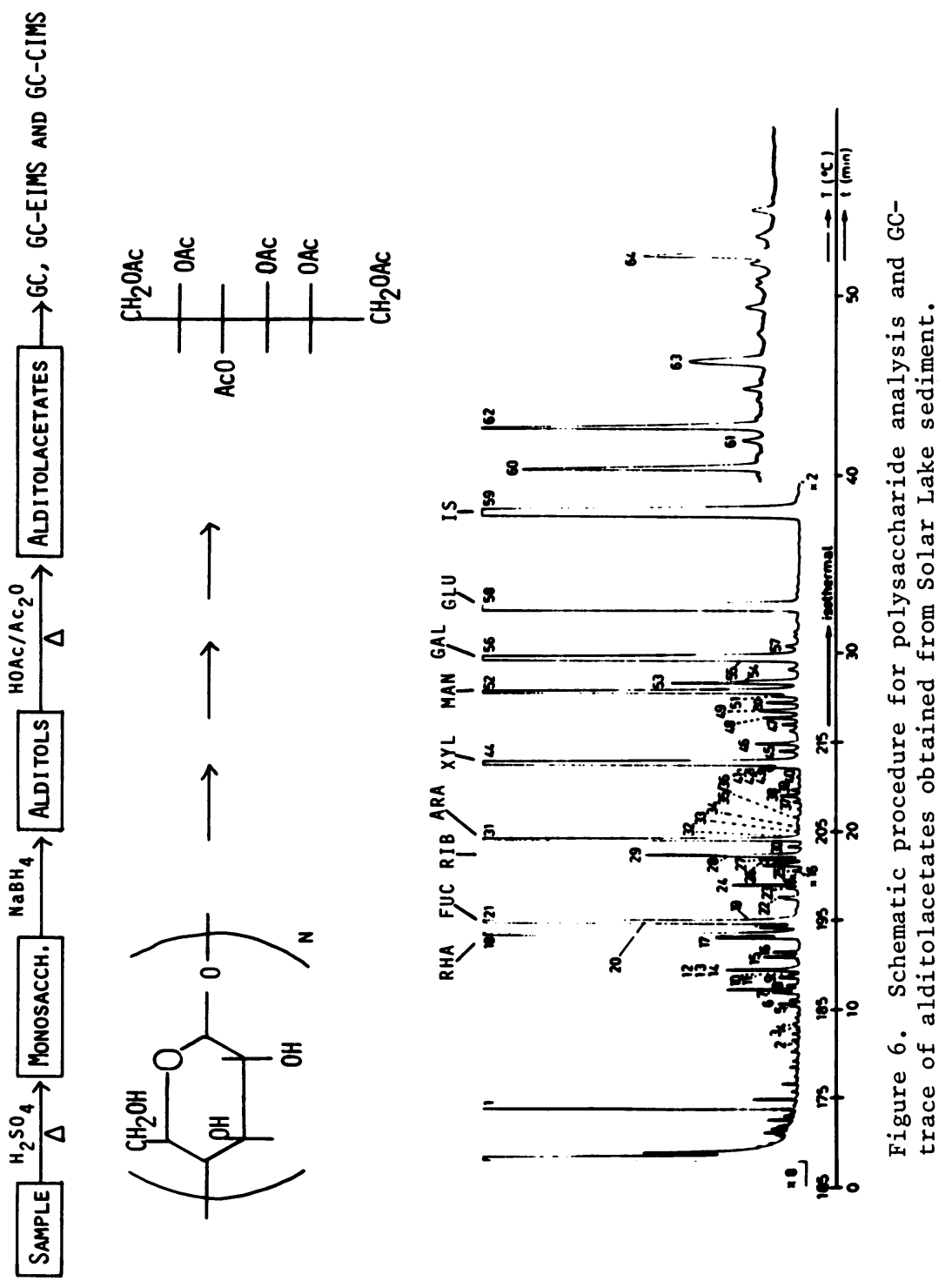

In Organic Marine Geochemistry; Sohn, M.; ACS Symposium Series; American Chemical Society: Washington, DC, 1986. 
4-Methylsteroids. Although 4-methylstanols and 4-methylsteranes are known to occur in recent and ancient sediments, for some time their origin was not very well understood $(24,25)$. However, after the structural elucidation of the so called "Black Sea Sterol" as $4 \alpha-$

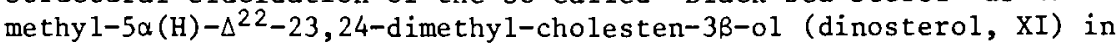
extracts from the Black Sea sapropel layer (Unit II) an origin from dinoflagellates became obvious (2).

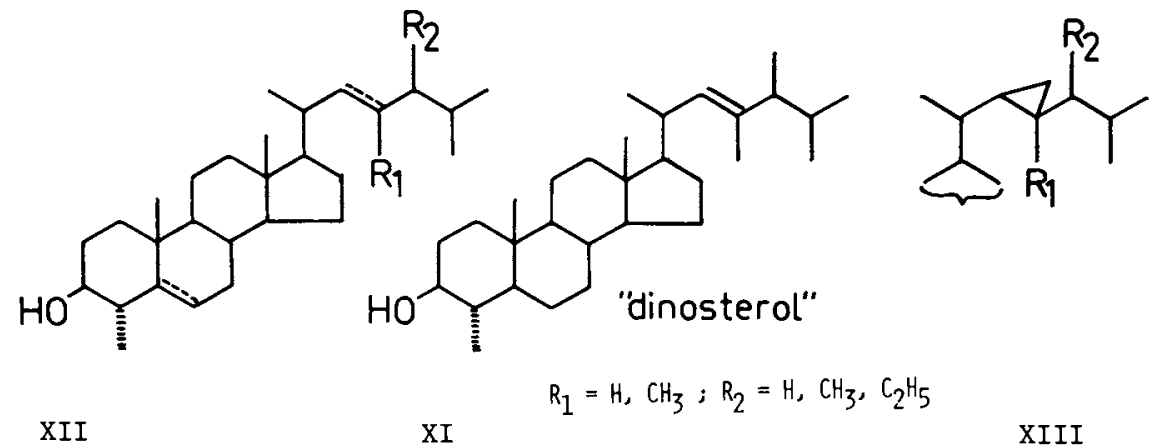

Ever since, dinosterol and many other 4-methylsterols (XII), including 4-methylsteroidketones, have been encountered in many sediments $(8,26,10)$. The large variety of 4 -methylsteroids encountered in a Black Sea Unit I sediment and their modes of occurrence very strongly support an origin from dinoflagellates due to the steadily increasing knowledge of steroids occurring in many species of dinoflagellates $(8,27)$. There are good reasons to believe that the ratio of dinosterol to gorgosterols (XIII), calculated from sediment extracts can inform us about the relative amount of free and symbiotically living dinoflagellates in the depositional environment (28). Because diagenetical pathways of steroids have been studied thoroughly (4), it can be concluded that 4-methyldiasterenes and -steranes present in ancient sediments and oils represent the geological fate of these dinoflagellate sterols. This is, unfortunately, one of the few examples where we believe that we understand both the origin and the fate of a group of sedimentary compounds.

In the above discussed examples we have dealt with sedimentary organic compounds which probably occur as such in living organisms. Hereafter several examples will be discussed in which information is also obtained about diagenetic pathways.

Prist-1-ene. Although prist-1-ene (XIV) does not occur in extracts of sediments, it is a major, sometimes the most abundant pyrolys is product of organic matter in immature sediments (29).<smiles>C=C(C)CCCC(C)CCCC(C)CCCC(C)C</smiles> 
Very recently it was demonstrated that tocopherol moieties in kerogen are likely precursors of prist-1-ene (Figure 7) (30). This idea was supported by the fact that tocopherols are widely distributed in photosynthetic tissues and that they also occur as such in several recent sediments ( 31 ). It is tempting to conclude that during "natural pyrolysis" the generated pristene will be transformed to the well known component, pristane, in ancient sediments and oils. This example nicely illustrates that we have to be very careful when we conclude that acyclic isoprenoid hydrocarbons such as pristane originate from the chlorophyll side chain, phytol, based solely on structural similarities.

Loliolides and dihydroactinidiolide. Although loliolides as such occur in living systems the recently discovered sedimentary loliolides (XV, XVI, XVII) isolated from Namibian Shelf diatomaceous ooze are thought to be compounds which have been generated by very early stage diagenetical pathways from carotenoids in the oxic zone of the water column (32).

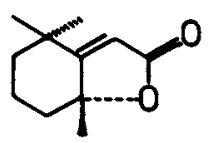

DIH-ACT.<smiles>CC1(C)CC(O)C[C@]2(C)OC(=O)C=C12</smiles>

iso-LOL.<smiles>CC1(C)CC(O)C[C@]2(C)OC(=O)C=C12</smiles>

LOL,

XVI

The conversion suggested in Figure 8 might proceed via the 5,8 furanoxides reported earlier (33). Although the structural features inform us about a possible origin, nothing can be said about subsequent transformation of these molecules upon increasing maturation.

A-nor-steranes and De-A-steranes. De-A-steroid ketones (XVIII), hydrocarbons (XIX) and A-norsteranes (XX) were shown to be present in extracts from Cretaceous black shales in the North Central Apennines $(34,35)$. The De-A-steroidal compounds are thought to be indicative of a diagenetical pathway as shown in Figure 9 . A similar pathway has been suggested for 3-oxy-triterpenoids (36). Although A-nor-steranes are not known to occur in living systems, some sponges can biosynthesize 3B-hydroxymethyl-A-norsteranes from dietary sterols (37). Therefore it is tempting to suggest that the A-nor-steranes originate from certain sponges and that their existance in sediments is the result of a specific diagenetic route (Figure 10).

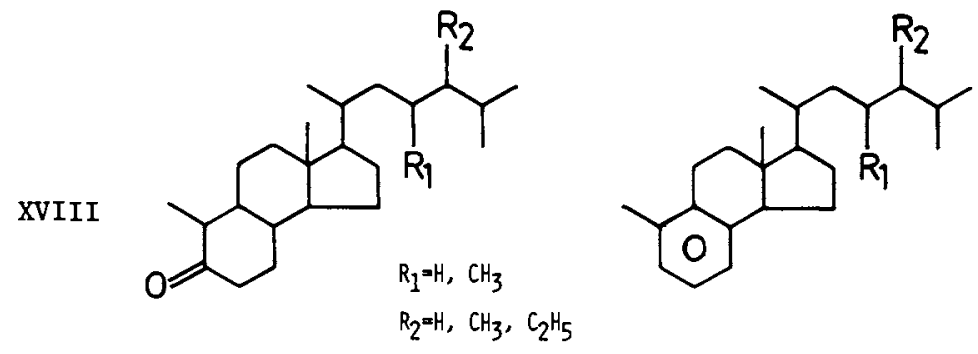




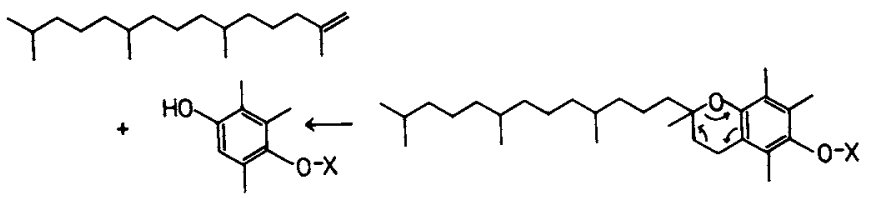

Figure 7. Tocopherols as precursors for pristene and pristane.

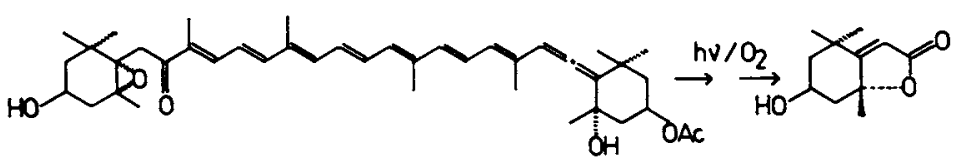

Figure 8. Fucoxanthin as a possible precursor of loliolide.<smiles>CC(C)CCCC(C)C1CCC2C3CC[C@@H](O)C(C)C3CCC12CCC(C)C</smiles>

Figure 9. Possible diagenetic pathway for De-A-steroids.

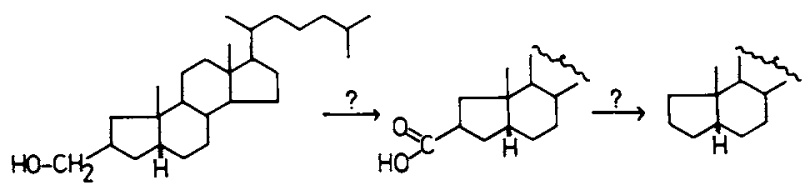

Figure 10. Possible diagenetic pathway for A-nor steroidal hydrocarbons.

\section{American Chemical Society Library 1155 16th St., N.W.

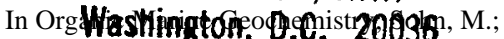


<smiles>[R]C(CC(C)C1CCC2C1CCC1C2CCC2CCCC21C)C([R2])C(C)C</smiles>

$$
\begin{aligned}
& \mathrm{R}_{1}=\mathrm{H}, \mathrm{CH}_{3} \\
& \mathrm{R}_{2}=\mathrm{H}, \mathrm{CH}_{3}, \mathrm{C}_{2} \mathrm{H}_{5}
\end{aligned}
$$

$\mathrm{XX}$

The above discussed 1oliolides, A-nor-steranes and De-A-steranes, are thought to carry information about particular diagenetic pathways since it is assumed that these compounds do not reflect compounds which, as such, occur in living biota. Once a certain pathway is proven, the precursor molecules are known and in this way additional information about the biological origins can be obtained.

As mentioned in the introduction, the information content of sedimentary organic compounds can also be expressed by their mode of occurrence. A general analytical procedure was set up to discriminate lipids which can be extracted as such, which are released after subsequent base treatment, and those which are released after subsequent acid treatment (Figure 11). Complex lipids present in the first extract can be further studied after saponification. The final residue can be investigated by other chemical degradation reactions or by flash pyrolysis. Extracts obtained are not further separated but are derivatized and analyzed by GC and GC-MS $(38,39)$. Since bacterial contributions to sediments are thought to be much more important than originally expected in the organic geochemistry field (40), exactly the same procedure as sketched above was applied to numerous bacteria and to several recent sediments (41). Results are shown here for the photosynthetic sulphur bacterium $\bar{R}$ hodobacter sulfidophilus and for a Mediterranean sapropel $\left(S_{7}, \overline{250,000 \mathrm{yr}_{\text {. }}}\right)$. Figure 12 shows the GC-traces of the directly extractable lipids (-Free-), the lipids released after base treatment of the first residue $\left(-\mathrm{OH}^{-}-\right)$and the lipids after acid treatment of the second residue $\left(-\mathrm{H}^{+}\right)$. Major compounds in both the free and $\mathrm{OH}^{-}$-fractions are the mono unsaturated and saturated $\mathrm{C}_{16}$ and $\mathrm{C}_{18}$-fatty acids and phytol. In this bacterium there obviously is not very much difference between the free and esterified lipids. The third GC-trace $\left(-\mathrm{H}^{+}\right)$, however, shows a completely different pattern. The major components are $\beta$-hydroxy fatty acids representing a very particular distribution pattern $\left(\mathrm{C}_{14}: 0, \mathrm{C}_{20: 1}\right.$ and $\mathrm{C}_{22: 0}$ are major components). The fatty acid composition is also different when compared with the first and second extracts. Besides the $C_{16}$ and $C_{18}$ fatty acids, $\alpha, \beta$-unsaturated $C_{14: 1}$ and $C_{20: 2}$ fatty acids are encountered. An isomeric mixture of dihydroxy fatty acids is also present.

This phenomenon was encountered in a11 gram-negative and cyanobacteria investigated. In most cases, however, the $\beta$-hydroxy fatty acid patterns are restricted to $C_{10}, C_{12}, C_{14}$ and $C_{16}$-components (41). The selective release of the $B$-hydroxy fatty acids upon acid treatment indicates that they are linked via amide bonds to complex substances. From numerous investigations it is well known that amide 


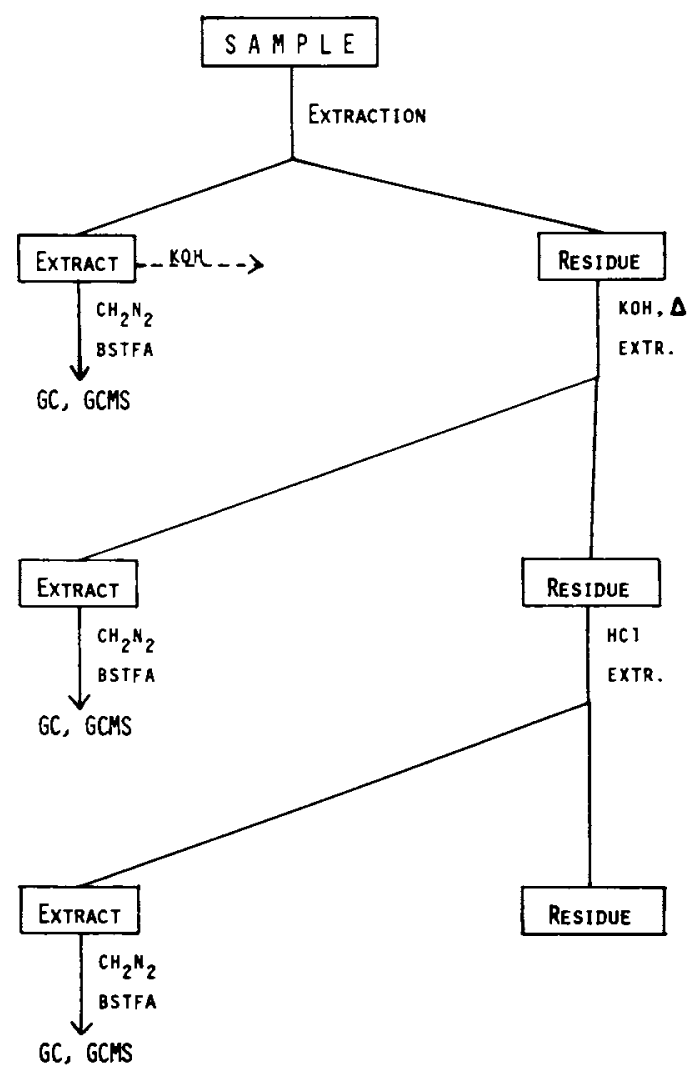

Figure 11. Analytical procedure to discriminate lipids by their mode of occurrence.

In Organic Marine Geochemistry; Sohn, M.; ACS Symposium Series; American Chemical Society: Washington, DC, 1986. 


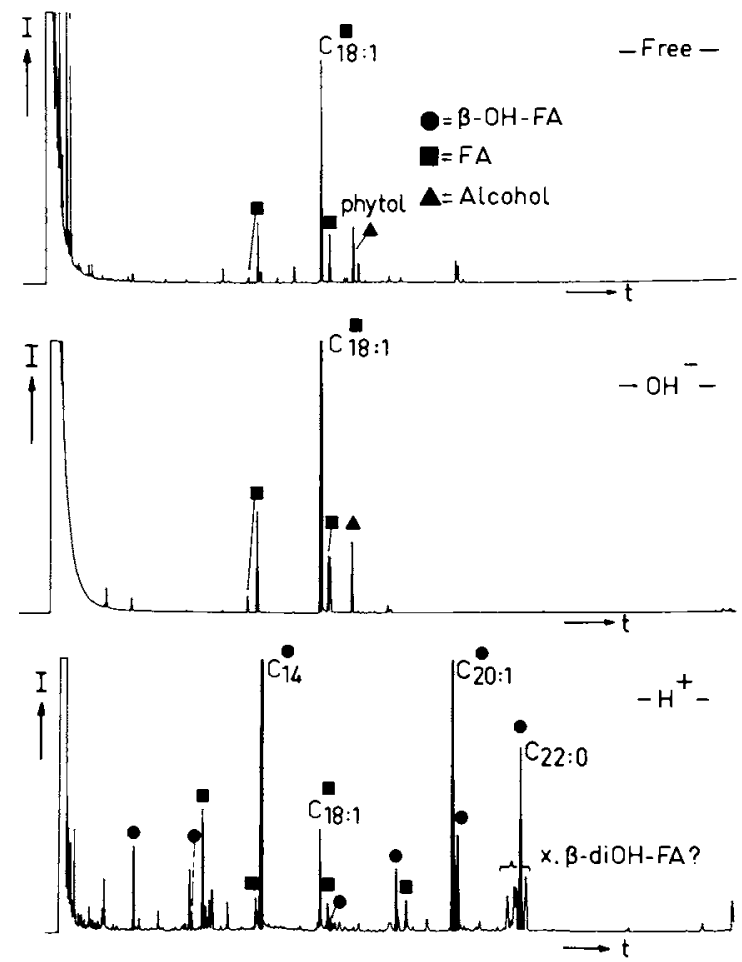

Figure 12. GC-traces of three different lipid fractions of Rhodobacter sulfidophilus.

In Organic Marine Geochemistry; Sohn, M.; ACS Symposium Series; American Chemical Society: Washington, DC, 1986. 
bound B-hydroxy fatty acids occur in bacterial substances like Lipopolysaccharides (LPS) and ornithin lipids $(42,43)$. The schematical drawing of a partial LPS-structure and its occurrence in the bacterial cell (Figure 13) shows the presence of amide linked Bhydroxy fatty acids and esterified fatty acids in this substance. In a separate study of Acinetobacter calcoaceticus it was indeed demonstrated that $\beta$-hydroxy fatty acids from LPS almost exclusively occur in the $-\mathrm{H}^{+}$- fraction when the mentioned isolation procedure is used (38). Using this approach we have studied several recent sediments. One study is discussed here. The fractions "-Free-", "-OH"-" and "-H+_" were obtained from a 225,000 yr old Mediterranean saprope 1 and the GC-traces generated contain all kinds of information (Figure 14). First of all, $B$-hydroxy fatty acids in the $C_{12}-C_{20}$ range, including straight chain-, iso- and anteiso components, are almost exclusively present in the $-\mathrm{H}^{+}$-fraction. Based upon their mode of occurrence (amide-bound), their distribution pattern $\left(C_{12}-C_{20}\right)$ and structural features (iso- and anteiso-branching) it is evident that these compounds originate from LPS and/or ornithine lipid substances and thus represent a bacterial contribution to the sedimentary organic matter. The almost exclusive presence of phytol in the $-\mathrm{OH}^{-}-$ fraction indicates that phytol is present in an esterified mode, probably as the phytol moiety in chlorophylls. The $\mathrm{C}_{30} \mathrm{O}^{-\mathrm{diol}}$ and keto01 as well as the very long unsaturated methyl- and ethylketones ("VLUK") occur as free lipids only, which is in agreement with their mode of occurrence noticed before in sediments and organisms. The fatty acids show different distribution patterns in the three fractions indicating that in this case, much information is hidden in the mode of occurrence.

Due to the GC and GC-MS analyses of whole extracts without any further separation, several classes of compounds with their own distribution patterns are visualized simultaneously in one gas chromatogram or total ion current trace. Comparison of these "total profiles" obtained from organic compounds of different sediments, from organisms, from recognizable geological macrostructures, etc., is another way by which information can be expressed. Figure 15 illustrates this approach. Extracts were obtained from a Mediterranean sapropel $\left(S_{1}, 8000\right.$ yr BP) and from fossil oak cuticles (Miocene) after base treatment of both samples. Without separation, these extracts were derivatized and analyzed by GC and GC-MS. Comparison of the total profiles shows that there is a striking similarity in the n-alkane, the fatty acid and the alcohol distribution patterns and in the alkane/fatty acid/alcohol ratios within the $\mathrm{C}_{22}-\mathrm{C}_{32}$ chain length region. Such a similarity, which is easily observed using this "total profiles" approach, indicates that a considerable part of the organic matter present in the sapropel is derived from plant cuticles which have been fluvially transported to this marine sediment. If this reasoning is correct, the mechanism of sapropel formation, as proposed by Rossignol-strick (44), is firmly supported by these observations.

Finally, some ongoing investigations are discussed dealing with the search for new information carriers among the organic compounds in sediments. One way to search for new informative compounds is to study organic compounds isolated from sediments which are well documented by other scientific disciplines. As an example, some results are shown from a Miocene sediment sample from the Northern 


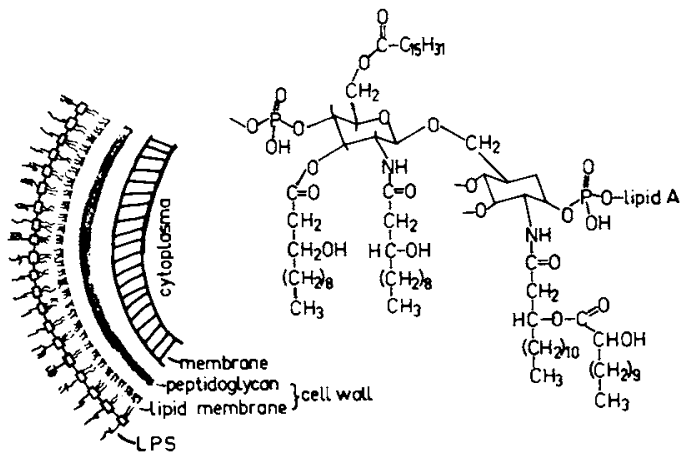

Figure 13. Schematical drawing of partial LPS-structure.
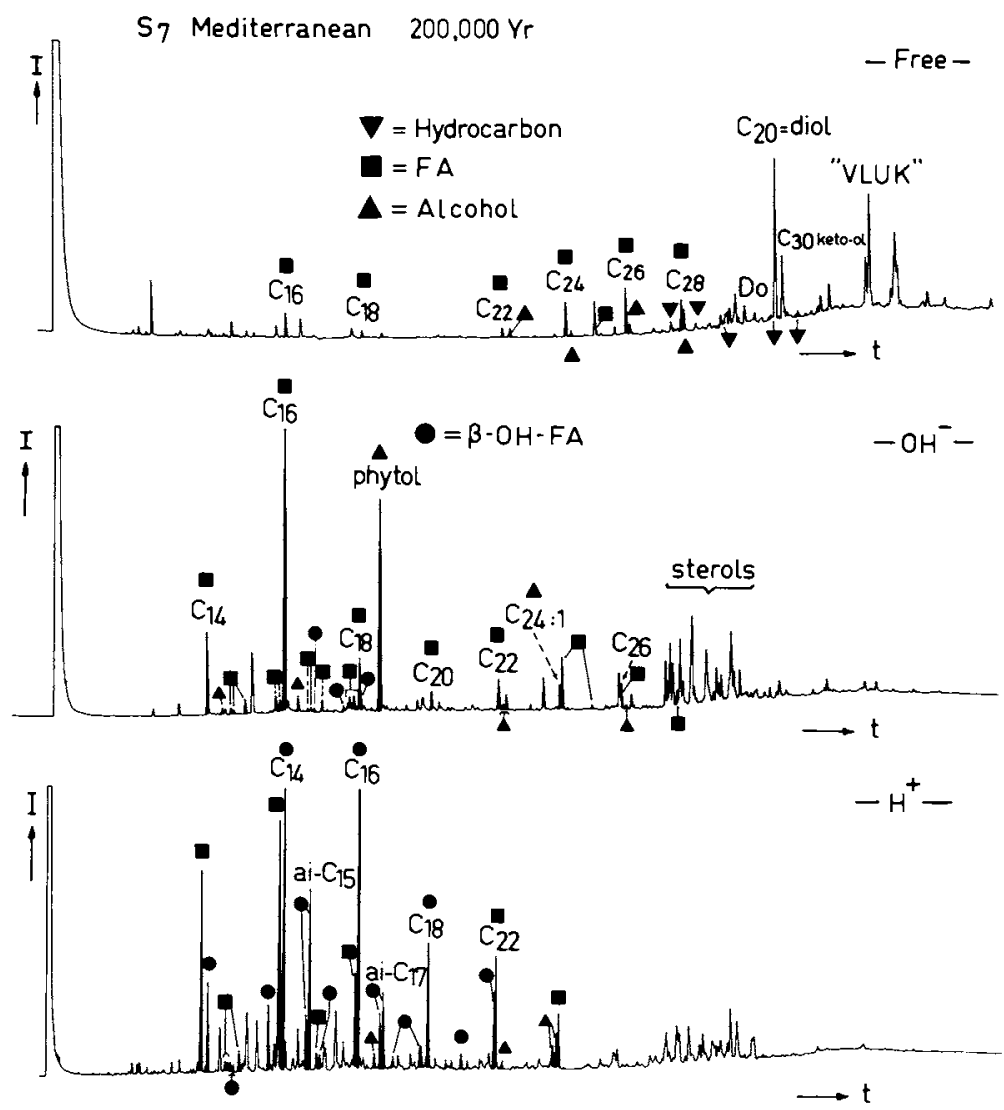

Figure 14. GC-traces of three different lipid fractions of the $\mathrm{S}_{7}$ Mediterranean sapropel extracts.

In Organic Marine Geochemistry; Sohn, M.; ACS Symposium Series; American Chemical Society: Washington, DC, 1986. 


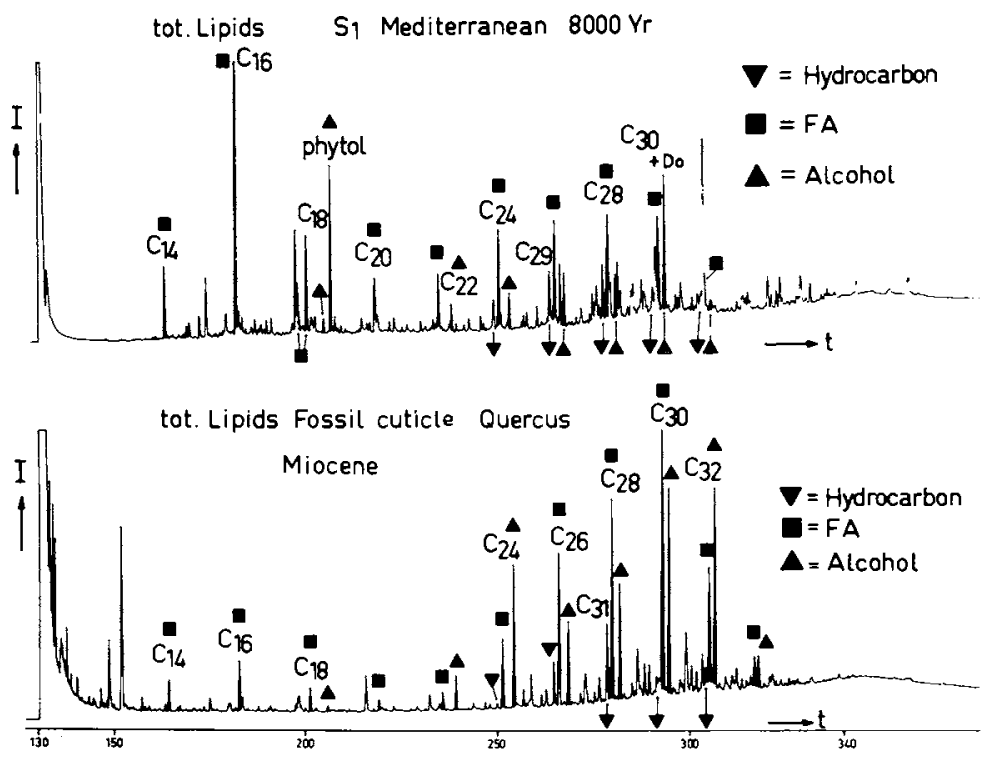

Figure 15. Total profiles of 1 ipids from an $S_{1}$ Mediterranean sapropel and from a fossil cuticle.

In Organic Marine Geochemistry; Sohn, M.; ACS Symposium Series; American Chemical Society: Washington, DC, 1986. 
Apennines which consists mainly of gypsum and marl layers and which has been deposited under hypersaline conditions (6). The gas chromatogram of the hydrocarbon fraction (urea non adduct) of the mar1 is shown in Figure 16. Figure 17 shows the hydrocarbon fraction of the gypsum layer. A number of phenomena are observed. The phytanepristane ratio is very high $(\geq 10)$ in both samples and a small even over odd predominance of the n-alkanes is noted in the gypsum sample. Extended $\Delta^{17(21)}$-hopenes are present in the mar1. The most abundant compounds in the gypsum sample are $14 \alpha(\mathrm{H}), 17 \alpha(\mathrm{H})-$ and $148(\mathrm{H}), 178(\mathrm{H})-$ pregnanes and homopregnanes. Further, a more or less typical pattern of $\alpha, \beta$-norhopane, $\alpha, \beta$-hopane and gammacerane is present in this sample. Several of these phenomena have been noticed before (45) in sediments which might have been deposited under hypersaline conditions. Some features were also observed in a recent Sabkha environment (39). Table II summarizes the phenomena mentioned.

Table II. Characteristics of Hypersaline Depositional Sedimentary Environments

Phenomena:

- phytane $\gg$ pristane (phythenes; diphytanylethers)

- isoprenoid and other thiophenes and thiolanes?

- pregnanes and homopregnanes

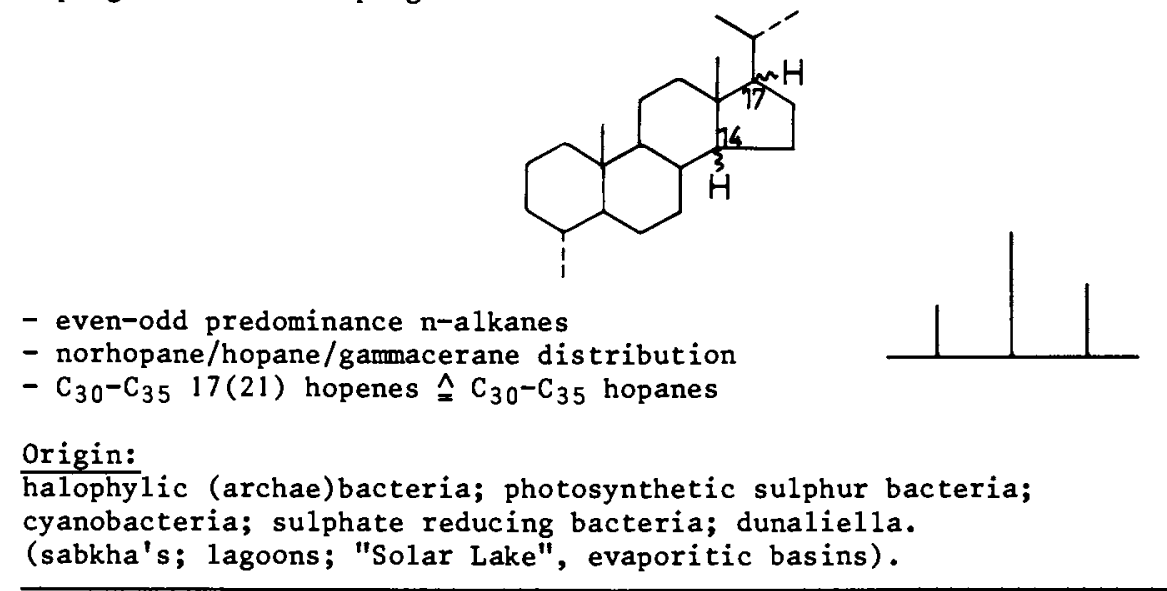

Further work is necessary to better understand and apply the obvious information present. For example, one wonders whether the high phytane/pristane ratio is the result of relatively high amounts of phytenes and/or diphytanylethers present in (halophilic) archaebacteria and is not at all an indication for anoxicity $(\underline{46}, \underline{47})$.

The isoprenoid thiophene compound shown in Figure 16 has been observed in other sediments also (48). Inspection of the so called aromatic hydrocarbon fraction of the marl sample with GC-FID, GC-FPD and GC-MS revealed the abundant presence of this compound. Moreover, this fraction is composed, for the most part, of organic sulphur compounds, as can be judged from the GC-trace shown in Figure 18. Other isoprenoid thiophenes, short chain and long chain benzo- 


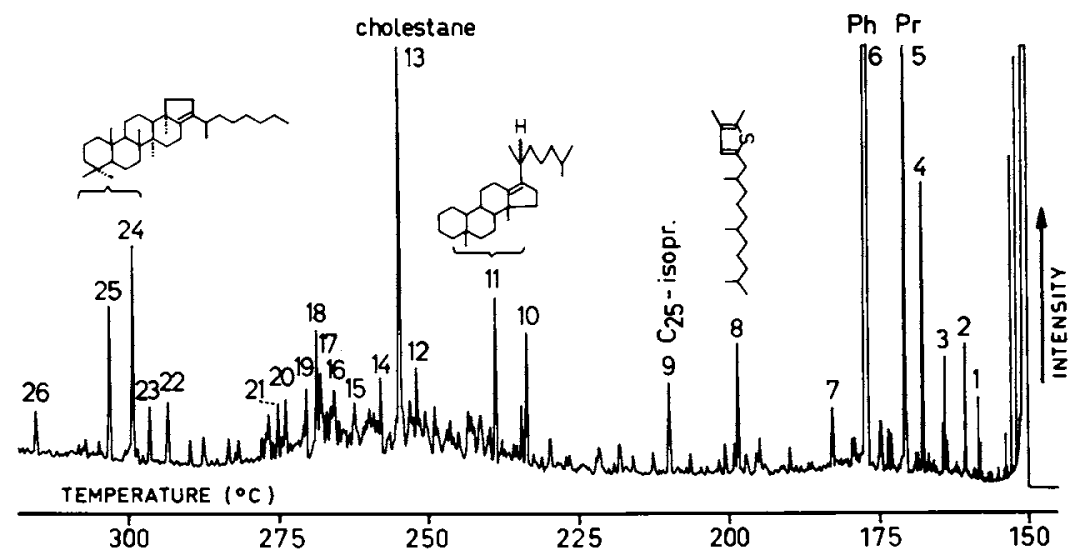

Figure 16. GC-trace of the hydrocarbon fraction (non adduct) of the marl extract of Sarsina sediment.

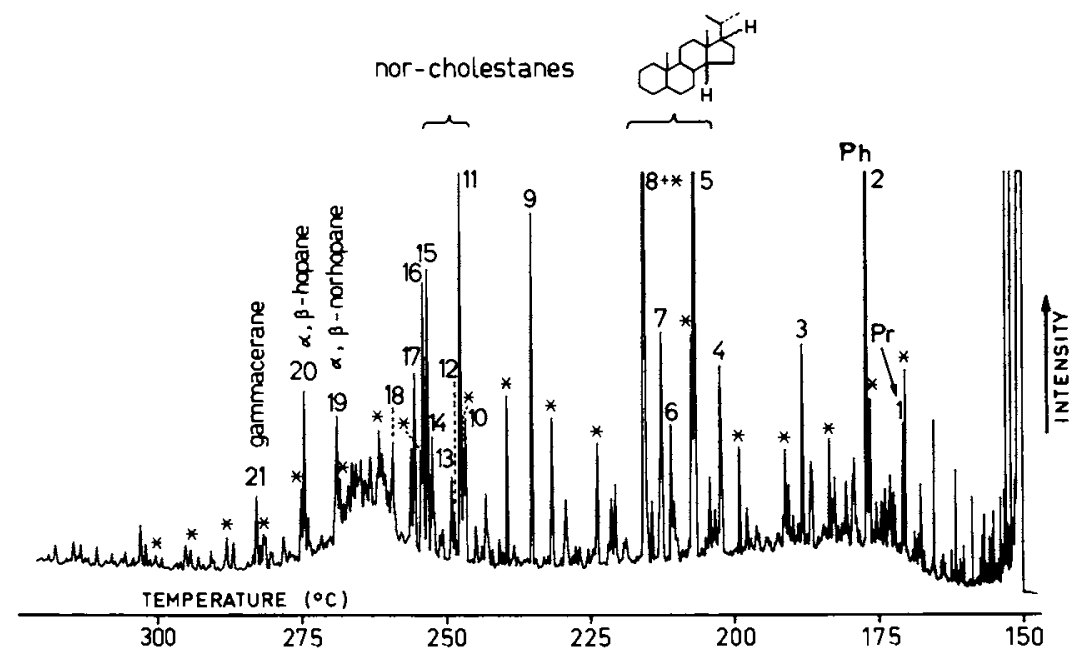

Figure 17. GC-trace of the hydrocarbon fraction of gypsum extract of Sarsina sediment.

In Organic Marine Geochemistry; Sohn, M.; ACS Symposium Series; American Chemical Society: Washington, DC, 1986. 


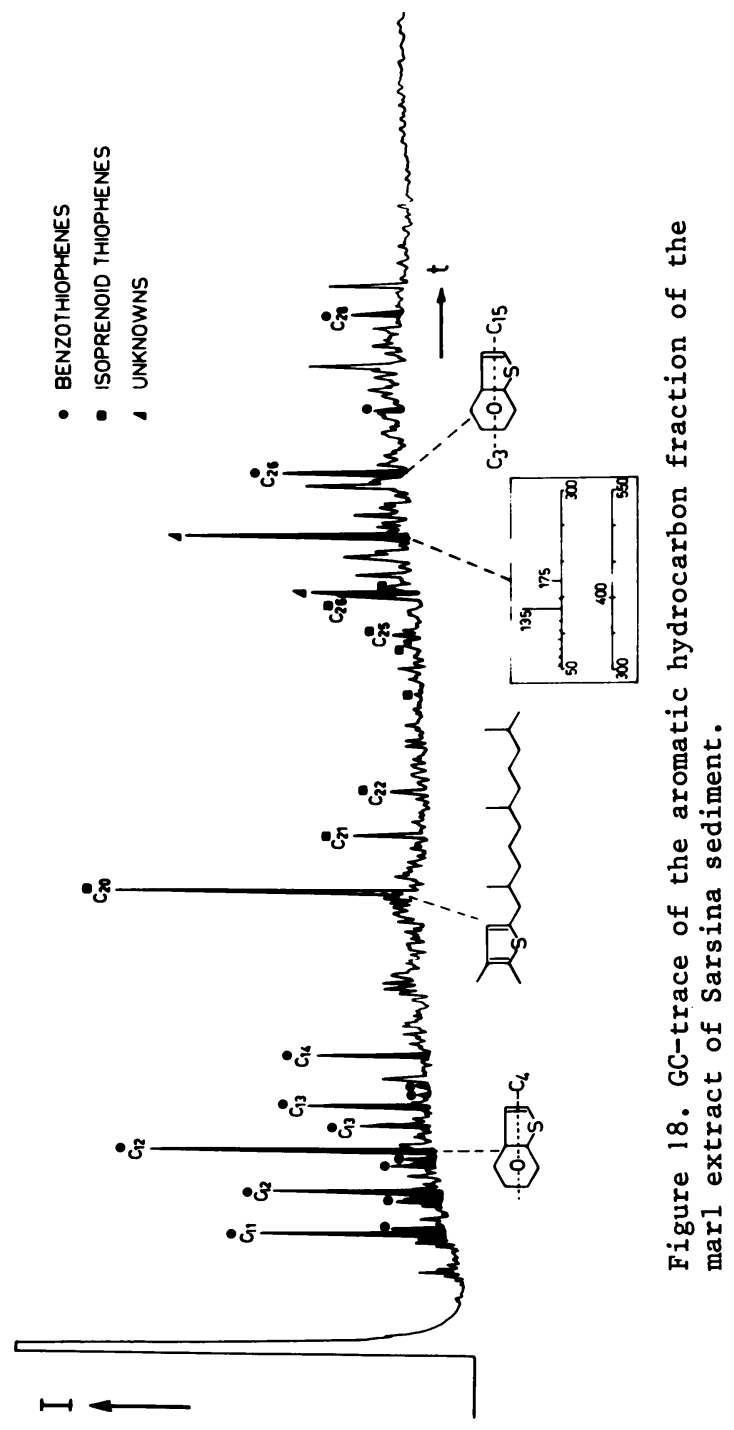

In Organic Marine Geochemistry; Sohn, M.; ACS Symposium Series; American Chemical Society: Washington, DC, 1986. 
thiophenes are also major compounds in this fraction. At the moment we can only speculate about the origin of these new organic sulphur compounds. It was shown by comparis on with a synthesized standard, that one of these isoprenoid thiophenes occurred as a single stereoisomer in a Cariaco Trench sediment sample (48). Therefore, we assume that these compounds are formed during the very early stages of diagenesis. Even a direct origin from organisms (sulphur reducing or oxidizing bacteria) cannot be ruled out at this stage.

A further separation by column chromatography yielded various fractions of the Sarsina aromatic hydrocarbon fraction. Homologous series of n-alkyl thiophenes with peculiar distribution patterns were observed by mass-chromatography generated after analysis of a particular fraction by GC-MS (see Figure 19). The $C_{1}$ substituted nalkylthiophenes $(\mathrm{m} / \mathrm{z}=111)$ exemplified an identical pattern as the n-alkane pattern; a clear odd/even predominance and $\mathrm{C}_{29}$ as the major component. The $\mathrm{C}_{2}$-substituted $\mathrm{n}$-alkyl thiophenes $(\mathrm{m} / z=125)$ showed similar patterns but in this case there is an even/odd predominance and $\mathrm{C}_{30}$ is now the major component. The same shift is observed when the $\mathrm{C}_{3}-$ and $\mathrm{C}_{4}$-substituted n-alkyl thiophenes $(\mathrm{m} / \mathrm{z}=139$ and 153 respectively) traces are observed. Although this kind of distribution pattern information is very clear in itself, the explanation has to await further studies. The characteristic patterns indicate, however, that an occurrence of compounds possessing long chain n-alkyl thiophene moieties in living biota is not unlikely.

Another striking distribution pattern was observed for isomeric mixtures of n-alkyl thiolanes observed in a fraction of Rozel Point oil. Figure 20 shows the GC-FPD trace of this fraction. Every major peak consists of numerous isomers (different values for $n$ an $m$ but per peak $n+m=$ constant) of these thiolanes. It is remarkable to see that the overall distribution pattern is very similar to fatty acid patterns in young sediments. This might be another indication that these thiolanes are either formed during early stages in the diagenesis or that they are present as such or in a functionalized form in organisms.

The above mentioned organic sulphur compounds represent new information but more work is necessary to trace their origin. To summarize, it can be stated that at this moment our knowledge about the information content of sedimentary organic compounds is increasing steadily. However, much more work is necessary to better understand the different ways by which the information contents are expressed before all information can be used efficiently to reconstruct paleo-environments. To better understand the information carried by sedimentary organic molecules we have to tune our analytical extraction and isolation procedures in such a way that modes of occurrences of lipids and total lipid profiles are optimally expressed without losing structural information of individual compounds or compound class distribution patterns. 


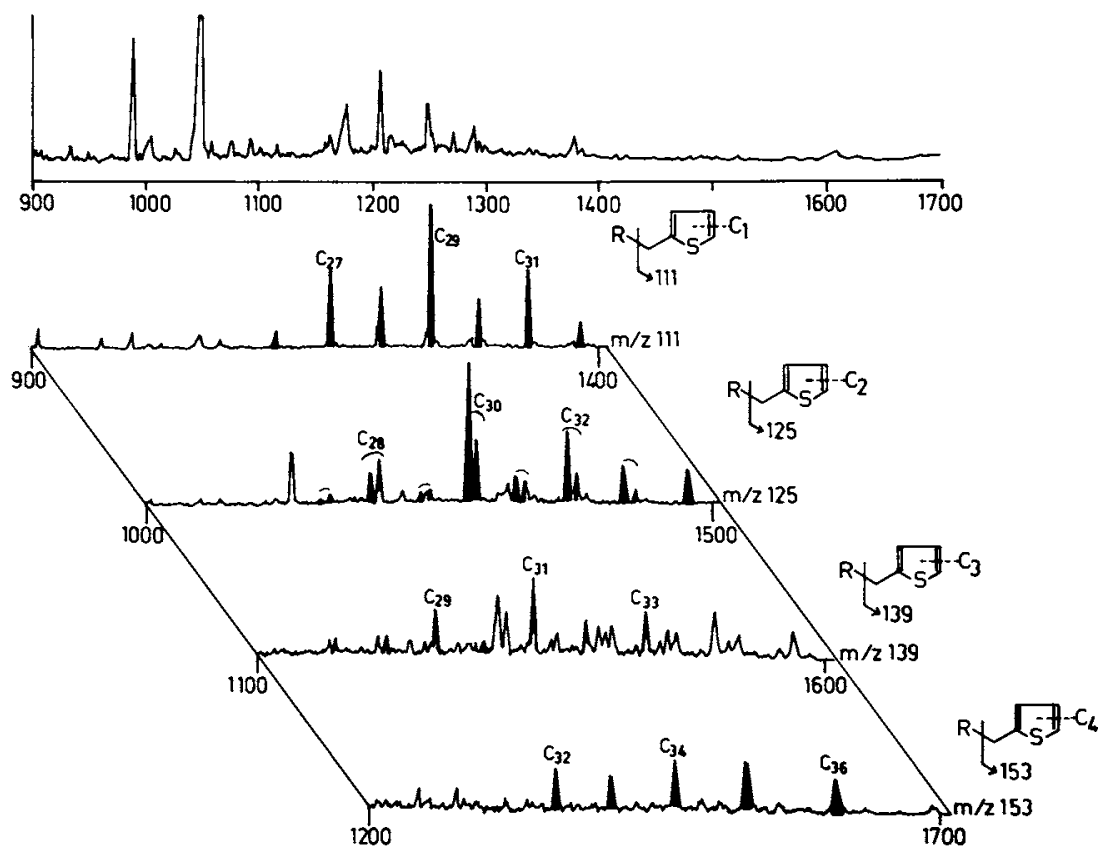

Figure 19. Mass chromatograms showing the distribution patterns of several groups of n-alkylthiophenes present in a Sarsina marl aromatic hydrocarbon fraction.

In Organic Marine Geochemistry; Sohn, M.; ACS Symposium Series; American Chemical Society: Washington, DC, 1986. 


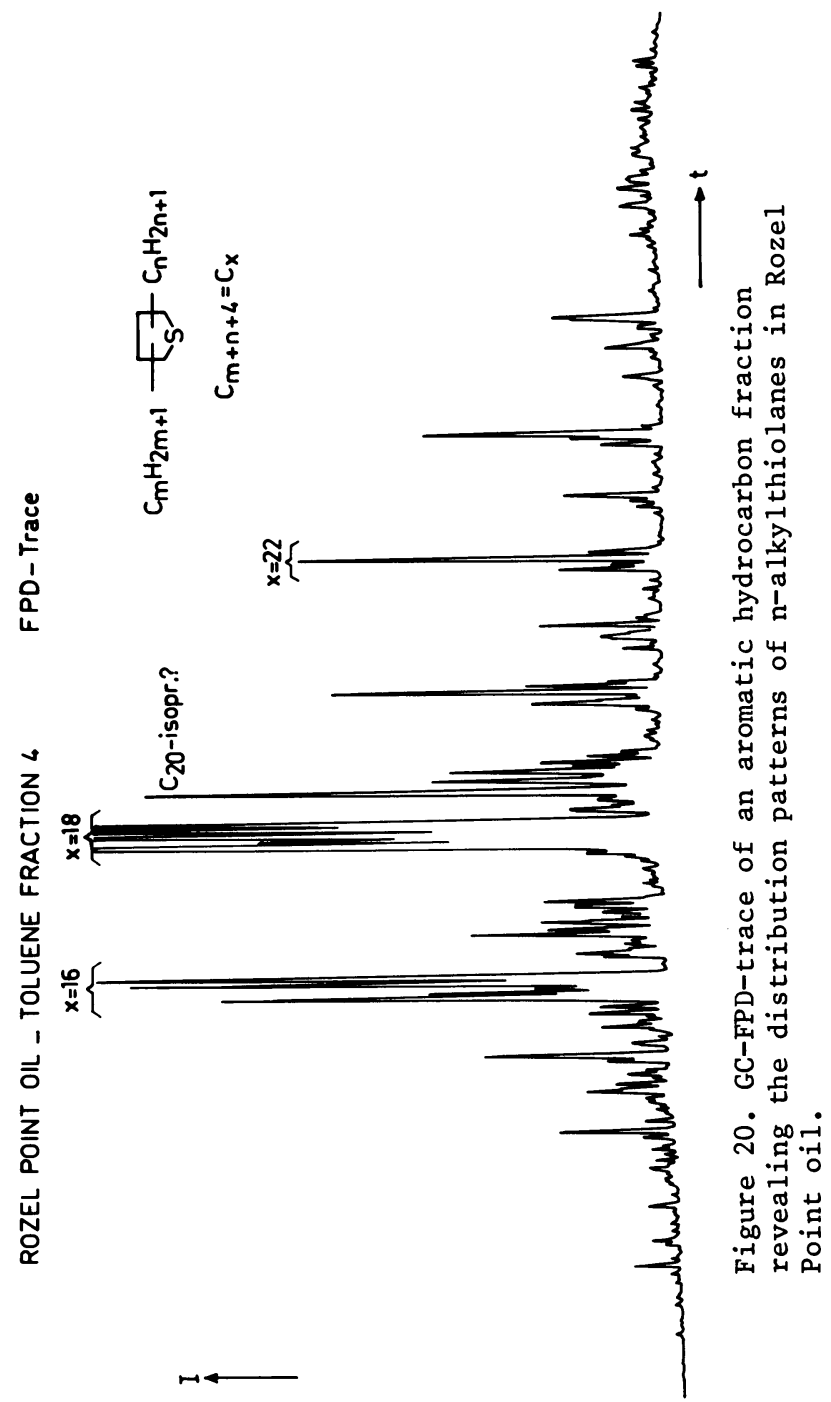

In Organic Marine Geochemistry; Sohn, M.;

ACS Symposium Series; American Chemical Society: Washington, DC, 1986. 


\section{Literature Cited}

1. Ourisson, G.; Albrecht, P.; Rohmer, M. Pure App1. Chem. 1979, 51, 709-729.

2. Boon, J.J.; Rijpstra, W.I.C.; de Lange, F.; de Leeuw, J.W.; Yoshioka, M.; Shimizu, Y. Nature 1979, 227, No. 5692, 125-127.

3. de Leeuw, J.W.; van der Meer, F.W.; Rijpstra, W.I.C.; Schenck, P.A. In "Advances in Organic Geochemistry 1979"; Douglas, A.G.; Maxwe11, J.R., Eds.; Pergamon Press, 0xford, 1980; p. 211.

4. Mackenzie, A.S.; Brassel1, S.C.; Eglinton, G.; Maxwe1l, J.R. Science 1982, 217, 491-504.

5. Simoneit, B.R.T. Geochim. Cosmochim. Acta 1977, 41, 463.

6. ten Haven, H.L.; de Leeuw, J.W.; Schenck, P.A. Geochim. Cosmochim Acta 1985, in press.

7. Cranwe11, P.A. Org. Geochem. 1984, 7, 25-37.

8. de Leeuw, J.W.; Rijpstra, W.I.C.; Schenck, P.A.; Volkman, J.K. Geochim. Cosmochim. Acta 1983, 47, 455-465.

9. Boon J.J.; de Leeuw, J.W. Mar. Chem. 1979, 7, 117-132.

10. Brasse11, S.C. Ph.D. Thesis, Bristol University, Bristo1, 1980.

11. Funasaki, J.; Gilbertson, J.R. J. Lipid Res. 1968, 9, 766-768.

12. Kolattukudy, P.E.; Croteau, R.; Buckner, J.S. In "Chemistry and Biochemistry of Natural Waxes"; Kolattukudy, P.E., Ed.; Elsevier; Ams terdam, Oxford, New York, 1976; p. 294.

13. de Leeuw, J.W.; Rijpstra, W.I.C.; Schenck, P.A. Geochim. Cosmochim. Acta 1981, 45, 2281-2285.

14. Smith, D.J. Ph.D. Thesis, Bristol University, Bristol, 1984.

15. Liefkens, W.; Boon, J.J.; de Leeuw, J.W. Neth. J. of Sea Res. $1979,13(3 / 4), 479-486$.

16. Chappe, B.; Michaelis, W.; Albrecht, P. In "Advances in Organic Geochemistry 1979"; Douglas, A.G.; Maxwe11, J.R., Eds.;

Pergamon Press, Oxford, 1980, p. 265.

17. Boon, J.J.; van der Meer, F.W.; Schuy 1, P.J.W.; de Leeuw, J.W.; Schenck, P.A. Init. Rep. of the Deep Sea Drill. Proj. XL. 1978, 627-637.

18. Marlowe, I.T.; Brasse11, S.C.; Eglinton, G.; Green, J.C. In "Advances in Organic Geochemistry 1983"; Schenck, P.A.; de Leeuw, J.W.; Lijmbach, G.J.W., Eds.; Pergamon Press, Oxford, 1984, p. 135.

19. Volkman, J.K.; Eglinton, G.; Corner, E.D.S.; Sargent, J.R. In "Advances in Organic Geochemistry 1979"; Douglas, A.G.; Maxwe11, J.R., Eds.; Pergamon Press, Oxford, 1980, p. 219.

20. Marlowe, I.T.; Green, J.C.; Neal, A.C.; Brasse11, S.C.; Eglinton, G.; Course, P.A. Br. Phyco1. J. 1984, 19, 203-216.

21. Klok, J.; Cox, H.C.; Baas, M.; Schuyl, P.J.W.; de Leeuw, J.W.; Schenck, P.A. Org. Geochem. 1984, 7, No. 1, 73-84.

22. Klok, J.; Cox, H.C.; Baas, M.; de Leeuw, J.W.; Schenck, P.A. Org. Geochem. 1984, 7, No. 2, 101-109.

23. Klok, J.; Baas, M.; Cox, H.C.; de Leeuw, J.W.; Rijpstra, W.I.C.; Schenck, P.A. In "Advances in Organic Geochemistry 1983";

Schenck, P.A.; de Leeuw, J.W.; Lijmbach, G.J.W.; Eds.; Pergamon Press, Oxford, 1984, p. 265.

24. Mattern, G.; Albrecht, P.; Ourisson, G. Chem. Comm. 1970, 15701571 .

25. Rubinstein, I.; Strausz, 0.P. Geochim. Cosmochim. Acta 1979, 43, $1387-1392$. 
26. Gagosian, R.B.; Smith, S. Nature 1979, 277, 287-289.

27. Kokke, W.C.M.C.; Fenica1, W.; Djerassi, C. Phytochem. 1981, 20, 127-134.

28. Djerassi, C. Pure App1. Chem. 1981, 53, 873-890.

29. Larter, S.R.; Solli, H.; Douglas, A.G.; de Lange, F.; de Leeuw, J.W. Nature 1979, 279, No. 5712, 405-408.

30. Goossens, H; de Leeuw, J.W.; Schenck, P.A.; Brasse11, S.C. Nature 1984,312 , No. 5993, 440-442.

31. Brasse11, S.C.; Eglinton, G.; Maxwe11, J.R. Biochem. Soc. Trans. $1983,11,575-586$.

32. Klok, J.; Baas, M.; Cox, H.C.; de Leeuw, J.W.; Schenck, P.A. Tetr. Hedr. Lett. 1984, 25, No. 48, 5577-5580.

33. Repeta, D.J.; Gagosian R.B.; In "Advances in Organic Geochemistry 1981"; Bjorøy, M., Ed.; John Wiley, Chichester, 1983; p. 380.

34. van Graas, G.; de Lange, F.; de Leeuw, J.W.; Schenck, P.A. Nature 1982 , 296, No. 5852, 59-61.

35. van Graas, G.; de Lange, F.; de Leeuw, J.W.; Schenck, P.A. Nature 1982 , 299, No. 5882, 437-439.

36. Schmitter, J.M.; Arpino, P.J.; Guiochon, G. Geochim. Cosmochim. Acta 1981, 45, 1951-1955.

37. Bohlin, L.; Sjöstrand, U.; Djerassi, C. JCS Perkin I 1981, 10231028.

38. Goossens, H.; de Leeuw, J.W.; Rijpstra, W.I.C.; Meijburg, G.J.; Schenck, P.A. Geochim. Cosmochim. Acta, submitted.

39. de Leeuw, J.W.; Sinninghe Damsté, J.S.; Klok, J.; Schenck, P.A.; Boon, J.J. In "Hypersaline Ecosystems - The Gavish Sabkha"; Krumbein, W.E., Ed.; Springer, Heidelberg; 1985, p. 350.

40. Ourisson, G.; Albrecht, P.; Rohmer, M. Scient. Amer. 1984, 251, 34-41.

41. Goossens, H.; Rijpstra, W.I.C.; Düren, R.R.; de Leeuw, J.W.; Schenck, P.A. Org. Geochem. submitted.

42. Lechevalier, M.P. Crit. Rev. Microbiol, 1977, 7, 109-210.

43. Galanos, C.; Lüderitz, 0.; Rietsche1, E.T.; Westphal, 0. In "Biochemistry of Lipids II"; Goodwin, T.W., Ed.; University Park Press, Baltimore, 1977; Vo1. 14, p.239.

44. Rossignol-Strick, M.; Nesteroff, W.; Olive, P.; Vergnaud-Grazzini, C. Nature 1982, 295, 105-110.

45. Sinninghe Damsté, J.S.; ten Haven, H.L.; de Leeuw, J.W.; Schenck, P.A. Org. Geochem., submitted.

46. Didyk, B.M.; Simoneit, B.R.T.; Brassel1, S.C.; Eglinton, G. Nature 1978, 272, 216-222.

47. Holzer, G.; Oro, J.; Tornabene, T.G. J. of Chromat. 1979, 186, 795-809.

48. Brasse11, S.C.; Lewis, C.A.; de Leeuw, J.W.; de Lange, F.; Sinninghe Damsté, J.S. Nature, submitted.

RECEIVED September 23, 1985 


\title{
Phenolic and Lignin Pyrolysis Products of Plants, Seston, and Sediment in a Georgia Estuary
}

\author{
Jean K. Whelan ${ }^{1}$, Martha E. Tarafa ${ }^{\prime}$, and Evelyn B. Sherr ${ }^{2}$
}

IChemistry Department, Woods Hole Oceanographic Institution, Woods Hole, MA 02543

${ }^{2}$ University of Georgia Marine Institute, Sapelo Island, GA 31327

\begin{abstract}
Phenolic and lignin pyrolysis products measured in plants, seston, and sediment in a Georgla estuary together with isotoplc data suggest that vascular plant material is present in estuarine organic matter pools. The pyrolysis products together with 1sotopic patterns of this plant material do not resemble those obtained from Spartina. The pyrolysis-GC-MS data also gave indications of changes in distribution of methoxy phenollc compounds in going from plant materlals to solls and seston, which could be due to elther degradation processes or to a change in source In seston and sediments. These phenolic and methoxyphenolic pyrolysis products have generally not been detected to date in elther surface or sub-surface deep ocean sediments from several areas of the world. The combination of 1sotopic data, together w1th $11 \mathrm{~g}-$ nin and higher plant pyrolysis products, appears to provide a useful method of determining plant sources of organic matter in estuaries.
\end{abstract}

Determining the plant origins of organic matter in coastal waters and sediments is of interest to geochemists and to ecologists in answering specific questions regarding the sources and fates of carbon in these systems. For Georgla salt marsh estuaries, the inftial view was that most of the organic carbon present in the suspended material (seston) in the water column, as well as in the marsh solls and estuarine sediment, and which supported the estuarine food web, was derived from production of the marsh cordgrass, Spartina alterniflora (1-2). This concept has had to be modifled based on stable carbon 1sotope analysis (3-5). Although the distinctive 1sotoplc signature of Spartina $\gamma \delta^{13} \mathrm{C}=-12$ to -13 $\%$ ) is present in the salt marsh soils and marsh animals, there is little 1sotopic evidence for significant amounts of Spartina-derlved organlc matter in the seston and sediment of the open estuary. Instead, there appears to be a large background of

0097-6156/86/0305-0062\$06.00/0

(c) 1986 American Chemical Society 
organic carbon with an isotopic composition $\left(\delta{ }^{13_{C}}\right.$ of -18 to $-24 \%$ ) depleted in ${ }^{13} \mathrm{C}$ compared to that of spartina. Stable carbon isotope analysis alone, however, cannot be used to determine whether this material originates primarily from in situ' phytoplankton production $\left(\delta 13_{C}\right.$ of -20 to $-26 \%$ oo or represents a mixture of algal carbon and Spartina detritus with terrestrial organic matter $\left(\delta 13_{C}\right.$ of around $-26 \%$ oo coming into the estuary via riverflow (5).

It is apparent that other types of geochemical analyses must be combined with stable isotope analysis to clarify the sources of organic matter in Georgia estuaries and similar coastal systems. Here we present preliminary evidence that characterization of higher plant and lignin pyrolysis and CuO oxidation products in the pools of organic carbon in estuaries can provide additional information concerning the relative importance of the potential vascular plant contributors to these pools. Lignin is produced only by vascular plants, and in surface sediments, appears to be more resistant to degradation in natural environments than some other blopolymers (6). When the complex polymer of lignin is chemically oxidized, a series of methoxy phenol derivatives are produced which are quantitatively related to the amount and type of the contribution vascular plant tissues (7). Analys is of lignin-derlved phenols via copper oxlde oxidation and subsequent gas chromatography has been used to trace terrigenous material in the estuaries and nearshore shelf of the Paciflc and Gulf of Mexico coasts $(\underline{6}, \underline{8-10})$.

Lignin derivatives have also been analyzed qualitatively in isolated, synthet1c, and degraded lignins (11), as well as in peats (12) and in sediments and particulates via pyrolysis-gas chromatography-mass spectrometry (PGCMS) both in Chesapeake Bay (13) and in the Rhine delta (14). A high correlation has been found between pyrolysis products and the lignin untts from which they arise (15-16). The technique is attractlve because of the small amount of sample (50-100 mg dry welght) and the minimal sample preparation required. This report describes an application of PGCMS to the analysis of $11 \mathrm{gnin}$ and phenolic pyrolysis products from vascular plants, sediments, and seston in the Georgia estuary.

\section{Methods}

Ground and sieved ( $1 \mathrm{~mm}$ to $52 \mathrm{~mm}$ partlcle size) dry samples were put into a $2 \mathrm{~mm} 1 . d$. $x 10 \mathrm{~mm}$ quartz tube, and held 1 place w1th quartz wool. The tube was mounted in a desorption probe and screwed Into the cool programmable Interface of a Chemical Data Systems (CDS) 820 Geological Reaction System (17). The sample was heated from $250^{\circ} \mathrm{C}$ to $550^{\circ} \mathrm{C}$ at $30^{\circ} \mathrm{C}$ per minute. Volatile C7-C28 compounds formed during the pyrolysis were collected on the CDS 820 System Tenax traps and then desorbed onto $1 / 8$ 1nch $0 . d$. $x 3$ inch Tenax traps, previously heated overnight in a helium stream at $280^{\circ} \mathrm{C}$, which were then either stored in screw cap vials ( $1 f$ the mass spectrum was to be run within 24 hours) or sealed in glass ampules in a nftrogen atmosphere and frozen (if they had to be stored for longer time perlods). 
Mass spectral analyses were carrled out by desorbing the Tenax traps into a GC mass spectrometer (Carlo Erba model 4160 GC equipped with a cryogenic oven attachment connected to a Finnigan 4500 quadrupole mass spectrometer). The traps were desorbed in a hellum stream via a heated desorption module which attached to the GC Injection port. The GC oven was cooled to $-20^{\circ} \mathrm{C}$ while the desorption heater was heated to $280^{\circ} \mathrm{C}$ and then maintained at that temperature for $15 \mathrm{~min}$. The GC oven was then ramped to $40^{\circ} \mathrm{C}$ and the J\&W DB-5 (5\% methyl pheny1 sillcone bonded phase) fused sillca caplllary column ( $0.32 \mathrm{~mm} 1 . d$. × $30 \mathrm{~mm}$ long) was programmed from $40^{\circ} \mathrm{C}$ to $280^{\circ} \mathrm{C}$ at $4^{\circ} \mathrm{C}$ per minute. Mass spectra were acquired using electron Impact lonization at $70 \mathrm{eV}$ and were collected via scanning from 40 to 350 amu at 1 second intervals. The GCMS system is interfaced to a Finnigan Incos 2300 Data System which contains the NBS/EPA/NIH reference library of 31,000 spectra. Compounds were tentatively identifled using the forward search algorithm included with the Incos system. Analyses of some of the same samples are being carried out by pyrolysis in the laboratory of Dr. Jap Boon, FOM Institute AMOLF, Krulslaan, The Netherlands.

\section{Results and Discussion}

A total of 5 plant, 2 seston, and 5 sediment samples from the Georgla estuary for which the stable carbon 1sotope composition had previously been determined were analyzed (see Table I).

Table I. Stable carbon 1sotope compositions of the plant, seston, and sediment samples from the Georgia estuary analyzed for lignin pyrolysis products

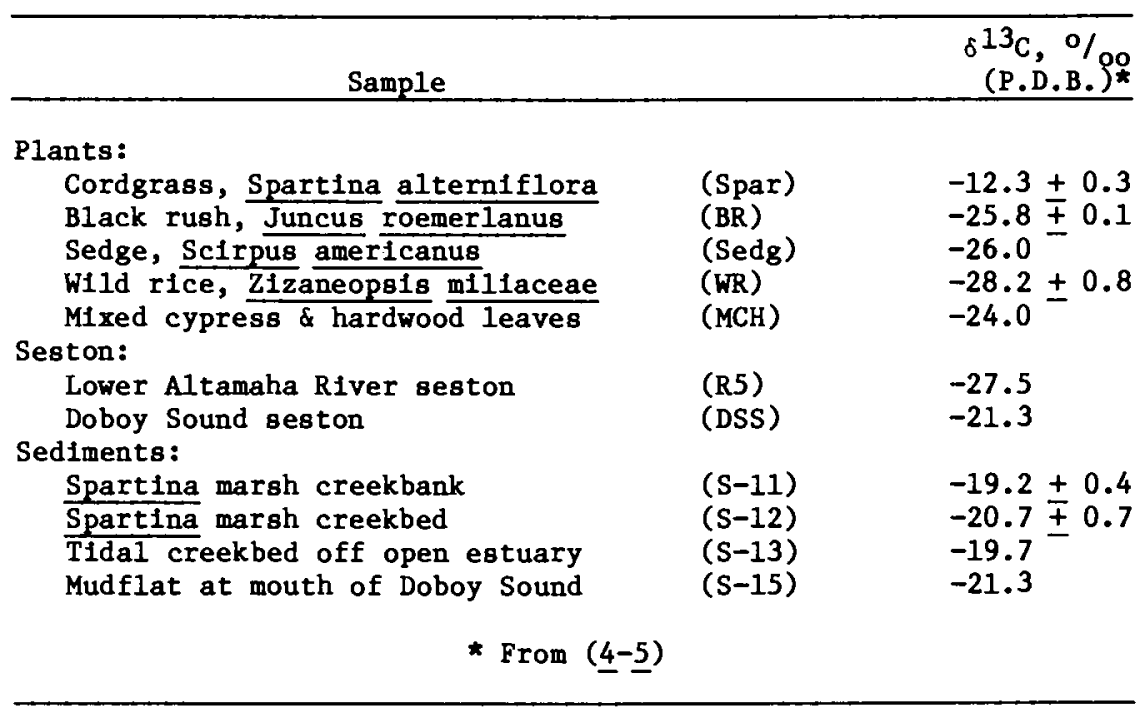


Pyrolysis products tentatively identifled as phenols and methoxy phenols (see discussion below) which appear to be diagnostic of particular inputs, are shown in Figure 1. Some of these, particularly the methoxyphenols, are almost certainly derived from Iignin (11-16). The approximate relative percentages of each, as shown in Figures 2-4, were calculated as follows: A specific region of the GCMS containing the peaks of interest was examined in each sample via mass scans, diagnostic of particular compounds (determined via detalled 1dentification of all peaks in the GC-mass spectrum), as shown in Table II. The helght of the GC peak for a

Table II. Mass spectral peaks diagnostlc of compounds in Figure I (ilsted in decreasing order of intensity for each compound)

\begin{tabular}{cl}
\hline Compound & \multicolumn{1}{c}{ Mass Spectral Peaks } \\
\hline A & m/e \\
B & $151,166,123$ \\
C & $151,182,108$ \\
D & 137,180 \\
E & 164,149 \\
F & 164,149 \\
G & $137,105,66$ \\
H & 152,151 \\
I & 164, \\
J & $151,166,123$ \\
K & 164,149 \\
L & 194,179 \\
M & $194,77,179$ \\
N & $181,196,95$ \\
O & $58,108,178$ \\
P & 167,182 \\
Q1 \& & $107,128,152$ \\
RI \& 2 & $137,152,122$ \\
S & $150,135,107$ \\
T & $91,150,135$ \\
U & $154,139,111,93$ \\
V & 137,152 \\
& 168,153 \\
\hline
\end{tabular}

particular mass chromatogram was then divided by the attentuation of the reconstructed total ion chromatogram (RIC) In the same scan range and multiplied by 100 . This procedure gives a rough estimate of the relative amount of each pyrolysis product in the sample as normalized to the strongest RIC peak (which generally remained constant throughout the sample set) in the region of the GCMS belng examined.

The proposed compound structures shown in Figure $I$ are based partly on mass-spectal computerized library searches as compared to the 31,000 compound NIH/NBS 11brary. It was also assumed that 


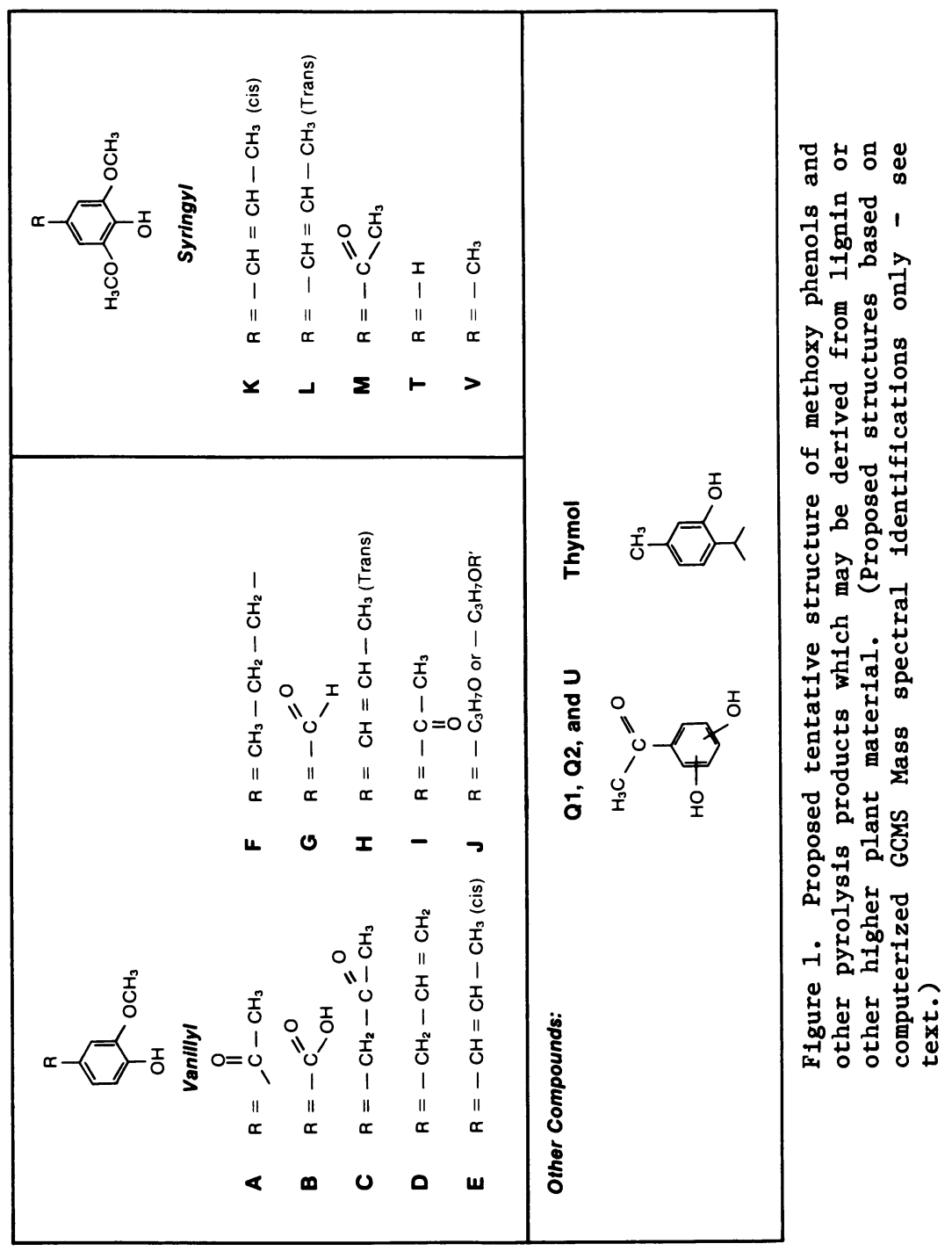

In Organic Marine Geochemistry; Sohn, M.; ACS Symposium Series; American Chemical Society: Washington, DC, 1986. 


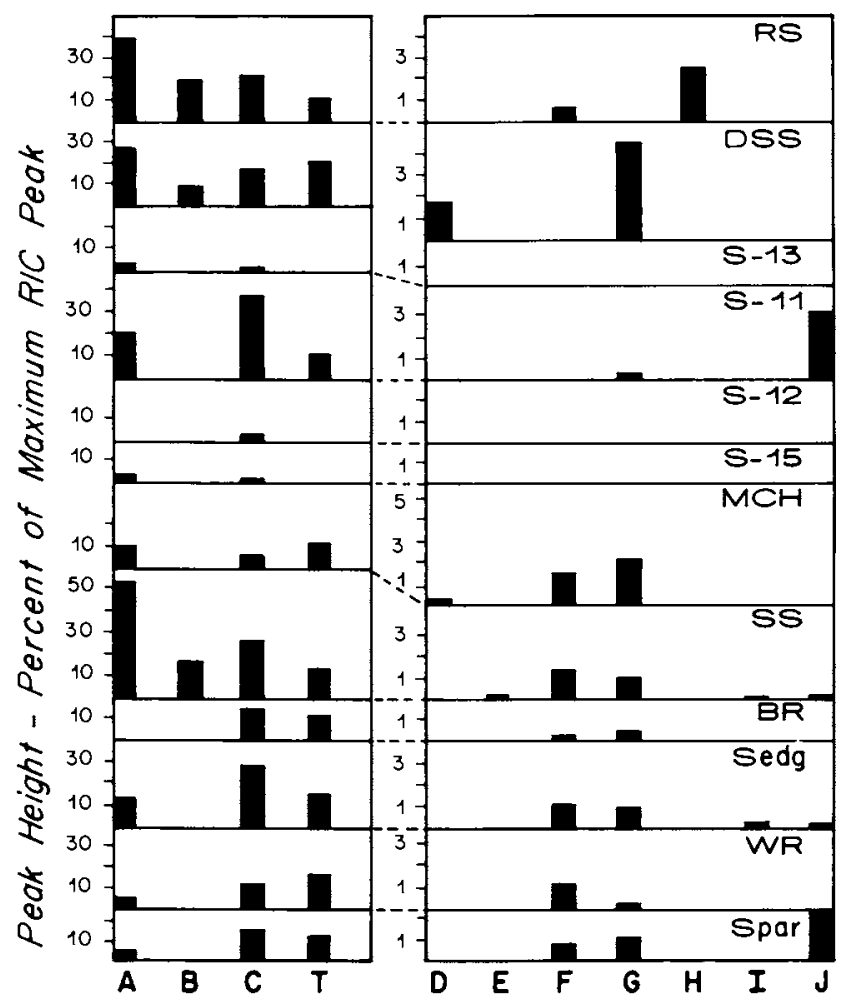

Figure 2. Levels of vanillyl derivatives in pyrolysis products of Georgla estuary samples. Sample code: River seston ( $>52 \mu \mathrm{m})$ (RS); Doboy Sound seston $(>52 \mu \mathrm{m}$ ) (DSS); sediment from open creekbed (S-13); sediment from tidal creek (marsh creekbank) (S-11); sediment from tidal creek (marsh creek bed) (S-12); sediment from open estuary (Doboy mudflat) ( $\mathrm{S}-15$ ); mixed cypress and hard-wood (MCH); swamp soll (SS); black rush (BR); sedge (sedg); wild rice (WR); and Spartina (Spar). See Figure 1 for compound identification. 


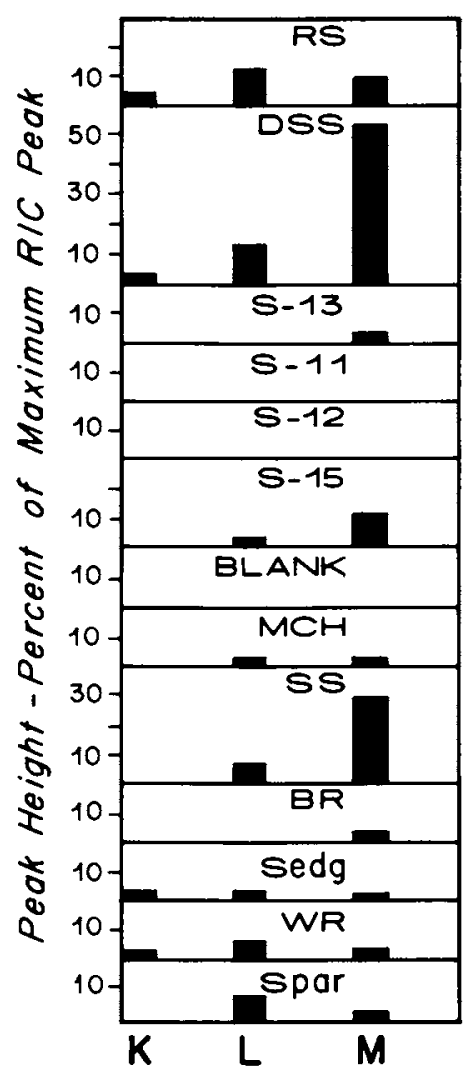

F1gure 3. Levels of syringyl derivatives among pyrolysis products from a Georgla estuary. Same sample and compound codes as for Figures 1 and 2 .

In Organic Marine Geochemistry; Sohn, M.;

ACS Symposium Series; American Chemical Society: Washington, DC, 1986. 

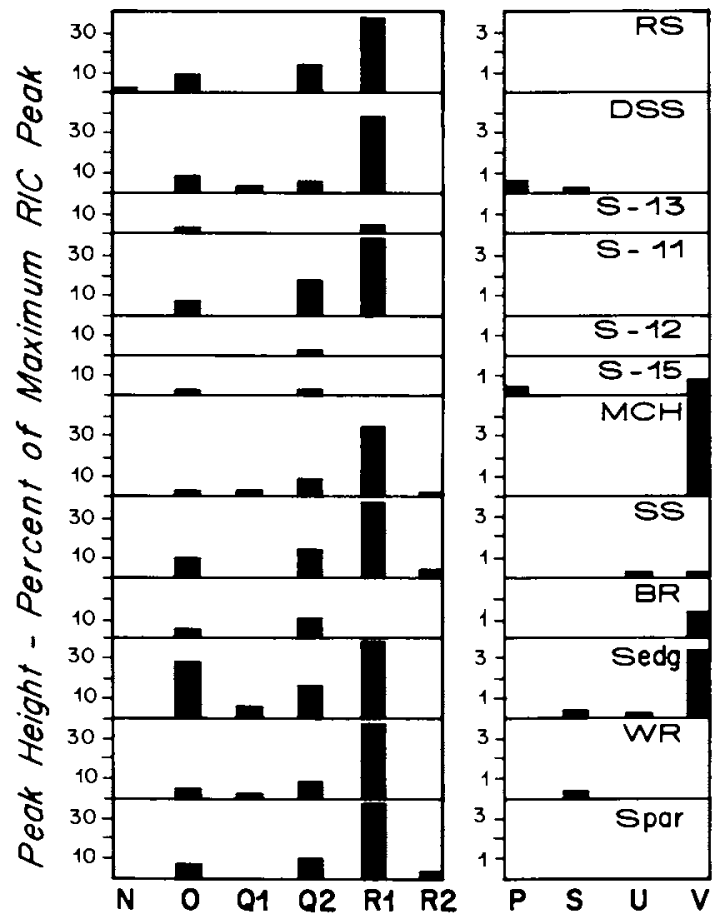

Figure 4. Leve1s of miscellaneous phenolic and methoxy pyrolysis products. Same sample and compound codes as in Figures 1 and 2.

In Organic Marine Geochemistry; Sohn, M.; ACS Symposium Series; American Chemical Society: Washington, DC, 1986. 
the carbon skeletons of methoxy-phenolic pyrolysis products are not drastically different from those found in the parent $11 \mathrm{gnin}$ (15-16, 18-19) and that structures of 1ignin pyrolysis products reported here are probably the same as those previously reported (11, 14). In addition, two of the samples analyzed in this work are also being analyzed by pyrolysis GCMS in the laboratory of $\mathrm{Dr}$. Jap Boon in the Netherlands which w111 allow comparison of our mass spectra with those of authentic standards. Because the bonded phase caplliary GC columns being used in both laboratories have the same liquid phase ( $\mathrm{J}$. Boon, private communication), it was asumed in the present work that the relative order of GC elution of Isomeric pyrolysis products was the same as in Ref. (11) and in other work of Salz-Jimenez and de Leeuw (unpublished manuscript).

The vanillyl and syringyl pyrolysis products shown in Figure 1 are probably correct, although these structures will have to be checked by comparison to authentic standards in future work. The mass spectal computer gave very high confidence ratings (greater than 900 out of a possible 1000 on Fit, Rfit, and purity parameters on the Incos data system) to the structures shown in Figure 1 for compounds $A-C, F, G, I$, and $M$. The mass spectra for all of these compounds are fairly unique, as shown in Table II. The computer Identified compounds $D, E$ and $H$ (which possessed almost identical mass spectra) as propenyl vantllyl compounds. The proposed structures shown in Figure 1 are based on the fact that the parent lignin contains only straight (rather than branched) C3 chains bonded to the phenyl groups (18-19) and on the expected GC elution order based on Ref. (11). A fourth compound, $J$ In Figure 1, was also identifled by the computer as propenyl benzene. It is proposed that this compound contains a hydroxyl or alkoxyl group (or some other easily eliminated group) bonded to a straight C3 side chain which is eliminated during electron impact fragmentation to produce a mass spectrum very similar to that of the corresponding olefin (20).

Simfiar arguments apply to the propenyl syringyl compounds $K$ and $\mathrm{L}$. Compounds $\mathrm{T}$ and $\mathrm{V}$ were Identifled by the mass spectal computer as 3,4-dimethoxyphenol and trimethoxyphenol, respectively. However, library spectra do not always contain the correct reference isomers (11). In addition, because pyrolysis product structures $T$ and $V$ in Figure 1 have been Identifled as abundant syringyl lignin pyrolysis products (11), and because isomers often give very similar mass spectra (20), we propose that compounds $\mathrm{T}$ and $\mathrm{V}$ are actually the unsubstituted and methyl syringyl derivatives, respectively.

A number of other pyrolysis products belleved to be elther phenols or methoxyphenols derived from higher plants were also Identified in the sample set. Identification of these, including $N$ through $P$ and $S$ in Figure 4, are less certain than those discussed above so that structures are not proposed. Compounds $Q 1$, $Q 2$, and $U$, which produce very similar mass spectra and, therefore, are proposed to be isomeric (20), were identified with a high degree of confidence by the mass spec computer as the diphenolic structure shown in Figure 1. Compounds R1 and R2, which also appear to be isomeric, gave mass spectra very similar (but not 
Identical) to thymol shown in Figure 1. Therefore, we propose that these two compounds, which occurred widely in the sample set, are terpene derivatives related to thymol.

Computerlzed GCMS data of other samples obtalned from more marine sediments have also been examined for the possible presence of lignin-derlved pyrolys is products (Whelan, unpublished data). Three marine gorgonian (coral) samples showed only traces of compound which might be $G$ and of a dialkyl phenol. Marine copepods, two sediment samples from a sub-bottom depth of 788 m near the Canary Islands, a sediment sample from a sub-bottom depth of $564 \mathrm{~m}$ in the Japan Trench, and two surface sediment samples from the Peru upwelling region all showed no traces of the pyrolysis products shown in Figures 1-4 (determined by careful searches of mass chromatograms of the masses shown in Table 1) with the possible exception of compound $U$. The fact that these marine samples generally do not produce these phenolic and methoxy phenolic compounds supports the source of these pyrolysis products as being non-marine, most probably from higher plants and/or lignin.

As shown In Figure 1, three general groups of phenolic pyrolysis products were found in the samples analysed: vanillyl phenols, syringy1 phenols, and miscellaneous phenolic and methoxy compounds. The relative proportions of the individual products in the various samples in each of the three groups are presented respectively in F1gures 2-4.

The vanillyl type of phenolic structure is produced in the lignin of all vascular plants (18-19). Levels of vanlllyl phenolic pyrolysis products were high In the plants, swamp soll, and in seston in the Altamaha River and in Doboy Sounds (Figure 2). In three of the estuarine sediment samples, however, these compounds were elther undetected or found in only trace amounts (F1gure 2). The acetyl derivative, $A$, was concentrated in swamp so1l, in river and estuarine seston, and in the Spartina creekbank sediment (S-11). We postulate that the seston and sediment have a significant contribution from swamp soll, or more likely all of these organic pools have a similar plant-derived component which produces a higher proportion of the acetyl structure upon pyrolysis. The latter hypothesis is supported by the presence of the vanillyl compound $J$ in significant amounts only in Spartina and in the Spartina marsh creekbank sediment (S-11). The low or non-existent levels of this compound in the other samples suggests that Spartina is the major contributor of higher plant carbon to marsh creekbank sediment. However, if this hypothesis is correct, it is difficult to see why the syringl products ( $K-M$ In, Figure 3 ) should be present in Spartina but missing in Sediment $S-11$.

Five syringyl derivatives (compounds $K-M, T$, and $V$, Figure 1 ) were detected among the pyrolysis products (F1gures 2-4). Syringyl phenols are also characterlstic of lignins, but occur in quantity only in anglosperm plants ( $7 ; 18-19)$. Small amounts of three different acetyl and propenyl syringyl pyrolysis products were produced by wild rice and sedge (F1gure 3 ), while only two of these structures were obtained from Spartina and the mixed cypress and hardwood tree leaves. A much larger proportion of the acetyl derivative, compound $M$, was found in swamp soll and Doboy Sound 
seston, suggesting a common organic source for these two pools of organic matter. Somewhat elevated levels of these three syringy1 compounds occurred in river seston. The lower proportion of compound $M$ to $L$ as compared to the Doboy Sound seston may indicate a less degraded or a different plant source contributing to seston in the river. The open estuary sediment samples, S-13 and $\mathrm{S}-15$, had syringyl structures which probably came from plant debris. In contrast, the creekbank sediment, which had abundant vanillyl structures, showed only the unsubstituted syringyl compound, $T$. The absence of other syringyl structures in sediment $S-11$ is somewhat surprising if Spartina is the main source of plant material to this sediment, since two additional syringyl structures (L and $M$ ) were found among the Spartina pyrolysis products.

Figure 4 shows levels of other phenoxy and methoxy pyrolysis products ( $N$ through $S$ and $U$, some of which are shown in Figure 1) which might be derived from lignin and/or other higher plant material. The specificity of these pyrolysis products as markers of higher plant material will have to be investigated in future work. Q1 and Q2 appear to be acety1 diphenolic structures, while both R1 and R2 were identifled by the computer as related to thymol (see Figure 1). Both types of structures may be typical of higher plants, but are not necessarily derived from lignin. Thymol (RI and R2) is a monoterpene which occurs widely in higher plants (21). For the Georgla estuary samples, the plants, swamp soil, seston, and sediment $\mathrm{S}-11$ from the tidal creekbank all showed similar distributions of compounds $Q 2$ and $R 1$. Compound 0 also occurred as a pyrolysis product in these samples, with the amount being more enriched in sedge than in the other plants. These compounds are either absent or present in lower levels in the spectra of pyrolysis products from the other sediment samples: S-13, S-12 and S-15. The results are consistent with the vanillyl product distribution (Figure 2) and suggest that these pyrolysis products also arise from vascular plants and that there is a significant vascular plant contribution to the seston and creekbank sediment. The smaller amounts of compounds $0, Q 2$, and $R 1$ in the open estuary sediments indicate either a lesser influence or a more diagenetically altered higher plant carbon.

Pyrolysis products $N, R 2, P, S, U$, and V, shown in Figure 4, were more specific than those discussed above. Compound V was produced only by sedge, black rush, mixed cypress and hardwood leaves, and in smaller amounts, by swamp sol1. The presence of this compound in sediment S-15, but not in other seston or sediment samples, suggests the contribution of specific higher plants to this sediment sample. The occurrence of compound $P$, in sediment S-15 and Doboy Sound seston, but not in the higher plants analyzed or in swamp soll may indicate a fairly specific marine precursor for this particular pyrolysis product.

In addition to the analyses of 1ignin products by PGCMS as discussed here, one sample of estuarine sediment, comparable to sample S-15, was analyzed for lignin oxtdation products by the cuo oxidation method (22). The distribution of various types of phenolic compounds in the sediment is compared to that of Spartina 
alterniflora and other types of plants previously analyzed with the CuO method (7) in Table III.

Table III. Comparison of three lignin parameters determined for an estuarine sediment sample with those of Spartina alterniflora and other vascular plants. $\mathrm{S} / \mathrm{V}=$ wt. ratio of syringy1 to vanllly1 phenols; $\mathrm{C} / \mathrm{V}=$ wt. ratio of cinnamyl to vanilly1 phenols; $\mathrm{Co} / \mathrm{Fe}=\mathrm{wt}$. ratio of the cinnamylphenols p-coumaric actd and ferulic actd.

\begin{tabular}{lccc}
\hline \multicolumn{1}{c}{ Sample } & S/V & C/V & Co/Fe \\
\hline & & & \\
Estuarine sediment & 1.24 & 0.46 & 2.89 \\
*Spartina altern1flora & 1.1 & 1.0 & 0.84 \\
Other nonwoody anglosperm t1ssue & 1.5 & 0.71 & 2.5 \\
Anglosperm woods & 2.5 & 0 & 0 \\
Gymnosperm nonwoody t1ssue & 0.02 & 0.49 & 5.0 \\
Gymosperm woods & 0 & 0 & 0
\end{tabular}

*plant data from Ref. 7.

The 11gnin signature in this sediment sample most closely resembles that of nonwoody anglosperm t1ssue, but it does not fit well with the specific distribution of lignin phenols obtained for Spartina. This result is consistent with those obtained by PGCMS, even though the specific relation between oxtdative and pyrolytic 1ignin degradation products has not yet been determined. Thus, sediment S-15 does not show the same pyrolysis products as Spartina in Figures 2-4. The strongest phenolic pyrolysis signal in S-15 is most like those of swamp soll and Doboy Sound seston as shown in Figure 3 and consists of a relatively strong syringyl component in comparison to other sediment samples.

Several sediment samples from the Mississippl Fan in the Gulf of Mexico did show traces of compound $U$. These sediments should have been heavily influenced by terrigenous organic matter. However, it 18 not currently known to what depths lignins survive in deep sea sediments ( 6 ). It has recently been shown that vanilly1 and p-hydroxy 11gnin are partlally preserved in some burled woods for periods of up to 2500 years (23). We plan to reanalyze DSDP Mississippi Fan samples, along with more hemlpelagic types of marine sediments, in future work to look in detall for the compounds in Figure 1.

Summary

Determining the relative contributions of marlne and terrestrial plant organic carbon to the pools of organic matter in coastal systems is often difficult. In Georgla salt marsh estuarles, the major sources of organic matter are in situ phytoplankton produc- 
tion, detritus from the marsh grass Spartina alterniflora, and terrestrial plant material introduced by river flow. Stable carbon isotope studies indicate that, although Spartina carbon is present in salt marsh sediment and to some extent in sediment in the open estuary, there is a large background of ${ }^{13} \mathrm{C}$-depleted organic matter in sediment and in suspended particulate material which could come elther from phytoplankton or from terrestrial material. In order to clarify the source of this materlal, samples of estuarine vascular plants, seston, and sediment were analysed for content and composition of phenolic and methoxy phenolic pyrolysis products by pyrolysis and subsequent gas chromatography and mass spectrometry. Some or all of these products (particularly the methoxy phenols) are proposed to be diagnostic lignin pyrolysis products. These products, which are not produced by more marine samples, appear to be diagnostic of terrigenous plants. Based on these analyses, Spartina has a unique signature which also appeared in a sample of surface mud from the bank of a tidal creek draining a Spartina marsh. Sediment from the tidal creek bed and from two open estuarine sites showed very little of these pyrolysis products, and the composition did not match that of Spartina. Suspended material in the estuary had a stronger signal which resembled that of tree leaves and soll in coastal freshwater swamps. Seston and some sediment in the open estuary also contained phenolic (probably non-1ignin) pyrolysis products which were not present in the plants and which were probably of marine origin. One estuarine sediment sample was independently analysed for lignin CuO oxidation products via gas chromatography. The composition of the lignin present in this sample resembled that of some non-woody anglosperm tissues from the swamp, but did not closely match the lignin products found for Spartina. It appears that organic carbon derived from vascular plants is present in estuarine seston and sediment, but Spartina may not be the primary source for this material.

\section{Acknowledgments}

Th1s work was supported by grants from the Sapelo Island Research Foundation to E. Sherr and by National Sclence Foundation Grant OCE83-00485 to J. K. Whelan and J. M. Hunt. We are grateful to Dr. John Hedges for lignin oxldation product analysis of one of our sediment samples, and to Drs. Jim Alberts, Chuck Hopkinson, John Ertel and John Hedges for their comments on the manuscript. Thanks also go to Dr. Nelson Frew for mass spectra and to Christine Burton and Richard Sawdo for technical assistance. Contribution No. 6055 of the Woods Hole Oceanographic Institution and No. 546 of the University of Georgla Marine Institute.

\section{Literature Cited}

1. Tea1, J. M., Ecology 1962, 43, 614-624.

2. Odum, E. P.; De La Cruz, A. A. In "Estuaries"; Lauff, G. H., Ed.; AMER. ASSOC. ADV. SCIENCE: Washington, D.C., 1967; pp. 383-388. 
3. Halnes, E. B. O1kos, 1977, 19, 254-260.

4. Halnes, E. B.; Montague, C. L. Ecology 1979, 60, 48-56.

5. Sherr, E. B. Geoch1m. Cosmoch1m. Acta $1982,46,1227-1232$.

6. Hedges, J. I.; Mann, D.C. Geochim. Cosmoch1m. Acta 1979, 43, 1809-1818.

7. Hedges, J. I.; Mann, D.C. Geoch1m. Cosmochim. Acta 1979, 43, 1803-1807.

8. Hedges, J. I.; Parker, P.L. Geochim. Cosmochim. Acta 1976, 40, 1019-1029.

9. Hedges, J. I.; Turin, H. J.; Erte1, J. R. L1mnol. Oceanogr. $1984,29,35-45$.

10. Erte1, J. R.; Hedges, H. I. Geochim. Cosmochim. Acta 1984, 48, 2065-2074.

11. Saiz-Jimenez, C.; de Leeuw, J. W. Org. Geochem. 1984, 6, 417-422.

12. Bracewe11, J. M.; Robertson, G. W.; Williams, B. L. J. Anal. App1. Pyr. 1980, 2, 53-62.

13. Sigleo, A. C.; Hoering, T.C.; Helz, G. R. Geochim. Cosmochim. Acta $1982,46,1619-1626$.

14. Van de Meent, D.; Deleeuw, J.W.; Schenek, P.A. J. Anal. App1. Pyr. 1980, 2, 249-263.

15. Obst, J. R. J. Wood Chem. Techno1. 1983, 3, pp. 377-397.

16. Martin, F.; Saiz-Jimenez, C.; Gonsalez-Vila, F. J. Holzforschung 1979, 33, 210-212.

17. Whelan, J. K.; Fitzgerald, M. G.; Tarafa, M. Environ. Sc1. Tech. 1983, 17, 292-298.

18 Sarkanen, K. V. In "The Chemistry of Wood"; Browning, B. L., Ed.; R. E. Krleger Publishing Co.: Florida, 1963 (reprinted 1981); pp. 249-311.

19. Sarkanen, K. V.; Ludw1g, C. H. "Lignins"; Wiley-Intersclence: New York, 1981.

20. Blemann, K. "Mass Spectrometry"; McGraw H111: N.Y. 1962; pp. 87-95.

21. Buchanan, M.A. In "The Chemlstry of Wood", Brown1ng, B. L., ed.; R. E. Krleger Publishing Co.: Florlda, 1963; pp. 324-325.

22. Hedges, J. I.; Erte1, J. R. Ana1. Chem. 1982, 54, 174-178.

23. Hedges, J. I.; Cowle, G. L.; Ertel, J. R.; Barbour, R. J.; Hatcher, P.G. Geochim. Cosmchim. Acta 1985, 49, 701-711.

RECEIVED October 31,1985 


\title{
Characterization of Particulate Organic Matter
}

\author{
From Sediments in the Estuary of the Rhine and \\ from Offshore Dump Sites of Dredging Spoils
}

\author{
Jaap J. Boon ${ }^{\prime}$, B. Brandt-de Boer ${ }^{\prime}$, Wim Genuit ${ }^{\prime}$, Jan Dallinga ${ }^{\prime}$, and E. Turkstra ${ }^{2}$ \\ ' FOM-Institute for Atomic and Molecular Physies, Kruislaan 407, 1098 SJ Amsterdam, \\ The Netherlands
}

2D. B. W. RIZA, P.O. Box 17, Lelystad, The Netherlands

\begin{abstract}
Screening of estuarine and marine sediment samples by automated pyrolysis mass spectrometry combined with factor-discriminant analysis leads to a useful classification related to the geographical position and the sources of the organic matter. The mass spectral data give preliminary information about the organic matter composition. Analysis of the characteristic mass peaks $\mathrm{m} / \mathrm{z}=86$ and 100 by PMSMS and PGCMS points to bacterial polyalkanoates in the mud fraction of the river sediments. These and other pyrolysis products show that sewage sludge with degraded lignocellulose material and bacterial biomass is an important source of particulate organic matter in river sediment of this heavily populated area in the Netherlands.
\end{abstract}

Extensive sedimentation of particulate matter from fluvial and marine origin takes place in the estuary of the Rhine, particularly in the harbors along the New Waterway, downstream from Rotterdam. Yearly about 20 million $\mathrm{m}^{3}$ of this mud is dredged and dumped into the North Sea (1). As these sediments have trapped organic and inorganic pollutants such as $\mathrm{Cr}, \mathrm{Cu}, \mathrm{Hg}, \mathrm{Cd}, \mathrm{Pb}, \mathrm{Zn}$ and $\mathrm{Ni}$, a considerable pollutant load is imposed on the North Sea ecosystem either directly by the outflowing river water or indirectly by dredging and dumping (2).

Detailed knowledge on the molecular level about the fate of the riverine particulate organic matter and its associated pollutant cocktail is still limited. The complex processes which occur in the mixing area between fluvial and marine water in the estuary, result in sediments with characteristics of aquatic and marine origin, mixed up or maybe even reacted with each other in some ways. When these sediments are dredged and dumped off shore, the sedimentary material is exposed to open sea conditions with increased chances of resuspension and resedimentation and consequently a new diagenetic regime for the organic matter.

In order to study aspects of the fate of these sediments, we have studied sedimentary particulate matter from sites in the estuary of the Rhine downstream from Rotterdam, from several dredging spoil dumpites offshore (Loswal Noord), and from sediments of the Flemish

0097-6156/86/0305-0076\$06.00/0

๑ 1986 American Chemical Society 
Banks in the Southern North Sea. The organic composition of the mud fraction from these sediments was investigated by Curie-point pyrolysis mass spectrometric techniques, whereas metal content, \% organic carbon, carbon isotopes, carbonate and mud content were determined separately on the same sediments. Although the analysis of estuarine particulates for the latter characteristics is widely known, the usefulness of pyrolysis methods for the characterization of the organic matter fractions has been demonstrated only recently. The fate of sewage sludge in the Boston harbor was traced with thermal distillation-pyrolysis GCMS (3). Colloidal matter in Chesapeake Bay was characterized by stepwise pyrolysis GCMS (4). The fate of organic materials and metals in the river Rhine delEa and in the IJsselmeer was investigated by Curie-point pyrolysis mass spectrometry and-GCMS (5). Pyrolysis mass spectrometry was used for the evaluation of the organic matter in the estuaries of the Ems (6) and Gironde (7). These studies demonstrated a good correlation between PMS data, carbon isotopes and other variables.

The pyrolysis methods applied in this study are used as a tool for a general characterization of the organic matter from the sediments. We describe here the results from screening of estuarine and open sea sediment samples by automated pyrolysis low voltage mass spectrometry combined with factor-discriminant analysis. Characteristic mass peaks resulting from this procedure were investigated in more detail by pyrolysis-tandem mass spectrometry and pyrolysisphotoionization GCMS.

Experimenta1

Sampling and Sample Preparation. Samples were collected by a team from the Netherlands Institute for Sea Research (Texe1) and Rijkswaterstaat (the Ministry of Transport and Public Works) by a boxcorer (North Sea stations) and Van Veen grab (Rhine stations). Figure 1 shows a map with the sample locations (for details, see (8)). Sediment samples were taken from the boxcorer or the grab and immediately afterwards resuspended in filtered $(0.45 \mu \mathrm{m})$ sea or river water; the suspension after settling of the sand fraction was passed over a 50 micron sieve to a Whatman GFF filter with a diameter of $9 \mathrm{~cm}$ under gentle suction. After filtration the filtered particulate matter was washed with destilled water to remove sea salts. The filters with their sediments were stored in glass petrie dishes and frozen. Generally five boxcores (coded by letter) were taken in one sampling area (coded by number), whereas in the Rhine estuary usually three separate samples were grabbed in different parts of the river bed. Samples from the North Sea were taken between 22 and 24 November 1983. Samples in the New Waterway (Rhine estuary) were taken on 2 February 1984.

Samples for pyrolysis analysis were taken from the filters and resuspended in water immediately before analysis. Aliquots of these suspensions (about 50 micrograms of dry matter) were transferred to the ferromagnetic sample wires and dried in vacuo. Samples were analyzed imnediately afterwards in quadruplicate.

Pyrolysis Mass Spectrometry and Multivariant Data Analysis. The automated pyrolysis mass spectrometer and the multivariant data analysis by factor-discriminant analysis (f.d.a.) procedure used have been 


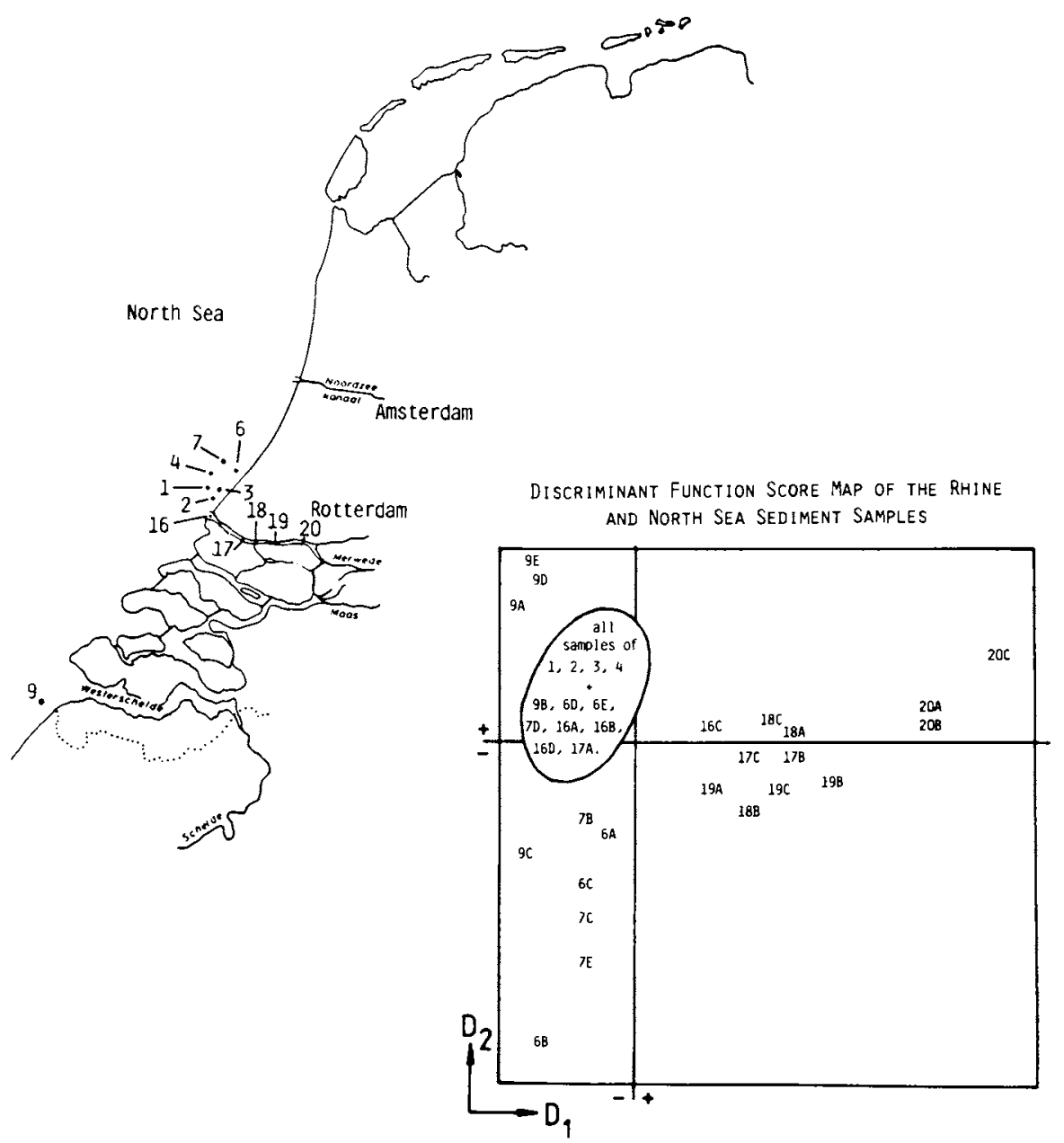

Figure 1. Discriminant function score map of the pyrolysis mass spectra of the sample sites and their geographical position along the New Waterway (Rhine estuary) and in the North Sea. The numbers indicate sampling areas, the letter codes sample sites within an area.

In Organic Marine Geochemistry; Sohn, M.;

ACS Symposium Series; American Chemical Society: Washington, DC, 1986. 
described recently (9). The Curie-point temperature of the ferromagnetic sample wires was $510^{\circ} \mathrm{C}$.

Pyrolysis Tandem Mass Spectrometry. Details of the instrument have been described (10). Pyrolysis conditions were similar to those used for the PMS instrument. The pyrolysate was ionized at $70 \mathrm{eV}$ and ions of interest were selected in the first magnetic sector (resolution 500). These ions were dissociated by collision with helium atoms (pressure $0.9 \mathrm{~Pa}$ ), accelerated at $15 \mathrm{kV}$ and analyzed in a second magnetic sector. Ions were detected by simultaneous ion detection using channel plates, a phosphor screen and a diode array camera. Total analysis time for each ion is $8 \mathrm{~s}$.

Pyrolysis Photoionization GCMS. Details of the instrument have been described earlier (11). Curie point pyrolysis was performed in nitrogen which also served as the carrier gas. Pyrolysis occurred directly in front of the capillary column, which exits in the photoionization chamber of the mass spectrometer. A 50 m fused silica column coated with CP-Sil 5-CB (I.D.=0.32 mm, film thickness: 1 micron) was used for the separation. The oven was programed from 80-260 C after a period at room temperature during pyrolysis of the sample. Argon I resonance photons $(11.6$ and $11.8 \mathrm{eV})$ were used for ionization of the GC effluent. Ion source temperature was $150^{\circ} \mathrm{C}$. Pressure in the ion source was $10^{-2}$ Torr and in the vacuum chamber $10^{-5}$ Torr. The quadrupole was scanned at $1 \mathrm{scan} / \mathrm{s}$ over 30 to $235 \mathrm{amu}$.

\section{Results and Discussion}

Sampling Plan and Sediment Workup. A number of choices have been made in design of the sampling program. Samples were taken in late autumn and winter in order to minimize contributions of phytoplankton to the bottom sediments. It was not possible to sample all materials in the same time frame. The open sea samples were taken by boxcoring to minimize loss of surface sediments during sampling. Generally the upper five centimeters were used for the isolation of the fraction smaller than 50 microns. Each sample area in Figure 1 consisted of five individual sample sites which were separated by several miles. This replication was chosen for statistical reasons in order to evaluate the reproducibility in the composition of the organic matter of the sediments in one area. Samples in the river were taken on the left side, on the right side and in the middle of the bedding for the same reasons.

The separation of mud and sand was necessary for the pyrolysis analysis, which is performed on suspended matter coated on a metal wire of $0.5 \mathrm{~mm}$, and because sand particles do not stick to these sample carriers. As the samples are continuously moved about in the natural environment, a resuspension procedure was thought to be a minor disturbance of the original sediment. The washing procedure, in which destilled water is passed over the filter with particulate matter may however result in loss of soluble organic matter together with the sea salts. This measure has been applied in the earlier profilling studies of estuaries $(6,7)$ with $P M S$ and no negative influence on the results could be shown. The technical advantage is that the $\mathrm{HCl}$ volatilized from sea salts during pyrolysis analysis is minimized and matrix effects on the organic matter pyrolysis patterns 
due to the presence of salts is avoided. It is clear that if differences are found in the composition of the samples despite this workup, the organic matter characteristics must be very stable and strongly connected to the particulate matter fraction.

Screening by Automated Pyrolysis Mass Spectrometry. The total data file after analysis of all samples in quadruplicate consisted of 172 pyrolysis mass spectra. All samples were significantly different from a procedural blank. In the total file only the mud fraction from station 7A (a11 replicates) was strongly different in pyrolysis mass spectrum from all other spectra. The pyrolysis spectrum of 7A was very similar to the spectrum of cellulose. The cellulose in this sediment may have originated from the outfall sewer of The Hague city, which exits nearby. The carbon isotope $\delta 13 \mathrm{C}$ of $-25.44 \%$ (8) points to a nonmarine origin. After removal of the $7 \mathrm{~A}$ analyses from the data file, factor discriminant analysis was performed again and a discriminant function score map, as shown in Figure 1, was calculated. The distances between the samples in this map are a measure for the differences in composition. Discriminant functions describe a combination of chemical substances, expressed in mass peaks, which are used for an optimal differentiation. The D-scores can be considered as the concentration of these substances. Positive and negative values are obtained, because concentration is expressed relative to the average concentration in all samples. About $50 \%$ and $15 \%$ of the characteristic variance in the data file was explained in the first and second discriminant functions respectively. Instrument replicates generally fall in the centroid (the station number) on the map.

If we consider on $1 y$ the first D-function, a striking separation between most samples from the river and the marine stations becomes evident. Samples 20A, B and C,collected highest upstream near Rotterdam, were found to have the highest positive $D_{1}$ scores, but all stations at 19,18 and two of the three stations at 17 have positive $\mathrm{D}_{1}$ scores. Most of the stations from 16 at the mouth of the New Waterway near Hoek of Holland and all open sea stations have negative $D_{1}$ values. The stations with negative $D_{1}$ scores, are separated by the second discriminant function into a distribution which seems to reflect their geographical position in the sea as we11: strongly positive values were found for a number of Flemish Bank stations, strongly negative values were found for most stations north of the Loswal Noord area. A cluster relating to the dredging spoil dumpite Loswal Noord $(1 A-E, 2 A-E, 3 A-E$ and $4 A-E)$, some stations from north of this area $(6 \mathrm{D}, 7 \mathrm{D})$ and some stations from the river mouth at Hoek of Holland (16A,B,D and 17A) and station 9B (Flemish Banks) represent samples which cannot be discriminated further. It is striking that the samples from area 9,6 and 7 are poorly reproducible which points to relatively strong differences in composition of the bottom sediments. The samples from the Loswal Noord area a11 plot on top of each other, which implies a common factor in all those samples. It is of interest to note that the dredging area in the mouth of the New Waterway is near station 16, which plots in the cluster of samples from the dredging spoil dump sites.

Chemical Interpretation of the PMS Data. Translation of the mass spectral information into chemical information is tentative unless MSMS or GCMS is used for the identification of mass peaks. Pyrolysis mass spectra and the discriminant function spectra resulting from the numerical analysis of a PMS data file can be interpreted tentatively 
by comparison with standards and reference materials (12). On this basis, the zero point spectrum in Figure 2, which represents the mass peaks common to all spectra, shows information from alkanes and alkenes, lignins, carbohydrates and proteinaceous material, although the characteristics for the latter substances are not so prominent as in soil organic matter and humic fractions (12). The mass peaks for $\mathrm{HCl}$ $(\mathrm{m} / \mathrm{z} 36$ and 38$)$ are of 1 ow intensity which indicates that the washing procedure has removed most of the interfering salts. The mass peaks at $\mathrm{m} / \mathrm{z} 34\left(\mathrm{H}_{2} \mathrm{~S}\right), 48\left(\mathrm{CH}_{3} \mathrm{SH}\right)$ and $64\left(\mathrm{SO}_{2}\right.$ and/or $\left.\mathrm{S}_{2}\right)$ point to the existence of sulphur compounds in the mud fraction.

Figure 3 presents the reconstructed mass spectrum of the first discriminant function which separated the river and marine stations in the $D_{1} D_{2}$-map of Figure 1 . The positive $D$-function describes the covariant mass peaks with higher intensities with respect to the zero point spectrum. All sample spectra with such characteristics will have positive score values. This spectrum is a representation of the characteristics of riverine material. The negative $\mathrm{D}$-function spectrum in Figure 3 is indicative of the marine characteristics. The $\mathrm{D}_{1}^{+}$spectrum shows a number of mass peaks indicative for carbohydrates, lignin and proteinaceous material (12). The mass peak $\mathrm{m} / \mathrm{z}=86$ and 100 are uncommon and a special characteristic of these fluvial samples. It can be speculated to be the molecular ion of (alkyl)thiadiazole (a metal binding pollutant), however a cyclic ketone, short chain alcohol or unsaturated acid are also possibilities. These mass peaks were chosen for further study because of their rare occurrence and their high discriminating power in the factor-discriminant analysis.

The $D_{1}^{-}$shows a number of characteristics related to sea salts such as the mass peaks $\mathrm{m} / \mathrm{z} 36$ and 38 from $\mathrm{HCl}$ generated from chlorides, $\mathrm{m} / \mathrm{z} 50$ and 52 from $\mathrm{CH}_{3} \mathrm{Cl}$ and $\mathrm{m} / \mathrm{z} 142$ from $\mathrm{CH}_{3} \mathrm{I}$. It is not clear how the methyl-chloride and-iodide are formed but they are very common in pyrolysates of marine samples (13). The mass peaks $\mathrm{m} / \mathrm{z} 95,96$, 109 and 110 are from furfural and methylfurfural, which are generated under sea salt conditions from carbohydrates (14). The mass peaks $\mathrm{m} / \mathrm{z}$ 67,81 and 79 are presumably from pyrrole, methylpyrrole and pyridine.

Tandem Mass Spectrometry of Mass 86 and 100. The sample from station $20 \mathrm{C}$ near Rotterdam was chosen for a detailed analysis of peaks 86 and 100 because these peaks are relatively abundant in the PMS spectrum of the sediment (see Figure 5). Figure 4A shows the collision induced dissociation spectrum of mass 86 , obtained by ionization of the pyrolyzate at $70 \mathrm{eV}$. This high voltage was chosen for reasons of increased sensitivity. CID spectra of unknowns may be compared qualitatively with electron impact mass spectra taken at $50 \mathrm{eV}(15,16)$. Based on this comparison using the EPA/NIH Mass Spectral Data Base, we conclude that $\mathrm{m} / \mathrm{z} 86$ cannot be the molecular ion of thiadiazole, however 2butenoic acid is a good possibility. The CID spectrum of this compound has been studied using the same instrument (17). Its spectrum has relatively abundant fragments at $\mathrm{m} / \mathrm{z}=38(10.5 \%), 39(29.3 \%), 40$ (8.3\%), $41(11.4 \%), 42(5.3 \%), 45(8.2 \%)$ and $68(2.7 \%)$. However, the presence of a relatively abundant mass 43,57 and 58 cannot be explained on the basis of this compound. We assume that other compounds with a molecular ion or fragment ion at 86 are present in the ionized pyrolysate. The CID spectrum of mass 100 (Figure 4B) shows a series of peaks at $43,57,71$, which points to a saturated hydrocarbon. A CID peak at 82 (loss of water) and peaks at 39 and 45 , point to a small contribution of an unsaturated acid. This CID spectrum is most likely not from one compound. These MSMS data are insufficient for a definite identifica- 


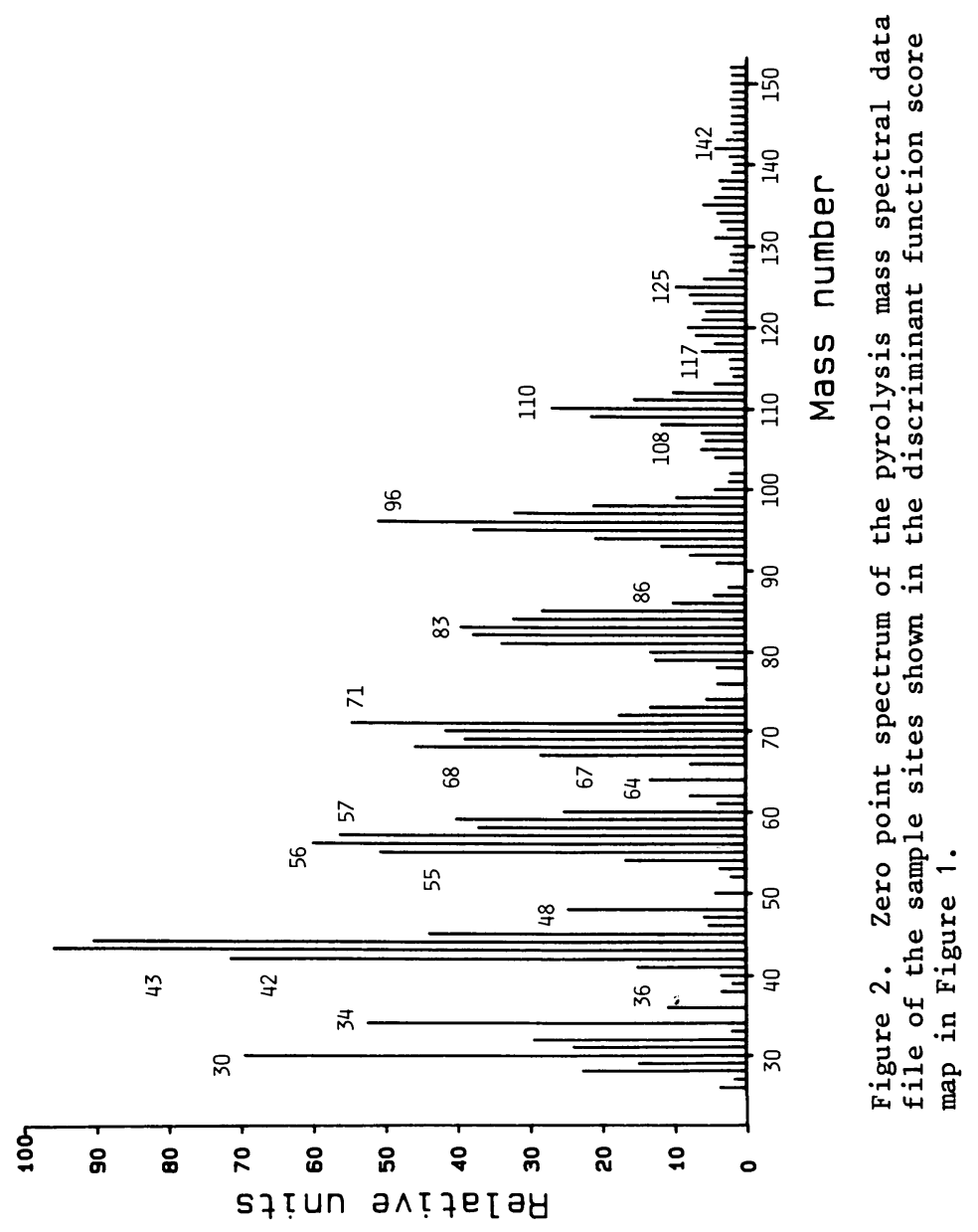

In Organic Marine Geochemistry; Sohn, M.; ACS Symposium Series; American Chemical Society: Washington, DC, 1986. 

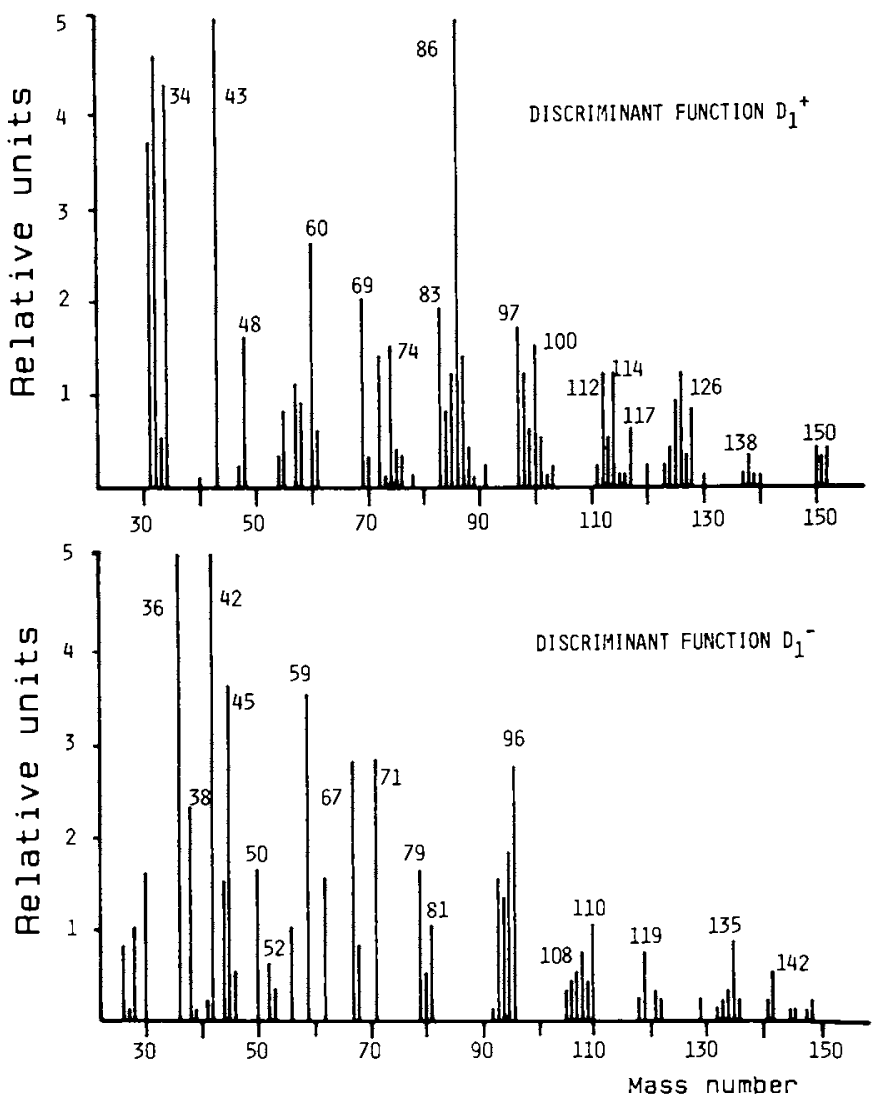

Figure 3. Reconstructed mass spectra of the first discriminant function calculated for a file consisting of pyrolysis mass spectra of sediments from sample sites shown in the discriminant function score map in Figure 1.

In Organic Marine Geochemistry; Sohn, M.;

ACS Symposium Series; American Chemical Society: Washington, DC, 1986. 

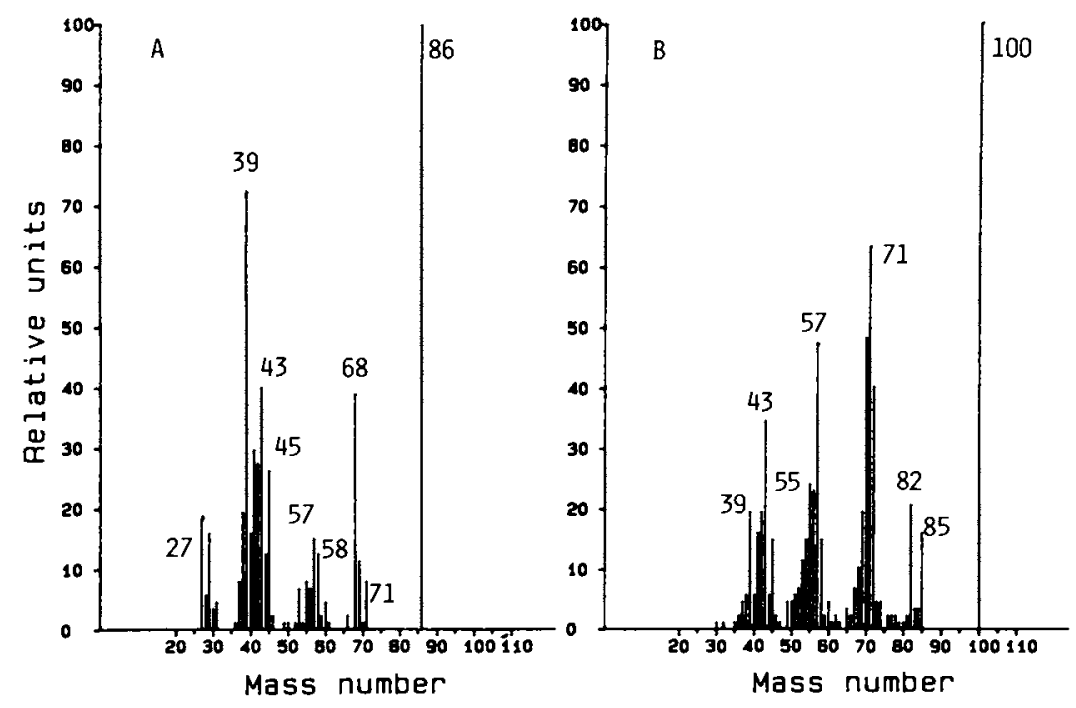

Figure 4. Pyrolysis tandem mass spectra for mass peak $m / z 86$ (A) and 100 (B) selected from the pyrolysate of sample $20 \mathrm{C}$ collected in the New Waterway.

In Organic Marine Geochemistry; Sohn, M.; ACS Symposium Series; American Chemical Society: Washington, DC, 1986. 
tion of both mass peaks, but clearly indicate it that several compounds of moderate polarity are contributing to these peaks. It should be possible to separate them by gas chromatography. The technique of pyrolysis GCPIMS was used for separation and low voltage ionization of the compounds.

Pyrolysis GC-Photoionization-MS. Genuit and Boon (1) have shown in a PGCPIMS study of amylose that a cumulative PI spectrum (a summation of all GCMS scans) ionized with argon I resonance photons is fairly similar to the low voltage $(15 \mathrm{ev})$ electron impact spectrum. The advantage of this approach compared to the direct introduction of the whole pyrolysate into the low voltage EI mass spectrometer is that mass peaks can be searched in the GCMS data file and the complete mass spectrum of a compound can be retrieved. Figure 5 shows the $15 \mathrm{eV}$ PMS and the argon I photon PI-PMS of sediment sample $20 \mathrm{C}$. There is a good resemblance between both spectra, a1though alkane fragment ions such as $\mathrm{m} / \mathrm{z}: 43,57,71,83,85,97,111$ and 125 are relatively more intense in the EI spectrum. In both spectra $\mathrm{m} / \mathrm{z}=86$ is a relatively intense mass peak.

Figure 6 shows the mass chromatograms of $\mathrm{m} / \mathrm{z}=68,86$ and 100 in the GCMS data file of this sample. The most abundant compound (e) with $\mathrm{m} / \mathrm{z}=86$ and $\mathrm{fragment}$ ion at $\mathrm{m} / \mathrm{z}=68$ was identified as 2,3 -butenoic acid (a fronting peak in the chromatogram due to its free acid group). An isomer (cis?) with a shorter retention time (d) has the same spectrum. The compounds $a, b$ and $c$ were respectively bi-acetyl, 2-methylbutanal and 3-methylbutanal. The spectrum of biacetyl shows a very intense fragment ion at $\mathrm{m} / \mathrm{z} 43$, whereas the methylbutanals have strong fragment ions at 57 and 58. This explains the CID peaks mentioned above, which could not be accounted for in the MSMS of peak 86 . The mass chromatogram at $\mathrm{m} / \mathrm{z}=100$ points to a compound at scan 550 , which was identified as a pentenoic acid. The other signals in the $\mathrm{m} / \mathrm{z}=100$ trace are noise. No contributions from alkanes to this mass peak could be detected in this data file, but the response for alkanes in the photoionization mass spectrometer is very poor. Analysis of this sample with GCMS at $70 \mathrm{eV}$ confirmed the presence of alkanes in the sample (13).

Studies on the bulk pyrolysis of polyhydroxybutyric acid from Bacilli and of bacterial polyalkanoates have shown the formation of 2,3-butenoic acid and 2,3-pentenoic acid (18). The presence of 2,3-butenoic acids and pentenoic acid in the pyrolysate of the particulate matter from sample $20 \mathrm{C}$ is interpreted as an indication of polyhydroxy-alkanoates in the sample. These mixed polyesters of hydroxy acids with 4,5 and sometimes 6 carbon atoms are especially abundant in activated sludges (19). The occurrence of $\mathrm{m} / \mathrm{z} 86$ and 100 as abundant mass peaks in the spectra of the fluvial material and as very characteristic peaks in the discriminant function spectrum indicates that a significant amount of the mud iraction may consist of sewage debris. This impression was confirmed by identification of a number of other pyrolysis products in the data file.

Figure 7 shows a number of pyrolysis products which were identified with PPIGCMS. The identity and molecular ions of a number of major peaks in the TIC have been marked in the chromatogram. The guaiacol $(\mathrm{m} / \mathrm{z}=124)$, hydroxystyrene $(\mathrm{m} / \mathrm{z}=120)$ and methoxyhydroxystyrene $(\mathrm{m} / \mathrm{z}=150)$ are the pyrolysis products of a monocotyledon lignin (20). Hydroxyacetic aldehyde, hydroxypropanone, furfural and 5-methylfurfural are pyrolysis products of carbohydrates (14), but the ab- 

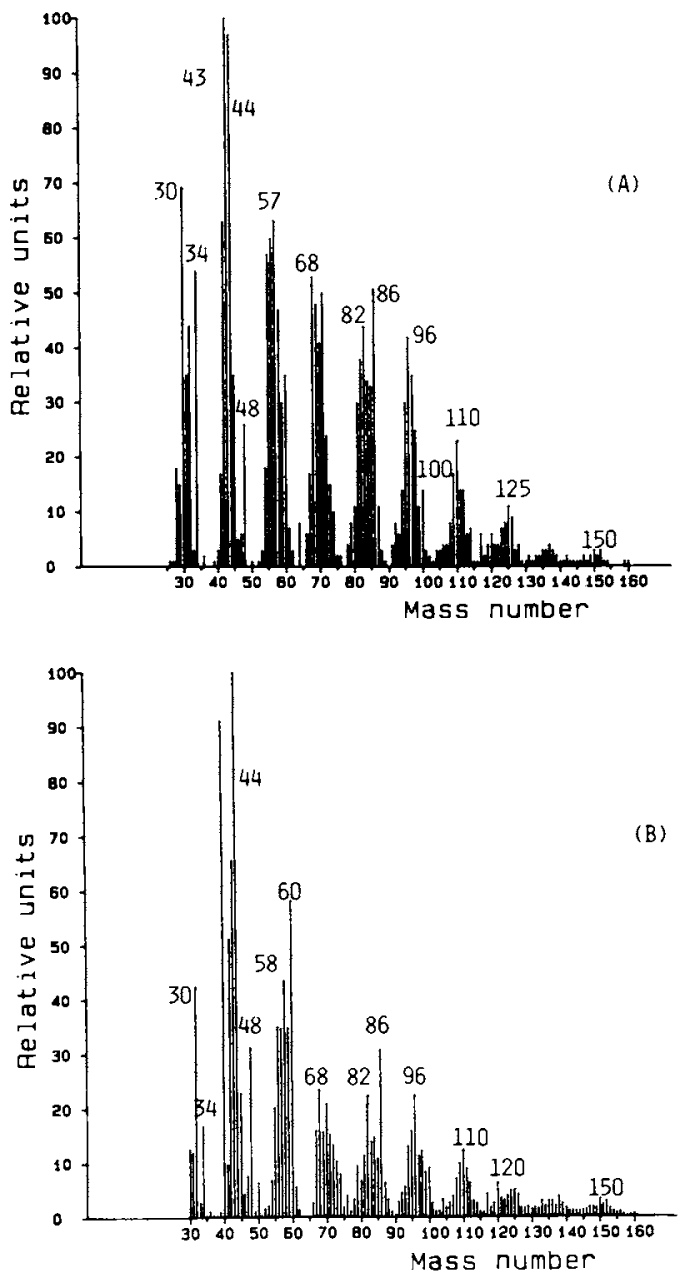

Figure 5. Pyrolysis $15 \mathrm{eV}$ electron impact mass spectrum (A) and pyrolysis argon I photoionization mass spectrum (B) of sample $20 \mathrm{C}$ collected in the New Waterway. Pyrolysis wire temperature $=510^{\circ} \mathrm{C}$.

In Organic Marine Geochemistry; Sohn, M.;

ACS Symposium Series; American Chemical Society: Washington, DC, 1986. 
T I C

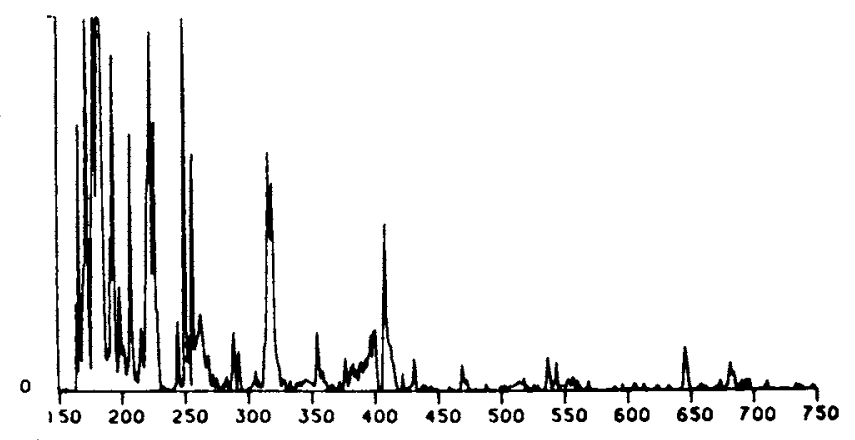

68
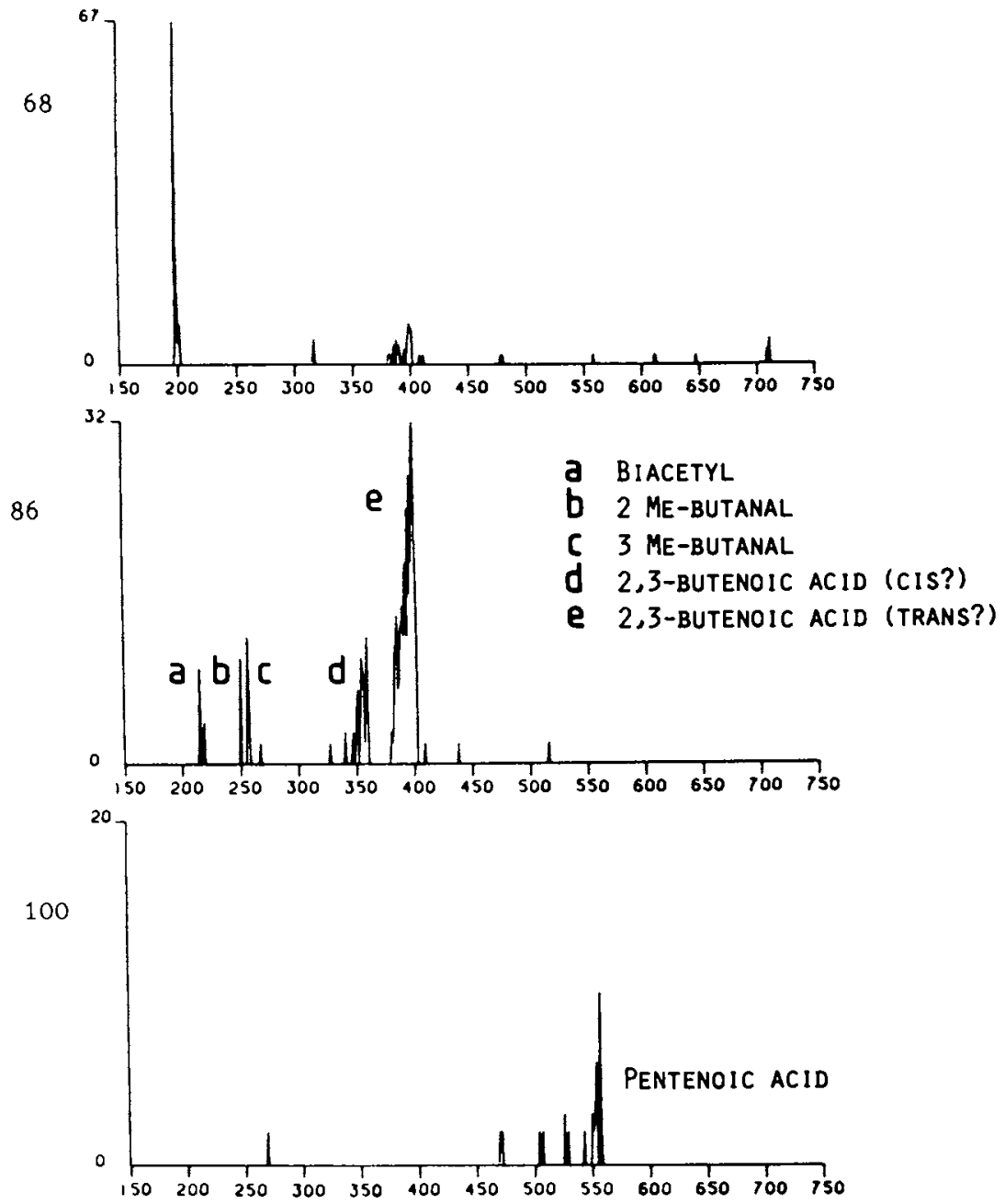

Figure 6. Total ion current and mass chromatogram for $\mathrm{m} / \mathrm{z} 68,86$ and 100 from the py-gc-PI-ms data file of sample $20 \mathrm{C}$.

In Organic Marine Geochemistry; Sohn, M.;

ACS Symposium Series; American Chemical Society: Washington, DC, 1986. 


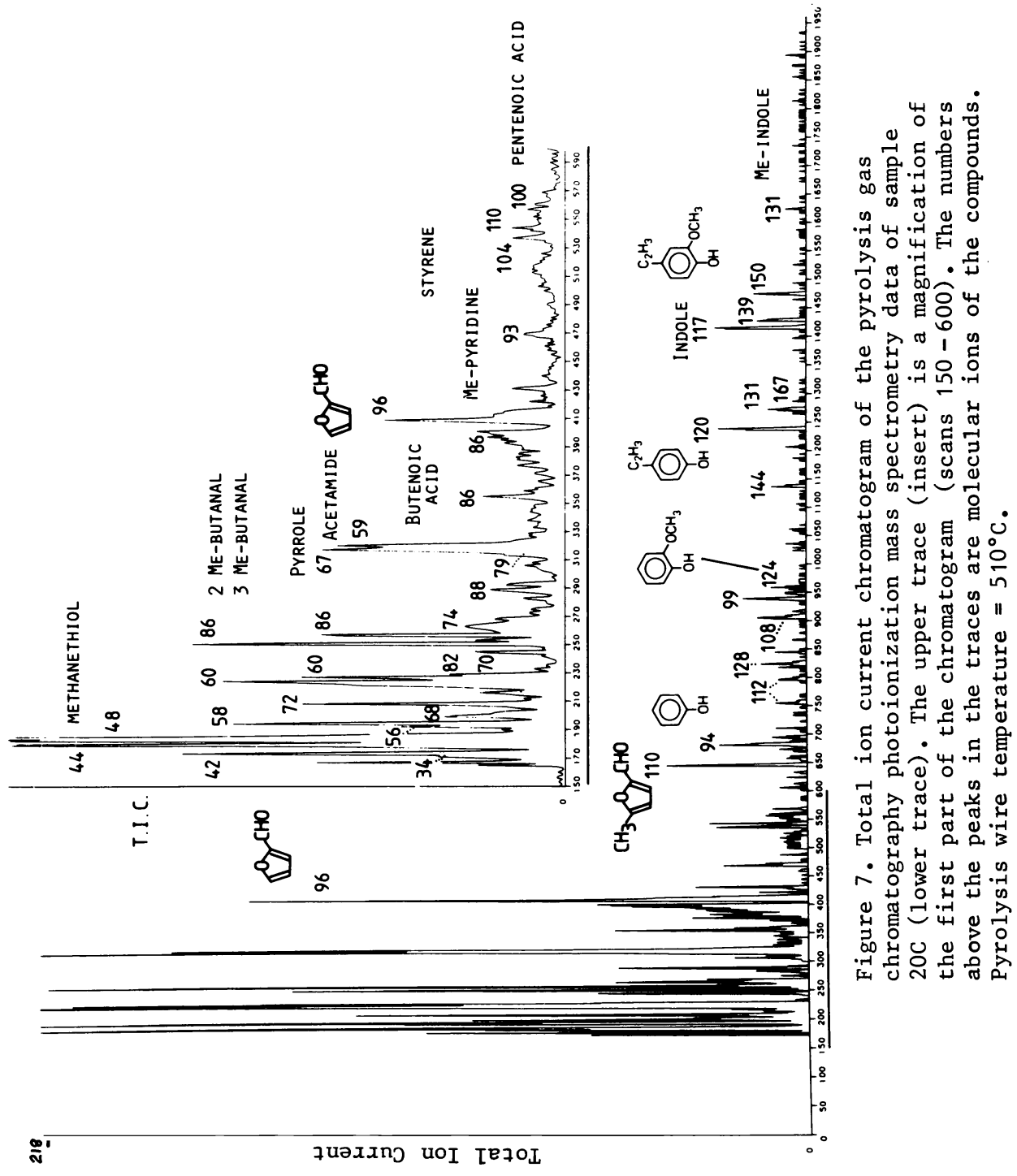

In Organic Marine Geochemistry; Sohn, M.; ACS Symposium Series; American Chemical Society: Washington, DC, 1986. 
sence of levoglucosan and related cyclic compounds may indicate that no intact polysaccharides are present. Methanethiol $(\mathrm{m} / z=48)$, methylpropanal $(\mathrm{m} / \mathrm{z}=72$, scan 205$)$, the methylbutunals $(\mathrm{m} / \mathrm{z}=86)$, pyrrole $(\mathrm{m} / \mathrm{z}=67)$, phenol $(\mathrm{m} / \mathrm{z}=94)$, $\mathrm{p}$-cresol $(\mathrm{m} / \mathrm{z}=108$, scan 905$)$, indole $(\mathrm{m} / \mathrm{z}=$ 117), methyl-indole $(m / z=131)$, phenylcyanoethane $(m / z=131$, scan 1270$)$ and the unknowns at $m / z=99$ (scan 940) and $m / z=167$ (scan 1275) are pyrolysis products from proteins $(13,21,22)$. The acetamide $(\mathrm{m} / z=59)$ has been proposed as a marker for bacterial cell walls (23), a1though it has been observed as a pyrolysis product of glycine $(24)$. The $\mathrm{m} / \mathrm{z}=144$ (scan 1140) is the molecular ion of a free octanoic acid. A11 these compounds in the pyrolysate also indicate that the particulate matter fraction sampled at site $20 \mathrm{C}$ must be considered as a sewage sludge with degraded lignocellulose material from plants and abundant in bacterial biomass. It is remarkable that the bacterial markers remain visible in most of the samples from the New Waterway. Their presence in the most recently dumped dredging spoils in sample area 4 (Loswal Noord) is indicated in factor discriminant data from a subfile of the Loswal Noord samples, but remains to be confirmed by GCMS analysis.

The relative abundance of bacterial biomass as well as the reducing sulphur (expressed as methanethiol in the PMS), may play an important role in the binding of metals in this sediment, which has high concentrations of $\mathrm{Zn}(900 \mathrm{ppm}), \mathrm{Cu}(135 \mathrm{ppm}), \mathrm{Pb}(200 \mathrm{ppm}), \mathrm{Cd}$ $(9 \mathrm{ppm})$ and $\mathrm{Hg}(4 \mathrm{ppm})(8)$. The strong adsorption of for example cadmium to suspended matter has been shown (25), as well as the incorporation of various metals into bacterial cel1 walls (26). Preliminary results from canonical correlation analysis of metal data, \% organic carbon, mud content and the PMS, data file have shown a strong correlation of $\mathrm{Zn}, \mathrm{Cu}, \mathrm{Pb}, \mathrm{Cr}, \mathrm{Hg}$ and $\mathrm{Cd}$ with the bacterial characteristics found in the riverine samples (27). Understanding of the fate of this organic matter may help to understand the fate of certain environmental pollutants.

Acknowledgments

This research was financially supported by the Netherlands Organization for the Advancement of Pure Research ( $(W W)$, the Foundation for Fundamental Research on Matter (FOM) and the Rijks Instituut voor de Zuivering van Afvalwater (RIZA), Lelystad.

\section{Literature cited}

1. Salomons, W., Eysink, W., In "Biogeochemical and Hydrodynamic Processes Affecting Heavy Metals in Rivers, Lakes and Estuaries". Delft Hydraulics Laboratory Publication No. 253: Delft 1981, The Netherlands.

2. Critchley, R.F., Wat.Sci.Techn. 1984 16, 83-94.

3. Whelan, J.K., Fitzgerald, M., Tarafa, M.E., Environm.Sci.Techn. $1983,17,292-298$.

4. Siglen, A.C., Hoering, T.C., Helz, G.R., Geochim.Cosmochim.Acta $1982,46,1619-$

5. Van der Meent, D., Los, A., De Leeuw, J.W., Schenck, P.A., Haverkamp, J., In "Advances in Organic Geochemistry, 1981", Bjordy, M., Ed.; Wiley and Sons: New York, 1983, 336-349.

6. Eisma, D., Boon, J.J., Groenewegen, R., Ittekot, V., Kalf, J., Mook, W.G., In "Transport of Carbon and Minerals in Major World Rivers"; Degens, E.T.; Kempe, S.; Soliman, H.; Eds.; SCOPE/UNEP Special Publication, Mitt.Geol.Paleont.Inst.Univ.Hamburg 1983, 55, p.295-314. 
7. Eisma, D., Bernard, P., Boon, J.J., Van Grieken, R., Kalf, J., Mook, W.G., Mitt.Geol.Paleont.Inst.Univ.Hamburg, in press.

8. Boon, J.J., "Verkennend Pyrolyse Massaspektrometrisch Fingerprint Onderzoek naar Organische Stof Karakteristieken in BodemSlib uit het Rijnmondgebied en in het Kustgebied bij Loswal Noord", AMOLF Report 84/177 (FOM nr. 59.714).

9. Boon, J.J., Tom, A., Brandt, B., Eijke1, G.B., Kistemaker, P.G., Notten, F.J.W., Mikx, F.H.M., Anal.Chim.Acta 1984, 163, 193-205.

10. Louter, G.J., Boerboom, A.J.H., Stalmeijer, P.F.M., Tuithof, H.H., Kistemaker, J., Int.J.Mass Spectr.Ion Phys. 1980, 33, 335-338.

11. Genuit, W., Boon, J.J., J.Anal.Appl.Pyro1. 1985, 8, 25-40.

12. Meuzelaar, H.L.C., Haverkamp, J., Hileman, F.D., "Pyrolysis Mass Spectrometry of Recent and Fossil Biomaterials", Elsevier, Amsterdam, 1982; pp.293.

13. Boon, unpublished observations.

14. Van der Kaaden, A., Haverkamp, J., Boon, J.J., De Leeuw, J.W., J.Ana 1.App1.Pyrol. 1983, 5, 199-220.

15. Cooks, R., "Collision Spectroscopy", Plenum Press, New York $1978, \mathrm{p} .458$.

16. McLafferty, F.W., Bente III, P.F., Kornfeld, R., Tsai, S.-C, Howe, I., J.Am.Chem.Soc. 1973, 95, 2120.

17. Dallinga, J.W., Nibbering, N.M.M., Boerboom, A.J.H., J.Chem.Soc., Perkin Trans. II 1984 , 1065-1076.

18. Morikawa, H., Marchessau1t, R.H., Can.J.Chem. 1981, 59, 23062313.

19. Wallen, L.L., Rohwedder, W.K., Environm.Sci.Technol, 1974, 8, 576-579.

20. Martin, F., Saiz-Jimenez, C., Gonzalez-Vila, F.J., Holzforschung $1979,33,210-212$.

21. Simmonds, P.G., App1.Microbiol. 1970, 20, 567-572.

22. Irwin, W.J., J.Ana1.App1.Pyro1. 1979, 1,3-27/89-122.

23. Hudson, J.R., Morgan, S.L., Fox, A., Ánal.Biochem. 1982, 120, 59-65.

24. Bruchet, M., personal communication.

25. Van der Meent, D., Los, A., De Leeuw, J.W., Schenck, P.A., Salomons, W., Environ.Technol.Letters 1981, 2, 569-578.

26. Beveridge, T.J., In "Environmenta1 Biogeochemistry and Geomicrobiology. Volume 3", Krumbein, W.E., Ed., Ann Arbor Science, Ann Arbor 1978, p.975.

27. Hoogerbrugge, R., Eijke1, G.B., Kistemaker, P.G., in preparation.

RECEIVED September 23, 1985 


\title{
Origin of Organic Matter in North American Basin Cretaceous Black Shales
}

\author{
Rosanne M. Joyce and Edward S. Van Vleet \\ Department of Marine Science, University of South Florida, St. Petersburg, FL 33701
}

\begin{abstract}
The expansion of the oxygen minimum zone in the incipient North Atlantic during the Upper Cretaceous enhanced the preservation of sedimentary organic matter. Organic carbon values ranging from 1.7 to $13.7 \%$ and the proportions of unbound lipid to total lipid content (>70\%) support this premise. A present point of contention is the origin of the organic matter-rich Upper Cretaceous deep-sea sediments. With eustatic sea level transgression and flooding of continental lowlands, transport of terrigenous organic matter into the North American basin may have increased. Analyses of Upper Cretaceous sediments from DSDP Site 603B, lower continental rise east of Cape Hatteras, indicate that the organic matter was continentally derived. $\delta{ }^{3} \mathrm{C}$ values of -23.5 to $-27.1 \% 00, \mathrm{C} / \mathrm{N}$ ratios of 32 to 72 , and lipid class maxima of unbound alkanes ( $\mathrm{C}_{31}$ and $\mathrm{C}_{29}$ ), unbound fatty acids $\left(\mathrm{C}_{30}\right.$ and $\mathrm{C}_{28}$ ) and bound fatty acids ( $\mathrm{C}_{28}$, $\mathrm{C}_{26}$ and $\mathrm{C}_{24}$ ) 30 provide ${ }^{28}$ supportive evidence for the terrigenous nature of the organic matter.
\end{abstract}

The Upper Cretaceous has been described as a period of many important global events. Enhanced sea-floor spreading (up to 18 $\mathrm{cm} / \mathrm{yr}$ ) at many mid-ocean $\mathrm{ridge}$ systems led to a reduction in ocean basin volume (1) particularly in the restricted, incipient North Atlantic. Sea level transgressed, surpassing present levels by as much as $350 \mathrm{~m}$ (2). As latitudinal temperature gradients diminished, deep-water circulation in the oceans waned. In the North Atlantic basin (3), stagnation and consequent expansion of the oxygen minimum zone to the deep-sea floor may account for the observed preservation of thick organic matter -rich sequences in mid-Cretaceous sediments $(4-6)$. The sluggish deep-water circulation which favored anoxic expansion may have also reduced nutrient recycling to surface waters, decreasing fertility and productivity in the euphotic zone of the open-ocean ( 7 ). Paleofertility estimates derived from organic carbon accumulation

$0097-6156 / 86 / 0305-0091 \$ 06.00 / 0$

() 1986 American Chemical Society 
rates of mid-cretaceous deep-sea deposits suggest that primary productivity was as much as an order of magnitude lower than productivity measured in today's oceans (8). If these scenarios are correct, increased input of terrestrial organic matter from the prograding continental shelf ( 9 ), coupled with reduced sea-surface productivity, would produce an obvious terrestrial influence on the sedimentary organic matter deposited on the continental shelf and slope.

Alternatively, Jenkyns (9) proposed that with the extension of the subaerial continent, terrigenous run-off not only enhanced primary productivity in shelf surface waters by increasing nutrient avallability, but also increased the deposition of terrigenous organic matter in the marine environment. In consideration of these scenarios, both marine organic matter and terrigenous organic matter may have been important components of the sediment.

The goals of the present study are to assess the local extent of anoxia on the lower continental rise, east of Cape Hatteras, during specific intervals of the Upper Cretaceous, to evaluate relative contributions to the bulk organic matter by marine and terrigenous sources, and to determine the extent of microbial alteration of specific lipid classes. The above assessments are based on $\delta{ }^{13} \mathrm{C}$, organic carbon/organic nitrogen ratios, and analyses of selected lipid classes of Upper Cretaceous black shale and variegated claystone samples from DSDP Site 603B.

\section{Experimental Methods}

Sediment was drilled from DSDP Site 603B (lower continental rise, $435 \mathrm{~km}$ east of Cape Hatteras, water depth $4643 \mathrm{~m}$, latitude $35^{\circ} 29.71^{\prime} \mathrm{N}$, longitude $\left.70^{\circ} 01.71^{\prime} \mathrm{E}\right)$ by the $\mathrm{D} / \mathrm{V}$ Glomar Challenger (E1gure 1). Subsurface sampling depths ranged from 1081 to $1146 \mathrm{~m}$ (Table I). Based on the evidence of sharp basal contacts and graded silts, it is presumed that the sediments were turbiditically emplaced to Site $603 \mathrm{~B}(10)$.

Table I. Site description of DSDP Site 603B lower continental rise, U.S. east coast (10).

\begin{tabular}{|c|c|c|c|c|}
\hline $\begin{array}{l}\text { Core } \\
\text { Section }(\mathrm{cm})\end{array}$ & $\begin{array}{l}29 \\
1(48-53)\end{array}$ & $\begin{array}{c}34 \\
1(13-116)\end{array}$ & $\begin{array}{c}34 \\
2(136-139)\end{array}$ & $\begin{array}{c}36 \\
1(39-43) \\
\end{array}$ \\
\hline Depth (m) & 1050 & 1127 & 1130 & 1146 \\
\hline Lithology & $\begin{array}{l}\text { varlegated } \\
\text { claystone }\end{array}$ & \multicolumn{3}{|c|}{--black carbonaceous claystones---- } \\
\hline \multirow[t]{2}{*}{ Age } & Conlacian- & \multicolumn{3}{|l|}{ Turonian } \\
\hline & $84-89 \mathrm{Ma}^{\mathrm{a}}$ & $89-91 \mathrm{Ma}$ & $91-98 \mathrm{Ma}$ & \\
\hline
\end{tabular}

$a_{\text {millions of years }}$

Unbound lipid was extracted by refluxing sediment in methanol/toluene/ $\mathrm{H}_{2} \mathrm{O}$ for three hours following sonication (6). 


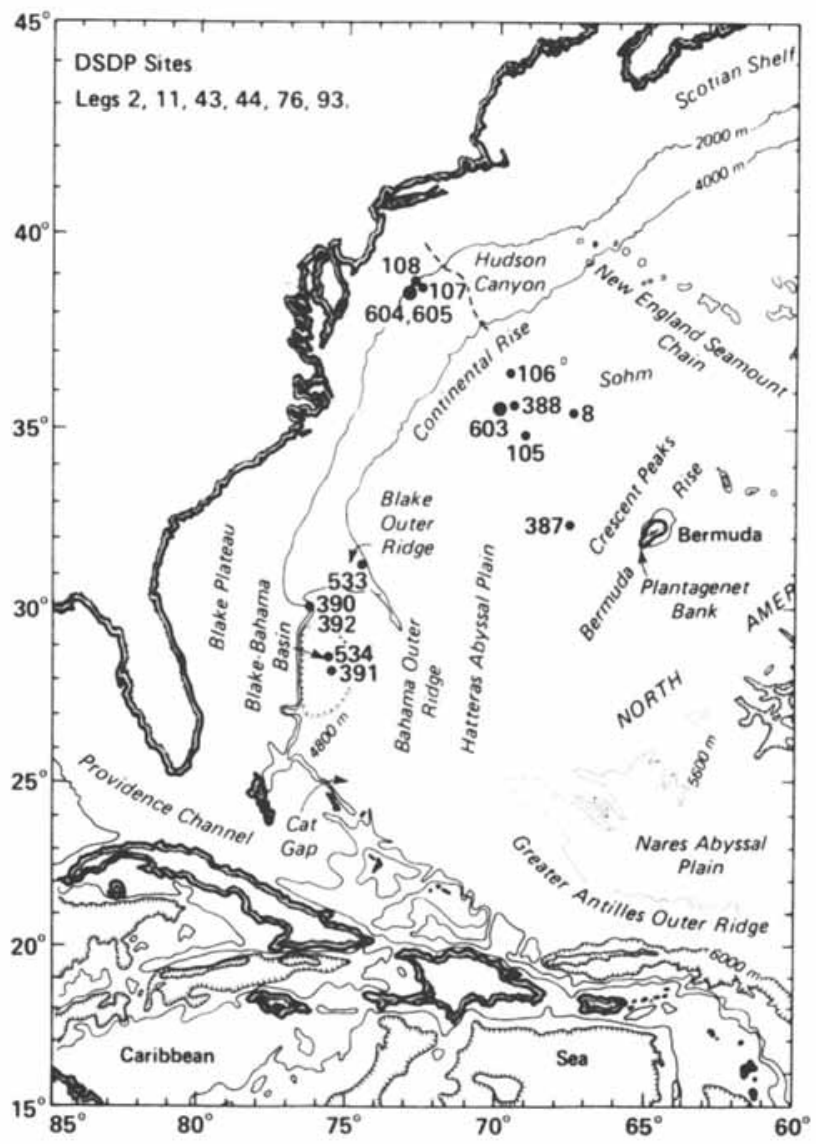

Figure 1. Location map with physiographic features of the North American Basin, and location of DSDP Site 603 and other DSDP drill sites in the North Atlantic Ocean. Bathymetry after Uchup1, 1971 (10).

In Organic Marine Geochemistry; Sohn, M.; ACS Symposium Series; American Chemical Society: Washington, DC, 1986. 
After partitioning and hexane extraction, the unbound lipid extract was concentrated to near dryness and diluted to a known volume. Aliquots of unbound lipld were partitioned employing a modified serial-elution column chromatography procedure $(6,11)$ to isolate aliphatic hydrocarbons and fatty acids. Fatty acids were methylated (12) and purified by thin-layer chromatography (6). Bound lipid was extracted by refluxing residual sediment in $0.5 \mathrm{~N}$ $\mathrm{KOH}$ in methanol/toluene/ $/ \mathrm{H}_{2} \mathrm{O}$ and then separated, derivitized and purifled to obtain the bound lipid classes. Aliquots of unbound and bound total lipid were measured gravimetrically after drying to constant welght.

Identification and quantitative determinations of lipid compounds were made by splitless injection capillary gasmliquid chromatography (GC). Samples were analyzed on a Hewlett-Packard $5880 \mathrm{~A}$ FID gas chromatograph equipped with a $15 \mathrm{~m} \times 0.2 \mathrm{~mm} 1$.d. DB-5 fused silica caplllary column, temperature programmed from 90 to $255^{\circ} \mathrm{C}$ at $4^{\circ} \mathrm{C} / \mathrm{min}$. using $\mathrm{H}_{2}$ as a carrler gas. Individual compounds were identifled by comparison of retention times with those of authentic standards and confirmed by combined high-resolution gas chromatography-mass spectrometry (6). Quantification of individual constituents was based on relative percents of integrated peak areas extrapolated to gravimetrically determined total lipid fraction weights. Analytical variation of sample replicates quantified by GC generally ranges from \pm 10 to $37 \%(13-14)$.

Stable carbon isotopes were analyzed on a Finnigan MAT 250 isotope ratio mass spectrometer according to the procedure of Craig (15). Results are reported relative to the Chicago PDB standard in terms of $\delta{ }^{3} \mathrm{C}$ defined as:

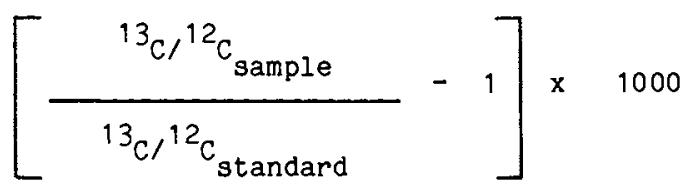

(15). Average analytical variability of sample preparation and stable carbon isotope ratio analysis is $\pm 0.2 \%(16)$. A Carlo-Erba Model 1106 Elemental Analyzer was employed to determine percent organic carbon and nitrogen in each sediment sample. Analytical variation of sample analysis is $\pm 20 \%$ (17).

\section{Results and Discussion}

Total organic carbon (TOC), $\delta^{13} \mathrm{C}$, and total lipid data are summarized in Table II (more detalled results can be found in Joyce [6]). Total organic carbon was highest in the Cenomanian-Turonian black shale samples, with ranges from $3.4 \%$ to 13.7\%. The Coniacian-Santonian varlegated claystone had the lowest TOC (1.7\%) in the sample set. TOC in Core 34-1 represents one of the highest values measured in sediments sampled from the North American basin. Conditions in the near-shore environment and lower continental rise following turbiditic emplacement of these sediments must have favored organlc matter preservation since values $>0.6 \%$ TOC are not typical of deep-sea sediments (18). Although an environment entirely depleted in oxygen is not a 
requisite for black shale formation (18), the unbloturbated nature of the sediments in the present study suggests that an oxygen-stressed system prevalled during their deposition and burlal.

Table II. Organlc geochemical data, DSDP Site 603B lower continental rise, U.S. east coast.

\begin{tabular}{|c|c|c|c|c|c|}
\hline$\overline{\text { Core }}$ & $29-1$ & $33-\mathrm{CC}$ & $\overline{34-1}$ & $34-2$ & $36-1$ \\
\hline Sub-bottom depth (m) & 1050 & 1127 & 1128 & 1130 & 1146 \\
\hline $\operatorname{TOC}^{\mathrm{a}}(q)$ & 1.7 & 3.4 & 13.7 & 4.8 & 3.9 \\
\hline$c \&$ rat $10^{b}$ & 72.0 & 38.6 & 43.8 & 40.0 & 32.0 \\
\hline$\delta^{13} \mathrm{C}(\% / 00)$ & -24.7 & -24.7 & -23.6 & -23.5 & -27.1 \\
\hline Total lipid (mg/g) & 0.3 & 0.7 & 3.3 & 1.4 & 1.9 \\
\hline Lipld in TOC (\%) & 1.5 & 2.2 & 2.4 & 2.8 & 4.8 \\
\hline Bound l1pid ( $\%$ of & 27 & 7 & 6 & 19 & 9 \\
\hline
\end{tabular}

total 11pid)

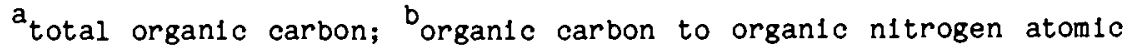
ratio

Unbound liplds, compounds which are generally more lablle than their bound counterparts (19), represented the greatest proportion of total lipid in each sediment sample. More than $80 \%$ of the total lipld was unbound in the black shales; Core 34-1 had the highest proportion of unbound lipid $(94 \%)$ as well as the highest concentration of TOC (13.7\%) and total l1pid $(3.3 \mathrm{mg} / \mathrm{g})$. Conversely, the varlegated claystone (Core 29-1) had the lowest proportion of unbound 11 pid $(73 \%)$, TOC $(1.7 \%)$ and total lipid $(0.3$ $\mathrm{mg} / \mathrm{g}$ ). Lipld concentration and the proportion of unbound to bound lipld may be coupled with the oxidation potential. During the Cenomanin-Turonian, black shale deposition and/or formation probably occurred under conditions of reduced oxidizing potential, and that of the Conlacian-Santonian varlegated claystone during elevated oxidation potential conditions.

The percentage of lipld in TOC increased with depth $(1.5$ to 4.8\%). Dean et al. (20) have related increases in 11 pld content to enhanced methanogentc bacterlal activity, a process that may have produced lighter $\delta{ }^{13} \mathrm{C}$ values. Work by Pauly (21) has shown that the input of archaebacterial lipids to these sediment samples is very low $(<0.1 \mu \mathrm{g} / \mathrm{g})$. This $\mathrm{f}$ inding suggests that the increase in $11 \mathrm{pld} / \mathrm{TOC}$ rat10 w1th depth in the present study may not be due to this type of input. The trend In fncreasing lipld with depth does not colncide with the trend in $\delta^{13} \mathrm{C}$ values. As discussed above, lipid content in these sediments is probably related to the oxidation potential and not to bacterial blomass.

The provenance of sedimentary organic matter in the present study appears to be primarily terrigenous. $\delta^{3} \mathrm{C}$ values of -23.5 to $-27.1 \%$ in the sample set fall within the 1sotoplc range of terrigenous organic matter. Generally, $\delta^{13} \mathrm{C}$ values ranging from -23 to $-33 \%$ are found in terrestrial plants utilizing the 
Calvin-Benson photosynthetic pathway, a maximum ${ }^{13} \mathrm{C}$ fraptionation mechanism. Most warm water marine phytoplankton have $\delta{ }_{C}$ values between -17 and $-22 \%$ (22). As global temperatures were thought to have been warm and equitable during the mid-Cretaceous (3), warm water phytoplankton probably dominated waters of the North Atlantic and had stable carbon 1sotope values typical of warm water organisms.

1 Recently, a point of contention has arisen concerning the use of $\delta^{13} \mathrm{C}$ as a source Indicator for mid-Cretaceous inputs. Dean et ${ }_{3}{ }_{\mathrm{C}}$ and ${ }^{2} \mathrm{C}$ by photosynthetic organisms occupying mid-Cretaceous oceans may not have been the same as in today's oceans. Atmospheric $\mathrm{CO}_{2}$ levels may have been as much as an order of magnitude greater than present day levels, according to the model developed by Berner et al. (23). This condition would shift oceanic blcarbonate to isotopically lighter values. The effects of isotoplcally lighter dissolved bicarbonate on organic carbon assimilation by phytoplankton have been studfed by wong and Sackett (24). It was found that the extent of $13_{\mathrm{C}} /{ }^{12} \mathrm{C}$ discrimination among species was varlable and not all values fell within the terrigenous isotopic range. Although Dean et al. (20) proposed that no systematic ${ }^{1} \mathrm{C}$ enrichment occurred in phytoplankton compared to terrestrial plants during the mid-Cretaceous, $\delta{ }^{3} \mathrm{C}$ values of -23.5 to $-27.1 \%$ oo observed in the present study are coincident with data from elemental and lipid analyses and Indicate that, at least at Site 603B, the Upper Cretaceous organic matter-rich deposits are primarily of continental origin.

Shifts in 1sotopic signals were observed in the analysis of these Upper Cretaceous sediments. The lightest isotopic value was measured in the oldest sample $(603 \mathrm{~B}-36-1 ;-27.1 \% / 00)$. 603B-34-2 and $603 \mathrm{~B}-34-1$ were isotopically heavier $(-23.5$ to $-23.6 \% \%$ $603 \mathrm{~B}-33-\mathrm{CC}$ and $603 \mathrm{~B}-29-1$ were again lighter $(-24.7 \%$ \% $\mathrm{A}$ simplistic interpretation of this fluctuation is the variable mixing of marine and terrigenous organic matter. Isotopically lighter values represent smaller contributions by marine organic matter, whereas heavier values indicate a greater marine input.

The trend toward lighter isotopic values from the upper Cenomanian $(603 \mathrm{~B}-34-2)$ to the Santonian $(603 \mathrm{~B}-29-1)$ may also indicate improvement in the oceanic water mass circulation. In oceanic water masses where circulation is diminished, density \$tratification prevents mixing of ${ }^{13} \mathrm{C}$ enriched surface 13 water with $\$ 3_{C}$ depleted bottorn waters. The surface enrichment of $13_{C}$ produces a 'heavier' phytoplankton community (25). Deposition and preservation of phytoplankton detritus would leave a heavier isotopic signal in the sedimentary organic matter. Alternatively, the range of values observed in this study may also represent natural $\delta{ }^{3} \mathrm{C}$ variations in species composition.

Elemental analyses provided supportive data for the origin of the sedimentary organic matter. Remineralization of nitrogen in marine organic matter produces $C / N$ ratios between 10 and 15 (26). $\mathrm{C} / \mathrm{N}$ ratios $>15$ in terrigenous organic matter result from the paucity of nitrogenous compounds in higher plant lignin and cellulose (27). C/N ratios of sediment samples from DSDP Site 603B ranged from 32 to 72 . These values may represent nitrogen-poor, 
terrestrially-derived plant detritus. If the sedimentary organic matter had been marine-derived and highly reworked, values closer to 15 would be expected.

In the analysis of selected lipid fractions, it was shown that the unbound non-aromatic hydrocarbons comprised $<12 \%$ of the total extractable lipid (Table III). Concentrations of the n-alkanes corresponded to those measured in organic matter-rich Cretaceous claystones from the northwestern Atlantic (4). $C_{29}$ and $C_{31}$, the most frequently observed alkanes in higher plant waxes ${ }^{31}$ (28), dominated the alkane distributions in the present study (Figure 2). Alkane maxima at $C_{3}$ have been noted in a number of other deep-sea environments inclualing DSDP Site 532B, Walvis Ridge (6) and site 386, Northwest Atlantic (29). $C_{29} / C_{17}$ ratios $\gg 1$ were consistent with the continental plant wax ${ }^{17}$ input inferred from the above-described alkane distributions (Table III). The short-chain alkanes $\left(\mathrm{C}_{17}-\mathrm{C}_{21}\right)$ are described by an odd-carbon/even-carbon predominance ( $\sigma E P)(30)$ of $\leq 1$. This distribution is typical of continentally-derived inputs. These alkanes are generally less abundant than the longer-chain counterparts and lack odd-carbon preference (31). The longer-chain compounds $\left(\mathrm{C}_{27}-\mathrm{C}_{31}\right)$ were odd-carbon predominated (OEPS $>1.7$ ) and are typical of terrestrial organic matter inputs. Strong odd-carbon preferences in the long-chain alkane distributions indicate early stages of maturation (32). In a highly evolved mature fraction, longer-chain alkanes would no longer be dominated by oddincarbon compounds. The substantial area of the unresolved complex mixtures may represent branched and cyclic compounds generated by long-term geochemical processes $(20,33)$.

Bound aliphatic hydrocarbons comprised $\leq 7 \%$ of the saponifiable lipid $(<1$ to $15 \mathrm{\mu g} / \mathrm{g})$. Unbound/bound ratios of $<1$ to 67 of this hydrocarbon fraction, with the exception of $603 \mathrm{~B}-29-1$, agree with values reported in other studies (34, 37). Bound alkane distributions were dominated by $\mathrm{C}_{20}$ or $\mathrm{C}_{22}$ (Figure 3 ). Eventcarbon predominance of alkanes is an anomaly, but distributions similar to those in the present study have been observed in other North Atlantic deep-sea sediments (29). The source of these compounds, however, is unknown.

Fatty acids comprised $7-29 \%$ of the unbound lipid extract (55-370 $\mathrm{\mu g} / \mathrm{g}$; Table IV). 603B-33-CC, 603B-34-1 and 603B-36-1 had fatty acid distributions which maximized at $C_{16}$ and $C_{18}$ and $603 \mathrm{~B}-29-1$ and $603 \mathrm{~B}-34-2$ at $\mathrm{C}_{30}$ and $\mathrm{C}_{28}$, respectively. Dominance of these short-chain acids in the presence of their long-chain counterparts suggests that the short-chain acids were not utilized as readily as the short-chain non-aromatic hydrocarbons. Input of these compounds may have also been subsequent to sediment deposition, possibly through microbial activity (Figure 4). Monoenolc fatty acids were detected in the black shale samples (603B-34-1 and 603B-36-1) but branched fatty acids were observed in all of the sediments analyzed. Alteration or remineralization of the monoenoic compounds, compared to the branched acids, may have occurred more readily.

The bound fatty acid component in the total lipid extract was one to three orders of magnitude less than the unbound fatty acid fraction. This relationship produced unbound/bound ratios 
Table III, Gravimetric and gas chromatographic data on unbound and non-aromatic hydrocarbon fractions, DSDP Site 603B lower continental rise, U.S, east coast.

\begin{tabular}{|c|c|c|c|c|c|}
\hline Lipid fractions & $\begin{array}{l}\text { Core } \\
29-1^{a} \\
\end{array}$ & $\begin{array}{c}\text { Core } \\
33-\mathrm{Cc}^{\mathrm{b}}\end{array}$ & $\begin{array}{l}\text { Core } \\
34-1 \text { c }\end{array}$ & $\begin{array}{l}\text { Core } \\
34-2^{c}\end{array}$ & $\begin{array}{l}\text { Core } \\
36-1\end{array}$ \\
\hline \multicolumn{6}{|c|}{ Unbound non-aromatic $\mathrm{HC}^{\mathrm{d}}$} \\
\hline$\mu g / g$ dry sediment & 4 & 27 & 336 & 44 & 134 \\
\hline$\%$ of unbound lipid & $2(3)^{e}$ & $4(3)$ & $11(15)$ & $4(5)$ & $8(4)$ \\
\hline$\left\langle C_{25}(q)\right.$ & 2 & 4 & 2 & 2 & 2 \\
\hline$\geq c_{25}^{25}(8)$ & 5 & 5 & 4 & 5 & 4 \\
\hline unflentified (q) & 6 & 44 & 40 & 47 & 20 \\
\hline $\mathrm{UCM}^{\mathrm{I}}(\phi)$ & 87 & 47 & 54 & 46 & 74 \\
\hline OEPE $\left(\mathrm{C}_{17}-\mathrm{C}_{21}\right)$ & 1.0 & 0.1 & 0.9 & 0.4 & 0.7 \\
\hline OEP $\quad\left(C^{11}-C_{21}^{2 l}\right)$ & 8.0 & 2.2 & 2.0 & 1.7 & 5.8 \\
\hline $\mathrm{C}_{20^{\prime}} \mathrm{C}_{17}{ }^{\mathrm{I}}$ & 21 & 17 & 33 & 50 & 4 \\
\hline pristane/phytane & 1.0 & 0.8 & 0.4 & 0.3 & 0.5 \\
\hline \multicolumn{6}{|l|}{ Bound nonmaromatic HC } \\
\hline$\mu g / g$ dry sediment & 5 & $<1$ & 5 & 15 & 3 \\
\hline$\%$ of bound lipid & 7 & $<1$ & 3 & 6 & 2 \\
\hline unbound/bound ratio & $<1$ & 27 & 67 & 3 & 4 \\
\hline$\left\langle c_{25}(q)\right.$ & 13 & 16 & 15 & 19 & 7 \\
\hline$\geq c_{25}^{20}(\phi)$ & 7 & 11 & 2 & 4 & 2 \\
\hline unflentified (q) & 11 & 49 & 54 & 45 & 70 \\
\hline $\mathrm{UCM}^{1}(\not)$ & 69 & 24 & $29 \mathrm{~h}$ & 32 & 22 \\
\hline OEP ${ }^{8}\left(C_{17}-C_{21}\right)$ & $<0.1$ & 0.1 & $\mathrm{NC}^{\mathrm{n}}$ & $\mathrm{NC}$ & $\mathrm{NC}$ \\
\hline OEP $\quad\left(\mathrm{C}_{27}^{1}-\mathrm{C}_{21}^{2-1}\right)$ & 1.7 & 0.8 & 0.3 & 1.1 & $0.6^{1}$ \\
\hline $\mathrm{C}_{29} \mathrm{C}_{17}{ }^{\mathrm{C}}$ & $\mathrm{NC}$ & $\mathrm{NC}$ & $\mathrm{NC}$ & $\mathrm{NC}$ & $\mathrm{NC}$ \\
\hline
\end{tabular}

$a_{5}$ replicates; $b_{4}$ replicates; $c_{3}$ replicates; dhydrocarbons; $\mathrm{e}_{\text {standard defiation; unresolved complex mixture; } 8 \text { oddreven }}$

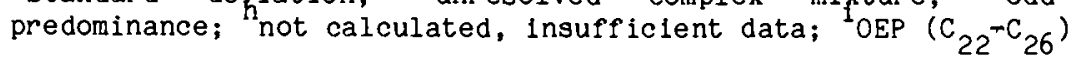




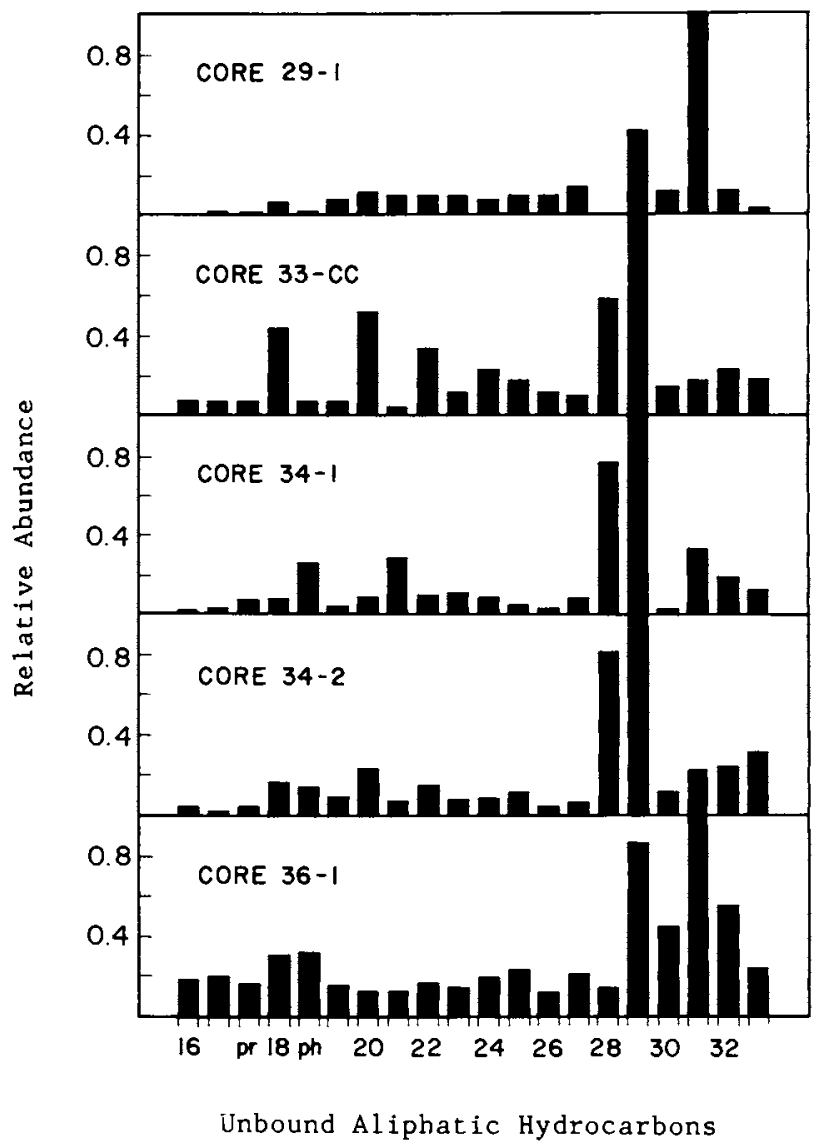

Figure 2. Carbon number distributions and relative abundances of unbound allphatic hydrocarbons normalized to the most abundant hydrocarbon, DSDP Site 603B lower continental rise, U.S. east coast.

In Organic Marine Geochemistry; Sohn, M.; ACS Symposium Series; American Chemical Society: Washington, DC, 1986. 


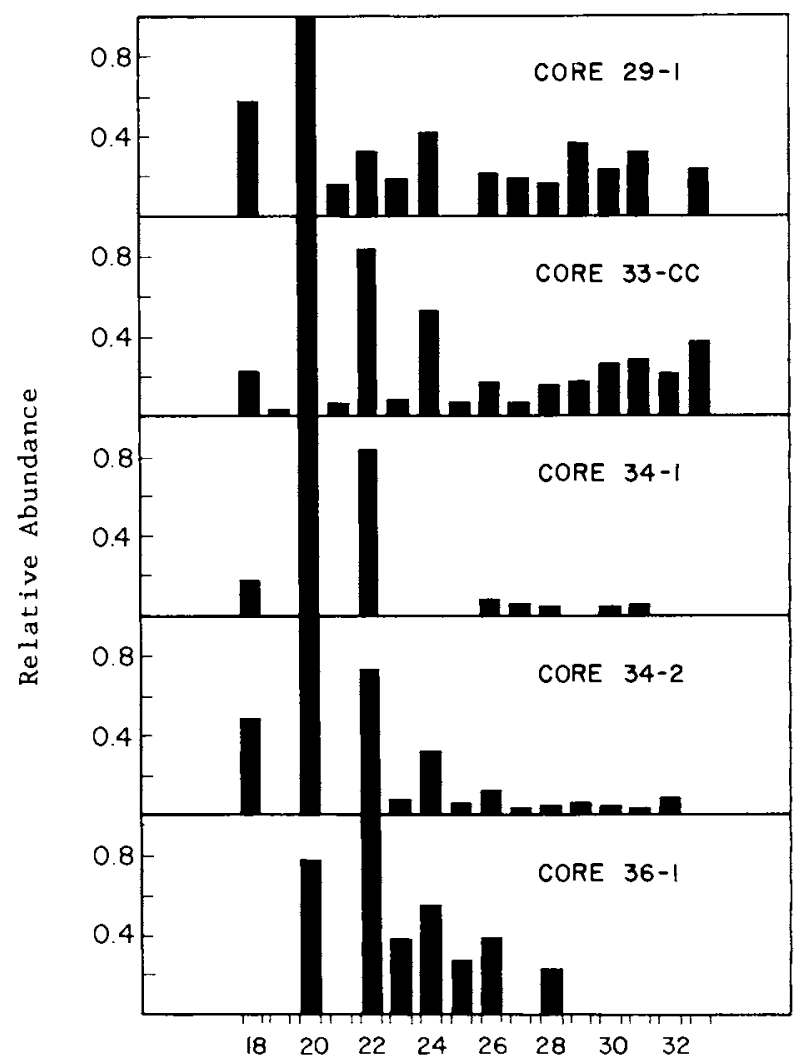

Bound Aliphatic Hydrocarbons

Figure 3. Carbon number distributions and relative abundances of bound aliphatic hydrocarbors normalized to the most abundant hydrocarbon, DSDP Site 603E lower continental rise, U.S. east coast.

In Organic Marine Geochemistry; Sohn, M.; ACS Symposium Series; American Chemical Society: Washington, DC, 1986. 


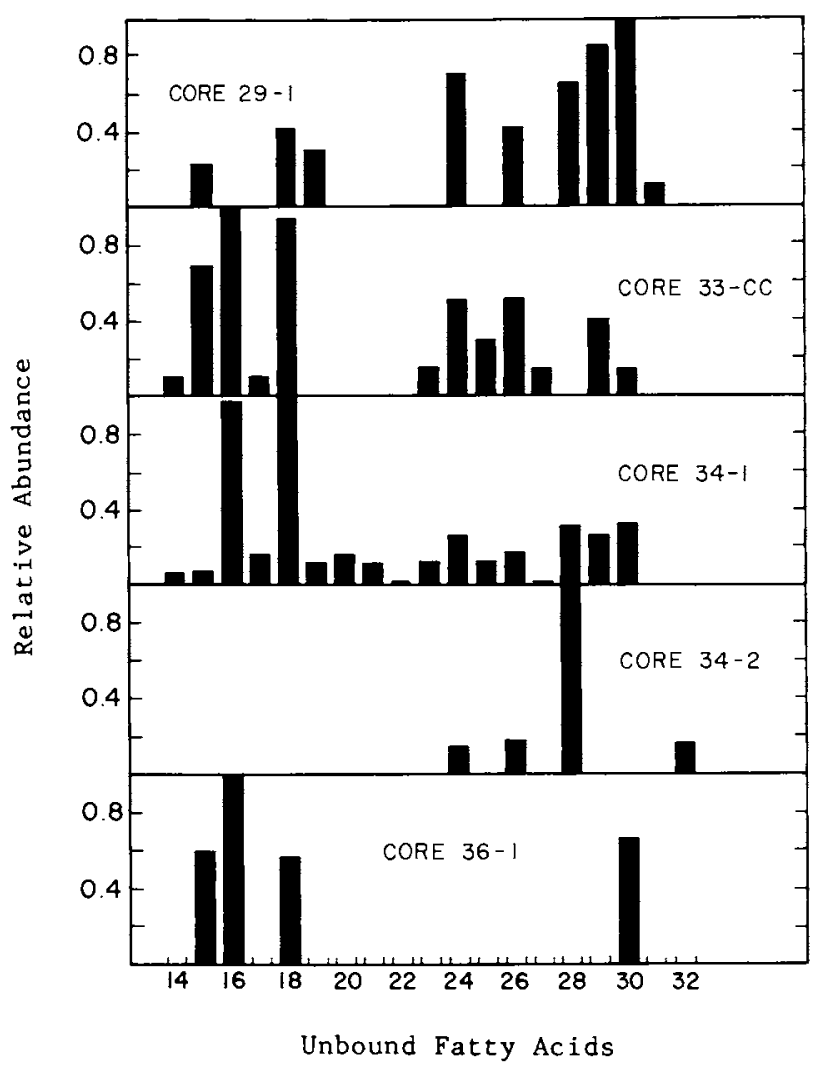

Figure 4. Carbon number distributions and relative abundances of unbound fatty acids normalized to the most abundant fatty acid, DSDP Site 603B lower continental rise, U.S. east coast.

In Organic Marine Geochemistry; Sohn, M.; ACS Symposium Series; American Chemical Society: Washington, DC, 1986. 
$\gg 1$. The greater proportion of the unbound fatty acid fraction compared to the bound fraction colncides with simflar proportions for total lipid and non-aromatic hydrocarbons. Fatty acids comprised <1-14\% of the bound lipid extract, values equivalent to $<1-10 \mu \mathrm{g} / \mathrm{g}$. A summary of gas chromatographic data is presented in Table IV.

Greater relative abundances of compounds $C_{24}-C_{32}$ (with the exception of $603 B-34-1$ ) and $C_{16}$ and $C_{18}$ (w1th the exception of 603B-34-2) (Figure 5), coupled with greater relative percentages of monoenolc and branched fatty aclds, suggest that the preservation of compounds in the bound fatty acid fraction was enhanced relative to the those in unbound fraction. Lipophilic humlc-like material and/or clay-mineral binding may have reduced the reactivity of these compounds (37). The longer chaln aclds probably represent components of terrigenous organic matter whereas the short-chain acids are probably components resulting from mlcrobial activity.

Bound and unbound short-chain and long-chaln fatty aclds were generally predominated by the even-carbon compounds. Even-carbon preference, both in the short-chain and long-chain range, is not uncommon for fatty acids in anclent sediments. Both the Devonian Antrim shale and the Soudan shale have shown similar even-carbon preferences although the respective nfalkane fractions lacked odd-carbon preference.

\section{Summary}

The world-wide distribution of organic matter-rich Upper Cretaceous sediments has prompted a number of organic geochemical Investigations to study their origin. Sediments of Upper Cretaceous age sampled from the lower continental rise east $_{\text {of }}$ North America (DSDP Site 603B) were characterlzed by $\delta{ }^{3} \mathrm{C}$ values ranging from -23 to $-27 \%$ and $\mathrm{C} / \mathrm{N}$ ratios from 32 to 72 . Although DSDP Site 603B was, and has been, a deep-sea environment, continental provenance of the organic matter was inferred from the results of TOC and selected lipld analyses. The terrigenous nature of the organic matter in these Upper Cretaceous sediment samples supports previous geological data of 1t's turbiditic emplacement to Site 603B. Unbound alkanes $\mathrm{C}_{29}$ and $\mathrm{C}_{31}$, unbound fatty acids $\mathrm{C}_{28}$ and $\mathrm{C}_{30}$, and bound fatty acids $\mathrm{C}_{24}, \mathrm{C}_{26}$, and $\mathrm{C}_{28}$ distribution maxima indicate that plant waxes were 1mportant components in the 11pid material. Organlo-rlchness $(1.7$ to $13.7 \%$ ) and the relatively large proportions of unbound lipld compared to the bound lipid support the theory that anoxla prevalled in the deep-sea during the time intervals represented by these sediments, particularly during black shale deposition. The limited contribution of marine organic matter in the sediments examined indicates that sea-surface fertility was probably not any higher than in today's oceans. 
Table IV. Gravimetric and gas chromatographic data on unbound and bound fatty acid fractions, DSDP Site 603B lower continental rise, U.S. east coast.

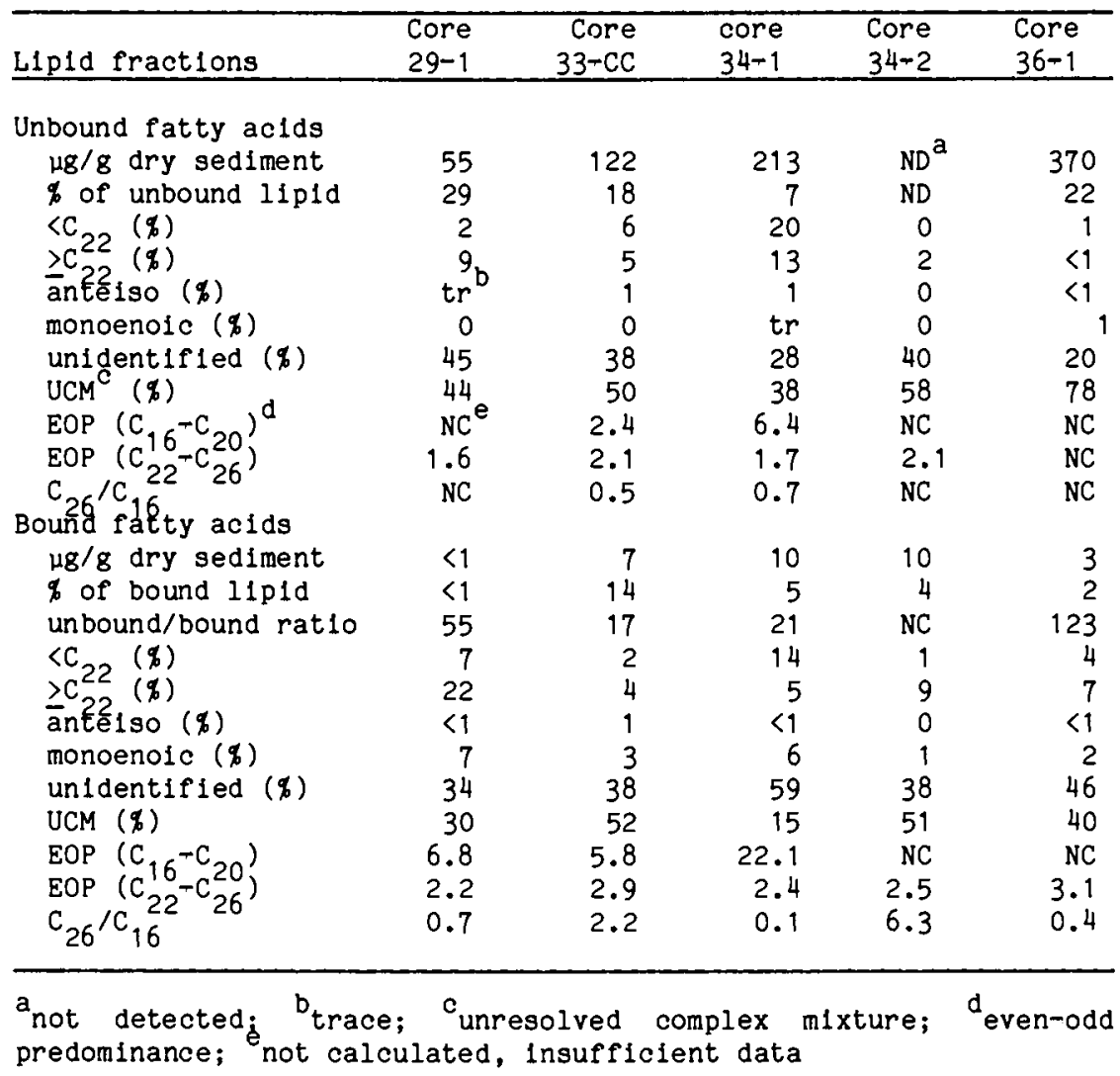

In Organic Marine Geochemistry; Sohn, M.; 


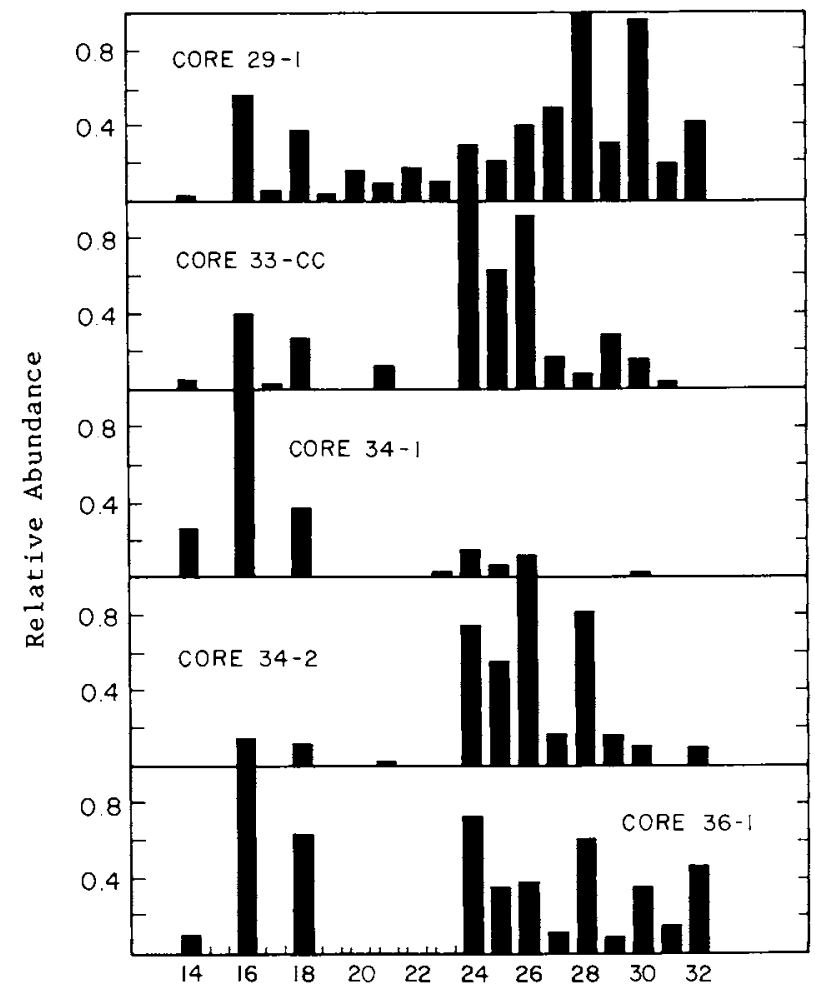

Bound Fatty Acids

Figure 5. Carbon number distributions and relative abundances of bound fatty acids normalized to the most abundant fatty acid, DSDP Site 603B lower continental rise, U.S. east coast.

In Organic Marine Geochemistry; Sohn, M.;

ACS Symposium Series; American Chemical Society: Washington, DC, 1986. 


\section{Acknowledgments}

Our thanks to Dr. Phil Meyers of the University of Michigan for providing the DSDP samples, and to Margarita Conkright for performing the stable carbon isotope analyses.

\section{Literature Cited}

1. Hays J.D.; Pitman, W.C. Nature 1973, 246, 18-22.

2. Van Graas, G. In "Advances in Organic Geochemistry, 1981"; Bjoroy, M. et al., Eds.; John Wiley: Chichester, 1981; pp. $471-476$.

3. Ryan, W.; Cita, M.B. Mar. Geol. 1977, 23, 197-215.

4. Simoneit, B.R.T. In "Init. Repts. DSDP, 43"; Tucholke B.E.; Vogt P.R. et al., Eds.; U.S. Govt. Printing office: Washington, D.C., 1979; pp. 643-649.

5. Demaison, G.J.; Moore, G.T. Org. Geochem. 1980, 9-31.

6. Joyce, R.M. M.S. Thesis, University of South Florida, St. Petersburg, 1985.

7. Fischer, A.G.; Arthur, M.A. In "Secular varlations in the pelag1c realm"; SEPM Spec. Publ. No. 25, 1977; pp. 19-50.

8. Bralower, T.J.; Thierstien, H.R. Geology 1984, 12, 614-618.

9. Jenkyns, H.C. J. Geol. Soc. London, 1980, 137, 171-188.

10. "Initial Core Descriptions, Leg 93", In1t. Repts. DSDP, 93: U.S. Govt. Printing office: Washington, D.C.; in press.

11. Wakeham, S.G. Geochim. Cosmochim. Acta 1982, 46, 2239-2257.

12. Metcalfe, L.D.; Schmitz, A.A.; Pelka, J.R. Anal. Chem 1966, 38, 514-515.

13. Farrington, J.W.; Tripp, B.W. Geochim. Cosmochim. Acta 1977, $41,1627-1641$.

14. Prahl, F.G; Bennett, J.T.; Carpenter, R. Geoch1m. Cosmochim. Acta 1980, 44, 1967-1976.

15. Cra18, H. Geochim. Cosmochim. Acta 1953, 3, 53-92.

16. Mangin1, M.E. M.S. Thesis, University of South Florida, St. Petersburg, 1983.

17. DeFlaun, M., personal communication.

18. Katz, B.J.; Elrod, L.W. Geoch1m. Cosmochim. Acta 1983, 47, 389-396.

19. Alzenshtat, Z.; Baedecker, M.J.; Kaplan, I.R. Geochim. Cosmoch1m. Acta 1973, 37, 1881-1898.

20. Dean W.E.; Claypool G.E.; Thlede, J. Org. Geochem. 1984, 7, 39-51.

21. Pauly, G., personal communication.

22. Anderson, T.F.; Arthur, M.A. In "Stable Isotopes in Sediment Geology"; Arthur M.A, et al., Eds; SEPM Short Course No. 10: Dallas, 1983; pp. 80-107.

23. Berner, R.A.; Lasaga, A.C.; Garrels R.M. American Journal of Sclence 1983, 283, 641-683.

24. Wong, W.W.; Sackett, W.M. Geochim. Cosmochim. Acta 1978, 42, 1809-1815.

25. Welssert H.; McKenzle J.; Hochuli P. Geology 1979, 7, 147-151.

26. Muller, P.J. Geochim. Cosmochim. Acta 1977, 41, 765-776.

27. Meyers, P.A.; Leenheer, M.J.; Eadie, B.J.; Maule, S.J. Geoch1m. Cosmoch1m. Acta 1984, 48, 443\%452. 
28. Tulloch, A.P. In "Chemistry and Blochemistry of Natural Waxes"; Kolattukudy, P.E., Ed.; Elsevier: Amsterdam, 1976; pp. 235-288.

29. Erdman, J.G.; Schorno, K.W. In "In1t. Repts. DSDP, 43"; Tucholke B.E.; Vogt P.R. et al., Eds.; U.S. Govt. Printing offlce: Washington, D.C., 1979; pp. 651-655.

30. Scalan, R.S.; Sm1th, J.E. Geochem. Cosmoch1m. Acta 1970, 34, 611-620.

31. Hunt, J.A. In "Journal of Petroleum Geochem1stry and Geology"; Gilluly J., Ed.; W. H. Freeman: San Franc1sco, 1979; pp. $69-149$.

32. Deroo, G.; Herbin, J.P.; Roucache, J.; Tissot, B. In "Init. Repts. DSDP, 47B"; Sibuet, J.C., Ryan, W.F.F., et al., Eds.; U.S. Govt. Printing Office: Washington, D.C., 1979; pp. 513-522.

33. Glger, W.; Schaffner, C.; Wakeham, S.G. Geochim. Cosmochim. Acta 1980, 44, 119-129.

34. Van Vleet, E.S.; Qu1nn, J.G. Geoch1m. Cosmoch1m. Acta 1979, $43,289-303$.

35. Meyers, P.A.; Powaser, J.M.; Dunham, K.W. In "Init. Repts. DSDP, 92"; Lelnen, M.; Rea, D.K. et al., Eds.; In press.

36. Van Hoeven, W.; Maxwell, J.R.; Calvin, M. Geochim. CosmochIm. Acta $1969,33,871-881$.

37. SmIth, D.J.; Eglinton, G.; Morris, R.J. Geochim. Cosmochim. Acta 1983, 47, 2225-2232.

RECEIVED September 16, 1985 


\title{
The Biogeochemistry of Chlorophyll
}

\author{
J. William Louda and Earl W. Baker
}

Organic Geochemistry Group, Florida Atlantic University, Boca Raton, FL 33431

\begin{abstract}
In this paper we attempt a first approximation of chlorophyll diagenesis, stressing the generation of DPEP-series geoporphyrins. Samples analyzed include viable and dead unialgal cultures, sediment traps, surface to near-surface $(0-2 m)$ sediments and long cores $(5-1,000 \mathrm{~m})$ obtained from DSDP/IPOD and industry. Results reveal that chlorophyll(-a) loses Mg and phytol through the actions of cellular senescence and autotrophic recycling in the water column and surface sediments. Following deposition these 'pheo-pigments' undergo the competing reactions of allomerization, yielding purpurin and chlorin acids in oxic conditions, or loss of the 10-carbomethoxy moiety, forming pyrophorbides in anoxic settings. These key reactions appear to fate subsequent diagenes is to either pigment destruction or fossilization, respectively. DPEPseries geoporphyrins are thought to be the result of the stepwise defunctionalization and aromatization of the pyro-phorbide type precursors. The phenomenology of chlorophyll geochemistry and tentative identification of several intermediates are described.
\end{abstract}

The present study is based on the assumption that geoporphyrins are the diagenetic products of biotic tetrapyrrole pigments. This we take as a reasonable premise, given the structural complexity of this class of biomarkers (see Figure 1), and was concluded years ago by the late Professor Alfred Treibs (1-5). However, the development of strong precursor-product relationships in organic geochemistry requires not only statement of plausible end-members (e.g. chlorophyll-a and DPEP-series geoporphyrins) but must include description of the intervening reactions and intermediate structures.

These investigations, albeit preliminary, are designed to ultimately fill the existing gaps in knowledge between biotic

0097-6156/86/0305-0107\$06.00/0

(c) 1986 American Chemical Society 
structures (6-8) and the growing data base of product (viz. geoporphyrins) structures (9-17).

\section{Experimental}

Samples. Unialgal cultures of the diatom Synedra sp. were purchased from Carolina Biological Supply. Sediment trap samples and near surface sediments $(0-2 m)$ from the Peruvian upwelling region, collected during Cruise $73 \mathrm{Leg} 2$ of the $R / V$ Knorr, were provided by Woods Hole Oceanographic Institution (18-19). Nearsurface sediments from the Guaymas Basin in the GuTf of California, collected by the $R / V$ Washington Leg 3-1978, were provided by Scripps Institute of Oceanography (20). Sediments and sapropel from Big Soda Lake (Nevada, U.S.A.- 21) and Mangrove Lake (Bermuda. 24) were obtained from the United State Geological Survey. Deeply buried (e.g. 15-1000 m., sub-bottom) marine sediments were obtained from the DSDP/IPOD program, Leg 64 (20-23). An immature marine shale of California (Pliocene/ Miocene. 24) was provided by Mobil Research and Development. Except for viable diatoms, all samples were frozen upon collection and maintained so until extraction.

Solvents, Extraction and Separation of Pigments. All solvents were freshly glass distilled and ethers were freed of peroxides over highly activated $\left(0 \% \mathrm{H}_{2} \mathrm{O}\right)$ basic alumina. All procedures were in dim yellow light and extracts/isolates maintained frozen under $\mathrm{N}_{2}$, whenever possible. Chromatographic separation ut ilized microcrystalline cellulose, Sephadex LH-20, and silica gel in normal and reverse phase modes. Extraction and chromatography is detailed el sewhere (20).

Purification and Identification of Isolates. In the case of extremely immature samples containing bacteriophytin-a (e.g. Big Soda Lake, Mangrove Lake), interferring carotenols were removed via phase separation into 90\% aqueous methanol (25-26). Low-pressure high-performance liquid-chromatography (LPHLC, Ace-Glass) using 13-24 silica in normal (Whatman \#LPS-1) and $\mathrm{C}-18$ reverse phase (Whatman \#LRP-1) modes was employed for final pigment purification and co-chromatographic tests. Isocractic elution employed methanol/acetone/water $(90: 5: 5, \mathrm{v} / \mathrm{v} / \mathrm{v}$ ) for pheophorbide free acids and methanol/acetone $(95: 5 \mathrm{v} / \mathrm{v})$ for pheophytins during RP-LPHPLC. The presence of more than trace (ca $0.5-1.0 \%$ ) water in the reverse phase mode lead to exceedingly long elution times ( $>1 \mathrm{hr}$.) with phytylated pigments. This fact served as a test for the presence of the phytyl ester. Non-polar pigments, pheophytins and decarboxylated species, were purified over normal phase silica with increasing percentages of acetone in petroleum ether.

Mass spectrometry was performed on a DuPont \#21-491B instrument operated at the lowest ionizing voltage (e.g. 4.5-12.0 eV, 40-60 A) possible per sample.

Electronic absorption spectra were recorded on a PerkinElmer 575 instrument calibrated with holmium oxide. The absorption spectra of native pigments, sodium borohydride reduction 
products (27-28), and the copper chelates of each (20) were compared to numerous authentic chlorophyll derivatives (standards) in order to classify the chromophore and its auxochromes.

Results and Discussion

Previously we have divided tetrapyrrole diagenesis into early-, middle-and late-stages (4-5). These divisions encompass the defunctionalization of dihydroporphyrins (e.g. phorbides), aromatization and chelation, in that order. The geoporphyrins formed during mid-and late-diagenes is are therefore free-base and metallo(e.g. $\mathrm{Ni} ;, \mathrm{V}=0$ ) porphyrins, respectively. Since this study deals primarily with early-diagenesis, the following section is presented only to reveal the nature of these initially formed geoporphyrins.

Products of Diagenesis, Immature Geoporphyrins. The progress of the tetrapyrrole diagenetic continuum is such that the arbitrarily defined stages $(4-5)$ can and do overlap. Thus, it is often possible to isolate more than one pigment type (e.g. free-base and metallo-porphyrins) from the same stratum. Shown in Figure 2 are the mass spectral histograms, or carbon-number distribution, of (a) the defunctionalized phorbides (i.e. 7,8-dihyroDPEP-series), (b) the free-base DPEP series and (c) the nickel DPEP-series isolated from a Miocene/Pliocene marine shale of California. While not totally identical, maxima at $C 31$ and the ranges of pseudohomologs (C27 to C34) reveal their similar origin. Past studies $(4,5,29)$ have shown that the DPEP- series can be geochemically generated with $C 30, \mathrm{C} 31$, or C 32 maxima. These pigments, DPEP-series porphyrins with a limited carbon number range, represent early diagenetic end products.

The metalloporphyrins (viz. nickel, vanadyl) characteristic of catagenesis appear to form via parallel diagenesis with the exceptions of the degree of alkylation and the immediate organic environment. That is, carbon-numbers up to $\mathrm{C} 40, \mathrm{C} 50$ and beyond exist in the vanadyl porphyrins $(5,30-33)$ and these pigments appear to arise from an inextractable organically bound state $(4,29,34,35)$. An example of the series and carbon-number distribution of the vanadyl porphyrins from a 'moderately mature' petroleum is given as Figure 3. The complexity of geoporphyrin arrays becomes evident upon examination of Figure 3 . That is, since this spectrum was averaged from low voltage $(4.5 \mathrm{eV})$ scans yielding only parent ions, at least twenty-nine compounds (14 DPEP and 15 ETIO), not counting isomers which are known to exist (13-15,9-12), must be present. Re-examination of Figure 2 reveals that this spreading of carbon number distributions amongst the tetrapyrroles probably begins early in the diagenesis of these pigments and occurs within the free or solvent-extractable species (e.g.Ni porphyrins), as well as the presumably bound forms thought to yield the vanadyi pigments. The maturational aspects of metalloporphyrins are covered elsewhere (6-7). Phytoplankton cultures (Synedra, Bacillariophyceae) and water-column detritus (sediment trap samples) were analyzed in order to describe the pre-depositional alteration of chlorophyll and therein type the immediate precursor complement to early diagenesis. 
a)

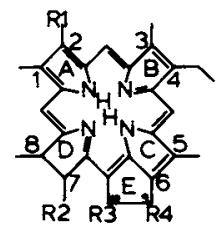

b)

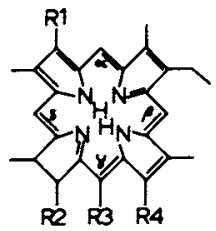

\begin{tabular}{|c|c|c|c|c|}
\hline $\begin{array}{l}\text { PHORBIDES,DPEPseries: } \\
\text { (RINGE PRESENT)/C\# }\end{array}$ & $\begin{array}{r}\mathrm{R} 1 \\
2\end{array}$ & $\begin{array}{l}\mathrm{R2} \\
7\end{array}$ & $\begin{array}{l}R 3 \\
10 \\
\end{array}$ & $\begin{array}{r}R 4 \\
9\end{array}$ \\
\hline $\begin{array}{l}\text { Pheophyt in-a } \\
\text { PPa } \\
\text { PPa-allomer } \\
\text { 7E7DP-PYROPPa } \\
\text { 9-OD-7E7DPPYPYOPPa } \\
\text { MESO-PYRO-PPa } \\
\text { DOMPPa } \\
\text { DPE (78dide H) } \\
\text { DPEP(7,8dideH) } \\
\text { Bacteriopheophytin-a } \\
\text { (3,4dinydro) }\end{array}$ & $\begin{array}{c}V \\
V \\
V \\
V \\
V \\
E \\
E \\
E \\
E \\
\mathrm{COCH}_{3}\end{array}$ & $\begin{array}{l}\text { Pr-phy } \\
\text { Pr } \\
P r \\
E \\
E \\
P r \\
P r \\
P r \\
E \\
\text { Pr-phy }\end{array}$ & 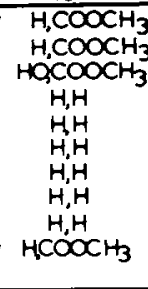 & $\begin{aligned} & 3=0 \\
& 3=0 \\
& 3=0 \\
&=0 \\
& H, O H \\
&==0 \\
& H, H \\
& H, H \\
& H, H \\
&=O\end{aligned}$ \\
\hline $\begin{array}{l}\text { CHLORINS,ETIO-Series: } \\
\text { (RINGE ABSENT)/C\# }\end{array}$ & $\begin{array}{c}\overline{R 1} \\
2\end{array}$ & $\begin{array}{l}\overline{R 2} \\
7\end{array}$ & $\begin{array}{l}\mathrm{R3} \\
\mathrm{\gamma}\end{array}$ & $\begin{array}{c}R 4 \\
6\end{array}$ \\
\hline $\begin{array}{l}\text { PURPURIN } \\
\text { PURPURIN } \\
\text { CHLORIN- } \\
\text { CHLORIN- } \\
\text { ETLOPORP }\end{array}$ & $\begin{array}{l}V \\
V \\
V \\
V \\
E\end{array}$ & $\begin{array}{l}\mathrm{Pr} \\
\mathrm{Pr} \\
\mathrm{Pr} \\
\mathrm{Pr} \\
\mathrm{E}\end{array}$ & $\begin{array}{c}\mathrm{O}=\mathrm{C}-\mathrm{C} \\
\mathrm{COOOOH} \\
\mathrm{CH} \mathrm{COOH} \\
\mathrm{C}\end{array}$ & $\begin{array}{l}\mathrm{CO} \\
\mathrm{COH} \\
\mathrm{COOH} \\
\mathrm{COOH} \\
\mathrm{E}\end{array}$ \\
\hline
\end{tabular}

Figure 1. Structures of tetrapyrrole pigments mentioned in text.

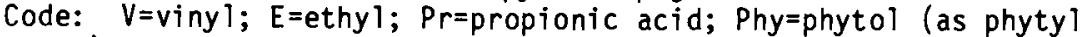
ester); $D P=$ despropio-; $P D=0 x y$ deoxo; $p p-a=$ pheophorbide- $a$; $D O M P P-a=$ deoxomesopyropheophorbi de-a; DPE=deoxophy 1 loerythrin; DPEP=deoxophylloerythroetioporphyrin (cf. $\underline{6}, \underline{7}$ ).
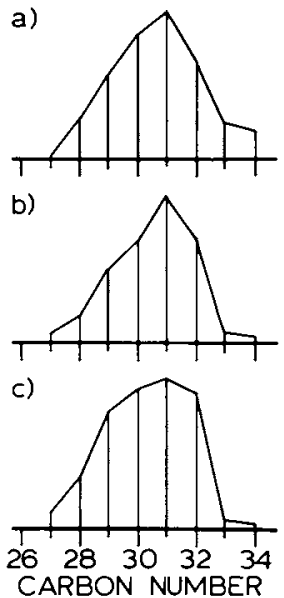

Figure 2. Mass spectral histograms of tetrapyrrole pigments characteristic of mid-/late-diagenesis. (a) free-base 7,8-dihydro-DPEP-series; (b) free-base DPEP-series; and (c) nickel DPEP (ETI0- omitted)-series. Sample; Pliocene/Miocene shale of marine origin (cf. 24 ). 
Phytoplankton Cultures. A viable unialgal culture of the diatom Synedra sp. was split into 2 aliquotes. The first portion ("VIABLE") was extracted immediately and analyzed. The second part ("DEAD") was purged with nitrogen, sealed and stored in the dark at room temperature $\left(20-22^{\circ} \mathrm{C}\right)$ for 2 months before analysis.

The electronic spectra of the crude extracts of "VIABLE" and "DEAD" diatoms, given as Figure 4 , reveals the total conversion of chlorophyl1-a to 'pheopigments' through the loss of $\mathrm{Mg}$. That is, Soret absorption has shifted hypsochromically (429 to $411 \mathrm{~nm}$ ) in concert with a bathchromic shift (663 to $667 \mathrm{~nm})$ in the position of band I ('red') absorption. Chromatographic analyses revealed that $94+\%$ of the a-series pigments in the "VIABLE" diatoms was chlorophyll-a. This pigment was below detectable limits $(<1 \%)$ in the "DEAD" diatoms. In the latter, a-series pigments consisted of pheophytin-a $(66 \%)$, pheophorbide-a $(32 \%)$ and chlorophyllide-a $(2 \%)$.

A more rapid destruction of chlorophyll-a series pigments, relative to chlorophyll-c, was also observed. That is, the ' $a$ '/ ' $c$ ' value was found to decrease from 33:1 ("VIABLE") to $7: 1$ ("DEAD") upon senescence and death.

Except for the slower demise of chlorophyll-c, the alteration of chlorophyll-a during senescence and death can be attributed to cellular decompartmentalization and resultant action of cellular acids (Mg-loss) and enzymes (e.g chlorophyllase, phytol loss, 36). The relative amounts of pheophytin-a versus pheophorbide-a resulting from senescence-death has been shown to be species specific and is related to chlorophyllase activity (37). Sediment Trap Samples. The alteration of chlorophyll due to senescence/death phenomena, described above, yield a certain suite of pigments. Such arrays, dominated by pheophytin-a, might be expected to form the precursor complement in sediments deposited in an environment free of consumers. Such is obviously not the case in nature. Since the vast majority (e.g. 95-99\%) of primary production serves as fodder in marine food webs (38) we must consider heterotrophic alteration of detrital tetrapyrrole pigments. Sediment trap samples from the Peruvian upwelling system (18-19) were analyzed for chlorophyll derivatives. These samples were collected at the base of the euphotic zone (FST-16, $Z=11 \mathrm{~m}$ ) and about $25 \mathrm{~m}$ beneath the major pycnocline and zone of remineralazation (FST-17, Z=53 m). Both samples were lyophilized (39) and any intact chlorophyll-a was converted to pheophytin-a. However, on-board hydrographic data (i.e. fo/fa. cf. 18) allowed back correction to in situ chlorophyll/pheopigment relationships.

Table 1 is the compilation of pigment data obtained from analyses of the sediment trap samples. The data reveal, from the increase in the relative amounts of pheophytin-a and pheophorbide-a, a large degree of $\mathrm{Mg}$ and $\mathrm{Mg}$ plus phytol loss, respective1y. The deeper sample, upon microscopic examination, was found to contain a majority of broken, relative to intact, phytoplankton cells (diatom dominated) occurring mainly in fecal pellets. Thus, the change in the distribution of tetrapyrrole pigments, occurring with depth in the water column, reveals the combined effects of senescence/death and predation. The latter is evidenced by the increase in pheophorbide-a relative to pheophytin-a $(37,40)$. 


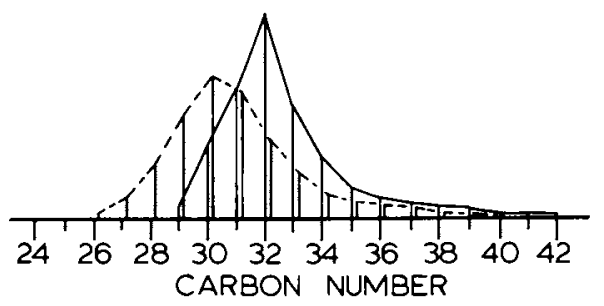

Figure 3. Mass spectral histogram of vanadyl porphyrins isolated from a marine sourced petroleum of 'moderate' maturity (Carboniferous; $\left.3.1 \% \mathrm{~S} ; 23.1^{\circ} \mathrm{API}\right)$. Solid trace = DPEP-, Dashed trace = Etio-series.

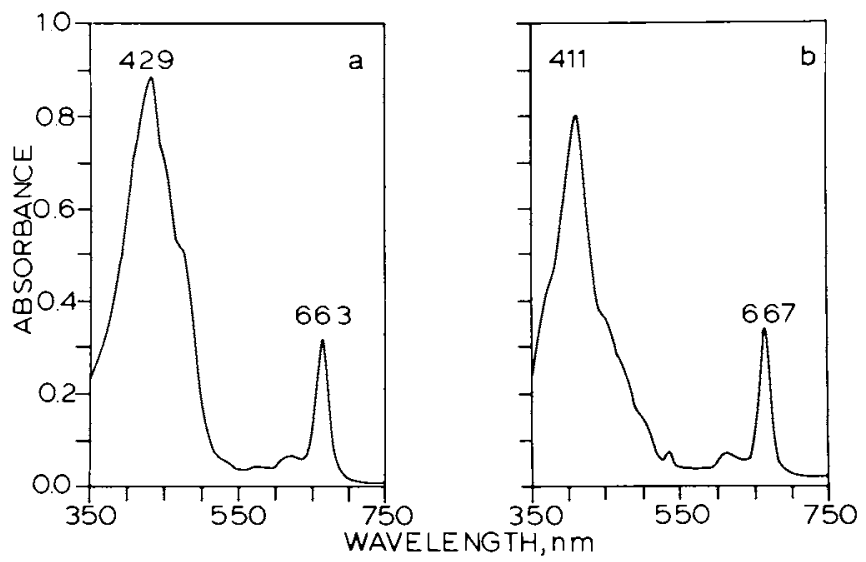

Figure 4. Electronic absorption spectra, in acetone, of the crude extracts of the diatom Synedra $s p$. (a) extracted fresh ("VIABLE") and (b) following dark anoxic storage for 2 months ("DEAD").

In Organic Marine Geochemistry; Sohn, M.; 
Table I. Tetrapyrrole pigments present in sediment-trap samples from the Peruvian upwelling system. (a)

\begin{tabular}{llr} 
& \multicolumn{3}{c}{ Molar Percentage } \\
\cline { 2 - 3 } Pigment & $Z=11 \mathrm{~m}$ & $Z=53 \mathrm{~m}$ \\
\hline Chlorophyll-a & 75 & 20 \\
Pheophytin-a & $<2(77)$ & $26(46)$ \\
Pheophorbide-a & $12(12)$ & $42(42)$ \\
Purpurins & $<2(<2)$ & $2(2)$ \\
Chlorin acids & $4(4)$ & $4(4)$ \\
Chlorophyll-c & $4(4)$ & $6(6)$ \\
\hline
\end{tabular}

a. $15^{\circ} 09^{\prime} \mathrm{S} \times 75^{\circ} 35^{\prime} \mathrm{W}$

b. Back - correct to on-site hydrographic values (18).

Parenthesized values are 'as-analyzed.'

Minor amounts of purpurin and chlorin acids, typical of oxidative pigment destruction in marine $(5,20,28)$ and terrestrial (41) ecosystems, were also found. These most likely reside in broken detrital cells exposed to oxygen. Further study is required to clarify destructive pathways.

'Chlorophyll-c, a known component of the diatoms and relatives $(6,7,37)$, was identified in both samples (Table I). The presence of 'chlorophyll-c' in marine destritus is expected, however, to date, its absence in marine sediments collected below the euphotic zone $(5,20,28,42)$ is enigmatic. That is, whether 'cholorophy $11-c$ ' is destroyed, complexed into unrecognizable macro-molecular forms or in other ways altered remains to be shown.

The rapid alteration of chlorophyll-a as phytoplankton leave the euphotic zone may well be expected to continue as passage through additional links in the food chain occurs. Thus, the detrital forms of chlorophyll-a, available to sedimentary diagenes is should contain a dominance of pheophorbide-a.

Sedimentary Chlorophyll Derivatives. In order to unravel the biogeochemistry of chlorophyll, a variety of depositional environments, each representing potentially different fossilized counterparts, require study. Though the present investigation stresses marine sediments, collected well beneath the photic zone in order to divorce detrital from viable photoautotrophic material, photic zone sapropels and peats have also been examined.

Marine Surface Sediments.. $(0-2 \mathrm{~m})$ sediments beneath the highly productive upwelling regions in the Gulf of California and off the coast of Peru were chromatographically separated (see "Experimental") into (a) pheophytins, (b) pheophorbides (viz. mono carboxylic acids) and (c) chlorin acids (i.e.di-/tri-acids). Table II contains the result of these preliminary analyses and includes the concentration of pigments, present depositional environment and sample depth.

In general, pheophorbides and chlorin acids have become the dominant tetrapyrrole pigments in surface sediments, relative to upper water column detritus. The averaged values for the relation- 


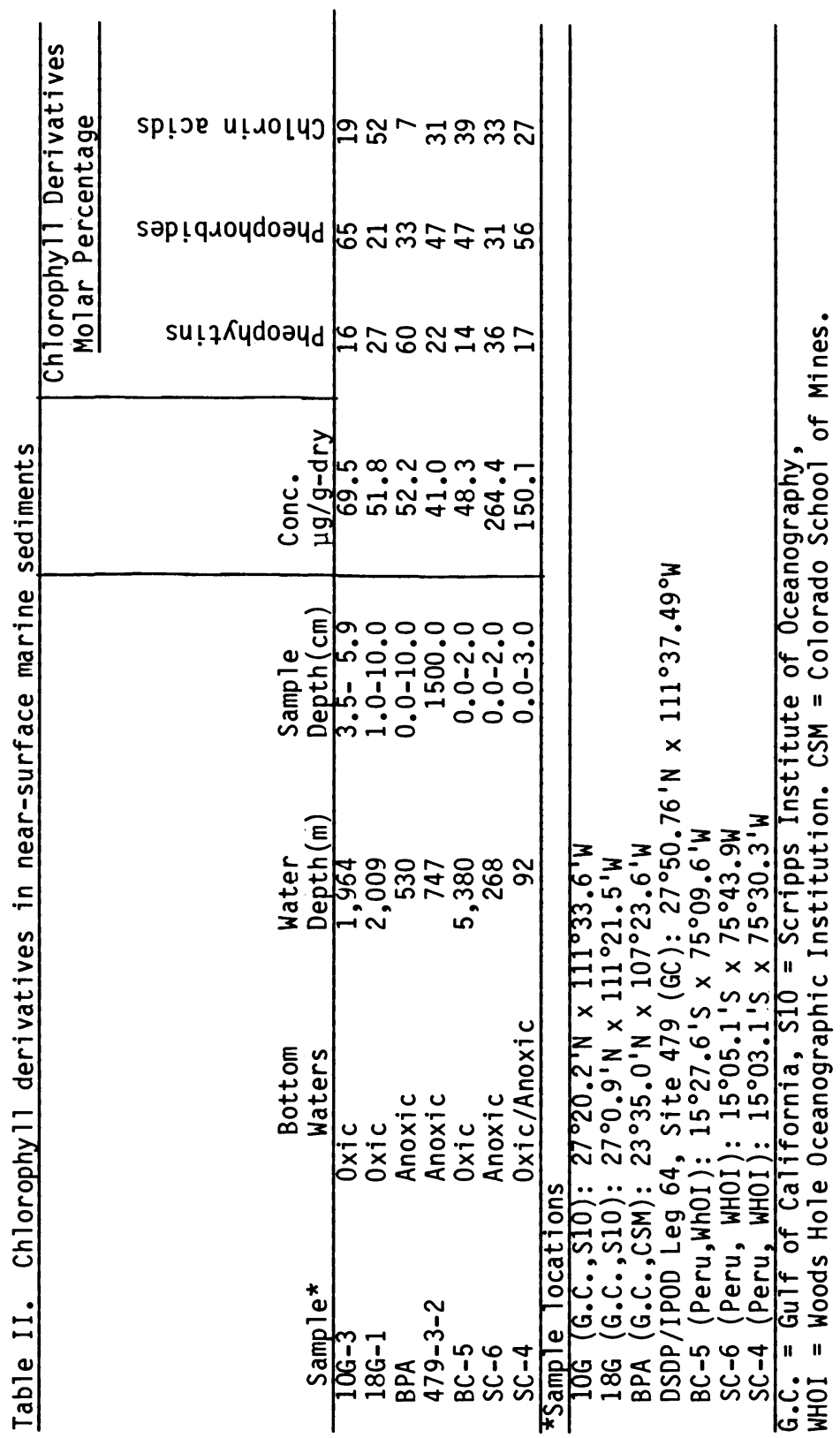


ship of pheophytins/pheophorbides/chlorin acids, given in Table II, are found to be $18 / 47 / 34$ or $39 / 37 / 24$ for sediments deposited through oxic or anoxic bottom waters, respectively. The overall increase of pheophorbides plus chlorin acids, relative to water column detritus or anoxically deposited sediments, is taken as a reflection of the prolonged effects of aerobic heterotrophy during oxic deposition. That is, benthic fauna, as well as zooplankton, appear able to remove phytol from sedimentary tetrapyrroles.

Overall, these marine sediments appear to contain about $30 \%$ pheophytins, $40 \%$ pheophorbides and $30 \%$ purpurin plus chlorin acids at the onset of diagenesis. This, of course, is only a rough 'rule-of-thumb.'

Photic Zone Anoxia. In environments such as meromictic lakes and peat bogs the oxy- and chemo-clines impinge the photic zone. In these cases, anoxigenic photosynthetic bacteria (e.g. Thiorhodacea, Athiorhodacea) contribute not only to overall productivity $(5,37,38$ but also to the supply of tetrapyrrole pigments in resultant sediments. That hacteriochlorophyll-a derivatives are present in such sediments, an intuitive conclusion, is shown through the analyses of Mangrove Lake (Bermuda) sapropel and sediments from Big Soda Lake (Nevada).

Bacteriopheophytin-a has been isolated from both sets of samples, as well as from a South Florida freshwater peat accumulation (43). Figure 5 is the electronic absorption spectrum of bacteriopheophytin-a, and its 'dioxy-dideoxo' derivative obtained by borohydride reduction. The unique chromophores and resultant spectra of the bacteriochlorophyll-a derivative makes initial estimation of the relative amounts of higher plant and bacterial chlorophylls quite easy. As an example, Figure $5 \mathrm{~b}$ is the spectrum of a crude extract of sapropel from Mangrove Lake. In this case, the ratio of chlorophyll-a to bacteriochlorophyll-a derivatives as the pheophytins, is approximately 1.3:1. Large amounts of bacterial carotenoids are also in evidence from their characteristic absorption maxima in the blue (ca.420-500nm) region.

The main point of this simple study is that, in cases such as peat/coal and aquatic sapropel/'paper shale' accumulations, ultimate geoporphyrin (i.e. DPEP-series) precursors beside chlorophyll-a need to be considered. In order to mold bacteriochlorophyll-a into current modified 'Treib's scheme' diagenesis (3-5) only the removal of the 3,4-dihydro and 2-acetyl features are required. That is, an aromatization and reduction/dehydration.

Tetrapyrrole Diagenesis; Increasing Sediment Depth, Age and Temperature. Organic-rich diatomaceous oozes recovered within the oxygen minimum (OMZ) of the northeast slope of the Guaymas Basin (Gulf of California, DSDP/IPOD Leg 64-Site 479. 23) have been found to contain a wide range of chlorophyll derivatives which, with depth, cover the entire period of early diagenesis (20).

Pigments as a Portion of Total Organic Carbon. The value obtained through the division of tetrapyrrole pigment concentration, in $\mu g$ sediment dry weight, by the percent organic carbon of the host sediment we have defined as the 'Pigment Yield Index,' or PYI (44). 
The plot of PYI versus sub-bottom depth for Site 479 , including a box-core sample as a surface sediment reference, is shown in Figure 6. The actual trend, dotted, reveals a series of alternating highs and lows down to about $200 \mathrm{~m}$, sub-bottom. This most likely represents corresponding increases and decreases in productivity and the severity of bottom water anoxia (i.e. paleoenvironment). However, by smoothing the curve we obtain what we suggest is the trend one might find for a hypothetical depositional environment which is constant through time.

Rapid pigment loss occurs within the first 50 meters of burial, after which the rate of loss slows and eventually ceases (Figure 6$)$. During the rapid loss period of early diagenes is it appears that defunctionalization and destructive reactions are competitive as purpurin and chlorin acids, in addition to phorbides, are present. Later and deeper, defunctionalization of the surviving phorbides continues until the pigments attain a higher degree of stability through aromatization, yielding porphyrins of the DPEP-series (cf. Figure 2). Intuitively, incorporation of phorbide and chlorin acids into proto-kerogen may occur during the earlier periods of pigment loss from the bitumen fraction, though little data beyond phenomenological insight $(4-5,20,29,34-35)$ exists to support this supposition.

Individual Tetrapyrrole Characteristic of Early Diagenesis. It should be noted that the 'identifications of individual pigments given below are only tentative. That is, characterization is based only upon chromatographic mobility, electronic spectroscopy, derivatizations with sodium borohydride and copper and comparisons to authentic pigments treated in like manner. As such, structuralproof is not claimed and resultant geochemical reaction scenarious are given only for the chromophore of each pigment type. That is, this study investigates only diagenetic defunctionalization and offers no insight as to alkyl substituents, beyond inference. Pheophytin-a as an initial isolate, exhibited the electronic spectrum given as Figure 7. Reaction with borohydride was found to yield the typical 9-oxy-deoxo derivative as well (Figure 6, dashed line). However, upon submitting pheophytin-a to LPHPLC, 2 forms of this pigment, neither identical to the authentic compound, were found. That is, as shown in Figure 8, 'pheophytin-a,' from these sediments were found to exist on a more polar and less polar form, relative to the co-injected standard, and both yielded identical electronic spectra (cf. Figure 7). Chromatographic mobility, including comparison to authentic pheophytin-a, and its 'allomer' (i.e. 10-oxy-pheophytin-a) shows that the more mobile form ('PP-al') may be pyro-pheophytin-a while the more polar form ('PP-a2') is most likely the allomer (i.e. 10-oxy-pheophytin-a 20). In some cases, such as sample 64-481-8-2 (Figure 8), small amounts of "true" pheophytin-a are present.

Meso-Pheophorbides. A compound, or series, exhibiting the electronic spectrum (alt. chromophore) of meso-pyropheophorbide-a has been isolated from Site 479 sediments recovered between 72 and 246 meters $\left(15-31^{\circ} \mathrm{C} \mathrm{23}\right)$ sub-bottom (20). Figure $9 \mathrm{a}$ is the electronic spectra of the native pigment and its borohydride reduction product. Reaction of each with copper (II) yielded the metallo- 


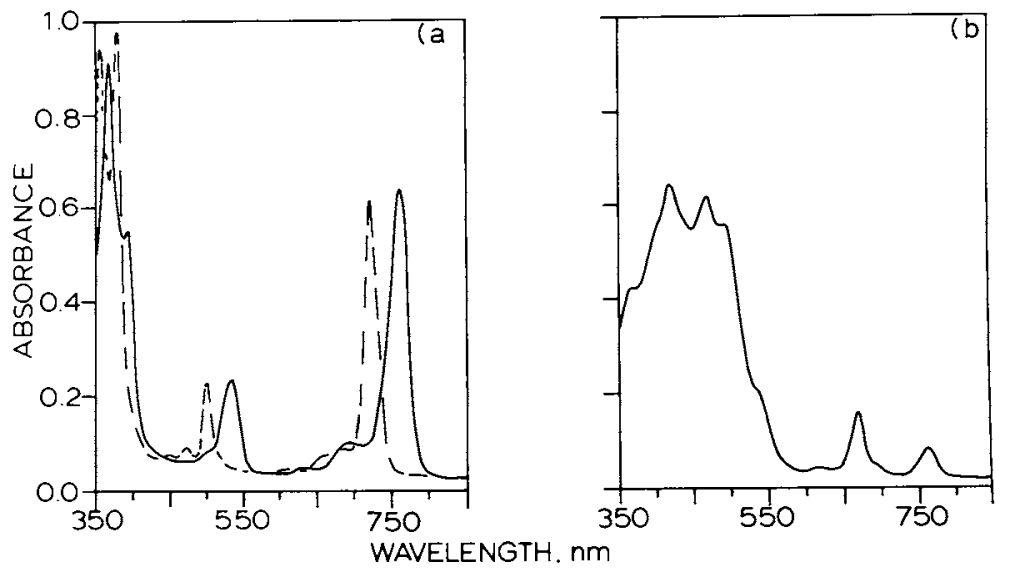

Figure 5. Electronic absorption spectra. (a) bacteriopheophytin-a(solid) and the dioxy-dideoxo derivative (dashed) obtained following reduction with sodium borohydride; and (b) the crude extract of Mangrove Lake (Bermuda) sapropel.

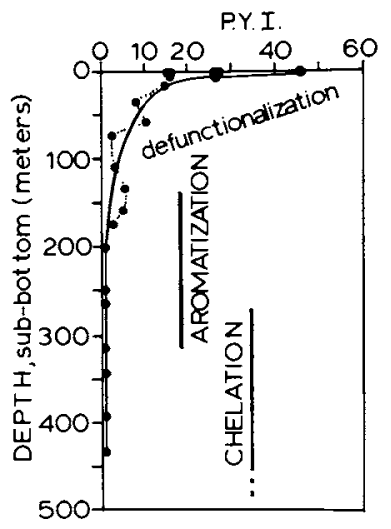

Figure 6. Plot of the 'pigment yield index' (PYI) versus depth of burial for DSDP/IPOD Site 479 in the northeastern Guaymas basin slope, Gulf of California (cf. 20).

In Organic Marine Geochemistry; Sohn, M.; 


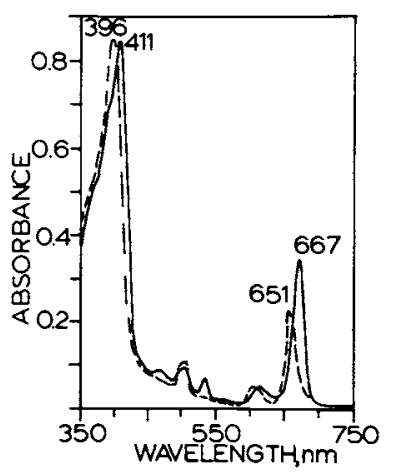

Figure 7. Electronic absorption spectra of pheophytin-a(solid) and the 9-oxy=deoxo derivative obtained following reduction with borohydride, (dashed) I solated from DSDP sample \#64-479-5-3 (20).

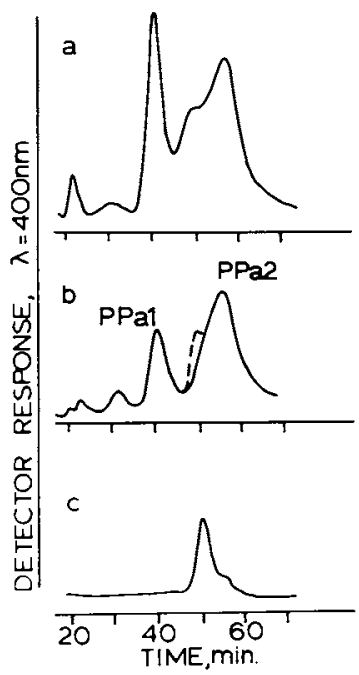

Figure 8. Partial LPHPLC chromatograms of "pheophytins-a." (a) Sample 64-481-8-2, (b) sample 64-479-3-2 (dashed = co-injected authentic pheophytin-a), and (c) partially air-'allomerized' authentic pheophytin-a. 
meso-phorbide spectra given as Figure 9b. All of these spectra and reaction products are consistent with the chromophore of authentic meso-pyropheophorbide-a. The very non-polar nature of the native pigment leads us to propose that this is 7-R-7-despropio-mesopyropheophorbide-a $\left(\mathrm{R}=\mathrm{H},-\mathrm{CH}_{3},-\mathrm{CH}_{2} \mathrm{CH}_{3}\right)$ generated by the reduction of the 2-vinyl-moiety and the decarboxylation of the corresponding phorbide acid.

0xydeoxomes opyropheophorbides. Pigments with the chromophore of the 9-oxy-deoxomesopheophorbides were isolated from the same strata as given above for the meso-pyropheophorbides. In these cases, the Soret (S) and band 1 (I) absorption maxima resemble authent ic 9-oxydeoxo-mes opyropheophorbide-a $(S=396.5, I=646.5 \mathrm{~nm})$, its $\mathrm{Cu}$ chelate $(S=402.0, I=614.5 \mathrm{~nm})$, and the pigment was totally unreactive to borohydride.

This compound, tentatively 9-oxy-deoxo-mes opyropheophorbide-a, is of interest as it offers a clue as to the mode of loss of the 9-ketone moiety inherited from chlorophyll-a. That is, it now appears that the 9-keto function is reduced to the alcohol which may then be dehydrated. If this were to occur, the product would contain a highly strained $6, \gamma$-cycloetheno moiety. Most likely, concerted or subsequent and rapid reduction would follow and result in the common $6, \gamma$-cycloethano type of isocyclic ring found in geoporphyrins of the DPEP-series. Oxydeoxo-Vinyl-Phorbides. Pigments exhibiting band I absorption at $651 \mathrm{~nm}$, and matching other physiochemical characteristics of authentic 9-oxydeoxo-pyropheophorbide-a, have been reported as being present in the Gulf of California sediment suite studied herein (20). Lack of sufficient material has precluded further study on these isolates.

Deoxomesopyropheophorbide-a and 7,8-Dihydro-DPEP. Sedimentary bitumen at or near a level of maturity such that free-base porphyrins are present or dominant also yield tetrapyrroles with electronic spectra characteristic of deoxomesopyropheophorbide-a (DOMPP-a). DOMPP-a is isolated, in the greatest amounts, from the non-polar chromatographic fractions, has an $\mathrm{HCL} \#$ of ca. 5-7 and, thus, are decarboxylated (7-R-7-despropio: $\left.\mathrm{R}=-\mathrm{H},-\mathrm{CH}_{3},-\mathrm{CH}_{2} \mathrm{CH}_{3}\right)$ analogs. As such, an alternate semi-systematic name would be 7,8-dihydro DPEP.

Mass spectra of one such isolate (Figure 2) reveals that diagenetic dealkylation has occurred. That is, at temperatures below that required for the tetrapyrrole aromatization reaction (e.g. $20-30^{\circ} \mathrm{C} .4-5$ ), thermal (viz. catagenetic) dealkylation is hardly likely. Thus, the presence of carbon numbers below $\mathrm{C}-32$, the expected product of 'Treibs' Scheme' geochemistry $(1,6-7)$, most likely reveals methylene-equivalency losses related to defunctionalization during early diagenesis. The intervention of sedimentary bacterial infauna is theoretically possible and is being studied.

The electronic spectra of the native pigment ( $S=393,1=640 \mathrm{~nm}$ ), isolated from a Miocene shale of the Sisquoc formation (California. 24), and numerous diatomaceous oozes from the Gulf of California (20), and its copper chelate $(S=395, I=606 \mathrm{~nm})$ match authent 1 C DOMPP-a and CUDOMPP-a, respectively. 
Generation of Chlorin and Purpurin Acids; Fating Functions. Sediments of known oxic deposition and/or redeposition have been found to be relatively enriched in the highly polar purpurin and chlorin poly-acids $(5,20,28,44)$.

The oxidative scission of the isocyclic ring on the nucleus of chlorophyll and its derivatives, via allomerization, consists of a series of well documented reactions (6-7) and leads to such products as chlorin (e.g. $-\mathrm{e}_{4},-\mathrm{e}_{6},-\mathrm{P}_{6}$ ) and purpurin (e.g. $-7,-9,-18$ ) carboxylic acids (cf. Figure 1).

Sediments from the north rift of the Guaymas Basin (DSDP/IPOD Leg 64 , Site 481.20 ) yielded 2 pigments of this series. Given as Figure 10 is the eTectronic spectra of purpurin-18 and chlorin$\mathrm{P}_{6}$ isolates from this site. Spectra, chromatographic behavior and reactivity towards borohydride match that of authentic pigments.

As it is known that allomerization is possible only with the phorbides which contain the 10-carbomethoxy group (45), we have proposed that competition between the formation of aTlomers (10-oxyphorbides) and the pyro-(10-H-10-decarbomethoxy) phorbides is a major branch point during very early diagenesis $(4-5,20)$. That is, the generation of allomerized pigments appears to Tead to subsequent pathways which end in pigment destruction. Mechanisms of tetrapyrrole destruction in sediments, beyond the purpurinchlorin stages, are totally unknown at present. Conversely, generation of the pyro-phorbides, essentially protecting the isocyclic ring from oxidation (viz. allomerization), imparts a first level of stability to these pigments. Subsequent diagenetic defunctionalization of the pyro-phorbide and aromatization then leads to the DPEP series, as given in previous sections.

Possible Oxidation of the 2-Vinyl Moiety; 2-Acetyl (or Formyl) -2-Desviny T-Pheophorbides. A first indication that, aside from reduction, the vinyl moiety of chlorophyll derivatives might be altered stems from the isolation of a pigment we first called "chlorin 686," after the spectral type and position of band I absorption. The electronic spectra of the native and borohydride reduced pigments are given as Figure 11 . The hypsochromic shift of $35.5 \mathrm{~nm}$ (i.e. $686.5-651.0 \mathrm{~nm}$ ) in the position of band I absorption is on the same order as that found for the removal of the auxochrome effects of 2 conjugated carbonyl functions from authentic test pigments (e.g. bacteriopheophytin-a, purpurin-18). These changes do not however mimic the removal of dicarbonyl conjugation from such pigments as pheophorbide-b.

Thus, 2 conjugated carbonyl moieties appear to be present and are most likely located on rings I and V. That is, on "opposite" side of the macrocycle. The bifurcated nature of the soret absorption for the native pigment is reminiscent of the 2-acetyl-2desvinyl (46) and 2-formy 1-2-desviny 1 (47) derivatives of pheophytin-a. Should phorbide "686" prove to contain either the 2-acetyl or 2-formyl moieties this could easily and mistakenly we feel, infer derivation from bacteriochlorophy 11-a or chlorophy11-d, respectively. As this pigments (s) was isolated from deep-sea diatomaceous oozes, ( $Z=747 \mathrm{~m}$, DSOP/IPOD Site $479.20,23)$ significant input of either purple photosynthetic bacteria or red algae, respectively, is unlikely. Rather, we feel, that early diagenetic oxidation of 


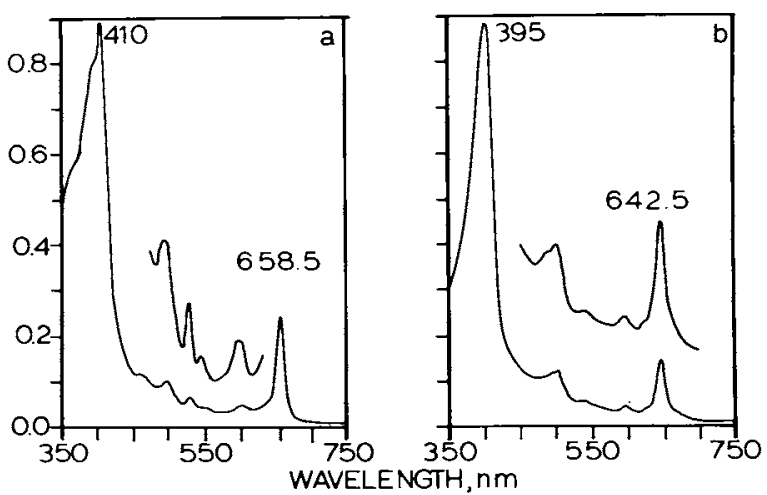

Figure 9. Electronic absorption spectra of (a) decarboxylated mesopyropheophorbide(s)-a and (b) the oxy-deoxo-derivative obtained via borohydride reduction. Sample 64-479-13-1 (20).

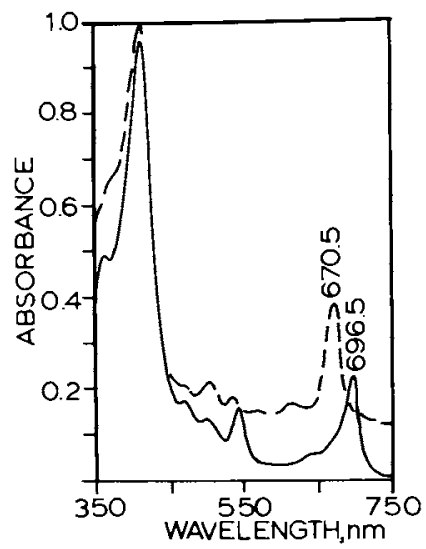

Figure 10. Electronic absorption spectra of purpurin-18 (solid) and chlorin-p6 (dashed)-like compounds isolated from sample 64$481 \mathrm{~A}-2-2$ (20). 
the 2-vinyl moiety, with potential cleavage to a 2-methyl-2-desvinyl structure akin to 'Abelsonite' (Ni-2-methyl-2-desvinyl-DPEP. 16) formation, is a more likely diagenetic pathway. Conclusion; Modified "Treibs' Scheme" Diagenesis of Chlorophyll. The investigations reported here allow a first approximation of the diagenesis of chlorophyll to be formulated. The scheme presented as Figure 12 summarizes the proposed reaction sequences, and are, for now, restricted to sedimentary environment.

The losses of magnesium and phytol through the combined effects of cellular senescence and predation (i.e. aerobic heterotrophy) in the water column lead to pheophytin-a and pheophorbide-a becoming the primary chlorophyll-a derivatives deposited in marine sedimentary environments. Though it is not known at present, the heterotrophic processes which cleave phytol more than likely also affect the 10-carbomethoxy group. Studies are underway to investigate the amounts of pyro-pheophorbides in water column detritus and surface sediments.

During very early diagenesis and, to some extent, in the water column, 2 key competing or 'fating' reactions appear to direct subsequent alteration, i.e. allomerization versus loss of the 10carbomethoxy moiety.

In the presence of oxygen, allomerization leads to the oxidative scission of the isocyclic ring. Products found in oxidative environments include the purpurin and chlorin acids (Figure 11). Tracing the down-hole fate of these compounds has proved futile, to date. That is, in cases were oxidation dominates, such as in sediments low in metabolizable organics (i.e. Philippine Sea. 48-50), tetrapyrrole pigments disappear with depth. Thus, we can but surmise that the chlorin acids are destroyed and yield unident ifiable low molecular weight colorless compounds (LMWCC), Figure 12). It is theoretically possible to derive various ETIOseries porphyrins from chlorin acids (5-7). However, no data yet exists to support this alternate pathway.

The loss of the 10-carbomethoxy moiety from the pheophorbides generates the pyropheophorbides and prevents allomerization (45). Based on the down-hole sequencing of pigments at DSDP/IPOD site $479(20)$, and past partial sequences $(4-5,28-29,44)$, the generation of free-base geoporphyrins, at least of the DPEP-series, appears to follow that given in Figure 12. It should be noted that tentative identifications have been made only for the decarboxylated species. However, an analogous series of these pigment types does appear to be present as the free-acid (viz.7-propionic) analogs. Reduction of the 2-vinyl and 9-keto moieties has been found to occur in the same strata and to be unconcerted. Early diagenesis thus yields meso-and 9-oxydeoxo-pyropheophorbides, with or without the carboxylic acid moeity inherited from chlorophy 11. Reduction of either the 9-keto or 2-vinyl of these derivatives, respectively, followed by dehydration and, ostensibly, rapid reduction yields the corresponding deoxomesopyropheorbide-a (DOMPPa).

Following the generation of DOMPP-a, again as either the carboxylated or decarboxylated forms, increasing thermal stress leads to aromatization and yields DPE or DPEP, respectively. 


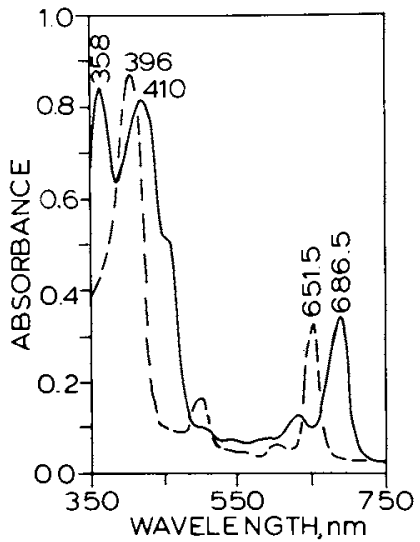

Figure 11. Electronic absorption spectra of a probable dioxophorbide before ('native,' solid trace) and after (dashed trace) reduction with borohydride. I solated from DSDP sample 64-479-5-3 (20).

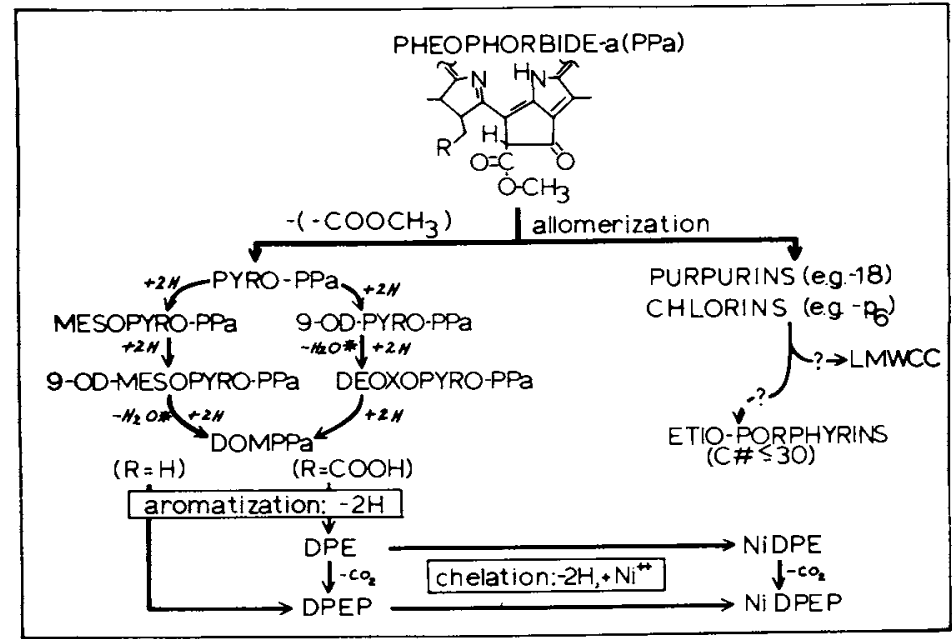

Figure 12. Proposed diagenesis of chlorophyl1-a derivatives. Code: MESO = 2-vinyl reduced to ethyl; PYRO = lacks C\#10 carbomethoxy group; $0 D=9$-oxydeoxo; asterisk = possible $6, \gamma$-cycloetheno intermediate; LMWCC = low molecular weight colorless compounds ( $c f$. Figure 1). 
In conclusion, the early diagenesis of chlorophyll-a derivatives and the generation of the DPEP-series porphyrins roughly parallels the predictions which Professor Treibs made a half a century ago (1). Though certain inroads have been made, much in the way of structural and mechanistic study remains. That is, the generation of dealkylated species and the highly likely incorporation of tetrapyrroles into kerogen during early diagenesis are all but unknown.

\section{Acknowledgments}

The authors' are funded by NSF grant \#0CE-82-08-107, the support of which is appreciated. The following people and institutions are heartily thanked for samples (see "Experimental" and Table II): The DSDP/IPOD program; B.R.T. Simoneit (U.C.L.A., SIO-Samples); B. Parker and D. Waples (C.S.M.); R. Oremland (U.S.G.S.), P. Hatcher (U.S.G.S.), and R. B. Gagosian and J. F. Farrington (W.H.O.I.). Sampling of The Peruvian upwelling system was funded by NSF grants OCE-77-26084, OCE-079-25352 and OCE-80-18436 to W.H.O.I.

(R.B.G.,J.W.F.). Mobil Research and Development Corporation (W. L. Orr) is thanked for shale and petroleum samples and a grant-in-aid. Drs. G. Eglinton and G. Wolff are thanked for their critical reading of the original manuscript. The patience of Ms. Cora Woodman during the revision of this text is appreciated.

\section{Literature Cited}

1. Treibs, A. Angew. Chem. 1936, 49, 682-6.

2. Baker, E. W. In "Organic Geochemistry;" Egl inton, A. and Murphy M. T. J., Eds.; Springer-Verlag; Berlin, 1969; pp. 464-97.

3. Baker, E. W.; Palmer, S. E. In "The Porphyrins Dolphin, D., Ed.; Academic Press: New York, 1978; Vol. I, pp: 486-552.

4. Baker, E. W.; Louda, J. W. In "Advances in Organic Geochemistry - 1981," Bjoroy, M. et al ., Eds.; John-Wiley: Chichester, 1983: pp. 401-21.

5. Baker, E. W.; Louda, J.W. In "Biological Markers," Johns, R. B., Pergamon: Oxford, in press.

6. "The Porphyrins," Dolphin, D., Ed.; Academic Press: New York, 1978-1979; Vols. I-VII.

7. "Porphyrins and Metalloporphyrins," Smith, K.M., Ed.; Elsevier: Amsterdam,1975; $910 \mathrm{pp}$.

8. Lemberg, R.; Barrett, J. "Cytochromes;" Academic Press: London, $580 \mathrm{pp}$.

9. Quirke, J. M. E.; Eglinton, G.; Maxwe11, J.R. J. Am. Chem. Soc., 1979, 101, pp. 7693-7.

10. Quirke, J.M. E.; Shaw, G. J.; Soper, P. D.; Maxwe 11, J.R. Tetrahedron, 1980, 3G, pp. 3261-7.

11. Quirke, J. M. E.; Maxwe11, J. R. Tetrahedron, 1980, 36, pp. $3453-6$.

12. Quirke, J. M. E., Maxwel1, J. R.; Eglinton, G; Sanders, J. K. M. Tetra. Letts., 1980, 21, pp. 2987-90. 
13. Quirke, J. M. E.; Eglinton, G.; Palmer, S. E. Baker, E. W. Chem. Geol., 1982, 35, pp. 69-85.

14. Wolff, G. A.; Murray, M.; Maxwel1, J. R.; Hunter, B. K.; Sanders, J. K. M. J. C. S. Chem. Commun., 1983, pp. 922-4.

15. Fookes, C. J. R. J.C. S. Chem. Commun., 1983, pp. 1474-6.

16. Storm, C. B.; Krane, J.; Skjetne, T.; Telnaes, N.; Brantharer, J. F.; Baker, E. W. Science, 1984, 223, pp. 1075-6.

17. Chicarelli, M. I.; Maxwell, J. R. Tetrahedron Letts., 1984 , 25, pp. 4701-4.

18. Gagosian, R. B.; Loder, T.; Nigrell: G.; Mlodzinska, Z.; Love, J.; Kogel schatz, J. W. H. 0. I. Tech. Rep., 1980, WHOI-80-1, $77 \mathrm{pp}$.

19. Henrichs, S. M.; Farrington, J. W. Limol. Oceanogr., 1984, 29, pp. 1-19.

20. Baker, E. W.; Louda, J. W. In "Init. Reps. D.S.D.P., " Curray, J. R.; Moore, D. G.; et al., Eds.; U.S. Govt. Printing Office: Washington, D.C., 1982, $\sqrt{0} 1.64$ - Part II, pp. 789-814.

21. Cloern, J.E.; Cole, B. E.; Oremland, R. S. Limnol. Oceanogr., 1983,28 , pp. 1049-1061.

22. Hatcher, P. G.; Simoneit, B. R. T.; Mackenzie, F. T.; Neuman, A. C.; Thortenson, D. C.; Gerchakov, S. M. Org. Geochem., 1982, 4, pp. 93-112.

23. Curray, J.R.; Moore, D. G.; et al. "Init. Reps. D.S.D.P. LXIV," U.S. Govt. Printing Office: Washington, D.C., Vol. G4-Part I, 507 pp.

24. Baker, E. W.; Louda, J. W.; Orr, W. L. unpubl ished data.

25. Petracek, F. J.; Zechmeister, L. Analyt. Chem., 1956, 28 , pp. 1484-5. s.; Springer-Verlag; Berlin, 1969; pp. 464-97.

26. Krinsky, N.I. Analyt. Biochem., 1983, 6, 283-302. phin,

27. Holt, A. S. Plant Physiol., 1959, 34, pp. 310-314.

28. Baker, E. W.; Louda, J.W. In "Init. Reps. D.S.D.P.LVI-LVII," Langseth, M.; Okado, $H_{0}$; et al., Eds.; U.S. Govt. Printing Office: Washington, D.C., VoT. 56/57 - Part 2, pp. 1397-1408.

29. Louda, J. W.; Baker, E. W. In "Init. Reps. D.S.D.P. -LXIII," Yeats, R. S.; Haq, B. V.; et al., Eds.; U.S. Govt. Printing Office: Washington, D.C., Vol. 63, pp. 785-818. ss: New York,

30. Baker, E. W. J. Am. Chem. Soc. 1966, 88, 2311-5.

31. Baker, E. W.; Yen, T. F.; Dickie, J. P.; Rhodes, R. E.; Clarke, L. E. J. Am. Chem. Soc. 1967, 89, 3631-9.

32. Didyk, B. M.; Alturk:, Y. I. A.; Pillinger, C. T.; Eglinton, G. Nature $1975,256,563-5$.

33. Yen, T. F.; Boucher, L. J.; Dickie, J. P.; Tynam, E. C.;em. Vaughn, G. B. J. Inst. Petrol., 1969, 55, pp. 87-99.

34. Baker, E. W.; Palmer, S. E.; Hwang, W. Y. In "Init. Reps.R. D.S.D.P. - XLI," Lancelot, Y.; Seibold, E.; et al., Eds.; U.S. Govt. Printing Office: Washington, D.C., V0T. 41, pp. 825-37.

35. Mackenzie, A. S.; Ouirke, J. M. E.; Maxwe11, J. R. In "Advances in Organic Geochemistry - 1979," Douglas, A. G.; Maxwe11, J. R., Eds.; Pergamon: Oxford, 1980, pp. 239-48.

36. Holden, M. In "Chemistry and Biochemistry of Plant Pigments, 2nd. Edit.," Goodwin, T. W., Ed.; Academic Press: London, Vol. 2, 1976, pp. 2-37. 
37. Jeffrey, S. W. In "Primary Productivity in the Sea," Falkowski, P. G., Ed.; Plenum: New York, 1980, pp. 33-58.

38. Steele, J.H. "The Structure of Marine Ecosystems;"

Harvard Univ. Press: Cambridge (U.S.A.), 1974, 128 pp.

39. Gagosian, R. B. personal communication.

40. Currie, R. I. Nature, 1962, 193, pp. 956-7.

41. Aronoff, S. Ad $\overline{v . F O 0 d ~ R e s . ~} 1953,4$, pp. 133-84.

42. Orr, W. L.; Emery, K. 0.; Grady, J. R. Bull. Am. Assoc. Petrol. Geol., 1958, 42, pp. 925-958.

43. Palmer, S. E.; Charney, L. S.; Baker, E. W.; Louda, J. W. Geochim. Cosmochim. Acta, 1982, 46, pp. 1233-41.

44. Louda, J.W.; Palmer, S. E.; Baker, E.W. In "Init. Reps. D.S.D.P.-LVI-LVII," Langseth, M.; Okado, H.; et al., Eds.; U.S. Govt. Printing Office: Washington, D.C., Vol. $56 / 57$ -

45. Pennington, F. C.; Strain, H. H.; Svec, W. A.; Katz, J. J. J. Am. Chem. Soc.., 1967, 89, pp. 3875.80.

46. Smith, J.R. L.; Calvin, M. J.Am. Chem. Soc., 1966, 88, pp. 4500-6.

47. Holt, A. S.; Morley, H. V. Can. J. Chem., 1959, 37, pp. 507-14.

48. Baker, E. W.; Louda, J. W. In "Init. Reps. D.S.D.P.-LVIII," DeVries-Klein, G.; Kobayashi, K.; et al., U.S. Govt.

Printing 0ffice: Washington, D. C. , VoT. 58, 1980, pp. 737-9.

49. Pennington, F. C.; Strain, H. H.; Svec, W. A.; Katz, J. J. J. Am. Chem. Soc.., 1967, 89, pp. 3875.80. D.S.D.P.LVI-LVII,"

50. Smith, J.R. L.; Calvin, M. J. Am. Chem. Soc., 1966, 88,ng pp. 4500-6.

51. Holt, A. S.; Morley, H. V. Can. J. Chem., 1959, 37, III," pp. 507-14.; Haq, B. V.; et al., Eds.; U.S. Govt. Printing

52. Storm, C. B.; Krane, J.; Skjetne, T.; Telnaes, N.; Brantharer, J. F.; Baker, E. W. Science, 1984, 223, pp. 1075-6. ; Yen, T. F.; Dickie, J. P.; Rhodes, R. E.;

53. Baker, E. W.; Louda, J.W. In "Init. Reps. D.S.D.P.-LVIII," deVries-Klein, G.; Kobayashi, K.; et al., Eds.; U.S. Govt.n, Printing office: Washington, D.C., VoT. 58, 1980, pp. 737-9.

54. Baker, E. W.; Louda, J. W. In "Init. Reps. D.S.D.P.-LX," Hussong, D.; Uyeda, S.; et al., Eds.; U.S. Govt. Printing Office: Washington, D.C., VoT. 60, 1981, pp. 497-500. ps.

55. Baker, E. W.; Louda, J. W. In "Init. Reps. D.S.D.P.-LXI," Larson, R. L.; Schlanger, S.; et al, Eds.; U.S. Govt. Printing Office: Washington, D.C., Vol. 61, 1980, pp. 619-20.

RECEIVED January 15,1986 


\title{
Structural Analysis of Aquatic Humic Substances by NMR Spectroscopy
}

\author{
Andrew H. Gillam ${ }^{1}$ and Michael A. Wilson' \\ ${ }^{I}$ Institute of Offshore Engineering, Heriot-Watt University, Research Park, Riccarton, \\ Edinburgh, EH14 4AS, Scotland \\ ${ }^{2}$ CSIRO Division of Fossil Fuels, P.O. Box 136, North Ryde, NSW 2113, Australia
}

\begin{abstract}
Recently developed techniques in NMR spectroscopy have been applied to the analysis of marine and estuarine organic material. For example, the advantages of dipolar dephasing NMR spectroscopy in elucidating the types of aliphatic and aromatic structural groups in these materials are demonstrated. It is shown that methoxy and amino acid carbon of similar chemical shift can be distinguished. Problems in quantifying the different functional groups in marine and estuarine organic material by NMR are discussed and specific examples are given in which nonquantitative data might be expected.
\end{abstract}

It was not so long ago that water chemists were content to measure the amount of dissolved organic carbon in fresh, estuarine or marine waters. At best, all that was known of chemical structure was the concentration of trace, albeit important organic compounds. Al1 that has now changed and the chemical structure of all the dissolved organic substances (humic substances) is being investigated at a detailed level.

Although conventional functional group analysis and Fourier transform Infra-red spectroscopy are providing useful information, new revelations concerning the chemical structure of these ubiquitous materials have been largely due to developments in $1 \mathrm{H}-$ and 13C-NMR spectroscopy. Although some questions need to be answered concerning quantitation, major advances have been made in determining the aromaticity (fraction of carbon which is aromatic) and carbohydrate content of these substances by NMR.

Recently, 'second generation' (dipolar dephasing, two dimensiona1 NMR) 13C-NMR experiments have begun to appear in the coal science literature which are particularly applicable to humic substances. In this paper, some applications of these techniques to the study of the structure of organic materials from aquatic systems are demonstrated. These studies concentrate on: 1) obtaining additional

0097-6156/86/0305-0128\$06.00/0

() 1986 American Chemical Society 
information on structure, particularly functional groups and 2) establishing limits on quantitation.

Experimenta1

The location and sampling methods of samples used in this work have been described elsewhere $(1-5)$.

$1 \mathrm{H}-$ and 13C-NMR solution spectra were determined on a Jeo1 FX90Q spectrometer. The sample $(\sim 20 \mathrm{mg})$ was added to $0.5 \mathrm{~cm}^{3}$ of deuterium oxide. A few drops of 1 mol $\mathrm{dm}^{-3}$ sodium deuteroxide were added until the sample dissolved.

$1 \mathrm{H}$-spectra were obtained at $89.99 \mathrm{MHz}$ under homogated decoupling conditions in which the HOD peak produced by adventitious water impurities and proton exchange was irradiated. The radiofrequency (RF) level of the HOD irradiation was optimized for each sample, i.e. a sufficient RF level to reduce the HOD peak to zero was applied but not enough to distort the intensity of the humic material in the vicinity of the HOD peak. Spectra were determined using a $45^{\circ}$ pulse and $8 \mathrm{~K}$ data were acquired using $1500 \mathrm{~Hz}$ spectral width. Acquisition time was $2.727 \mathrm{~s}$, with a pulse delay of $2.0 \mathrm{~s}$. Approximately 1000 scans were collected for adequate signal to noise ratio. Chemical shifts are quoted with respect to internal tetramethylsilane (TMS) but were measured with respect to external TMS. A capillary inserted into the sample tube was used as a reference. The values so obtained were corrected by measuring the chemical shifts of n-butanoic acid with respect to both internal and external TMS.

Solution 13C-NMR spectra were determined at $22.5 \mathrm{MHz}$. 8K data were collected using a $7000 \mathrm{~Hz}$ spectral width. Acquisition time was $0.584 \mathrm{~s}$. Pulse delays of 1.0 to $5.0 \mathrm{~s}$ were used with, and without, inverse gated decoupling. Up to 60,000 scans were collected.

$13 \mathrm{C}$-cross polarization magic angle spinning (CP-MAS) spectra were obtained on a Bruker CXP-100 instrument. A rotor consisting of a barrel of boron nitride and a base of Kel-F was used. Rotor speed was $\sim 3.8 \mathrm{kHz}$. Recycle time was varied from 0.3 to $1 \mathrm{~s}$. A variety of contact times from 0.5 to $3 \mathrm{~ms}$ were employed. The Hartmann-Hahn condition was set using a sample of hexamethylbenzene. Chemical shifts were measured with respect to external hexamethylbenzene (by storing the hexamethylbenzene spectrum in another computer memory block) but are quoted with respect to TMS. It is assumed that the chemical shifts of hexamethylbenzene with respect to TMS are the same in solution as in the solid state.

Dipolar dephasing experiments were performed by inserting a delay before data acquisition in which the decoupler was gated off. A $180^{\circ}$ refocussing pulse along the spin locked coordinate was inserted midway in the delay period. Full details are given elsewhere $(\underline{6})$.

In general, data was worked up using line broadening factors of $50 \mathrm{~Hz}$ or greater for $13 \mathrm{C}$ or $1 \mathrm{~Hz}$ or less for $1 \mathrm{H}$. This is particularly important for solution 13C-spectra where signal to noise is poor.

Solution versus solid state NMR

In princlple, solution or solid state NMR can be used to study the 
structure of dissolved organic carbon. Both methods have advantages and disadvantages. The main advantages of solution NMR are:

1. some degree of extra resolution might be expected because of conformational freedom of the organic macromolecules;

2. quantitative aspects are more fully understood than for solid state techniques.

Advantages of the solid state techniques are:

1. increased sensitivity due to signal enhancement techniques, rapid relaxation, and the fact that a higher concentration of nuclei are between the poles of the magnet;

2. no ambiguity concerning degradation by the solvents used for solution NMR.

\section{$1 \mathrm{H}-\mathrm{NMR}$}

To obtain a solid state NMR spectrum it is necessary to remove interactions from nuclei closely bonded to the nucleus under investigation. For 13C-nuclei this is done through a combination of magic angle spinning and high power proton decoupling techniques. In the latter case, the protons are irradiated close to thelr resonant frequency. To obtain a high resolution 1 H-spectrum of a solid, high power decoupling techniques cannot be employed. Moreover, using magic angle spinning alone, the required spinning speeds are unobtainable. Thus, spectra obtained with current technology are unsatisfactory in that they do not give high resolution information. Although multiple pulse techniques may solve this problem (7), at present it is necessary to obtain $1 \mathrm{H}-\mathrm{NMR}$ spectra of estuarine and marine organic matter by solution techniques. This presents other difficulties mainly due to the high concentration of adventitious water. For example, even when deuterated solvents are used, only a broad featureless spectrum of water is obtained unless additional techniques are employed.

One method that has been successful is to continuously gate and irradiate the water peak so that these molecules cannot relax and hence, give an NMR signal (F1gure 1). Figure 1 also shows spectra of marine, sea loch and terrestrial humic substances. The main application of $1 \mathrm{H}-\mathrm{NMR}$ is to estimate the proton aromaticity of the samples by integrating the 6-8 ppm region against the rest of the spectrum, and secondly, to measure the amount of branching in the aliphatic structures. The peak at $<0.9 \mathrm{ppm}$ arises from methyl groups at the end of alkyl chains and can be integrated against the other aliphatic protons. It should be appreclated that protons which exchange with the solvent are not observed.

\section{$\underline{13 C-N M R}$}

Typical 13C-spectra for humic acids from a range of sources are shown in Figures 2 and 3. Five major regions of resonance can be recognised. These are 0-50 ppm (alkyl carbon), 50-108 ppm (carbohydrate, alcohol, ether and the $\mathrm{COOH} \alpha$-carbon of amino acid), 108$160 \mathrm{ppm}$ (aromatic carbon), 160-200 ppm (carboxylic, ester, amide carbon) and 200-220 ppm (ketonic or aldehydic carbon). 


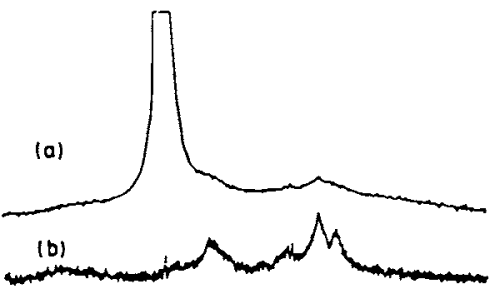

(c)
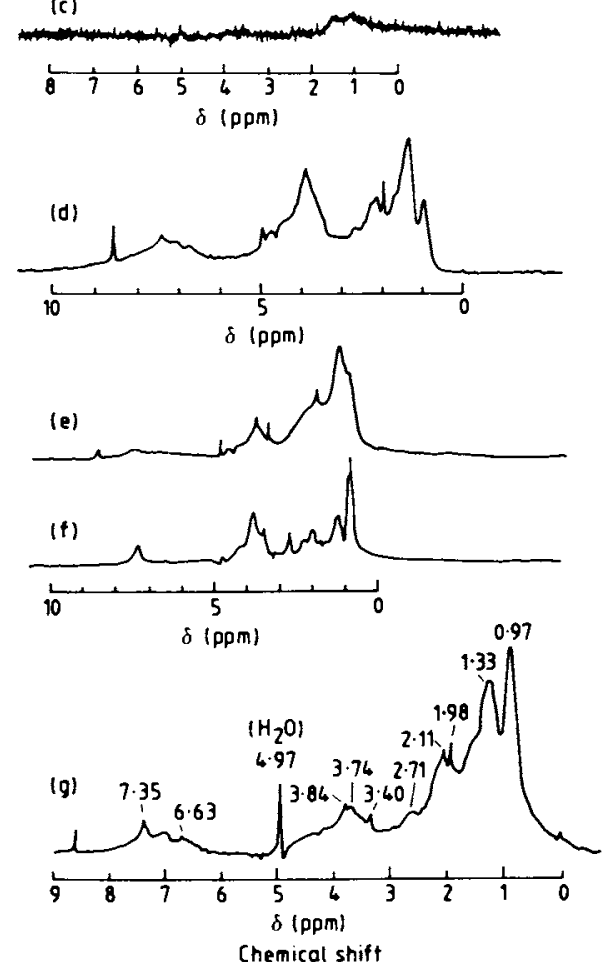

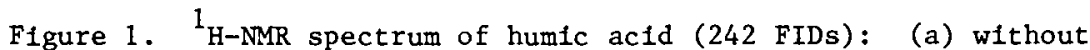
irradiation of water peak; (b) with optimum irradiation of water peak; (c) with over irradiation of water peak; (d) terrestrial humic acid (Levin) (refn 4); (e) dissolved marine humic acid (refn 1); (f) intracellular algal material (refn 1); (g) sea loch sedimentary material. (Reproduced with permission from reference 4. Copyright 1983 Blackwell Scientiflc Publications.)

In Organic Marine Geochemistry; Sohn, M.;

ACS Symposium Series; American Chemical Society: Washington, DC, 1986. 


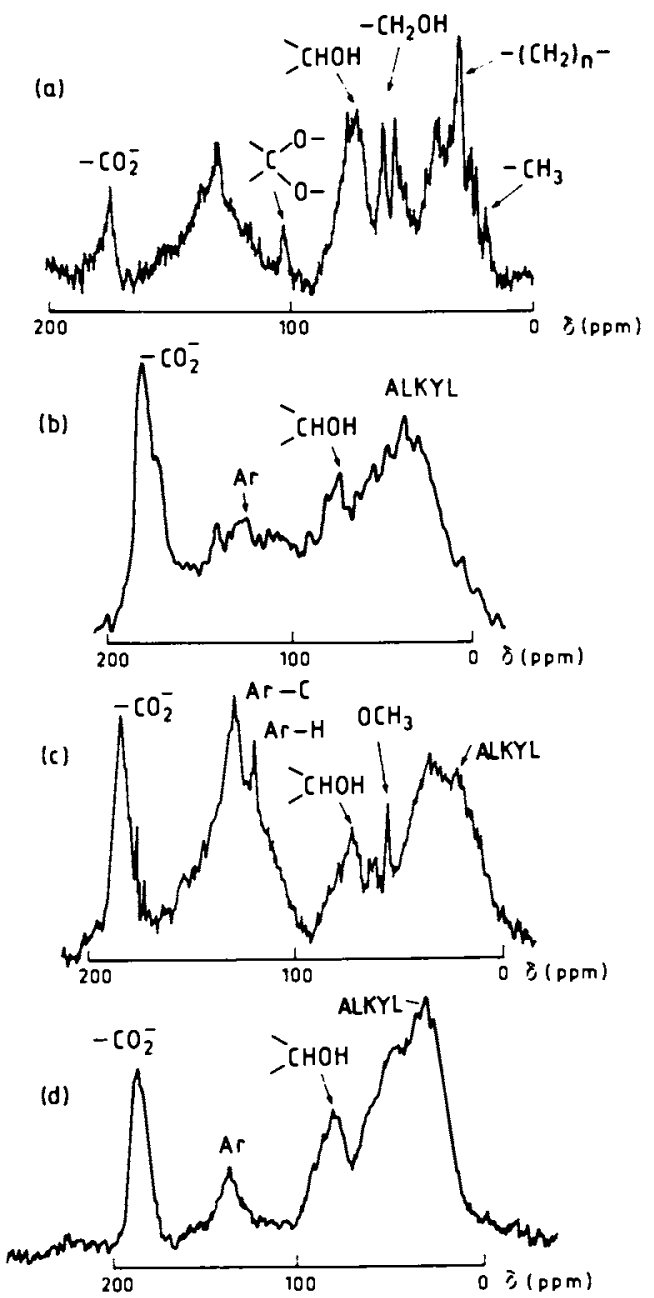

Figure 2. Typical ${ }^{13}$ C-NMR spectra of humic substances from varlous sources. (a) terrestrial (Levin) (solution) (refn 5); (b) terrestrial (Patua) (solution); (c) freshwater aquatic (solution) (refn 2); (d) dissolved marine (solid state) (refn 1)

In Organic Marine Geochemistry; Sohn, M.; ACS Symposium Series; American Chemical Society: Washington, DC, 1986. 
Recent developments in high resolution 13C-solid state NMR spectroscopy have demonstrated that additional information can be obtained if the proton decoupler is turned off for a short period between irradiating the nuclei in the sample under investigation and observing their subsequent behaviour (8). If the correct period of time is left, (dipolar dephasing period), spectra can be obtained from only methyl and non-protonated carbon. However, during the dipolar dephasing period the signal intensities of these resonances are also attenuated, albeit at different rates from tertiary and secondary carbons. Hence for quantitative analysis of structural groups in complex materials such as dissolved organic matter in marine and estuarine waters, knowledge of the decay constants for different structural groups is essential.

To this end, the dipolar dephasing behaviour of a wide range of organic compounds has been established (9-12). Various types of carbons experience a wide range of $13 \mathrm{C}-1 \mathrm{H}$ interactions. Carbons weakly coupled to protons, e.g. quarternary carbons follow a single exponential law given by

$$
I_{B}=I_{B}^{0} \exp \left(-t_{1} / T_{2}^{\prime}\right)
$$

where $I_{B}^{o}$ is the signal intensity at zero time and $T_{2}^{\prime}$ is the exponential decay constant for the signal intensity. When the carbons are strongly coupled to protons, e.g. methine and methylene carbons, the signal decay is modulated by the strong $13 \mathrm{C}-1 \mathrm{H}$ coupling and the overall decay of the signal in the short time limit is better described by the equation

$$
I_{A}=I_{A}^{0} \exp \left(-t_{1}^{2} / 2 T_{2}^{\prime 2}\right)
$$

Values of $T_{2}^{\prime}$ for various carbon types are listed in Table $I$. In principle, It should be possible to identify a number of structural groups in aquatic organics by their decay constants.

Nevertheless, for a complex material such as the organic matter in marine and estuarine waters, each resonance is broad and arises from a number of structural groups. For example, in the aromatic region the broad signal is due to $\mathrm{CH}$ and non-protonated carbon. In this case signal decay will be given by the sum of equations (1) and (2) as (3).

$$
I=I_{A}+I_{B}=I_{A}^{0} \exp \left(-t_{1}^{2} / 2 T_{2 A}^{\prime 2}\right)+I_{B}^{0} \exp \left(-t_{1} / T_{2 B}^{\prime}\right)
$$

However, this equation can be computer fitted to give time constants

$T_{2 A}^{\prime}, T_{2 B}^{\prime}$ and $I_{g}$ and $I_{A}^{0}$. For the aromatic resonance, $I_{B}^{0} /\left(I_{A}^{0}+I_{B}^{0}\right)$ is a measure of the fraction of aromatic carbon which is non-protonated and the time constants tell us which structural groups are present.

Typical dipolar dephased spectra of a sedimentary sea loch humic acid are shown in Figure 4 as a function of dephasing time.

Comparison of Figure 4 with Figure 3 clearly shows substantially more alkyl and 0-alkyl carbon is protonated than aromatic carbon since the signal from these two types of carbon are attenuated at long ( $40 \mu \mathrm{s}$ ) 


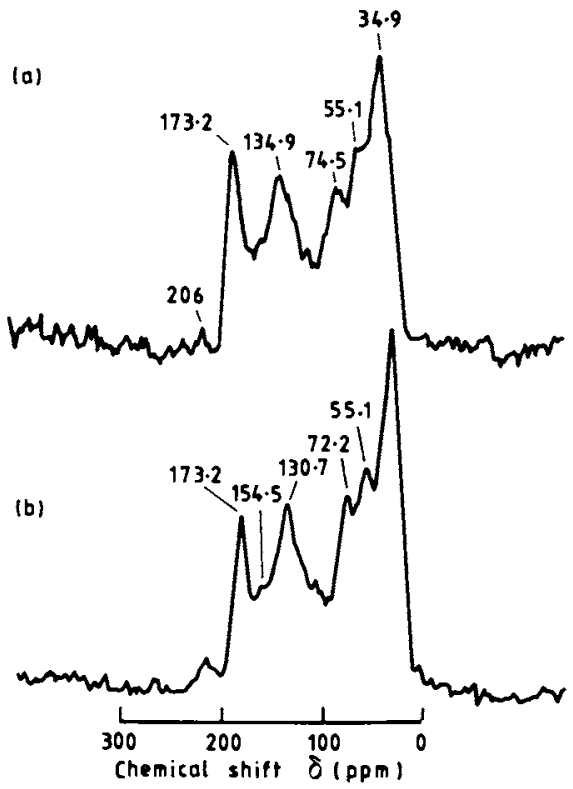

Figure 3. ${ }^{13} \mathrm{C}-\mathrm{NMR}$ (solid state) spectra of sea loch sedimentary humic substances. (a) fulvic acid; (b) humic acid.

Table I. Typical $T_{2}^{\prime}$ Values for Various Carbon Types

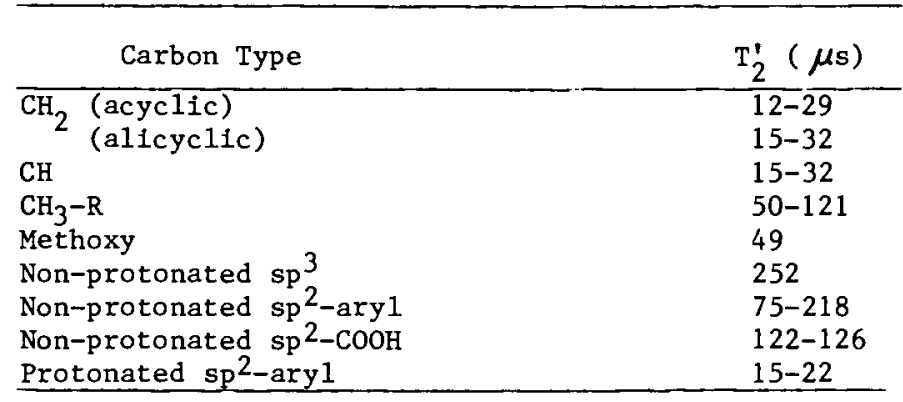

In Organic Marine Geochemistry; Sohn, M.;

ACS Symposium Series; American Chemical Society: Washington, DC, 1986. 


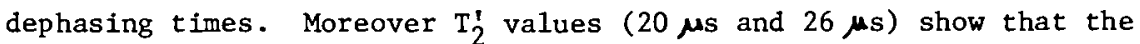
resonances at 30 and $75 \mathrm{ppm}$ arise from protonated carbons. The resonance at $155 \mathrm{ppm}$ has a long $\mathrm{T}_{2}$ value ( $>120 \mu \mathrm{s}$ ) and is more prominent in the dipolar dephased spectrum (Figure $4, t_{1}=40 \mu \mathrm{s}$ ) showing that these carbons are non-protonated, 1.e. oxygenated. This signal is due to the presence of phenols or aryl ether functionalities. An approximate estimate of various protonated structures, using equation (3), shows that $85 \%$ of the aromatic carbon in the humic acid is non-protonated. The corresponding figure for the fulvic acid sample is $90 \%$.

The decay constant $\left(\mathrm{T}_{2}^{\prime}=26 \mu \mathrm{s}\right)$ for the resonance at $55 \mathrm{ppm}$ is considerably shorter than expected for methoxy groups but similar to that expected for $\mathrm{CH}$ carbons in amino acids. Hence the results suggest a substantial contribution of amino acid carbon to the sample. In contrast, we have observed relatively long decay constants $\left(\mathrm{T}_{2}^{\prime}=60 \mu \mathrm{s}\right)$ for resonances at similar chemical shifts in terrestrial organic materials which can therefore be assigned to methoxy groups.

Table II illustrates the types of structures which may be distinguished from each other by dipolar dephasing experiments on humic substances. Clearly, methine and methyl, protonated aromatic and non-protonated aromatic, ketone and aldehyde, ketal and acetal carbons and also protonated olefinic and non-protonated olefinic carbon can be distinguished. Examples of the use of the method (6, 13), are shown in Figure 5 .

\section{Quantitation}

The question of how quantitatively MMR measurements on macromolecules such as those comprising organic matter in coals, sediments and soils can be interpreted, is a matter of continuing debate. Similar considerations are applicable to studies on aquatic organic samples.

\section{Solution NMR}

There is general agreement about the problems of measurement by solution MMR. To determine whether data is quantitative, it is necessary to determine the magnitude of the spin-spin $\left(T_{2}\right)$ and spinlattice $\left(T_{1}\right)$ relaxation times of the sample. The spin-Iattice relaxation time constants of carbon in organic substances can be as short as $0.1 \mathrm{msec}$ or as long as $1,000 \mathrm{sec}$. Unfortunately, short pulse delays of $1 \mathrm{sec}$ or less must be employed when obtaining 13Cspectra of humic substances because large numbers of transients (scans) must be collected with signal averaging to obtain reasonable signal to noise ratios. Thus, it is not always possible to allow nuclei to fully relax between pulses and this can cause problems when attempting to estimate the proportions of various carbon types in humic extracts by NMR. The use of short pulse delays may lead to an over estimation of rapidly relaxing functional groups and an under estimation of slowly relaxing functional groups.

Because a large number of transients are needed to obtain even a nonquantitative $13 \mathrm{C}$-spectrum of humic substances in solution, the time needed for measurement of relaxation times can be prohibitive. 


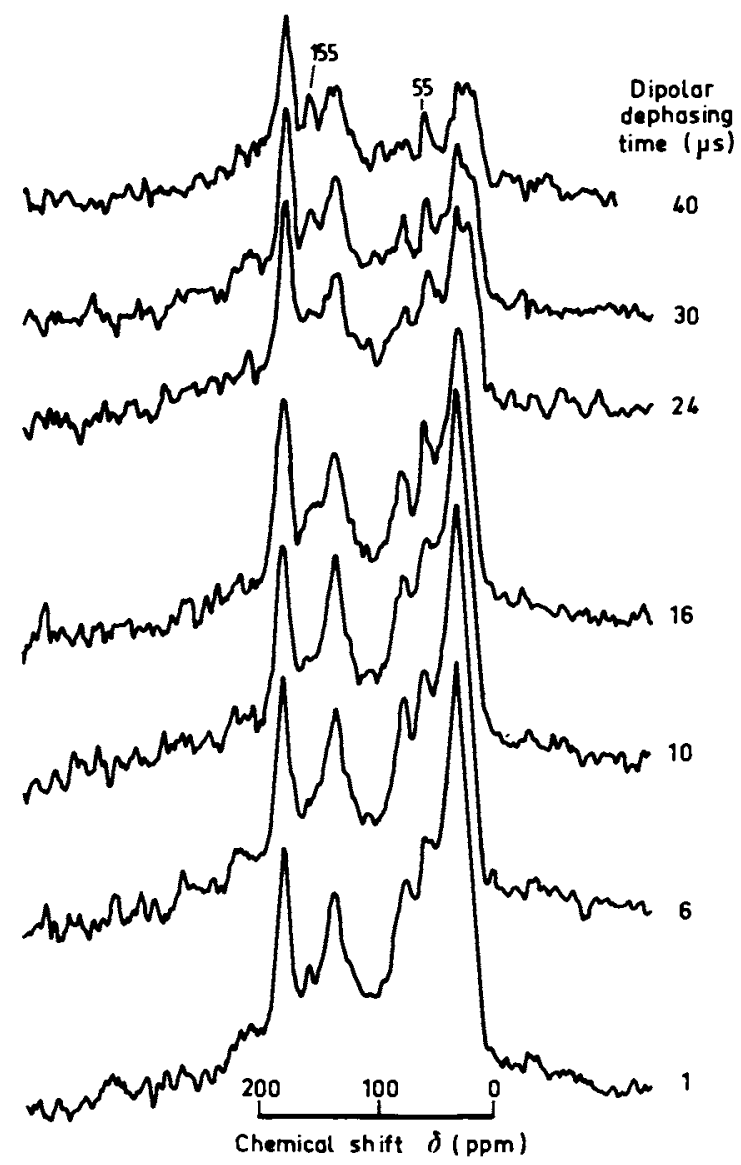

Figure 4. Effect of varying dipolar dephasing time on signal intensity from sea loch sedimentary humic acid.

Table II. Differentiation of Functional Groups In Organic Material in Terrestrial and Aquatic Environments by Dipolar Dephasing

\begin{tabular}{|c|c|}
\hline Chemical Shift & Structure \\
\hline $\begin{array}{l}0-30 \mathrm{ppm} \\
50-60 \mathrm{ppm} \\
100-108 \mathrm{ppm} \\
110-160 \mathrm{ppm} \\
200-220 \mathrm{ppm}\end{array}$ & $\begin{array}{l}\text { methyl groups from methine and methylene } \\
\text { amino acid } \mathrm{CH} \text { carbon from methoxy } \\
\text { acetal from ketal } \\
\text { protonated from non-protonated aromatics, } \\
\text { protonated from non-protonated olefins } \\
\text { aldehyde from ketone }\end{array}$ \\
\hline
\end{tabular}




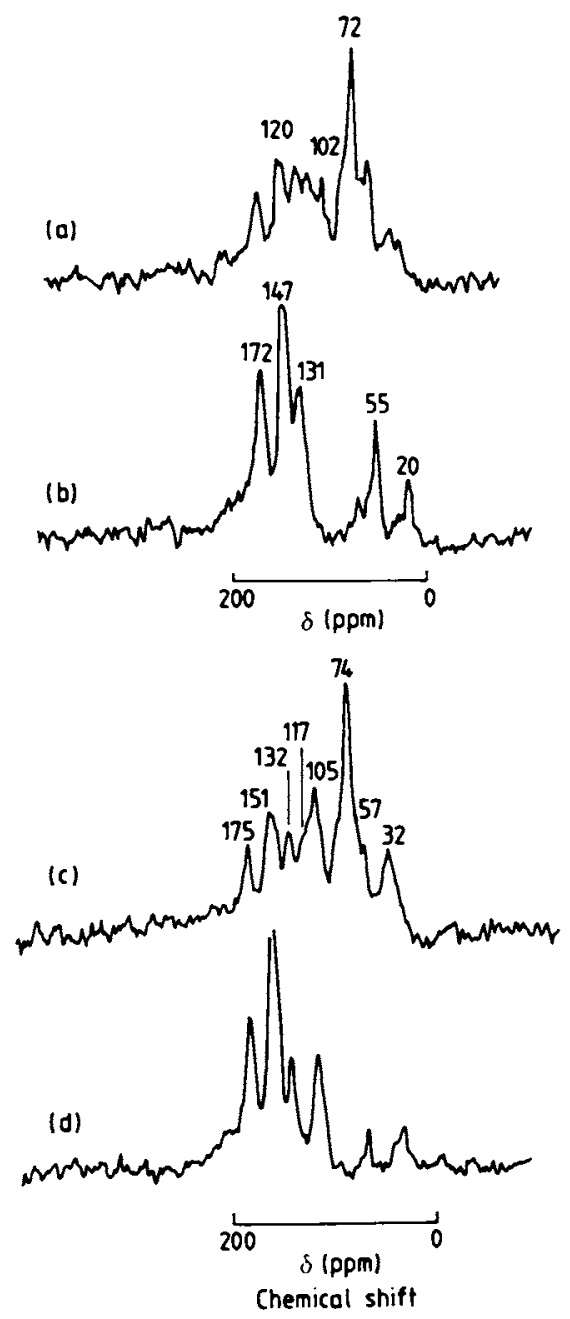

Figure 5. Effect of dipolar dephasing on signal intensities from vartous carbons in (a), (b) peat and (c), (d) decayed pine leaves. The methoxy (55 ppm) and methyl (20 ppm) signals in conventional spectrum (a) are retalned after $40 \mu \mathrm{s}$ dipolar dephasing (spectrum b). Also acetal resonance (102 ppm) (spectrum a) is lost after dipolar dephasing in (spectrum b). In decayed pine leaf spectra, ketal resonance (105 ppm) in conventlonal spectrum (c) is retained after $40 \mu \mathrm{s}$ dipolar dephasing, spectrum (d). (Reproduced with permission from reference 6 . Copyright 1983 Pergamon Press.)

In Organic Marine Geochemistry; Sohn, M.; 
However, a number of authors have been concerned whether the area of the resonances in 13C-solution NMR spectra ascribed to aromatic plus olefinic carbon $\left(f_{a}\right)$, can be integrated quantitatively. Hence, experiments have been carried out in which the pulse delay between transients is varied $(1,2,5,14)$. The effect of pulse delay on $f_{a}$ appears to be quite sma11, which suggests that most carbons in the sample relax at similar rates. Nevertheless, it is clear that signal intensity increases rapidly with increasing pulse delay and at pulse delays ( $\leqslant 1 \mathrm{sec}$ ) normally used to obtain 13c-spectra of humic substances, nuclei have not fully relaxed and carboxyl carbon is underestimated.

In samples relaxing through nuclear-nuclear dipole-dipole mechanisms, another source of error in quantitative 13C-MMR is the nuclear Overhauser effect. This arises in double resonance experiments when one nucleus (in this case $\mathrm{l}_{\mathrm{H}}$ ) is irradiated to simplify the spectrum while another (in this case ${ }^{13} \mathrm{C}$ ) is observed. The signal from the observed species will differ in intensity from that of the signal from a single resonance experiment. Nuclear Overhauser enhancements $(\eta)$ have been measured on humic substances $(2,14)$. The enhancements, while not large, are significant and suggest that substantial numbers of humic substances can relax through nuclear-nuclear dipole-dipole mechanisms. Different functional groups in molecules relax by different mechanisms, so they will experience different N.O.E.'s. Indeed $13 \mathrm{C}$ experiments on humic substances obtained so far indicate that N.O.E.'s for carboxyl carbons are different so that irradiating protons causes problems $(\underline{1}, \underline{2}, \underline{5}, \underline{14})$. For soil humic materials this has little effect on aromaticity measurements but in aquatic materials the carboxyl content can constitute nearly one quarter of the total carbon (2). Hence to obtain spectra of these samples, it is necessary to turn off the proton irradiation during the delay period between pulses to reduce N.O.E. This is commonly termed inverse gated decoupling.

Further complications in quantifying data can occur because of unusually short relaxation times. In the close proximity of paramagnetic ions, relaxation can be extremely fast. In effect, if $\mathrm{T}_{2}$ is extremely short, the nucleus will not be observed. One way of avoiding this possible source of error is to demineralise humic substances. Nevertheless, the intrinsic organic free radicals may assist relaxation of certain structures in humic substances. If the radicals are sufficiently delocalised, this may affect quantitation.

\section{Solid state NMR}

Solid state 13C-NMR spectra of humic substances are usually obtained by cross polarization techniques (15). In this method, relaxation occurs at almost the proton $\mathrm{T}_{1}$ rate, rather than the carbon $\mathrm{T}_{1}$ rate which can be slower by a factor of 100 . Hence, in principle, the problems of long carbon $\mathrm{T}$ 's in solution are overcome by obtaining the spectrum in the solid state. However, solid state T's are intrinsically much longer than in solution and hence $1 t$ is possible that some molecules are not observed because now the proton $T$ 's are too long. These species are normally small polycyclic aromatics (12), although, fortunately, when these materials are coordinated together as polymers, $\mathrm{T}_{1}(\mathrm{H})$ is reduced. It can be expected that 
$\mathrm{T}_{1}(\mathrm{H})$ problems in quantitation can be restricted to low molecular weight material ( $<1000)$.

There are several other problems associated with quantitation using cross polarization techniques. In determining the aromaticity of humic substances, cross polarization is achieved by applying $r . f$. magnetic fields at the resonant frequency of both $13 \mathrm{C}$ and $1 \mathrm{H}$ nuclef. By adjusting their relative Intensities, contact between the two populations is established and cross polarization occurs between protons and carbons. However, the decay of polarization of the population of nuclei occurs at a rate determined by a time constant $\mathrm{T}_{1 \mathrm{p}}(\mathrm{H})$ which is independent of the rate of cross polarization.

During the cross polarization process magnetization is transferred from protons to carbons according to the strength of the $\mathrm{C}-\mathrm{H}$ dipole interaction, at a rate governed by a second time constant $\mathrm{T}_{\mathrm{CH}^{*}}$ If $\mathrm{T}_{1 \mathrm{p}}(\mathrm{H})$ is smaller than the time needed for the most weakly coupled carbons to cross polarize, these signals will be reduced in intensity and in the extreme case, become lost in the background noise. Several laboratories have turned to model compound studies to elucidate the magnitude of this problem (16-18). The rate of cross polarization depends on the proximity of protons to carbons and on molecular motion. Hence carbons remote from protons may not be observed. Alemany et al. $(17,18)$ have suggested that a serious reduction in intensity is obtained when carbons are four bonds removed from protons. It is difficult to imagine such structures constituting more than a minor proportion of the carbon in humic subst ances.

of more concern for humic substances than the effect of long ${ }^{\mathrm{T}} \mathrm{CH}^{\prime}$ 's is the variable nature of $\mathrm{T}_{1 \mathrm{P}}(\mathrm{H})$. Paramagnetic ions are of particular concern since they may assist relaxation and greatly shorten $\mathrm{T}_{1 \mathrm{p}}(\mathrm{H})$ 's in their immediate vicinity.

We have measured average $(\langle\rangle) \mathrm{T}_{1 \mathrm{p}}(\mathrm{H})$ and $\mathrm{T}_{\mathrm{CH}}$ 's of humic materials (6) through cross polarization experiments. Whereas the $\left\langle\mathrm{T}_{\mathrm{CH}}\right\rangle$ 's for aliphatic and aromatic carbons are of the order of 50 and $\mathrm{CH}_{00} \mu \mathrm{s}$ respectively, $\left\langle\mathrm{T}_{1 \mathrm{p}}(\mathrm{H})\right\rangle$ 's are much greater and range between 3.5 and $7 \mathrm{~ms}$. Although encouraging, these results do not demonstrate that quantitative data are obtained. In rigid solids, polarization diffusion between protons usually operates to average $\mathrm{T}_{1 \mathrm{p}}(\mathrm{H})$ values. However, in a complex mixture like humic substances, a number of $\mathrm{T}_{1 \mathrm{p}}(\mathrm{H})$ 's may exist. Indeed we have been able to demonstrate lack of spin diffusion in some humic substances (6).

A method of checking whether all protons in a sample have $T_{1 P}(H)$ 's long enough for carbons to cross polarize, is to measure the $\mathrm{T}_{\mathrm{T}}^{1 \mathrm{P}}(\mathrm{H})$ 's independently of carbon and directly through protons. Data

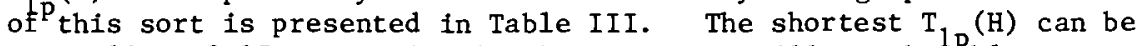
as small as 0.15 ms. Clearly these protons will not be $\mathrm{bble}_{\mathrm{b}}$ to transfer polarization quantitatively to carbons. Whether these protons are associated with organic as well as inorganic matter has, however, yet to be established. This is important because it is only the organically bound protons which may influence aromaticity measurements.

One way to check whether the cross polarization method is responsible for introducing errors in aromaticity measurements, is to perform experiments using single pulse excitation in much the same way as solution NMR measurements are made. Th1s method is time 
consuming and unsuitable for routine measurements because long delays are needed between pulses in solids to ensure complete relaxation of $13 \mathrm{C}$ nuclei. There is also a considerably lower signal to noise ratio compared with cross polarization experiments of equal number of transients. Single pulse experiments have been reported by Hatcher (19) to be consistent with cross polarization experiments. Moreover, data obtained by solution and solid state MMR is similar $(\underline{1}, \underline{3}, \underline{19})$.

Table III. Relaxation Data for Some Humic Materials

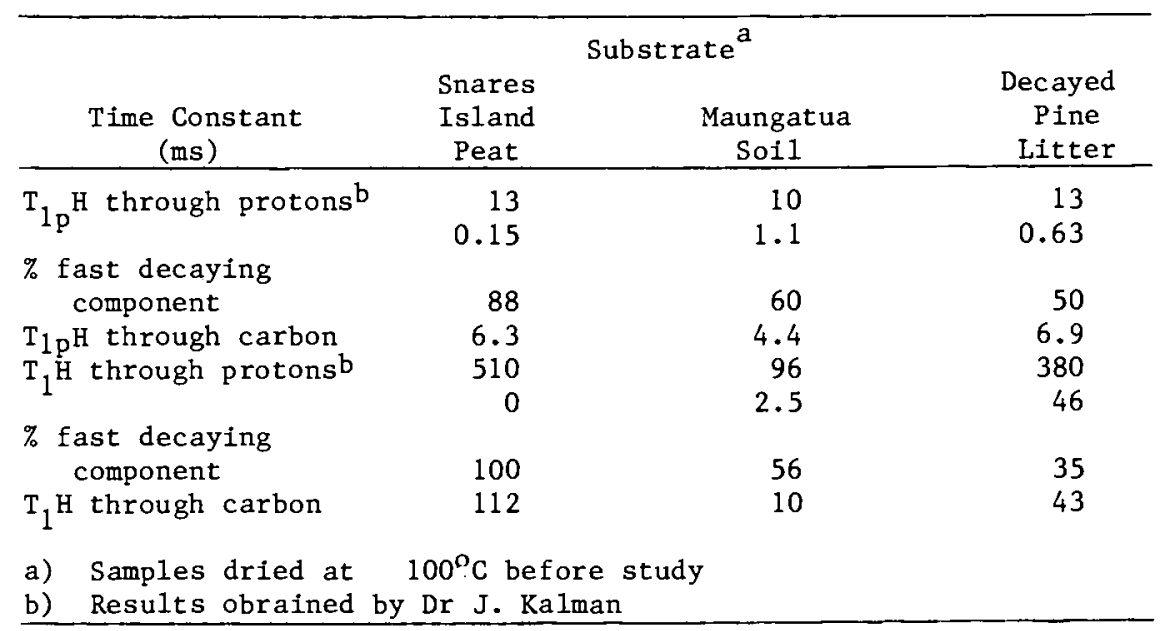

\section{Conclusions}

It is clear that caution should be taken when quantitatively interpreting 13C-spectra of humic substances, including aquatic humic substances, unless an in depth study of relaxation is undertaken. Unfortunately these studies are not routine. It has been established that certain structures may cause problems in quantitation. These are:

a) in solution:

1. molecules with carbons having long $\mathrm{T}_{1}$ 's. These are invariably non-protonated carbons;

2. molecules with carbons with very short $\mathrm{T}_{2}$ 's. These are those carbons bonded to paramagnetic ions or intrinsic free electrons.

b) in the solid state:

1. molecules with carbons with long $\mathrm{T}_{\mathrm{CH}_{\mathrm{H}}}$ 's and long $\mathrm{T}_{1}(\mathrm{H})$ 's, e.g. polycyclic hydrocarbons which have carbons remote from protons;

2. molecules with protons with short $T_{1_{p}}(H)$ 's. These are molecules with protons bonded to, or $\mathrm{p}_{\mathrm{close}}$ to, paramagnetic ions. 
If the proviso's above are met, dipolar dephasing methods provide useful quantitative information on methoxy, aldehyde, ketone and protonated and non-protonated aromatic and olefinic carbon content.

\section{Literature Cited}

1. Wilson, M.A.; Gillam, A.H.; Collin P.J. Chem. Geol. 1983, 40, 187.

2. Wilson, M.A.; Barron, P.F.; Gillam, A.H. Geochim Cosmochim. Acta. 1981, 45, 1743.

3. Gillam, A.H.; Wilson, M.A. Org. Geochem. 1985, 8, 15.

4. Wilson, M.A.; Collin, P.J.; Tate, K.R. J. Soil Sci. 1983, 34, 297.

5. Newman, R.H.; Tate, K.R.; Barron, P.F.; Wilson, M.A. J. Soil Sci. 1980, 31, 623.

6. Wilson, M.A.; Pugmire, R.J.; Grant, D.M. Org. Geochem. 1983, 5,121 .

7. Gerstein, B.C. Phil. Trans. R. Soc. London A. 1981, 299, 521.

8. Ope11a, S.J.; Frey, M.H. J. Amer. Chem. Soc. 1979, $101,5854$.

9. Alemany, L.B.; Grant, D.M. ; Alger, T.D.; Pugmire, R.J. J. Amer. Chem. Soc. 1983, 105, 6697.

10. Wilson, M.A.; Pugmire, R.J. Trends Ana1. Chem. 1984, 3, 144-147.

11. Murphy, P.D.; Cassady, T.J.; Gerstein, B.C. Fue1 1982, 61, 1230 .

12. Wilson, M.A.; Vassa11o, A.M.; Collin, P.J.; Rottendorf H. Anal. Chem. 1984, 56, 433.

13. Wilson, M.A.; Vassallo, A.M.; Russe11, N.J. Org. Geochem. $1984,7,161$.

14. Newman, R.J.; Tate, K.R. J. Soil Sci. 1984, 35, 47.

15. Pines, A.; Gibby, M.G.; Waugh, J.S. J. Chem. Phys. 1973, $59,569$.

16. Wemmer, D.W.; Pines, A.; Whitehurst, D.D. Ph11. Trans. R. Soc. London 1981, A300, 15.

17. Alemany, L.B.; Grant, D.M.; Pugmire, R.J.; Alger, T.D.; Zilm, K.W. J. Amer. Chem. Soc. 1983, 105, 2133.

18. Alemany, L.B.; Grant, D.M.; Pugmire, R.J.; Alger, T.D.; Z11m, K.W. J. Amer. Chem. Soc. 1983, 105, 2142.

19. Hatcher, P.G.; Breger, I.A.; Dennis, L.W.; Maciel, G.E. In: "Aquatic and Terrestrial Humic Materials"; R.F. Christman; E.T. Gjessing, Eds., Ann Arbor, Michigan, 1983, pp.46-48.

RECEIVED November 19, 1985

In Organic Marine Geochemistry; Sohn, M.; 


\title{
Structural Interrelationships among Humic Substances in Marine and Estuarine Sediments
}

\author{
As Delineated by Cross-Polarization/Magic Angle Spinning ${ }^{13} \mathrm{C}$ NMR
}

\author{
Patrick G. Hatcher and William H. Orem
}

U.S. Geological Survey, Reston, VA 22092

\begin{abstract}
Nuclear magnetic resonance studies of the structural composition of humic substances in marine and estuarine sediments have provided a wealth of information regarding the mode of formation for these macromolecular organic substances. The NMR data show that humic acids are highly aliphatic in nature. The aliphatic structures are thought to be derived from macromolecular residues of algae and other micro-organisms and have a high degree of branching and cross-1inking. Fulvic acids, the most soluble of the humic substances, are generally unlike their less soluble counterparts, humic acids and humin, in that they appear to be mostly composed of carbohydrates and/or polyuronic acids. The interrelationships among fulvic acids, humic acids, and humin in a variety of marine and estuarine sediments suggests that humin is the parent material from which humic and fulvic acids are formed. The pathway for this formation appears to be oxidative, either chemical or biological oxidation. Fulvic acids are metabolic products of bacterial degradation of plant remains, whereas humic acids appear to be oxidized structural equivalents of the macromolecular insoluble humin in sediments receiving most of their contibutions from algal or microbial biomass. This humin probably originates from primary macromolecular structures in algae and/or bacteria and is concentrated in sediments by a process of selective preservation during early diagenesis. Humin from some coastal marine and estuarine sediments appears to contain a significant proportion of refractory, coallike materials. In these sediments, humic acids bear no structural relationship to the humin.
\end{abstract}

The use of nuclear magnetic resonance spectroscopy for structural studies of humic substances has become commonplace since some of the

This chapter not subject to U.S. copyright.

Published 1986, American Chemical Society 
early work of Vila and others (1) , Stuermer and Payne (2), Wilson and Goh ( 3 ), and Hatcher and others (4). These early studies relied on solution ${ }^{H}$ and ${ }^{13}$ C NMR to derive structural information on humic substances, primarily humic and fulvic acids, that are soluble in a suitable solvent, usually $0.5 \mathrm{~N} \mathrm{NaOD}$. The development of a technique that was capable of examining solids, solid-state 13 C NMR using cross polarization with magic-angle spinning (CPMAS), provided an opportunity to not on $1 y$ examine soluble humic substances but also the insoluble humin ( $2-8)$ and whole soil ( $9-11)$. Such a capability has for the first time al lowed for direct chemical structural comparisons between the various humic fractions in marine and estuarine sediments. Some of these comparisons were made earlier for marine sediments (6). This paper provides new data for estuarine sediments and attempts to provide a more complete analysis of the structural interrelationships.

Solid-state ${ }^{13} \mathrm{C}$ NMR is the method of choice in this study for a number of reasons. First, the method is not 1 imited by solubility, al lowing intercomparisons among al 1 humic isolates including the insoluble humin. We felt it important that humin be comparatively examined because our previous studies $(\underline{q}, \underline{8})$ have suggested that this humic fraction may be the precursor from which humic acids originate. Second, the CPMAS technique is more sensitive and provides a spectrum we feel is more representative of carbon structures than solution ${ }^{13} \mathrm{C}$ NMR. Finally, the structural information obtained by NMR is far more useful for intercomparison purposes than that obtained from many other organic geochemical methods such as infrared spectroscopy, pyrolysis/gas chromatography/mass spectrometry (Py/GC/MS), elemental analysis, and others. The spectral data provides a striking visual presentation that enables rapid structural intercomparisons among humic fractions. Though the data cannot provide detailed discrimination at the molecular level like Py/GC/MS and similar techniques, major structural differences are readily discernable with NMR. When used in combination with other organic geochemical techniques, ${ }^{13} \mathrm{C}$ NMR becomes a powerful tool for chemical structural determinations.

\section{Methods}

Humic and fulvic acids as well as humin were isolated from the samples described in Table I by standard methods ( 6 ). In short, humic and fulvic acids are extracted with $0.5 \mathrm{~N} \mathrm{NaOH}$ under $\mathrm{N}_{2}$. Humic acids are protonated on an ion exchange resin, precipitated by acidifying to $\mathrm{pH} 2$, separated by centrifugation, and lyophilyzed. The soluble fulvic acids are concentrated by ultrafiltration and 1 yophilyzed. Humin, the residue after treatment with $\mathrm{NaOH}$, is treated with concentrated HC $1: H F$ to remove a large portion of the mineral matter and hydrolyzable substances such as proteins and polysaccharides.

Dried humic substances were analyzed by ${ }_{13}$ lacing them in a bullet-type rotor machined from $\mathrm{Rel}-\mathrm{F}$. CPMAS $13_{\mathrm{C}}$ NMR spectra were obtained on a Chemagnetics CMC 100S/200L spectrometer operating at a field strength of $2.35 \mathrm{Tes} 1 \mathrm{a}$. Approximately $10,000-50,000$ scans were obtained with a 1 s delay and 1 ms contact time. Spinning speeds of 3 to $3.5 \mathrm{kHz}$ were achieved to minimize spinning sidebands. 
Table I. Sample locations and descriptions

Sample Name

Location and Description

Mangrove Lake

Potomac River (fluvial)
Samples collected in Mangrove Lake, Bermuda, a small marine lake located on the northeastern corner of the island. A core (5.5m in depth) of the organicrich sapropel at the bottom of the 1 ake was obtained.

Sample of humic acid was obtained from G. Diachenko (U.S. Department of Agriculture). Sediment was collected at Point of Rocks, Maryland, in the Potomac River.

Potomac River (estuarine) Samples were collected at the mouth of the Potomac River near Piney Point, Maryland. A $1-m$ core was obtained.

New York Bight

Samples were collected on the Continental Shelf, 10 nautical miles southeast of Rockaway Point, New York.

Hudson Canyon

Samples were collected at the head of the Hudson Canyon inthe New York Bight 100 nautical miles east of Rockaway Point, New York, in 266m of water.

Walvis Bay

Samples were collected on the Continental Shelf, Walvis Bay, Namibia (South West Africa) in $846 \mathrm{~m}$ of water. Surface sediment was collected on Cruise AII-93-3 of the At lantis II in 1975 by J.W. Farrington (Woods Hole Oceanographic Institution).

Georgia soil
Surficial soil sample was collected from a fallow agricultural field near Ringsland, Georgia. 


\section{$\underline{\text { Results }}$}

Fulvic acids. Marine sedimentary humic substances soluble in base and acid (fulvic acids) have previous $1 \mathrm{y}$ been examined by $1_{\mathrm{H}}$ and ${ }^{13} \mathrm{C}$ NMR (12). The dominant structural components were postulated to be polysaccharide - like substances, probably polyuronic acids. Solidstate ${ }^{13} \mathrm{C}$ NMR spectra of fulvic acids isolated from a number of marine and estuarine sediments are shown in Figure 1. Major peaks at 72 and $106 \mathrm{ppm}$ betray the overwhelming presence of polysaccharide 1 ike substances, and, as shown by Hatcher and others (12), the moderate peak for carboxyl or amide carbon at 175 ppm suggests that these polysaccharides are more like polyuronides. Aromatic carbons (110 to $160 \mathrm{ppm}$ ) are decidedly minor components. Aliphatic carbons $(0-50 \mathrm{ppm})$ are also minor components. $1_{\mathrm{H}}$ NMR spectra shown by Hatcher and others (12) indicate that these aliphatic structures are highly branched.

It is noteworthy that fulvic acids from aerobic and anaerobic sediments and from offshore marine and estuarine sediments all have similar ${ }^{13} \mathrm{C}$ NMR spectra. The abundance of polysaccharides and structural similarity in this fraction precludes attempts to correlate sources of sedimentary organic matter on the basis of structural differences. The uniform structural character also suggests that the process leading to the production of fulvic acids is ubiquitous. If polyuronides are the likely structural components of fulvic acids, then it is likely that these components derive from algal or microbial remains known to be enriched in polyuronides.

The classical definition of fulvic acids is not very specific. Many biochemical substances such as proteins, sugars, and fatty acids would fall under this classification. These substances, in many instances, can hardly be considered "humic" in nature. But, if one uses the classical definition of fulvic acids these substances are included. No doubt the observations made above that polysaccharidelike substances constitute the major components of sedimentary fulvic acids is partly attributable to the fact that the operational definition classes polyuronides as fulvic acids. It is not the intent of this paper to discuss the merits of using the classical operational definition for fulvic acids as opposed to one's perception of what true fulvic acids are. We know far too little about the composition of humic isolates and about their origin to begin discussions of whether they are humified or not. We therefore chose to use operational definition with recognition that we 1 defined structural entities can sometimes be a part of what is isolated.

Humic acids. CPMAS 13 NMR spectra of representative marine and estuarine humic acids are shown in Figure 2 .Solution $1_{\mathrm{H}}$ and ${ }^{13} \mathrm{C}$ NMR and solid state ${ }^{13}$ C NMR spectra of marine sedimentary humic acids have previously been described by Hatcher and others (4) and Dereppe and others ( $\underline{13})$. These spectra showed that marine sedimentary humic acids are predominantly composed of paraffinic structures that have a relatively high degree of branching, compared to long-chain alkyl structures. Aromatic structures are generally depleted in marine humic acids whose source is predominant ly from algal or microbial detritus. 

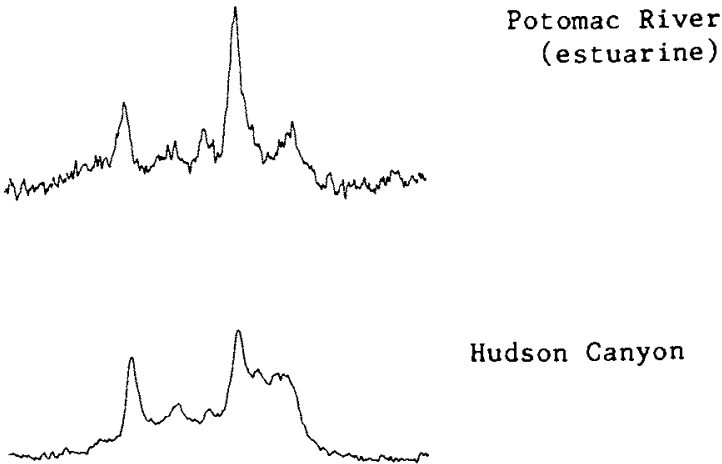

Hudson Canyon

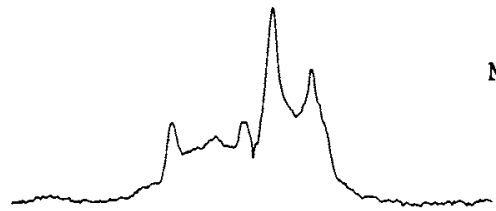

Mangrove Lake

( $3 \mathrm{~m}$ depth)

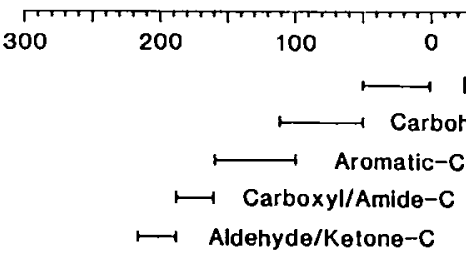

Figure 1. Representative CPMAS ${ }^{13} \mathrm{C}$ NMR spectra of fulvic acids from marine and estuarine sediments.

In Organic Marine Geochemistry; Sohn, M.; ACS Symposium Series; American Chemical Society: Washington, DC, 1986. 


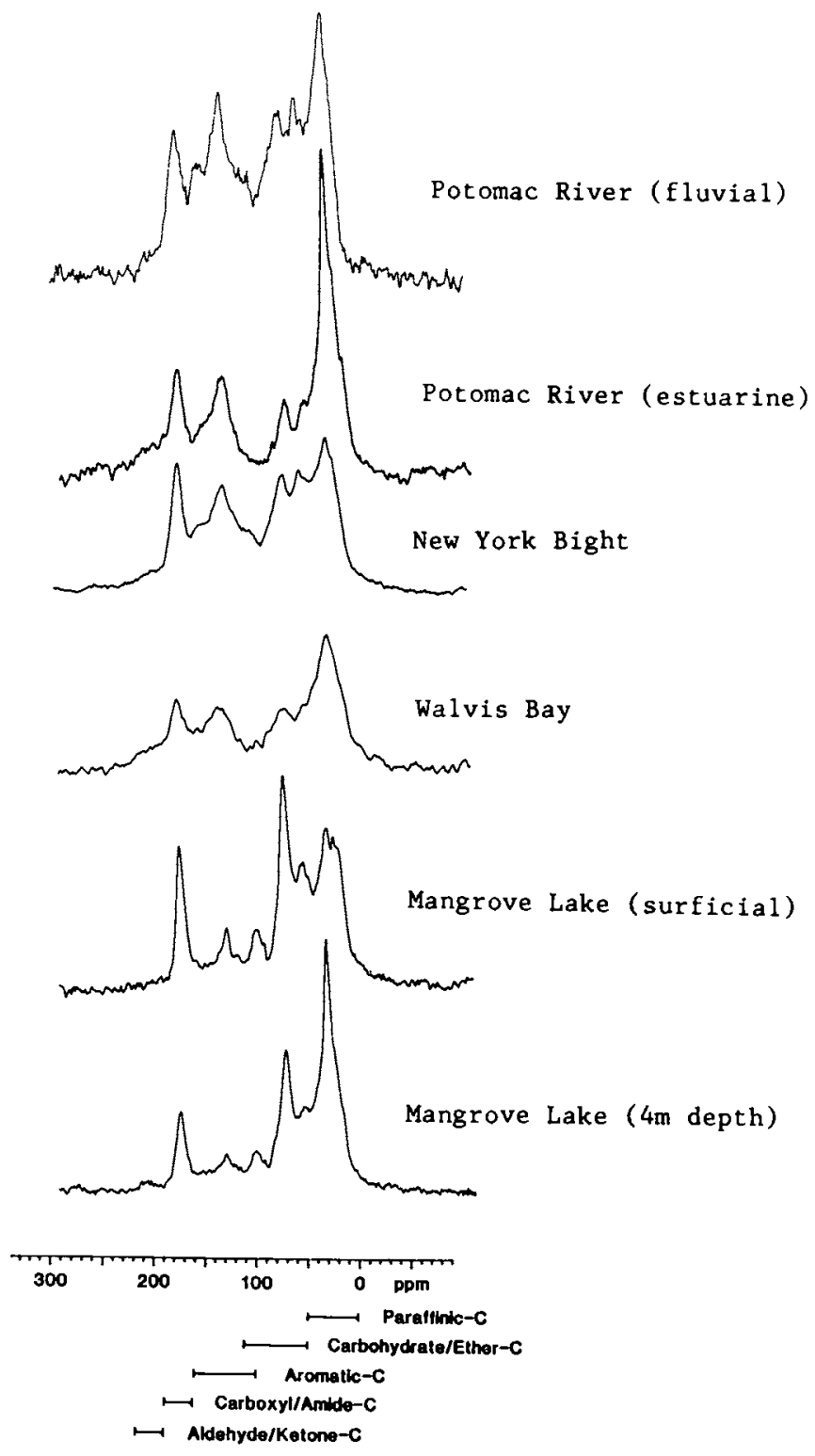

Figure 2. Representative CPMAS ${ }^{13}$ C NMR spectra of humic acid from marine and estuarine sediments.

\section{American Chemical Society Library \\ 1155 16th St., N.W. \\ In OrgarWashing fonpchondstry260136 $\mathrm{M}$;}


The spectrum of humic acid from an algal sapropel from Mangrove Lake ( $4 \mathrm{~m}$ depth) shown in Figure 2 is characteristic of 8 uch marine humic acids. Note the strong signals for paraffinic, carbohydrate/ether, and carboxyl/amide carbons at 30,72 , and 175 ppm, respectively. Carbohydrates have been shown to be present in humic acid isolates, probably existing as uronic-acid-like carbohydrates (4). The spectrum of humic acids from surficial sediments in Mangrove Lake (Figure 2) shows a greater proportion of carbohydrate signals, probably representing biological degradation products from early diagenetic reactions. Hatcher and others ( $\mathcal{Z}$ ) and Spiker and Hatcher (14) showed that early diagenesis leads to the degradation and removal of carbohydrates in Mangrove Lake saprope 1. Presumably, these degraded or partially degraded carbohydrates could become incorporated in humic acid isolates, especially if they contain carboxyl functional groups. Yields of humic acids from Mangrove Lake sediments are low (2\%); thus it is likely that carbohydrates or uronic acid-like carbohydrates, usual ly a major fraction of the total sapropel in surficial layers, are being incorporated into humic acid isolates. The carbohydrates are most likely incorporated in humic acids from Mangrove Lake because the sapropel is in its initial stages of diagenesis and, as such, still contains sizeable quantities of carbohydrates (ㄱ). At depth, where the sapropel has been diagenetically altered further, carbohydrates are minor components of humic acids, whereas the paraffinic structures, alluded to above, are dominant. Associated with the paraffinic structures are carboxyl/amide groups (175 ppm) and alcoholic/etheric groups other than carbohydrates $(70 \mathrm{ppm})$. Note a lso that a small peak is observed at about $50 \mathrm{ppm}$. Peaks in this region are usual ly assigned to methoxyl or amino groups. Because methoxyl carbons in humic acids are usually associated with aromatic structures (from lignin-like substances) and because contributions of aromatic, 1ignin-derived components are lacking in Mangrove Lake, the peak at $50 \mathrm{ppm}$ is probably that of amino groups. The elemental data which indicate approximately 4 to 5 percent nitrogen in these humic acids ( 7 ) are in accord with this assignment.

Solid-state ${ }^{13} \mathrm{C}$ NMR spectra of humic acids from other marine and estuarine sediments (Figure 2) show peaks in similar regions as those noted for the Mangrove Lake humic acids, but the relative intensities vary considerably. Most marine and estuarine humic acids contan few carbohydrate-1ike structures, as the peaks for carbohydrates at 72 and $106 \mathrm{ppm}$ are minor. This probably is because these sediments are more advanced diagenetical ly than those from Mangrove Lake. The yields of humic acids are greater than those from Mangrove Lake ( 6 ) and it is likely that less extractable carbohydrate-1ike material from undegraded plant detritus has been incorporated.

The content of aromatic carbon varies considerably in marine and estuarine humic acids, but is, in al cases, greater than that of Mangrove Lake humic acids. This is probably a reflection of the greater contribution of vascular plant-derived material which can be expected to provide lignin-like components rich in aromatic structures. Note that the humic acids from fluvial sediments of the Potomac River are the most aromatic. Peaks at 150 and $55 \mathrm{ppm}$ are characteristic of oxygen-substituted aromatic carbons typically associated with 1 ignin of vascular plants. Humic acids from New York 
Bight sediments (Figure 2) also contain considerable quantities of lignin-derived structures, as expected, because large quantities of sewage sludge and dredge spoils are being dumped at the site.

Sediments from Walvis Bay, a coastal upwelling zone off the west coast of Africa, and estuarine muds from the lower Potomac River contain humic acids that show lesser proportions of aromatic structures than those mentioned above. Their NMR spectra (Figure 2) very nearly approximate those of marine algal or microbial detritus (Mangrove Lake saprope 1). The carbohydrate signals (72 ppm) are less, however, probably reflecting the fact that a greater degree of decomposition of algal biomass has occurred in these sediments. Like humic acids from Mangrove Lake, paraffinic structures are dominant.

In summary, solid-state ${ }^{13} \mathrm{C}$ NMR spectra of humic acids from marine and estuarine sediments reveal some diagenetic structural changes. In recent $1 \mathrm{y}$ deposited and well preserved marine sediments such as those from Mangrove Lake, Bermuda, carbohydrates and paraffinic structures constitute the major structural entities. Burial or increasing degree of decomposition, leads to the diminution of carbohydrates, whereupon paraffinic structures become dominant. In marine sediments derived from algal or microbial sources, that are more exposed to decomposition, paraffinic structures predominate in humic acids. Such is the case for sediments from Walvis Bay and the lower Potomac River estuary. It is important to note that these latter sediments contain humic acids that have a predominanty algal or microbial signature even though substantial contributions of terrestrial materials are expected due to their proximity to sources of such contributions. The high algal productivity and organic rich sediment accumulation rates for the 1 ower Potomac, as we 11 as the stable isotopic compositions of the sedimentary organic matter (E.C. Spiker, personal comunication), are consistent with a finding that algal detritus is the major contributor to sedimentary carbon. Thus the NMR data for humic acids are consistent with this conclusion.

As one examines humic acids from sediments where 1 arge terrestrial or vascular plant inputs are expected, the CPMAS ${ }^{13} \mathrm{C}$ NMR spectra show higher proportions of aromatic carbons and notable peaks for 1 ignin-1ike contributions at 55 and $150 \mathrm{ppm}$. Such distinctions could possibly be used to estimate the relative contribution of vascular plant residues to the sediments.

Humin. Humin, the fraction of humic material that is insoluble in alkali, has often been referred to as kerogen, protokerogen, or stable residue in the geochemical literature(15-17). Because it exists as a residue and is admixed with inorganic components of sediments, which generally constitute the sizeable portion of the total weight, it has been necessary to concentrate the humin prior to analysis. The most common means of achieving this is by removal of mineral matter. Usual1y, the sediment residue from alkali extraction is treated with concentrated $\mathrm{HC} 1$ mixed in a $1: 1 \mathrm{v} / \mathrm{v}$ ratio with $48 \%$ aqueous HF. Carbohydrates and proteins are selectively hydrolyzed in the process, but these substances cannot strictly be called humic in nature. Their removal from the sediment allows us to examine refractory organic matter or stable residue. Of course, we must concern ourselves with the effect of such treatment on the humic 
material. Sediments from Mangrove Lake, Bermuda provide idea 1 samples for testing the effect of acid treatment because the carbon content of the whole sapropel is high enough to obtain CPMAS ${ }^{13} \mathrm{C}$ NMR direct $1 \mathrm{y}$ without concentration. Figure 3 shows the NMR spectra of algal sapropel near the sediment surface $(0.2 \mathrm{~m})$ and at depth $(2.9 \mathrm{~m})$, humin obtained after alkali extraction, and humin after HF/HCl treatment. Note that very little difference exists between spectra of the whole sapropel and the humin after alkali-extraction. Carbohydrates (peaks at 72 and $106 \mathrm{ppm}$ ) are major contributors to the sapropel in the surface intervals and diminish in concentration with depth. Hatcher and others (7) have described the diagenetic trends as being attributable to degradation and $108 \mathrm{~s}$ of carbohydrates with selective preservation of the insoluble, macromolecular paraffinic substances, which are the dominant components of humin. When treated with HF/HC 1, the humin is altered, primarily by $108 \mathrm{~s}$ of carbohydrates. Peak intensities for non-carbohydrate moieties (paraffinic structures) remain relatively unchanged, to the extent that can be detected by NMR. Thus, humin treated with HF/HC1 is primarily altered by removal of carbohydrates. This is essentially the same process that is the result of early diagenetic transformations described above (7). Because carbohydrates cannot be considered "humic" in nature ( $\underline{18})$, the $\mathrm{HF} / \mathrm{HC} 1$ removal of carbohydrates is useful in al lowing intercomparisons among the various humic fractions of sediment 8 .

Solid-state ${ }^{13} \mathrm{C}$ NMR spectra of humin, isolated by the HF/HC1 treatment, from various representative marine and estuarine sediments are shown in Figure 4. Humin from Mangrove Lake was described as being essentially composed of parafinic structures ( $30 \mathrm{ppm}$ ) containing carboxyl/amide (175 ppm) and etheric carbon (70 ppm) functional groups ( 7 ). The low aromaticity $(7 \%)$ is typical of humin from algal and microbial sources. The peak at $70 \mathrm{ppm}$ can be attributed to ether or alcohol-like structures because the compounds that are usually characteristic of this resonance, the carbohydrates, have most 1 ikely been removed by the acid treatment. Spectra of humin from other samples examined here also show an intense peak at $30 \mathrm{ppm}$ for paraffinic structures, but the relative proportion of aromatic carbon (130 ppm) increases significant ly in some samples. Those having strong contributions from algal/microbial sources, namely sediments from Walvis Bay and the Hudson Canyon, show a greater proportion of parafinic structures. The increased amounts of aromatic carbons when compared to humin from Mangrove Lake probably reflects increased contributions from vascular plants.

Humin isolates from sediments of the New York Bight and Potomac River estuary have spectra that are notably different in that aromatic carbons are the dominant components. The spectra resemble that of humin isolated in the same manner from an aerobic soil from southern Georgia (Figure 5). However, unlike the humin from soil which shows a significant peak for carboxyl carbon (175 ppm), spectra of humin from the New York Bight and the Potomac River do not display a discreet peak at $175 \mathrm{ppm}$ and appear to be depleted of carboxy $1 /$ amide groups. Elemental data for these humins (19) are consistent with the NMR results. Atomic H/C ratios of 1 ess than 0.8 are not typical of humic material but more like those of highly aromatic coal or coal-1ike products. The NMR spectra also resemble 


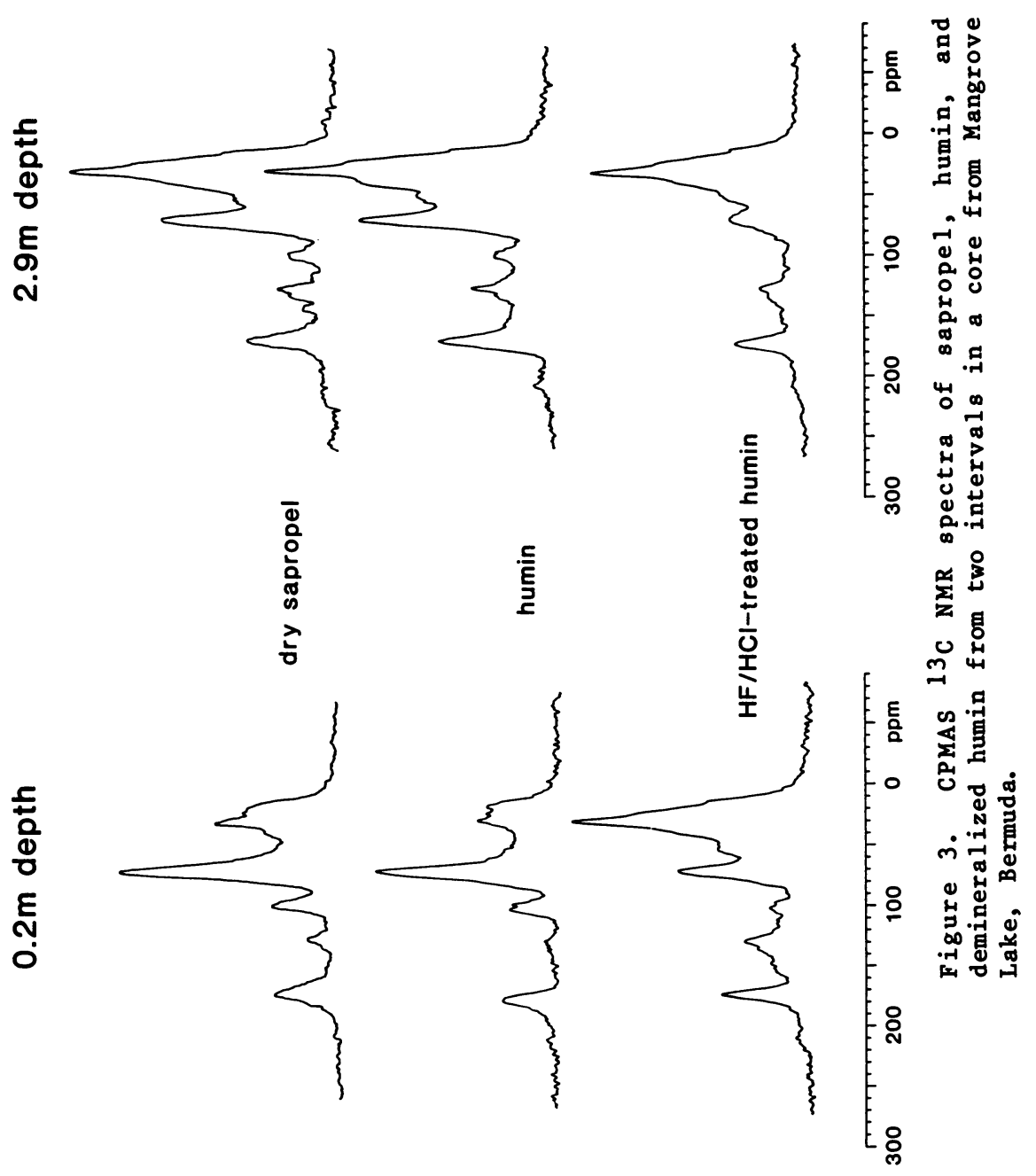

In Organic Marine Geochemistry; Sohn, M.; ACS Symposium Series; American Chemical Society: Washington, DC, 1986. 

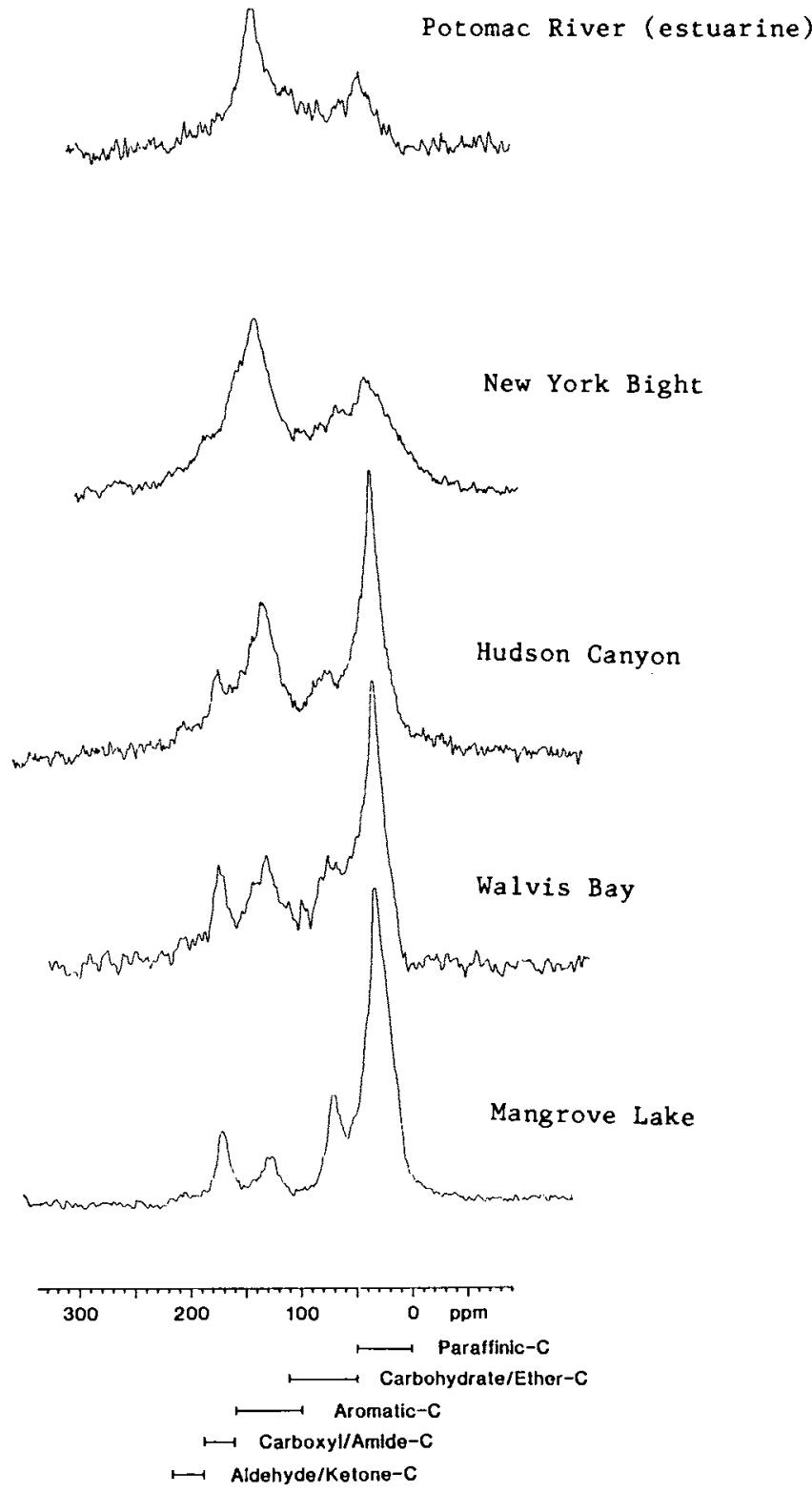

Figure 4. Representative CPMAS ${ }^{13} \mathrm{C}$ NMR spectra of demineralized humin from marine and estuarine sediments.

In Organic Marine Geochemistry; Sohn, M.; ACS Symposium Series; American Chemical Society: Washington, DC, 1986. 


\section{humin- $\mathrm{HF} / \mathrm{HCl}$}

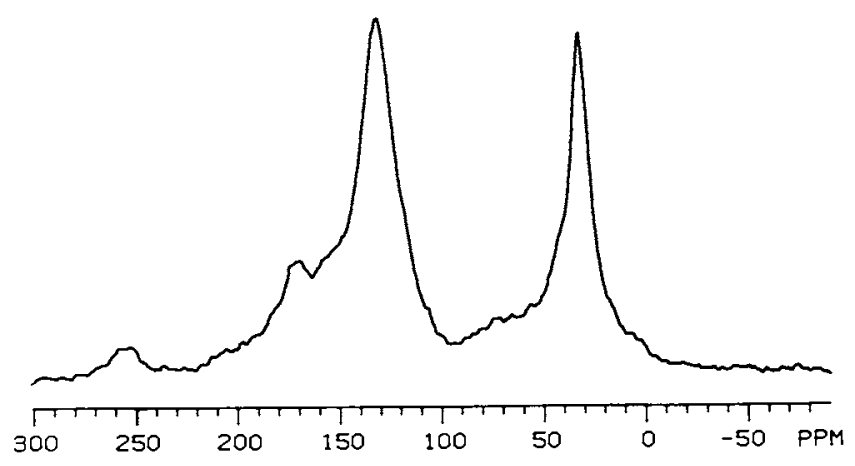

Figure 5. CPMAS ${ }^{13} \mathrm{C}$ NMR spectrum of demineralized humin from the Georgia soil.

In Organic Marine Geochemistry; Sohn, M.; ACS Symposium Series; American Chemical Society: Washington, DC, 1986. 
those of coal, with 1 ittle or no carboxyl peaks and broad, unresolved peaks for mostly aromatic carbons $(\underline{20})$. The presence of coal and coal-1ike materials in estuarine sediments is not unexpected. The presence of coal has been noted in sediments of the Chesapeake Bay (21). Storm runoff and sewage from New York City, which are both collected and dumped in the New York Bight, are also likely to contain coal-derived substances. Certainly, dredge spoils from the Hudson-Raritan estuary, which are also dumped in the New York Bight, are likely to contain coal-like substances as well.

The possibility exists that carboxyl functional groups and the chemical composition of the humin from the two samples in question have been affected by the HF/HCl treatment. Decarboxylation and hydrolysis of proteinaceous substances by strong acid treatment is possible and cyclization of carbohydrates, if present, to form aromatic groups could also take place. This seems unlikely, considering that a similar treatment of Mangrove Lake saprope1, that is rich in carbohydrates and carboxyl functional groups, did not produce such components. We believe that the highly aromatic structures are indigenous and possibly indicative of contributions of coa 1-1ike material. Based on the relatively low yield of humin in these two sediments, the contribution of coal-1ike material may be relatively minor.

\section{Discussion}

The solid-state ${ }^{13} \mathrm{C}$ NMR spectra of humin from algal or microbially derived sediments are similar to those of corresponding humic acids. Aside from the presence of carbohydrates in humic acids from the Mangrove Lake saprope1, the spectra of humins are almost identical to those of humic acids, suggesting a close structural relationship and possibly a close genetic relationship. Humic acids generally contain more oxygen in their elemental analysis (6) and we would suspect that this would be refelected in the presence of more carboxyl, ether/alcohol, and carbonyl groups. In comparing spectra of humlc acids and humin from Walvis Bay sediments, the incressed contents of such functional groups in humic acids are subtle but noticeable as mostly increased relative intensities at 175 and $190 \mathrm{ppm}$. Because of the close structural similarities, we believe that humic acids are structural equivalents of humin that have been oxidized, resulting in the introduction of oxygen-functional groups (i.e. carboxyl groups). The increased oxygen functionality allows these structures to be more readily extracted by dilute base. When acidified, the carboxyl groups are protonated, thereby reducing solubility such that the oxidized remains precipitate as humic acids. In estuarine and coastal sediments strong structural relationships between humic acids and humin are not observed (see Figures 2 and 4 ). This is most likely attributable to the fact that highly refractory, coal-1ike components dominate the humin residue. These refractory materials probably do not produce humic acids as readily as modern plant remains upon oxidation. However, modern plant-derived materials within the sediment, whose detection by NMR may be masked by the broad peaks of coal-like substances, are probably responsible for the 
production of humic acids. Thus, the humic acids in these sediments have structural features that are 1 ike those expected from modern source materials but the humin is probably not representative of source materials derived from modern carbon.

\section{CONCLUSIONS}

Solid-state ${ }^{13} \mathrm{C}$ NMR provides a visual presentation of the chemical structural composition of humic isolates that allows for direct structural intercomparisons among fulvic acids, humic acids, and the insoluble humin in marine and estuarine sediments. Though the structural detail provided by this technique is no more than a "broad brush" examination, such an approach is useful from the standpoint that gross structural interrelationships can provide clues to the origin of humic substances. Previous studies involving the use of solid-state ${ }^{13} \mathrm{C}$ NMR in combination with other organic geochemical and stable isotopic analyses have led to the suggestion that insoluble macromolecular humin is an original component of algal/microbial biomass in marine sediments and that this material, rich in parafinic structures, is selectively preserved during early diagenesis ( 7 ). Early diagenesis basically involves degradation and loss of microbially labile substances such as carbohydrates, proteins, and lipids. With this frame of reference we examined structural features of marine and estuarine humic substances by CPMAS ${ }^{13} \mathrm{C}$ NMR and conclude the following:

1. Fulvic acids, the most soluble humic fraction, are predominantly polysaccharides in all marine and estuarine sediments examined. Uronic acid-like polysaccharides are the most likely entities. Fulvic acids may be the degradation products that evolve during diagenetic alteration of sedimentary plant residues. We envision that microbial degradation renders plant polysaccharides soluble, entraining them into a fulvic acid fraction by definition. Ultimately, this material is degraded further to $\mathrm{CO}_{2}, \mathrm{CH}_{4}$, and other low molecular weight organic compounds.

2. Humic acids of marine and estuarine sediments are characterized by major amounts of paraffinic structures that previous studies have shown to be highly branched and to contain significant quantities of carboxyl/amide and alcohol/ether carbon. Some humic acids, namely those from well preserved sapropelic marine sediments show significant quantities of carbohydrate-like structures incorporated. This, no doubt, is a reflection of the solubility characteristics of polysaccharides which may have some carboxyl functionalities (uronic acid groups).

3. Humin varies widely in composition. Sediments derived from algal/microbial biomass have humin with paraffinic structures resembling those of corresponding humic acids. Estuarine or coastal marine sediments examined in this study have humin with highly aromatic structures which resemble coal-1ike materials rather than modern $p$ lant residues. In these latter sediments no structural correspondence exists between humin and humic acids which appear to more nearly reflect the nature of modern plant 
residues being incorporated in sedimentary organic matter. Consequent $1 y$, a certain amount of caution must be exercized when using aromaticity and possibly other structural characteristics as source discriminants.

4. Finally, the structural interrelationships among humic fractions in marine and estuarine sediments suggest that the pathway for humification is one of degradation rather than condensation as proposed by others (15, 22). Insoluble humin, an original component of sedimentary detritus, is degraded to smaller molecules which become extractable and thereby classed as humic acids. Fulvic acids are ultimately formed by intense degradation; but degradation products of 1 abile macromolecules of sedimentary detritus such as carbohydrates also become incorporated and, in fact, dominate the fulvic acid fraction.

\section{LITERATURE CITED}

1. Vila, F.J.G.; Lentz, H.; Ludemann, H.D. Biochem. Biophys. Res. Commun. 1976, 72, $1063-9$.

2. Stuermer, D.H.; Payne, J.R. Geochim. Cosmochim. Acta, 1976, 40, 1109-14.

3. Wilson, M.A.; Goh, K.H. J. Soil Sci., 1977, 28, 645-52.

4. Hatcher, P.G.; Rowan, R.; Mattingly, M.A. Org. Geochem. $1980,2,77-85$.

5. Hatcher, P.G.; VanderHart, D.L.; Ear 1, W.L. Org. Geochem., $1980,2,87-92$.

6. Hatcher, P.G.; Breger, I.A.; Dennis, L.W.; Macie1, G.E. In "Aquatic and Terrestrial Humic Materials", Christman, R.F.; Gjessing, E.T.; Eds.; Ann Arbor Science: Michigan, 1983; Chap. 3 .

7. Hatcher, P.G.; Spiker, E.S.; Szeverenyi, N.M.; Macie1, G.E. Nature $1983,305,498-501$.

8. Hatcher, P.G.; Breger, I.A.; Maciel, G.E.; Szeverenyi, N.M. In "Humic Substances in Soil, Sediment, and Water"; Aiken, G.; Mcknight, D.; Wershaw, R.; MacCarthy, P. Eds., JohnWiley: New York, 1985 ; Chap. 11.

9. Wilson, M.A.; Pugmire, R.J.; Zilm, K.M.; Goh, K.M.; Heng, S.; Grant, D.M. Nature $1981,294,648-50$.

10. Wilson, M.A.; Pugmire, R.J.; Grant, D.M. 0rg. Geochem. 1983, $5,121-9$.

11. Preston, C.M.; Ripmeester, J.A. Can. J. Spectrosc. 1982, 27 , 99-105.

12. Hatcher, P.G.; Breger, I.A.; Matting 1y, M.A. Nature 1980, 285, 560-2.

13. Dereppe, J.M.; Moreaux, C.; Debyser, Y. Org. Geochem. 1980 , $2,117-124$.

14. Spiker, E.C.; Hatcher, P.G. Org. Geochem. 1984, 5, 283-90.

15. Huc, A.Y.; Durand, B. Fue $11977,56,73-80$.

16. Stuermer, D.H.; Kap 1 an, I.R.; Peters, R.E. Geochim. Cosmochim. Acta 1978, 42, 989-97.

17. Pelet, R. In Advances in Organic Geochemistry, 1981, Bjoroy, M., Ed., John Wiley: New York, 1983; Pp.241-250. 
18. Stevenson, F.J. Humus Chemistry, Genesis, Composition, Reactions, John Wiley: New York, 1982, Chap. 2.

19. Hatcher, P.G. Ph.D. Dissertation, The University of Maryland, 1980.

20. Miknis, F.P; Sul1 ivan, M.; Bartuska, V.J.; Macie1, G.E. Org. Geochem. 1981, 3, 19-28.

21. Goldberg, E.D.; Hodge, V.; Koide, M.; Griffin, J.; Gamble, E.; Bricker,O.P.; Matisoff, G.; Holdren, G.R. Jr.; Braun, R. Geochim, Cosmochim. Acta 1978, 42, 1413-25.

22. Nissenbaum, A.; Kaplan, I.R. Limno1. Oceanogr. 1972, 17, 570-2.

RECEIVED September 23, 1985

In Organic Marine Geochemistry; Sohn, M.; 


\title{
Early Diagenesis of Organic Carbon in Sediments from the Peruvian Upwelling Zone
}

\author{
W. T. Cooper, A. S. Heiman, and R. R. Yates
}

Department of Chemistry, Florida State University, Tallahassee, FL 32306-3006

\begin{abstract}
The diagenesis of organic matter in recent sediments from the Peruvian Upwelling Zone has been studied by solid state ${ }^{1{ }^{3} \mathrm{C}} \mathrm{NMR}$ spectroscopy of the intact sedimentary organic carbon and by conventional GC and GCMS analyses of sterol biomarkers in lipid extracts of the sediments. The distribution of sterols in surficlal sediments from two sites on the continental margin indicate that the distinction between marine and terrestrial sources of organic carbon in aquatic sediments is not as well defined as previously thought. Both sites exhibit large relative abundances of twentyeight $(\mathrm{C}-28)$ and thirty (C-30) carbon atom sterols, suggesting a marine source. The $\mathrm{C}-27$ and $\mathrm{C}-29$ abundances do not reflect this expected marine source, however, confirming recent observations that sterol distribution patterns in nature are extremely complex. Magic angle spinning ${ }^{13} \mathrm{C}$ NMR spectra with variable cross polarization contact times were obtained on the intact, non-extracted sediments. The time-dependent spectra reveal subtle differences in organic carbon with depth; differences not observed in single contact experiments. Dipolar-dephased spectra of these same sediments indicate the presence of substantial amounts of substituted aromatic/olefinic carbons which are rapidly altered with depth.
\end{abstract}

The transformations of organic matter in young, recently deposited aquatic sediments play a unique role in the biogeochemical cycle of organic carbon. During sedimentation and residence in the upper sediment horizons, organic matter is subject to a number of chemical, blological and physical processes which alter it in various ways. While the nature and extent of these transformations depend on both the type and amount of organic material and the depositional environment at the time of burial, it is clear that the composition of sedimentary organic matter is significantly altered, and its fate during subsequent geochemical/geophysical evolution is largely dependent on these initial transformations.

$0097-6156 / 86 / 0305-0158 \$ 06.00 / 0$

(c) 1986 American Chemical Society 
The process by which biopolymers, the remnants of living organisms buried in sediments, are degraded and rearranged into insoluble geopolymers is usually referred to as diagenesis. One theory (1) holds that diagenesis includes microbial degradation of blological macromolecules into smaller components; condensation of these small, highly functionalized compounds into geopolymers such as humic acids, fulvic acids and less functionalized humin residues; and insolubilization of these condensed structures via elimination of hydrophilic functional groups to form insoluble kerogen. While other scenarios have been proposed for the formation of kerogen (2), it is generally considered the main source of petroleum and is the primary organic material found in ancient sediments.

Degradation occurs rapidly in the overall evolution of organic matter; usually in the first 1-10 m interval of a sediment. Inso1ubilization is much slower, normally occurring in the 10-100 $\mathrm{m}$ range. At this point, temperature and pressure become important, and the second phase of the evolution of organic matter commences; catagenesis, thermal alteration and the resulting formation of oil and gas.

In this paper we present the inftial results of studies of early diagenesis of organic carbon in the upper horizons $(0-30 \mathrm{~cm})$ of marine sediments. Studies of this sort are complicated by the inherent complexity of sedimentary carbon and the presence of large geopolymers. These geopolymers are in general insoluble and extractable only by extreme treatments (3). These treatments are such that there is real doubt about whether the extract is truly representative of the organic material as it exists in the sedimentary environment (4).

Our approach is significantly different. We have attempted to obtain information we feel is representative of the in-situ character of sedimentary organic matter. This approach has involved two distinct phases of sediment evaluation:

-analysis of biomarkers, or geochemical fossils, in the lipid fraction of the sedimentary organic matter, and

-solid state NMR studies of intact sediments, where the organic fraction is viewed in-situ.

\section{Lipid Biomarkers}

Lipids incorporated into aquatic sediments behave somewhat different1y than most other forms of organic debris. By lipid, we are using the geochemist's definition; those compounds extractable with organic solvents. Containing less functional groups and thus more hydrophobic, lipids generally are much less reactive and persist in discrete chemical forms longer than proteins, polysaccharides, etc.. Indeed, a number of different lipid molecules of known blological origin are routinely found in petroleum, coal and ancient sediments. Molecules which persist in sediments over geologic time spans in an unaltered or slightly altered state and which can be attributed directly or indirectly to living organisms are frequently referred to as "biomarkers", "molecular fossils", or "geochemical fossils".

A number of geochemical fossils have been identified and their presence in sedimentary organic matter utilized for various 
geochemical purposes (5). These include: n-alkanes, 2-methy1 (iso) and 3-methy1 (anteiso) branched alkanes; n-alkanolc acids; acyclic isoprenoid-type molecules; steroids; and a varlety of cyclic triterpenoids.

One of the most valuable groups of geochemical fossils is the steroida1 alcohols, or sterols. Regulators of metabolic processes and major components of eucaryotic cell membranes, sterol structures appear to be strongly related to the organisms that produce them. Marine organisms produce primarily twenty-seven carbon atom sterols (C-27) (6-8), while terrestrial plants produce primarily twenty-nine carbon atom stero1s (C-29) (9). This specificity has been used by a number of investigators to characterize the ecological history of water columns. Gaske11 and Eglinton (10), for example, attributed variations in the $\mathrm{C}-27 / \mathrm{C}-29$ ratio with depth in a recent lacustrine sediment to a change in the lipid source of the organic carbon in the sediment.

In addition to this source specificity, sterols undergo a variety of reactions which are of particular value in studies of early diagenesis. These reactions are not only indicative of the sedimentary environment, but also result in products which are similar enough to precursor molecules to be easily related to them. One of the most intensely investigated reactions has been the hydrogenation which converts $\Delta^{5}, \Delta^{7}$ and $\Delta^{24}$ unsaturated sterols (stenols) into their saturated analogues (stanols) (11-13). Other reactions identified include bacterial dealkylation of the sterol side chain (14), and aromatization to form phenanthrene homologues (15). Sedimentary reactions of sterols which have been identified or suggested are summarized in Figure 1.

\section{NMR Studies of Sedimentary Organic Matter}

Recent developments in ${ }^{13} \mathrm{C}$ nuclear magnetic resonance spectroscopy have made it possible to probe the chemical environment of carbon atoms in rigid and semi-rigid systems. Using the techniques of cross polarization (CP) (16) and magic angle spinning (MAS) (17), the primary obstacles to obtaining NMR spectra of solids with reasonable line widths (chemical shift anisotropy, anisotropic dipoledipole interactions (dipole coupling), and long spin-lattice relaxation times) can now be circumvented. Since its introduction by Schaefer and Stejskal (17), the ${ }^{1{ }^{3} \mathrm{C}} \mathrm{NMR}$ technique combining cross polarization and magic angle spinning (CP-MAS-NMR) has been applied to a wide variety of insoluble organic complexes such as fossil fuels, polymers, coal, kerogen and humic/fulvic acids (18). These applications represent what Maciel (18) describes as the "first generation" of NMR solids applications.

It is the "second generation" of solid state techniques, in which the onset of relaxation of magnetization is observed in the time domain, which offer promise for the detailed, in-situ investigation of early diagenetic processes. For example, Hagaman and Woody (19) showed that the time dependence of cross polarization could be used to improve the resolution of complex spectra of coal, since different carbon types cross polarize at different rates. Wilson (20-21) has used dipolar dephasing to distinguish carbon types in soils and resins based on relaxation rates.

We have used both time dependent cross polarization and dipolar 
dephasing techniques to view carbon atoms in recent marine sediments. Variations in cross polarization contact times have been used to improve the resolution of adjacent resonances which would otherwise overlap. Dipolar dephasing experiments were employed to distinguish protonated and nonprotonated carbon atoms, particularly in the aromatic region.

\section{Experimenta1}

Sampling. Sediment samples from the coast of Peru were collected during Cruise 23-06 of the R/V Robert Conrad, June - July, 1982. Sampling locations are indicated in Figure 2. A specially designed box corer (22) was used in order to obtain undisturbed surface sediments $(<50 \mathrm{~cm}$ depth). Subcores were taken on board, sectioned over $2 \mathrm{~cm}$ intervals, and each subsection immediately frozen. The frozen samples were packaged in dry ice and shipped to the FSU chemistry department, where they were stored in a $-10^{\circ} \mathrm{C}$ freezer until analyzed.

Sediments from two locations have been analyzed for this study. These are sites $\mathrm{BX}-3$ and $\mathrm{BX}-6$ of Figure 2. Important characteristics of these sites are listed in Table $I$.

Table I. Characteristics of Surficial Sediments, Peruvian Coast

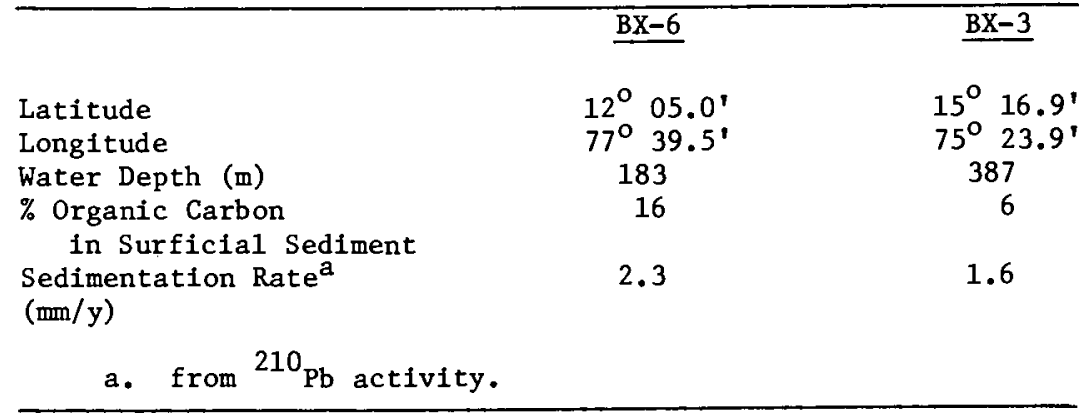

Sterol Analyses. The overall analytical procedure for each $2 \mathrm{~cm}$ subcore section is schematically represented in Figure 3. After homogenization and 1yophilization, approximately $1 \mathrm{~g}$ of each sediment was mixed with $37.5 \mathrm{ml}$ of chloroform, $75 \mathrm{ml}$ of methanol and $30 \mathrm{~m} 1$ of a buffered aqueous solution $(\mathrm{pH}=7)$. The sediment-solvent slurry was then sonicated for 3-5 minutes and the extract decanted to a separatory funnel. Seventy five $\mathrm{m} 1$ of water was then added to the funnel, resulting in separate aqueous and organic phases. The chloroform layer was then removed and the aqueous phase washed five times with chloroform. The chloroform fractions were then combined and the volume reduced to $10 \mathrm{ml}$ under nitrogen at $37^{\circ} \mathrm{C}$. The entire extraction was repeated until the chloroform phase was visually colorless (6-9 extractions).

Extracted lipids were then separated into neutral, glyco-, and phospholipid fractions by silica gel column chromatography. Neutral lipids were eluted with $10 \mathrm{~m} 1$ of chloroform per $\mathrm{g}$ of silica gel. Glycolipids were eluted with $20 \mathrm{ml} / \mathrm{g}$ of acetone, followed by phospholipids with $20 \mathrm{ml} / \mathrm{g}$ of methanol. The neutral lipid fraction 


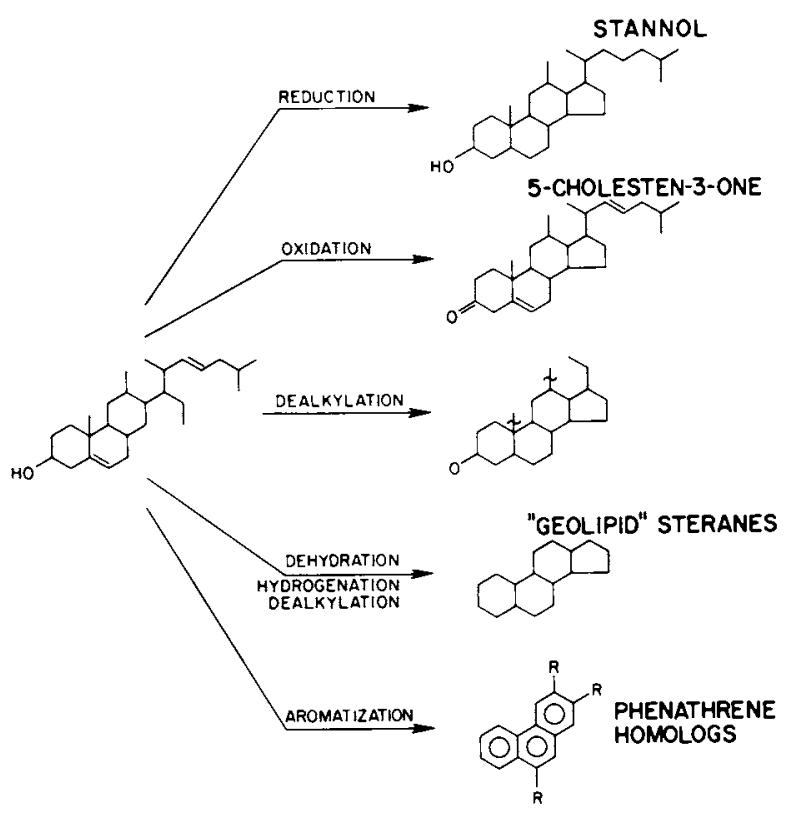

Figure 1. Sedimentary reactions of sterols.

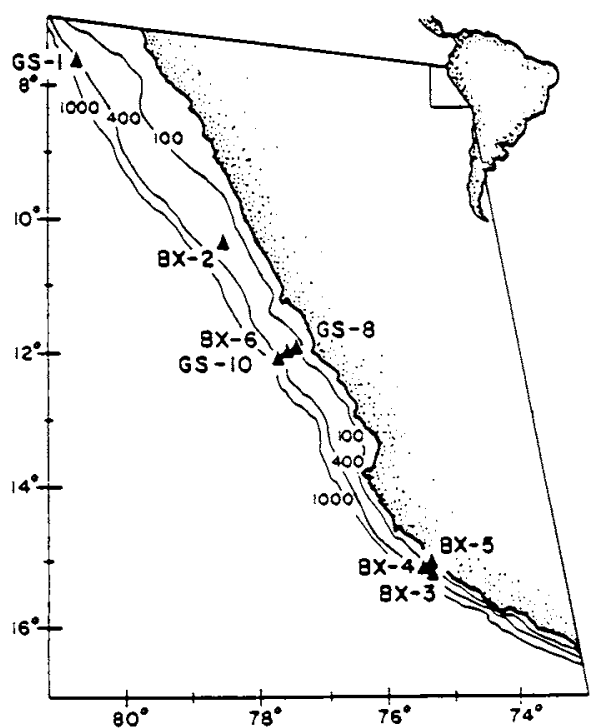

Figure 2. Cruise track of R/V Conrad, June - July, 1982. Samples for this study obtained from sites labelled BX-6 and BX-3.

In Organic Marine Geochemistry; Sohn, M.;

ACS Symposium Series; American Chemical Society: Washington, DC, 1986. 
was then concentrated and fractionated by TLC into n-alkane, sterane, sterol, sterone and fatty ac1d subfractions using a 55/45 hexane/ chloroform solvent. The sterol fraction was further purifled by TLC with 45/55 hexane/chloroform. The sterol spot was scraped from the plate and sterols were extracted with hexane/chloroform.

After concentration under nitrogen at $37^{\circ} \mathrm{C}$, sterols were derlvatized to silyl ethers with BSTFA (Plerce Chemical Co.). The derivatized sterols were then diluted to a known volume in chloroform containing 100 picomoles of hexadecane, cholestane, cholestanol, cholesterol, stigmasterol and sitosterol as internal standards. The mixture was then analyzed with a Hewlett-Packard 5880A GC equipped with a flame lonization detector. Separations were achleved with a Hewlett-Packard 50m x .322 ID crosslinked methyl silicone fused silica capillary column. The column temperature was held inftially at $50{ }^{\circ} \mathrm{C}$ for $1 \mathrm{~min}$, programed at $10^{\circ} \mathrm{C} / \mathrm{min}$ to $160^{\circ} \mathrm{C}$, then $4{ }^{\circ} \mathrm{C} / \mathrm{mln}$ to a final temperature of $300^{\circ} \mathrm{C}$. Samples were injected via the splitless method $(\underline{23})$ with the injector at $375^{\circ} \mathrm{C}$. The spiltter was turned on at $30 \mathrm{sec}$. The FID was held at $350^{\circ} \mathrm{C}$.

Sterol identifications were made by comparing relative retention times of unknowns with those of authentic standards obtained from Applied Sclence Labs, Inc. and Suppelco, Inc. Identifications were conflrmed by gas chromatography/mass spectrometry using a Hewlett-Packard 5890 GC/MS.

NMR Experiments. Cross polarization/magic angle ${ }^{1}{ }^{3} \mathrm{C}-\mathrm{NMR}$ spectra were obtalned with a Bruker WP-200SY spectrometer equipped with an IBM solids control accessory, operating at $50.325 \mathrm{MHz}$ for carbon and externally tuned with t-butylbenzene. Samples were spun (a1r driven) at the maglc angle at $3 \mathrm{KHz}$.

A vartety of pulse sequence programs were employed. A conventional cross polarization, single contact program was used to obtain spectra of intact sediments. Contact times were varied from 200-3000 $\mathrm{sec}$ with a three sec recycle time. For dephasing delay experiments, a $50 \mu \mathrm{sec}$ delay was inserted prior to data collection. This delay consisted of two $25 \mu \mathrm{sec}$ intervals separated by a $10 \mu \mathrm{sec}$, $180^{\circ}$ refocusing pulse. Data was collected in $2 \mathrm{~K}$ of memory, exponentially multiplied with $50 \mathrm{~Hz}$ of line broadenting, and expanded to $8 \mathrm{~K}$ prior to Fourier transformation. All spectra are the result of 5000 accumulations.

\section{Results and Discussion}

Sterols. Distributions of free sterols in the surficlal sediments $(0-2 \mathrm{~cm})$ at both sampling stations are displayed as a function of carbon number in Figure 4 . $\mathrm{BX}-6$ sediments exhibit a total $\mathrm{C}-27 / \mathrm{C}-29$ ratio greater than unity as expected, since this is an indication of a marine source of organic carbon in sediments. The ratio of C-27/C-29 sterols in the BX-3 sediments, however, is indicative of significant terrestrial input, in spite of the fact that BX-3 sediments are at greater depth. This situation has been observed by other workers (24). However, it has also been noted that certain marlne organisms produce $\mathrm{C}-29$ sterols $(25)$. These and other results suggest that use of sterol compositions to determine biological sources of organic carbon in aquatic sediments may not be completely 


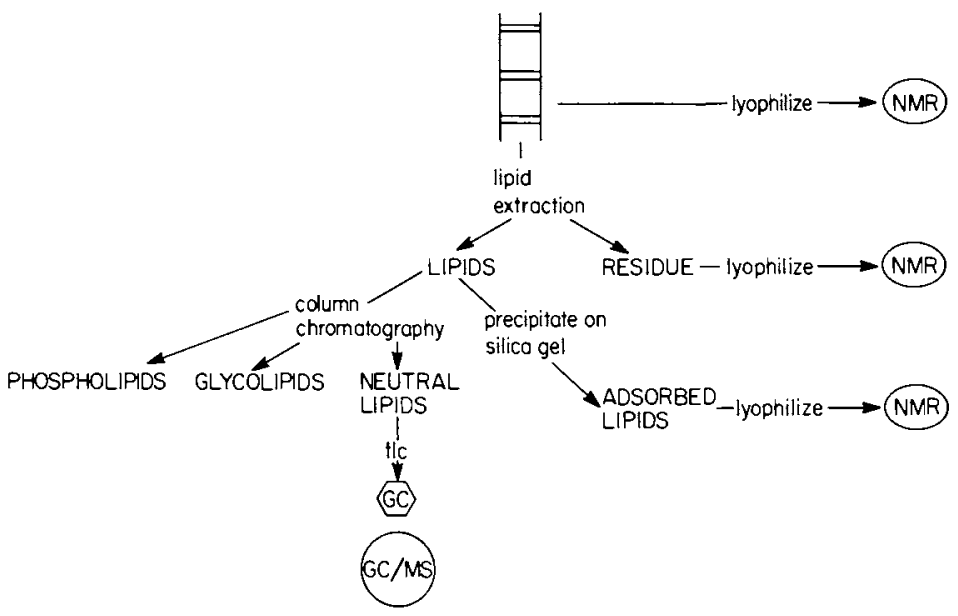

Figure 3. General analytical scheme for analysis of sediment Ilpids by extraction and GC/MS, and intact organic carbon by solid state NMR.

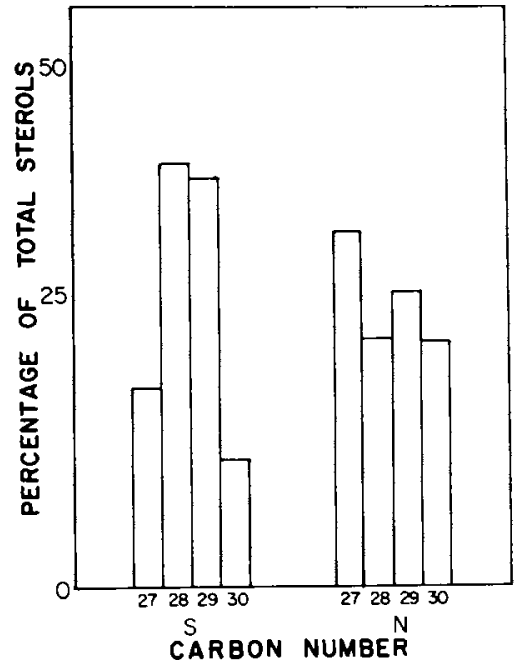

Figure 4. Histogram depicting relative proportions of sedimentary sterols by carbon number. S refers to $B X-3, N$ refers to $\mathrm{BX}-6$.

In Organic Marine Geochemistry; Sohn, M.; ACS Symposium Series; American Chemical Society: Washington, DC, 1986. 
valid. Huang and Meinschein (9), for example, maintain that the relative abundance of $\mathrm{C}-27, \mathrm{C}-\overline{28}$ and $\mathrm{C}-29$ sterols can be used to determine the proportions of terrigenous and autochthonous organic materials in marine and lascustrine sediments, since $\mathrm{C}-27$ and $\mathrm{C}-28$ sterols are most abundant in plankton and marine invertebrates (marine source) whereas $\mathrm{C}-29$ and $\mathrm{C}-27$ sterols are more prominent in higher plants and animals (terrigenous source).

Also noteworthy in Figure 4 are the large relative abundances of $\mathrm{C}-28$ and $\mathrm{C}-30$ sterols at both sites. The $\mathrm{C}-28$ sterols are most commonly associated with marine diatoms and bacterla $(\underline{26}, \underline{27})$. The C-28 abundance is not surprising, since the Peruvian coast is known to contain large amounts of diatoms. The $\mathrm{C}-30$ abundance is due primarily to dinosterol, a 4-methyl sterol characteristic of dinoflagellate input (28). de Leeuw et al. (29) also observed large relative abundances of 4-methyl sterols in a Black Sea surface sediment and concluded that free, living dinoflagellates were the major contributors of organic matter to this sediment. The overall sterol pattern observed by de Leeuw was quite different from that observed by Lee et al. $(30)$ in a similar Black sea sediment, however, indicating that the nature of phytoplankton living in the water column varies at different geographical sites and these variations are reflected in the organic matter contained in the underlying sediments.

Active blological reworking of organic carbon at the sedimentwater interface is also supported by the data of Figure 5a. The most obvious feature of Figure 5 is the pronounced reduction in monounsaturated sterols (stenols) and diunsaturated sterols (stenol-dienes) below the upper $(0-2 \mathrm{~cm}$ ) horizon. This rapid depletion is probably due to biodegradation. It also appears that stenols are decreasing more rapidly with depth than saturated sterols (stanols); that is, there is not a corresponding increase in stanols associated with the decrease in stenols. This suggests that not only simple biogenic hydrogenation reactions are occurring, but also reactions which alter the basic hydrocarbon skeleton possibly microbially mediated dealkylations.

NMR Studies of Intact Sediments. Figure 6 contains spectra of intact $\mathrm{BX}-6$ core material from three separate core depths. The sedimentation rates listed in Table I indicate that this interval represents approximately 100 years of sedimentary history. While the spectra contain interesting features, such as the sharpening of certain resonances in the carboxyl region $(165-180 \mathrm{ppm})$ and the loss of some resonances in the aromatic region (135 - $160 \mathrm{ppm})$ with depth, it is difficult to draw definitive conclusions regarding subtle diagenetic changes. These data are valuable, however, in the gross characterization of sedimentary organic matter. Table II contains the relative areas of peaks from selected regions of the spectra. Within the experimental uncertainty of such an analysis (approximately 10\%), there appears to be little or no change in the gross composition of organic matter with depth at either site. One interesting result in the data of Table II is the suggestion that surficial sediments from BX-3 contain less methy 1 and methylene carbon than the corresponding sediments from BX-6. This is in contrast to the data of Figure 4 , in which $\mathrm{C}-29$ sterols are relatively 

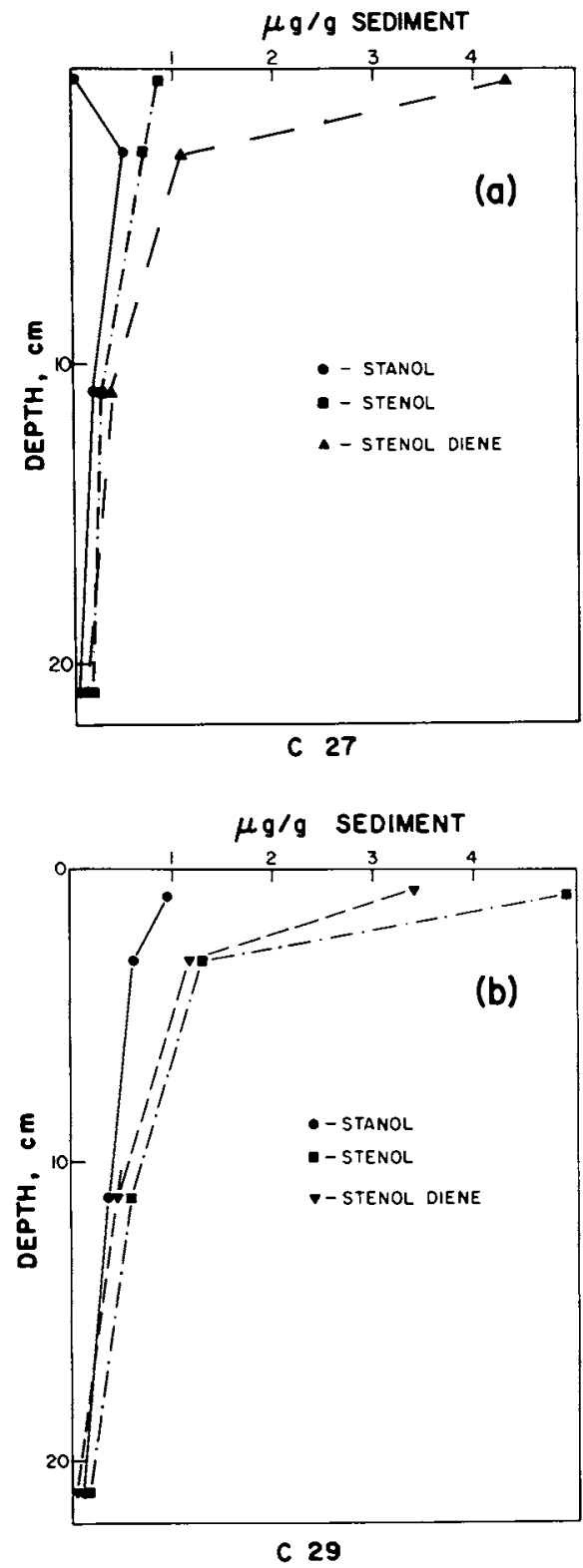

Figure 5. (a) P1ot of total $\mathrm{C}-27$ stenol and stanol concentrations with sediment depth, BX-3. (b) Plot of total C-29 stenol and stanol concentrations with sediment depth, BX-3.

In Organic Marine Geochemistry; Sohn, M.; ACS Symposium Series; American Chemical Society: Washington, DC, 1986. 
more pronounced in $B X-3$ surficial sediments than in $B X-6$. This further suggests that extractable lipids may not always be representative of the total organic carbon in sediments.

Table II. Intensities of Resonances from Selected Spectra1 Regions with Core Depth, Intact Sediments.

\begin{tabular}{|c|c|c|c|c|c|c|c|}
\hline \multirow{3}{*}{$\begin{array}{l}\text { Chemical } \\
\text { Shift (ppm) }\end{array}$} & & \multicolumn{6}{|c|}{ Relative Integrated Peak Areas \% } \\
\hline & & & $\overline{B X}-6$ & & & $\mathrm{BX}-3$ & \\
\hline & Depth $(\mathrm{cm})$ & $\overline{0-2}$ & $10-12$ & $20-22$ & $0-2$ & $10-12$ & $20-22$ \\
\hline $0-50$ & & 45 & 49 & 41 & 38 & 40 & 42 \\
\hline $60-90$ & & 16 & 13 & 13 & 13 & 14 & 12 \\
\hline $120-150$ & & 8 & 10 & 13 & 13 & 16 & 14 \\
\hline $165-190$ & & 6 & 4 & 7 & 5 & 6 & $\underline{3}$ \\
\hline
\end{tabular}

More definitive conclusions about subtle changes with depth can be drawn from spectra which exploit the time dependence of carbon magnetization. Figure 7 a contains plots of cross polarization contact times vs. peak intensities for a number of different resonances. Clearly, different types of carbon atoms relax at different rates in these sediments. This is a completely expected result based on previous studies of carbon atoms in model compounds (31) and other geochemical matrices such as coal resins (32).

Figure 8 demonstrates how this time dependence can be exploited to improve spectral resolution and delineate subtle diagenetic changes in bulk organic matter. At short contact times (200 and $800 \mu \mathrm{sec})$, carboxyl and/or amide carbons are only partially magnetized (Figure $7 \mathrm{~b}$ ), and only the most prominent appear in the spectra. This improves resolution of the peaks at 172 and $175 \mathrm{ppm}$ relative to the $1000 \mu \mathrm{sec}$ spectra. The importance of this is apparent when comparing the $800 \mu \mathrm{sec}$ spectra of Figure $8 \mathrm{a}(10-12 \mathrm{~cm})$ and $8 \mathrm{~b}(20-22 \mathrm{~cm})$. In $8 \mathrm{a}$, the 175 peak is more prominent, albeit slightly, whereas in $8 \mathrm{~b}$, the 172 peak dominates.

It is important to note that the experiments which generate the data of Figure 7 are a necessary part of any NMR studies of intact sedimentary carbon. Before characterizations can be made, it is first necessary to establish that there exist no selective relaxation pathways for any particular carbon type. Otherwise, quantitative comparisons such as those of Table II could not be made, since carbon types with fast relaxation would be underestimated. For example, Figure $7 a$ indicates that spectra obtained with $800 \mu \mathrm{sec}$ contact times (Table II) may underestimate the methyl and methylene content of the organic carbon in these sediments. Figure 7 further indicates that magnetic relaxation in these intact sediments is very rapid relative to previously studied carbonaceous materials. In general, $1000 \mu \mathrm{sec}$ contact times have been used for studies of coal, kerogen and extracted humic/fulvic acids. We presume contact time experiments were done to maximize the magnetization of all carbon types. However, the optimum contact times indicated in Figure 7 are much shorter than $1000 \mu \mathrm{sec}$.

Further information about diagenetic alteration of sedimentary organic matter can be obtained by exploiting the time dependence of magnetic relaxation. For example, it has been shown by several workers that nonprotonated carbon atoms relax at much slower rates 


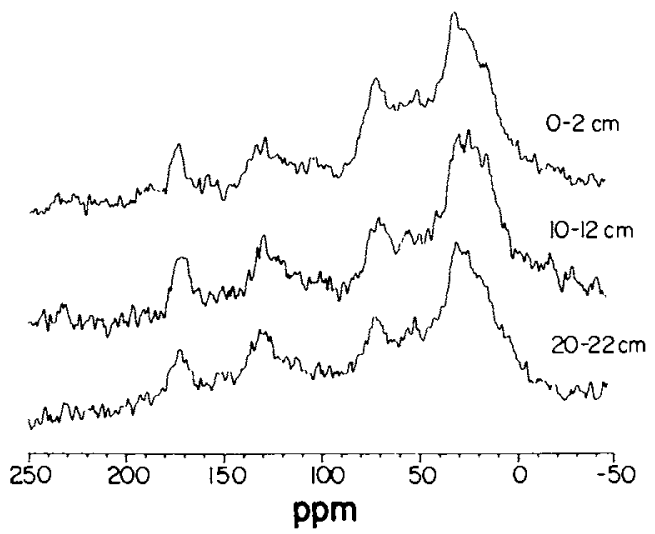

Figure 6. NMR spectra of intact core materia1, BX-6.

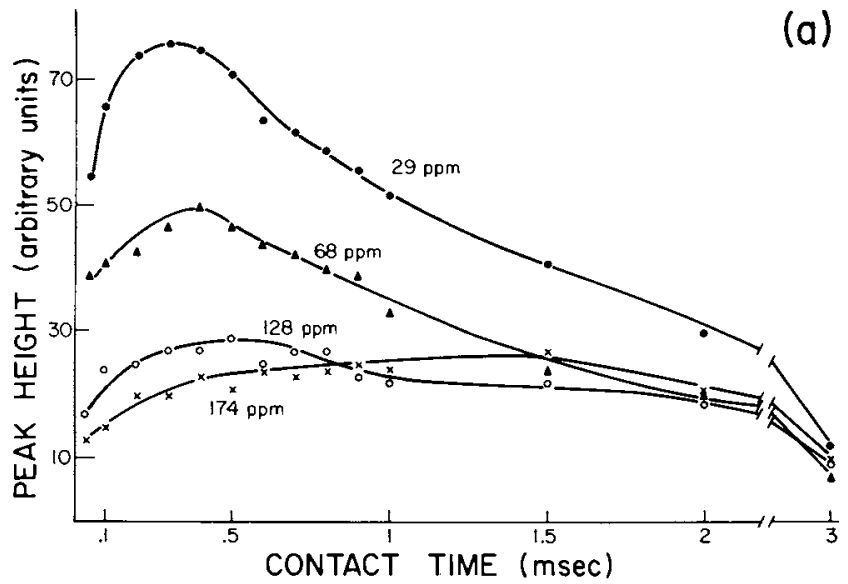

Figure 7. (a) Peak intensity plotted as function of cross polarization contact time, selected resonances.

In Organic Marine Geochemistry; Sohn, M.;

ACS Symposium Series; American Chemical Society: Washington, DC, 1986. 


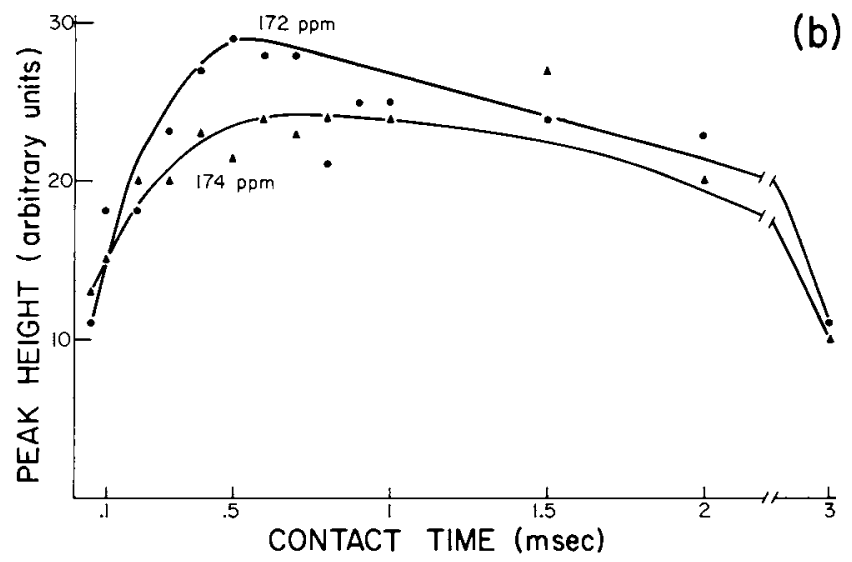

Figure 7. (b) Peak intensity plotted as a function of cross polarization contact time, carboxyl/amide resonances.

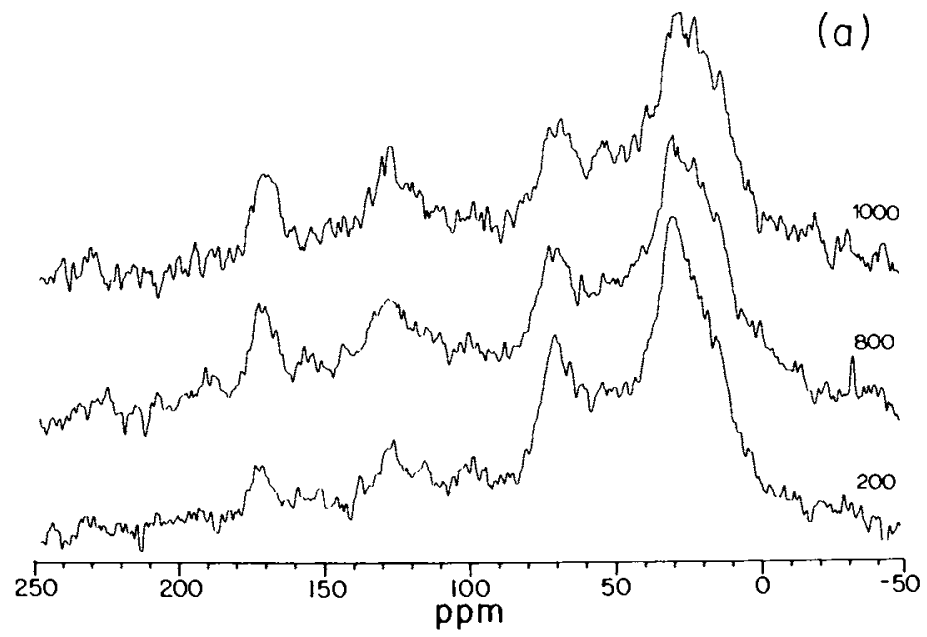

Figure 8. (a) NMR spectra obtained with varying contact times, 10-12 cm, BX-3.

In Organic Marine Geochemistry; Sohn, M.; ACS Symposium Series; American Chemical Society: Washington, DC, 1986. 


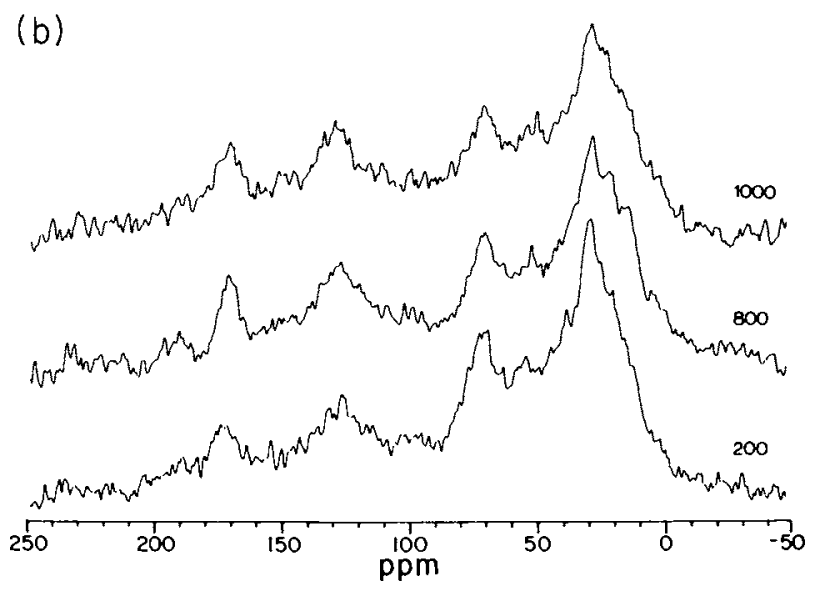

Figure 8. (b) NMR spectra obtained with varying contact times, $20-22 \mathrm{~cm}, \mathrm{BX}-3$.

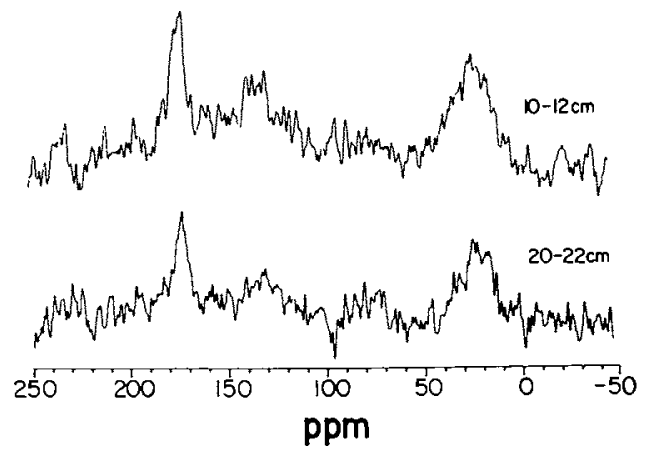

F1gure 9. D1polar dephased spectra of intact sediments, BX-3.

than protonated carbons $(20)$. By delaying the onset of data acquisition after cross polarization has ceased (dipolar dephasing), this effect can be used to discriminate between protonated and nonprotonated carbon types. Figure 9 contains the dipolar dephased spectra of Figure 8 . These spectra were obtalned with a $50 \mu \mathrm{sec}$ dephasing delay inserted prior to data acquisition. The most prominent feature of Figure 9 is the greatly enhanced carboxyl signal of both spectra. However, there is also a substantial signal In the 130-145 ppm region of these spectra, indicating that most of the aryl/olefinic carbons are non-protonated. The aryl/olefinic spectra of the upper core section $(10-12 \mathrm{~cm})$ also appear more intense than the corresponding peaks in the lower section. This would indicate diagenetic alteration involving some loss of aromatic/olefinic functional groups, provided that the signal-tonolse ratios are sufficlently large so that the differences in the spectra are real and the presence of paramagnetlcs are not affecting relaxation rates to an appreclable degree. These questions are currently being investigated in order to determine whether the dlagenetic pathway suggested is actually occurring. 


\section{$\underline{\text { Summary }}$}

In this paper we have demonstrated the utility and potential of time-resolved NMR spectroscopy for studying early diagenetic alteration of sedimentary organic matter. Conventional analyses such as the identification and quantification of lipid biomarkers give complimentary information. We anticipate that, as NMR techniques become more widely used in studies of sedimentary organic matter, the complimentary nature of conventional and spectroscopic results will become more apparent, leading to a better understanding of the chemical processes involved in early diagenesis.

\section{Acknowledgments}

This work was supported by a grant from the Petroleum Research Fund, administered by the American Chemical Society. Sediment samples were obtained by Professors P. Froelich, W. Burnett and M. Andreae of the Florida State University Oceanography Department. The assistance of D. Rosanske and T. Gedris of the FSU Magnetic Resonance Lab is greatly appreciated, as are the helpful discussions with P. Nichols and J. W. de Leeuw concerning sterol distributions.

\section{Literature Cited}

1. Tissot, B. P., Welte, D. H. "Petroleum Formation and Occurrence"; Springer - Verlag: New York, 1984; pp. 69-92.

2. Hatcher, P. G.; Spiker, E. C.; Szevereny1, N. M.; Macie1, G. E. Nature, 1983, 305, 498.

3. Scnitzer, M.; Khan, S. U. "Humtc Substances in the Environment"; Marce1 Dekker: New York, 1972, p. 327.

4. Eglinton, G. In "Organic Geochemistry, Methods and Results"; Murphy, M. T. J.; Eglinton, G. Eds; Springer-Verlag: New York, 1966; Chap. 2.

5. Blumer, M. Pure Appl. Chem. 1973, 34, 591.

6. Huang, W. Y.; Meinschein, W. G. Geochem. Cosmochem. Acta 1978, $42,1391$.

7. Attaway, D. H.; Parker, P. L. Science 1970, 169, 674.

8. Gagosian, R.B. Geochem. Cosmochem. Acta 1975, 39, 1443.

9. Huang, W. Y.; Melnschein, W. G. Geochem. Cosmochem. Acta 1979, 43, 739.

10. Gaskell, S. J.; Eglinton, G.; In "Advances in Organic Geochemistry"; Tissot, B.; Bienner, F., Eds; Editions Technip, 1973; pp. 936-976.

11. Gaskel1, S. J.; Eglinton, G. Nature 1975, 254, 209.

12. Nishimura, M.; Kayoma, T. Geochem- Cosmochem. Acta 1977, 41, 379 .

13. Nishimura, M. Geochem. Cosmochem. Acta 1978, 42, 349.

14. Mallory, F. B.; Connor, R. L. Lipids 1971, 6, 149.

15. Wakeham, S. G.; Schaffner, C.; Giger, W. Geochem. Cosmochem. Acta $1980,44,403$.

16. Pines, A.; Gibby, M. G.; Waugh, J. S. J. Chem. Phys. 1973, $59,569$.

17. Schaefer, J.; Stejskal, E. O. J. Am. Chem. Soc. 1976, 98, 1031.

18. Macie1, G. E. Science $1984,22 \overline{6}, \overline{28} 2$. 
19. Hagaman, E. W.; Woody, M. C. Fuel 1982, 61, 53.

20. Wilson, M. A.; Pugmire, R. J. ; Grant, D. M. Org. Geochem. $1983,5,121$.

21. Wilson, M. A.; Collin, P. J.; Vassallo, A. M.; Russe11, N. J. Org. Geochem. 1984, 7, 161 .

22. Soutar, A.; Johnson, S.; Fisher, K.; Dymond, J. EOS 1981, 62, 45.

23. Grob, K.; Krob, K., Jr. J. Chromatogr. 1974, 94, 53.

24. Lee, C.; Farrington, J. W.; Gagosian, R. B. Geochem. Cosmochem. Acta $1979,43,35$.

25. Wardroper, A. M. K.; Maxwe11, J. R.; Morris, R. J. Sterolds $1978,32,203$.

26. Rubenstein, I.; Goad, L. J. Phytochem. 1974, 13, 485.

27. Orcutt, D. M.; Patterson, G. W. Comp. Blochem. Phystol. 1975, 50B, 579.

28. Boon, J. J.; RIjpstra, W. I. C.; de Lange, F; de Leeuw, J. W.; Yoshioka, M.; Shimizu, Y. Nature 1979, 277, 125.

29. de Leeuw, J. W.; Rijpstra, W. I. C.; Schenk, P. A.; Volkman, J. K. Geochem. Cosmochem. Acta 1983, 47, 455.

30. Lee, C.; Gagosian, R. B.; Farrington, J. W. Org. Geochem. 1980, $2,103$.

31. Alemany, L. B.; Grant, D. M.; Pugmire, R. J.; Alger, T. D.; Z11m, K. W. J. Am. Chem. Soc. 1983, 105, 2142.

32. Wilson, M. A.; Gollin, P. J.; Vassa1lo, A. M.; Russe11, N. J. Org. Geochem. $1984,7,161$.

RECEIVED September 16, 1985 


\title{
The Biogeochemistry of Polychlorinated Biphenyls in the Acushnet River Estuary, Massachusetts
}

\author{
John W. Farrington, Alan C. Davis, Bruce J. Brownawell, Bruce W. Tripp, \\ C. Hovey Clifford, and Joaquim B. Livramento
}

Chemistry Department and Coastal Research Center, Woods Hole Oceanographic Institution, Woods Hole, MA 02543

\begin{abstract}
Analyses of PCBs in sediment, water and organisms by high resolution gas chromatographlc quantitative determination of individual chlorobipheny 1 s revealed marked compositional differences in segments of the Acushnet River estuary ecosystem. Dramatic differences in chlorobiphenyl compositions in tissues of lobster, crab and fish compared to compositions in industrial $\mathrm{PCB}$ mixtures released to the environment suggest that public health criterla based on PCB industrial mixture determinations should be revised. Predictions of bioconcentration based on $K_{o w}$ of chlorobiphenyls are of limited accuracy for several chlorobiphenyls for which metabolism or membrane transfer selectivity are apparently the major determinants in some organisms. The importance of understanding the blogeochemistry of individual chlorobiphenyls as toxic compounds and as model compounds for studies of blogeochemistry of organtc matter in aquatic ecosystems 18 discussed briefly.
\end{abstract}

An understanding of the blogeochemistry of organic matter in the contemporary marine environment is important in order to facilitate a greater understanding of: 1 ) the $C, N, S$ and $P$ cycle; 11) interactions between organic compounds and blota, e.g. chemotaxis; 111) interpretations of molecular paleontology in ancient sediments and petroleum formation; iv) the inputs, fates and effects of pollutants as has been set forth in several reviews $(1-6)$.

Our study reported herein primarily addresses this latter issue although we think that xenoblottc compounds can be used as valuable tracers of processes influencing most naturally occurring organic compounds. This is analogous to the use of anthropogenic releases of radioactive elements in the studies of the biogeochemistry of metals $(7,8)$. Polychlorinated biphenyls are useful compounds in this regard because of the wide range of solubilities and reactivities among individual chlorobiphenyls ( $(-12)$. In addition, there are continuing concerns about the adverse impacts of environmental burdens of PCBs with respect to human health and the viability of

0097-6156/86/0305-0174\$07.00/0

(c) 1986 American Chemical Society 
valuable living natural resources even though releases to the environment have been markedly reduced $(12-14)$. This is the result, In part, of the preferential accumulation of PCBs in parts of contemporary environments such as landf11ls, toxic waste disposal areas, and aquatic sediments near prior effluent discharges, and the probability of release of PCBs back to other components of contiguous ecosystems long after the initial input to the environment $(12,15)$. For example, in estuaries there is a close dynamic coupling between the atmosphere/water/sediment/biota at relatively short time scales.

Most of the previous research on the blogeochemistry of PCBs has focused on the measurement of types of industrial mixtures (e.g. Aroclor 1016, 1242, 1254) by packed column gas chromatography, although it was recognized that several of the individial chlorobiphenyls had different types and intensities of blological effects (12, 14). Recent advances in analytical methodology, particularly glass caplllary gas chromatography with electron capture detection $(16,17)$, and the more general avallability of standards of individual chlorobiphenyls via Impressive synthesis and verification analyses (e.g. 18) have made it feasible to undertake indepth studies of the biogeochemistry of individual chlorobiphenyls $(10,17-20)$.

We report here on the distributions of several chlorobiphenyls in samples of water, sediment and blota of the Acushnet River Estuary - New Bedford Harbor, Buzzards Bay, Massachusetts, U.S.A. Our general objective 18 to gain information of generic utility in addition to providing specific data and interpretations of assigtance to remedial action at this Superfund site. Our specific objectives in this paper are to: 1) document the composition of individual chlorobiphenyls in blota normally harvested by commerclal and recreational fishermen and discuss factors which could lead to the observed distributions and potential implications for public health standards for PCBs in fish; and 11) to investigate, in a preliminary manner, the adherence of bloconcentration of PCBs to predictions based on equilibrium assumptions and octanol/water (Kow) partition coefficients (21, 22).

The study site is shown in Figure 1 which also presents a generalized composite of PCB concentrations in surface sediments based on analyses of hundreds of surface sediment samples by several different laboratorles (23). Concentrations range from over 1 part per thousand $\left(10^{-3} \mathrm{~g} / \mathrm{g}\right.$ dry welght) in segments of the Inner harbor sediments to generally less than 1 × $10^{-6} \mathrm{~g} / \mathrm{g}$ dry welght (ppm) in segments of the outer harbor area (Figure 1 ). The commerclal harvesting of lobsters in the harbor area and of certain fish and bivalves in segments of the harbor 18 banned by the Massachusetts Department of Public Health because of PCB concentrations in excess of the $5 \mathrm{ppm}$ wet welght edible tissue guidelines (24). Warnlngs have been posted to inform recreational and subsistence flshermen about the PCB pollution in these same areas. Descriptions of the history and severity of PCB contamination in the area leading to designation as a U.S. EPA Superfund site are avallable (24, $\underline{25}$ ). 


\section{Sampling and Methods}

The dates and types of samples are given in Table I and locations of stations in Flgure 1. Water samples were obtained using glass sampling devices $(26,30)$. Sediment samples were obtained by coring using a box core and careful sectioning (10). Blota were obtalned by hand collection techniques or by net hauls, and precautions were taken to avold contamination during sampling and dissection (27).

Water samples were stored in precleaned glass carboys and returned to the laboratory where they were filtered and extracted within 18 hours of sampling. Filters were Soxhlet extracted with hexane/acetone (1:1) for 24 hours and again with fresh hexane/acetone for an additional 24 hours. Water and pore water samples were extracted three times with $\mathrm{CH}_{2} \mathrm{Cl}_{2}$ in a separatory funnel. Extracts were drled over $\mathrm{Na}_{2} \mathrm{SO}_{4}$, concentrated to near dryness, and hexane was added with further concentration by rotary evaporation under vacuum unt1l hexane replaced the $\mathrm{CH}_{2} \mathrm{Cl}_{2}$.

Sediments were Soxhlet extracted with acetone/hexane and the extract was concentrated (10). Blota samples were extracted by aqueous $\mathrm{KOH}$ digestion followed by extraction of non-saponiflable 11pids into ethyl ether (28).

Column chromatography of the lipid or non-saponifiable lipid extracts on alumina over slilica gel columns, or silica gel columns, to partially isolate polychlorinated biphenyls from other classes of compounds used procedures described previously $(10,28,29)$.

Chlorobiphenyls were quantified by high resolution capillary chromatography using response curves generated for a standard of each chlorobipheny1. A $0.32 \mathrm{~mm} \mathrm{1.d.} \mathrm{x} 30 \mathrm{M} \mathrm{SE}-52$ column ( $\&$ W Scientific Company) installed in a Carlo Erba Model $2150 \mathrm{GC}$ equipped with a split/splitless injector and N1-63 electron capture detector, interfaced with a Columbia Scientific Instruments Supergrator 3 electronic integrator and a $30 \mathrm{~m}$ DB5 fused silica column ( $J \& W$ Scientiflc Company) installed in a Hewlett-Packard Model 5840 GC equipped with N1-63 electron capture detector and splitless injector were used for analyses. A Finnigan 4510 quadrupole mass spectrometer Interfaced with a Carlo Erba 4160 gas chromatograph (0.32 mm i.d. x $25 \mathrm{M} \mathrm{DB}-5$ bonded fused silica column - $J \& W$ Scientific), and interfaced with a Finnigan INCOS 2300 data system and standard EI/CI Ion source and PRNICI accessory, was employed for GC-MS analyses to confirm that the compounds under study were chlorobiphenyls.

Duplicate analyses of homogenate samples agree within $\pm 20 \%$ based on replicate analyses of tissue homogenates of Myt1lus edulis. All data are corrected for recovery of internal standards (chlorobiphenyls number 29 and 143), added at the time of extraction. Average recoverles were $80-95 \%$ for the different types of samples.

\section{Results and Discussion}

Figure 2 presents representative glass capillary gas chromatograms for two industrial Aroclor mixtures used in the area. Aroclor 1242 is very similar to Aroclor 1016 (not shown) which was the predominant mixture used, but for which we had no standard. Figures 3 and 
Table I. Sampling Data (see Figure 1 for station locations).

\begin{tabular}{|c|c|c|}
\hline $\begin{array}{l}\text { Station } \\
\text { (yea }\end{array}$ & Date & Sample Type* \\
\hline \multirow[t]{2}{*}{67} & 830901 & $\begin{array}{l}\text { Ast. } 67-0.25 \mathrm{~m}^{2} \text { Sandia Hessler MKIII } \\
\text { Box Core. }\end{array}$ \\
\hline & 790709 & $\begin{array}{l}\text { Pseudopleuronectes americanus (black } \\
\text { back, winter flounder) } 15-49 \mathrm{~cm} \text { length, } \\
3 \text { each, fillets edible tissue homo- } \\
\text { genized; Lephopsetta maculata (sand } \\
\text { flounder) } 20-28 \mathrm{~cm} \text { length, } 3 \text { each, fil- } \\
\text { lets of edlble tissue homogenized; } \\
\text { Homarus amerlcanus (1obsters) } 2 \text { each, } \\
\text { tall and claw muscle tissue, and viscers } \\
\text { analyzed for each 1ndividual; Neopanope } \\
\text { taxons (green crab) } 16 \text { each, whole crabs } \\
\text { homogenized. }\end{array}$ \\
\hline \multicolumn{2}{|c|}{$\begin{array}{l}\text { approx. } 1 \text { mile } \\
\text { south of Station } \\
92 \text { - not shown }\end{array}$} & $\begin{array}{l}\text { Homarus americanus (one each), tail } \\
\text { and claw muscle tissue and viscera } \\
\text { analyzed. }\end{array}$ \\
\hline 74 & 820922 & $\begin{array}{l}\text { Ast. } 65-14-17 \text { L composite of } 2 \text { L sam- } \\
\text { ples each hour during ebb and flood } \\
\text { tides sampled with glass stoppered } 2 \text { I } \\
\text { glass flask (29). }\end{array}$ \\
\hline 92 & 810724 & $\begin{array}{l}\text { Ast. } 49-20 \text { I sample obtained with } \\
\text { glass Bodman type sampler }(25) \text {. }\end{array}$ \\
\hline 48 & 780311 & $\begin{array}{l}\text { Clarks Point - Mercenarla mercenaria } \\
\text { (hard she11 clam, quahog) } \frac{\text { pooled }}{- \text { ind }} \\
\text { tissue samples, 2-10 individuals. }\end{array}$ \\
\hline $\begin{array}{l}\text { Fort Phoenix } \\
\text { (intertidal } \\
\text { area near } \\
\text { hurricane bar }\end{array}$ & 810504 & $\begin{array}{l}\frac{\text { Mytilus edulis (blue mussel) - homo- }}{\text { genized pooled tissue, from 20-30 }} \\
\text { Individuals. }\end{array}$ \\
\hline $\begin{array}{l}\text { Cleveland } \\
\text { Ledge Light } \\
\text { (eastern Buzz } \\
\text { Station 227-n }\end{array}$ & $\begin{array}{l}780320 \\
\text { rds Bay } \\
\text { shown) }\end{array}$ & $\begin{array}{l}\text { Aequipectan } \\
\begin{array}{l}\text { genized pooled tissue from 10-15 indi- } \\
\text { viduals. }\end{array}\end{array}$ \\
\hline
\end{tabular}

*Ast. means $R / V$ Asterlas Crulse No. 


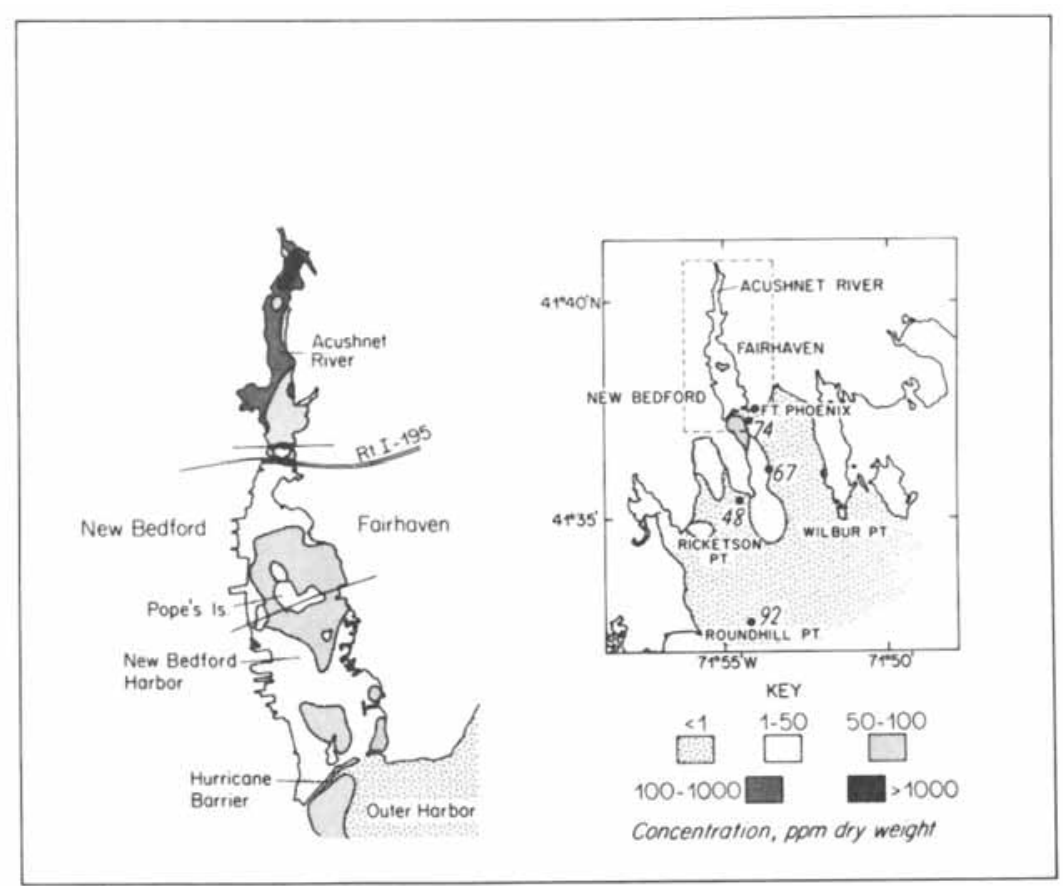

F1gure 1. Study site location, station locations and contours of PCB concentrations in surface sediments.

AROCLOR 1242
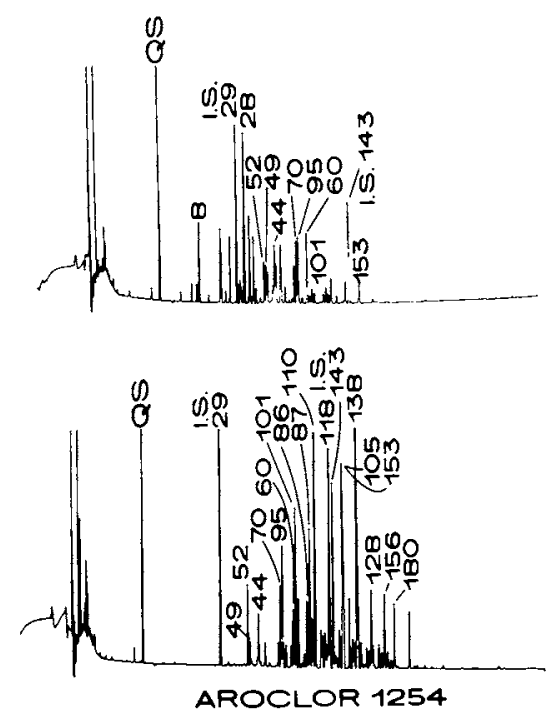

F1gure 2. H1gh resolution gas chromatograms of Aroclor 1242 and Aroclor 1254. QS refers to quantitation standard, IS refers to Internal standard, and numbers are IUPAC numbers for chlorobtphenyls.

In Organic Marine Geochemistry; Sohn, M.;

ACS Symposium Series; American Chemical Society: Washington, DC, 1986. 
4 present glass capillary gas chromatograms of PCBs in lobster (Homarus americanus), a small crab (Neopanope tarons), surface sediments and tissue of Mytilus edulis (the common blue mussel). Table II gives the IUPAC numbers for chlorobiphenyls and corresponding chlorine substitution patterns as a key to the peaks identified in the gas chromatograms with IUPAC numbers. Figure 5 gives examples of packed column gas chromatograms of some of the same samples shown in Figures 2-4. The increased information content about PCBs in glass capillary gas chromagography is 1llustrated by comparison of Figure 5 with Figures 2-4.

The composition of the chlorobiphenyl mixtures present in the surface sediment, particulate matter in the water column, filtrate from water column samples, and mussels reflect a combination of Aroclor 1242 and $1254 \mathrm{mixtures}$ of chlorobiphenyls although there are distinct differences in each sample type. The chlorobiphenyl composition of water column samples (gas chromatograms not shown) resembles that of the mussels and surface sediments, although further measurements of a larger set of samples may reveal small but significant differences in composition.

Examination of the gas chromatograms of PCBB in the samples of lobster and crab reveals the marked contrast in composition of PCBs in these types of biota samples and the composition of PCBs in water, sediment, bivalves and Aroclor mixtures. For example, the chlorobiphenyl composition of the lobsters are dominated by IUPAC chlorobiphenyl (CB) numbers 118,153 and 138 while numbers 118 and 153 dominate the composition in the crab (Figure 2). Several more chlorobiphenyls, e.8. $28,52,44,70,95,101,110$, are present in the mussel and sediment samples in addition to 118, 153 and 138 (Figure 2). PCBs in flesh of flounder species (L. maculata and $\underline{P}$. americanus) were intermediate in composition between the lobsters and the mussels based upon examination of the gas chromatograms (not shown), 1.e. 118, 153 and 138 predominate but not as much as in the lobsters. The possible reasons for these differences will be discussed below.

Table III contains data for concentrations of several individual chlorobiphenyls dissolved in the water or assoclated with particulate matter in the water column, and in surface sediments and pore waters. Concentrations of total PCBs estimated from these data are quite high for water, sediments and biota (2, 24). There are few quantitative data for individual chlorobiphenyls in water samples and this prevents extensive comparisons with other data of this type. The concentrations we report are within a factor of two to four of individual chlorobiphenyl data for a few water samples from the upper hudson River (31). We have discussed water column and sediment data in more detail in two other papers (10, 30).

Concentrations of individual chlorobiphenyls in selected biota samples are presented in Table IV. The data for viscera and combined tail and claw muscle tissue from two different lobsters collected at the same location and one lobster collected at a second location provides an example of the variation in concentrations to be found for biota samples when comparing individuals. Concentrations in the viscera are expected to be higher than in muscle tissue because of the lipid rich nature of the viscera and the 11pophilicity of the chiorobiphenyls. 
LOBSTER TISSUE
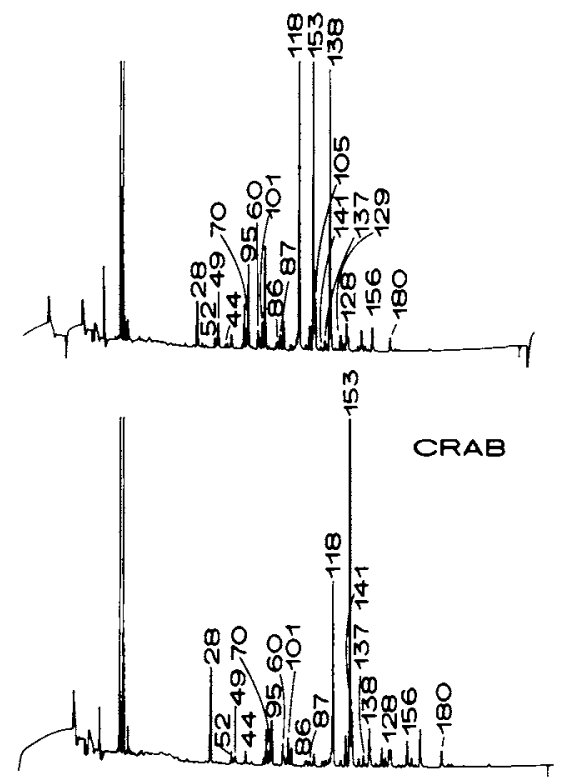

Figure 3. High resolution gas chromatograms of PCBs in lobster tail and claw mussel tissue and whole green crab (N. taxons). Also see legend Figure 2.
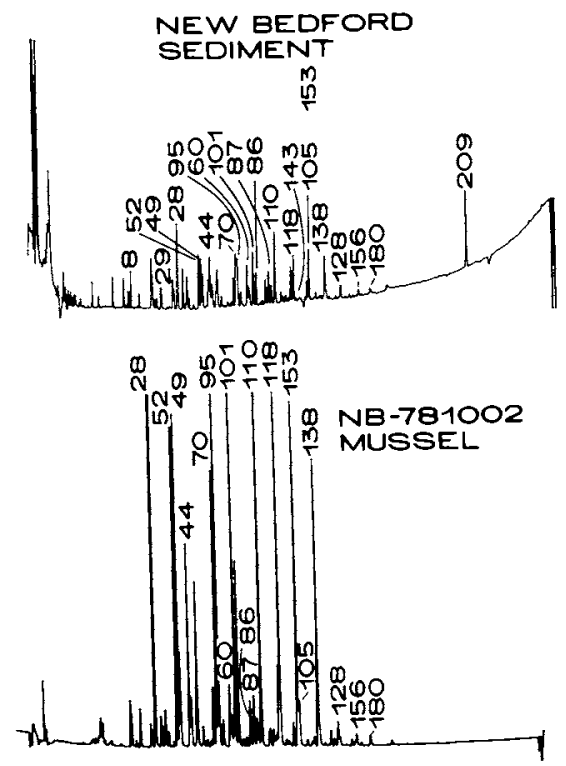

Figure 4. High resolution gas chromatograms of PCBs in surface sediment and mussel (M. edulis $)$ tissue. Also see legend Figure 2. 
Table II. Individual Chlorobiphenyls

\begin{tabular}{|c|c|}
\hline IUPAC No. & Chlorine Substitution \\
\hline 28 & $2,4,4$ \\
\hline 29 & $2,4,5$ \\
\hline 44 & $2,2^{\prime}, 3,5^{\prime}$ \\
\hline 49 & $2,2^{\circ}, 4,5^{\circ}$ \\
\hline 52 & $2,2^{\prime}, 5,5^{\prime}$ \\
\hline 60 & $2,3,4,4$ \\
\hline 70 & $2,3^{\prime}, 4^{\prime}, 5$ \\
\hline 86 & $2,2^{\prime}, 3,4,5$ \\
\hline 87 & $2,2^{\prime}, 3,4,5^{\prime}$ \\
\hline 95 & $2,2^{\prime}, 3,5^{\prime}, 6$ \\
\hline 101 & $2,2^{\prime}, 4,5,5^{\prime}$ \\
\hline 105 & $2,3,3^{\prime}, 4,4^{\prime}$ \\
\hline 110 & $2,3,3^{\prime}, 4^{\prime}, 6$ \\
\hline 118 & $2,3^{\prime}, 4,4^{\prime}, 5$ \\
\hline 128 & $2,2^{\prime}, 3,3^{\prime}, 4,4^{\prime}$ \\
\hline 129 & $2,2^{\prime}, 3,3^{\prime}, 4,5$ \\
\hline 137 & $2,2 \cdot, 3,4,4 \cdot 5$ \\
\hline 138 & $2,2^{\prime}, 3,4,4^{\prime}, 5^{\prime}$ \\
\hline 143 & $2,2^{\circ}, 3,4,5,6^{\prime}$ \\
\hline 153 & $2,2^{\circ}, 4^{\prime}, 4^{\circ}, 5,5^{\prime}$ \\
\hline 156 & $2,3,3^{\prime}, 4,4^{\prime}, 5$ \\
\hline 180 & $2,2^{\circ}, 3,4^{\prime}, 4^{\circ}, 5,5^{\prime}$ \\
\hline
\end{tabular}

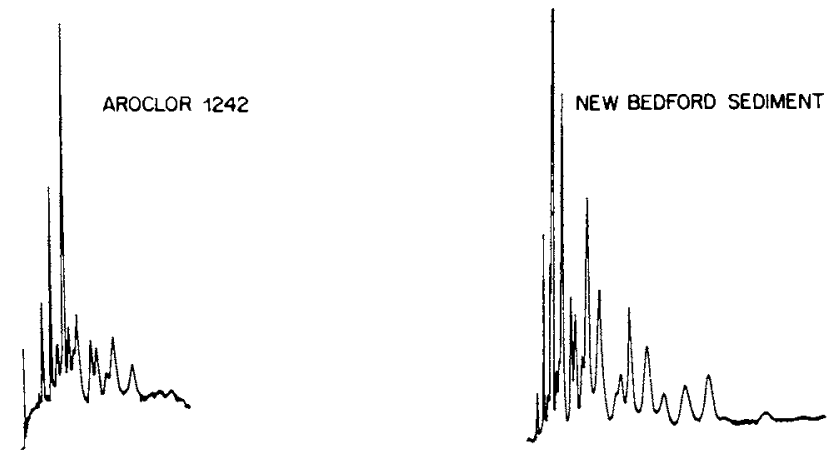

AROCLOR 1254
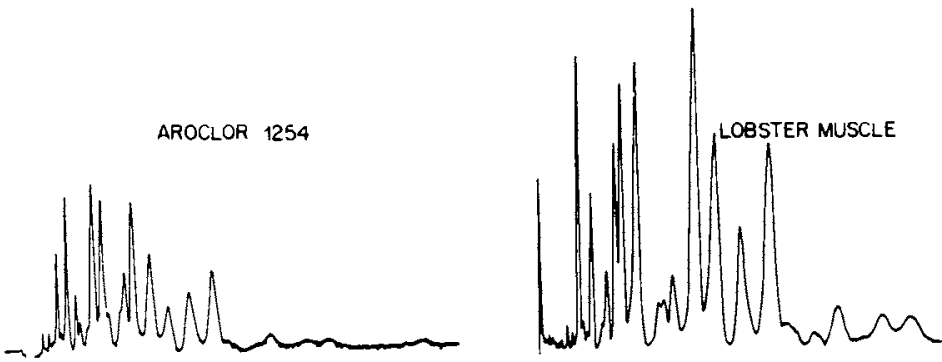

Figure 5. Packed column gas chromatograms of PCBs in representative samples from the study site. 


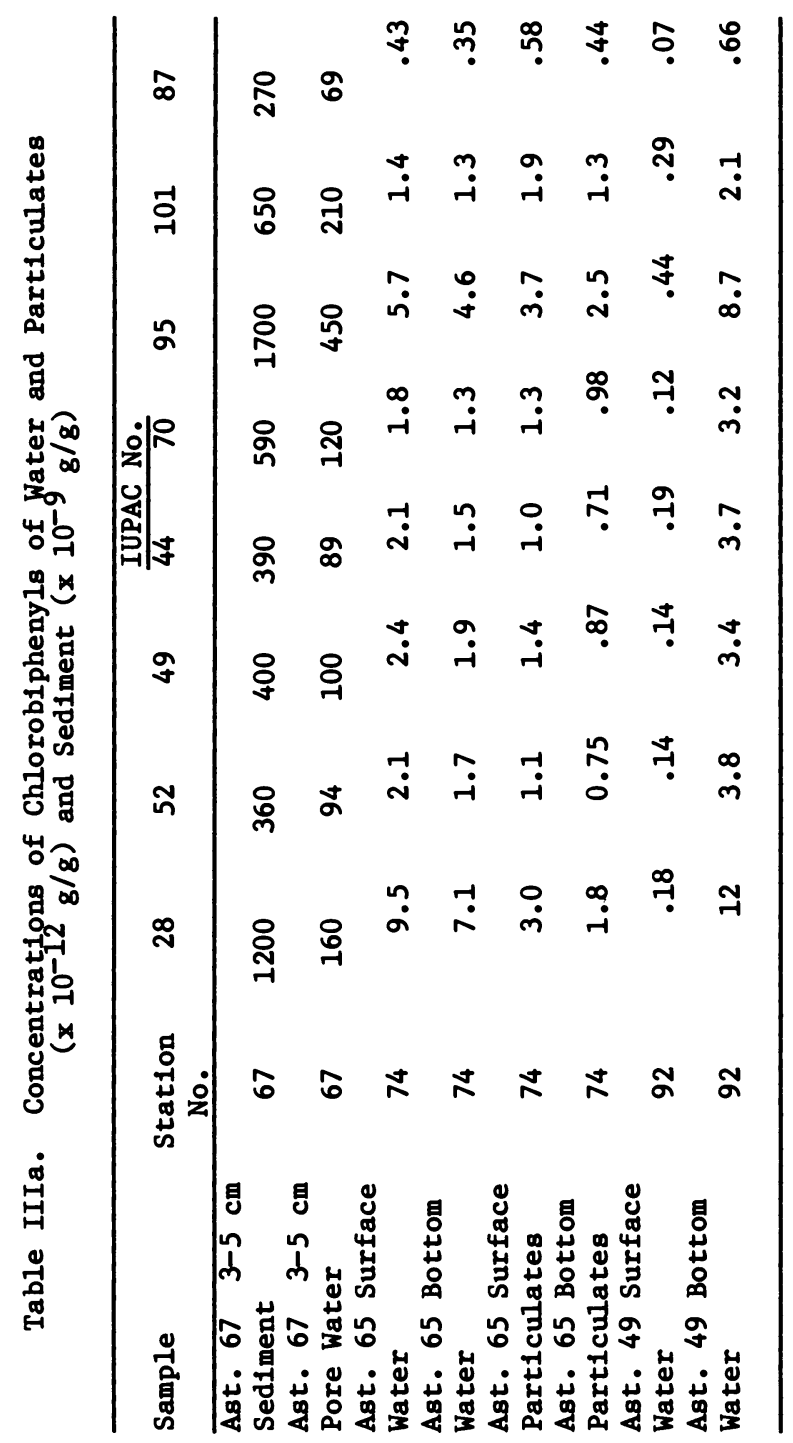

In Organic Marine Geochemistry; Sohn, M.;

ACS Symposium Series; American Chemical Society: Washington, DC, 1986. 


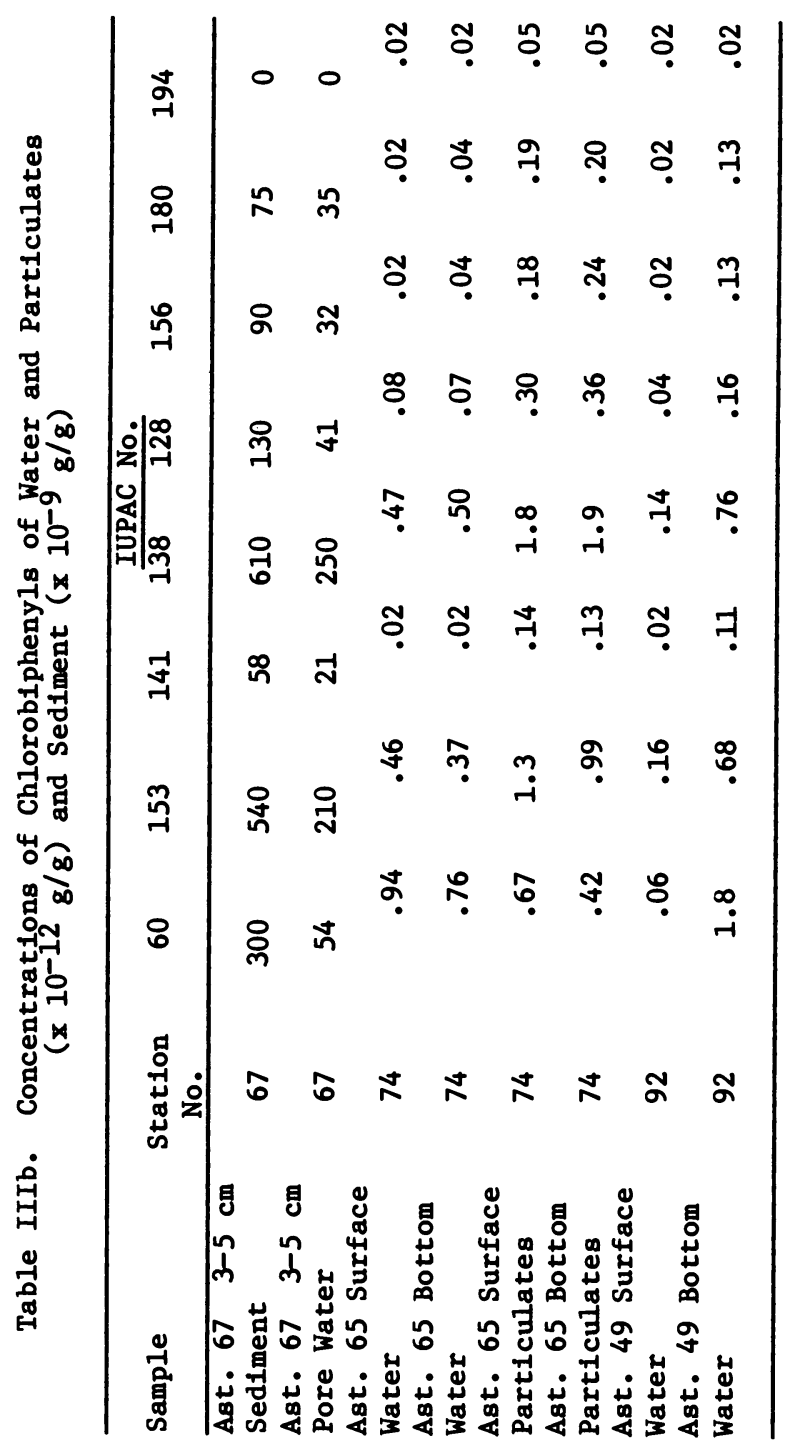

In Organic Marine Geochemistry; Sohn, M.;

ACS Symposium Series; American Chemical Society: Washington, DC, 1986. 


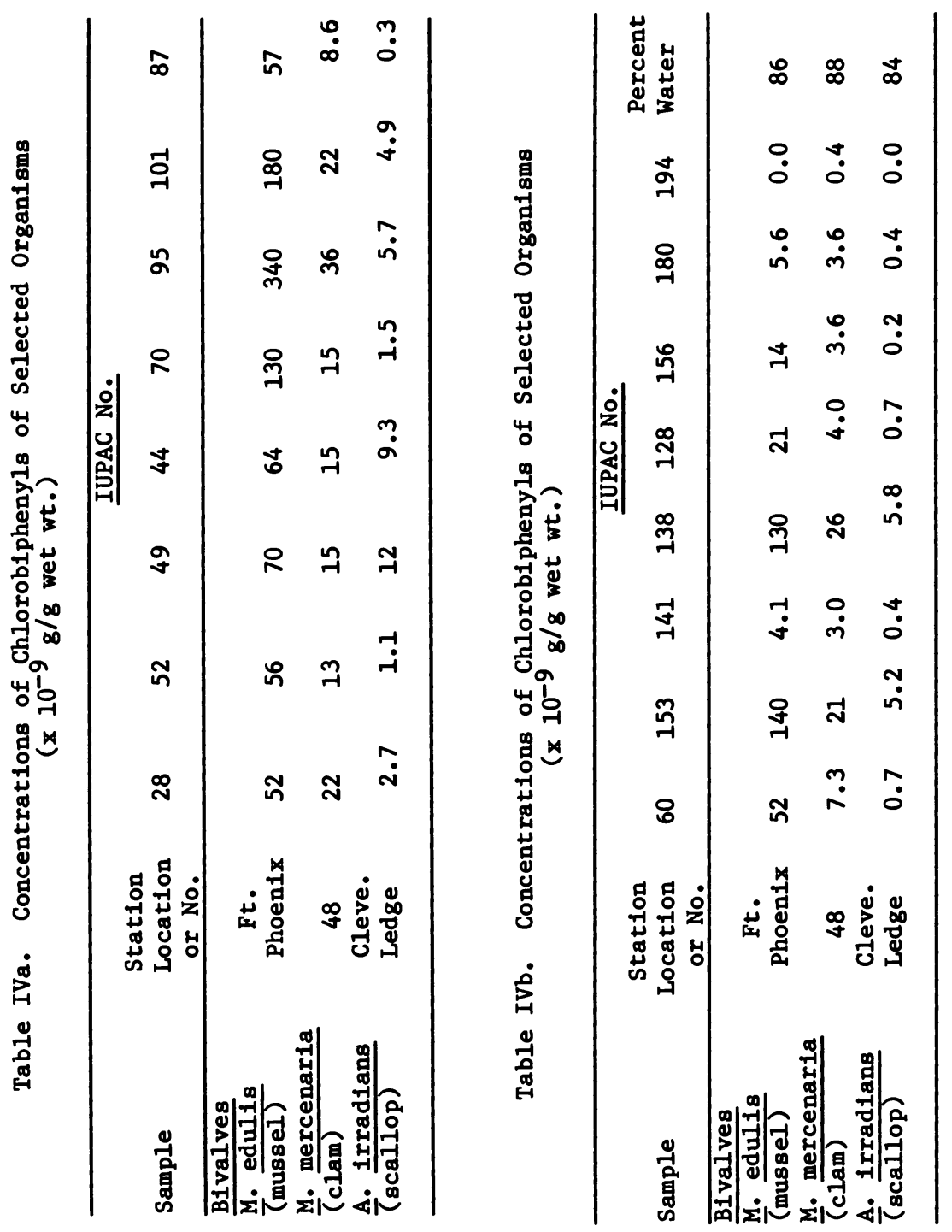

In Organic Marine Geochemistry; Sohn, M.; 


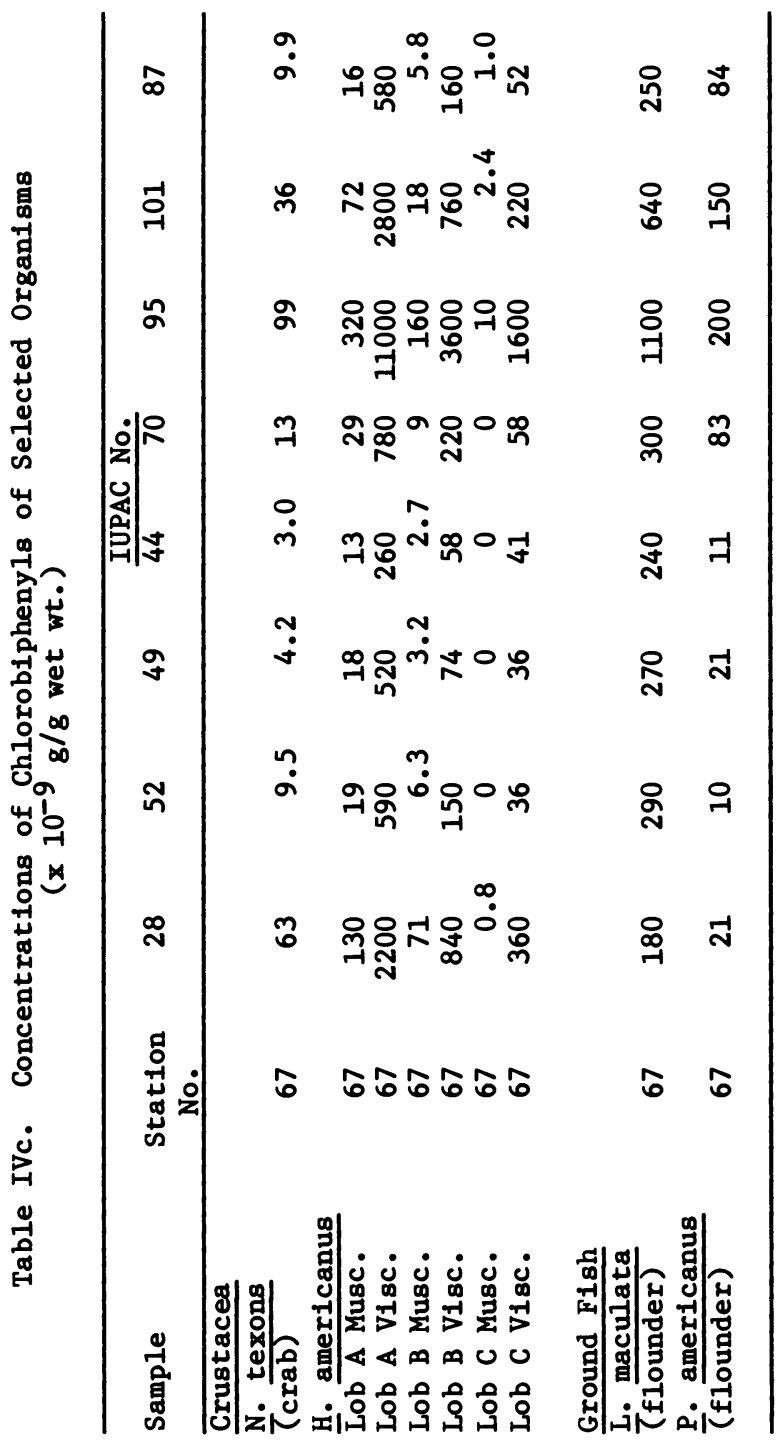

In Organic Marine Geochemistry; Sohn, M.; 


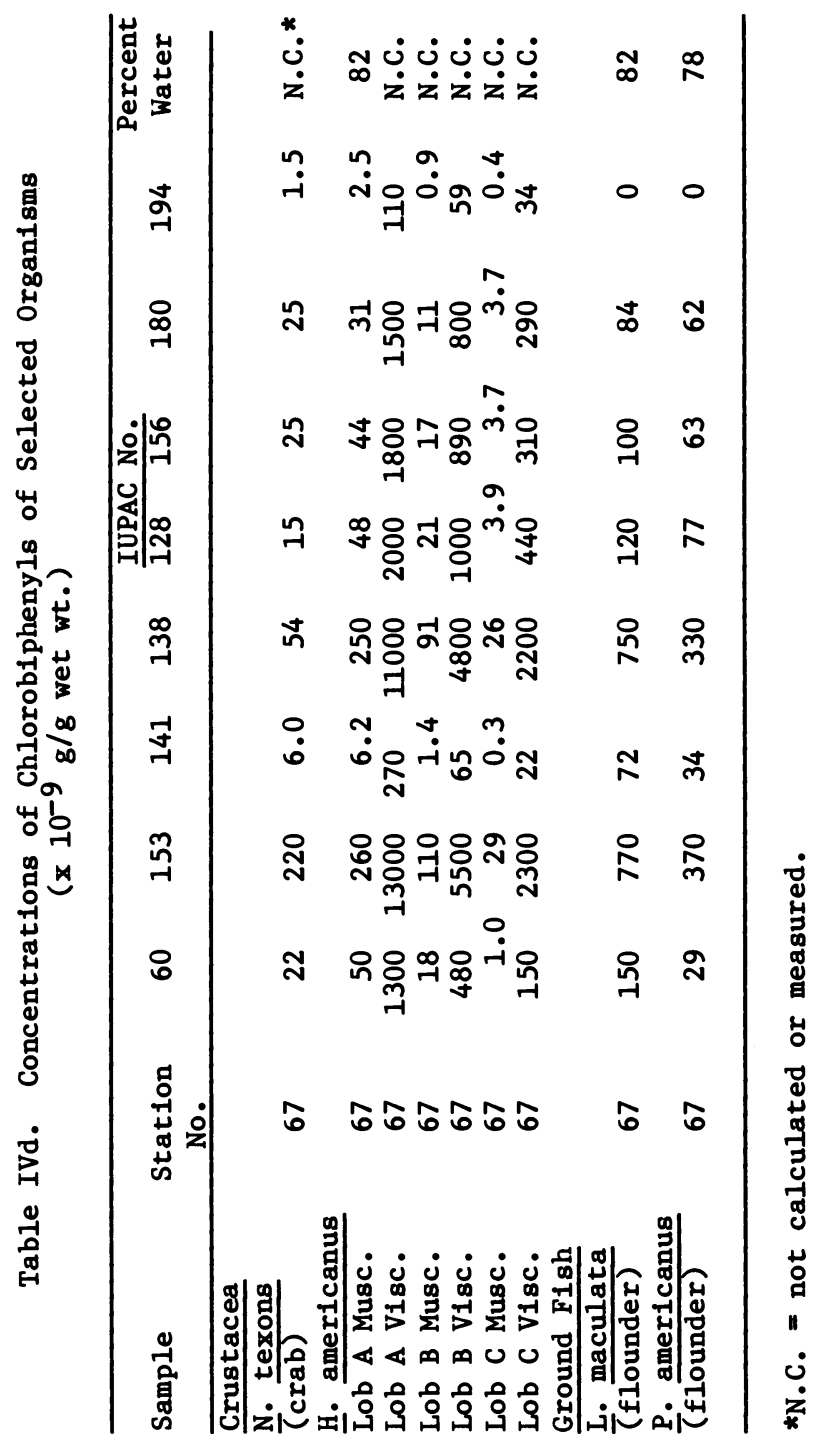

In Organic Marine Geochemistry; Sohn, M.; 
The visual inspection of gas chromatograms (FIgures 2-4) provides only a qualitative impression of the relative differences in composition of PCBs in the biota and their habitat. Therefore, we have calculated a parameter to provide a more quantitative means for evaluating the differences in composition. We have chosen a chlorobipheny1, IUPAC No. 153, which is present in appreciable quantities in the industrial mixture of Aroclor 1254 and was identified as one of the major components in the samples of biota from the study area, and calculated the following ratio:

$\frac{\text { [chlorobiphenyl 1] }}{\text { [IUPAC No. 153] }}$

sample

[chlorobiphenyl 1]

[IUPAC No. 153] PCB standard Aroclor 1254

where 1 = any specific chlorobiphenyl.

Calculated ratios for several chlorobiphenyls are given in

Tables V and VI. Values greater than 1.0 indicate that the chlorobiphenyl is enriched in that segment of the ecosystem being sampled, relative to No. 153. Values less than 1 indicate the opposite and values close to 1 indicate that the chlorobiphenyl has a biogeochemical behavior close to that of No. 153. There are groupings of chlorobiphenyls in all three categorles $(>1, \approx 1,<1)$, (Tables $\mathrm{V}$ and VI).

The processes which change the chlorobiphenyl composition of the Aroclor type mixtures once they are discharged to the estuary are: 1) volatilization - the lesser chlorinated biphenyls, e.8. tri- and tetrachlorobiphenyls, would be partitioned to the atmosphere to a greater extent than the more chlorinated penta-, hexa-, and heptachlorobiphenyls (12); i1) sorption - the complicated partitioning interactions between particulate matter, colloids, water in the water column, and surface sediments, can have a marked influence on compositions of chlorobiphenyl mixtures $(10, \underline{30})$; i11) microbial degradation - evidence to date suggests that lesser chlorinated biphenyls would be more rapidly degraded than the more chlorinated biphenyls (12); iv) selective uptake and metabolism by marine biota - the influence of this on compositions of chlorobiphenyls in our biota samples is discussed in the next several paragraphs.

The hypothesis has been advanced that changes in relative concentrations of lipid type compounds, when comparing aquatic biota and their habitat, can be explained in large part by an estimate of their tendency to partition into tissues which has been related to octanol/water partition coefficlents - $\mathrm{K}_{\mathrm{OW}} \mathrm{s}(21,22)$. Table VII presents tabulated data for $K_{o w}$ and water to biota bloaccumulation concentration factors calculated from data in Tables III and IV. Representative data from Table VII are plotted in Figure 6 in the manner of Mackay (21) and Chiou (22), who have reviewed data on bioaccumulation of neutral hydrophobic compounds in aquatic biota. The solid line is the expected distribution of data based on Chiou's review (22) of predictability for equilibrium situations. Our data is different in an absolute sense than the data used by Mackay and Chlou, because they used concentrations in biota 
Table Va. Concentration of Chlorobiphenyls Relat1ve to No. 153

\begin{tabular}{|c|c|c|c|c|c|c|c|}
\hline Sample & 52 & $\frac{\text { IUPAC }}{49}$ & $\frac{10 .}{44}$ & 70 & 95 & 101 & 87 \\
\hline $\begin{array}{ll}\text { Ast. } 67 & 3-5 \mathrm{~cm} \\
\text { Sediment }\end{array}$ & 1.5 & 6.2 & 2.5 & 2.7 & 2.2 & 1.2 & .85 \\
\hline $\begin{array}{l}\text { Ast. } 67 \quad 3-5 \mathrm{~cm} \\
\text { Pore Water } \\
\text { Ast. } 65\end{array}$ & 1.0 & 4.0 & 1.5 & 1.4 & 1.5 & 1.0 & .55 \\
\hline $\begin{array}{l}\text { Surface } \\
\text { Ast. } 65 \text { Water }\end{array}$ & 7.0 & 25 & 9.3 & 7.1 & 6.2 & 2.2 & 1.2 \\
\hline $\begin{array}{l}\text { Bottom } \\
\text { Ast. } 65 \text { Part. }\end{array}$ & 7.1 & 25 & 8.5 & 6.4 & 6.4 & 2.6 & 1.2 \\
\hline $\begin{array}{l}\text { Surface } \\
\text { ABt. } 65 \text { part. }\end{array}$ & 1.4 & 5.5 & 1.6 & 1.9 & 1.5 & 1.1 & .57 \\
\hline $\begin{array}{l}\text { Bottom } \\
\text { Ast. } 49 \text { Water }\end{array}$ & 1.2 & 4.3 & 1.5 & 1.8 & 1.3 & .93 & .55 \\
\hline $\begin{array}{l}\text { Surface } \\
\text { Ast. } 49 \text { Water }\end{array}$ & 2.1 & 7.3 & 4.1 & 1.8 & 2.0 & 1.9 & .81 \\
\hline Bottom & 12 & 41 & 19 & 12 & 9.1 & 3.1 & 1.6 \\
\hline
\end{tabular}

Table Vb. Concentration of Chlorobiphenyls Relative to No. 153

\begin{tabular}{|c|c|c|c|c|c|c|}
\hline & & IUPAC No. & & & & \\
\hline Sample & 60 & 141 & 138 & 128 & 156 & 180 \\
\hline Ast. $67 \quad 3-5 \mathrm{~cm}$ & & & & & & \\
\hline $\begin{array}{l}\text { Sediment } \\
\text { Ast. } 67 \quad 3-5 \mathrm{~cm}\end{array}$ & 8.9 & .77 & 1.2 & 1.5 & 1.1 & 1.4 \\
\hline $\begin{array}{l}\text { Pore Water } \\
\text { Ast. } 65 \text { Water }\end{array}$ & 4.1 & .70 & 1.2 & 1.2 & .95 & 1.7 \\
\hline $\begin{array}{l}\text { Surface } \\
\text { Ast. } 65 \text { Water }\end{array}$ & 24 & .33 & .70 & .70 & .29 & .48 \\
\hline $\begin{array}{l}\text { Bottom } \\
\text { Ast. } 65 \text { Part. }\end{array}$ & 24 & .42 & .92 & .76 & .48 & .80 \\
\hline $\begin{array}{l}\text { Surface } \\
\text { Ast. } 65 \text { Part. }\end{array}$ & 6.2 & .58 & .99 & .97 & .63 & 1.1 \\
\hline $\begin{array}{l}\text { Bottom } \\
\text { Ast. } 49 \text { Water }\end{array}$ & 5.0 & .68 & 1.3 & 1.5 & 1.1 & 1.5 \\
\hline $\begin{array}{l}\text { Surface } \\
\text { Ast. } 49 \text { Water }\end{array}$ & 5.7 & 1.1 & .93 & 1.8 & .56 & .84 \\
\hline Bottom & 3.9 & 1.1 & 1.1 & 1.4 & 1.2 & 1.9 \\
\hline
\end{tabular}


Table VIa. Concentration of Chlorobiphenyls Relative to No. 153

\begin{tabular}{|c|c|c|c|c|c|c|c|}
\hline \multicolumn{8}{|c|}{ IUPAC No. } \\
\hline Sample & 52 & 49 & 44 & 70 & 95 & 101 & 87 \\
\hline 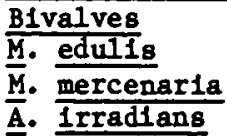 & $\begin{array}{c}0.93 \\
1.4 \\
.48\end{array}$ & $\begin{array}{c}4.2 \\
6.0 \\
19\end{array}$ & $\begin{array}{l}1.6 \\
2.5 \\
6.2\end{array}$ & $\begin{array}{l}2.2 \\
1.7 \\
.71\end{array}$ & $\begin{array}{c}1.8 \\
1.2 \\
.79\end{array}$ & $\begin{array}{l}1.3 \\
1.0 \\
.94\end{array}$ & $\begin{array}{l}.69 \\
.69 \\
.10\end{array}$ \\
\hline
\end{tabular}

Table VIb. Concentration of Chlorobiphenyls Relative to No. 153

\begin{tabular}{|c|c|c|c|c|c|c|}
\hline Samole & 60 & 141 & AC No. & 128 & 156 & 180 \\
\hline Bivalves & 00 & 141 & & & & 100 \\
\hline $\begin{array}{l}\bar{M} \cdot \frac{\text { edulis }}{\text { Mercenarla }} \\
\bar{A} \cdot \frac{\text { Irradlans }}{\text { Iradis }}\end{array}$ & $\begin{array}{l}6.1 \\
5.7 \\
2.1\end{array}$ & $\begin{array}{l}.21 \\
1.0 \\
.57\end{array}$ & $\begin{array}{l}.97 \\
1.3 \\
1.1\end{array}$ & $\begin{array}{c}.94 \\
1.2 \\
.81\end{array}$ & $\begin{array}{c}.63 \\
1.1 \\
.25\end{array}$ & $\begin{array}{l}.40 \\
1.7 \\
.80\end{array}$ \\
\hline
\end{tabular}


Table VIc. Concentration of Chlorobiphenyls Relative to No. 153

\begin{tabular}{|c|c|c|c|c|c|c|c|}
\hline Sample & 52 & 49 & $\frac{\text { PAC No. }}{44}$ & 70 & 95 & 101 & 87 \\
\hline \multicolumn{8}{|l|}{ Crustacea } \\
\hline$\frac{\mathrm{N} \cdot}{\mathrm{H}} \cdot \frac{\operatorname{texons}}{\text { americanus }}$ & .09 & .16 & .05 & .15 & .33 & .17 & .08 \\
\hline Lob A Musc. & .16 & .58 & .17 & .27 & .86 & .28 & .10 \\
\hline Lob A V1sc. & .09 & .33 & .07 & .15 & .57 & .21 & .07 \\
\hline Lob B Musc. & .14 & .24 & .09 & .20 & 1.1 & .17 & .08 \\
\hline Lob B Visc. & .07 & .11 & .04 & .10 & .47 & .14 & .04 \\
\hline Lob C Musc. & .05 & 0 & 0 & .05 & .24 & .08 & .04 \\
\hline $\begin{array}{l}\text { Lob C Visc. } \\
\text { Fish }\end{array}$ & .05 & .13 & .06 & .07 & .51 & .10 & .03 \\
\hline L. maculata & .86 & 2.9 & 1.1 & .95 & 1.1 & .84 & .54 \\
\hline ㅁ. Americanus & .07 & .47 & .10 & .56 & .40 & .40 & .39 \\
\hline
\end{tabular}

Table VId. Concentration of Chlorobiphenyls Relative to No. 153

\begin{tabular}{|c|c|c|c|c|c|c|}
\hline Sample & 60 & 141 & $\frac{\text { PAC No. }}{138}$ & 128 & 156 & 180 \\
\hline \multicolumn{7}{|l|}{ Crustacea } \\
\hline$\frac{\mathrm{N} \cdot}{\overline{\mathrm{H}} \cdot \frac{\text { texons }}{\text { americanus }}}$ & 1.6 & .21 & .25 & .44 & .75 & 1.2 \\
\hline Lob A Musc. & 3.1 & .14 & .97 & 1.2 & 1.1 & 1.2 \\
\hline Lob A Visc. & 1.6 & .07 & .86 & .94 & .88 & 1.1 \\
\hline Lob B Musc. & 2.7 & .07 & .86 & 1.3 & 1.0 & 1.0 \\
\hline Lob B Visc. & 1.5 & .07 & .89 & 1.2 & 1.0 & 1.4 \\
\hline Lob C Musc. & .48 & .07 & .91 & .81 & .81 & 1.3 \\
\hline $\begin{array}{l}\text { Lob C V1sc. } \\
\text { Fish }\end{array}$ & 1.1 & .07 & .96 & 1.2 & .81 & 1.3 \\
\hline L. maculata & 3.2 & .64 & .99 & 1.0 & .81 & 1.1 \\
\hline $\bar{P}$. americanus & 1.3 & .64 & .91 & 1.3 & 1.1 & 1.7 \\
\hline
\end{tabular}




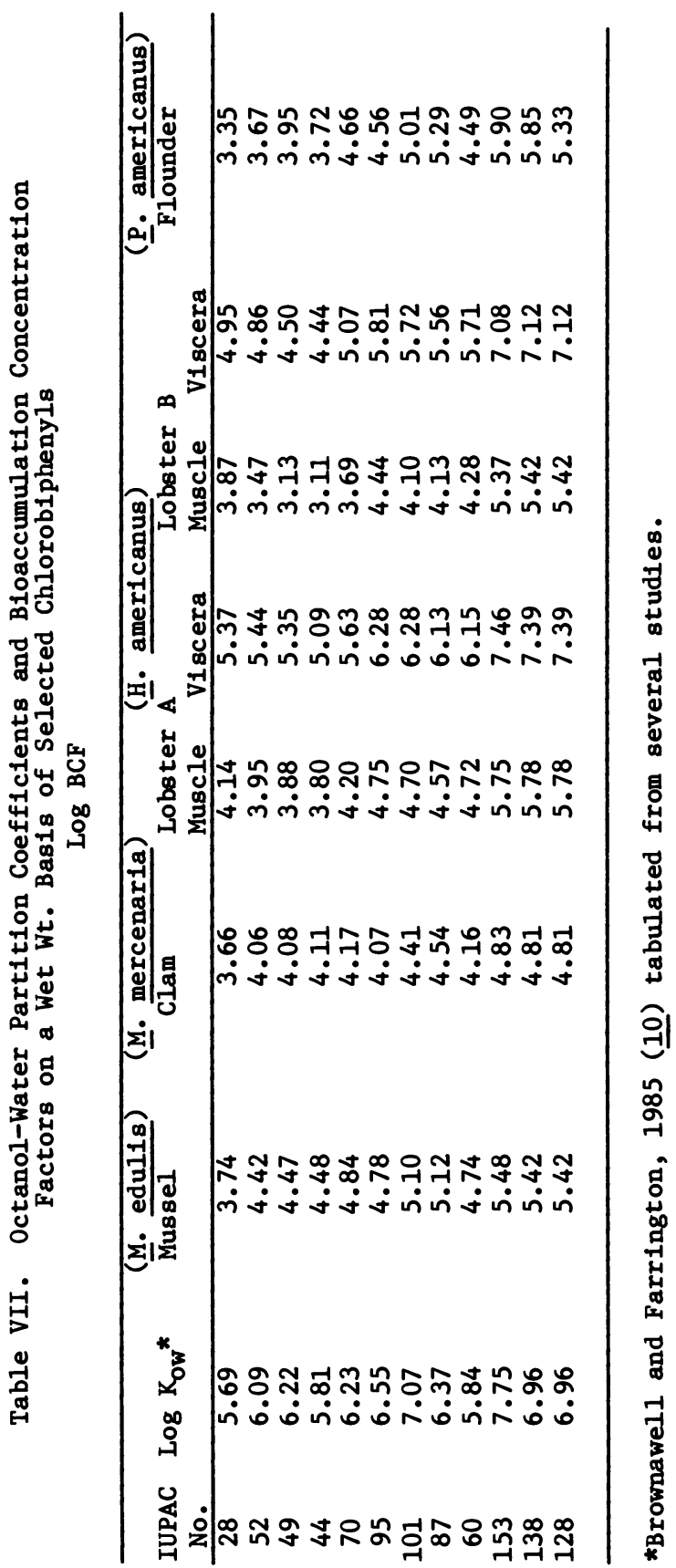

In Organic Marine Geochemistry; Sohn, M.; 

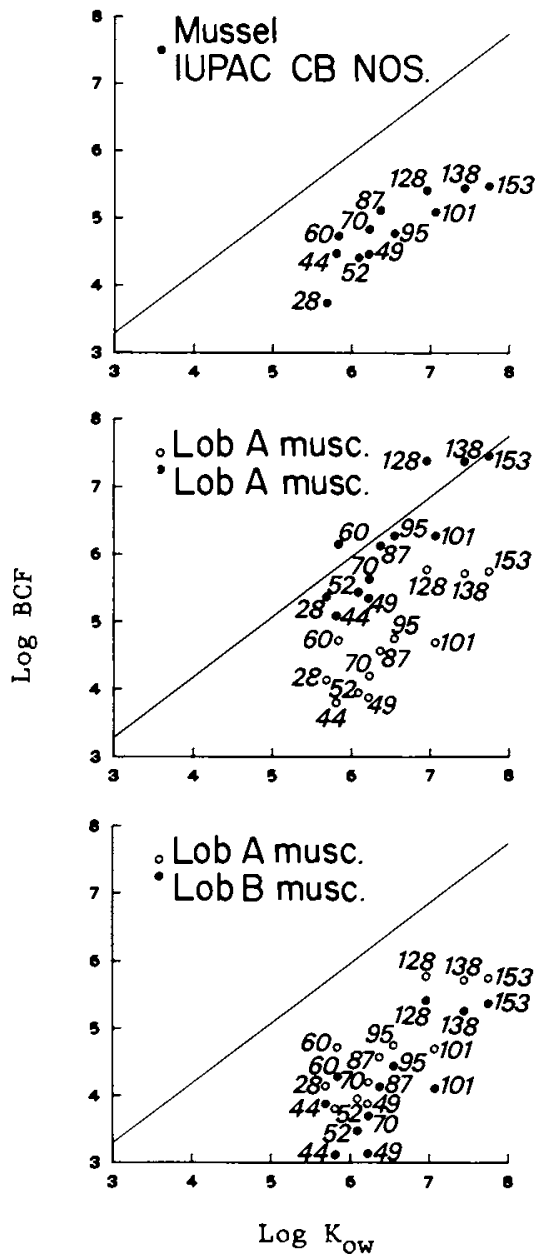

F1gure 6. Plot of $\log \mathrm{K}_{\text {ow }}$ vs. $\log \mathrm{BCF}$. Numbers are IUPAC numbers for chloroblphenyls. Solld line 18 expected plot from Chiou (22) using his equation $\log (B C F)=0.893 \log \mathrm{K}_{\text {ow }}+0.607$. 
normalized to 11pid concentrations. However, we have not done this for three reasons. First, we do not have lipid concentration data for these samples; unfortunately. Second, methods of lipld determination are operational in practice, and standardized or even common methodology for "total" lipld measurements are not commonly used. Third, Incorporation of 11pid values does not alter the expected linear correlation in a $10 \mathrm{~g}-10 \mathrm{~g}$ plot and thus the 11p1d data are not essential to our interpretations and discussion which follow.

We have included examples for $M$. edulls and $H$. americanus muscle and viscera from an Individual organism and $\mathrm{H}$. americanus muscle from duplicate samples at the same station and sampling time to indicate the range of variability for these types of plots. The viscera data plot closer to the region of the theoretical ine because of the lipid rich nature of viscera relative to muscle and whole mussel t1ssue. The data for the mussel are arranged in a more linear fashion or more tightly grouped around a linear plot than the lobster data. Our data agree with those reviewed by MacKay (21) and Chiou (22) in that $K_{0 w}$ provides an estimate of bioconcentration for neutral hydrophoblc molecules.

There appear to be some significant departures from 1inearity In the $\log$ BCF- $\log K_{\text {ow }}$ plot, but we camnot be certain because of the limited set of data. Also, we must caution that our assessment is only prellminary in this regard because we have assumed for purposes of this paper that our data are representative of the field situation over a perlod of time sufficient for "equilibrium" to be approximated closely. There are very few water measurements of this type avallable and certainly more are needed to test these assumptions of equilibrium. The few measurements we have made over the last few years have indicated that fluctuations of a factor of 2 to 4 may occur in total PCBs in the water column in this area. Storm conditions may be an exception to this, but no data are available. Blota samples in this study were not obtalned immediately after a storm. Repeated measurements of total PCBB in 1obsters from this area by Massachusetts agency laboratorles using packed column gas chromatography $(23,32)$, and less voluminous (unpublished) data from our laboratory by both packed column and glass cap1llary gas chromatography, suggest that concentrations of $\mathrm{PCBs}$ and more Importantly relative amounts of chloroblphenyls, do not fluctuate temporally by a factor of more than 4 in a given area, when averaging over a number of organisms. Data for the mussel $\mathrm{M}$. edulis at a station near Ft. Phoenix (FIgure 1 ) on the hurricane barrler, remalned within a factor of 3 for the period 1978 to $1981(25)$, encompassing the sampling period for most of the samples being considered.

There can be errors in estimation or measurement of $\mathrm{K}_{\mathrm{ow}}$ values that could cause some departure from linearity in these plots by as much as factors of 2 to 4 (less than a $10 \mathrm{~g}$ unit or factor of 10 ), which 18 much less than some of the departures from 11nearity for a few chlorobiphenyls. Chiou (22) has noted that non-steady state exposure concentrations, short exposure times, storage of compounds in non-11pld portlons of t1seues, and metabo11sm by organisms will lead to discrepancles between predicted and measured $\mathrm{BCF}-\mathrm{K}_{\mathrm{OW}}$ relationshlps. 
We think that factors other than non-equilibrium conditions explain much of the departure from prediction of BCFs using $K_{o w}$ 's. There 1s evidence to suggest selective metabolism of chlorob1phenyls in certain species (14) and it has been shown that some specles of flsh and crustacea contain mixed function oxidase activity that 18 probably capable of metabolizing certain biphenyls at different rates (33). Furthermore, the mlxed function oxidase activity in selected specles of fish and crustacea tested has been induced to higher levels of activity by exposure to xenoblotics while, thus far, only low levels of activity can be demonstrated in bivalves (33). This is interesting as it is consistent with our finding that the mixture of chlorobiphenyls in bivalves more closely approximates a mlxture of Aroclors than does the mixture of chlorobiphenyls in lobster, crab and flounder.

Dulnker and co-workers (20) noted results simtlar to ours for comparison of PCBs in Crangon sp. (a shrimp) and PCBs in its habitat. Ballschmltter and co-workers have published detalled analyses of chlorinated hydrocarbon pesticides and PCBs in varlous individual fish from different habitats, usually well removed from the immediate vicinity of point source inputs (34). The glass capillary gas chromatographic patterns they report are generally simlar to those we have found for flsh from our study site in that they depart 8ignificantly from an Aroclor 1254 or 1242 type mixture. There are some differences in detall among specles in our study and in their studies, that are as yet unexplained, but could be related to specificity of uptake or metabolism by blota. For example, there is the marked difference of the presence of chlorobiphenyl No. 138 in the lobster and 1ts absence in appreclable amounts in the small green crab (Figure 3), even though both are crustacea and inhabit the same benthic region.

This may be due to specificity of metabolism of certain chlorobiphenyls by specles specific enzyme systems.

There are as yet no conclusions nor even a consensus hypothesis as to which types of chlorine substitution patterns govern ease of metabolism by enzymes. Some researchers favor the hypothesis that chlorine substitution at the $4,4^{\prime}$ or combinations at the 3,$5 ; 3,5^{\prime}$ positions of the biphenyl molecule block ease of enzymatic epoxidation of easily accessible vicinal carbons $(14,35)$. Other researchers suggest that $2,2^{\prime}$ or $6,6^{\prime}$ substitutions or some combination reduce coplanarity of the biphenyl rings thereby causing a steric hinderance to enzymatic activity or transfer across membranes (14, 36). Our data on Individual chlorobiphenyls in biota does not yet encompass a wide enough range of chlorobiphenyl structures to test these hypotheses which must be tested rigorously with isotopically labeled chlorobiphenyls in carefully controlled experiments in any event.

\section{General Discussion}

It should have been obvious from first principles and certalnly reinforced by the advent of several sets of data by glass cap1lary gas chromatography, that packed column gas chromatographic analyses do not provide adequate information about marked compositional differences between specles of biota and between specles and their habitat. More detalled compositional information is 
Important for understanding factors controlling the blogeochemical cycle of PCBs in the environment; more specifically aquatic ecosystems including estuaries. Our data have demonstrated this for the case of a severely polluted coastal estuarine area, both for the data discussed herein and for pore water, sediment and water column data presented and discussed elsewhere $(10,30)$.

Parameters such as solubilities and $K_{\text {ow's }}$ provide a first order predictive capability concerning bloconcentration in blota, but departures from predicted distributions due to kinetic factors Involved with uptake and release and metabolic transformations have a marked influence. While equilibrium considerations are a good starting point, it is necessary to move beyond these to dynamical considerations to provide better general knowledge for such questions as risk assessment in waste disposal to the ocean, and cleanup of severely polluted estuarine coastal areas. There has been some progress, but more research concerned with kinetic factors and dynamics in blogeochemical cycles of pollutant organics is needed.

The most Important message contained in our glass capillary gas chromatograph1c analyses of PCBs, and those of others, 18 that public health standards are probably outdated. The edible portions of flsh and lobsters in samples from our study area contain mixtures of PCBs markedly different in composition compared to industrial Aroclor mlxtures used in most experiments assessing adverse effects on animals. The 2 to $5 \mathrm{ppm}$ (wet welght) total PCBs guideline may be overprotecting or underprotecting public health. This dual edge sword problem could cut either way and needs evaluation in the public health research sector. Some attention has been focused on this issue in the European community (37). Since it has been established that individual chlorobiphenyls can have a range of potency in regard to blological activity (14), it is important to understand the biogeochemlcal cycles of Individual chloroblphenyls as well as the bulk mixture, for which there is a significant amount of information in regard to first order environmental behavior (12, 14).

Furthermore, as we emphasized in the introduction, PCBs can serve as model compounds for studying several aspects of processes active on a wide range of organic compounds. The full potential of this approach can be realized only via experiments and field programs involving determinations and interpretations of a range of types of individual chlorobiphenyls.

\section{Acknowledgments}

We wish to thank Capt. A. D. Colburn for assistance in sampling, Dr. N. M. Frew for GCMS analyses, and Ms. Nancy Hayward for assistance. Financial support was provided by the Andrew W. Mellon Foundation and the Mobil Foundation to the Coastal Research Center, Woods Hole Oceanographic Institution; the Education Office of the Woods Hole Oceanographic Inst1tut1on/Massachusetts Institute of Technology Jolnt Program in Oceanography; and the U.S. Dept. of Commerce, NOAA, Natlonal Sea Grant Program under grants NA 83 $A A-D-00049(R / P-13)$ and NA $84 A A-D-00033(R / P-17)$. Th1s is Contribution No. 6043 from the Woods Hole Oceanographic Institution. 


\section{Literature C1ted}

1. Duursma, E. K.; Dawson, R., Eds. "Mar1ne Organ1c Chem1stry"; Elbevier Sclentiflc Publishing Co.: New York, 1981.

2. Brasse1, S.; Eglinton G. In "Coastal Upwelling: Its Sediment Record", Part A; Suess, E.; Thlede, J., Eds.; NATO CONFERENCE SERIES, Plenum Pres8: New York, 1983; pp. 545-571.

3. Hunt, J. M. "Petroleum Geochemlstry and Geology"; W. H. Freeman and Co.: San Francisco, CA, 1979.

4. Tissot, B. P.; Welte, D. H. "Petroleum Formation and 0ccurrence"; Springer-Verlag: New York, 1978.

5. "Proceedings of a Workshop on Sclentiflc Problems Relating to Ocean Pollution," National Ocesnic and Atmospheric Administration, 1978.

6. "O11 in the Sea; Inputs, Fates, and Effects," U.S. National Academy of Sclences, 1985.

7. Bowen, V. T.; Noshkin, V. E.; Lfvingston, H. D.; Volchok, H. L. Earth Planet. Sc1. Lett. 1980, 49, 411-434.

8. Sholkovitz, E. R. Earth-Science Rev. 1983, 19, 95-161.

9. Mackay, D.; Mascarenhas, R.; ShIu, W. Y. Chemosph. 1980, 9, 257-264.

10. Brownawe11, B. J.; Parrington, J. W. Geoch1m. Cosmoch1m. Acta, 1985, in press.

11. Rappaport, R. A.; Elsenrelch, S. J. Environ. Sc1. Technol. $1984,18,163-170$.

12. "Polychlorinated B1phenyls," National Academy of Sclences, 1979.

13. Miller, S. Environ. Sc1. Technol. 1982, 16, 98A-99A.

14. Kimbrough, R. D., Ed. Elsevier/North Holland Blomedical Press: New York, 1980; 406 pp.

15. Brown, M. P.; Werner, M. B.; Sloan, R. J.; Simpson, K. W. Environ. Sc1. Technol. 1985, 19, 656-661.

16. Dulnker, J. C.; H1llebrand, M.T.J. Environ. Sc1. Technol. $1983,17,449-456$.

17. Ballschmiter, K.; Zell, M. Frezenlus Z. Anal. Chem. 1980, $302,20-31$.

18. Muliin, M. D.; Pochini, C. M.; McCrindle, S.; Romkes, M.; Safe S. H.; Safe, L. M. Environ. Sc1. Technol. 1984, 18, 468-476.

19. Gschwend, P. M.; Wu, S. Environ. Sc1. Technol. 1985, 19, 90-96.

20. Dulnker, J. C.; Hillebrand, M.T.J.; Boon, J. P. Netherlands J. Sea Res. $1983,17,19-38$.

21. Mackay, D. Environ. Sc1. Technol. 1982, 16, 274-278.

22. Chiou, C. T. Environ. Sc1. Technol. 1985, 19, 57-62.

23. "Acushnet RIver PCBs: Data Management, FInal Report U.S. EPA Contract 68-04-1009, U.S. EPA Region I," Metcalf and Eddy, Inc., 1983.

24. Weaver, G. Environ. Sc1. Technol. 1984, 18, 22A-27A.

25. Farrington, J. W.; Tr1pp, B. W.; Davis, A. C.; Sulanowsk1, J. Proc. Internat1. Symp. Ut111z. Coast. Ecosyst.: Planning, Pollution, Productivity, 1982, in press.

26. Gagosian, R. B.; Dean, J. P.; Hamblin, R.; Zafiriou, O. C. Limnol. Oceanogr. 1979, 24, 583-588.

27. Grice, G. D.; Harvey, G. R.; Bowen, V. T.; Backus, R. H. Bull. Environ. Contam. Toxico1. 1972, 1, 125-132. 
28. Farrington, J. W.; RIsebrough, R. W.; Parker, P. L.; Dav1s, A. C.; deIappe, B.; Winters, J. K.; Boatwright, D.; Frew, N. M. Technical Report WHOI-82-42, Woods Hole Oceanographic Institut1on, Woods Hole, MA, 1982.

29. Galloway, W. B.; Lake, J. L.; Phelps, D. K.; Rogerson, P. F.; Bowen, V. T.; Farrington, J. W.; E. D. Goldberg, Laseter, J. L.; Lawler, G. C.; Martin, J. H.; R1sebrough R. W. Environ. Tox1col. Chem. 1983, 2, 395-410.

30. Brownawe11, B. J.; Farrington, J. W. In "Marine and Estuarine Geochemistry"; S1gleo, A. C.; Hattor1, A., Eds.; Lew1s Pub11shers, 1985, in press.

31. Bush, B.; SImpson, K. W.; Shane, L.; Koblintz, R. R. Bull. Environ. Contam. Toxicol. 1985, 34, 96-105.

32. Report of the Massachusetts Division of Marine Fisheries, 1984.

33. Stegeman, J. J. In "Polycyclic Hydrocarbons and Cancer"; Ge1boln, H. V.; Ts'o, P.O.P., Eds.; Academlc Press: 1981; Vol. 3, pp. $1-60$.

34. Ballschmltter, K.; Buchest, H.; BIhler S.; Ze11, M. Frezentus Z. Anal. Chem. 1981, 306, 323-329.

35. Shulte, E.; Acker, L. Naturw188. 1974, 61, 79-81.

36. Shaw, G. R.; Connel, D. W. Aust. J. Mar. Freshw. Res, 1982, $33,1057-1070$.

37. "Nederlandse Staatscourant nr. 2396 December 1984" ava1lable from State Institute for Quality Control of Agricultural Products (RIKILT), Wageningen, The Netherlands.

RECEIVED October 11, 1985 


\title{
Polychlorinated Biphenyls and Hydrocarbons
}

\section{Distributions among Bound and Unbound Lipid Fractions of Estuarine Sediments}

\author{
H. R. Beller $I$ and B. R. T. Simoneit \\ Environmental Geochemistry Group, College of Oceanography, Oregon State University, \\ Corvallis, OR 97331
}

\begin{abstract}
Selective extraction was used to operationally determine the quantitative and qualitative distributions of PCB's and saturated hydrocarbons among free lipld (FL), humic acid (HA), and humin (HU) fractions of four contaminated estuarine sediments. In all samples, over 90\% of the total sedimentary PCB's and hydrocarbons were extracted with FL fractions. Bound (HA and HU) and free assemblages of these compounds may have derived from different sources. Two polar, chlorinated pollutants also detected in this study, hexachlorophene (HCP) and pentachlorophenol (PCP), were proportionately more concentrated in bound fractions than the non-polar compounds; HCP was detected only in HA fractions and was probably chemically bound to refractory organic matter. Selective extraction is a promising technique for investigating strongly bound polar pollutants, such as HCP, which apparently are not recovered by conventional solvent extraction.
\end{abstract}

Suspended and bottom sediments are widely regarded as a sink for PCB's and other hydrophoblc organic pollutants released into aquatic systems. The mechanism commonly proposed to explain the affinity of PCB's for sediments is equilibrium sorption or partitioning, which is a function of the aqueous solubility of PCB isomers and the attractiveness of the sedimentary matrix to PCB's $(1-4)$. Field and laboratory studies indicate that sedimentary organic matter plays a fundamental role in $\mathrm{PCB}-$ sediment assoclations $(5-12)$ and that humic substances are important components of the sedimentary organic matrix for such associations $(6,13-16)$. For example, Chol and Chen (6) found that sedimentary $\mathrm{PCB}$ and $\mathrm{DDT}$ concentrations were 1inearly related to the humic acid content of sediments from Los Angeles Harbor. Pierce et a1. (15) determined that humic acid could account

${ }^{\prime}$ Current address: Tetra Tech, Inc., 11820 Northup Way, Bellevue, WA 98005.

0097-6156/86/0305-0198\$06.00/0

() 1986 American Chemical Society 
for over half the sorption capacity of marine sediments in a laboratory experiment involving $\mathrm{p}, \mathrm{p}^{\prime}-\mathrm{DDT}$; simflar results were obtained in an experiment with hexachlorobutadiene (13). More recent studies have demonstrated that $\mathrm{PCB}$ isomers and $\overline{\mathrm{DT}}$ can become assoclated with or incorporated into dissolved humic substances $(17-19)$ and Lichtenstein et al. have shown that $p, p^{\prime}-D D T$ can become partially "bound" (solvent inextractable) in wetted solls after brief incubation (20). While the incorporation of synthetic, hydrophobic po1lutants into refractory organic matter has been implicated by these studies, it has not been explicitly investigated in the fleld.

The objective of this study was to determine, by selective extraction, whether or not non-polar, non-ionic pollutants (e.g., $\mathrm{PCB}$ 's and petroleim hydrocarbons) can become "bound" in natural sediments, and, if so, whether their qualitative distributions provide information about the incorporation process.

The incorporation of non-polar compounds into sedimentary organic matter is of interest in a pure geochemical sense, but also has practical environmental implications. "Bound" pollutants would be undetected in many environmental studies because such studies typically employ simple solvent extraction; the quantitative significance of bound pollutants must be ascertained to produce an accurate assessment of contamination. Also, the biological avallability of sedimentary pollutants could depend on the nature of their association with organic matter. For example, "bound" PCB's entrapped within humic matrices might be less accessible to benthic fauna than "free" PCB's.

\section{Methods}

Figure 1 presents a flow diagram of the selective extraction procedure. This procedure was designed to effect exhaustive extractions at each stage and to treat $\mathrm{FL}$, $\mathrm{HA}$, $\mathrm{HU}$ fractions as similarly as possible. Dried sediment samples ( $c a .90$ to $140 \mathrm{~g}$, dry wt) were Soxhlet extracted with azeotropic toluene/methanol $(1: 3, v / v)$ for over $95 \mathrm{hr}$ (ca. 115 cycles) with a solvent change at $30 \mathrm{hr}$; all solvents used were distilled-in-glass and of high purity (Burdick and Jackson). Humic substances were extracted with five successive one liter additions of solvent-cleaned $0.2 \mathrm{~N} \mathrm{KOH}$. The combined aqueous extract was filtered through a Whatman GF/A glass fiber filter (to remove suspended sediments from the extract), acidified (to precipitate the humic acid), and re-filtered (to separate humic and fulvic acids). The humic acid precipitate was rinsed through the filter with $0.2 \mathrm{~N} \mathrm{KOH}$, resulting in a basic humic extract without fine particles. The filters and trapped particles were added to the residual sediment. The purpose of saponifying humic fractions was to disperse the polymers in the presence of organic solvents, thus releasing entrapped or sorbed compounds. The FL extracts were saponifled to make them comparable to HA and HU fractions. The strong base used to saponify FL, HA, and HU fractions converted DDT (dichlorodiphenyltrichloroethane) to DDE (dichlorodiphenyldichloroethylene) by dehydrohalogenation; thus, DDT is reported as DDE in this study. Separatory funnel extractions of saponifled extracts were carried out at $>\mathrm{pH} 12$ and $\langle\mathrm{pH} 2$. The organic extracts from liquid-1iquid extraction were rotoevaporated to near dryness and 


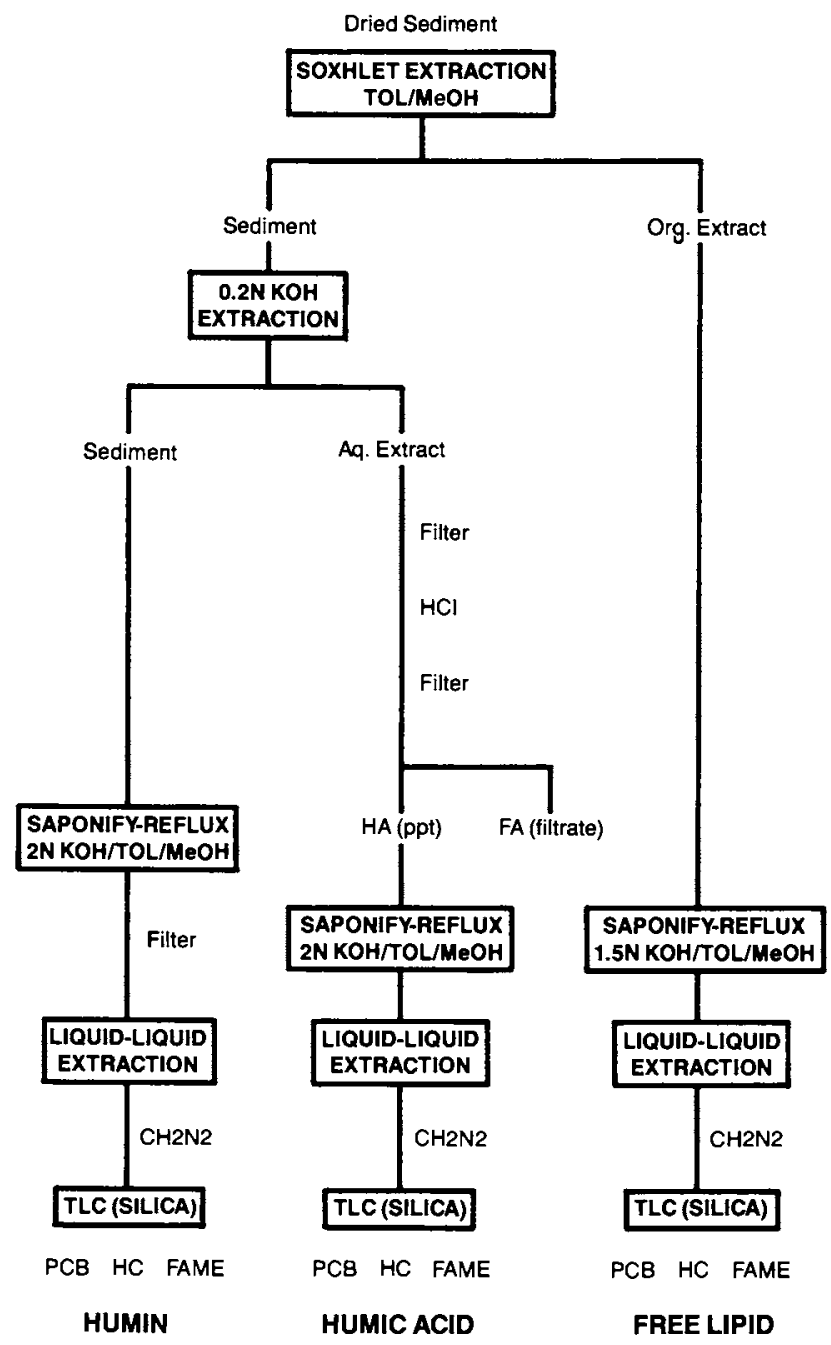

Figure 1. Flow diagram of selective extraction procedure.

In Organic Marine Geochemistry; Sohn, M.;

ACS Symposium Series; American Chemical Society: Washington, DC, 1986. 
treated with diazomethane according to the procedure of Fales et al. (21). Extracts were methylated to facllitate the analys ls of fatty aclds (results not reported in this paper). Derlvatized extracts were subjected to preparatory thin layer chromatography (TLC) on Analtech silica GHL plates; the elution solvent was $6.6 \%$ diethyl ether/hexane. Bands were visualized by exposing the plates to lodine vapor. Saturated hydrocarbons and chlorinated compounds were collected together in a broad band directly beneath the solvent front. These hydrocarbon/РCB fractions were dissolved in hexane and treated with metallic mercury to remove elemental sulfur prior to gas chromatographic analysis.

Examination of TLC fractions beneath hydrocarbon/PCB bands indicated that certain PCB Isomers did not elute with the collected bands and were not analyzed. However, collection techniques were consistent and quantlative and qualitative intrasample comparisons are valld inasmuch as they are based on the same pool of 1somers.

Chlorinated compounds were analyzed by gas chromatography-electron capture detection (GC-ECD) on a Vista 44 GC System equipped with a DB-1701 fused silica, caplllary column ( $30 \mathrm{~m}, 0.25 \mathrm{~mm} 1 . \mathrm{d}$.; J \& Wcientific). Helium and nitrogen were the carrier and make-up gases, respectively. The injector and detector temperatures were $260^{\circ} \mathrm{C}$ and $285^{\circ} \mathrm{C}$. The column oven was temperature programmed from $65^{\circ} \mathrm{C}$ (held $1 \mathrm{~min}$ ) to $230^{\circ} \mathrm{C}$ at $25^{\circ} \mathrm{C} / \mathrm{min}$, held at $230^{\circ} \mathrm{C}$ for $7.4 \mathrm{~min}$, and then heated to $245^{\circ} \mathrm{C}$ at $10^{\circ} \mathrm{c} / \mathrm{min}$. The linear velocity at maximum temperature was ca. $50 \mathrm{~cm} / \mathrm{sec}$. All GC Injections in this study were splitless with the inlet purged 1 minute after injection. The retention time of decachlorobiphenyl under these conditions was approximately 26 minutes.

Non-chlorinated hydrocarbons were analyzed by gas chromatography-flame Ionization detection (GC-FID) with a Hewlett-Packard Model $5890 \mathrm{GC}$ fitted with a $30 \mathrm{~m}, 0.25 \mathrm{~mm} 1 . \mathrm{d}$. DB-5 column (J \& W Sclentific). As for the ECD analyses, hellum and nitrogen were the carrier and make-up gases. The column oven was programmed from $65^{\circ} \mathrm{C}$ (he1d $5 \mathrm{~min}$ ) to $130^{\circ} \mathrm{C}$ at $10^{\circ} \mathrm{C} / \mathrm{mln}$ and then heated to $275^{\circ} \mathrm{C}$ at $5^{\circ} \mathrm{C} / \mathrm{min}$. The linear velocity at $275^{\circ}$ was $\mathrm{ca} ; 20 \mathrm{~cm} / \mathrm{sec}$. Injector and detector temperatures were $290^{\circ} \mathrm{C}$ and $325^{\circ} \mathrm{C}$.

Gas chromatography-mass spectrometry (GC-MS) was carrled out on selected samples elther to confirm compounds identified by retention times or to investigate the 1dentities of other peaks of interest. Samples were run on a Finnigan Model 9610 GC coupled to a Finnigan Model 4021 quadrupole MS. Mass spectrometric data were acquired and processed with a Finnigan-INCOS 2300 Data System. The MS was operated in electron Impact mode with $70 \mathrm{eV}$ electron energy. Gas chromatographic conditions were comparable to those used for GC-FID.

$P C B$ quantification is difficult because the ECD has a variable response to the 209 possible 1somers depending on their degree of chlorination, and secondarily, on their chlorine substitution patterns (22-26). While this study only required relative (intrasample) $P C B$ quantification, detector response still had to be standardized so FL, $\mathrm{HA}$, and $\mathrm{HU}$ assemblages with distribution maxima in different chlorine content ranges could be compared rellably. The co-elution of isomers and the cost of authentic isomer standards precluded isomer-specific quantification. Thus, PCB peaks were grouped according to their retention times (strongly related to 
number of chlorine substituents) and the summed area of each group was corrected with an appropriate response factor. Total PCB concentrations were estimated as the sum of all individual group concentrations. Retention time boundaries for each homolog group (d1through decachlorobiphenyl) were constructed from the retention times of peaks of known chlorine content in a $1: 1: 1$ (wt/wt/wt) standard mixture of Aroclor 1242:1254:1260 (standard used in 25). This technique was possible because retention times were very reproducible and virtually all sample peaks corresponded to peaks in the standard. Non-PCB peaks (e.g., methylated chlorinated phenols) were excluded from this quantification. Relative response factors were estlmated for each homolog group using two types of data from recent 1iterature: the abundances of isomers in Aroclors 1242, 1254 and $1260(27,28)$ and the response factors of each of these 1somers (24). Forty five isomers including representatives from all homolog groups were chosen that account for over 70 mole percent of the chlorobiphenyls in each of the Aroclor mixtures. Average homolog group response factors relative to decachlorobiphenyl, the co-injection standard, were calculated from the 45 isomers. Selected isomer standards were used to verify that literature values were applicable to the GC-ECD system used in this study.

This quantification technique was tested on a commerclal mixture of known composition, Aroclor 1242. The welght percentages of each homolog class in the Aroclor were determined and compared to approximate values provided by the manufacturer (Table I). Agreement between the determined and manufacturer's values was considered sufficient for this study.

Table I. Homolog Composition of Aroclor 1242 (wt. \%)

\begin{tabular}{lccccccccc}
\hline & $1 \mathrm{Cl}$ & $2 \mathrm{Cl}$ & $3 \mathrm{C} 1$ & $4 \mathrm{Cl}$ & $5 \mathrm{C} 1$ & $6 \mathrm{Cl} 1$ & $7 \mathrm{Cl}$ & $8 \mathrm{C} 1$ & $9 \mathrm{C} 1$ \\
\cline { 2 - 9 } Manufacturer & 1.0 & 16.0 & 43.0 & 27.0 & 9.0 & 4.0 & - & - & - \\
Determined & - & 14.0 & 45.7 & 24.5 & 9.5 & 2.9 & 2.1 & 1.3 & 0.1 \\
\hline
\end{tabular}

Saturated hydrocarbons were quantified with perdeuterated tetracosane as a co- 1 jection standard. Total hydrocarbon concentrations were determined by electronically integrating the area above a blank baseline; resolved hydrocarbon concentrations were determined by integrating peak areas above an unresolved envelope. Individual n-alkanes were identifled by comparison of sample peak retention times to those of an external standard mixture.

Sedimentary organic carbon contents were determined by wet oxidation and dry combustion according to the procedure of Weliky et a1. $(\underline{29})$.

\section{Sample Descriptions}

All samples consisted of flne-gralned, organlc matter-rich sediments from areas of known $\mathrm{PCB}$ contamination.

Samples $\mathrm{NB}(0-3)$ and $\mathrm{NB}(29-31)$ were derived from the $0-3 \mathrm{~cm}$ and 29-31 cm horizons of a large volume box core taken at station 67 of Summerhayes et al. (30) in Buzzards Bay, near New Bedford, Mass. The sedimentation rate at this site, which borders a dredged naviga- 
tion channel, is unknown. The organic carbon contents of $N B(0-3)$ and $\mathrm{NB}(29-31)$ were $5.76 \%$ and $4.79 \%$. The Acushnet RIver and ad jacent areas of Buzzards Bay are severely contaminated with PCB's due to chronic releases from two capacitor manufacturing plants (31-33). Sample HR ( $3.70 \%$ organic carbon) was collected with a Shipek grab sampler from a marginal cove in the Hudson River approximately 60 river miles north of the southern tip of Manhattan (1). The s3mple consisted of the top $10 \mathrm{~cm}$ of sediment, which according to a Cs profile of this core, encompassed 25 years of sedimentation (Dr. R. Bopp, pers. comm.). PCB contamination in the Hudson River, due predominantly to two capacitor manufacturing plants, is well documented $(1,34,35)$.

Sample LA (3.71\% organic carbon) was a composite of $0-2 \mathrm{~cm}$ sections of sediment cores taken from near the Terminal Island sewage outfall in Los Angeles-Long Beach Harbor ( $33^{\circ} 43^{\prime} 51^{\prime \prime} \mathrm{N}$, $\left.118^{\circ} 14^{\prime} 27^{\prime \prime} \mathrm{W}\right)$.

Sulfides, indicative of sulfate-reducing conditions, were prevalent in samples $\mathrm{NB}(0-3), \mathrm{NB}(29-31)$, and $\mathrm{LA}$.

Results and Discussion

Chlorinated hydrocarbons: PCB's and DDE. Table II displays the distributions of PCB's and $\overline{\mathrm{DDE}}$ among $\mathrm{FL}, \mathrm{HA}$, and HU fractions (as percent of total sedimentary concentrations) and the total sedimentary concentrations on a dry wt. basis. The tabulated concentrations are intended only to denote relative trends in PCB distribution and are not considered absolute. Over $90 \%$ of the total PCB's and DDE is associated with the FL fraction. This finding is not in accord with sorption experiments $(\mathrm{e} \cdot \mathrm{g} \cdot, 15)$, which indicate that over half of the PCB's or DDE should be associated with humic substances. Thus, sorption may not be a controlling factor in the distributions of PCB's among organic matter fractions. While exhaustive Soxhlet extraction may have removed some humic acid-assoclated PCB's along with free PCB's, a trial humic acid extraction of a subsample that had not been solvent extracted indicated that such procedural artifacts could not explain the discrepancy between the results of this study and those of Plerce et al. (15).

Table II. Relative $\mathrm{PCB}$ and DDE Distributions ${ }^{a, b}$

\begin{tabular}{lllll}
\hline Sample & FL & HA & HU & Total \\
\hline NB(0-3) & $91 \%$ & $0.96 \%$ & $8.1 \%$ & 1.3 ppm PCB \\
NB (29-31) & $99 \%$ & $0.12 \%$ & $1.2 \%$ & 6.5 ppm PCB \\
HR & $98 \%$ & $0.87 \%$ & $1.4 \%$ & 1.4 ppm PCB \& DDE \\
LA & $99.9 \%$ & - & $0.10 \%$ & 100 ppb DDE \\
& ca. $100 \%$ & & $91 \mathrm{ppb}$ PCB
\end{tabular}

a as percent of total sedimentary concentrations

b

Total percentages may deviate from 100 due to rounding error.

Qualitative PCB distributions of the New Bedford samples suggest that free and bound PCB's may have derived from different sources. Figure 2 presents capillary ECD chromatograms of the FL 


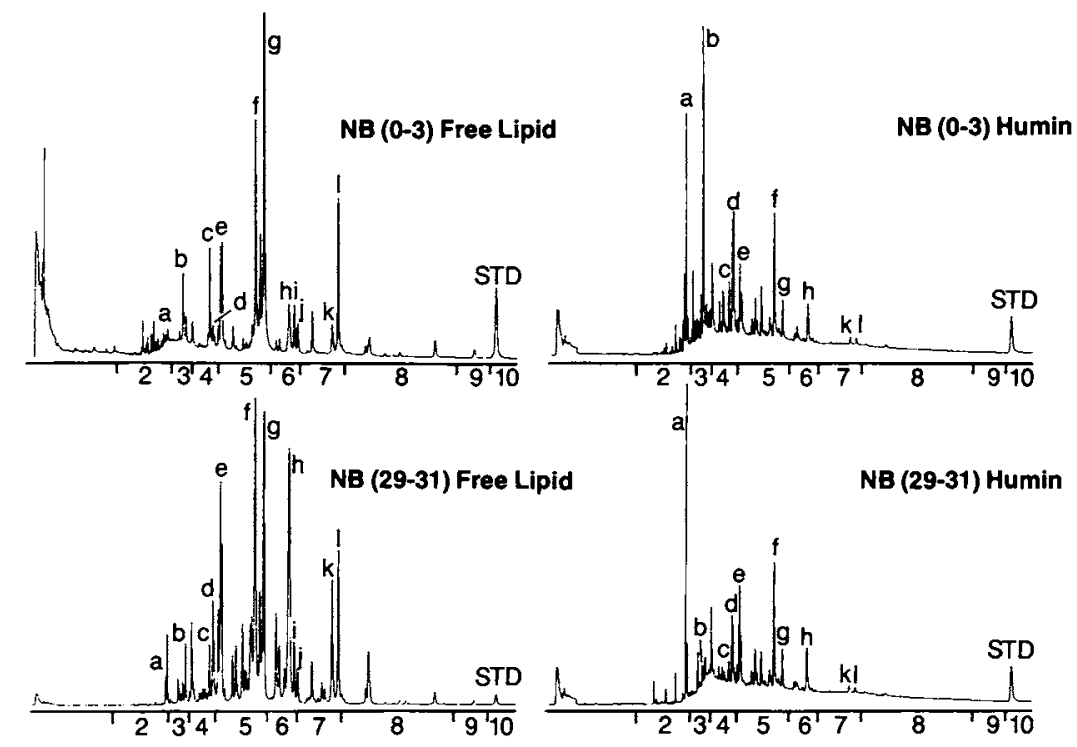

Figure 2. Capillary GC-ECD traces of FL and HU fractions of samples $\mathrm{NB}(0-3)$ and $\mathrm{NB}(29-31)$. Peak a is pentachlorophenol (as methyl ether derivative); the remaining peaks are $\mathrm{PCB}^{\prime} s$. STD co-injection standard, decachlorobiphenyl. Approximate elution ranges of di- through decachlorobiphenyl are delineated.

In Organic Marine Geochemistry; Sohn, M.;

ACS Symposium Series; American Chemical Society: Washington, DC, 1986. 
and $\mathrm{HU}$ fractions of samples $\mathrm{NB}(0-3)$ and $\mathrm{NB}(29-31)$. PCB's with five or more chlorine substituents, which are highly resistant to microbial degradation ( 36 ), provide a good basis for qualitative compar1son of sample fractions. The relative intensities of peaks $f$ through 1 in the two FL fractions (Figure 2) are markedly different than in the corresponding HU fractions. Furthermore, the relative intensities of several peaks differ considerably between the two FL fractions (e.g., peak clusters $g, h$ and $k, 1$ ), yet these differences are not apparent in the two HU fractions. In fact, the assemblages of higher chlorinated isomers (peaks $f$ through 1) in the HU fractions are very similar and may derive from the same source. If the PCB sources for the FL and $H U$ fractions of each sample were the same, then a strong qualitative similarity between FL and HU fractions of a given sample would be expected, barring selective incorporation processes. Even selective Incorporation or selective diagenetic processes could not explain the similarity of the HU fractions since the FL fractions reflect amblent assemblages of the same PCB peaks at different relative concentrations.

Given that PCB mixtures are subject to numerous types of environmental modification and that the agents of modification cannot be specifled with certainty for a given sample, it is not possible to definitively assign sources to free and bound PCB assemblages based on qualitative information. However, it seems likely that free $P C B$ 's were derived from the untreated, $P C B$-contaminated effluents that were discharged in large quantities by capacitor manufacturers near the New Bedford site and upriver from the Hudson River site. PCB's, often combined with olls for industrial use, could have been components of particle surface coatings that were extractable with organic solvents.

Possible sources for bound PCB's are more problematic. How ever, a qualitative trend may yield useful information about bound PCB sources: In samples $\mathrm{NB}(0-3), \mathrm{NB}(29-31)$, and $\mathrm{HR}$, the bound fractions displayed narrower ranges of homolog groups and greater relative concentrations of less chlorinated isomers than did FL fractions (Table III). (HA fractions are not included because procedural blanks revealed possible laboratory contamination.)

Table III. PCB Homolog Compositions of FL and HU Fractions (as wt. \%)

\begin{tabular}{lllllllllll}
\hline Sample & Fraction & $2 \mathrm{C} 1$ & $3 \mathrm{C} 1$ & $4 \mathrm{C} 1$ & $5 \mathrm{Cl}$ & $6 \mathrm{Cl}$ & $7 \mathrm{Cl}$ & $8 \mathrm{C} 1$ & $9 \mathrm{C} 1$ & $10 \mathrm{Cl}$ \\
\hline NB(0-3) & FL & 22 & 10 & 5.7 & 49 & 5.0 & 6.2 & 2.0 & 0.28 & - \\
& HU & 23 & 45 & 15 & 14 & 2.8 & 0.39 & 0.08 & - & - \\
$\mathrm{NB}(29-31)$ & FL & 6.7 & 6.7 & 8.0 & 49 & 21 & 6.9 & 2.2 & 0.09 & - \\
& HU & 30 & 12 & 15 & 34 & 6.8 & 1.3 & 0.29 & - & - \\
$\mathrm{HR}$ & $\mathrm{FL}$ & 9.4 & 31 & 19 & 22 & 7.1 & 2.7 & 4.4 & 1.4 & 3.4 \\
& $\mathrm{HU}$ & 18 & 46 & 19 & 13 & 1.8 & 0.75 & 2.0 & 0.61 & - \\
\hline
\end{tabular}

One possible explanation for this trend is that bound PCB's derived from an atmospheric source and were assoclated with soot particles. Several physicochemical properties of PCB's could favor the generation of atmospheric assemblages enriched in less chlorinated isomers; laboratory studies of PCB's demonstrate that there is a trend toward higher vapor pressure with decreasing chlorine content (37) and that photodecomposition selectively destroys higher 
chlorinated 1somers ( 38$)$. Furthermore, a possible source of atmospheric PCB's exists in the New Bedford area, as significant atmospheric loadings from incineration of $\mathrm{PCB}$-contaminated sewage sludge have been reported near the sample site $(32,33)$. PCB's associated with soot particles would be operationally defined as bound if they were inextractable with organic solvents but were released by saponiflcation.

Environmental transformation processes, such as microblal degradation, may have affected qualitative PCB distributions and may, in part, account for the greater abundances of less chlorinated isomers in bound relative to free PCB assemblages. oxidative microbial activity tends to selectively degrade less chlorinated $P C B$ 's $(36,39-41)$ whereas reductive microblal dehalogenation is thought to preferentlally affect more highly chlorinated PCB's (42). Thus, the effect of microbial activity would have depended on sedimentary redox conditions and on the relative accessibility of free and bound PCB's to microbes.

Saturated Hydrocarbons. Saturated hydrocarbons, like chlorinated hydrocarbons, tended to distribute predominantly in the FL fractions of sediments (Table IV). Simllar quantitative results were reported in studies of estuarine (녀) and lacustrine (44) sediments.

Table IV. Relative Saturated Hydrocarbon Distributions ${ }^{a}$

\begin{tabular}{|c|c|c|c|c|}
\hline Sample & $\overline{F L}$ & $\mathrm{HA}$ & HU & Total \\
\hline$\overline{\mathrm{NB}(0-3)}$ & $\begin{array}{l}99.8 \% \\
(10)^{\mathrm{b}}\end{array}$ & $0.11 \%$ & $\begin{array}{l}0.11 \% \\
(45)\end{array}$ & $719 \mathrm{ppm}$ \\
\hline $\mathrm{NB}(29-31)$ & $\begin{array}{l}99.8 \% \\
(10)\end{array}$ & $0.04 \%$ & $\begin{array}{l}0.17 \% \\
(28)\end{array}$ & 637 ppm \\
\hline HR & $\begin{array}{l}99.5 \% \\
(18)\end{array}$ & $0.05 \%$ & $\begin{array}{l}0.48 \% \\
(17)\end{array}$ & 204 ppm \\
\hline $\mathrm{LA}$ & $\begin{array}{l}99.9 \% \\
(10)\end{array}$ & $0.05 \%$ & $\begin{array}{l}0.09 \% \\
(67)\end{array}$ & 64 ppm \\
\hline \multicolumn{5}{|c|}{ a percent of total sedimentary concentrations } \\
\hline
\end{tabular}

Several lines of evidence suggest that all of the samples were from petroleum-contaminated areas: 1) FL fractions of all samples contained a large unresolved complex mlxture (UCM) of hydrocarbons with a broad bolling point range, which is a strong indication of petroleum contamination $(45,46), 2)$ the levels of total hydrocarbons were generally above levels consistent with blogenic production, and 3) a sertes of $(17 \alpha \mathrm{H}, 21 \mathrm{BH})$-hopanes, consldered to be good markers of petroleum contamination (47), were the predominant triterpenolds in FL fractions from all study areas.

A general pattern of hydrocarbon distribution characterizes samples $\mathrm{NB}(0-3), \mathrm{NB}(29-31)$, and LA: the UCM is the predominant component of FL fractions but is much less significant in HU fractions (see resolved/total values in Table IV; qualitative HA distributions will not be discussed as procedural blanks indicated possible laboratory contamination). This trend is most pronounced in 
sample LA (Figure 3), the HU fraction of which contains n-alkanes characteristic of terrestrial plant waxes (a predominance of $\mathrm{n}$ alkanes from $\mathrm{C}_{23}-\mathrm{C}_{31}$ with a high odd:even preference; 48-50) whereas the FL fraction has a large UCM whth superimposed terrestrial a1kanes. The NB samples display a similar trend but the HU fractions are more complicated (Figure 4). Peaks a and b, major components of the HU fractions, yielded mass spectra with molecular ions at $\mathrm{m} / \mathrm{z}$ 362 and base peaks at $\mathrm{m} / \mathrm{z} 81$. These unidentified compounds may be cyclic olefins with elemental compositions of $\mathrm{C}_{26} \mathrm{H}_{50}$. Sample HR is an exception to this trend and 1 ts FL and HU hydrocarbon distributions are similar, as can be inferred from the resolved/unresolved values in Table IV.

One possible explanation for the general trend in hydrocarbon distribution is that detrital particles (e.g., vascular plant fragments) contalning some solvent-inextractable hydrocarbons are major contributors to the HU hydrocarbon fractions, whereas the FL hydrocarbons (mostly petroleum hydrocarbons) exist as easily extractable components, perhaps as surface coatings on particles (43). A size fractionation study supports the idea that within a sedimentary matrix, hydrocarbons of different sources can be associated with distinct particle types or surfaces (51). If a portion of hydrocarbons in plant detritus were entrapped and unavallable to solvents during extraction, this material might be released during saponification.

Chlorinated Phenols: HCP and PCP. Two phenolic pollutants derivatized as methyl ethers, pentachlorophenol (PCP) and hexachlorophene (HCP or 2,2'-methylenebis(3,4,6-trichlorophenol)), eluted with $\mathrm{PCB}^{\prime} \mathrm{s}$ during TLC separation. The identitles of these compounds in samples were confirmed by comparison of retention times and mass spectra to those of methylated standards. Sallent features of these mass spectra are described by Buhler et al. (52).

In the two samples in which its presence was confirmed, $H R$ and $\mathrm{NB}(0-3)$, HCP occurred only in HA fractions and was a major chlorinated component of these fractions. Figure 5 depicts this distribution pattern in sample HR. Note that the chlorinated phenols, HCP and PCP, were essentially the only chlorinated compounds in the HA fraction. HCP may have occurred in the HA fractions of samples LA and $\mathrm{NB}(29-31)$ but was not confirmed due to low concentrations. HCP was not detected in any blanks.

The occurrence of HCP in HA fractions and 1 ts absence in FL fractions suggests that the pollutant was strongly associated with organic matter and was probably deposited in the sediments in bound form. HCP may have been covalently bound to organic matter and released hydrolytically during base treatment. Laboratory studies support these observations: M11ler et a1. (53) demonstrated that HCP covalently binds to rat tissue protein (in vitro) and Mathur and Morley (54) showed that a structurally similar compound, methoxychlor (2,2'-b1s (p-methoxyphenyl)1,1,1-trichloroethane), strong1y associated with a synthetic humlc acid.

While some HCP may have been recovered with FL fractions if Soxhlet extractions had been performed at lower pH's, PCP distributions (Table V) indicate that the 3:1 methano1/toluene mixture was capable of efficiently extracting phenolic compounds and that inter- 

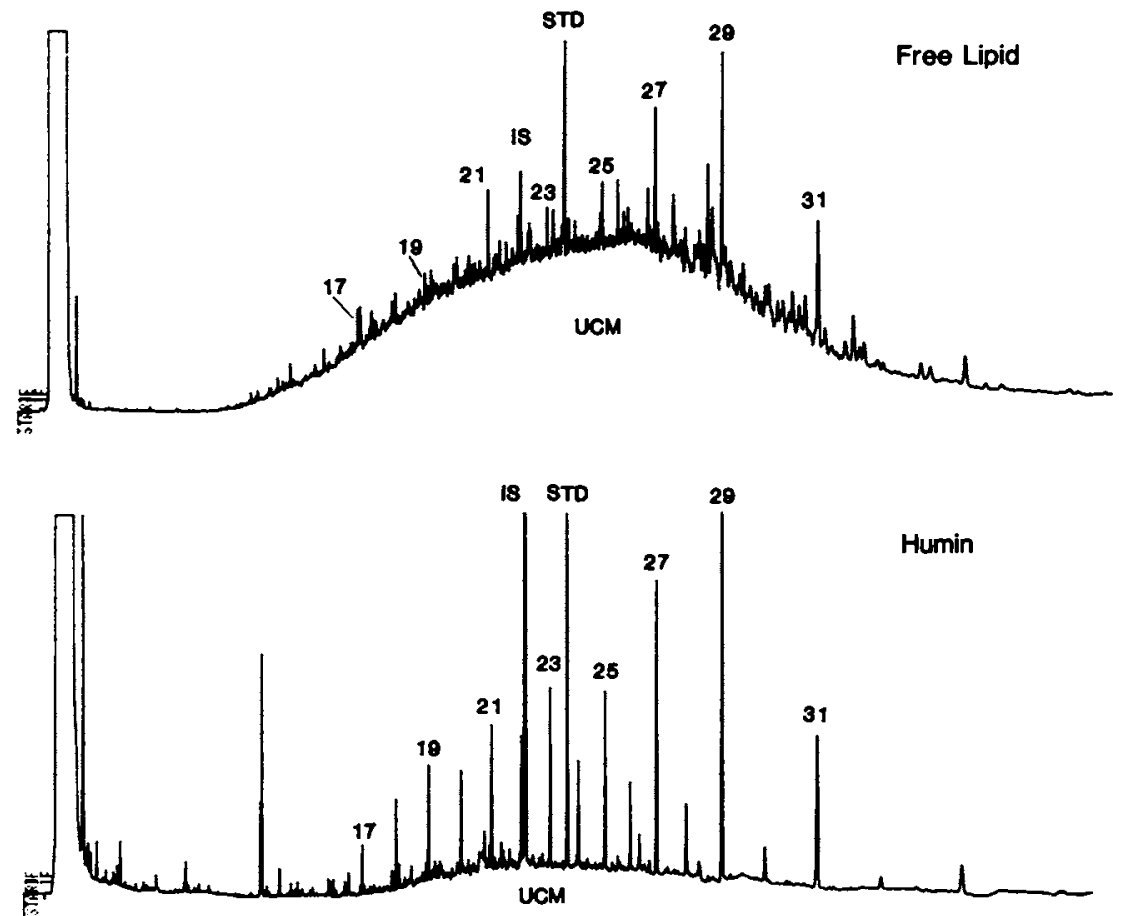

Figure 3. Capillary GC-FID traces of saturated hydrocarbons in FL and HU fractions of sample LA. STD - co-Injection standard, perdeuterated tetracosane; IS - Internal standard, p-terphenyl; UCM - unresolved complex mixture. Chain lengths of odd-numbered n-alkanes are denoted.

In Organic Marine Geochemistry; Sohn, M.;

ACS Symposium Series; American Chemical Society: Washington, DC, 1986. 


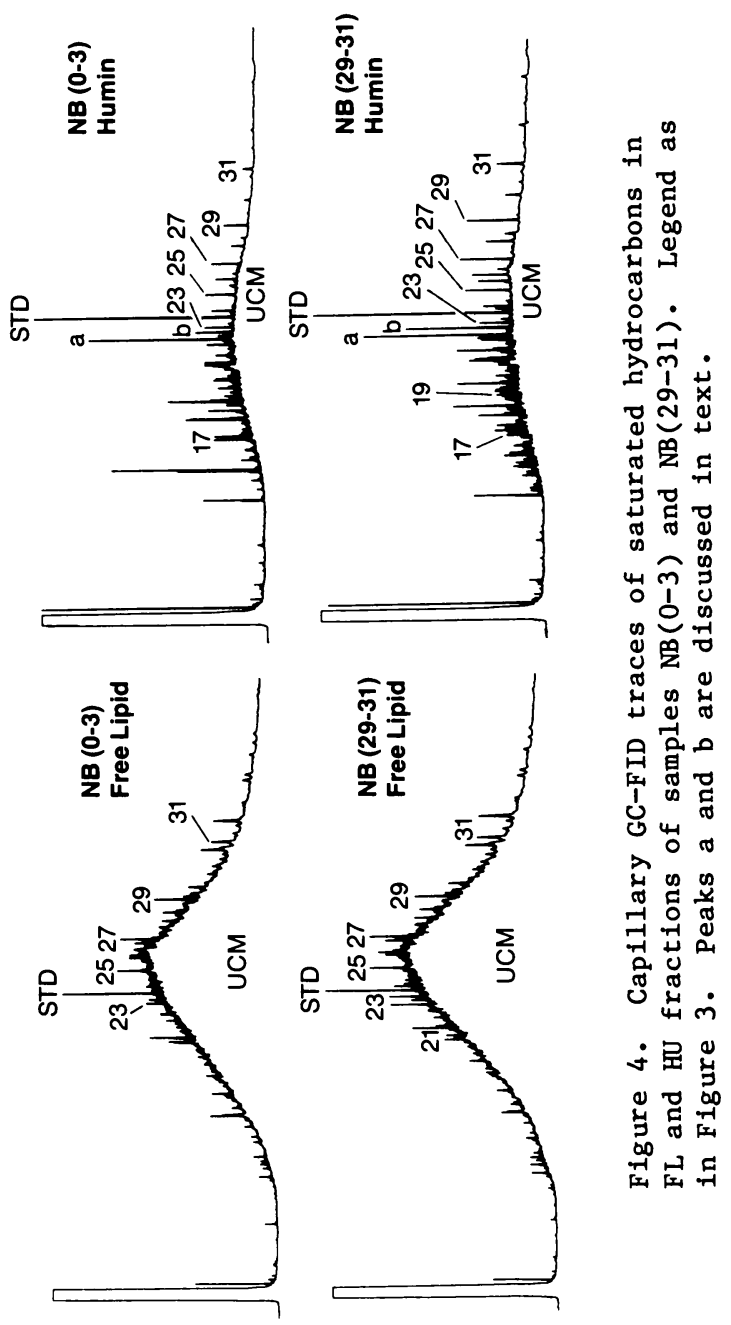

In Organic Marine Geochemistry; Sohn, M.; 


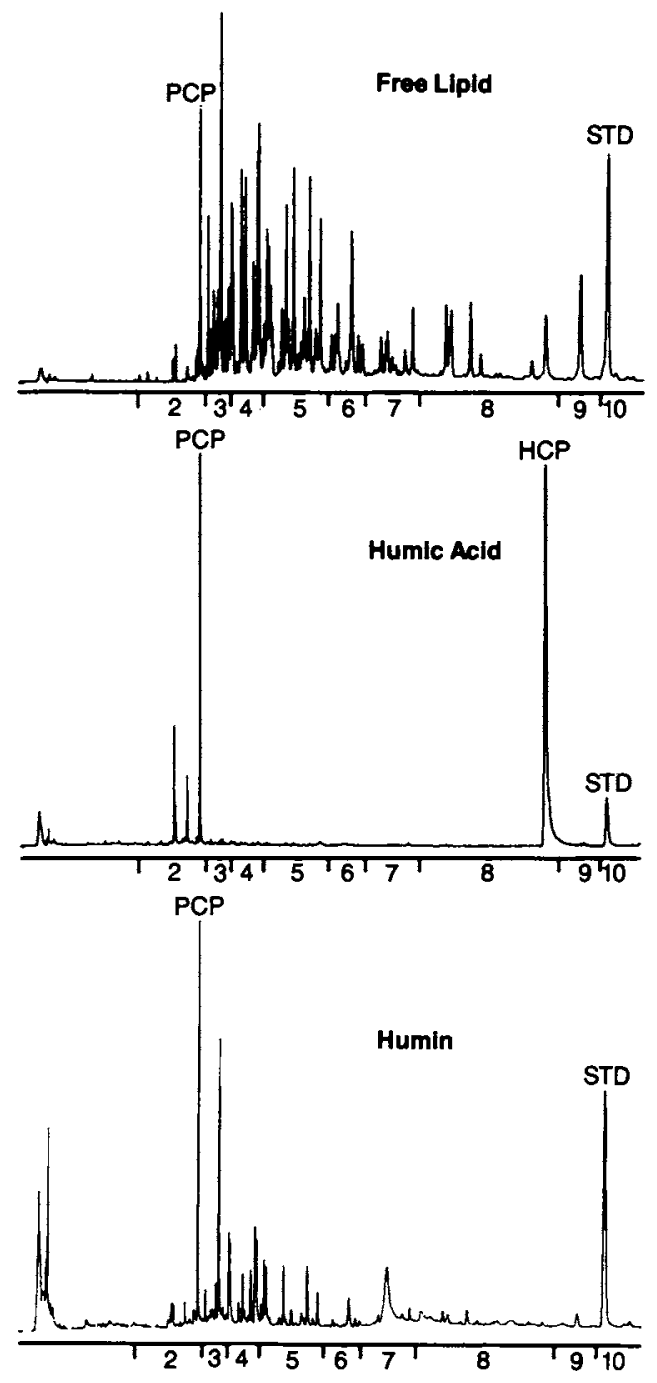

Figure 5. Cap1llary GC-ECD traces of FL, HA, and HU fractions of sample HR. PCP - pentachlorophenol (as methyl ether derivative); HCP - hexachlorophene (as dimethyl ether derivative); STD - decachlorobiphenyl. Approximate $\mathrm{PCB}$ homolog elution ranges are delineated.

In Organic Marine Geochemistry; Sohn, M.;

ACS Symposium Series; American Chemical Society: Washington, DC, 1986. 
sample differences in phenolic distributions were controlled by factors other than the $\mathrm{pH}$ of Soxhlet extraction (which was the same for all samples).

The detection of HCP in environmental samples is noteworthy not only because of 1 ts unique distribution, but also because it is seldom reported in environmental 11terature. Apparently, only two papers document environmental HCP distributions and both were written in the early to mid $1970^{\prime} \mathrm{s}$. HCP concentrations in the ppb range were reported for municipal sewage effluents (52) and for water and sediments near sewage outfalls (55). The comnercial use of HCP, a powerful bacteriostatic agent and germicide, has been greatly reduced since a ban was instituted by the FDA in 1972. However, HCP is very persistent: a laboratory study revealed that HCP was apparently not degraded in river water and had a "half 1 ife" of 290 days in estuarine sediments at $22{ }^{\circ} \mathrm{C}(56)$. Furthermore, the environmental release of HCP after 1972 is plausible since some hospitals st111 use the chemical and may discharge their effluents through municipal sewage treatment plants.

PCP, a general blocide widely used as a wood preservative, may also have been chemically bound to sediments, although the evidence for this is not as strong as that for HCP. Table $V$, which presents PCP concentrations for FL, HA, and HU fractions of all samples, shows that PCP was a more significant component of bound fractions than were the less polar PCB's. Simllarly, Murthy et al. found that PCP and a microbially methylated metabolite, pentachloroanisole, bound to HA and HU fractions of aerobic and anaerobic solls over a 24 day laboratory incubation period (57).

Table V. Relative PCP Distributions (as $\%$ of total sed. conc.)

\begin{tabular}{llll}
\hline Sample & FL & HA & HU \\
\hline NB(0-3) & $38 \%$ & $17 \%$ & $45 \%$ \\
NB $(29-31)$ & $74 \%$ & $3 \%$ & $23 \%$ \\
HR & $86 \%$ & $9 \%$ & $5 \%$ \\
LA & $94 \%$ & $2 \%$ & $3 \%$ \\
\hline
\end{tabular}

\section{Conclusions}

1) Over $90 \%$ of total sedimentary PCB's and petroleum hydrocarbons were recovered with FL fractions.

2) Qualitative PCB and hydrocarbon distributions among organic matter fractions suggest that free and bound assemblages may derive from different sources in a given sediment.

3) Polar pollutants, such as chlorinated phenols, can occur largely as chemically bound components of refractory organic matter.

4) Selective extraction could be a useful technique for investigating chemically bound pollutants, which are not detectable by conventional solvent extraction. 


\section{Acknowledgments}

Samples and background information were generously provided by Bruce Brownawe 11 and Dr. J. Farrington (New Bedford samples), Dr. R. Bopp (Hudson River sample), and Tony Phillips (Los Angeles sample). We thank Dr. F. I. Onuska for donating the $1: 1: 1$ Aroclor standard and Dr. F. Prahl, James Butler, and Orest Kawka for their helpful comments on the investigation and manuscript.

\section{Literature Cited}

1. Bopp, R.F.; Simpson, H.J.; Olsen, C.R.; Kostyk, N. Env. Sci. \& Tech. $1981,15,210-16$.

2. Chiou, C.T.; Peters, L.J.; Freed, V.H. Science 1979, 206, 83132.

3. Dexter, R.N.; Pavlou, S.P. Mar. Chem. 1978, 7, 67-84.

4. Pavlou, S.P.; Dexter, R.N. Env. Sci. \& Tech. 1979, 13, 65-71.

5. Abdullah, M.I.; Kveseth, N.J.; Ringstad, 0. Water, Air Soll Poll. 1982, 18, 485-97.

6. Cho1, W.W.; Chen, K.Y. Env. Sci. \& Tech. 1976, 10, 782-86.

7. Halcrow, W.; Mackay, 0.W.; Bogan, J. Mar. Poll. Bull. 1974, $5,134-36$.

8. Hiraizumi, Y.; Takahashi, M.; N1shimura, H. Env. Sci.\& Tech. 1979, 13, 580-84.

9. Karickhoff, S.W.; Brown, D.S.; Scott, T.A. Water Research $1979,13,241-48$.

10. Schwarzenbach, R.P.; Westa11, J. Env. Sc1. \& Tech. 1981, 15, 1360-1367.

11. Steen, W.C.; Paris, D.F.; Baughman, G.L. Water Research 1978, $12,655-57$.

12. Wildish, D.J.; Metcalfe, C.D.; Akag1, H.M.; McLeese, D.W. B. Env. Contam. Tox. 1980, 24, 20-26.

13. Diachenko, G.W. Ph.D. Thes1s, University of Maryland, 1981.

14. Haque, R.; Schmedding, D. J. Env. Sc1. Health 1976, B11, 129137 .

15. Pierce, R.H., Jr.; Olney, C.E.; Felbeck, G.T., Jr. Geochim. Cosmoch1m. Acta 1974, 38, 1061-1073.

16. Sawhney, B.L.; Frink, C.R.; Glowa, W. J. Env.Qual. 1981, 10, 444-48.

17. Carter, C.W.; Suffet, I.H. Env. Sci.\& Tech. 1982, 16, 735-40.

18. Hassett, J.P.; Anderson, M.A. Env. Sci.\& Tech. 1979, 13, 1526-1529.

19. Landrum, P.F.; Nihart, S.R.; Ead1e, B.J.; Gardner, W.S. Env. Sci. \& Tech. 1984, 18, 187-92.

20. Lichtenstein, E.P.; Katan, J.; Anderegg, B.N. J.Agric. Food Chem. 1977, 25, 43-47.

21. Fales, H.M.; Jaouni, T.M.; Babashak, J.F. Ana1. Chem. 1973, $45,2302-2303$.

22. Ballschmiter, K.; Zel1, M. Fresenius 2. Anal. Chem. 1980, 302, 20-31.

23. Duinker, J.C.; Hillebrand, M.T.J. Env. Sc1.\& Tech. 1983, 17, 449-56.

24. Mullin, M.D.; Pochini, C.M.; McCrindle, S.; Romkes, M.; Safe, S.H.; Safe, L.M. Env. Sci.\& Tech. 1984, 18, 468-76. 
25. Onuska, F.I.; Kominar, R.J.; Terry, K.A. J. Chromatography $1983,279,111-18$.

26. Dulnker, J.C.; HIllebrand, M.T.J.; Palmork, K.H.; W1lhelmsen, S. B. Env. Contam. Tox. $1980,25,956-64$.

27. Albro, P.W.; Corbett, J.T.; Schroeder, J.L. J. Chromatography $1981,205,103-11$.

28. Albro, P.W.; Parker, C.E. J. Chromatography 1979, 169, 161-66.

29. Wellky, K.; Suess, E.; Ungerer, C.A.; Muller, P.J.; Flscher, K. Limnology and Oceanography 1983, 28, 1252-59.

30. Summerhayes, C.P.; E111s, J.P.; Stoffers, P.; Briggs, S.R.;

Fitzgerald, M.G. WHOI Tech. Report, WHOI-76-115, 1977.

31. Metcalf and Eddy, Inc. "Acushnet Estuary PCB's Data ManagementFinal Report"; for EPA Region I, 1983.

32. Weaver, G. Env. Sc1. \& Tech. 1984, 18, 22A-27A.

33. Weaver, G. "PCB Pollution In the New Bedford, Mass. Area: A Status Report", Mass. Coastal Zone Management, 1982.

34. Bopp, R.F.; Simpson, H.J.; Olsen, C.R.; Trier, R.M.; Kostyk, N. Env. Sc1. \& Tech. 1982, 16, 666-76.

35. Hetling, L.; Horn, E.; Tofflemire, J. "Sumary of Hudson River PCB Study Results", N.Y. State D.E.C., Tech. Paper \#51, 1978.

36. Furukawa, K.; Tonomura, K.; Kamtbayash1, A. Appl. Env. Microbiol. 1978, 35, 223-27.

37. Bopp, R. J. Geophys. Research 1983, 88, 2521-2529.

38. Hutzinger, 0.; Safe, S.; Z1tko, V. "The Chemlstry of PCB's"; CRC Press: Cleveland, Oh1o, 1974.

39. Furukawa, K.; Matsumura, F. J. Agr. Food Chem. 1976, 24, 25156.

40. Clark, R.R.; Chlan, E.S.K.; Griffin, R.A. Appl. Env. Microbio1. 1979, 37, 680-85.

41. Tucker, E.S.; Saeger, V.W.; Hicks, 0. B. Env. Contam. Tox. $1975,14,705-13$.

42. Brown, J.F., Jr.; Wagner, R.E.; Bedard, D.L.; Brennan, M.J.; Carnahan, J.C.; May, R.J.; Tofflemire, T.J. Northeastern Environmental Sclence 1984, 3, 167-179.

43. Van Vleet, E.S.; Quinn, J.G. J. Fish. Res. Board Can. 1978, $35,536-43$.

44. Cranwel1, P.A. Org. Geochem. 1981, 3, 79-89.

45. Boehm, P.D.; Quinn, J.G. Est. Coast. Mar. Sci. 1978, 6, 741-94.

46. Farrington, J.W.; Quinn, J.G. Est. Coast.Mar. Sci. 1973, 1, 71-79.

47. Simone1t, B.R.T.; Kaplan, I.R. Mar. Env. Research 1980, 3, 113128.

48. Eglinton, G.; Hamilton, R.J. Science 1967, 156, 1322-1335.

49. Simonelt, B.R.T. In "Chemical Oceanography"; RIley, J.P.; Chester, R., Eds.; Academlc Press: N.Y., 1978; Vo1. 7, Chap. 39, pp. 233-311.

50. Smith, D.J.; Eglinton, G.; Morris, R.J. Gecochim. Cosmochim. Acta 1983, 47, 2225-2232.

51. Thompson, S.; Eglinton, G. Geochim. Cosmochlm. Acta 1978, 42, 199-207.

52. Buhler, D.R.; Rasmusson, M.E.; Nakaue, H.S. Env. Sci. \& Tech. 1973, 7, 929-34.

53. Miller, A., III; Henderson, M.C.; Buhler, D.R. Molecular Pharmaco1. 1978, 14, 323-36. 
54. Mathur, S.P.; Morley, H.V. B. Env. Contam. Tox. 1978, 20, 26874 .

55. SIms, J.L.; Pfaender, F.K. B. Env. Contam. Tox. 1975, 14, 21420 .

56. Lee, R.F.; Ryan, C. Proc. Workshop: Microblal Degradation Pollut. Mar. Env1., 1979, pp. 443-50. EPA-600/9-79-012.

57. Murthy, N.B.K.; Kaufman, D.D.; Fries, G.F. J.Env. Sc1. Health $1979, \mathrm{~B} 14,1-14$.

RECEIVED September 16, 1985

In Organic Marine Geochemistry; Sohn, M.;

ACS Symposium Series; American Chemical Society: Washington, DC, 1986. 


\title{
Fate of Carbonized Coal Hydrocarbons in a Highly Industrialized Estuary
}

\author{
Terry L. Wade ${ }^{\text {, }}$ Mahlon C. Kennicutt II ${ }^{\prime}$, and Elizabeth G. Merrill ${ }^{2}$ \\ ${ }^{1}$ Department of Oceanography, Texas A\&M University, College Station, TX 77843 \\ ${ }^{2}$ Department of Environmental Regulations, Jacksonville, FL 32207
}

\begin{abstract}
Fluorescence and GC/MS analyses show that carbonized coal hydrocarbons are widespread contaminants of sediments in the Elizabeth River, Norfolk, Va. The highest levels are found in the vicinity of suspected sources and generally decrease with increased distance from these sources. Parent aromatic compounds are the predominant hydrocarbon component of carbonized coal and can be uniquely detected even in the presence of petroleum hydrocarbons. Carbonized coal products are a chronic source of priority pollutant polynuclear aromatic hydrocarbons in the Elizabeth River.
\end{abstract}

Determination of the quantities and types of anthropogenic hydrocarbons in the marine environment is essential in order to understand their fates and long- and short-term effects. Of particular interest are the polynuclear aromatic hydrocarbons (PNA's), because some of these compounds are known carcinogens. One of the major sinks for hydrocarbons released in the coastal environment is their incorporation into bottom sediments (1). Sediments near large urban areas may contain high concentrations of anthropogenic hydrocarbons due to their proximity to source areas ( $\underline{2})$. Resuspension of contaminated sedimentary material by natural (tides, storms, etc.) or by artificial (dredging, shipping, etc.) means can disperse these pollutants to areas much larger than were originally effected.

The Elizabeth River is located in a highly industrialized urban area and empties into lower Chesapeake Bay. The river is a major shipping channel for the Norfolk area and is regularly dredged to deepen channels or bulld new docking facilities. The industries along the river that could be considered potential sources of hydrocarbons include marine shipping terminals, ship drydock facilities, sewage treatment plants, wood preserving facilities, a coal-fired electric power plant, dredging operations, and a dredge disposal site.

Due to the large number of creosoted docking facilities, the existence of wood preserving plants, and the occurrence of creosote

$0097-6156 / 86 / 0305-0215 \$ 06.00 / 0$

c) 1986 American Chemical Society 
spills in the past, creosote may be a major contributor of PNA's to Elizabeth River sediments.

The objectives of this study were to characterize the hydrocarbon signature in carbonized coal products (creosote and coal tar), and then using this signature, determine if carbonized coal products are a contaminant of Elizabeth River sediments, and whether this contamination is transported into Chesapeake Bay. The carbonized coal product signature was developed using capillary gas chromatography (GC), gas chromatography/mass spectroscopy (GC/MS), and total scanning fluorescence.

\section{Methods and Materials}

Sediment samples were collected using a grab sampler (which samples approximately the top $10 \mathrm{~cm}$ ) aboard 01d Dominion University's research vessels, $O D U-1$ and Linwood Holton. The sample locations are shown in Figure 1 . The samples were stored frozen in clean, solvent-washed jars until analyzed. Creosoted wood samples were collected from areas adjacent to the Elizabeth River (Figure 1). Three samples of refined creosote and one sample of coal tar were also analyzed. Creosote samples from Atlantic Wood Industries, the remaining operative creosoting facility on the Elizabeth River, were not available. The woodstove soot sample was obtained from a domestic woodstove in which predominantly hardwoods were burned. The diesel stack soot sample was taken from the Linwood Holton. The No. 2 Fuel 011 sample is of the type used locally for home heating. The Kuwait Crude 011 was kindly supplied by Robert Brown of Mote Marine Lab, Sarasota, Florida.

Sediment samples were thawed and mixed to ensure homogeneity. The dry weight and percent water content of the sediments were determined by drying approximately $5 \mathrm{~g}$ of the sediment at $105-110^{\circ} \mathrm{C}$ for several hours until a constant weight was reached. Grain-size distribution was determined by wet sieving and pipette analysis.

For hydrocarbon GC and GC/MS analysis, sediment or other solid sample (such as creosoted wood, soot, etc.) was placed in a $50-\mathrm{m} 1$ centrifuge tube; internal standards, n-eicosane (n-C20) and 3methylfluoranthene, were added and the sample was saponified/ extracted (Metholic $\mathrm{KOH}$ ) ( $(3)$. Sediment hydrocarbon concentrations determined using the above test tube extraction technique were within the range of concentrations determined by Soxhlet and reflux/saponification extraction of larger sediment samples (4). Liquid samples (such as creosote, oil, etc.) were analyzed by dissolving the sample in dichloromethane. The aliphatic ( $f 1$ ) and aromatic (f2) hydrocarbons were separated from other organics by thin-layer chromatography (TLC) $(\underline{5,6})$.

The ILC sample fractions were injected on a Hewlett-Packard Mode1 5830 gas chromatograph equipped with a $25-\mathrm{m} \mathrm{SE}-54$ fused silica capillary column, utilizing a flame ionization detector (FID). The signal from the FID was recorded by a Hewlett-Packard Model $18850 \mathrm{~A}$ reporting integrator. The gas chromatograph was programmed from $70^{\circ} \mathrm{C}$ to $300^{\circ} \mathrm{C}$ at $10^{\circ} \mathrm{C}$ per minute.

Quantitative determinations of hydrocarbon concentrations were made by comparing integrator area counts of the internal standard with integrator area counts of the peaks or planimetry of the 


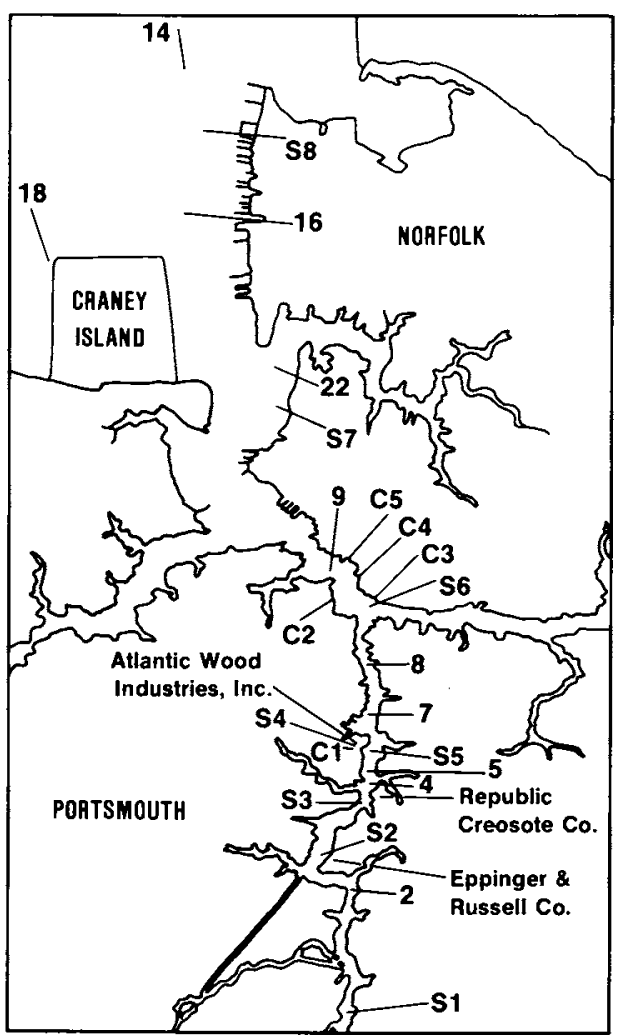

Figure 1. Sampling locations for creosoted wood (C) and sediments (S) and the location of the wood preserving facilities on the Elizabeth River, Norfolk, VA.

In Organic Marine Geochemistry; Sohn, M.;

ACS Symposium Series; American Chemical Society: Washington, DC, 1986. 
unresolved complex mixture. Qualitative determination of hydrocarbons in the samples were made by comparison of retention times of known compounds, co-injection with known compounds, and by GC/MS . A Finnigan OWA-Model 20 mass spectrometer coupled to a Sigma 3B gas chromatograph was used for the GC/MS analysis. Procedural blanks and standards were run systematically throughout the analysis period to determine if contamination had occurred and to ensure the proper functioning of the gas chromatograph. The sample values reported are corrected for the presence of these procedural blanks.

Samples for fluorescence analyses $(15 \mathrm{~g})$ were lyophilized, ground to a uniform size with a mortar and pestle, and Soxhlet extracted with hexane for 12 hours. All glassware and alundum thimbles were pre-cleaned with Micro cleaning solution, washed with nanograde solvents, and combusted at $500^{\circ} \mathrm{C}$ for at least 4 hours. The extracts were concentrated to a volume of about $5 \mathrm{ml}$ using a Buchi Rotovapor R. Care was exercised at all times to ensure that the extract was not brought to complete dryness to prevent volatilization of lighter sample components. The volume of the extract was brought up to $7 \mathrm{ml}$ and stored at $4^{\circ} \mathrm{C}$ in the dark until further analysis. This treatment minimizes photolytic losses and the chemical interactions of the extracted compounds. A total system blank was routinely run for every set of samples processed and checked by both fluorescence and gas chromatography to ensure acceptable blank levels.

The extract was scanned to acquire a three-dimensional fluorescence spectra of emission wavelength, excitation wavelength, and intensity using a Perkin-Elmer Model 650-40 UV-spectrofluorometer. This fluorometer is controlled by a Perkin-Elmer Model 3500 or 3600 data station. The total fluorescence excitation-emission wavelength array is filled for each sample by sequential stepping of the excitation monochromator over the wavelength range of interest and scanning with the emission monochromator. Standard wavelength intervals are 200-500 nm for both excitation and emission.

\section{Results}

$\mathrm{GC}$ and GC/MS. A detailed discussion of the results of the GC and GC/MS analyses will be presented elsewhere (3). Gas chromatograms of hydrocarbon distributions provide a visual comparison of the similarities and differences between carbonized coal products, oil products, and sediment samples. Chromatograms of the aliphatic (f1) and aromatic (f2) fractions of Creosote A, the oil spill sample, and sediments from Station $S 6$ are shown in Figures 2, 3 , and 4 , respectively. The $\mathrm{f} 1$ and $\mathrm{f} 2$ fractions may contain resolved peaks and a UCM. The fl fraction contains resolved peaks including n-alkanes, pristane and phytane. The resolved f2 peaks were divided into three groupings (Figure 2). The first group (PP) consists of the 16 Environmental Protection Agency priority pollutant PNA's ( $Z$ ). The second group consists of 25 other major resolved peaks (MRP) that were found in most of the creosote samples. These peaks were identified by comparison of peak retention times, co-injection with standards, and/or confirmation 


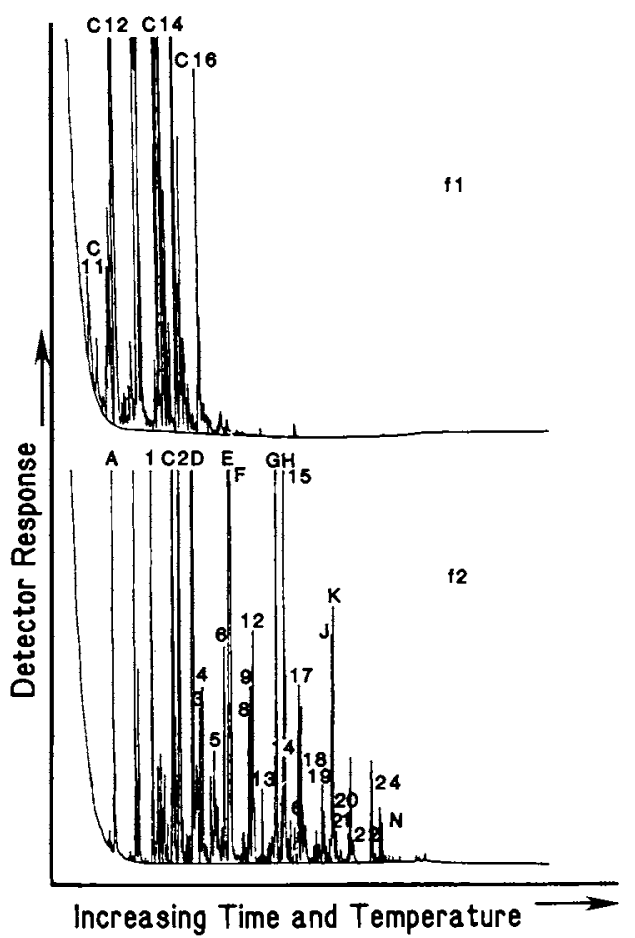

Figure 2. Gas chromatograms of the aliphatic (f1) and aromatic (f2) fractions of Creosote $A$. The f1 fraction contains identified $n$-alkanes in the range of $n$-C11 through $n$-C16.

In Organic Marine Geochemistry; Sohn, M.; ACS Symposium Series; American Chemical Society: Washington, DC, 1986. 


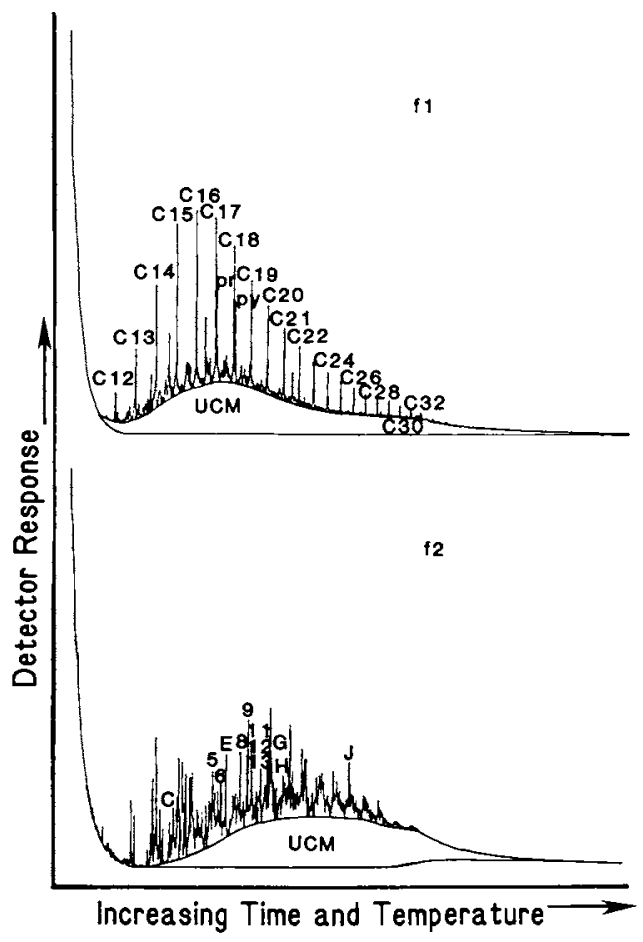

Figure 3. Gas chromatograms of the aliphatic ( $f 1$ ) and aromatic (f2) fractions of the oil spill sample. The fl fraction contains identified $n$-alkanes in the range of $n-C l 2$ through $n$ C32 and pristane (pr) and phytane (py). UCM-unresolved complex mixture.

In Organic Marine Geochemistry; Sohn, M.; ACS Symposium Series; American Chemical Society: Washington, DC, 1986. 


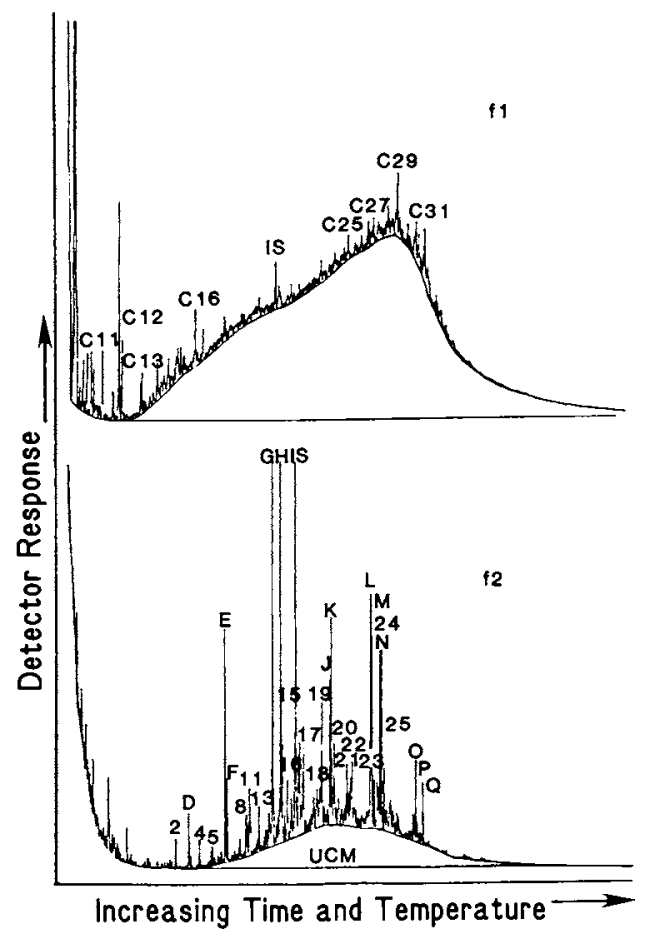

Figure 4. Gas chromatograms of the aliphatic (f1) and aromatic (f2) fractions of the sediment sample from station S6. The f1 fraction contains identified $n$-alkanes in the range of $n-C 11$ through $n-C 31$. UCM-unresolved complex mixture, IS-internal standard.

In Organic Marine Geochemistry; Sohn, M.; 
by GC/MS. Specific peak Identities and the level of Identification (8) are given elsewhere (3). The third group of peaks consists of all of the remaining resolved peaks (RRP). All carbonized coal products had chromatograms similar to that shown by Figure 2. Few n-alkanes of higher molecular welght than $\mathrm{n}-\mathrm{Cl} 6$ were detected and n-C15, normally present in unweathered petroleum and biogenic samples ( $(9)$, was not usually detected. The carbonized coal products contalned 28 or less of their hydrocarbons in the form of an unresolved complex mixture, with the majority (41-638) of the hydrocarbons present as resolved PP (Figure 2). Roof tar and coal tar, which are by-products of the coal tar distillation process $(\underline{10})$, had distributions similar to that of creosote, but with a greater relative percent of the higher molecular weight compounds.

In contrast, the fl fraction of the oil spill sample (Figure 3) has a homologous series of n-alkanes from n-C12 through n-C31 with the dominant peaks in the $n-C 15$ through $n-C 18$ range. There is also a UCM in both the $f 1$ and $f 2$ fractions. There are resolved peaks in the f2 fraction including some PP, but they constitute less than 18 of the hydrocarbons on a weight percent basis. The Kuwait Crude 011 has no detectable aliphatic UCM which is unusual for weathered petroleum products (11). Woodstove soot, No. 2 Fuel 011, diesel stack soot, the oil spill sample, and Kuwalt Crude 011 all contained a substantial percentage of their $f 2$ hydrocarbon in the form of a UCM. With the exception of woodstove soot, the f2 fractions of these samples contained the highest percentages of RRP and the lowest percentages of PP. Woodstove soot contained 218 PP and 14.28 RRP.

The chromatogram of the sediment sample extract (Figure 4) has a hydrocarbon distribution that could be the result of weathered petroleum products mixed with carbonized coal products. There is a UCM present in both the f1 and $f 2$ fractions, similar to the oil spill sample (Figure 3 ). The resolved fl fraction contained lower molecular weight (n-C16 and below) n-alkanes, but n-C15 was not detected, as with the creosote sample (Figure 2). The higher molecular weight resolved n-alkane peaks, $n-C 25,27,29$ and 31 are Indicative of a biogenic input (12). The resolved peaks in the $f 2$ fraction are also similar to resolved f2 peaks found in the creosote sample (Figure 2).

Hydrocarbon concentrations determined by GC for the sediment samples ranged from 0.1 to $2.9 \mathrm{mg} / \mathrm{g}$. The concentrations are within the range of values previously reported for the Elizabeth River $(13,14)$. Hydrocarbons have been shown to be preferentially associated with fine-grained sediments $(5,15)$. The f2 fractions normalized to fine-grain sediment content (16) have decreasing aromatic hydrocarbon concentrations with increasing distance from the area of the creosoting facility sites, indicating the probability of an aromatic hydrocarbon source in this area. The fl normalized fraction does not have a similar decreasing concentration pattern, but instead has varled concentrations along the length of the Elizabeth River, Indicating the presence of multiple sources for the aliphatic hydrocarbons which do not add sufficient quantities of aromatic hydrocarbons to influence the decreasing concentration pattern of the 12 fraction (5). 
Fluorescence Analysis. Aromatic compounds constitute a very high percentage of carbonized coal products (17), and therefore these compounds may provide a useful fingerprint for carbonized coal products. Fluorescence methods are particularly useful for the detection and measurement of complex organic compounds containing one or more aromatic functional groups. Petroleum contains significant amounts of aromatics with one to four (or more) aromatic rings and their alkylated analogues. The aromatic composition of an oll provides a distinctive fingerprint which can be used in conjunction with other analyses to provide additional typing information $(18,19)$. The distribution of aromatic compounds in carbonized coal products may provide a unique fluorescence fingerprint.

Fixed wavelength and synchronous scanning fluorescence suffer from non-selectivity and are generally ineffective in structural elucidation (particularly for mixtures). Despite the ability to select both the excitation and emission wavelengths, the conventional luminescence methods have limited applicability since most spectra of complex mixtures often cannot be satisfactorily resolved. The use of a computer-controlled total scanning fluorometer can overcome many of the limitations of previous methods.

The three-dimensional fluorescence spectra of a creosote sample, a sediment sample from the vicinity of the creosote facilities (S5), a sediment sample from the entrance to the Elizabeth River (S8), and No. 2 Fuel 011 are shown in Figure 5. The fluorescence spectra for the creosote (a) and the sediment extract from Station S5 (b) are very similar, while the extract from station $\mathbf{5 8}$ has no emission at lower wavelengths (Table I). This difference can be quantified based on a statistical point-topoint comparison of spectra (20). On a scale of 0 to 1 , a similarity index (SI) of 1 indicates that the two spectra are identical and a SI of zero means they are completely dissimilar. This type of comparison uses more than 800 individual spectral intensities under the given instrumental conditions. Fluorescence SI between a creosote sample and sediment extracts near the spil1 range from 0.90 to 0.81 . The SI decreases away from the spili to $\sim 0.65$ at the mouth of the Elizabeth River and to -0.40 in the bay proper. Different creosotes also showed significantly different fluorescence signatures, suggesting that multiple creosote sources may be discernible by fluorescence fingerprinting. Three-

dimensional fluorescence spectra provide a unique fingerprint for creosote. The fluorescence spectra of a No. 2 Fuel oil (d) is significantly different from the creosote $(\mathrm{SI}-0.6$ ) and sediment spectra (SI $=0.63$ to 0.14 ) (Table I).

The maximum fluorescence intensities of emission spectra at selected wavelengths are given in Table $I$. There is a general pattern of higher intensities at stations near the creosoting facilities ( 33 and $\mathrm{S} 5$ ), and lower intensities at stations both upstream and downstream ( $\mathrm{S} 1$ and S8). Maximum fluorescence intensity for individual compounds is related to concentration, though it is not always linear when mixtures are analyzed. At six stations both fluorescence and total aromatic hydrocarbon concentration measured by GC were available (Table I). The maximum 

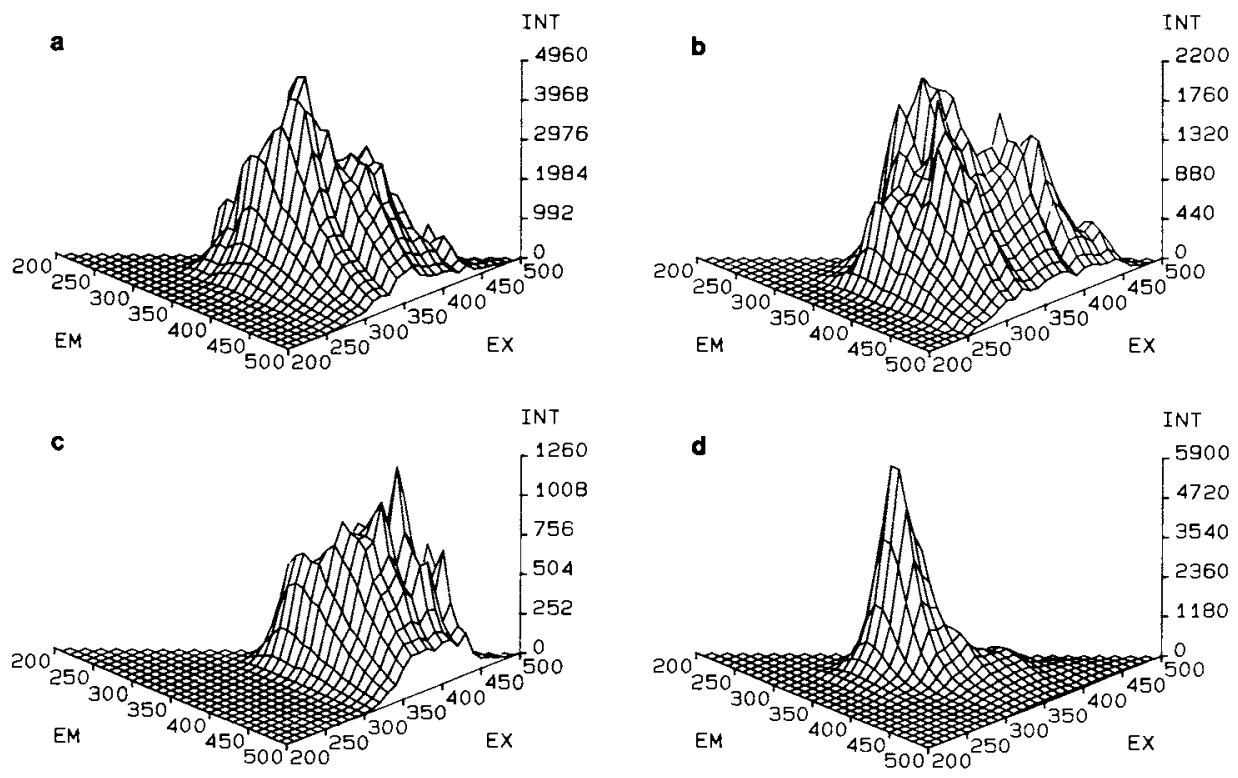

Figure 5. Three-dimensional total scanning fluorescence of a) creosote, b) S5, c) S8, d) No. 2 Fuel 011.

In Organic Marine Geochemistry; Sohn, M.;

ACS Symposium Series; American Chemical Society: Washington, DC, 1986. 


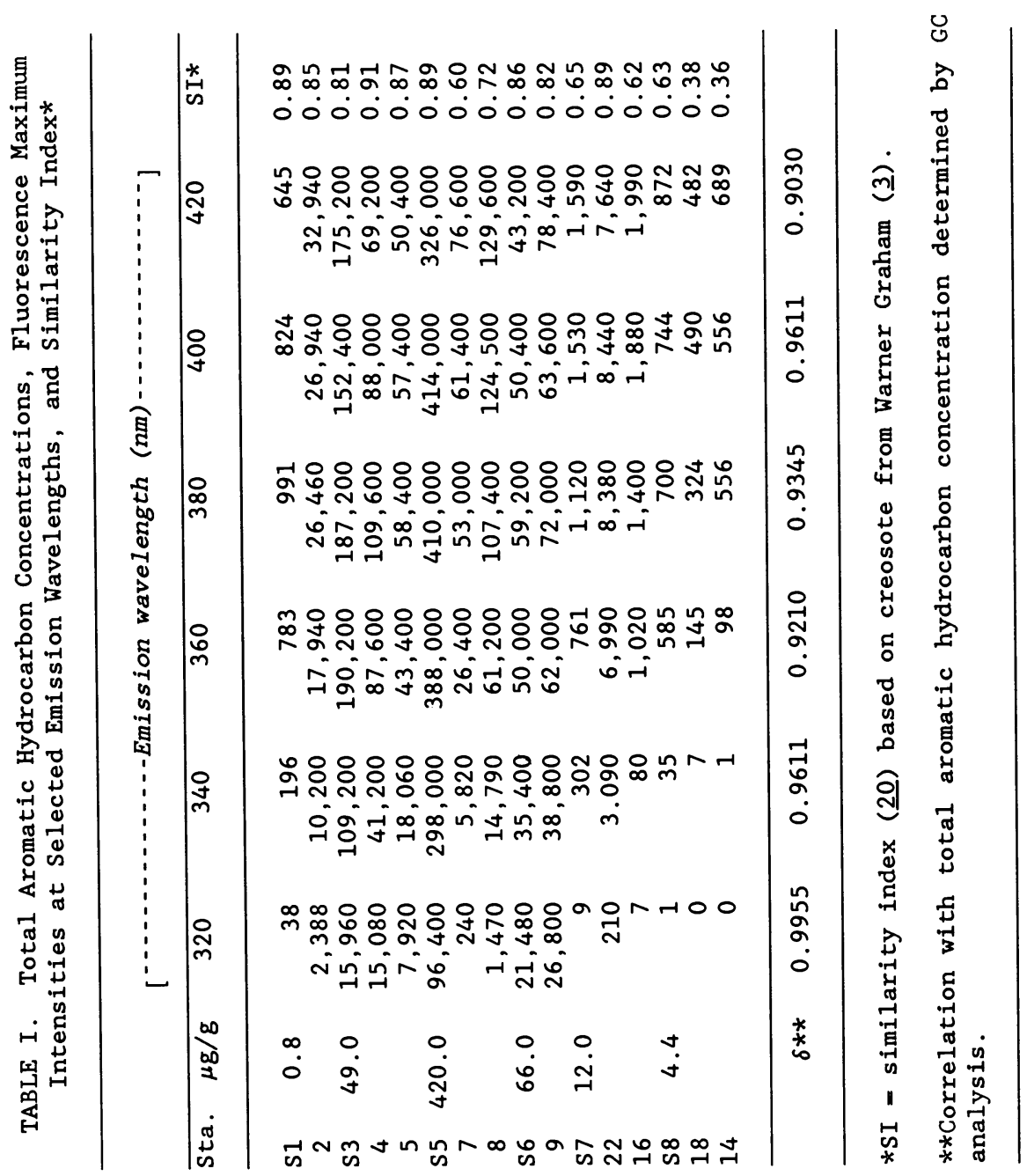


intensity of fluorescence emission was found to be linearly related to total aromatic hydrocarbon concentration with correlation coefficients that range from 0.9030 to 0.9955 (Table I).

The fluorescence data support the conclusions from the GC data that creosote is a contaminant of Elizabeth River sediments. Because fluorescence is more sensitive and a less labor-intensive analytical technique, it is possible to process more samples at a lower cost than by GC techniques. Total scanning fluorescence, therefore, would be a useful tool for prescreening large numbers of samples to determine which ones should be further analyzed by GC.

\section{Discussion and Conclusions}

The characteristic PNA distribution in creosote can be altered by environmental processes. PNA's introduced into the marine environment may experience biological uptake, microbial degradation, volatilization, dissolution and dilution, photo-oxidation, and sedimentation $(5,21,22)$. Microbial degradation in the water column and evaporation may be the primary removal processes for the lower molecular weight aromatics, such as naphthalenes, anthracenes, and phenanthrenes (23). For the higher molecular welght aromatics, such as chrysenes, benzanthracenes and benzpyrenes, removal processes are dominated by sedimentation and photo-oxidation ( $\underline{23})$. Once deposited in the sediments, the PNA's including benz(a)anthracene, chrysene, fluorene, and anthracene are readily degraded at the sediment/water interface; whereas the higher molecular weight PNA's including benz(a)pyrene and dibenz(a,h)anthracene show only slight degradation at the sediment/water interface (22). When PNA's are added to a natural aqueous environment, the removal processes may be dominated by processes such as dissolution and dilution with ultimate sedimentation (22). Degradation and removal is less important once the PNA's reach the sediment where they can remain unaltered for years $(21,24)$. Preferential removal processes for the lower molecular weight PNA's in creosote, before reaching the subsurface sediments, could lead to the PNA, GC, and fluorescence distributions seen in the sediments from Stations S5, S6, S1, S8, and 57 . The fact that high concentrations of PNA's remain in these sediments may be due to the large inputs, or to toxic materials contained in creosote (such as phenols) which would surpress microbial activity. Given the observed preservations, the sediments may act as a chronic source of PNA's to the water column by resuspension.

Differences in the physical properties of creosote and oils may also affect PNA distributions. When creosote was mixed with seawater in the laboratory, three phases were formed: one more dense than seawater, one dissolved in seawater, and one less dense than seawater. Analysis of the phase more dense than seawater produced a gas chromatogram indistinguishable from that of intact creosote. At a spill site, the phase with a density greater than seawater may be rapidly removed to the sediments with only slight alteration. The water-soluble compounds may then be slowly leached into the water column and act as a chronic PNA source. Petroleum, 
which is less dense than seawater, would be subject to more weathering and dispersal processes than creosote before reaching the sediments.

Since the sediment samples appeared to contain a mixture of carbonized coal products and weathered petroleum products, a plot of the percent PP (main component of carbonized coal products) was plotted against the percent $f 1$ UCM (main component of weathered petroleum products). This plot (Figure 6) shows a linear relationship (correlation of -0.955 ) which would be expected if the changes in the percent composition were due to simple mixing of these two end members. Sediments that are contaminated predominantly by weathered petroleum (25) are calculated to contain 898 on a weight basis of their hydrocarbons as a UCM and less than 0.48 as PP ( These percentages are in good agreement with our $X$-intercept of 888 UCM. The Y-intercept (398) should reflect the carbonized coal end member which ranges from 41 to 638 PP. The reason this percentage is low could be due to preferential weathering (such as dissolution) of the PP compounds in the sediments.

Carbonized coal products have a unique fingerprint by both GC and fluorescence analyses. Both these fingerprints confirm that sediments from the Elizabeth River are contaminated with carbonized coal products and allow for the detection of carbonized coal hydrocarbons, even in the presence of petroleum-derived hydrocarbons. Fluorescence allows for the rapid analysis of more samples and shows the contamination within the Elizabeth River to be widespread. Carbonized coal products in the sediments may constitute a chronic long-term source of PNA's to the water column.

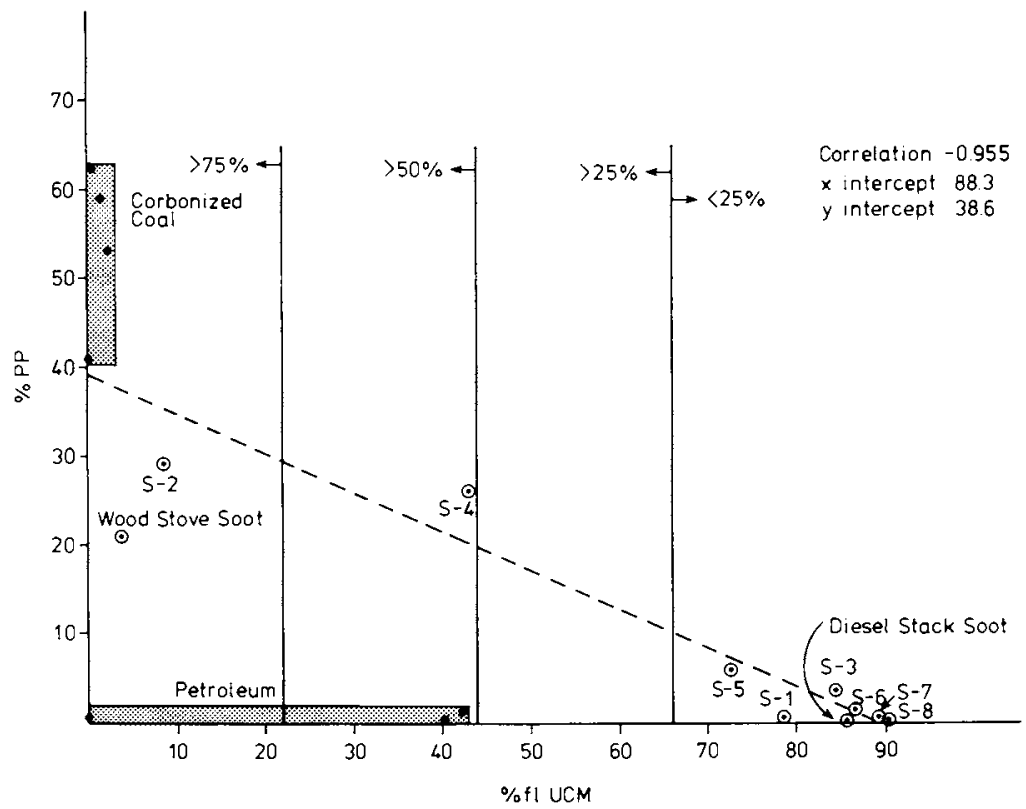

Figure 6. Graph showing the linear relationship between $8 P P$ and $8 f 1$ UCM of the sediment samples. Source sample areas are identified. Solid lines indicate the percentage contribution of carbonized coal products in the mixing relationship. 
Acknowledgments

Partial funding for this research was provided by National Science Foundation Grant OCE 8301538.

\section{Literature Cited}

1. "Petroleum in Marine Environment"; National Academy of Sclences, Washington, D.C., May 21-25, 1973.

2. Wakeham, S.G.; Farrington, J.W. In: "Contaminants and Sediments"; Baker, R. A., Ed.; Ann Arbor Sclence Publishers; Ann Arbor, MI, 1980; Vo1. 1, pp. 3-32.

3. Merril1, E.G.; Wade, T. L. Environ, Sc1, Technol. 1985, 19, 597.

4. Merrill, E. G. M.S. Thesis, old Dominion University, Norfolk, VA, 1984.

5. Wade, T. L. ; Quinn, J. G. Org. Geochem. 1979, 1, 157.

6. Moore, W. E.; Effland, M. J.; Roth, H. G. J. Chromatogr. 1968, 38,522 .

7. Fed, Regist, $1979,44,69-494$.

8. Environ, Sc1, Technol. 1984, 18, 203A.

9. Blumer, M.; Guillard, R. R. L.; Chase, T. Mar, Blol. 1971, 8, 183.

10. Berkowitz, N. "An Introduction to Coal Technology"; Academic Press; New York, 1979.

11. Farrington, J. W.; Meyers, P. A. In "Environmental Chemistry"; Eglinton, G., Ed.; The Chemical Society: London, 1975; Vol. 1, Chap. 5.

12. Ehrhardt, G.; Blumer, M. Environ. Pollut. 1972, 3, 179.

13. Bieri, R. H.; Hein, C.; Huggett, R. J.; Shou, P.; Slone, H.; Smith, C.; Su, C. "Toxic Organic Compounds in Surface Sediments from the Elizabeth and Patapsco Rivers and Estuaries"; VA Institute of Marine Science: Glouchester Pt., VA, 1982.

14. Virginia State Water Pollution Control Board, "The Elizabeth River: An Environmental Perspective"; 1983, VA SWPCB Basic Data Bulletin 61 .

15. Meyers, P. A.; Quinn, J. G. Nature (London) 1973, 244, 23.

16. Brown, R. B.; Wade, T. L. Water Res. 1984, 18, 621.

17. McNeil, D. Rec Annu, Conv, Bd, Wood Preserv, Assoc. 1959, $136-150$.

18. Brooks, J. M.; Kennicutt, M. C. II; Barnard, I. A.; Denoux, G. J.; Carey, B. C. In "Proc. 15th Annual offshore Technol. Conf.", OTC 8624 , Offshore Technology Conference, 1983, pp. 393-400.

19. Kennicutt, M.C. II; Brooks, J.M. Mar. Pollut, Bu11. 1983, 14, 335.

20. Kennicutt, M.C. II; Brooks, J.M.; Denoux, G.J. In "Analysis of North Slope Crude"; Magoon, L.B., and Claypool, G.E., Eds.; Custom Editorial Productions, Inc., Cincinnati, OH, 1985; Chap. 15.

21. Lee, R. F.; Ryan, D. Can, J, Fish, Aquat, Sci. 1983, 40, 86.

22. Farrington, J. W.; Quinn, J. G. Est. Coast.Mar. Sc1. 1973, 1,71 .

23. Lee, R. F.; Gardner, W. S.; Anderson, J. W.; Blaylock, J. W.; Barwell-Clarke, J. Environ. Sc1. Technol. 1978, 12, 832.

24. Gschwend, P.M.; Hites, R. A. Geochim, Cosmochim. Acta 1981, 45,2359 .

25. Zafiriou, O. C. Est. Coast, Mar, Sci. 1973, 1, 81.

RECEIVED January 27, 1986 


\title{
Hydrocarbon Contamination from Coastal Development
}

\author{
Richard H. Pierce ${ }^{\prime}$, Robert C. Brown ${ }^{1}$, Edward S. Van Vleet ${ }^{2}$, and Rosanne M. Joyce ${ }^{2}$ \\ ' Mote Marine Laboratory, Sarasota, FL 33577 \\ ${ }^{2}$ Department of Marine Science, University of South Florida, St. Petersburg, FL 33701
}

Hydrocarbon analyses were obtained for samples of surface sediment, oysters and water from four areas in Charlotte Harbor, Florida. Each area represented a different type of coastal development activity including: residential development canals; municipal and industrial impact; commercial fishing and marine industry facilities; and a nondeveloped control area. Characterization of hydrocarbons was performed using high resolution glass capillary GC-FID chromatograms of the aliphatic (saturated) and aromatic/olefinic (unsaturated) hydrocarbon fractions and by GC-MS analysis of select aromatic components. Residential canal systems contained petroleum contamination resulting from marina and highway service station activities, contamination indicative of crankcase oil which diminished with distance from the source. Total hydrocarbon content of canal sediment ranged from more than $50 \mathrm{ug} / \mathrm{g}$ air-dry sediment at a marina to less than $5 \mathrm{ug} / \mathrm{g}$ at nonimpacted areas. Sediment collected near municipal-industrial activities exhibited high concentrations of a broad range of heavy, residual fuel oils $(85 \mathrm{ug} / \mathrm{g}$ sediment). The highest contamination was observed at commercial fishing port areas, contamination indicative of a low to mid-boiling range fuel oil attaining a concentration of $142 \mathrm{ug} / \mathrm{g}$ sediment, compared to less than $5 \mathrm{ug} / \mathrm{g}$ in unimpacted areas. Oyster samples generally reflected the contamination observed in sediment. Water samples exhibited different hydrocarbon patterns than oysters or sediment, consisting primarily of terrigenous and marine biogenic material. Biogenic hydrocarbons with chromatographic patterns that mimic some petroleum characteristics were observed in certain areas, showing the importance of obtaining pre-oil spill data for accurate interpretation of oil spill impact. Additional information from time series sampling is needed to ascertain rates of hydrocarbon input and degradation.

$0097-6156 / 86 / 0305-0229 \$ 06.00 / 0$

๑ 1986 American Chemical Society

In Organic Marine Geochemistry; Sohn, M.; 
This project was undertaken to identify petroleum hydrocarbon contamination resulting from coastal development activities in the charlotte Harbor estuarine system located on the southwest Florida coast (Figure 1). The overall goal was to assess present petroleum contamination and to provide baseline data to prove the extent and duration of additional impact from future coastal development and oil spills.

Environmental impact from large oil spills in the coastal marine environment is readily observable and easily documented. The extent and curation of contamination after the surface oil has been removed and weathered, however, are not so easily ascertained especially when pre-spill conditions are not known (1-6). Problems also arise when attempting to document chronic petroleum discharges from various coastal development activities. The detection of petroleum hydrocarbons is hindered by the presence of recently biosynthesized (biogenic) hydrocarbons and hydrocarbons resulting from combustion (pyrogenic). Source identification also is complicated by differential weathering through degradation, evaporation and solubilization of petroleum components (1-6).

The charlotte Harbor estuarine system was chosen for this study because it is one of the largest and possibly one of the least contaminated estuaries in Florida (7). Recently, however, the area has become one of the most rapidly developing in the United states (8). A recent review of scientific information about charlotte Harbor emphasized the potential for environmental impact from development and various sources of petroleum contamination ( 9 ).

A two-year investigation was undertaken to determine the composition and concentration of hydrocarbons in sediment, water and commercially important marine organisms throughout charlotte Harbor. The entire project was detailed in an unpublished report to the Florida Department of Natural Resources (10). The first-year project revealed limited petroleum contamination associated with certain land-use activities $(6,10)$. The second-year study, the primary subject of this presentation, investigated the problem areas in more detail to characterize the type of petroleum contamination and to identify probable sources.

\section{Methods}

Study Location. Charlotte Harbor is located on the Southwest Florida coast between $27^{\circ} 05^{\prime} \mathrm{N}$ and $26^{\circ} 27^{\prime} \mathrm{N}$ latitude (Figure 1). During the first year study, certain areas were identified as containing petroleum contamination $(\underline{6,10})$. Three areas were chosen for more intensive study during the second year of the investigation including: Port Charlotte-Punta Gorda development canal systems (Area A, Figure 1); Caloosahatchee River downstream from Fort Myers (Area B, Figure 1); and the Matanzas Pass area behind Fort Myers Beach (Area C, Figure 1). A nondeveloped area in an aquatic preserve at Sanibel Island was chosen as the control area (Area $D$, Figure 1).

The study areas are described as follows: 


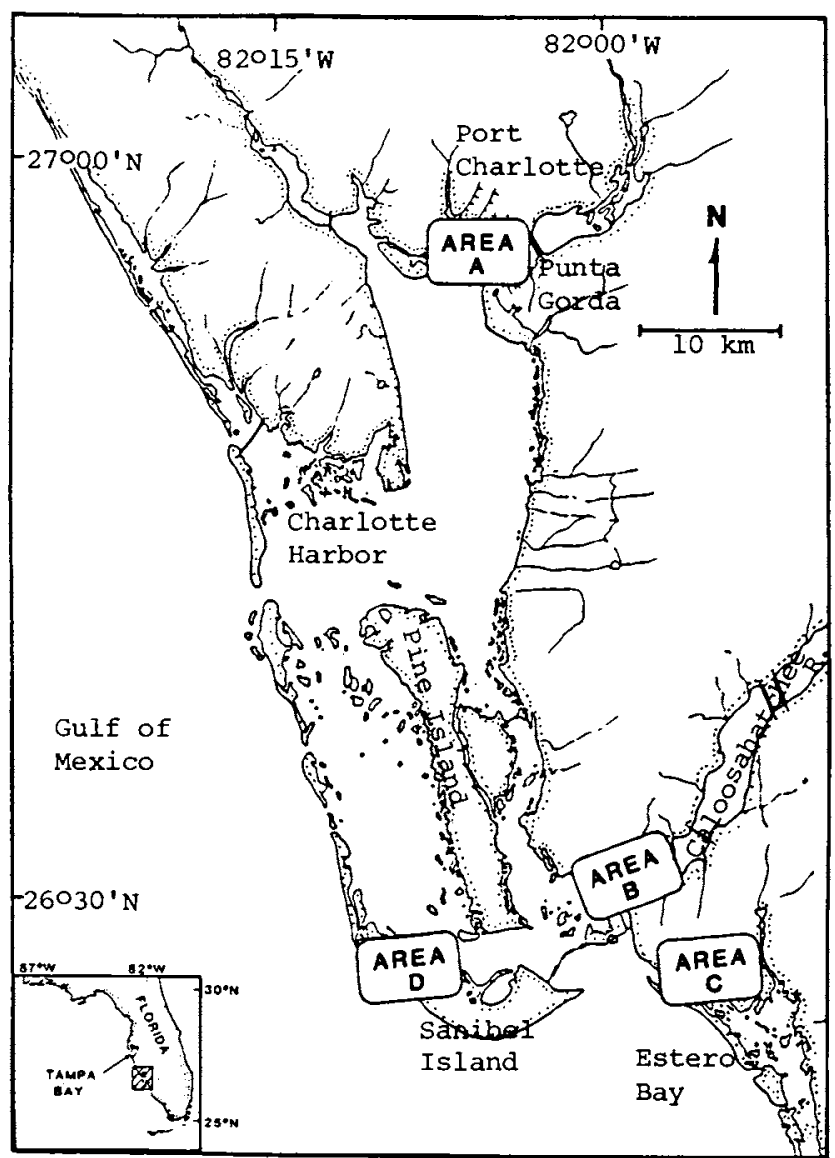

Figure 1. Charlotte Harbor hydrocarbon study, year-2 sampling areas location.

In Organic Marine Geochemistry; Sohn, M.; ACS Symposium Series; American Chemical Society: Washington, DC, 1986. 
AREA A. This area represents impact from coastal residential development, extending into the mouth of the Peace River and upper Charlotte Harbor. Primary sources of contamination are expected to be stormwater runoff (automobile related petroleum), municipal sewage and small boat marina activities. Surface sediment was collected from fourteen sites, water from eight sites and oysters from three sites, representing conditions in the development canals at Port charlotte across the mouth of the Peace River and into the canals of Punta Gorda.

AREA B. This area includes the Caloosahatchee River at Fort Myers and the mouth of the river at San Carlos Bay, downstream from Fort Myers. It is particularly susceptible to oil spills because of the Intracoastal waterway (ICW) and the Caloosahatchee River, which would carry any spill downriver from the Fort Myers area. It was chosen to represent an area which receives chronic input from municipal and industrial activities and represents a high risk area for future oil spills. Surface sediment and oysters were collected from various sites.

AREA C. Matanzas Pass, behind Fort Myers Beach on Estero Island, represents impact from commercial fishing and heavy marine industry operations. The entire area from Carlos Bay through Matanzas Pass to Big Carlos Pass in Estero Bay was studied in an attempt to understand the distribution of contamination from the developed marine industrial area out into the nondeveloped Estero Bay. sediment samples were collected from eight sites, oysters from five sites and water from four sites.

AREA D. This area includes sediment from three sites approximately one mile offshore from Sanibel Island and Captiva Island and oysters and sediment from mangrove fringes within the wildlife preserve on the estuarine side of the island, representing nonimpacted control areas.

Sampling Technique. Surface sediment (top $5 \mathrm{~cm}$ ) was collected as a composite of at least three grabs with a Petite ponar sediment sampler, to provide $500 \mathrm{~g}$ wet weight of relatively undisturbed sediment from each site. Each sediment grab was placed in a stainless steel tray and the top $5 \mathrm{~cm}$ of sediment retrieved with a stainless steel scoop and placed in a precleaned glass jar with aluminum lined caps. Jars were placed on ice for transport and stored at $4^{\circ} \mathrm{C}$ until analyzed. Sufficient sediment was collected for duplicate hydrocarbon analysis with extra sediment for additional analyses if necessary. Efficacy of storage at $4^{\circ} \mathrm{C}$ was verified by analysis of samples before and after storage for several months and by analysis of standard intercalibration sediment after storage for several months.

The oyster, Crassostrea virginica, was the species used to monitor uptake by sessile filter-feeding organisms. At least two dozen large oysters were collected from each organism sampling site. These were rinsed in ambient water, wrapped in aluminum foil and stored in plastic bags on ice for transport to the laboratory where they were then frozen in their shells until ready for analysis.

Near surface water samples were collected with a precleaned metal sampler. Samples of 10 to 15 liters were collected at each site and placed in 20 liter glass carboys for in-field extraction as 
described below. No attempt was made to differentiate dissolved from particulate fractions so that total water column hydrocarbons were observed.

Hydrocarbon Analysis. Sediment samples were thawed and mixed to provide a homogeneous sample. Approximately $150 \mathrm{~g}$ wet weight was placed in a soxhlet extraction apparatus and saponified-extracted with benzene $/ 0.5 \mathrm{~N}$ KOH-methanol $(50 / 50$ ) (ca. $250 \mathrm{ml}$ total) for 24 hours, or until the extraction solution was clear $(6,11,12)$. An internal standard consisting of ca. $50 \mathrm{ug}$ each of $5, \alpha$-androstane and o-terphenyl was added prior to extraction to provide assurance of extraction efficiency, separation of saturated and unsaturated fractions and to provide a standard reference for the gas chromatographic data system. Methylstearate (the methyl ester of stearic acid) was added to select samples to verify saponification efficiency.

The saponified solution was extracted with $3 \times 50 \mathrm{ml}$ hexane and the resulting hexane-benzene solution was washed with distilled water to remove residual $\mathrm{KOH}-\mathrm{MeOH}$. The benzene-hexane was then reduced to a volume of $\mathrm{ca} .0 .1 \mathrm{ml}$ by rotary evaporation, followed by purging with $\mathrm{N}_{2}$ gas in a warm bead bath $\left(45^{\circ} \mathrm{C}\right)$ and repeated addition of hexane to replace benzene with hexane. A final sample volume of $1 \mathrm{ml}$ hexane was added to a column of $2 \mathrm{~g}$ neutral alumina (80/20 mesh), $2 \mathrm{~g}$ silica gel $(100 / 200 \mathrm{mesh})$ and $1 \mathrm{~g}$ sodium sulfate (granular) for clean-up and separation into aliphatic (saturated) and aromatic/olefinic (unsaturated) fractions. Alumina, silica gel and sodium sulfate were activated at $500^{\circ} \mathrm{C}$ for 4 hours and stored at $110^{\circ} \mathrm{C}$ until used. The saturated fraction was eluted with 3 bed volumes (bv) of hexane and the unsaturated fraction was eluted with 3 bv of hexane and benzene $(50 / 50)$. Each fraction was then reduced to $0.5 \mathrm{ml}$ volume under a stream of $\mathrm{N}_{2}$ gas as described above in preparation for GC analysis.

Oysters were thawed, opened with a clean knife, the liquid drained off, and a composite of several whole oysters collected. The entire sample of each site was homogenized and divided into four subsamples. Two were subjected to the analytical scheme, the third archived and frozen for further analysis, if necessary, and the fourth dried at $103^{\circ} \mathrm{C}$ to obtain the dry weight.

For analysis, ca. 10-15 g wet-weight tissue was transferred to a tared, hexane washed $250 \mathrm{ml}$ boiling flask. The internal standard mixture was added at this point in acetone solution. A $50 \mathrm{ml}$ portion of $2.0 \mathrm{~N}$ aqueous $\mathrm{KOH}$ was added to the flask containing the tissue for saponification under reflux for 4 hours $(h)$ or until the tissue was well digested. An equal volume of saturated NaCl solution was added to the mixture, and the solution extracted with three $50 \mathrm{ml}$ portions of hexane. The extracts were combined, reduced in volume with a vacuum rotary evaporator and transferred to a cleaned vial. The remaining solvent was reduced to $1 \mathrm{ml}$ volume in preparation for separation into saturated and unsaturated fractions and GC analysis as described above for sediments.

water samples were processed in the field using a portable water extractor consisting of a stirring blade operated by a battery powered reversible drill which fits into the 20 liter glass carboy (10). The extraction procedure consisted of placing 10 to 15 liters 
of a water sample in the carboy. The internal standard mixture was added $(5, \alpha$-androstane and o-terphenyl in acetone solution), followed by 500 to $750 \mathrm{ml}$ of $\mathrm{CH}_{2} \mathrm{Cl}_{2}$. The mixture was stirred vigorously for 5 min and allowed to settle for one hour (until phases separated). water was siphoned off the top and the $\mathrm{CH}_{2} \mathrm{Cl}_{2}$ recovered for hydrocarbon analyses as described above for sediments. prior to field use, the extractor was evaluated for recovery and precision by spiking distilled water with $1 \mathrm{mg} 1^{-1}$ of Kuwait crude oil and comparing recovery with that obtained from separatory funnel, liquid-liquid extraction (10).

Gas chromatographic analysis was performed with each fraction using a varian Vista 6000 gas chromatography (GC) system coupled with a Vista 401 data system (Varian Instruments, Sunnyvale, CA). A flame ionization detector (FID) was used and the sample was separated on a glass capillary column $(30 \mathrm{~m} \times 0.25 \mathrm{~mm}$ with wCOT $\mathrm{SE}-30$ ), temperature programmed from $100^{\circ} \mathrm{C}$ to $280^{\circ} \mathrm{C}$ at $8 \% / \mathrm{min}$, and held at $280^{\circ} \mathrm{C}$ for $10 \mathrm{~min}$, which allowed observation of the n-alkane homologous series from $n-C_{13}$ through $n-C_{32^{\circ}}$ The injector was operated in the splitless mode with septum purge after $30 \mathrm{sec}$. The carrier and make up gass was $\mathrm{N}_{2}$. Injection volume was $2 \mathrm{ul}$; with an attenuation of $4 \times 10^{-11}$.

Approximately 108 of the sediment and organism samples were analyzed by combined high resolution gas chromatography-mass spectrometry. Samples were analyzed on a Hewlett-Packard Model 5992B computerized GC-MS system (Hewlett-Packard, Avondale, PA) equipped with a $30 \mathrm{~m} \mathrm{DB}-5$ fused silica capillary column. Running conditions were as follows: carrier gas = helium; column flow rate $=1.7 \mathrm{ml} \mathrm{min}{ }^{-1}$; injection port temperature $=240^{\circ} \mathrm{C}$; splitless injection mode; column oven temperature programmed from $90-250^{\circ} \mathrm{C}$ at $4^{\circ} \mathrm{C} \mathrm{min}{ }^{-1}$; electron multiplier voltage $=1200-2000 \mathrm{eV}$; GC-MS run in selected ion monitoring mode; dwell time $=100 \mathrm{msec}$ for each ion. Samples were first analyzed by electron impact to obtain the total ion spectra to check for interfering ions. Samples were then analyzed by selected ion monitoring to identify and quantitate specific polynuclear aromatic hydrocarbons (PNA) homologues.

quality Assurance. The quality assurance program consisted of a sample chain of custody verification, precautions to guard against and to detect sample contamination, verification of precision and accuracy and intercalibration with two other laboratories to verify results from our extraction and analysis procedures. This program is detailed in the unpublished Final Report of the overall study to the FL Department of Natural Resources (10). Interlaboratory calibration consisted of three phases: 1) instrument intercalibration by comparing results of standard hydrocarbon solutions; 2) methods intercalibration by comparing results of analyses of a standard sediment sample (Duwamish-I), supplied by Dr. William MacLeod of the NOAA, Northwest and Alaska Fisheries Center, Seattle, WA (13); and 3) sample intercalibration, consisting of the exchange among the three participating laboratories of three sediment samples from the study areas.

\section{Results and Discussion}

Petroleum hydrocarbon identification was based primarily on the GC-FID chromatogram patterns of the saturated and unsaturated 
hydrocarbon fractions. Additional information regarding petrogenic vs. pyrogenic or biogenic hydrocarbons was provided by GC-MS analysis of specific PNA series from the unsaturated fraction with select samples $(3,5,14,15)$.

For comparison, GC-FID chromatograms of representative petroleum contaminants are shown in Figure 2 and chromatograms of hydrocarbons from various marine plants (biogenic) are given in Figure 3. Key parameters used for hydrocarbon characterization are listed in Table $I$.

Area A. Samples from Area A included sediment, water and oysters from Port Charlotte canals (Sites A-1 through A-4), the Peace River (Sites A-5 through $\mathrm{A}-9$ ), and Punta Gorda residential canals (Sites A-10 through $A-14$ ). Sediment hydrocarbons from both canal systems showed a heavy residual crankcase oil-like petroleum contamination from marina and highway service station activities (site $A-1$, and A-12, Figure 4). This contamination diminished in residential canals away from pollution sources and did not appear to be exported to nearby bay and river sediment which exhibited a totally different hydrocarbon pattern somewhat representative of hydrocarbons in red mangrove leaves (Site A-6, Figure 4, Table I).

oysters collected within the canal systems near the marinas exhibited the crankcase oil-like patterns, whereas those away from the marina exhibited biogenic material patterns.

water samples in the port Charlotte canal system yielded mangrove-hydrocarbon patterns similar to that found in sediment and oysters outside the canals along the Peace River and Alligator Bay, whereas water collected from the Peace River exhibited very little discernable hydrocarbon pattern. Water in Punta Gorda canals more closely reflected the hydrocarbon patterns found in sediment and oysters, i.e. highly contaminated at the marina diminishing to very low levels within about a mile into or out of the canals.

Localized contamination of water and sediment was observed near a docking area for commercial fishing boats, at Fisherman's Wharf along the Peace River. This pattern was unique to the area showing a bimodal unresolved complex mixture (UCM) and a total sediment hydrocarbon content of $90 \mathrm{ug} / 1$ (Site 10, Table I).

Analysis of select PNA to verify petroleum origin showed that all sediment contained mixed petrogenic and pyrogenic material. The relative abundance of PNA in marina sediment, however, was much greater ( $180 \mathrm{ng} / \mathrm{g}$ benzanthracenes) than that found in sediment from non-marina areas ( $<0.1 \mathrm{ng} / \mathrm{g}$ benzanthracenes).

Oyster samples reflected specific PNA patterns similar to the adjacent sediment. Because of the low concentration of PNA's in water, results from water PNA analyses were inconclusive.

Area B. Area $B$ samples included sediment collected from the Caloosahatchee River at Fort Myers, sediment collected downstream, and sediment and oysters collected at the mouth of the river (Figure 3, Table I). Sediment collected near the municipal-area exhibited a very large, bimodal UCM, indicative of heavy industrial heating oil transported by tanker or oil barge (site B-1, Figure 5). The sample contained primarily highly weathered oil as evidenced by the lack of the large unresolved complex. The resolved component 

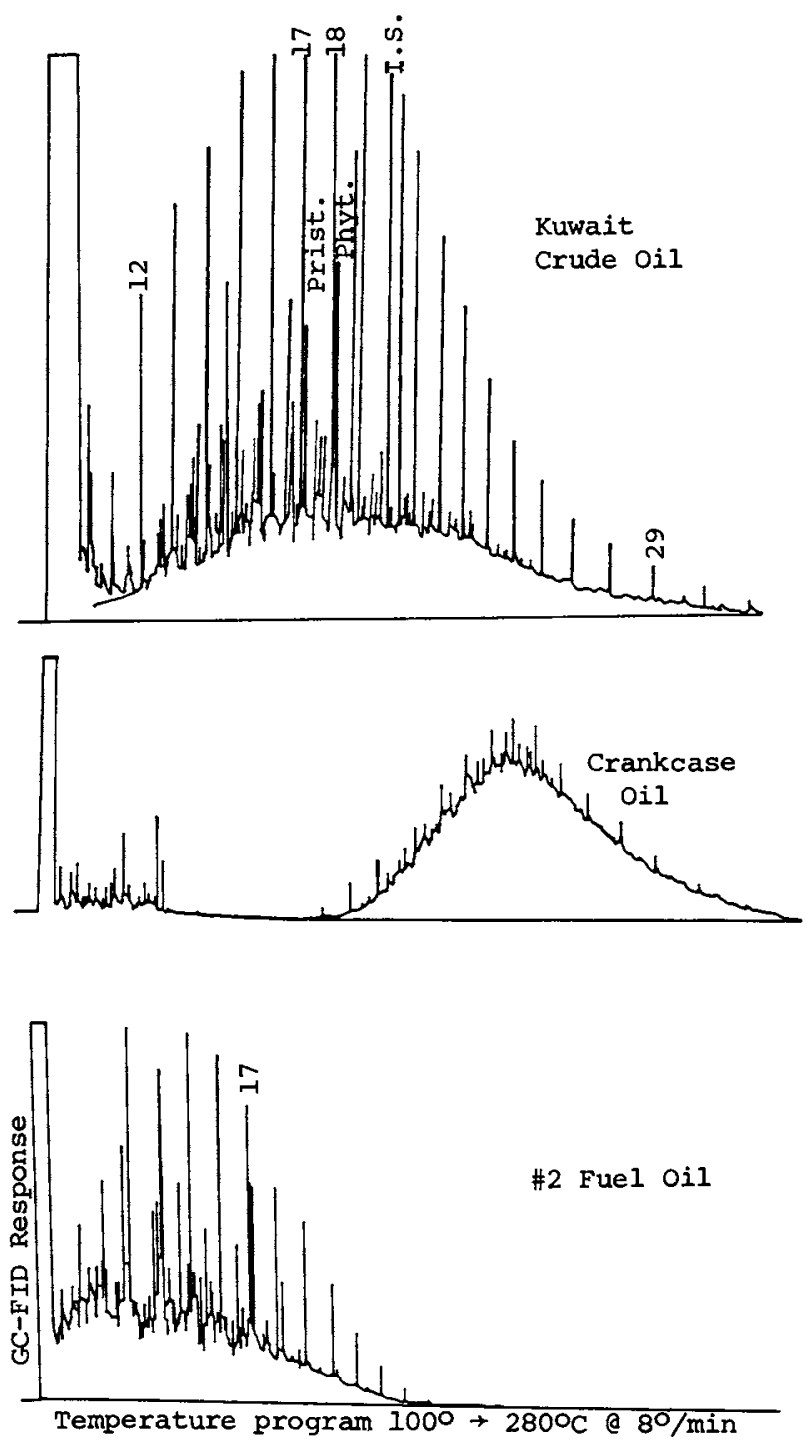

Figure 2. GC-FID chromatograms of reference petroleum products. Numbers indicate n-alkane carbon number represented by the adjacent chromatographic peak. I.s. indicates the position of the internal standard $(5, \alpha$-androstane) chromatographic peak.

In Organic Marine Geochemistry; Sohn, M.;

ACS Symposium Series; American Chemical Society: Washington, DC, 1986. 

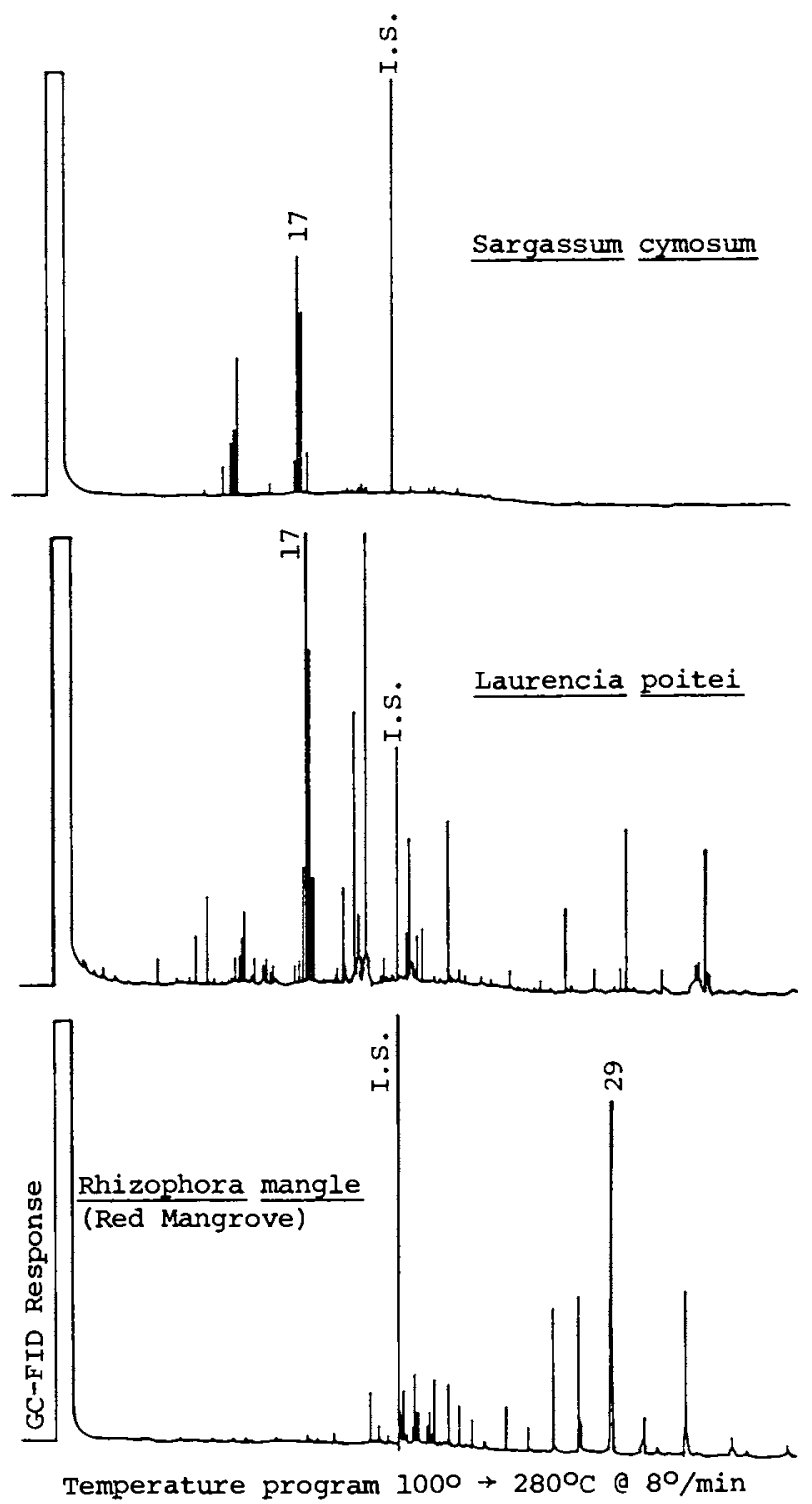

Figure 3. GC-FID chromatograms of the saturated hydrocarbon fraction from marine and coastal flora. Numbers indicate n-alkane carbon number represented by the adjacent chromatographic peak. I.S. indicates the position of the internal standard $(5, \alpha$-androstane) chromatographic peak.

In Organic Marine Geochemistry; Sohn, M.;

ACS Symposium Series; American Chemical Society: Washington, DC, 1986. 


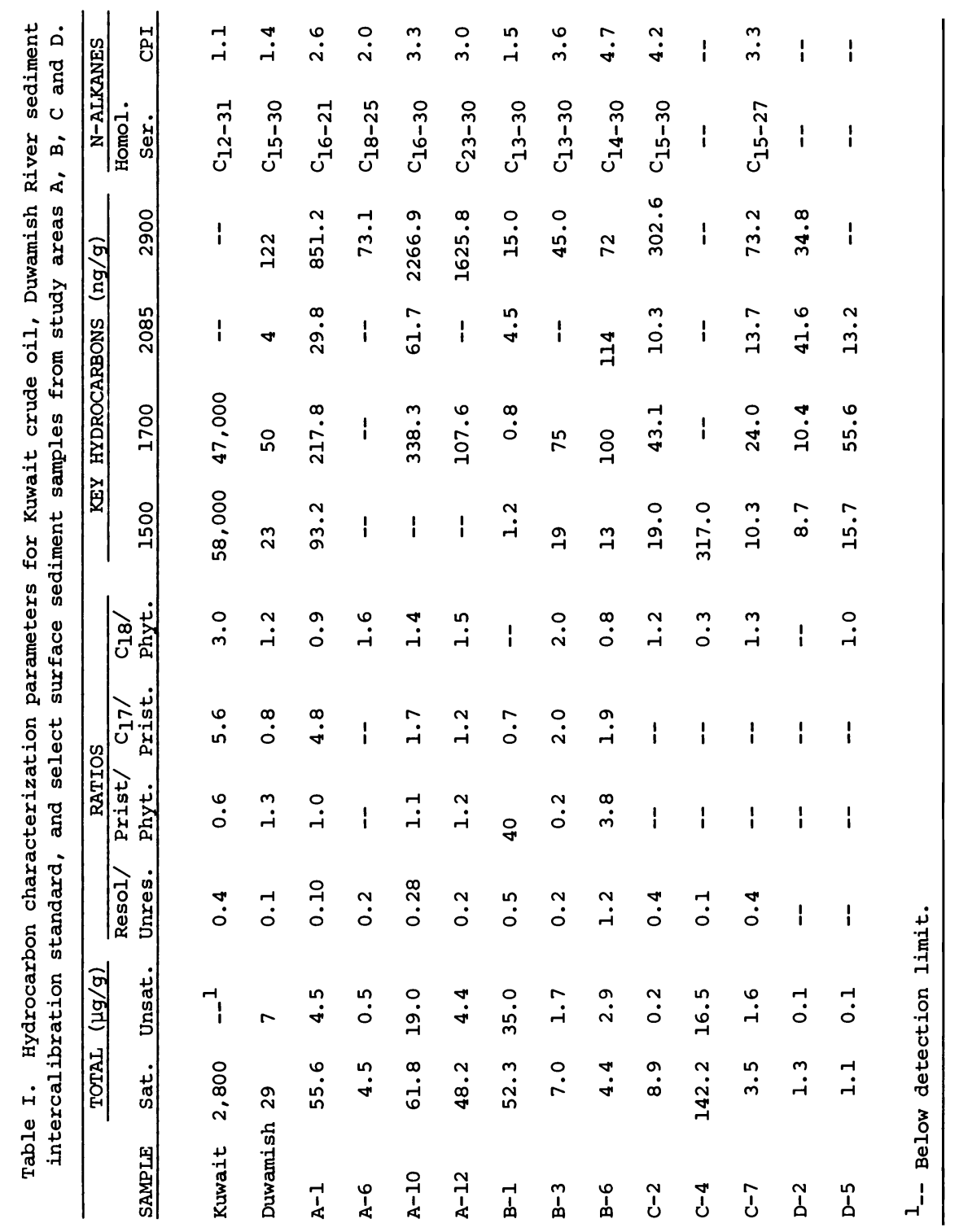

In Organic Marine Geochemistry; Sohn, M.; 

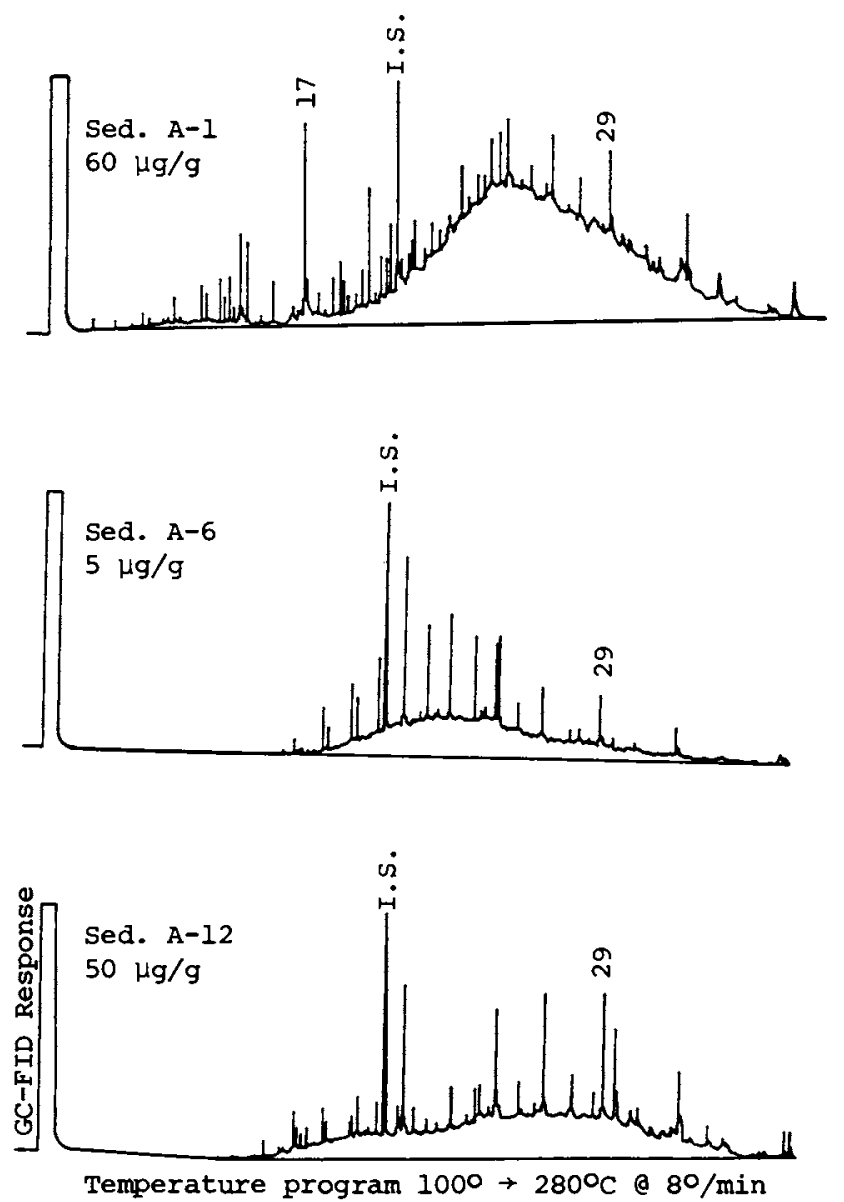

Figure 4. GC-FID chromatograms of the saturated hydrocarbon fraction of sediments collected from sampling Area $A$. Numbers indicate n-alkane carbon number represented by the adjacent chromatographic peak. I.S. indicates the position of the internal standard $(5, \alpha$-androstane) chromatographic peak.

In Organic Marine Geochemistry; Sohn, M.;

ACS Symposium Series; American Chemical Society: Washington, DC, 1986. 


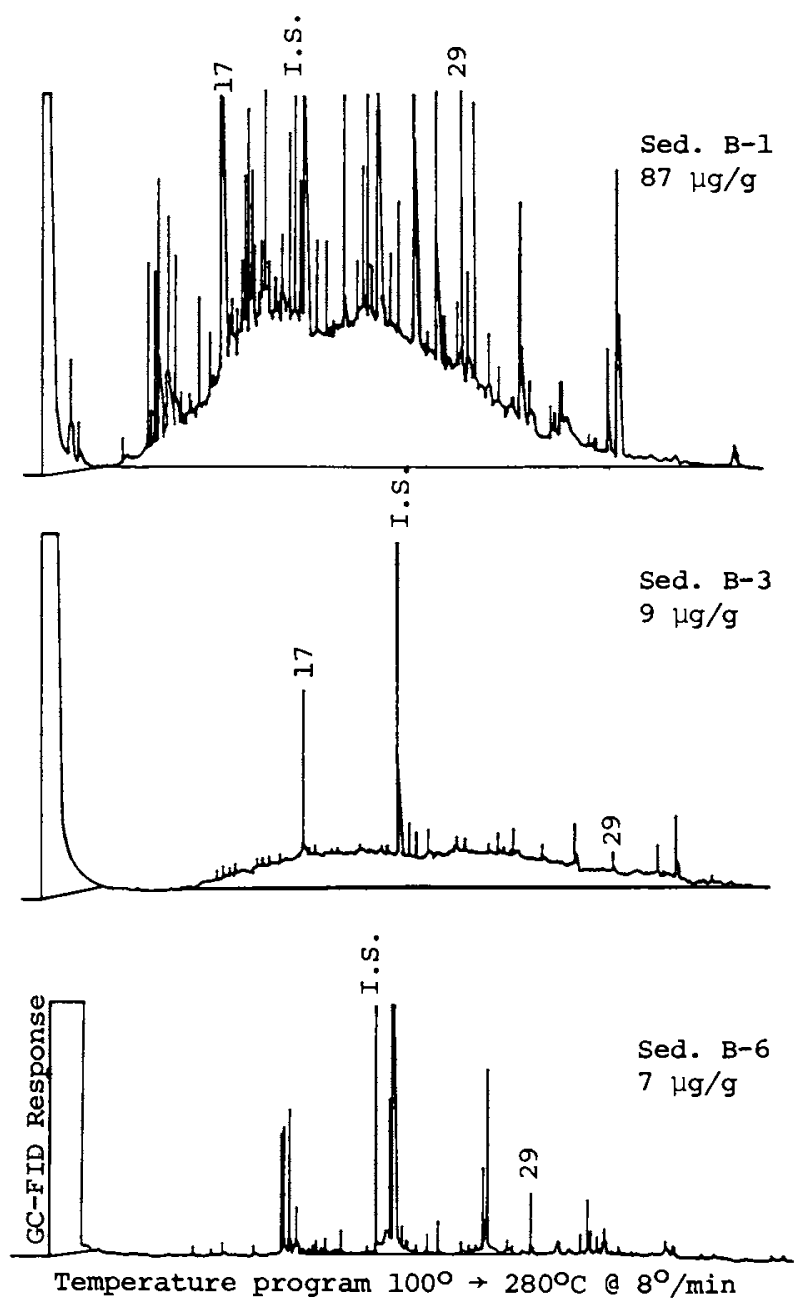

Figure 5. GC-FID chromatograms of the saturated hydrocarbon fraction of sediments collected from sampling Area B. Numbers indicate n-alkane carbon number represented by the adjacent chromatographic peak. I.S. indicates the position of the internal standard $(5, \alpha$-androstane) chromatographic peak.

In Organic Marine Geochemistry; Sohn, M.;

ACS Symposium Series; American Chemical Society: Washington, DC, 1986. 
contained a considerable amount of biogenic hydrocarbons indicated by the predominance of specific odd-numbered carbon compounds. Sediment collected approximately $10 \mathrm{~km}$ downstream showed diminished concentrations of weathered oil (Site B-3, Figure 5, Table I).

sediment and oyster samples collected approximately $25 \mathrm{~km}$ downstream at the mouth of the river, produced chromatograms indicating primarily biogenic hydrocarbons (Site $8-6$, Figure 5), providing excellent background data for comparison in the event of a future oil spill.

Area C. Sediment, water and oyster samples were collected from the marine industry port areas in Matanzas pass and from nonimpacted sites extending to both ends of the pass to observe the distribution of petroleum pollutants. Samples collected adjacent to the fishing fleet docks exhibited a preponderance of No. 2 fuel oil-like hydrocarbons with some crankcase oil-like GC-FID patterns (Site 4, Figure 6, Table I). Sediment and oysters provided the best evidence for petroleum contamination, whereas hydrocarbons in water samples were dominated by biogenic compounds. Sediment and oyster contamination dropped to background biogenic hydrocarbon levels within one mile of the marine industrial activities (site 2 and site 7, Figure 6). The petrogenic nature of contaminated samples was verified with GC-MS analysis of select PNA compounds.

Area D. Samples from Area D were analyzed to provide background hydrocarbon data from low organic content Gulf of Mexico samples (Sites $D-1, D-2$ and $D-3$ ) and from high biogenic input mangrove fringe areas (Sites 4 and 5 ). These samples provided excellent insight about non-petroleum contaminated biogenic hydrocarbons representative of nearshore Gulf of Mexico and barrier island mangrove fringe areas (Site $\mathrm{D}-2$ and $\mathrm{D}-5$, Table $\mathrm{I}$ ).

A most important observation regarding biogenic hydrocarbons at Area $D$ as well as other areas was that those sediments receiving high biomass input, such as in mangrove forests, exhibited chromatographic patterns of the saturated hydrocarbon fraction containing a UCM as well as a homologous series of compounds (not necessarily n-alkanes) in the $c-18$ to $c-25$ region (Figure 3 , Red Mangrove; Figure 4, Sed. A-6; Figure 6, Sed. C-7). Sediments receiving low biogenic input, such as Gulf of Mexico samples (Table I, Sed. D-2) and areas of limited deposition (Figure 5, Sed. B-6), show characteristic marine biogenic chromatographic patterns. Such characterization of endemic biogenic hydrocarbons is needed to establish the natural hydrocarbon content in specific areas of critical concern. These data are essential for accurate interpretation of petroleum impact from coastal development and oil spills. Additional information should be obtained over time to establish the dynamic relationships regulating hydrocarbon input, accumulation and degradation within the various coastal marine environments.

Data Interpretation. Interpretation of these results is based on specific distinctions among biogenic, pyrogenic and petrogenic hydrocarbons. Biogenic hydrocarbons exhibit discrete sets of n-alkanes and alkenes, whereas petroleum contains the homologous series of n-alkanes, branched and cyclic alkanes and substituted polynuclear aromatic hydrocarbons. A predominance of specific 

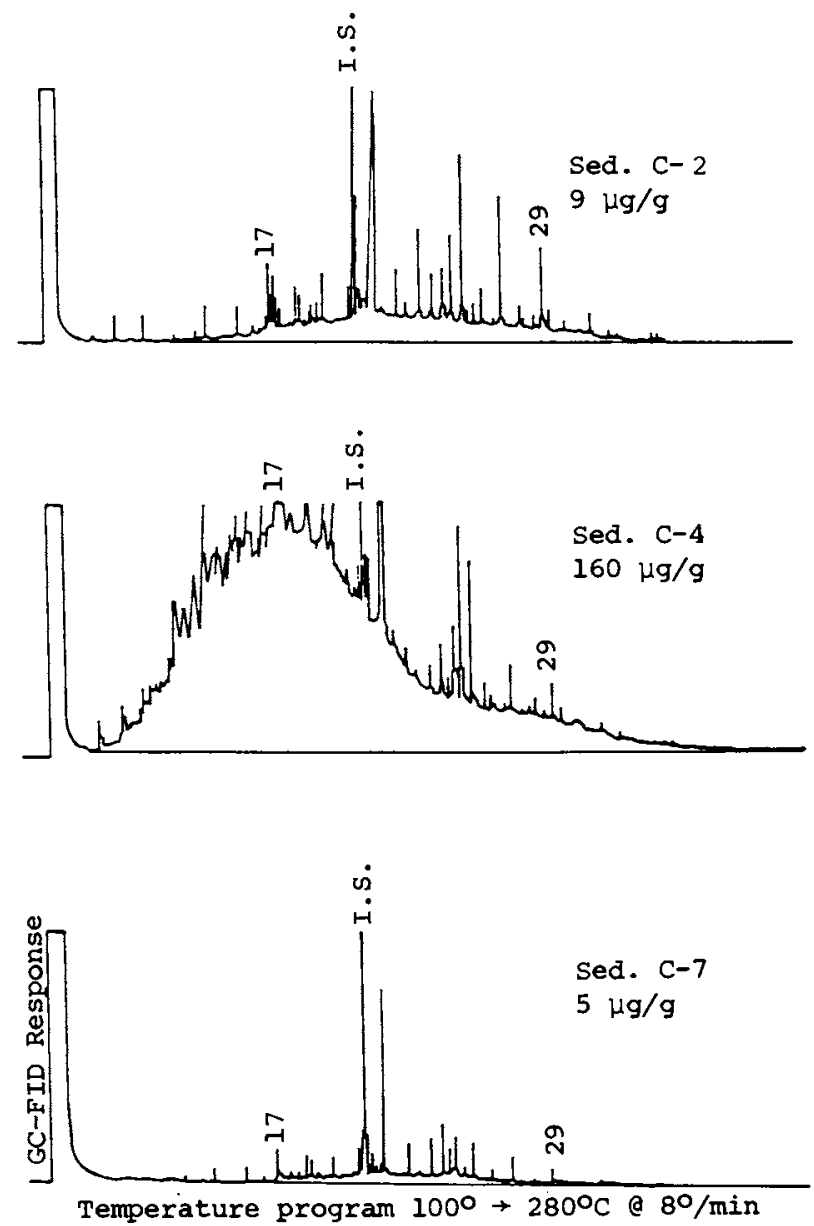

Figure 6. GC-FID chromatograms of the saturated hydrocarbon fraction of sediments collected from sampling Area $C$. Numbers indicate n-alkane carbon number represented by the adjacent chromatographic peak. I.S. indicates the position of the internal standard $(5, \alpha$-androstane) chromatographic peak.

In Organic Marine Geochemistry; Sohn, M.;

ACS Symposium Series; American Chemical Society: Washington, DC, 1986. 
compounds such as pristane $(2,6,10,14$-tetramethylpentadecane), pentadecane $\left(n-c_{15}\right)$, and heptadecane $\left(n-c_{17}\right)$ are indicative of marine biogenic sources, while pristane in the presence of the isoprenoid, phytane, and a homologous series of n-alkanes, indicates petroleum hydrocarbons $(\underline{16-18})$. Hydrocarbons of terrigenous flora exhibit a strong odd/even carbon predominance index (CPI) in the ${ }^{n-C_{23}}$ through $n-C_{31}$ n-alkane region $(18-20)$.

3 petrogenic hydrocarbons are characterized by a UCM of hydrocarbons in the aliphatic fraction, which is comprised primarily of branched and cyclic saturated hydrocarbons too numerous to be resolved by gas chromatographic techniques (21-23). Various petrogenic hydrocarbon sources include tanker washings, storage transfer spills, outboard motors, sewage and land runoff. Classification may include refined or crude oil, recent or weathered oil. Source identification can be accomplished through specific diagnostic compounds in the aliphatic and aromatic/olefinic fractions, aided by GC-MS analyses to verify compound identification $(\underline{24-26)}$.

Petroleum that has been recently introduced into the marine environment is indicated by a smooth alkane distribution (CPI $=1$ ) over a UCM $(14,26,27)$. Crude oil GC patterns are characteristic of geographical origin, but generally exhibit a wide boiling range of n-alkanes and UCM, sometimes with a bimodal UCM distribution indicative of tanker spillage (26). Refined petroleum distillates favor low-boiling components, whereas residual oils show a predominance of the higher boiling compounds $(28-30)$.

Interpretation of the aromatic/olefinic hydrocarbon distribution has recently been developed to help characterize hydrocarbon sources. Olefinic compounds are not abundant in petroleum; thus their predominance would indicate biogenic input $(4,11,20,31)$.

Although much information can be obtained from GC-FID, one of the most diagnostic characteristics of a petroleum sample is the molecular nature of the aromatic hydrocarbon fraction which can only be determined by GC-MS $(6,18,24,32)$. The reason for this is that in addition to the many PNA parent compounds, there also exist $\mathrm{C}_{1}-\mathrm{C}_{3}$ alkylated homology series for each parent PNA. In addition, each of these alkylated homologs can be present as a number of different isomers for each parent structure.

Polynuclear aromatic hydrocarbons have routinely been used in order to differentiate suites of compounds in petroleum fram those originating from combustion processes $(24,25,33)$. This differentiation is based upon the relationship between the parent aromatic compounds (such as phenanthrene) and the alkylated homologs such as methyl phenanthrene, dimethyl phenanthrene and trimethyl phenanthrene, designated $C_{1} P, C_{2} P$, and $C_{3} P$, respectively. Under conditions of relatively low temperatures and slow heating, such as in petroleum formation, the alkylated homologs are formed in the greatest abundance. Under conditions of higher temperature and more rapid heating, such as during combustion, the alkylated homologs undergo thermal cracking, resulting in a greater abundance of the nonalkylated parent compounds. Sporstol et al. (34) have shown that the naphthalene homologs show a similar homolog distribution but the dibenzothiophenes do not. These authors suggest that the 
benzothiophene alkyl homolog series is not a sufficiently sensitive tool for distinguishing petroleum from combustion PNA sources. overton et al. (35) have shown that the ratios of alkyl phenanthrenes to alkyldibenzothiophenes are useful indicators for tracing petroleum hydrocarbon sources in environmentally impacted samples. The ratios of $\mathrm{C}_{1}, \mathrm{C}_{2}$ and $\mathrm{C}_{3}$ alkyl homologs for these PAH's have been shown to be uniquely characteristic of specific oils and are not rapidly altered by weathering processes. In an attempt to identify weathered petroleum between biogenic and pyrogenic hydrocarbons, we determined the concentrations of individual PNA compounds and reported the phenanthrene to dibenzothiophene homolog ratio as suggested by overton et al. (35). In addition, the total amount of $\mathrm{C}_{0}-\mathrm{C}_{3}$ naphthalenes, phenanthrenes, dibenzothiophenes and pyrenes as detêrmined by GC-MS was calculated for each sample and used to determine the ratios of alkylated homolog to parent PHA compounds. These homolog distributions were also plotted and then used to differentiate petrogenic from pyrogenic hydrocarbons.

In summary, hydrocarbon analyses of water, sediment, and oysters collected from the four study areas described above have provided information regarding hydrocarbon contamination from specific coastal development activities as well as background data from unimpacted areas. Although these data establish areas of existing petroleum pollution with identified source material, the baseline data represent samples collected at one point in time. Baseline information needed to assess the full impact of an oil spill should include samples collected over time as well as space. These additional data are needed to establish rates of hydrocarbon input and degradation during different seasonal and environmental conditions.

\section{Conclusions}

1) Petroleum contanination from specific land use activities was identified through GC-FID hydrocarbon characterization supported by GC-MS analysis of specific PNA compounds.

2) Commercial marina and highway service station activities were found to provide a source for crankcase oil-like contamination to residential canal systems.

3) Residential canal systems not exposed to major highways or marinas did not exhibit the oil contamination.

4) Hyarocarbon contamination from commercial fishing port facilities was primarily from No. 2 fuel oil. Oysters within the intertidal region were contaminated up to one mile away.

5) Samples collected near municipal-industrial activities at Fort Myers exhibited petroleum contamination representative of heavy residual fuel oil used for electric power plant generators.

6) Samples collected several miles downstream from the municipal-industrial area, however, did not reflect significant petroleum hydrocarbon transport.

7) Samples from nonimpacted areas exhibited biogenic hydrocarbon chromatographic patterns which in high biomass areas, such as mangroves, exhibited chromatograms similar to certain petroleum components. These data provide information essential to avoid erroneous conclusions regarding impact following an oil spill. 
8) Characterization of petroleum contamination from certain land use activities and from biogenic sources has provided information for assessing impact from continued coastal development activities and to assess the curation and extent of impact in the event of a major oil spill in the areas studied. However, time series samples are needed to establish rates of hydrocarbon input and degradation.

\section{Acknowledgments}

This project was funded by the Florida Department of Natural Resources. The authors are grateful to Alan Huff, DNR Project Coordinator. Special thanks to Stephanie Boggess, Shawn Murphy, Jim Mullin and Kathy Peck for assisting with sample collection and analysis.

\section{Literature Cited}

1. "Oil in the Sea: Input, Fates and Effects", National Academy of Sciences and National Research Council, National Academy Press, Washington, D.C., 1985.

2. Atlas, R. M. Environ. Int. 1981, 5, 33-38.

3. Boehm, P. D. IXTOC Oil Spill Assessment, Final Report. BLMYM-PT-82-005-3331, U.S. Department of Interior, Bureau of Land Management: Washington, D.C., 1982.

4. Farrington, J. W. In "Petroleum in the Marine Environment"; Petraleis, L.; and weiss, F. T., Eds.; ADVANCES IN CHEMISTRY SERIES No. 185, American Chemical society: Washington, D.C., 1980 ; pp. 1-22.

5. Pierce, R. H.; Anne, D. C.; Saksa, F. I.; and Weichert, B. A. In "Wastes in the Ocean, volume 4: Energy wastes in the Ocean"; Duedall, I. W.; Kester, D. R.; and Park, P. K., Eds.; John Wiley and Sons, Inc.: New York, 1985, Chap. 7.

6. Van Vleet, E. S.; Pierce, R. H.; Brown, R. C.; and Reinhardt, S. B. Org. Geochem. 1984, 6, 249-257.

7. Wang, J. C. S.; and Raney, E. C. Distribution and fluctuations in the fish fauna of the Charlotte Harbor Estuary, Florida. Mote Marine Laboratory Collected Papers No. 112, Sarasota, FL, 1971.

8. Department of Community Affairs. Final recommendations of the Governor's Nomination Review Committee, Charlotte Harbor Estuarine Ecosystem Complex, Tallahassee, FL, 1981.

9. Estevez, E. D. A review of scientific information: Charlotte Harbor (Florida) estuarine ecosystem complex, Final Report to Southwest Florida Regional planning Council, Fort Myers, FL. Mote Marine Laboratory Review Series No. 3, 1981.

10. Pierce, R. H.; Brown, R. C.; and Van Vleet, E. S.; Charlotte Harbor Hydrocarbon Study, Year-2, Final Report. Florida Department of Natural Resources, St. Petersburg, FL, 1983.

11. Farrington, J. W.; and Tripp, B. W. In "Marine Chemistry in the Coastal Environment"; Church, T., Ed.; ACS SYMPOSIUM SERIES No. 18, American Chemical Society: Washington, D.C., 1975; pp. 267-284.

12. Gearing, P.; Gearing, J. N.; Lytle, T. F.; and Lytle, J. S. Geochim. Cosmochim. Acta. 1976, 40, 1005-1017.

13. Macleod, W. D.; Prohaska, P. G.; Gennero, D. D.; and Brown, D. W. Analyt. Chem. 1982, 306-392. 
14. Farrington, J. W.; and Meyers, P. A.; "Environmental Chemistry"; Eglinton, G., Ed.; The Chemical Society: United Kingdom, 1975; pp. 109-136.

15. Boehm, P. D. Interpretation of sediment hydrocarbon data, Volume II, Chap. 10, Final Report for BLM-MAFLA Study 1977/1978 project period, 1978.

16. Blumer, M.; Guillard, R. R. L.; and Chase, T. Mar. Biol. 1971, $8(30), 183-189$.

17. Ehrhardt, M.; and Blumer, M. Environ. Pollut. 1972; 3 , 179-194.

18. Farrington, J. W.; and Tripp, B. W. Geochim. Cosmochim. Acta. $1977,41,1627-1641$.

19. Bieri, R. H.; Cueman, M. K.; Simith, D. L., and Su, C-W. International J. of Environ. Analyt. Chem. 1978, 5(4), 293-310.

20. Boehm, P. D.; and Quinn, J. G. Estuarine and Coast. Mar. Sci. 1978, 6, 471-494.

21. Boehm, P. D., and Fiest, D. L. Proc. Conf. Prelim. Sci. Results Pierce/Researcher Cruise to the IXTOC-I Blowout, NOAA Office of Marine Pollution Assessment, Rockville, MD, 1980 .

22. Wakeham, S. G.; and Farrington, J. W. In "Contaminants and Sediments, Volume 1: Fate and Transport, case studies, Modeling, Toxicity"; Baker, R. A., Ed.; Ann Arbor Science, Ann Arbor, MI, 1980, Chap. 1.

23. Brown, R. C.; Pierce, R. H.; and Rice, S. A. Mar. Pollut. Bull. 1985, 16(6), 236-240.

24. Youngblood, W. W.; and Blumer, M. Geochim. Cosmochim. Acta. $1975,39,1301-1314$.

25. Hites, R. A.; Laflamme, R. E.; Windsor, J. G.: Farrington, J. W.; and Deuser, W. G. Geochim. Cosmochim. Acta. 1980, 44, 873-878.

26. Boehm, P. D.; Barak, J. E.; Fiest, D. L.; and Ekskus, A. A. Mar. Environ. Res. 1982, 6, 157-158.

27. Pierce, R. H., Jr.; Cundell, A. M.; and Traxler, R. W. Appl. Micro. 1975, 29(6), 646-652.

28. Butler, J. N.; Morris, B. F.; and Sass, J. Pelagic tar from Bermuda and the Sargasso sea. Bermuda Biological station Special publication No. 10, Bermuda. 1973.

29. Thompson, S.; and Eglinton, G. Mar. Pollut. Bul1. 1978, 9, 133-136.

30. Traxler, R. W.; and Pierce, R. H. Standard and intercomparison criteria: tar balls and particulate matter, NBS special publication No. 409, Marine pollution Monitoring (Petroleum) Symposium, 1974, pp. 161-162.

31. Keizer, P. D.; Dale, J.; and Garden, D. C. Geochim. Cosmochim. Acta. $1978,42,105-172$.

32. Giger, W.; and Schaffner, C. Analyt. Chem. 1978, 50, 243-249.

33. Laflamme, R. E.: and Hites, R. A. Geochim. Cosmochim. Acta. $1978,42,289-303$.

34. Sporstol, S.; Gjos, N.; Lichtenthaler, R. G.; Gustavsen, J. O.; Urdal, K.; and Oreld, F. Environ. Sci. Technol., 1983, 17(5), 282-286.

35. Overton, E. B.; McFall, J.; Mascarella, S. W.; Steel, C. F.; Antonine, S. A.; Politzer, I. R.; and Laseter, J. L., American Petroleum Institute: Washington, D.C., 1981, 541-546.

RECEIVED September 16, 1985 


\title{
Distribution of Trace Organics, Heavy Metals, and Conventional Pollutants in Lake Pontchartrain, Louisiana
}

\author{
Edward B. Overton', Michael H. Schurtz ${ }^{2}$, Kerry M. St. Pé2 ${ }^{2}$ and Christian Byme ${ }^{3}$ \\ IInstitute for Environmental Studies, Louisiana State University, Baton Rouge, LA 70803 \\ ${ }^{2}$ Louisiana Department of Environmental Quality, Baton Rouge, LA 70804 \\ ${ }^{3}$ Center for BioOrganic Studies, University of New Orleans, New Orleans, LA 70148
}

\begin{abstract}
Polynuclear aromatic hydrocarbons from urban runoff were found at elevated levels in nearshore sediment samples from Lake Pontchartrain. Concentrations decreased with distance from the New Orleans shoreline and approached background levels three to six miles offshore. Quantitative profiles for individual $\mathrm{PAH}$ isomers differed significantly between nearshore and offshore sediments. Similar trends were observed with chlorocarbons and lead, but concentrations of other heavy metals did not decrease with distance from the shoreline. Salt water intrusion causes stratification over the southeastern portion of the Lake in the summer. This stratification contributes to and exacerbates bottom anoxic conditions during warm weather months.
\end{abstract}

The objectives of this year long study were twofold and included: (A) determination of the occurrence and distribution of chemicals in Lake Pontchartrain, Louisiana (particularly in the southern portion of the Lake near New orleans) that resulted from anthropogenic activity; and $(B)$ an overall water quality assessment of the Lake to ascertain any phenomena, in particular urban runoff related water pollution, that may be adversely affecting the ecological balance of the Lake. The strategies developed to address these objectives included: (1) Collection of biota and sediment samples and their analyses for a broad spectrum of chemical substances which included, but were not Iimited to, those designated as priority pollutants by the U.S. EPA. (2) Examination of the temporal and spatlal variation of Important estuarlne water quality parameters, as well as conventional pollutants, that contribute to nutrient enrichment and other impalrments such as increased turbidity and dissolved oxygen depression.

\section{American Chemical Society Library 1155 16th St., N.W. Washington, D.C. 20036}


Fleld and laboratory work was begun in March of 1982. Fleld work was undertaken by blologists with the Loulsiana Department of Environmental Quality. Analyses of blota and sediment samples for anthropogentc substances were performed at the Center for Blo-organic Studies at the University of New Orleans. Water Quality and conventional pollutant analyses were provided by the laboratory staff of the Department of Environmental Quality.

Lake Pontchartrain is a shallow, open water embayment of a major estuarine system in southeastern Loulsiana. It has 2 , surface area of approximately 630 square miles $\left(1.60 \times 10^{9} \mathrm{~m}^{2}\right)$. Depths in offshore areas (greater than one mile from shore) range typlcally from $12-18$ feet ( 4 to $6 \mathrm{~m}$ ) with the bottom exhibiting a gradual rellef. Locallzed depressions proximate to three tidal passes, which connect the lake to the Gulf of Mexico, slope to depths up to 40 feet $(12 \mathrm{~m})$. The passes themselves have depths approaching 100 feet $(30 \mathrm{~m})$.

Lake Pontchartrain recelves dralnage from an area of approximately 5,000 square miles located mostly to its north. Several rivers drain the Louisiana coastal plain terraces while two other rivers drain the former Mississippi River floodplain southwest and west of the lake. From the south, Lake Pontchartrain recelves extensive wetland (marsh and swamp) drainage. The greater New Orleans area, which includes Jefferson and Orleans Parishes, is now leveed of $\mathrm{f}$ from the lake. However, this metropolitan area, home for over a million people, is dralned by pumplng from an extensive network of man-made canals Into Lake Pontchartrain.

In addition to man-made stormwater drainage canals along the southern shoreline, Lake Pontchartrain is influenced by a deep draft (12m) channel known as the Mississippi River Gulf Outlet (MRG0). Highly saline waters are introduced directly into Lake Pontchartrain via this canal.

Because of the close proximity of the Greater New Orleans Metropolitan Area to Lake Pontchartrain, with no intervening buffer zone, the southern portion of the lake should logically be the most affected by anthropogentc impacts. As such it should serve as a "worst case" barometer of the lake's environmental health. Therefore the major focus of this study was directed toward the southern area of Lake Pontchartrain.

\section{Sampling Sites}

Primary sampling stations for the study were established at 16 fixed localities in the southern region of Lake Pontchartrain. These stafions were selected from an approximate 100 square mile $\left(2.6 \times 10^{2} \mathrm{~m}\right.$ ) grid adjacent to the southern shoreline extending 20 statute miles along Jefferson and orleans Parlshes and extending to six miles offshore at its widest point (see Figure $1)$. E1ght of these stations were located in the Immediate nearshore area adjacent to the mouths of major dratnage canals. Each was established approximately $.23 \mathrm{mtles}(370 \mathrm{~m})$ north of the respective canal's mouth. LORAN C coordinates for each were recorded during the first sampling crulse and then used during subsequent cruises to re-occupy the same sampling locality. Ten 


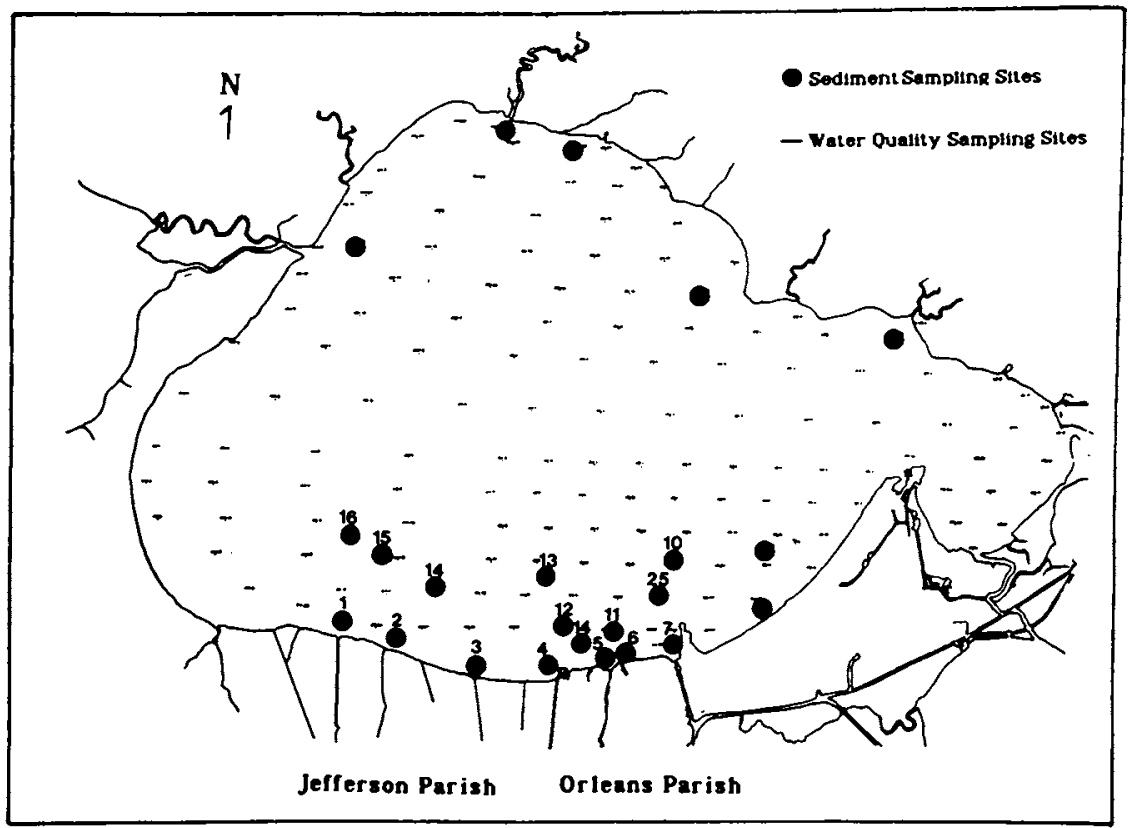

F1gure 1. Map of Lake Pontchartrain showing locations of the 148 water quality sampling stations and the locations which were also sampled for sediments.

In Organic Marine Geochemistry; Sohn, M.;

ACS Symposium Series; American Chemical Society: Washington, DC, 1986. 
additional stations were established offshore within the 100 square mile study area. On a monthly basis, March 1982 to March 1983, fleld and laboratory water quality analyses were taken at 16 of the primary stations. Fleld WQ readings were taken during the summer months over the ent1re area of Lake Pontchartrain at 148 sampling stations (see Figure 1). Fleld water quality measurements were made at one meter (m) 1ntervals from one meter below the surface to $0.5 \mathrm{~m}$ above the lake bottom. Readings were taken with Martek Instruments, Inc. (Irvine, $\mathrm{CA}$ ) multiprobe analyzers.

On a quarterly bas1s between March 1982 and March 1983 lake sediment and biota samples were collected from ten of the sixteen primary stations and analyzed for anthropogenic organic chemicals and trace metals. Stations were selected alternately so that each was sampled at least once during the study period. Four stations des1gnated LPO7, LP10,LP11, and LP12, were sampled during each quarter. Sediment samples consisted of three separate dredge grabs with Pet1te Ponar samplers (Wildilfe Supply Company). Sediment grabs were composited in stalnless steel buckets ( 3 gallon) that were washed and then rinsed with nanograde hexane between each sampling station. Aliquots of composited sediments were placed in wide-mouth quart jars, prerinsed with nanograde hexane. Nearshore sediments were well sorted fine silts with between 1 and 2 percent organic carbon content. Offshore sediments were fine silts or clays and generally contalned between 2 and 3 percent organic carbon content.

\section{Analytical Methods}

Analytical methods were designed to screen a relatively large number of samples for a broad spectrum of organic compounds and selected heavy metals. In the fleld, all samples were placed on ice Immediately following collection. Upon dellvery to the laboratory, samples were frozen and maintained at $-10^{\circ} \mathrm{C}$. Just prior to analyses, the samples were thawed and thoroughly homogenized.

The analytical procedure for trace organics included extraction of all samples, fractionation of the extracts by liquid-solid chromatography, and instrumental analyses of the fractions by fused silica capillary gas chromatography using flame lonization (general) detection, and, for some samples, electron capture (halogen specific) detection. Selected fractions were then chosen for detalled instrumental analyses using computerized high resolution gas chromatography-mass spectrometry (GCMS) (1).

A11 GCMS data files were examined with a general search procedure developed for scanning GCMS data for anthropogenic chemicals at trace levels. Hard coples of the mass spectral data were examined manually to verify computer matches and identify compounds not selected by the computer program. Identifled compounds were then quantitated by multiplying their peak area with appropriate response factors obtalned from analyses of quantitative standards under identical instrumental tunes and 
conditions. Standard compounds were not avallable for all the substances identifled in samples. Quantitative response factors were estimated for those compounds not contalned in analytical standards. It is important to note that the use of estimated response factors gives data that can be compared with equivalent data within a given data base. Comparison of the data with other results outside of the data base should be done within the context of the 11mitations Imposed by quantitative GCMS analyses. In general, these limitations in the quantitative results are not significantly large when compared with varlabllitles observed between samples collected from marine environments. Experience from analyses of many replicate samples and particlpation in round-robin type Interlaboratory calibration programs (2) has produced data which indicates the analytical varlabilities are compound dependent and range from $5 \%$ to $30 \%$. This analytical varlabllity is generally small when compared to varlabilities found between samples collected in the marine environment.

EPA approved atomic adsorption methods were used in all trace metal analyses (3).

Standard quality control procedures were followed. These Included: a) careful washing of all glassware in strong oxidizing solutions and with Type I water; b) frequent analyses of glassware and reagent blanks; c) analyses of procedural blanks with each batch of samples; and d) callbration of instruments before each set of analyses by analyzing standard solutions. Analytical proficlency in the analysis of biota and sediment samples have been demonstrated by participation in round-robin type interlaboratory calibration exerc1ses (2).

\section{Discussion of Resu1ts}

Salinity. Concentration profiles for top and bottom salinities and d1ssolved oxygen concentrations at four selected stations are shown 1n F1gure 2. Similaritles in surface salinity are apparent, but the surface dissolved oxygen concentrations varled appreclably. The maximum surface salinity at all four stations occurred in the early Fall (September and October, 1982). The minimum surface salinity at all stations was measured in February, 1983. Surface salinity readings ranged from 1.3 ppt (parts per thousand) at stations LP10 to $9.0 \mathrm{ppt}$ at station LP07. Seasonal simllarities in bottom salinities between all

stations were not apparent. Bottom salinitles differed appreclably in both magnitude and the t1me at which 1ncreases began. Significant increases in bottom salinitles at the station nearest to the MRGO began between Apr11 and May, 1982. Th1s was followed by a marked salinity increase at stations 1.5 and 4.2 m1les offshore between June and July, 1982. The station 4.1 m1les offshore in Jefferson Parish (the most remote from the MRGO) did not exhib1t the abrupt bottom salinity increases that were noted at the other stations. Bottom salinities of 7 to 9 ppt and up generally resulted in stratification with significant decreases in bottom dissolved oxygen concentrations. 


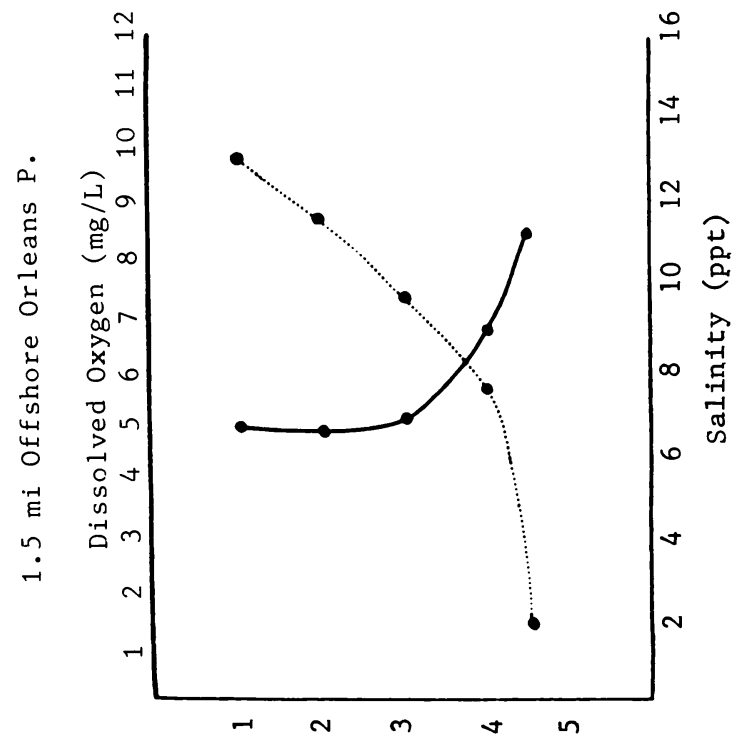

(யi) чวdəa

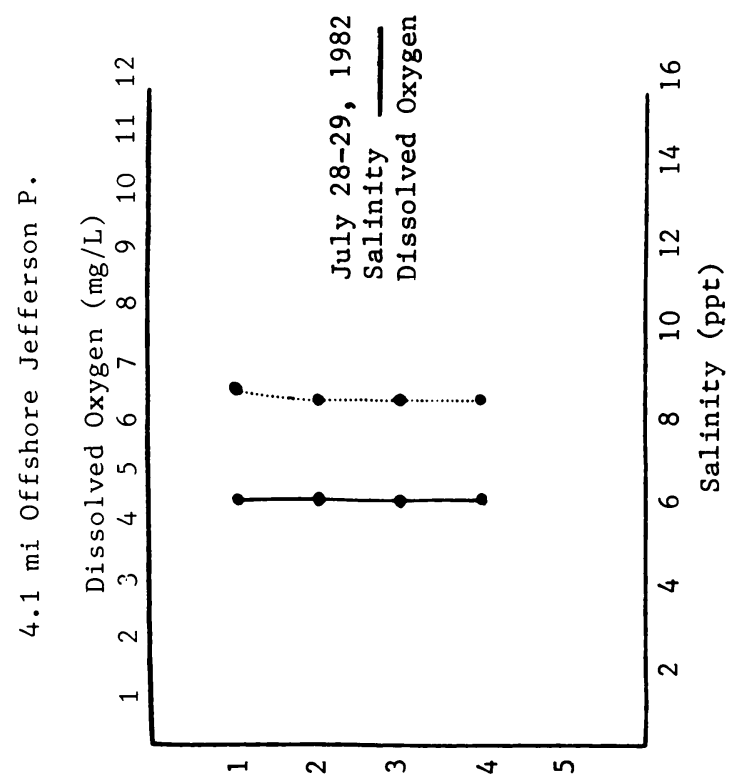

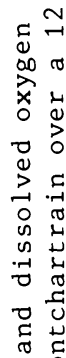

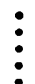

तิ

$\stackrel{+1}{\mathrm{E}}$ $\underset{\pi}{\rightarrow}$

is

(n)

E

营

ำ

ฮ

त 0

0, 3

定

$\Leftrightarrow+\overrightarrow{0}$

$\therefore$ in

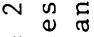

(1)

는

$\infty$ 을

江

(w) प7dəव

In Organic Marine Geochemistry; Sohn, M.;

ACS Symposium Series; American Chemical Society: Washington, DC, 1986. 


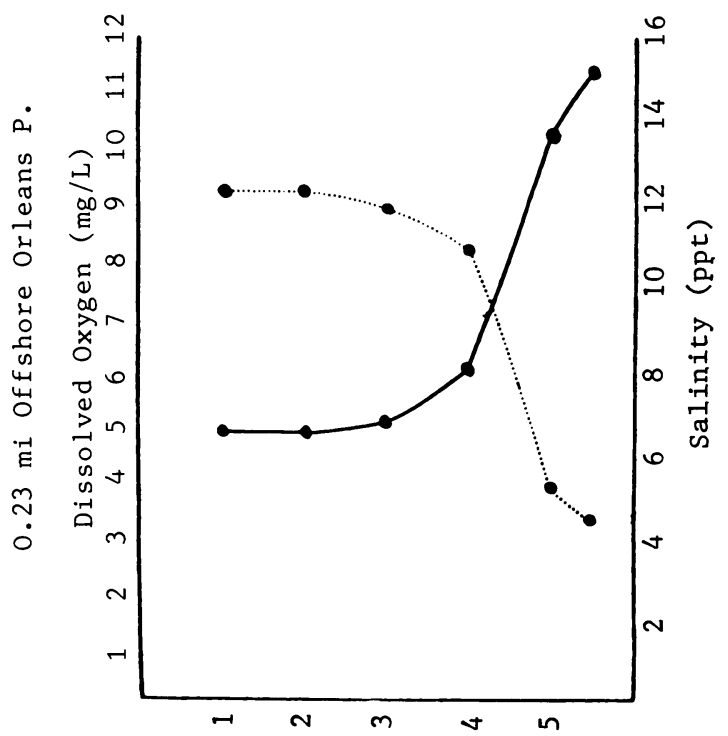

(w) पวdəब
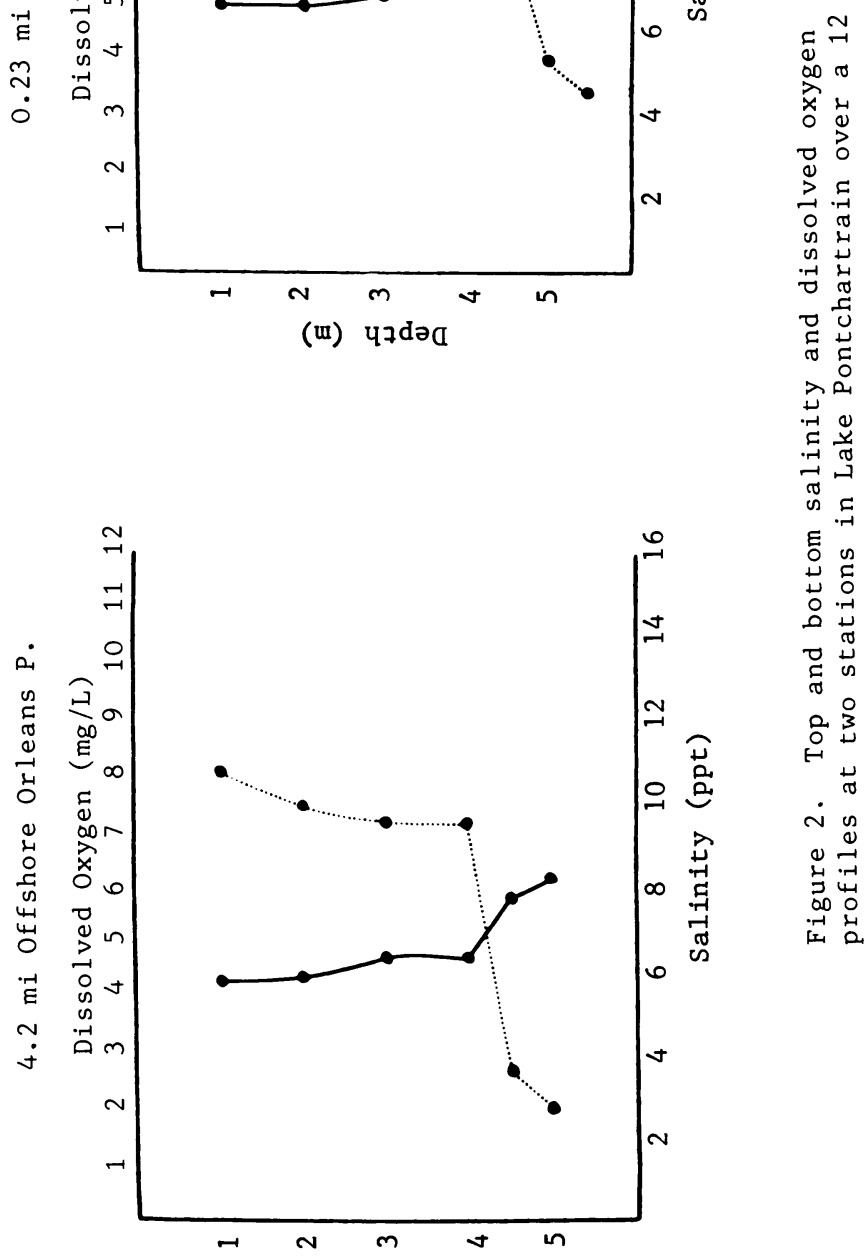

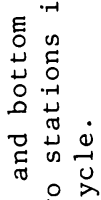

2. उे

$\therefore$

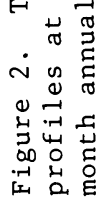

(w) ५७dəd

In Organic Marine Geochemistry; Sohn, M.;

ACS Symposium Series; American Chemical Society: Washington, DC, 1986. 
Data collected at $0.5 \mathrm{~m}$ above the Lake's bottom, from the 148 lakewlde stations in July and August 1982, are presented as 1sopleths in Figure 3. Highest bottom salinities in Lake Pontchartrain, during the two month sampling perlod, occurred at and near the MRGO-Lake connection. Much lower salinitles were recorded in the northern sectlons of the Lake due to freshwater inputs from northshore rivers and passes. Bottom dissolved oxygen concentrations taken in July were lowest (1.0 ppm) in the south central area of the lake and $3.0 \mathrm{ppm}$ along the south shore and in mid-lake reglons. The lowest dissolved oxygen readings recorded in August were found to be centralized in mid-lake areas. In general, low Do readings closely follow reglons of signiflcant stratification during the summer months when mixing of the shallow lake from weather fronts was minimized.

Examination of the isohalines shown in Figure 3 clearly indicates that the major source of highly sallne waters was the MRG0. Salinitles at the mouths of two natural passes, which are also contributors of saltwater into Lake Pontchartraln, are not as high as at the mouth of the MRGO. The MRGO complex which provides a direct man-made connection for highly sallne waters from the Gulf of Mexico to enter Lake Pontchartrain, contributes significantly to stratification. On the other hand, the two natural passes allow Inflow of waters characterized by salinities that are closer in concentration to those in Lake Pontchartrain.

Trace Organics. High resolution gas chromatograms from analyses of the saturated hydrocarbon fractions of four sediment samples collected from the lake in January 1983 are shown in Figure 4. The samples collected off Jefferson Parlsh contained saturated hydrocarbon profiles typical of terrestrlal biogentc hydrocarbon inputs (4). These inputs are characterized by odd carbon number hydrocarbons, in the range of $n-C 24$ to $n-C 30$, and have greater abundances than their even carbon numbered homologs. The samples collected of $f$ orleans Parish contained large complex unresolved mixtures (CUM) which are Indicative of weathered petrogenic hydrocarbons. The source of the extremely high levels of weathered petrogentc hydrocarbons in the nearshore Jeffersonorleans Parish sample is unclear. However, the hydrocarbon loads in samples from this station were not typical of those found at any of the other sampling stations in Lake Pontchartrain. Consequently, these levels cannot be attributed to the normal types and loads of hydrocarbons found in urban runoff and probably resulted from the splllage of weathered petrogenic hydrocarbons into the drainage canal situated near this sampling station. Because the levels of petrogenlc hydrocarbon were so elevated at this station, we have chosen to consider all data from this station as anomalous. Consequently, data from this station have been excluded from further discussions of the distributions and sources of organtc contaminants in Lake Pontchartrain.

Figures 5 through 7 show concentrations of several important classes of organic compounds, as well as specific organics as a function of distance of $f$ shore and date of sample collection. The types of compounds, which are represented as sub-classes of the 

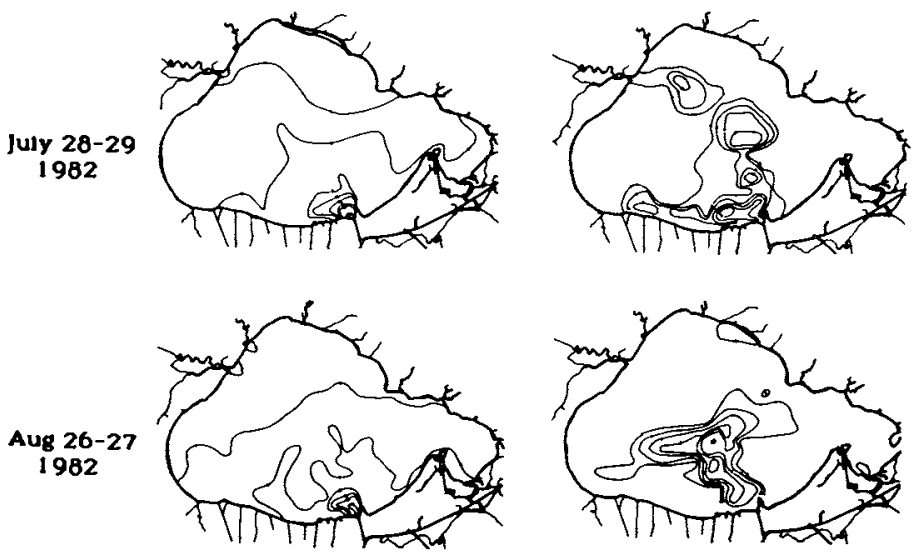

Figure 3. Isohalines and dissolved oxygen isopleths in Lake Pontchartrain on consecutive months in the summer of 1982 . 

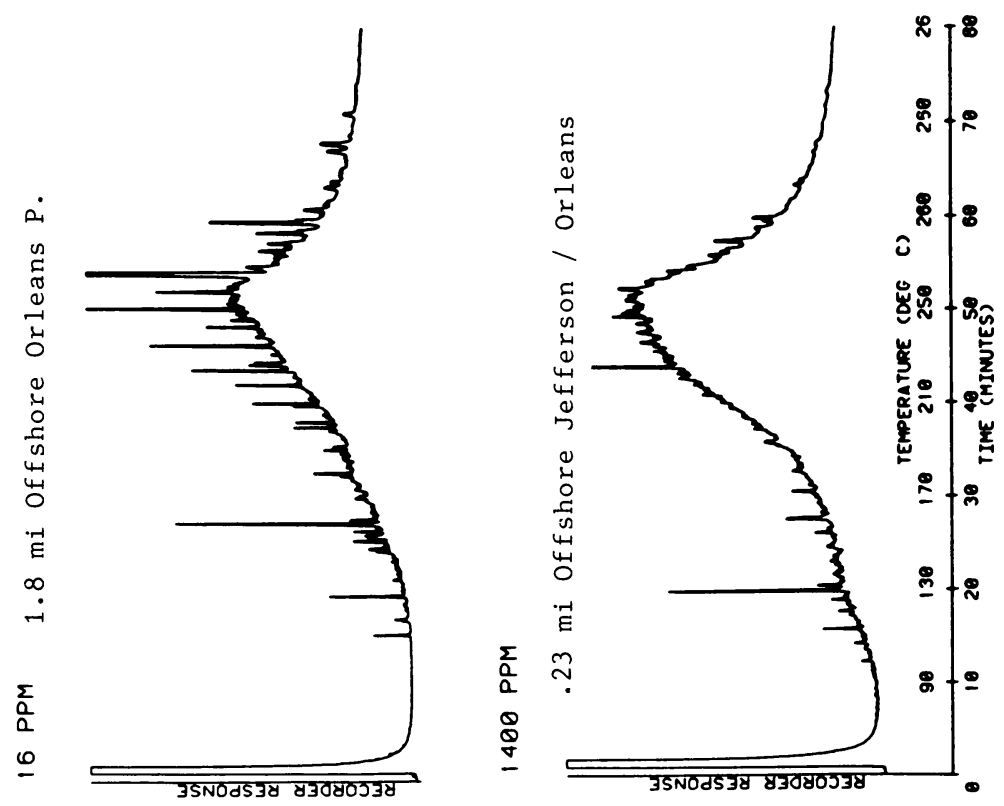

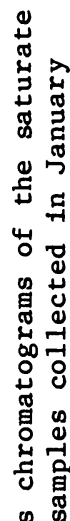
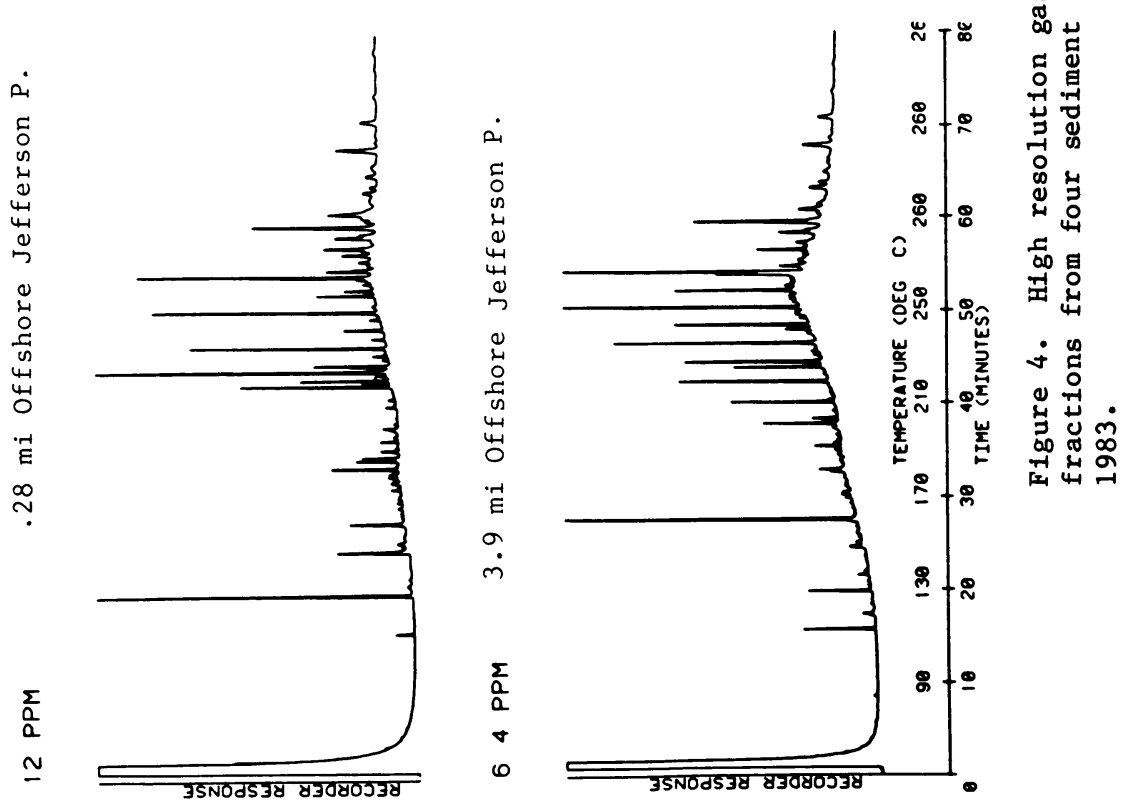

In Organic Marine Geochemistry; Sohn, M.; ACS Symposium Series; American Chemical Society: Washington, DC, 1986. 
total organics found in mass spectra data, are shown in Table I and include: TIC (total identifiable compounds; PPAH (parent polynuclear aromatic hydrocarbons); TAAH (total alkyl aromatic hydrocarbons); $\mathrm{C} / \mathrm{N}$ (chlordane and nonachlor); $\mathrm{PCB}$ (polychlorinated biphenyls); and DDT (sum of the DDT environmental degradation products). Total hydrocarbon concentrations (THC) were derived from GC data. The quantities of these various substances generally decrease, in a general exponential fashion, with distance from the southern shoreline, reaching background levels at distances of 3 to 6 miles offshore. This is as expected since the majority of organic substances found in these samples have extremely low water solubility ( $\underline{5}$ ). Consequently, they are generally transported in the marine environment as particulate matter $(6,7)$. There are several exceptions to this general observation. For example, perylene concentrations showed no downward trend with distance from the shore. This compound is produced by both high temperature combustion and natural diagenetic processes ( 8$)$. Consequently, it is not surprising that no significant trends were observed relating perylene concentrations with distance from shore. The most abundant class of organics found in Lake Pontchartrain sediments was the unsubstituted polynuclear aromatic hydrocarbon (PPAH). Figure 8 shows the quantities and relative distributions of nine different PAH compounds at three different sampling stations. These stations were chosen to show the PAH distributions with distance from the southern shoreline. As a general rule, similar distributions were noted at other sampling sites as a function of distance offshore. Offshore PAH levels were characterized by elevated concentrations of perylene while near-shore samples contalned mostly four ring PAH compounds.

Table II shows the concentrations of selected trace organics in biota samples examined during this study. In general, highest concentrations were observed in the spring. Chlorocarbon concentrations were comparable to other areas along the Gulf Coast and generally lower than commonly encountered along the eastern seaboard ( $\underline{9})$.

Heavy Metals. The concentrations of Barlum, Lead and Cadmium, with distance from the shoreline, are shown in Figure 9. Lead concentrations generally decreased with distance from the shoreline but there was considerable varlability in this trend. Lead is transported as particulate matter in the marine environment $(10,11)$. Consequently, lower but highly variable concentrations offshore are to be expected. Other heavy metals studied did not exhibit any detectable trend with distance from the shoreline. Even the highly insoluble heavy metal, $\mathrm{Ba}$, did not show significantly lower concentrations in of fshore areas.

Conclusions

Factors which are currently affecting environmental quality in Lake Pontchartrain are generally those related to urban development and urban pollution, altered land use patterns, and hydrologic modification within the lake's watershed. Paramount 


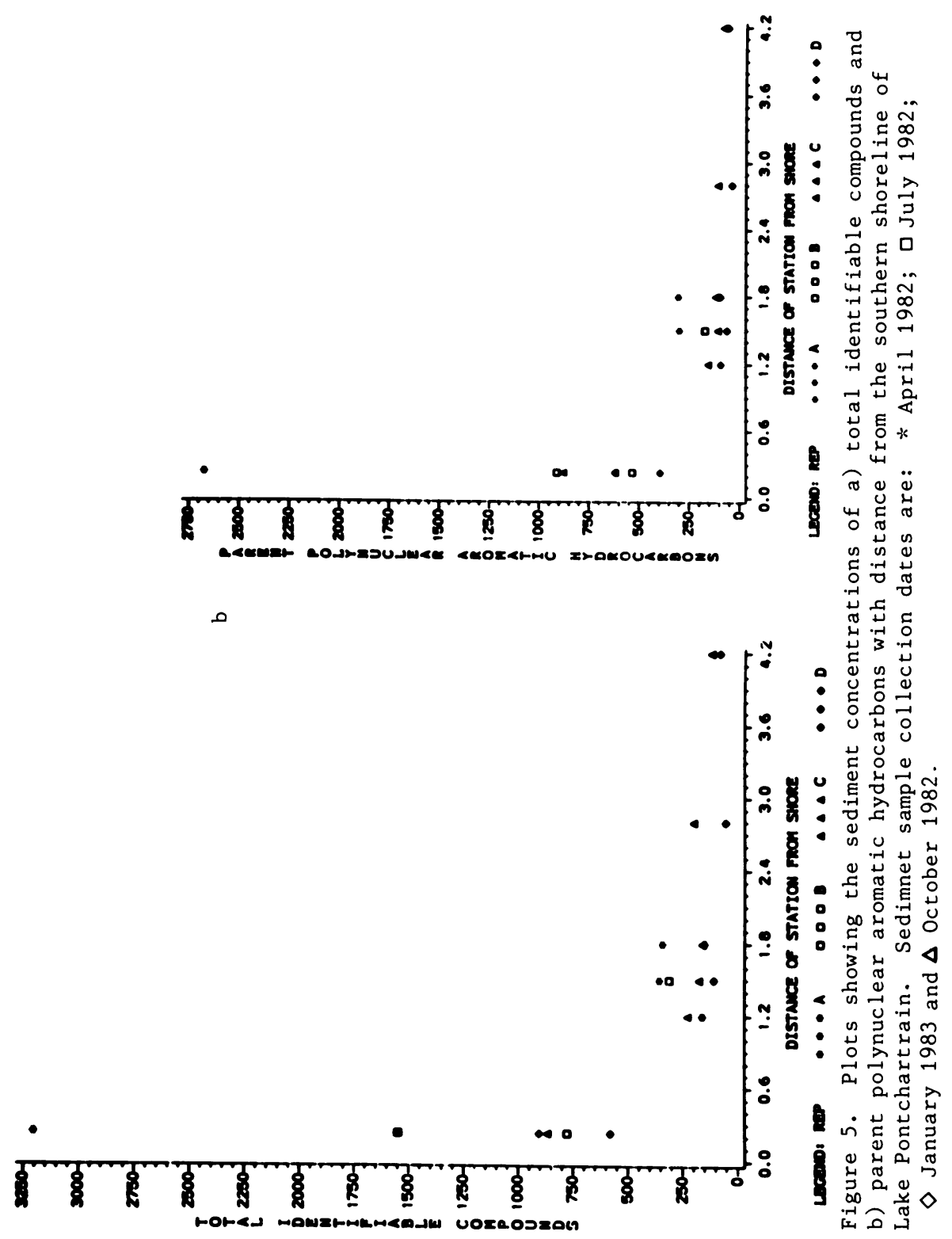




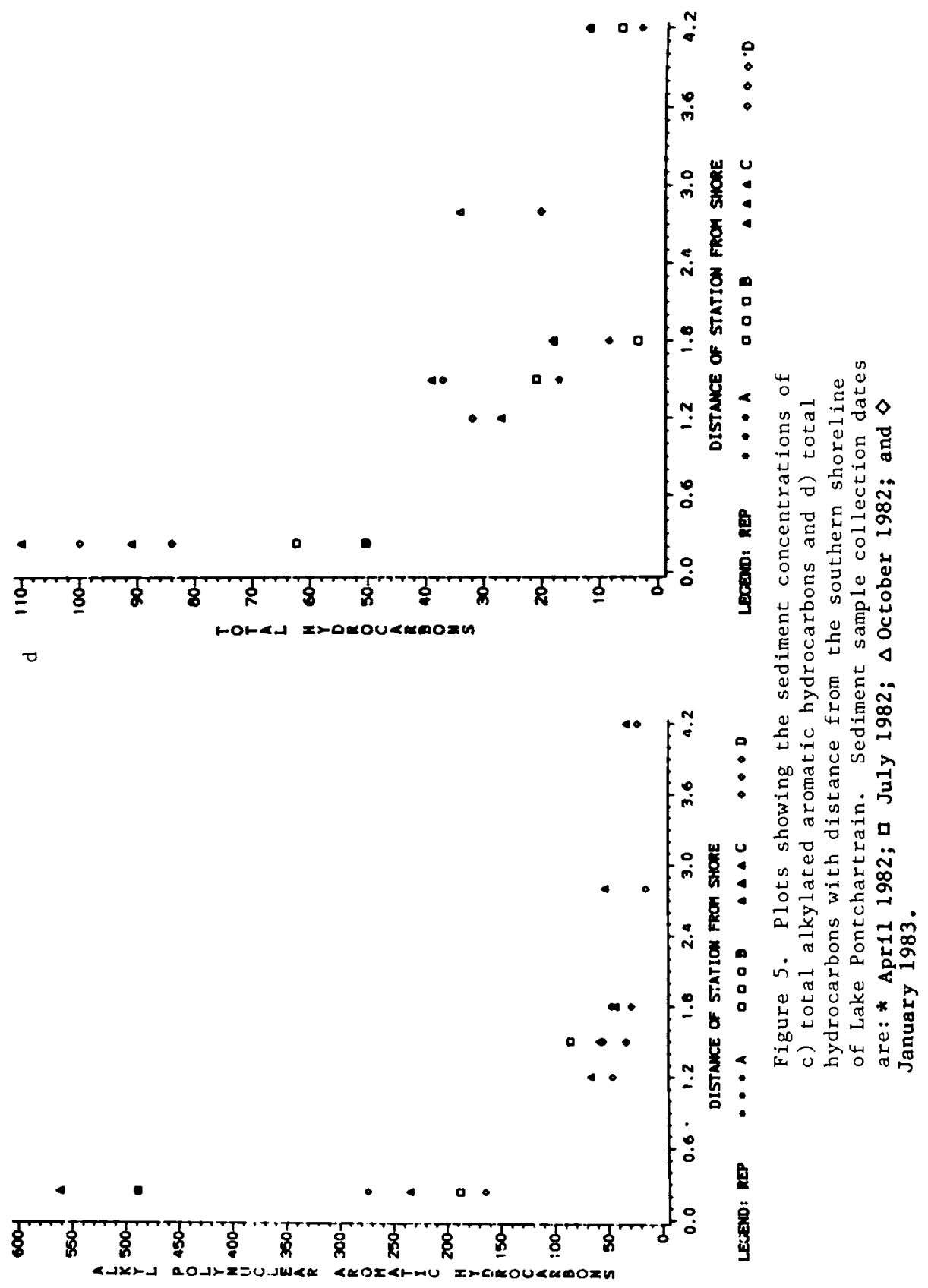




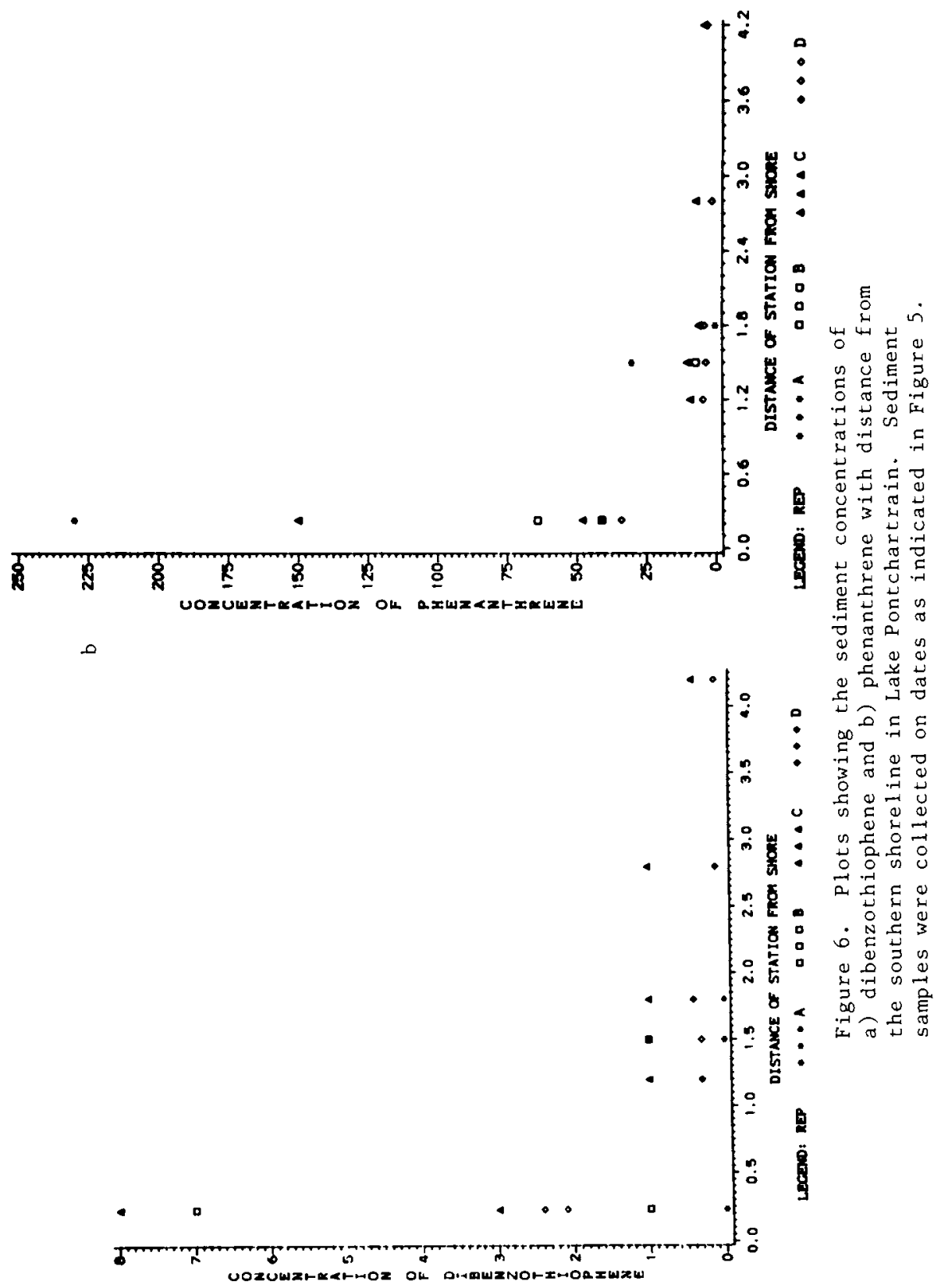




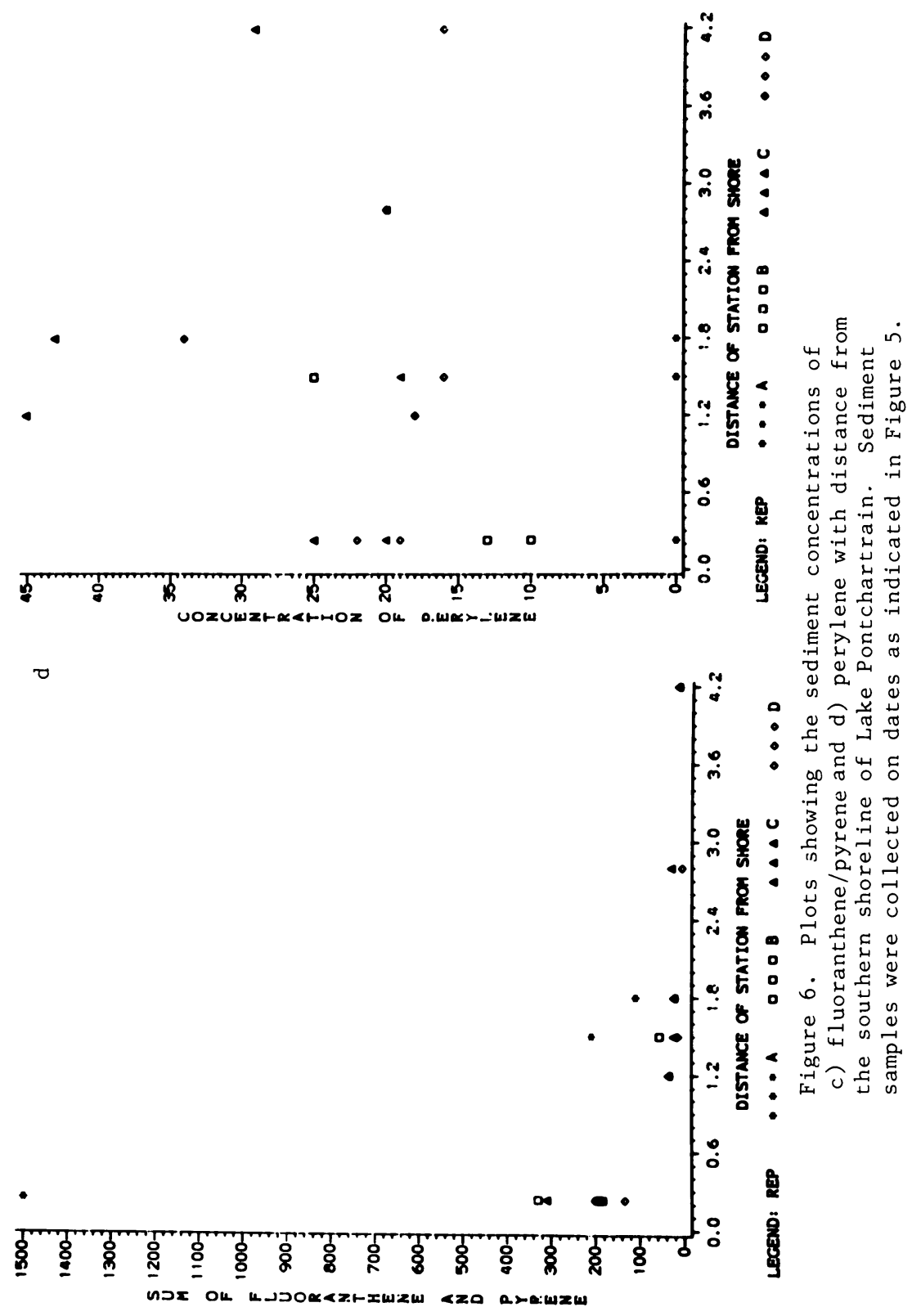




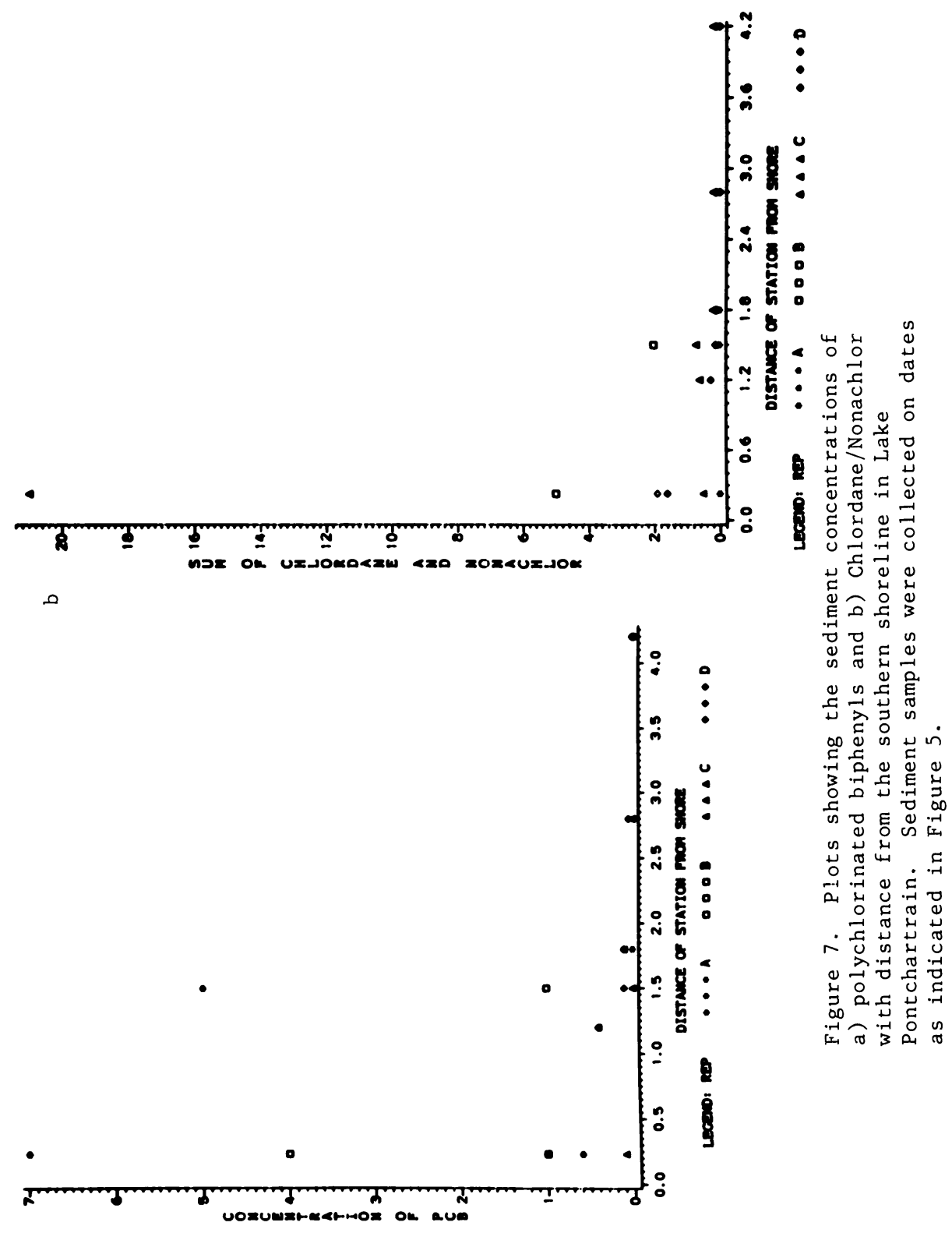




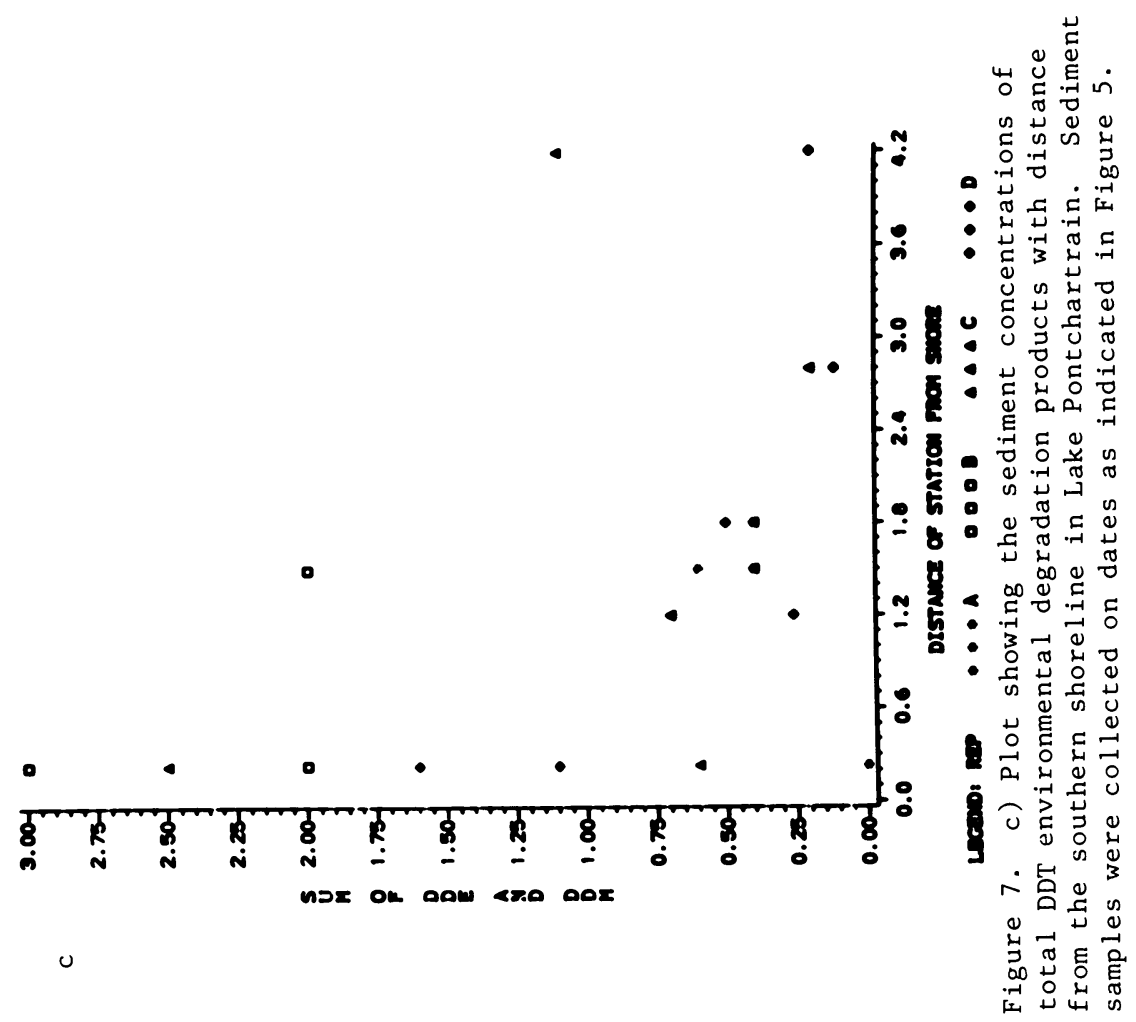

In Organic Marine Geochemistry; Sohn, M.; ACS Symposium Series; American Chemical Society: Washington, DC, 1986. 
Table I. Specific Compounds Found in Lake Pontchartrain Sediment Samples as well as the Identities of Compounds that Comprise the Varlous Sub-classes of Pollutants whose Concentration Trends are Highlighted in this Report.

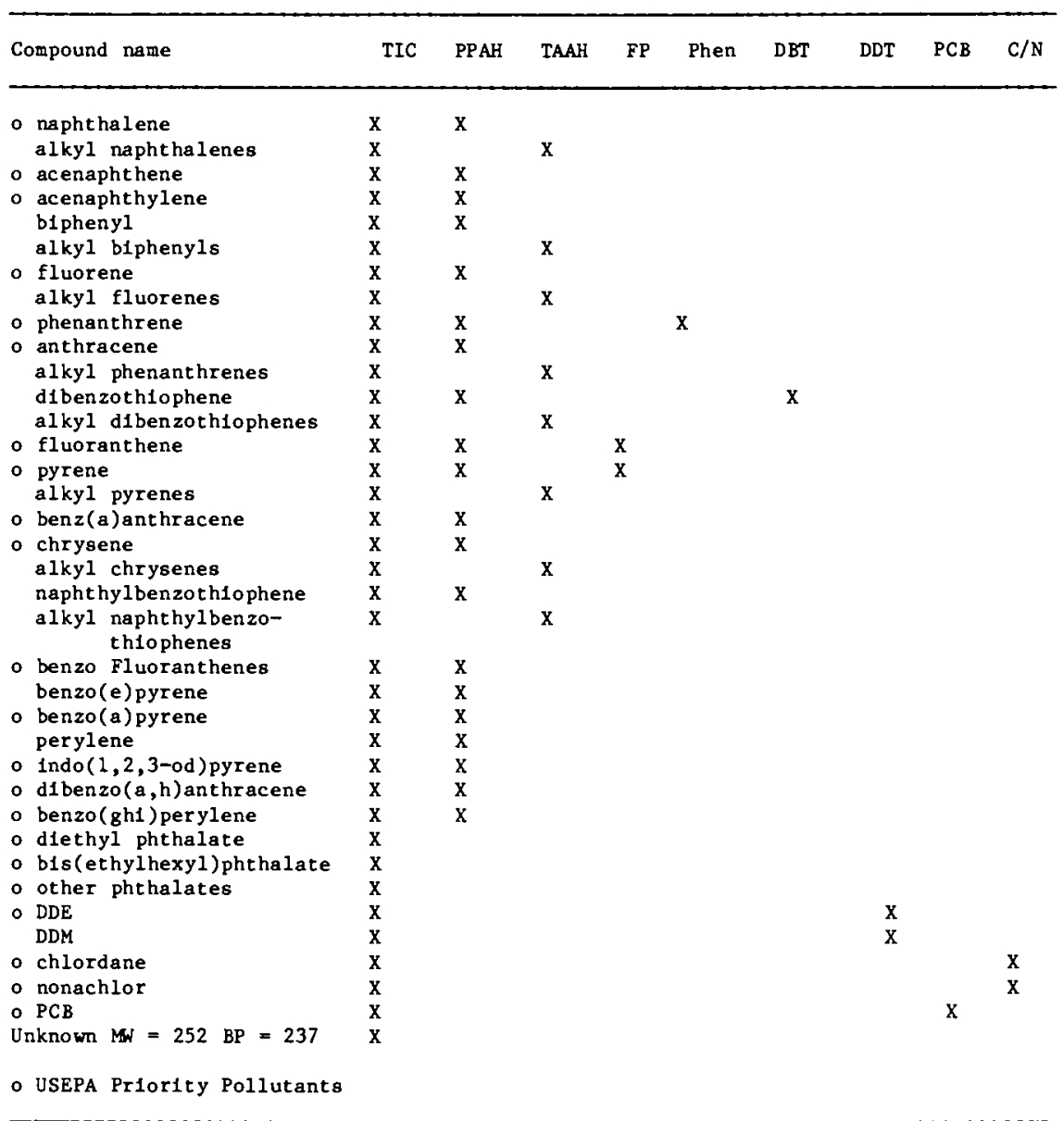

In Organic Marine Geochemistry; Sohn, M.;

ACS Symposium Series; American Chemical Society: Washington, DC, 1986. 


\section{$.23 \mathrm{mi}$} offshore

$1.5 \mathrm{mi}$

offshore

\section{$4.2 \mathrm{mi}$}

offshore

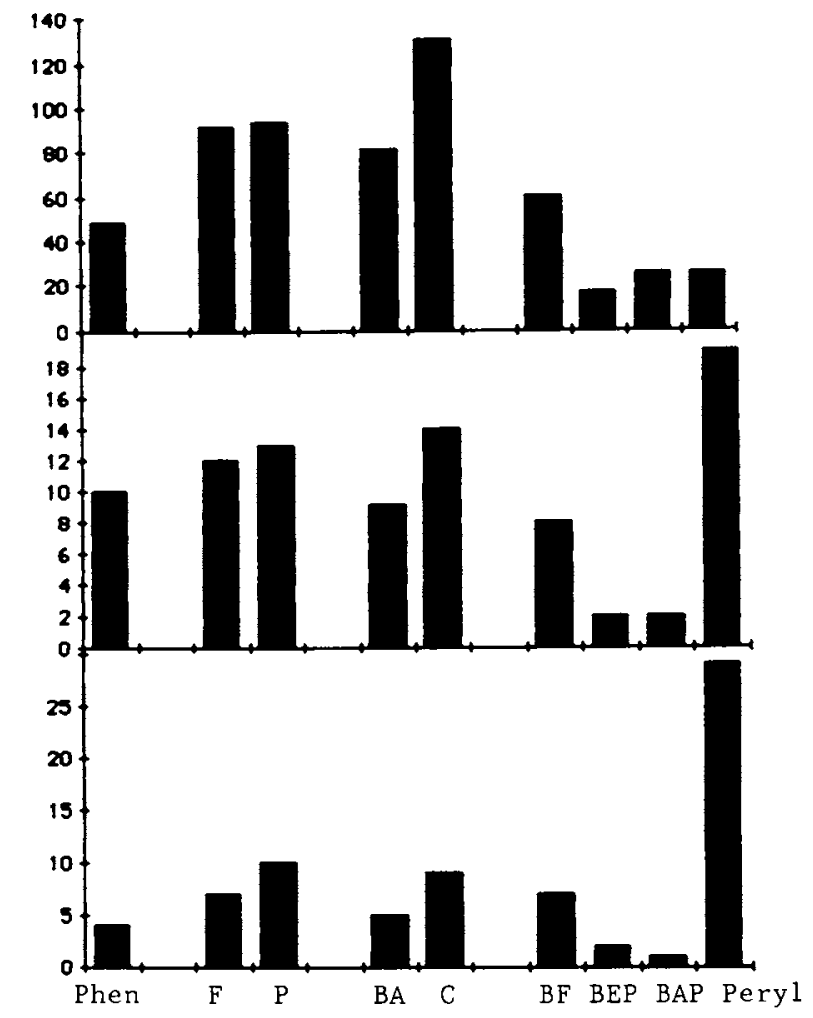

Figure 8. The quantities ( $\mathrm{ppb}$ ) and distribution of nine polynuclear aromatic hydrocarbons, at three sampling stations, in Lake Pontchartrain sediments. Phen = phenanthrene, $F=$ fluoranthene, $\mathrm{P}=$ pyrene, $\mathrm{Bz}=$ benzanthracene, $\mathrm{C}=$ chrysene, $\mathrm{BF}=$ benzofluoranthenes, $\mathrm{BEP}=$ benzo-e-pyrene, BAP =benzo-a-pyrene, Peryl = perylene.

In Organic Marine Geochemistry; Sohn, M.;

ACS Symposium Series; American Chemical Society: Washington, DC, 1986. 
Table II. Concentration of: Total Identifiable Compounds/Parent Polynuclear Aromatic Hydrocarbons (Top); PCBs/DDTs (Bottom) in the Selected Blota Samples Expressed as PPB wet Welght.

\begin{tabular}{|c|c|c|c|c|}
\hline Sample Location & April ' 82 & July ' 82 & oct.' 82 & Jan ' 83 \\
\hline LP01 & & $\begin{array}{c}\text { Shrimp } \\
\star 800 / 15 \\
3 / 2\end{array}$ & $\begin{array}{c}\text { Crab } \\
66 / 17 \\
1 / 2\end{array}$ & \\
\hline LP02 & $\begin{array}{l}\text { Clam } \\
360 / 114 \\
6 / 6\end{array}$ & & & \\
\hline $\mathrm{LPO3}$ & & & $\begin{array}{l}\text { Crab } \\
178 / 48 \\
12 / 8\end{array}$ & \\
\hline LP0S & & $\begin{array}{l}\text { Clam } \\
570 / 190 \\
130 / 13\end{array}$ & & \\
\hline \multirow[t]{2}{*}{ LP07 } & $\begin{array}{r}\text { Croaker } \\
2000 / 85 \\
180 / 70\end{array}$ & & $\begin{array}{c}\text { Oyster } \\
140 / 63 \\
4 / 1\end{array}$ & $\begin{array}{l}\text { Crab } \\
44 / 5 \\
\text { ND/5 }\end{array}$ \\
\hline & $\begin{array}{l}\text { Crab } \\
1600 / 27 \\
100 / 27\end{array}$ & & & \\
\hline LP10 & $\begin{array}{c}\text { Spot F1sh } \\
2000 / 280 \\
200 / 130\end{array}$ & $\begin{array}{l}\text { Spot F1sh } \\
130 / 34 \\
17 / 14\end{array}$ & & $\begin{array}{l}\text { Croaker } \\
33 / 4 \\
1 / 4\end{array}$ \\
\hline LP15 & & $\begin{array}{r}\text { Crab } \\
66 / 4 \\
2 / 4\end{array}$ & & $\begin{array}{c}\text { Catf1sh } \\
\text { *370/10 } \\
\text { ND } / 1\end{array}$ \\
\hline
\end{tabular}

* Contaulnated with diethylhexyl phthalate.

In Organic Marine Geochemistry; Sohn, M.;

ACS Symposium Series; American Chemical Society: Washington, DC, 1986. 


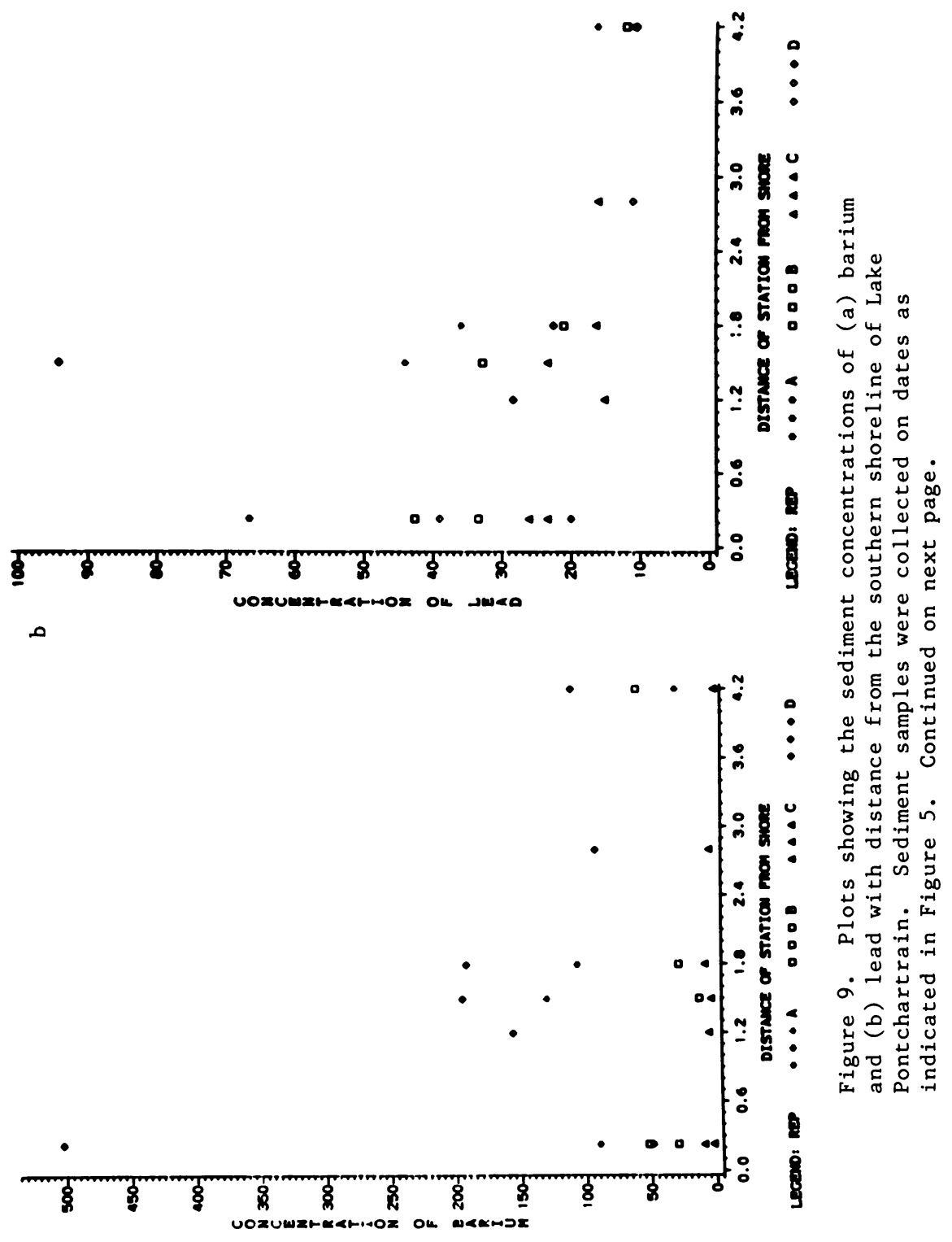




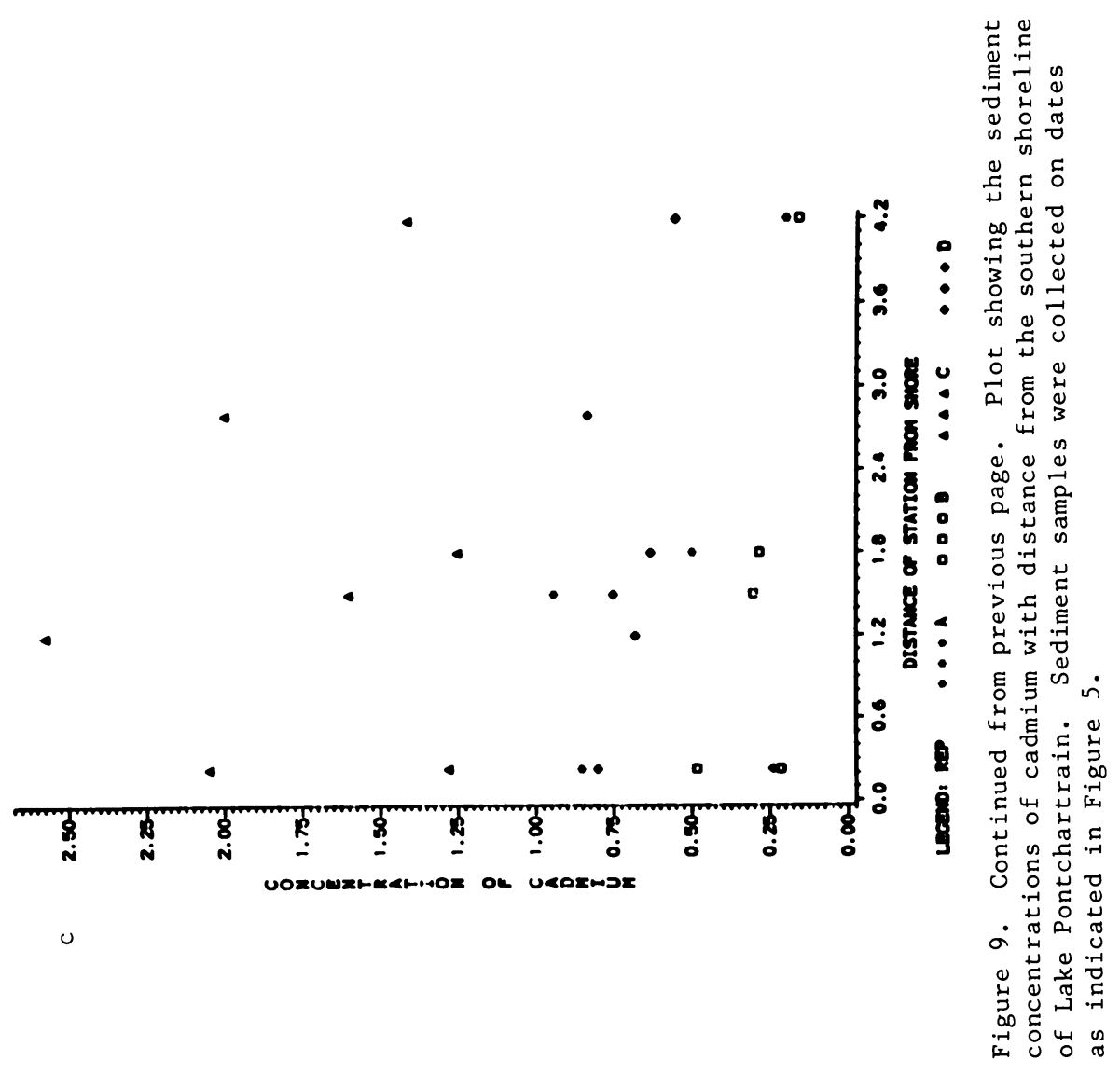

In Organic Marine Geochemistry; Sohn, M.;

ACS Symposium Series; American Chemical Society: Washington, DC, 1986. 
among these is the tremendous rate of urbanization that has spread in recent decades from the metropolitan New Orleans area which occupies a major portion of the southern lakeshore. Because of its immediate proximity to the lake and the fact that much of this area is at or below sea level, a network of canals on the east side of the Mississippi River drains the area into the lake. These canals are catch basins for the street drainage, stormwater runoff, and point source discharges of treated, partially treated and untreated sewage. In addition, many discharges from small commercial facilities are made either to the sewage systems or directly to the canals. No major industrial facilities (e.g. petrochemical or organic chemical manufacturing) are permitted to discharge into Lake Pontchartrain. Therefore, the major chemical inputs of pollutants into the lake may be categorized as coming from three major source categories. These are (1) urban stormwater drainage, (2) discharges of domest1c sewage that is generally treated to less than acceptable levels, and (3) discharges and spills from marine related facilities and marine vessels.

Examination of the data suggest that urban runoff is responsible for the greater variety and the higher levels of anthropogenic chemicals introduced into the lake. Sewerage discharges introduce pollutants that contribute to oxygen depletion and eutrophication.

The contribution of ofl and other organic substances from marine associated facilities and vessels is more related to spill events, either accidental or intentional, rather than regular, long term input. Data reviewed to date indicate that specific areas are impacted by ofls and other petroleum hydrocarbons.

Another factor of significant environmental influence is the alteration of salinity patterns in the southeastern and eastcentral region of the lake of $f$ the mouth of the MRGO. This hydrologic modification facilitates the intrusion of highly saline marine waters from the Gulf of Mexico into Lake Pontchartrain. This saltwater intrusion is most pronounced during the warm water months (May to October) of years with normal and below normal rainfall. Its effects reach their peak during the late summer (August/September) when prevailing southerly and southeasterly winds greatly facilitate the movement of marine waters up the MRGO and into Lake Pontchartrain.

\section{Acknowledgments}

The authors would like to express thanks and appreciation to: $D$. Sabins, W. Tucker, K. Cormier, C. Melchior, L. Racca, J. Dixon, L. Wellman and J. Akielaszek for collection of samples; J. McFa11 and S. Antoine for analyses of samples; P. Benoit, S. Stewart and D. Meyers for help in preparation of this manuscript; and the Louisiana Department of Environmental Quality for their financial support. 


\section{Literature Cited}

1. Brown, P.W.; Ramos, L.S.; Uyeda, M.Y.; Friedman, A.J.; MacLeod, W.D. In "Petroleum in the Marine Environment"; Petrak1s L.; Welss, F.T., Eds.; ADVANCES IN CHEMISTRY SERIES No. 185, American Chemical Society: Washington, D.C., 1980; p. 313 .

2. Macleod, W.D.; Prokaska, P.G.; Gennero, D.D.; Brown, D.W. Ana1. Chem., 1982, 54, 386.

3. "Interim Methods for the Sampling and Analyses of Priority Pollutants in Sediments and F1sh Tissue," U.S. Environmental Protection Agency, 1981.

4. Wakeham, A.J.; Farrington, J.W.; In "Contaminants and Sediments"; Baker, R.A., Eds.; Science Publishers Inc.: Ann Arbor, 1980; p. 3.

5. Lopez-Avila, V.; H1tes, R.A. Environ. Sc1. Technol. 1980, 14, 1382 .

6. Hamilton, A.E.; Bates, T.A.; Cline, J.D. Environ Sc1. Technol. $1984,18,72$.

7. Eganhouse, R.P.; Blumfield, D.L.; Kaplan, I.R. Environ. Sc1. Technol. 1983, 17, 523.

8. Laflame, R.E.; Hites, R.A. Geochim Cosmochem Acta. 1978, $42,289$.

9. "Review of PCB levels in the environment" US Environmental Protection Agency, 1976.

10. Whipple, W.; Hunter, J.V. I. Water Pollution Control Fed. $1977,49,15$.

11. Boyden, C.R.; Afton, S.R.; Thorton, I. Estuarine and Coasta1 Marine Sc1. 1977, 9, 303.

RECEIVED November 8, 1985 


\title{
Seasonal Cycles of Dissolved Methane in the Southeastern Bering Sea
}

\author{
Joel D. Cline' ${ }^{1}$, Charles N. Katz ${ }^{2}$, and Kimberly Kelly-Hansen ${ }^{3}$ \\ 'Mobil Research and Development Corporation, Dallas, TX 75234 \\ 2InterOcean Systems, Inc., San Diego, CA 92123 \\ ${ }^{3}$ Pacific Marine Environmental Laboratory, National Oceanic and Atmospheric \\ Administration, Seattle, WA 98115
}

\begin{abstract}
Seasonal measurements of dissolved methane were made in the southeastern Bering Sea shelf waters between 1975-1981. This region is a large, coastal-shelf environment that is characterized by large variations in biological activity and climate. For these reasons, and others, this region is well suited to examine the seasonal distributions of methane and other biologically-generated gasses.

Maximum concentrations of methane were observed in the fall of 1981 , followed by a minimum in spring. Surface concentrations, on the average, were about 400 $\mathrm{nL} / \mathrm{L}$ (STP) in fall, dipping to concentrations near 100 $\mathrm{nL} / \mathrm{L}$ (STP) in spring. Near bottom concentrations were generally higher throughout the region, and in particular over St. George Basin, where concentrations in excess of $2500 \mathrm{~nL} / \mathrm{L}$ (STP) were observed.

The sea to air flux of methane ranged from $0.021 \mathrm{~g}$ $\mathrm{CH}_{4} \mathrm{~m}-2 \mathrm{yr}-1$ in May 1981 to $0.34 \mathrm{~g} \mathrm{CH}_{4} \mathrm{~m}^{-2} \mathrm{yr}^{-1}$ in October 1980; the mean flux was about $0.14 \mathrm{~g} \mathrm{CH}_{4} \mathrm{~m}^{-2}$ $\mathrm{yr}^{-1}$. Based on a total area of $31.9 \times 10^{10} \mathrm{~m}^{2}$ and correcting for average ice coverage in winter, the annual transport of methane to the atmosphere for $1980-81$ was $4.6 \times 10^{10} \mathrm{~g}$.

Seasonal and interannual variations in the concentration methane are large in the southeastern Bering Sea shelf. The driving force for these variations is the timing and flux of organic carbon as well as the severity (i.e., amount of ice cover) of the winters. These observations point to the need for seasonal observations in near shore coastal waters if meaningful budgets of methane, and presumably other trace gasses, are to be constructed.
\end{abstract}

$0097-6156 / 86 / 0305-0272 \$ 07.25 / 0$

(c) 1986 American Chemical Society 
Methane is an ubiquitous trace gas found in all marine and freshwaters. Its concentration in the surface waters of the open ocean is near saturation (1-3), however in some near shore areas, in anoxic basins, and in marine sediments the concentrations are significantly higher $(4,7)$ because of increased production rates. The highest production rates of methane are usually restricted to anoxic environments, but significant rates of production also have been observed in oxic marine water columns $(8,9)$.

The most complete set of published observations on the sources, sinks, and distributions of methane in coastal waters is that by researchers at Texas A\&M University. Without detailing an exhaustive list of the observations, many of which deal with the thermogenic as well as biogenic sources of methane, the following papers are most relevant to our own discussion of coastal distributions of methane $(7,10-14)$.

our intent here is not to summarize the extensive observations of methane in the marine environment, but rather to set the stage for a discussion of seasonal distributions in a high latitude shelf environment. There are few studies of the seasonal variations of trace gases in a marine environment, and to our knowledge, none in a high latitude, shallow sea, where biological influences are apt to be large. In this report, we will specifically exanine the seasonal distributions of dissolved methane in the southeastern Bering Sea and qualitatively discuss the physical and biological forcing that results in the observed distributions.

observations discussed in this report were made as a part of an environmental study of Alaskan coastal waters.

\section{Methods}

Sampling. Discrete water column samples were obtained with $5-L$ Niskin bottles attached to a General Oceanics Rosette fitted with Plessey Environmental Systems model 9040 CTD. A $1-L$ aliquot of seawater was transferred from the Niskin samplers into glassstoppered bottles in such a way that air bubbles were not trapped. The bottles were then stored in the dark at approximately $5^{\circ} \mathrm{C}$ until analyzed; usually within one hour of sampling.

Analys is Concentration. The analys is of methane was accomplished routinely in the field using a purge and trap technique (15). The method involves removal of the dissolved gases from a $0.2[$ volume of seawater by helium purging. The gasses removed from solution are passed through Ascarite ${ }^{\otimes}$, Drierite and Tenax G.C. traps to remove carbon dioxide, water vapor and heavy hydrocarbons respectively, before being concentrated on an activated alumina trap held at $-196^{\circ} \mathrm{C}$. After quantitative removal of the gasses from solution (approx. 6 minutes with a purge rate of $100 \mathrm{~mL} \mathrm{~min}^{-1}$ ), the activated alumina trap was warmed to $100^{\circ} \mathrm{C}$ and the gasses backflushed into a gas chromatograph.

Gas Chromatography. Detection and quantitation of methane was carried out on a Hewlett-Packard $5710 \mathrm{~A}$ gas chromatograph equipped with a flame ionization detector (FID). The column packing used 
was activated alumina, $60-80$ mesh $(1.8 \mathrm{~m} \times 0.48 \mathrm{~cm} 0$. d.). The column temperature was held isothermally at $100^{\circ} \mathrm{C}$.

Quantitation of the methane was obtained by comparing the detector response of a methane gas standard with that of the sample. The FID response was found to be linear with concentration throughout the entire range of methane concentrations encountered in the study. Standard gasses prepared by Matheson Gas Products were intercalibrated with a standard gas analyzed by the National Bureau of Standards (NBS). Analytical precision was generally less than $1 \%$ while accuracy, based on the NBS intercalibration, was $5 \%$. The detection limit of the method, based on a signal-to-noise ratio of 2 is approximately $5 \mathrm{~nL} \mathrm{CH}_{4} \mathrm{~L}^{-1}$ seawater (STP).

Sal inity-Temperature-Pressure (Depth). Conductivity, temperature and pressure data were collected using a Plessey Systems CTD with model 8400 data logger. These sensors were interrogated five times per second for values of temperature, conductivity (salinity), and pressure (depth). Data were recorded during the down-cast using a lowering rate of $30 \mathrm{~m} \mathrm{min-1}^{-1}$. Niskin bottle samples were taken on every other cast to provide temperature and salinity calibration. Nominal precision of the salinity, temperature and depth measurments was $\pm 0.02 \mathrm{~g} \mathrm{~kg}^{-1}, \pm 0.02{ }^{\circ} \mathrm{C}$ and $\pm 0.2 \mathrm{~m}$, respectively.

\section{Physical Setting}

The survey area, which includes Bristol Bay, is a broad shelf region located in the southeastern Bering Sea (Figure 1). It is bounded on the south by the Alaska Peninsula, on the west by the shelf break, and on the north by the coast of Alaska (16). The area out to the $200 \mathrm{~m}$ isobath is about $32 \times 10^{10 \mathrm{~m}^{2}}$; the area-weighted mean depth is about $70 \mathrm{~m}$. The principal sources of fresh water are the Kuskokwim and Kvichak rivers, which are located at the northern and eastern boundaries (Figure 1). Estimated discharge of these rivers is about $47 \mathrm{~km}^{3}$ annuaily (17), but there are also numerous small, diffuse sources of fresh water along the entire coastline. Notable among them is the Port Moller estuary located along the north side of the Alaska Peninsula. Winter cooling results in a maximun of $60 \%$ of the southeastern Bering Sea being covered with ice between the months of December and April (16). This ice is largely wind driven from the north, although during severe winters there is local ice formation.

Hydrographically, the region is divided into three domains: coastal waters $(z<50 \mathrm{~m})$, middle shelf $(50 \mathrm{~m}<z<100 \mathrm{~m})$, and the outer shelf $(z>100 \mathrm{~m})(18)$. The greatest seasonal variations in temperature and salinity are found in the coastal zone because of its shallow depth and close proximity to sources of fresh water. In contrast to the coastal regime, which is unstratified most of the year because of wind and tidal mixing, the middle shelf is thermally stratified much of the year. The outer shelf, principally St. George Basin (Figure 1), is characterized by salinites 


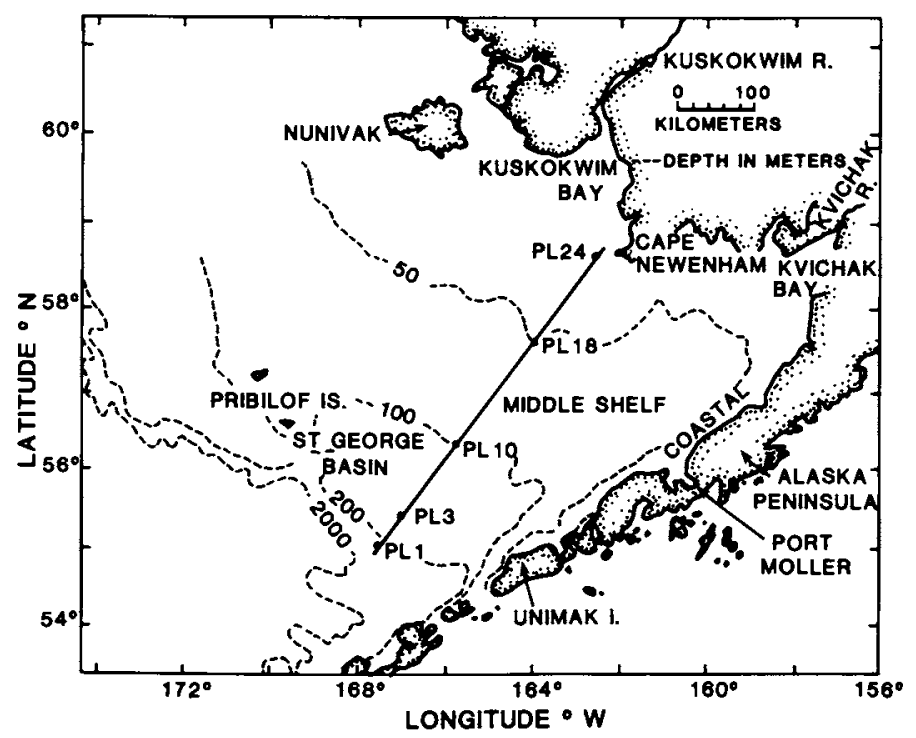

Figure 1. Location of the southeastern Bering Sea, showing hydrographic regimes and bathymetry. Also shown in the position of a vertical section across the region (see Figure 4 ). Individual station locations, which varied from cruise to cruise, are shown on the areal distribution maps. 
near $33^{\circ} \%$ and a temperature range of $3-4^{\circ} \mathrm{C}$. Surface temperatures and salinities are somewhat greater in summer. Currents over the shelf are generally weak $(19,20)$. Along the outer shelf in summer, current trajectories trend northwest at speeds of approximately $5 \mathrm{~cm} / \mathrm{sec}$. Across the inner shelf, currents are weak $(\sim 1 \mathrm{~cm} / \mathrm{sec})$ and counterclockwise.

\section{Seasonal Distributions of Dissolved Methane}

The vertical and horizontal distributions of dissolved methane are not only controlled by biological processes, but also by the local hydrography, which has a marked seasonal signature. Stratification strongly influences the vertical transport of methane and other gasses, and is largest where the buoyancy input is the greatest. Warming of the surface layers and the addition of fresh water from land drainage leads to a reduction in the density of the surface waters and subsequent stratification. Because stratification also affects in a significant way the vertical transport of methane, a brief description of the seasonal changes in salinity and temperature is instructive.

The coastal regime experiences large seasonal changes in water properties, because of its nearness to 1 and and its shallow depth. Figure (2a) shows the temperature and salinity fields for the three seasons, superimposed on the lines of constant density $\left\{\sigma_{t}=(\rho-1) \times 1000\right\}$. A large change in salinity is seen in August and is the result of fresh water runoff along the Alaska Peninsula. The lowest salinities are found near the Kvichak River, and the highest salinities are found near Unimak Pass. Relatively saline water entering Unimak Pass is driven cyclonically around the basin and gradually becomes less saline due to freshwater dilution. Winter and spring are characterized by isohaline conditions $(30-32 \%)$, however the temperature rises from near freezing in winter to $4-8{ }^{\circ} \mathrm{C}$ in May.

The middle shelf is not so strongly influenced by seasonal changes in salinity because it is farther removed from 1 and. However, temperatures there range from near freezing in winter to about $10{ }^{\circ} \mathrm{C}$ in August (Fig. $2 \mathrm{~b}$ ). The salinity range is $30-32$ $\%$, about the same as observed in the coastal zone away from major sources of freshwater.

Methane: August, 1980 . The surface distribution of dissolved methane ( $\mathrm{nL} / \mathrm{L}$, STP) in August 1980 is shown in Figure 3a. The highest surface concentrations were found near the entrance to Port Moller and near Unimak Pass (see Figure 1). At the entrance to Port Moller, concentrations of $d$ issolved methane were greater than $2500 \mathrm{~nL} / \mathrm{L}$ (about 35 times the equilibrium value) and decreased along the coast toward the northeast. The direction of the methane plume marks the mean drift of the coastal current. 

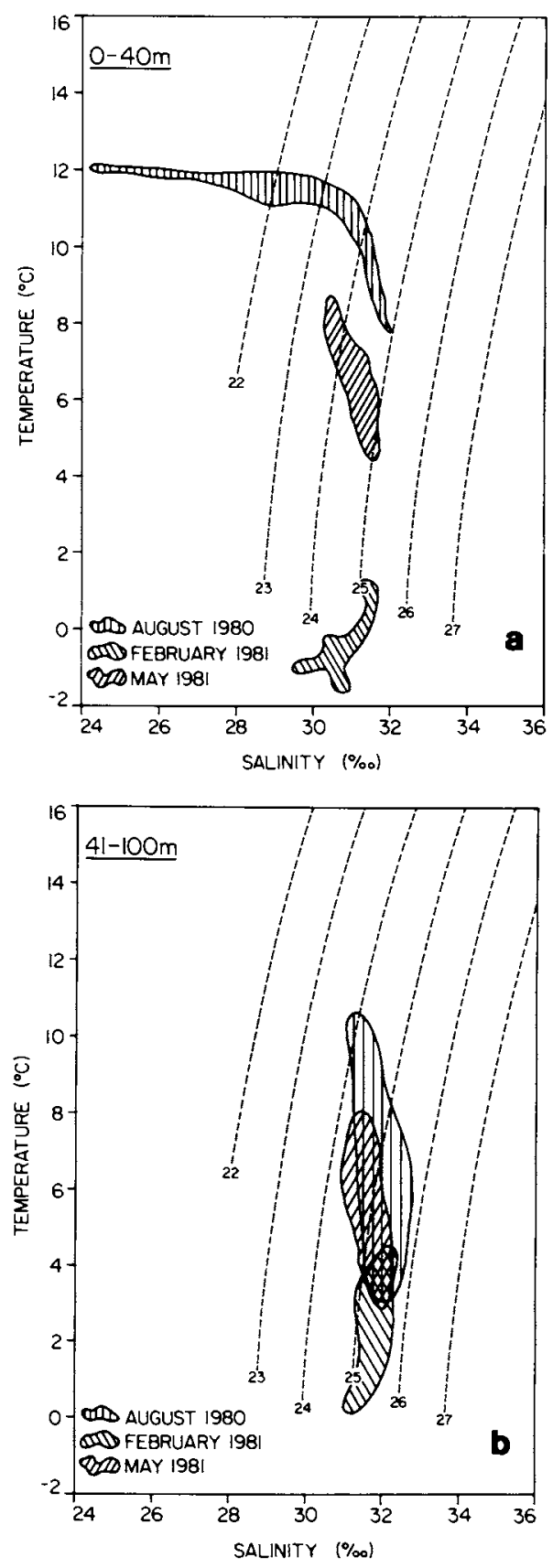

Figure 2. Temperature and salinity fields for the coastal (a) and middle shelf (b) regions. Surface measurements at each station were averaged and plotted for the three observational periods.

In Organic Marine Geochemistry; Sohn, M.;

ACS Symposium Series; American Chemical Society: Washington, DC, 1986. 

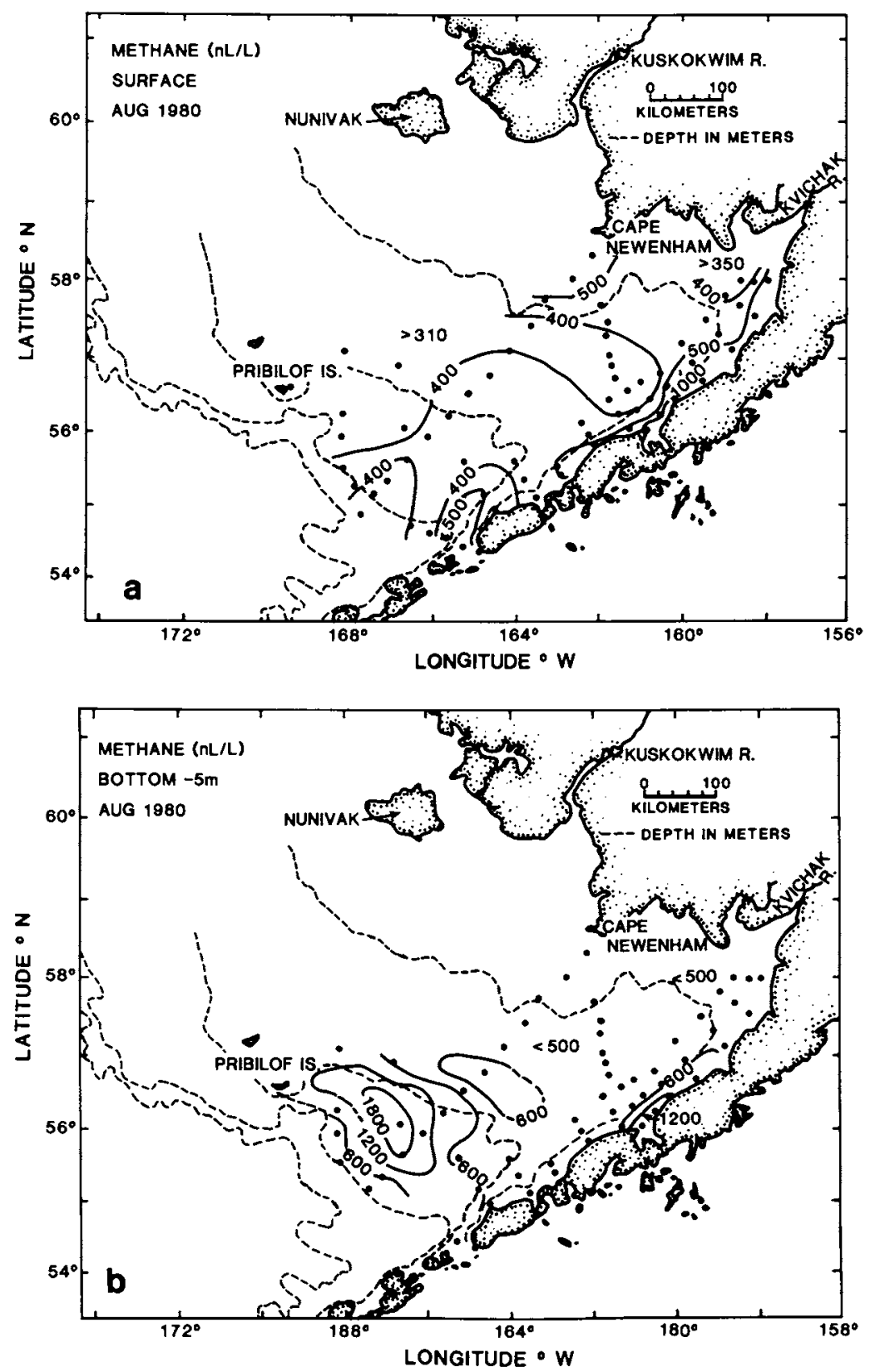

Figure 3. The surface (a) and near-bottom (b) concentrations of methane ( $\mathrm{nL} / \mathrm{L} ;$ S.T.P.) observed in August, 1980. The near-bottom measurements were routinely taken $5 \mathrm{~m}$ above the bottom. 
Over the remainder of the region, concentrations of methane ranged from 300-500 $\mathrm{nL} / \mathrm{L}$. The small surface maximum observed near Unimak Pass arises from vertical turbulence in Unimak Pass. Near-bottom waters south of the Alaska Peninsula are enriched in methane, which becomes entrained in the northerly flow through the pass. Again, the surface concentrations of methane indicate the mean surface current drift as water moves into the Bering Sea.

Distributions of dissolved methane near the bottom (i.e., $5 \mathrm{~m}$ above the bottom) are shown in Figure $3 \mathrm{~b}$. The largest accumulations were found over St. George Basin, a topographic depression located on the outer shelf. These sediments are fine-grained and relatively rich in organic carbon $\left(T O C_{\max }=1 \%\right)(21)$. Contours of methane concentration generally follow the bas in bathymetry, indicating weak circulation and a localized source of methane in the basin. The maximum concentration of methane observed in August 1980 was $2500 \mathrm{~nL} / \mathrm{L}$, decreasing to background concentrations of $500 \mathrm{~nL} / \mathrm{L}$ over the middle shelf.

In contrast, concentrations of methane over the middle shelf and the coastal region were similar to the concentrations seen in the surface waters of St. George Basin. Over most of the middle shelf, near-bottom concentrations of methane ranged from 400-600 $\mathrm{nL} / \mathrm{L}$.

An example of cross-shelf variations in water properties and their influence on the distribution of methane is shown in Figure 4 (see Figure 1 for the location of the vertical section). The estuarine character of the embayment is clearly shown by the distribution of salinity, where low salinity water at the surface moving seaward is being replaced by higher salinity water at depth. High concentrations of methane are evident in the bottom waters of St. George Bas in (PL4-PL8) and are the result of increased production and stratification. There, vertical stratification (Figure $4 \mathrm{c}$ ) restricts the upward transport of methane. In the coastal zone $(z<50 \mathrm{~m})$, the concentration of methane is homogeneous with depth, indicating more intense mixing.

Methane: January, 1981. In winter, surface concentrations of methane had fallen to $200-400 \mathrm{~nL} / \mathrm{L}$, or about $50 \%$ of that seen the previous summer (Figure $5 \mathrm{a}$ ). Once again, the highest surface concentrations were found near the entrance to Port Moller and northeast of Unimak Pass. Ice covered much of the middle shelf and northern coastal regions, which restricted observations to the southern reaches of the area. The maximum surface concentration of methane observed was $2500 \mathrm{~nL} / \mathrm{L}$ at the entrance to Port Moller, once again demonstrating that this estuary is a significant source of methane to the coastal regime, even in winter.

High concentrations were again evident in the near-bottom waters of St. George Basin (Figure 5b). In contrast to concentrations approaching $2500 \mathrm{~nL} / \mathrm{L}$ seen the previous August (Fig. 3b), maximum concentrations had decreased to about $1100 \mathrm{~nL} / \mathrm{L}$. Bottom concentrations over the middle shelf were about $200-300 \mathrm{~nL} / \mathrm{L}$, the same as the surface waters. 

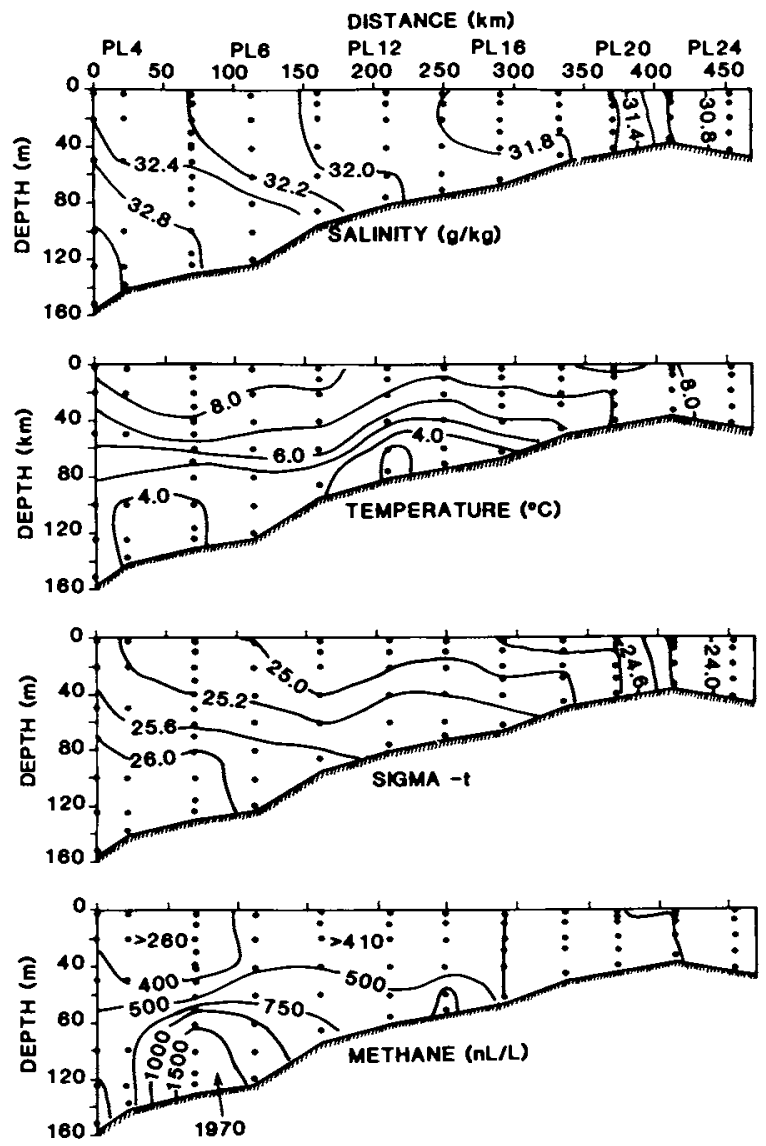

Figure 4. The vertical distributions of salinity, temperature, sigma-t (i.e., density) and methane observed along PL1-PL24 in August, 1980. See Figure 1 for the location of this section. Sigma-t is equal to $(\rho-1) \times 1000$, where $\rho$ is the specific-gravity seawater. 

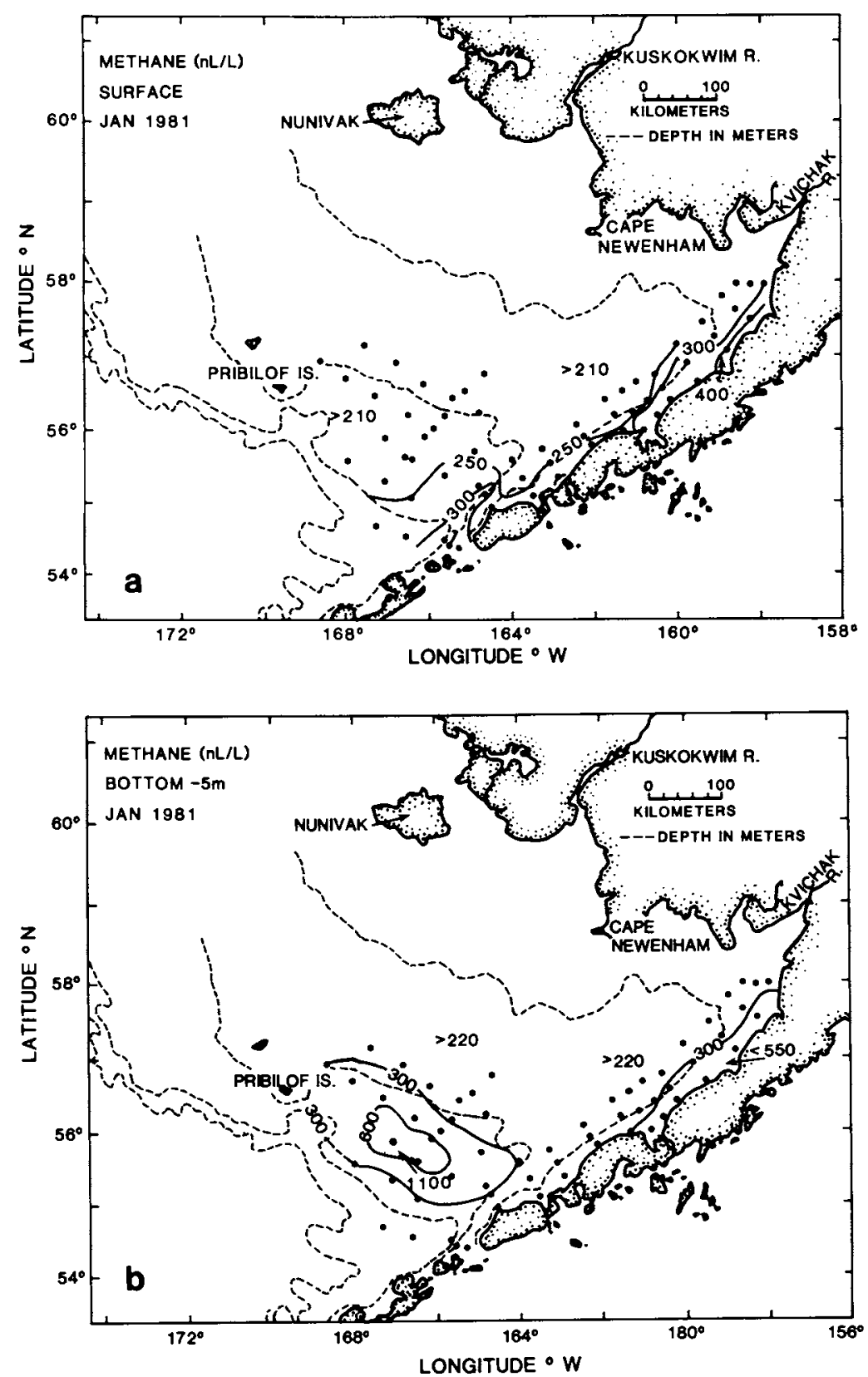

Figure 5. The surface (a) and near-bottom (b) concentrations of methane $(\mathrm{nL} / \mathrm{L})$ observed in January, 1981. 
Methane: May, 1981, By late spring, surface concentrations had decreased to about $70 \mathrm{~nL} / \mathrm{L}$ over much of the middle shelf, but remained high in the North Aleutian coastal waters (Figure 6a). The maximum concentration near Port Moller had decreased to about $600 \mathrm{~nL} / \mathrm{L}$.

Maximum concentrations of methane near the bottom of St. George Bas in approached $1200 \mathrm{~nL} / \mathrm{L}$, which was about the same concentration seen in January (Figure 6b). Near-bottom concentrations over the middle shelf were only slightly greater than the concentrations seen in the surface waters.

Methane: September, 1975 and July, 1976. Concentrations of dissolved methane also were measured in the southeastern Bering Sea in the fall of 1975 and again during the following summer. These observations are shown for both surface and near-bottom waters in Figures $(7 a, b$, and $8 a, b)$.

As noted earlier, the highest surface concentrations of methane were near Port Moller, where the concentration exceeded $1500 \mathrm{~nL} / \mathrm{L}$ in July 1976. Measurements were not obtained near the mouth of the estuary in September 1975, so comparable values were not available, but the coastal plume appears weaker than that seen in July 1976 (compare Figures 7a and $8 \mathrm{a}$ ). Over the remainder of the embayment, concentrations were generally less than $100 \mathrm{~nL} / \mathrm{L}$, except as previously noted in the coastal zone.

Maximum concentrations of methane were again observed in the near-bottom waters of St. George Basin, however, the relatively large amounts observed in 1980-1981 were significantly lower in July 1976 (Figure 8b). The near bottom plume was more pronounced in 0ctober 1975, but maximum concentrations of $600 \mathrm{~nL} / \mathrm{L}$ were below the concentrations seen in 1980-1981.

\section{Processes Controlling the Distribution of Methane}

Internal Sources and Atmospheric Exchange of Methane, Methane is produced by specialized groups of obligate anaerobic bacteria $(22,23)$. The formation of methane as a metabolic product results either from the microbial reduction of $\mathrm{CO}_{2}$ with molecular $\mathrm{H}_{2}$, or via the fermentation of acetic acid. More structuraliy complex substrates may also serve as electron acceptors/donors, but the end result of methanogenes is is to produce methane and $\mathrm{CO}_{2}$ as end products (23).

Large production rates of methane are apparentiy only realized in the absence of dissolved oxygen and sulfate ions $(6,24)$, although methanogenes is and sulfate reduction should not be thought of as mutually exclusive processes $(24,25)$. While it may be macroscopically unrealistic to consider methane production in the presence of oxygen and/or sulfate ions, significant amounts of methane can be produced in oxic (9) and sulfatebearing waters $(24,26)$, presumably with in organic-rich microenvironments. These microenvironments might be organic particles in the water column, organic flocs at the sedimentwater interface, or anaerobic metabolism in the gut of planktonic animals. For these reasons, it is reasonable to 

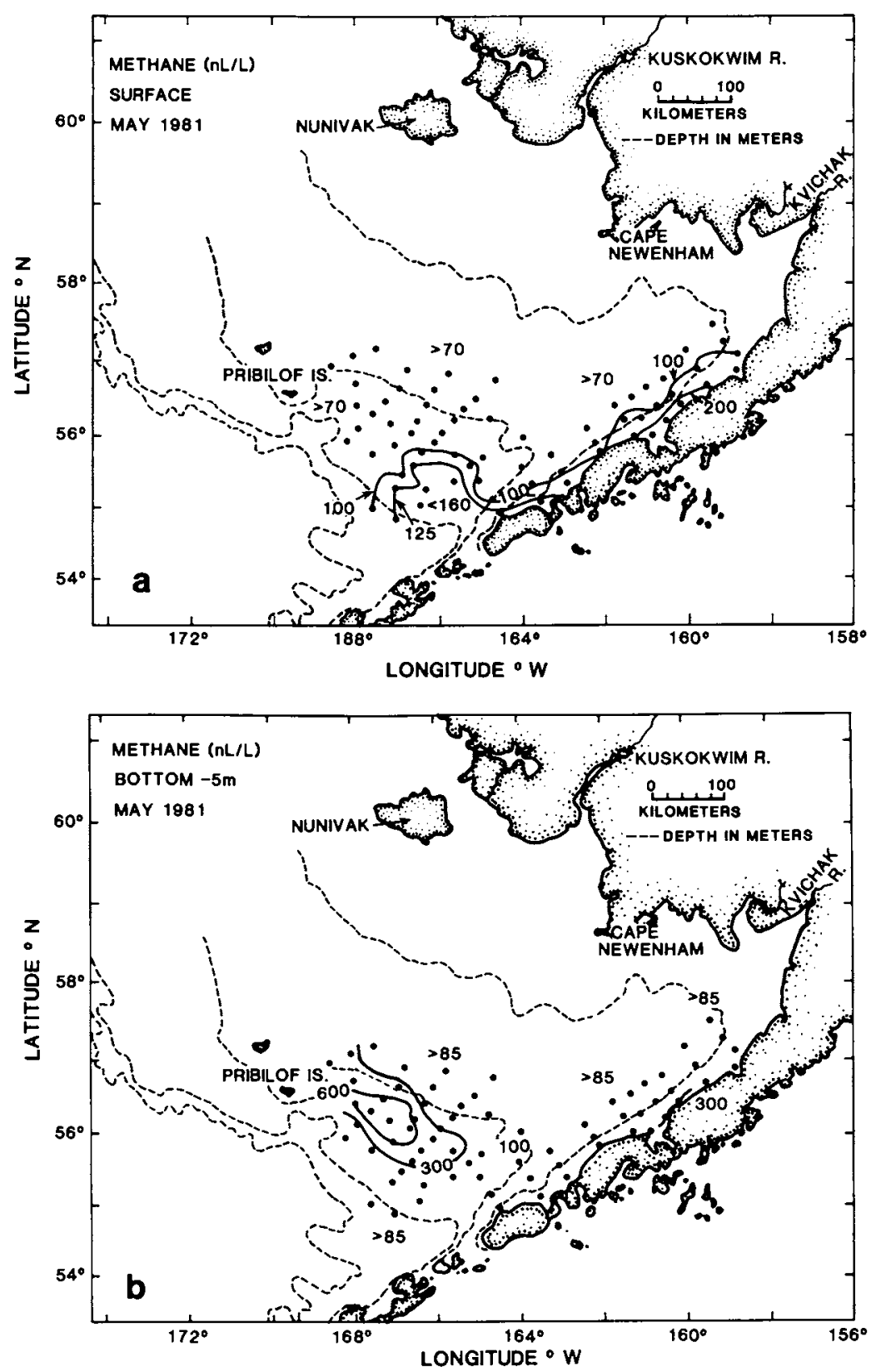

Figure 6. The surface (a) and near-bottom (b) concentrations of methane $(\mathrm{nL} / \mathrm{L})$ observed in May, 1981. 

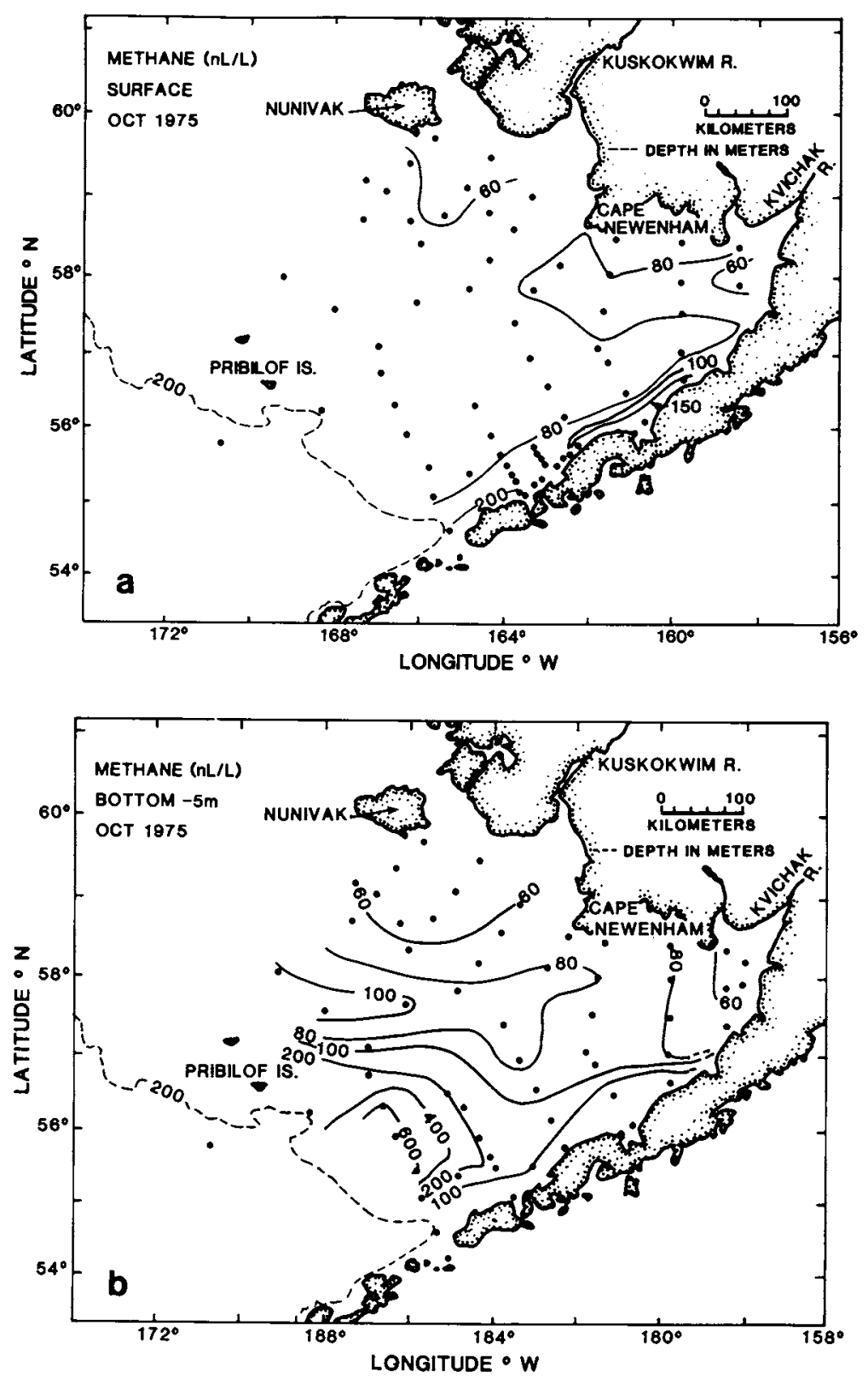

Figure 7. The surface (a) and near-bottom (b) concentrations of methane $(\mathrm{nL} / \mathrm{L})$ observed in October, 1975. 

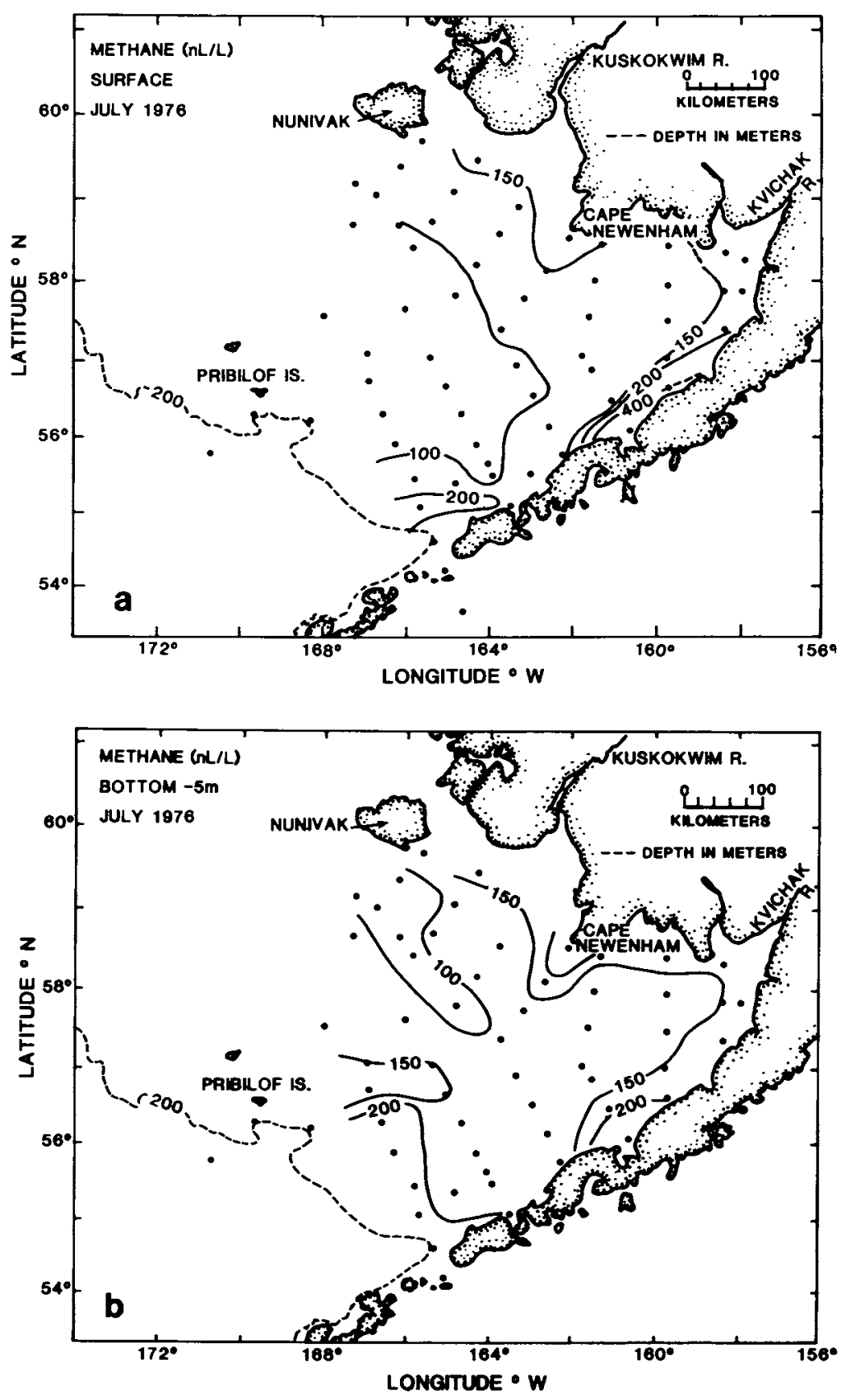

Figure 8 . The surface (a) and near-bottom (b) concentrations of methane $(\mathrm{nL} / \mathrm{L})$ observed in July, 1976. 
assume that the bulk of the methane production occurs in marine sediments at depths where both oxygen and sulfate are absent.

However, much of the methane produced in bottom sediments never reaches the atmosphere because it is oxidized to $\mathrm{CO}_{2}$ by microorganisms living in the surficial layers of the sediments and in the oxic, overlying waters. The oxidation of methane by sulfate reducers (or other organisms in the community) also has been examined and it is the principal removal mechanism of methane from shallow marine sediments $(24,25)$. Methane is also oxidized by certain chemoautotrophic bacteria in the presence of dissolved oxygen, although at much lower rates compared to those observed in sediments (27).

Methane is also lost from surface waters by air-sea exchange. If the surface concentration of methane exceeds its equilibrium concentration, there will be a net flux to the atmosphere. The empirical relationship commonly used to quantify the transfer flux $(F)$ is the stagnant-film boundary layer model $(28,29)$.

$$
F=v\left\{\left[\mathrm{CH}_{4}\right]-\left[\mathrm{CH}_{4}\right]^{\prime}\right\}
$$

where $\left[\mathrm{CH}_{4}\right]$ is the observed mixed layer concentration of methane, $\left[\mathrm{CH}_{4}\right]^{\prime}$ is the equilibrium concentration, and $v$ is the exchange velocity, a quantity proportional to the thickness of the hypothetical diffusive film at the sea surface. Later in the discussion we will adopt this model to compute the flux from the surface waters of the southeastern Bering Sea.

In the southeastern Bering Sea, the seasonal variations in the concentration of methane are large, as shown in Table 1. The seasonal range is about a factor of four; the highest concentrations occur in late summer and the lowest in spring. There did not appear to be much difference in the mean concentrations for each hydrographic area during a given season, which was unexpected because the production rates and bottom sediment organic carbon concentrations are rather different in that each of the three hydrodynamic domains examined $(21,30)$. The observed surface concentrations of methane represent a balance between in-situ production and oxidation rates, vertical transport rates, and air-sea exchange. Since the air-sea exchange and in-situ oxidation rates are both proportional to the seawater concentrations $(27,29)$, which are seasonally invariant over the entire study area, uniform surface concentrations are largely maintained by differences in local production rates and vertical transport rates. Primary production rates control the former, while the later is largely a function of vertical stratification and mixing.

The coastal zone is somewhat anomalous. There, the depth of water is shallow $(z<50 \mathrm{~m})$ and the bottom sediments are coarse-grained and low in organic carbon. Because of these factors, the concentration of methane in the water column should be near its atmospheric equilibrium solubility, however the coastal waters receive large amounts of freshwater, which are rich in dissolved methane, thus raising the concentration above that expected from in situ sources along. 
There is undoubtedly some water column production of methane, but its contribution relative to freshwater runoff is probably small.

Table I. Mean values for salinity, temperature, and methane in the three hydrographic regions of the southeastern Bering Sea. The number of values $(n)$ used to compute the mean and standard deviation is also given. These observations were taken from the data report by Katz et al., (39).

\begin{tabular}{|c|c|c|c|c|c|c|}
\hline Region & $\mathrm{Se}$ & son & $n$ & Salinity & $\begin{array}{c}\text { Temper ature } \\
{ }^{\circ} \mathrm{C}\end{array}$ & $\begin{array}{l}\mathrm{CH}_{4} \\
\mathrm{~nL} / \mathrm{L}\end{array}$ \\
\hline $\begin{array}{l}\text { Coastal } \\
\quad(z<50 \mathrm{~m})\end{array}$ & $\begin{array}{l}\text { Aug. } \\
\text { Feb. } \\
\text { May }\end{array}$ & $\begin{array}{l}1980 \\
1981 \\
1981\end{array}$ & $\begin{array}{r}104 \\
182 \\
45\end{array}$ & $\begin{array}{l}30.6 \pm 1.8 \\
31.2 \pm 0.4 \\
31.3 \pm 0.2\end{array}$ & $\begin{array}{r}10.0 \pm 1.0 \\
0.3 \pm 1.2 \\
6.3 \pm 0.9\end{array}$ & $\begin{array}{l}418 \pm 78 \\
288 \pm 72 \\
120 \pm 43\end{array}$ \\
\hline $\begin{array}{l}\text { Middle Shelf } \\
(50 \mathrm{~m}<z<100 \mathrm{~m})\end{array}$ & $\begin{array}{l}\text { Aug. } \\
\text { Feb. } \\
\text { May }\end{array}$ & $\begin{array}{l}1980 \\
1981 \\
1981\end{array}$ & $\begin{array}{r}92 \\
188 \\
48\end{array}$ & $\begin{array}{l}31.6 \pm 0.2 \\
31.8 \pm 0.2 \\
31.8 \pm 0.2\end{array}$ & $\begin{array}{l}5.9 \pm 0.8 \\
2.2 \pm 0.8 \\
5.9 \pm 1.0\end{array}$ & $\begin{array}{r}400 \pm 55 \\
248 \pm 52 \\
88 \pm 13\end{array}$ \\
\hline $\begin{array}{l}\text { St. George } \\
(z>100 \mathrm{~m})\end{array}$ & $\begin{array}{l}\text { Aug. } \\
\text { Feb. } \\
\text { May }\end{array}$ & $\begin{array}{l}1980 \\
1981 \\
1981\end{array}$ & $\begin{array}{l}22 \\
77 \\
38\end{array}$ & $\begin{array}{l}32.4 \pm 0.3 \\
31.8 \pm 0.2 \\
31.9 \pm 0.2\end{array}$ & $\begin{array}{l}8.0 \pm 0.4 \\
3.4 \pm 0.3 \\
5.8 \pm 0.6\end{array}$ & $\begin{array}{l}404 \pm 68 \\
275 \pm 65 \\
103 \pm 17\end{array}$ \\
\hline
\end{tabular}

The surface waters over St. George basin are the most productive waters in the southeastern Bering Sea (30). Some of this carbon finds its way to the sea floor and is converted into methane, which is turbulently mixed upward into the pycnocline (see Figure 4). Stratification and higher net production over St. George Basin results in higher concentrations observed in the bottom waters. Because of this stratification (Figure 4), surface concentrations are balanced by vertical transport through the pycnocline and air-sea exchange, modulated to some degree by in-situ water column production and oxidation. In-situ oxidation of methane may be an important removal process in the pycnocline because the concentrations are relatively high and the mixing rate is low. Unfortunately we have no information on in-situ production and oxidation rates or the vertical transport parameters.

Surface waters over the middle shelf are characterized by methane concentrations similar to that seen over St. George basin (Table I). Here the water column and sediment production rates are lower than those in St. George Basin, principally because the primary production rates are lower. Also, vertical stratification is reduced, resulting in near bottom and surface concentrations being more nearly the same.

The sea to air seasonal flux of methane was computed for each hydrographic domain according to equation (1). Mean monthly averages were obtained by linear interpolation of the 
seasonal data collected over the period 1980-81. These calculations are summarized in Table II. The mean monthly flux was computed for the entire survey region by summing the contributions from each of the three hydrographic domains (area-weighted).

In order to estimate the sea to air flux, the exchange velocity must be known or estimated. We assume that the exchange velocity is proportional to the quotient of the molecular diffusivity of methane, $D$, and the hypothetical thickness of the surface diffusive film, $h^{\star}$ (29). The exchange velocity was computed from estimates of the fiTm thickness (31) as a function of wind velocities (32) and temperature dependent molecular diffusivities (33). The equilibrium concentration of methane, $\left[\mathrm{CH}_{4}\right]^{\prime}$, was computed from solubility data (34) and the temperatures given in Table III. The atmospheric partial pressure of methane at the time the measurements were made was about $1.66 \mathrm{ppm}(\mathrm{v})(35)$ and when multiplied by the solubility coefficient predicts an equilibrium solubility concentration range of $61-70 \mathrm{~nL} / \mathrm{L}$, depending on temperature. These calculations, together with the mean monthly methane flux, also are summarized Table III.

The minimum flux of methane occurs in late spring when the wind velocity and surface concentrations of methane are near both relatively low. The maximum flux is observed in late fall at a time when surface concentration and wind velocities are near their maxima. The average flux, based on the observations made in 1980-1981, is $5.1 \pm 3.9 \mathrm{ng} \mathrm{CH}_{4} \mathrm{~m}^{-2} \mathrm{~s}^{-1}$, while the seasonal range is about $12 \mathrm{ng} \mathrm{CH} \mathrm{m}^{-2} \mathrm{~s}^{-1}$, with a factor of 20 difference between the spring minimum and fall maximum.

The largest uncertainty in the calculation is the dependence of the flux on the film thickness, or the wind velocity. Intuitively one would expect the flux of methane to be related to the magnitude of surface wind stress, however, the dependence may not be the factor of five indicated in Table III. Even if the wind had no effect on the methane transfer flux, the seasonal variation in the concentration alone would predict a factor of 3.5 between the spring minimum and fall maximum.

The mean monthly transport of methane (Mt month-1) is shown in the last column of Table III. Sumning the estimated monthly contributions after correction for ice cover, the total annual transport for the southeastern Bering Sea is $46 \times 10^{3}$, Mt, based on a total area of $31.9 \times 10^{10} \mathrm{~m}^{2}$. Correction for ice coverage was based on probability curves (36). We assumed that the flux of methane was zero for probabilities $>50 \%$, which may turn out to be too severe a restriction. On a statistical basis, it is seen that the maximum ice cover occurs in March (Table III), which may reduce the effective area for gas transfer in that month to about $50 \%$ of the total. Whether or not the probability curves are representative of conditions in 1980-1981 is not known, however, the flux of methane under partial to total ice cover is certainly not zero, although the flux will undoubtedly decrease due to a reduction in both surface area and the effective wind stress on the surface. 
Table II. Mean monthly values of methane and temperature computed by linear interpolation of the mean values given in Table I. The areas of the coastal zone, middle shelf, and St. George Basin are $1.4 \times 10^{11} \mathrm{~m}^{2}, 1.3 \times 10^{11} \mathrm{~m}^{2}$, and $4.6 \times 10^{10} \mathrm{~m}^{2}$, respectively.

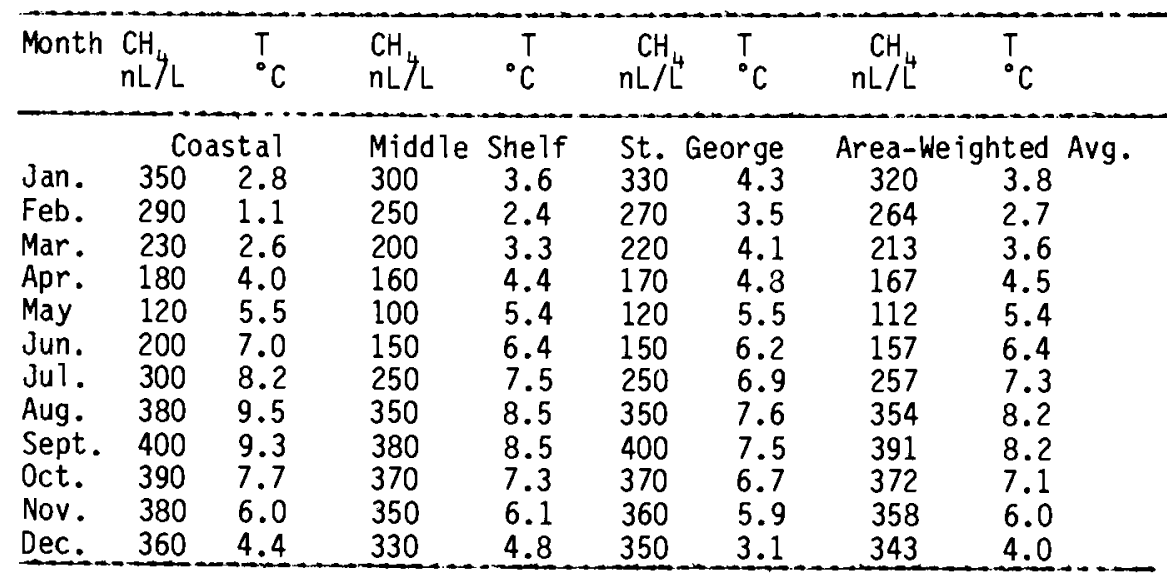




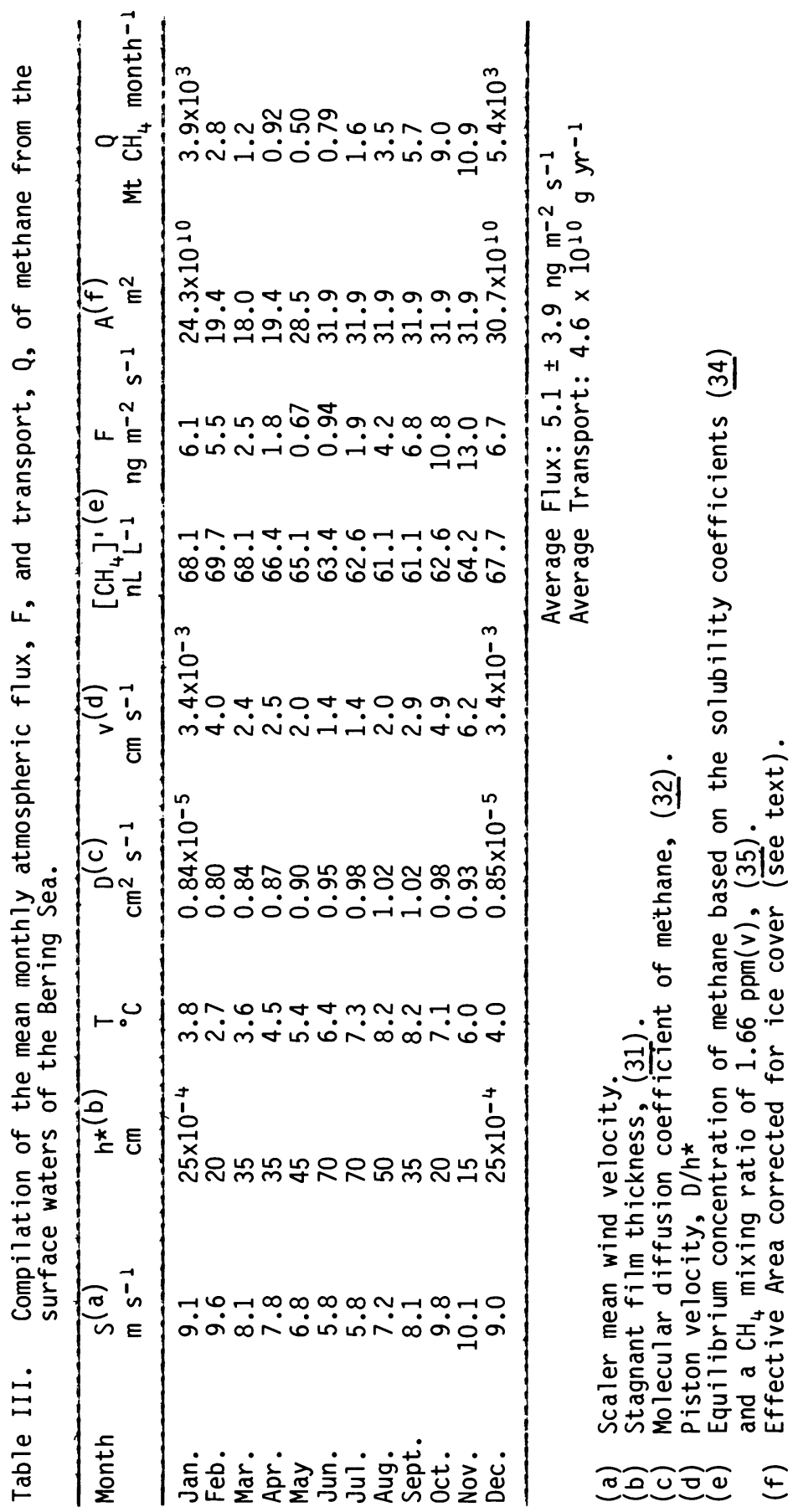

In Organic Marine Geochemistry; Sohn, M.; 
The mean annual flux of methane from the shelf waters of the southeastern Bering Sea is about $0.14 \mathrm{~g} \mathrm{CH}_{4} \mathrm{~m}^{-2} \mathrm{yr}^{-1}$, or a factor of three greater than observed in the pristine shelf waters of the Gulf of Mexico (Table IV). However, air-sea exchange from the shelf waters of Texas and Louisiana are much larger because of thermogenic gas seepage and underwater venting from offshore petroleum operations (13). By way of comparison, the flux of methane from the Bering Sea shelf is considerably larger than the open ocean estimate by Ehhalt (37). His estimate, based on few measurements, was about $0.012 \mathrm{~g} \mathrm{CH}_{4} \mathrm{~m}^{-2} \mathrm{yr}-1$ and that value is probably excessive. The surface concentration of methane is probably no more than $10 \%$ supersaturated on the average (Weiss, R., Scripps Institute of Oceanography, personal communication), which translates into a mean oceanic flux of $<0.003 \mathrm{~g} \mathrm{CH}_{4} \mathrm{~m}^{-2} \mathrm{yr}-1$, again assuming a mean piston velocity of $2.1 \mathrm{~m}^{\mathrm{day}}{ }^{-1}$. If the numbers are reasonably correct, then we might expect other high latitude shelf environments to be equally important contributors to the marine methane flux, at least seasonally. On a global basis, ocean waters probably contribute less than $1 \%$ of the atmospheric transport of methane $(35,37)$, but in terms of marine sources of methane to the atmosphere, the coastal and shelf environments are the most important. Shelf waters are generally more productive than the open ocean and are much shallower, hence the time scale for cycling methane to the atmosphere is much shorter in shelf waters.

Table IV. A comparison of sea-air exchange fluxes for several different marine environments. The area of the open ocean is $3.34 \times 10^{14} \mathrm{~m}^{2}(42)$.

\begin{tabular}{lcc}
\multicolumn{1}{c}{ Region } & $\mathrm{g} \mathrm{CH}_{4} \mathrm{~m}^{-2} \mathrm{yr}-1$ & Investigators \\
\hline $\begin{array}{l}\text { S.E. Bering Sea } \\
\text { Gulf of Mexico } 1\end{array}$ & 0.14 & This study \\
Texas/Louisiana ${ }^{2}$ & 0.04 & $(\underline{13})$ \\
& 0.85 & $(\underline{13})$ \\
$\begin{array}{l}\text { Open 0cean } \\
\text { Open Ocean }\end{array}$ & 0.012 & (37) \\
\hline
\end{tabular}

1 Does not include the Texas-Louisiana Shelf.

2 Recalculated, assuming a piston velocity of $2.1 \mathrm{~m} \mathrm{~d}-1$.

3 Assumes that the mean supersaturation of surface waters is < $10 \%$ (Weiss, R., Scripps Institute of Oceanography, personal communication).

Inter-Annual Variations of Dissolved Methane

Methane concentrations also were measured in Fall of 1975 and Summer of 1976. The average surface concentrations for the three regions are summarized in Figure 9 . It is readily obvious 

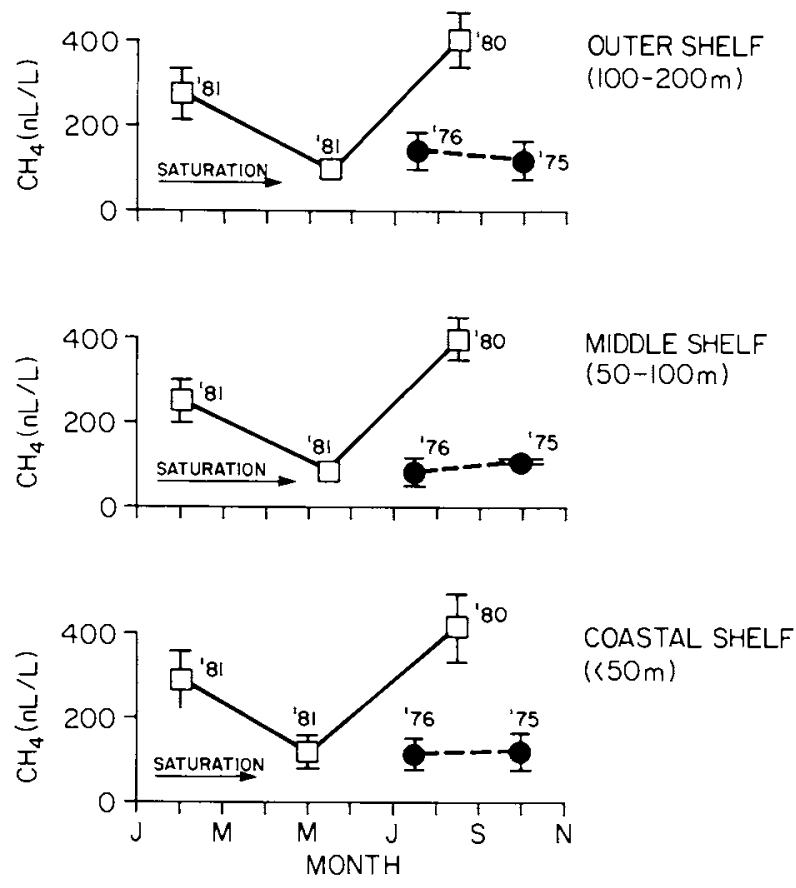

Figure 9. The average surface concentration of methane for each of the three hydrographic domains (see Table III). The equilibrium concentration of methane ranged from about $62-68 \mathrm{~nL} / \mathrm{L}$, assuming an atmospheric mixing ratio of $1.66 \mathrm{ppm}(\mathrm{v})$.

In Organic Marine Geochemistry; Sohn, M.; 
that the concentrations of methane were suppressed in 1975-76 compared to 1980-81. Surface concentrations in October 1975 were only 100-150 $\mathrm{nL} / \mathrm{L}$, roughly the same as those seen in May 1981 . The cause of the lower concentrations in 1975-76 is not precisely known, but one clue comes from the near-bottom concentrations of methane in St. George Basin. The maximum concentrations in October 1975 and July 1976 were only $600 \mathrm{~nL} / \mathrm{L}$ and $400 \mathrm{~nL} / \mathrm{L}$, respect ively (38), compared to concentrations in excess of $1800 \mathrm{~nL} / \mathrm{L}$ in 1980-8I (Figures 3-5). While the lower concentrations were most evident in St. George Basin, near-bottom concentrations were also lower throughout the shelf waters of the southeastern Bering Sea in 1975-76.

The lower concentrations of methane correlate with lower sea surface temperatures (SST) and near-bottom temperatures over the middle shelf. Bottom temperatures over the middle shelf were $<-1^{\circ} \mathrm{C}$ in October 1975 and July 1976, compared to temperatures of $3.5-4.5{ }^{\circ} \mathrm{C}$ observed in May 1981 (39). Water temperatures this low indicate local ice formation the previous winter. On the other hand, bottom temperatures in St. George Bas in in May 1981 were about the same as those observed in October 1975 and July 1976 (17) indicating that these waters were less influenced by the abnormally cold winters than the middle shelf region. This is expected because the north-setting coastal current brings relatively warm Gulf of Alaska water across the outer shelf (19).

NevertheTess, the lower than normal SST and near-bottom temperatures signaled a significant short term climatic event over the eastern Bering Sea (40). The winters of 1974-75 and 1975-76 caused extensive ice formation over the region (41). For example, the southern limit of ice in April 1979 (a normaT year), was near Nunivak Island (Figure 1), whereas it was southwest of the Pribilof Islands in April $1976(36)$. It is hypothesized that the extensive ice coverage and its persistence into the late spring of 1975 and 1976 significantly affected the supply of carbon to the benthos, thus reducing the seasonal production rate of methane. This seems to be the case for St. George Basin and the middle shelf. Another important factor is the near-bottom water temperature over the middle shelf. Temperatures near and below freezing may have inhibited methanogenous in the near-bottom waters long after the ice had melted. We have independent evidence from Port Moller that methanogeneous is severely retarded in organic-rich sediments at temperatures near the freezing point of seawater (unpublished data), hence the low concentrations of methane over the middle shelf may be due to the combined effects of a reduced flux of carbon and cold bottom temperatures.

The apparent importance of the seasonal production of carbon to the water column inventory of methane suggests that the surface layers of the bottom sediments or the water column itself are important loci for methanogenesis. Deeper horizons within the sediment column are not going to be influenced by seasonal productivity and will generate methane at some integrated rate determined by the long term depositional rate of carbon.

Summarizing, we observed that the low surface concentrations of methane seen in October 1975 and July 1976 were correlated 
with low water temperatures and severe ice conditions in the winters of 1974-75 and 1975-76. Extensive ice coverage had presumably reduced the flux of carbon below the euphotic zone, thereby decreasing the amount of carbon available for methanogenes is at the sediment-water interface and in the water column. These observations indicate that high latitude shelf environments experience large inter-annual variations in the concentration of dissolved methane, and presumably other biogenic gases as well.

\section{Summary}

Distributions of dissolved methane in the southeastern Bering Sea were made in 1975-76 and again 1980-81. These observations show large seasonal and inter-annual variations that appear to be related to the magnitude and timing of primary production. However, the relationship is not simple because minimum concentrations of methane correlate with the season of maximum productivity. Seasonal and inter-annual production rates of methane suggest that significant quantities are produced in the water column or from surficial layers of bottom sediments. The relative proportions of of methane produced in the water column and bottom sediments could not be determined from these observations, however.

The highest concentrations of dissolved methane are found in the near-bottom waters of St. George Basin, which overlie organicrich sediments and are thermally stratified much of the year. Weak circulation and mixing allows concentrations to reach $2,500 \mathrm{~nL} / \mathrm{L}$ (STP). High concentrations of methane also were observed near Port Moller, but this source of methane is related to freshwater sources within the estuary.

Season distributions of methane also show that methane is a qualitative descriptor of mean current flows in Unimak Pass, along the North Aleutian shelf, and in the near-bottom waters of St. Geoge Basin.

\section{Acknowledgments}

We are sincerely indebted to the Captains and crews of the NOAA ships, DISCOVERER and SURVEYOR, without whose dedication to purpose these measurements could not have been made. We are especially grateful to Mr. Lee Ohler, Mr. Anthony Young, and Ms. Susan Hamilton, who ensured that the measurements were the best that could be obtained. Lastly, we would like to thank the Mobil Corporation who graciously agreed to prepare the manuscript and figures for publication.

This study was supported by the Bureau of Land Management, through an interagency agreement with the National Oceanic and Atmospheric Administration, while one of us (JDC) was an oceanographer with NOAA. 


\section{Literature Cited}

1. Lamontagne, R. A.; Swinnerton, J. W.; Linnenbom, V. J. Tellus, 1974 24, 71.

2. Lamontagne, R. S.; Smith, W. D.; Swinnerton, J. W. In "Analytical Methods in Oceanography"; Gibbs, Jr., T. R. P., Ed.; ADVANCES IN CHEMISTRY SERIES No. 147, American Chemical Society; Washington D. C., 1975; p. 163.

3. Swinnerton, J. W.; Lamontagne, R. A. Environ. Sci. Technol. $1974,8,657$.

4. Atkinson, L. P.; Richards, F. A. Deep-Sea Res. 1967, 14, 675.

5. Lamontagne, R. A. ; Swinnerton, J. W.; Linnenbom, V. J.; Smith, W. D. J. Geophys. Res. 1973, 78, 5318.

6. Reeburgh, W. J.; Heggie, D. T. Limnol. Oceanogr. 1977 , 22, 1 .

7. Bernard, B. B.; Brooks, J. M.; Sackett, W. M. J. Geophys. Res. 1978, 83, 4053.

8. Scranton, M. I.; Farrington, J. W. J. Geophys. Res. $1977,82.4947$.

9. Scranton, M. I.; Brewer, P. G. Deep-Sea.Res. 1977, 24, 127.

10. Frank, D. J.; Sackett, W. M.; Hall, R.; Fredericks, A. D. Amer. Assoc, Petrol. Geol. Bull. 1970, 54, 933.

11. Brooks, J. M.; Sackett, W. M.; Sackett, W. M.. J. Geophys. Res. 1973, 78, 5124 .

12. Bernard, B. B.; Brooks, J. M.; Sackett, W. M. Earth Plant. Sci. Lett. 1976, 31, 48.

13. Brooks, J. M.; Sackett, W. M. In "Advances in Organic Geochemistry"; Compos, R.; Coni, J., Eds.; Revista Espanola de Micropaleontologia, Madrid, Spain; 1977; p. 455.

14. Brooks, J. M.; Gormly, J. R.; Sackett, W. M. Geophys. Res. Lett. 1974, 1, 213.

15. Swinnerton, J. W.; Linnenbom, V. J. J. Chromatogr. Sci. $1967,5,570$.

16. Schümacher, J. D.; Kinder, T. H.; Pashinski, D. H.; Charnell, R. L. J. Phys. Oceanogr. 1979, 9, 79.

17. Kinder, T. H.; Schumacher, J. D. In "The Eastern Bering Sea Shelf: Oceanography and Resources, Vol. I"; Hood, D. W.; Calder, J. A., Eds.; Univ. Washington Press, Seattle, WA., 1981 ; p. 31 .

18. Coachman, L. K.; Charnell, R. L. Deep-Sea Res. 1977, 24,869 .

19. Kinder, T. H.; Coachman, L. K. J. Geophys. Res. 1978, $83,4551$.

20. Coachman, L. K.; Charnell, R. L. J. Phys. Oceanogr. $1979,9,278$.

21. Sharma, G. D. In "Oceanography of the Bering Sea; Hood, D. W.; Kelley, E. J., Eds.; Inst. Mar. Sci., Univ. Alaska, Fairbanks, AK, 1974; p. 517.

22. Wolfe, R. S. In "Advances in Microbial Physiology"; Hose, A. H.; Wilkinson, J. F., Eds.; Academic Press, New York, 1971; p. 107. 
23. McCarty, P. L. In "Principles and Applications in Aquat ic Microbiology"; Huekelekian, H.; Dondero, N. C., Eds.; John Wiley, New York, 1964; p. 324.

24. Barnes, R. 0.; Goldberg, E. D. Geology 1976, May, 297.

25. Oremland, R. S.; Taylor, B. F. Geochim. Cosmochim. Acta $1978,42,209$.

26. Martins, C. S.; Berner, R. A. Science 1974, 185, 1167.

27. Griffiths, R. P.; Caldwell, B. A.; CTine, J. D.; Broich, W. A.; Morita, R. Y. Appl. Environ. Microbiol. 1982, Aug., 435.

28. Liss, P. S. Deep-Sea Res. 1973, 20, 221.

29. Broecker, W. S.; Peng, T. H. Tellus 1974, 26, 21.

30. Goering, J. J.; Iverson, R. L. In "The Eastern Bering Shelf: Oceanography and Resources, Vol. II"; Hood, D. W.; Calder, J. A., Eds.; Univ. Washington Press, Seattle, 1981 ; p. 933.

31. Emerson, S. Limnol. Oceanogr. 1975, 20, 754.

32. Brower, Jr., W. A.; Searby, H. W.; Wise, J. L.; Diaz, H. F.; Prechtel, A. S. "Climatic Atlas of the Outer Continental Shelf Waters and Coastal Regions of Alaska, Vol. II, Bering Sea"; Univ. Alaska, Anchorage, AK, 1977.

33. Bonoli, L; Witherspoon, P. A. In "Advances in Organic Chemistry"; Schench, P. A.; Havenaar, I., Eds.; Pergamon Press, New York, 1968; p. 373.

34. Yamamoto, S.; Alcaushas, J. B.; Grozier, T. E. J. Chem/ Eng. Data 1976, $21,78$.

35. Khali,, M. A. K.; Rasmussen, R. A. J. Geophys. Res. $1983,88,5131$.

36. Webster, B. D. "A Climatology of the Ice Extent in the Bering Sea"; NOAA Tech. Memo., NWS AR-33, DOC/NOAA/EDS, Washington, D. C., 1981.

37. Ehhalt, D. H. Telius 1974, 26, 58.

38. Cline, J. D. In The Eastern Bering Sea Shelf: Oceanography and Resources, Vol. I"; Hood, D. W.; Calder, J. A., Eds.; Univ. Washington Press, Seattle, WA, 1981 ; p. 425.

39. Katz, C. N.; Cline, J. D.; Kelly-Hansen, K. "Dissolved Methane Concentrations in the Southeastern Bering Sea, 1980-1981"; NOAA Data Rept. ERL/PMEL-6; DOC/NOAA/ERL, Boulder, Co., 1982.

40. Niebauer, H. J. In "The Eastern Bering Sea Shelf: Oeanography and Resources, Vol. I"; Hood, D. W.; Calder, J. A., Eds.; Univ. Washington Press, Seattle, WA, 1981 ; p. 23.

41. Niebauer, H. J. In "The Eastern Bering Sea Shelf: Oceanography and Resources, Vol. I"; Hood, D. W.; Calder, J. A., Eds.; Univ. Washington Press, Seattle, Washington, 1981; p. 133.

42. Sverdrup, H. U.; Johnson, M. W.; Fleming, R. H. "The Oceans"; Prentice Hal1, Inc. Englewood Ci iffs, N.J., 1942.

RECEIVED November 11, 1985 


\title{
Stable Hydrogen and Carbon Isotopic Compositions of Biogenic Methanes from Several Shallow Aquatic Environments
}

\author{
Roger A. Burke, Jr., and William M. Sackett
}

Department of Marine Science, University of South Florida, St. Petersburg, FL 33701

Stable hydrogen $(\delta D)$ and carbon $\left(\delta^{13} \mathrm{C}\right)$ Isotopic compositions of methane gas bubbles formed in the sediments of several shallow aquatic environments were measured and found to range from $-346 \%$ to $-263 \%$ and from $-75.0 \%$ oo to $-51.5 \%$, respectively. Evaluation of the $\delta D$ data with a previously published model implies that acetate dissimilation accounts for about $50 \%$ to $80 \%$ of the total methane production. $\delta \mathrm{D}-\mathrm{CH}_{4}$ and $\delta^{13} \mathrm{C}-\mathrm{CH}_{4}$ are generally inversely correlated; this indicates that the observed 1sotopic variation is not solely due to differential methane oxidation. $\delta 13 \mathrm{C}-\mathrm{CH}_{4}$ values reported in this paper f.mply that methane produced in these sediments is generally substantially more $13 \mathrm{C}$-depleted than the estimated average atmospheric methane source. Methane with a $\delta D$ near the estimated atmospheric source average is produced in some of these sediments; this apparent agreement may be fortultous as few relevant data are avallable.

The process of blological methane formation is of considerable current interest because blogenic methane can accumulate in commerclally significant quantities in certain geological situations, and methane emitted to the atmosphere may affect the earth's climate. It has been estimated that more than $20 \%$ of the world's proven gas reserves are of biogenic origin (1). Recent studies $(2,3)$ of polar ice cores indicated an apparent doubling of atmospheric methane concentrations during the past few hundred years. Because methane strongly absorbs infrared radiation within the atmospheric window (700 to $1400 \mathrm{~cm}^{-1}$ ) that transmits most of the thermal radiation from the earth's surface to outer space (4), the atmospheric methane increase is a potential contributor to global warming. Various investigators $(2, \underline{4}, \underline{5})$ estimated the contribution of methane to increasing global temperatures to be about $20-40 \%$ of that attributed to the carbon dioxide increases. The microblal decomposition of complex organic matter under

0097-6156/86/0305-0297\$06.00/0

(c) 1986 American Chemical Society 
anaerobic conditions to methane and carbon dioxide is a multi-step process requiring the participation of at least three $(\underline{6}, \underline{7})$ different trophic groups of bacteria. The final step in this process, methanogenesis, is thought to occur mainly via two pathways, $\mathrm{CO}_{2}$ reduction and acetate dissimilation (8). Carbon-14 labelling studies have suggested that acetate dissimilation normally accounts for about $60-70 \%$ of the total methane production in sewage sludge digestors $(\underline{9}, 10)$, paddy solls $(11,12)$, and some freshwater lake sediments $(\overline{3}-15)$ with $\mathrm{CO}_{2}$ reduction responsible for the remainder. In other freshwater lake sediments, however, the $\mathrm{CO}_{2}$ reduction pathway is apparently predominant, accounting for $\$ 90 \%$ of the total methane production in Russian Lake Kuznechikha (16) and about $75 \%$ of the methane generated in the sediments of B1elham Tarn in the English Lake District (17). Incubation of sediment samples from Cape Lookout Bight, North Carolina (CLB), a sma11, nearshore marine basin with rapidly accumulating, organic rich sediments, with $(1,2-14 \mathrm{C})$ sodium acetate indicated that more than $50 \%$ of the CLB sumertime methane flux could be accounted for by acetate dissimilation (18). In certa1n situations in which sediments recelve a fairly specific type of organic matter input or when methanogens are competing with sulfate reducing bacteria for $\mathrm{H}_{2}$ and acetate, a significant fraction of the total methane production can result from alternate substrates such as methanol and trimethylamine $(19,20)$. A11 of the aforementioned studies used C-14 labelled substrates as tracers to estimate the relative contributions of the methanogenic pathways to total methane production. An alternate method of obtaining an estimate of relative pathway contribution, based on measurements of the stable hydrogen 1sotopic compositions of blogenic methane and the associated water, has been proposed $(21,22)$. Estimates obtained using this method for methane generated from sewage sludge (21) and freshwater lake sediments (22) are in good agreement w1th some of the estimates of relative pathway contribution $(\underline{9}, 10,13-15)$ obtained from C-14 labelling studies.

We report here measurements of the stable hydrogen Isotopic composition of methane and water, the stable carbon isotopic composition of methane and carbon dioxide, and ancillary parameters from several freshwater environments and from a few locations within the Tampa Bay estuary. The stable isotopic compositions determined in this study are reported as a parts-per-mi1 $(\%)$ deviation $(\delta)$ from a standard with a known stable isotopic ratio. The definition of the $\delta$ value is:

$$
\delta=(\mathrm{R}(\text { Sample }) / \mathrm{R}(\text { Standard })-1) \times 1000
$$

where $R$ is $D / H$ and ${ }^{13} \mathrm{C} /{ }^{12} \mathrm{C}$ and the standards are SMOW and $P D B$, for hydrogen and carbon isotopic compositions, respectively. Using these measurements and the model proposed by Woltemate et al. (22) we can estimate the relative importance of the two primary methanogenic pathways, acetate dissimilation and $\mathrm{CO}_{2}$ reduction, to methane production in these systems. 


\section{Methods}

Gas samples were obtained by agitating the sediment with a rod and funneling the released gases into $12.5 \mathrm{ml}$ serum bottles (Wheaton Sclentific, Millville, N.J.) that were inftially filled with lake water. The bottles were filled as completely as possible with gas and stoppered with a speclally manufactured black rubber stopper (no. 2048-11800, Bellco Glass, Inc., Vineland, N.J.) that was then crimped with an aluminum seal (Wheaton). The samples were stored on lce during transit back to the laboratory where they were kept in a freezer until analysis. Water samples for $\delta D$ determinations were collected in screw cap vials, the mouths of which were covered with parafilm to retard evaporation. Sediment samples were obtalned by scraping surficlal materfal into Whirlpak plastic bags and were frozen unt1l analysis.

The methane gas samples were prepared for 1sotop1c analyses with the system 1llustrated in Figure 1. Preparation involves gas chromatographic (GC) separation of methane from other gases followed by combustion to $\mathrm{CO}_{2}$ and water in a vacuum 1 ine. Methane is combusted in a cupric oxide furnace $\left(280^{\circ} \mathrm{C}\right)$, to which 5-10 torr of oxygen has been added, as 1t 1s swept through by the GC carrier gas. Addition of oxygen gas to the system is necessary to assure complete combustion of the methane. We have found that the Isotopic values of incompletely combusted methane are significantly more negative than the actual values; $\delta \mathrm{D}-\mathrm{CH}_{4}$ and ${ }^{1}{ }^{3} \mathrm{C}-\mathrm{CH}_{4}$ deviations of up to $60 \%$ and $3.5 \%$, respective $1 \mathrm{y}$, were observed. The $\mathrm{CO}_{2}$ and water resulting from the combustion of methane are condensed by liquid nitrogen $\left(\sim-196^{\circ} \mathrm{C}\right)$ in the trap immediately downstream from the combustion oven, the excess oxygen and hellum are pumped away, and the $\mathrm{CO}_{2}$ and water are cryogenfcally $\left(\sim-90^{\circ} \mathrm{C}\right)$ separated. The ${ }^{2} 13 \mathrm{C}$ of the $\mathrm{CO}$, is then measured using a Finnigan-Varian MAT 250 1sotope ratto mass spectrometer (IRMS). The water from the combustion is reduced to hydrogen gas using the zinc metal method (23) and analyzed with the IRMS. The GC used is a Hewlett-Packard 5710 A equipped with a thermal conductivity detector and two $6 \mathrm{~mm}$ OD stalnless steel columns ( $3 \mathrm{~m}$ grade 12 silica gel and $2 \mathrm{~m}$ molecular sleve $5 \mathrm{~A}$ ) connected in serles through a Valco ten port switching valve configured for column sequence reversal and backflush of the silica gel column to the detector. This GC configuration allows baseline separation of $\mathrm{H}_{2}, \mathrm{O}_{2}, \mathrm{~N}_{2}, \mathrm{CH}_{4}$ and $\mathrm{CO}_{2}$. Helium carrier flow is $50 \mathrm{ml} / \mathrm{min}$ and the oven temperature $1 \mathrm{~s}^{2}$ held constant at $90^{\circ} \mathrm{C}$. The system described here is a flow-through system in which methane is combusted as it is swept through the furnace by the GC carrier gas. There is no Toepler pump or bellows to cycle the gas repeatedly through the furnace. As a result, it is reasonable to expect that the time the methane spends in the oven, which is determined by the GC carrier gas flow rate, could be an important variable. To test this, a methane working standard was analyzed several times using GC carrier gas flow rates of $25 \mathrm{ml} / \mathrm{min}$ and 50 $\mathrm{ml} / \mathrm{min}$. Isotopic values obtained at $50 \mathrm{~m} 1 / \mathrm{min}$ (mean $\delta \mathrm{D}-\mathrm{CH}_{4}=$ $-164^{\circ} \%$, std.dev. $=1.0 \%, \mathrm{n}=12 ;$ mean $\delta^{13} \mathrm{C}-\mathrm{CH}_{4}=-44.2 \%$, std.dev. $=0.14^{\circ} \%, \mathrm{n}=12$ ) were not significant 14 different from those obtained at a GC flow of $25 \mathrm{ml} / \mathrm{min}$ (mean $\delta \mathrm{D}-\mathrm{CH}_{4}=-164^{\circ} / 00$, 


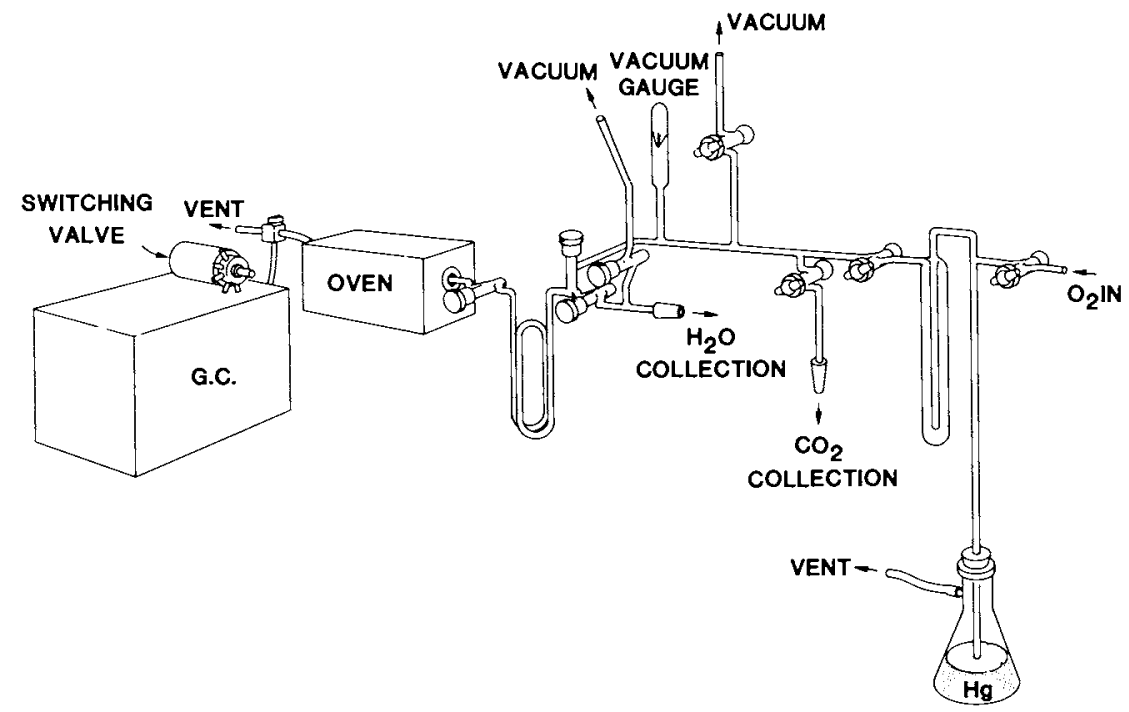

Figure 1. System for preparing methane for 1sotoplc analyses.

In Organic Marine Geochemistry; Sohn, M.; ACS Symposium Series; American Chemical Society: Washington, DC, 1986. 
std.dev. $=1.7^{\circ} \%, \mathrm{oo}=6$; mean $\delta^{13} \mathrm{C}-\mathrm{CH}_{4}=-44.1 \%$ oo, std.dev. $=$ $0.17 \%, \mathrm{n}=10)$. Repeated analyses of a second working standard, analyzed dally during the course of this work, ylelded standard deviations (mean $\delta \mathrm{D}-\mathrm{CH}_{4}=-189.3 \%$, std. dev. $=1.7 \%$, $\mathrm{n}=36$; mean $\delta^{13} \mathrm{C}-\mathrm{CH}_{4}=-39.6 \%$ oo, std.dev. $=0.21 \%, \mathrm{n}=32$ ) that are similar to those obtained above for the GC flow rate test and are comparable to those reported by Schoell (21).

The combustion efficiency of the GC-combustion system (Figure 1) was tested by comparing the methane concentration of the gas atmosphere in the vacuum line that resulted from the injection of $\sim 2 \mathrm{ml}$ of methane under normal operating conditions (three separate trials) to the methane concentration of the vacuum-line gas atmosphere after injection of $\sim 2 \mathrm{ml}$ of methane with the combustion furnace turned off (three separate trlals). The trap immediately downstream from the combustion oven was immersed in a Dewar flask containing an isopropyl alcohol slush $\left(v-90^{\circ} \mathrm{C}\right)$. The resulting methane concentrations, which were obtained with a GC equipped with dual flame lonization detectors, indicated a combustion efficiency $>99 \%$.

Water samples were prepared for $\delta D$ determination by the zinc metal method as described by Coleman et a1. (23). Repeated analyses of the water reference samples $\mathrm{V}$-SMOW $(n=10$, std. dev. $=1.4 \%$ oo $)$ and NBS-1 $(n=10$, std. dev. $=1.3 \%$ oo $)$ performed during the course of this work, indicated that the uncertainty (one standard deviation) involved with the $\delta \mathrm{D}-\mathrm{H}_{2} \mathrm{O}$ analyses was about $1.5 \%$. Preparation of the carbon dioxide gas for analysis by IRMS Involved cryogentc separation of the $\mathrm{CO}_{2}$ from the other gases. Th1s was accomplished by infecting an aliquot of the gas through a rubber septum into a vacuum line with a trap cooled by liquid nitrogen and then simply pumping away the liquid nitrogen non-condensable gases $\left(\mathrm{O}_{2}, \mathrm{~N}_{2}, \mathrm{CH}_{4}\right)$. Water vapor was then removed cryogentcally $\left(\sim-90^{\circ} \mathrm{C}\right)$ from the $\mathrm{CO}_{2}$. The methane and carbon dloxide concentrations (mol\%) of the gas samples were calculated from the GC-integration units (HP-3390A Integrator) following application of appropriate T.C. Welght Factors as given by McNair and Bonelli (24). Sedimentary organfc matter was prepared for $\delta^{13} \mathrm{C}$ analysis by IRMS in a Cralg type combustion apparatus (25).

\section{Model of Methane Formation}

Figure 2 is a plot of $\delta \mathrm{D}-\mathrm{H}_{2} \mathrm{O}$ versus $\delta \mathrm{D}-\mathrm{CH}_{4}$ for samples obtained from littoral zone sediments of several freshwater lakes and from several shallow ( 1 m or less water depth) areas of the Tampa Bay estuary. Also shown on Flgure 2 are lines that describe predicted $\delta \mathrm{D}-\mathrm{H}_{2} \mathrm{O} / \delta \mathrm{D}-\mathrm{CH}_{4}$ isotopic pairs resulting from varying the relative contributions to methane production of the acetate dissimilation and $\mathrm{CO}_{2}$ reduction pathways. This model was originally proposed by Woltemate et a1. (22) and used in that study to estimate that methyl group transfer (from acetate or other methyl group donors such as methanol) was responsible for about $76 \%$ of total methane production in the sediments of Wurmsee, a shallow lake near Hannover, FRG.

In constructing this model, Woltemate et al. (22) assumed that for the $\mathrm{CO}_{2}$ reduction pathway all four methane hydrogens are 
supplied by the environmental water $(21,26)$, and for the acetate dissimilation pathway only one hydrogen comes from water, with the remaining three coming from the methyl group of acetate (27). As a result, the slopes of the $0: 100$ (acetate dissimilation: $\mathrm{CO}_{2}$ reduction, not shown here) and the 100:0 (not shown here) lines are 1 and 0.25 , respectively. The slopes of the intermediate lines are obtained by multiplying the relative amount of each pathway by the appropriate slope ( 1 or 0.25 ) and summing. For example, the slope of the $80: 20$ line would be: $0.80(0.25)+$ $0.20(1)=0.4$. The $y$-intercept of the $80: 20$ line was obtained from the sewage sludge incubation experiment of Schoell (21). In that experiment, aliquots of sewage sludge were incubated in plastic bottles spiked with different amounts of $D_{2} O$. The results Indicated a linear correlation between $\delta \mathrm{D}-\mathrm{H}_{2} \mathrm{O}$ and ${ }^{2} \mathrm{SD}-\mathrm{CH}$
described $(\underline{21})$ by:

$$
\delta \mathrm{D}-\mathrm{CH}_{4}=0.4 \delta \mathrm{DH}_{2} \mathrm{O}-323^{\circ} \%
$$

The $y$-intercept of the $0: 100$ line resulted from the observation that $\delta \mathrm{D}-\mathrm{H}_{2} \mathrm{O} / \delta \mathrm{D}-\mathrm{CH}_{4}$ palrs obtained from the measurement of natural samples, in which methane was presumably formed via $\mathrm{CO}_{2}$ reduction $(\underline{21})$, fit the relationship $(\underline{21}, \underline{28})$ :

$$
\delta \mathrm{D}-\mathrm{CH}_{4}=\delta \mathrm{D}-\mathrm{H}_{2} \mathrm{O}-160( \pm 10) \%
$$

The $y$-intercepts of the remaining lines (22) are obtained by assuming that the $y$-intercepts are spaced equally $((323-160) / 4=$ $41 \%$ o ) apart. Equations (2) and (3) are based on analyses of methane formed under widely different environmental conditions. Varlations in the magnitude of 1sotopic fractionation, due to varlation in parameters such as the rate of reaction and time (degree of isotopic equilibration), may introduce error into predictions of relative methanogenic pathway selection obtained with the model (Figure 2). We belleve, however, that the model yields results that are generally valld, and that application of the model to our data yields useful interpretation.

Importance of Alternate Methanogenlc Substrates

Lovley and Klug (29) reported that methanol and methylamines were the precursors for less than 5 and $1 \%$, respectively, of total methane production in the sediments of eutrophic Lake Wintergreen, Michigan. The likely explanation for this is the low abundance of methanol and methylamine precursors relative to $\mathrm{H}_{2}$ and acetate precursors in the organic matter input to the sediments (29). Low rates of methane production from methanol and methylamines in near-surface, sulfate-rich marine sediments have been reported recently $(20,30)$. Although methane production from these "noncompetitive" substrates $(30)$ is of interest for several reasons, we would argue that it is 1ikely to generate large quantities of methane (defined here as a significant fraction of that required to achieve saturation) only under relatively unusual conditions. Many marine organisms use methylamines or methylamine precursors (31) in osmoregulation (32). In response to salt 
stress, the halophyte Spartina alterniflora has been shown to concentrate up to $30 \%$ of its total leaf nitrogen in glycine betaine (33), which can be metabolized to acetate and trimethylamine in marine sediments (31). Oremland et a1. (19) reported that metabolism of methanol and trimethylamine could account for the bulk of methane produced in salt marsh sediments contalning $8 \mathrm{ml}$ of methane per liter of wet sediment. The experiments that ylelded these results were conducted in flasks containing $60 \mathrm{ml}$ of San Francisco Bay water, $40 \mathrm{ml}$ of sediment, and $10 \mathrm{ml}$ of homogenized Spartina follosa materials (19). While known (macroalgae (34)) and potential (mangroves, seagrasses) contributors of methylamine precursors (unknown concentrations) account for some organic input, sediments as rich in organic matter as those used above (19), are rarely encountered (35) in the Tampa Bay estuary. From all of this, we conclude that methane production from methanol and methylamines is quantitatively unimportant in the samples we have analyzed during this study; therefore, in applying the model (22) to the data presented here, we consider acetate to be by far the major source of methyl groups to the methanogens active in these sediments.

\section{Relative Contributions of the Methanogen1c Pathways}

Our measurements of $\delta \mathrm{D}-\mathrm{H}_{2} \mathrm{O} / \delta \mathrm{D}-\mathrm{CH}_{4}$ palrs from varlous freshwater and estuarine sediments ${ }^{2}$ (Figure ${ }^{4}$ ) 1mply that about $50 \%$ to $80 \%$ of the total methane production in these sediments can be attributed to acetate dissimilation. Th1s agrees with some earlier studies $(13-15,22)$, but $1 \mathrm{~s}$ in conflict with others that indicated that $\mathrm{CO}_{2}$ reduction dominates methane production in other freshwater lake sediments $(16,17)$. Th1s varlation in pathway importance between individual lakes and even between different locations within the same lake (F1gure 2) may be attributable to natural qualitative and quantitative varlations in the organic matter and bacterla occuring in these sediments as suggested by Belyaev et al. (16). The predominance of the acetate dissimllation pathway under estuarine-marine (Salinity $(S)=6-34 \%$ ) conditions inferred from our data has been found in other nearshore-marine circumstances $(18,36)$. In contrast, the blogenlc methane found in deep-sea sediments is thought to originate almost exclusively from $\mathrm{CO}_{2}$ reduction $(21,37)$ and 1 s 1sotopically distinguishable ( $\delta \mathrm{D}=$ -170 to $-190^{\circ} \% 0(\overline{38)})$ from the marine methane measured here (F1gure 2). The $\delta \overline{\mathrm{D}-\mathrm{CH}_{4}}$ values reported here support the 1dea that with respect to methane production, highly productive brackish and marlne sediments can bear a greater resemblance to freshwater than deep-sea sediments if sulfate is depleted near the sediment water interface due to high rates of respiration $(\underline{30}, \underline{39})$.

\section{Methane Oxidation}

An 1mportant area of study in organic geochemistry concerns the origin of natural gas; two of the more useful parameters in addressing this problem are $\delta \mathrm{D}-\mathrm{CH}_{4}$ and $\delta^{13} \mathrm{C}-\mathrm{CH}_{4}$. As discussed above, $\delta \mathrm{D}-\mathrm{CH}_{4}$ is useful in estimating relative pathway contribution in blological methane formation. Combined with 
information concerning the molecular composition of a natural gas, $\delta 13 \mathrm{C}-\mathrm{CH}_{4}$ can be useful in determining whether the gas was formed biologically or from the thermocatalytic breakdown of complex organic matter (40). Consequently, processes that alter the isotopic compositions and confuse interpretation are of great interest. One process that can cause extensive isotopic fractionation is biological methane oxidation (41). Based on results obtalned from a laboratory study by Coleman et al. (41), it can be calculated that aerobic oxidation of $40 \%$ of an aliquot of methane would leave the remaining $60 \%$ about $12.5 \%$ and $125 \%$ oo more $13 \mathrm{C}$ - and $\mathrm{D}$-enriched, respectively. If the percentage of methane oxidation and the degree of isotopic fractionation varied depending upon location within a given freshwater lake, for example, isotopic variation (Figure 2) could be created. The generally negative correlation between $\delta^{13} \mathrm{C}-\mathrm{CH}_{4}$ and $\delta \mathrm{D}-\mathrm{CH}_{4}$ indicated in Figure 3 indicates that the isotopic variation seen in our samples is not solely due to this process. The negative correlation does not mean that our samples were totally unaffected by in situ methane oxidation, but it does imply that some additional process (1.e., variation in pathway) contributed to the isotopic variation. All currently known examples of anaerobic methane oxidation, other than minor (2\% of the rate of $\mathrm{CH}_{4}$ production) oxidation by methanogenic bacteria (42) have taken place in the presence of dissolved sulfate, which is apparently required as an electron acceptor (39). Thus, it is unlikely that extensive anaerobic methane oxidation would occur in low sulfate freshwater environments. Methanogenic bacteria are strict anaerobes and produce methane only under highly reducing conditions (6). Methane produced under these conditions could only be oxidized by the aerobic process if it either migrated (as a bubble or in solution) to a less reducing location, or if the depth of oxygen penetration into the sediment increased. If a bubble moved upward from the depth at which it was formed, it would probably exit the sediments entirely because the distance between the methane production zone and the sediment is short $(<50 \mathrm{~cm})$, and would not be sampled by the methods employed here. Likewise, methane that dissolved would not be sampled, and because the process of partial dissolution itself would not be expected to induce much isotopic fractionation (43), any methane remaining in bubble form should maintain its isotopic signature. Deeper penetration of oxygen into the sediments, because of a temperature induced decrease in oxygen consumption, might allow partial oxidation of trapped bubbles. This could be responsible for the slight increase (Table I) in the isotopic compositions of methane sampled from Crescent Lake (非) on $1 / 23 / 85$ compared to that sampled at the same location on $12 / 21 / 84$. This slight difference has very little effect on any of our interpretations, and when considered along with the other arguments advanced above, argues against extensive isotopic fractionation of samples reported here (Figures 2,3 ) by aerobic methane oxidation.

Ancillary Data

All of the isotopic and ancillary data considered in this study 


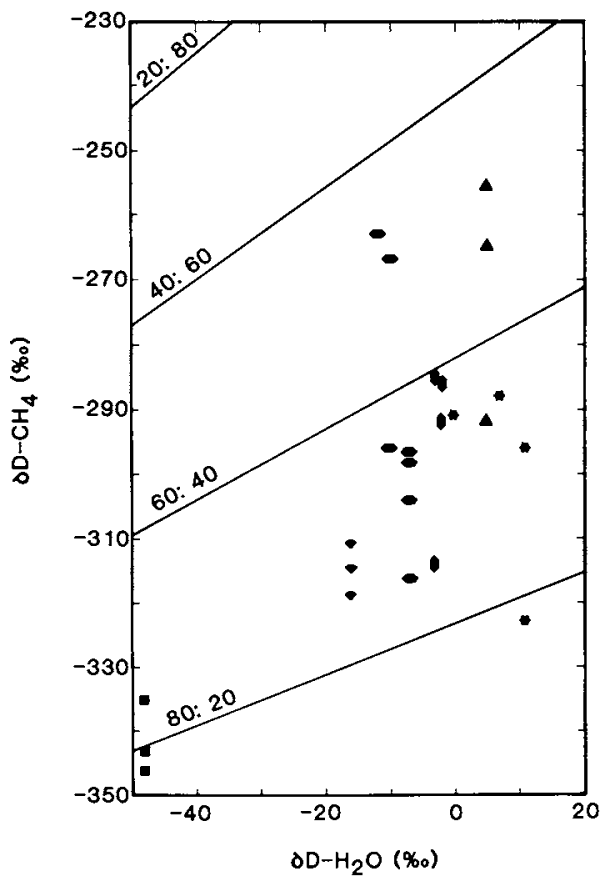

Figure 2. P1ot of $\delta \mathrm{D}-\mathrm{CH}_{4}$ vs. $\delta \mathrm{D}-\mathrm{H}_{2} \mathrm{O}$. Lines represent the percentage mix of the acetate dissimilation and $\mathrm{CO}_{2}$ reduction methanogenic pathways. Symbols:-Crescent Lake, FL; -Mirror Lake, FL; $\Delta$-Lake Dias, FL;

-Kilmer Pond, SC; 口-Mississippi Delta, LA; -Tampa Bay Estuary, FL. (Reproduced with permission from Ref. 22. Copyright 1984 American Society of Limnology and Oceanography, Inc.)

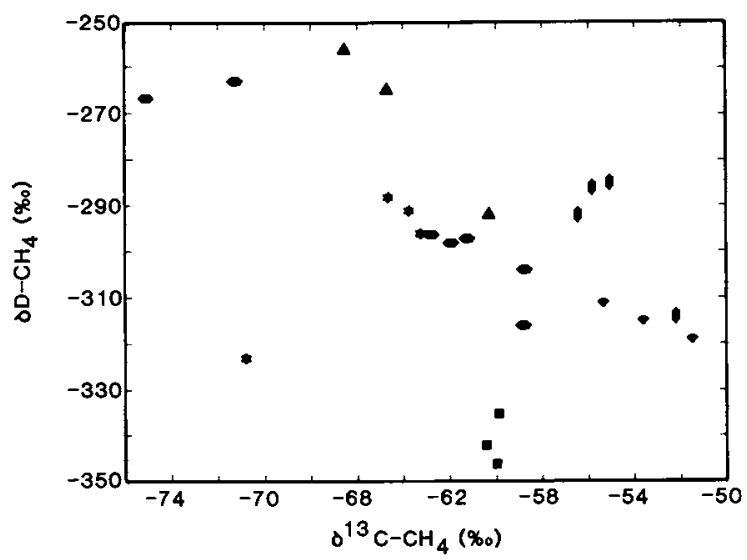

Figure 3. Plot of $\delta \mathrm{D}-\mathrm{CH}_{4}$ vs. $\delta{ }^{13} \mathrm{C}_{-} \mathrm{CH}_{4}$, Symbols as In Figure 2.

In Organic Marine Geochemistry; Sohn, M.;

ACS Symposium Series; American Chemical Society: Washington, DC, 1986. 


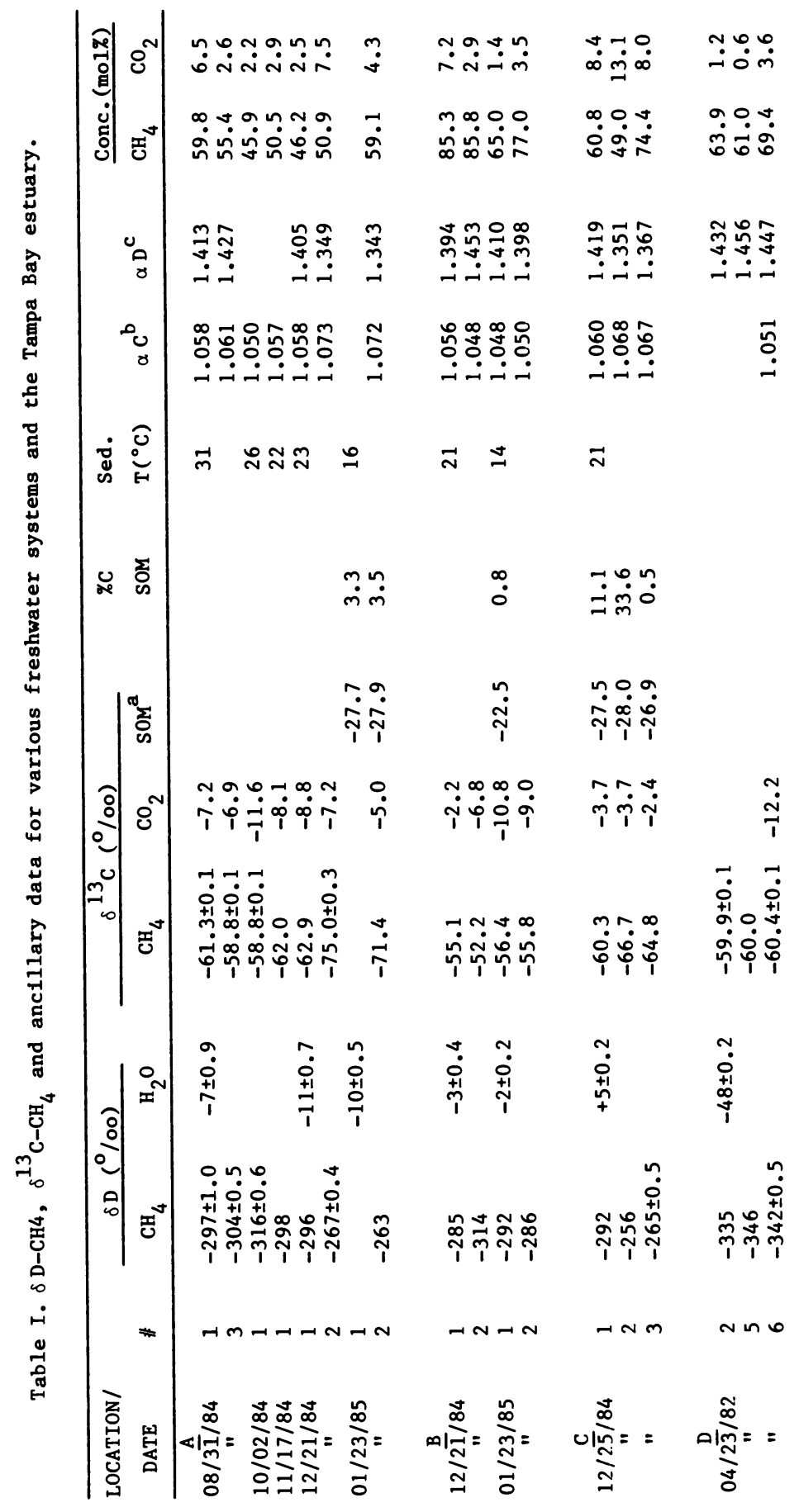

In Organic Marine Geochemistry; Sohn, M.; 
i̊̃

守昆

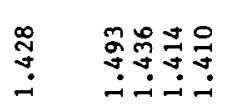

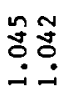

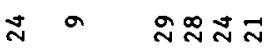

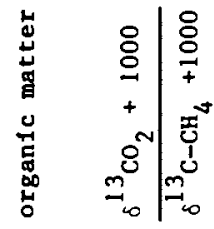

4

:

مُ

$\stackrel{-}{-}$

$\stackrel{\sim}{\sim}$

$\stackrel{0}{0}_{1}^{0}$

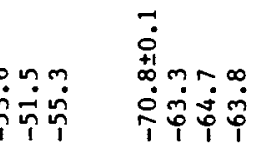

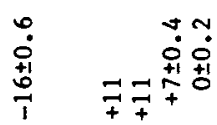

ติๆ

AnT MnO

m小

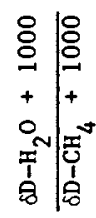

॥

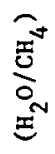

II

ㅇำ

I 
are listed in Table $I$. Concentrations of methane and carbon dioxide ranged from $33 \%$ to $86 \%$ and from $4 \%$ to $13 \%$, respectively, in the samples that we analyzed. The carbon isotopic composition of the sedimentary organic matter (SOM) ranged from $-26.9 \%$ to $-28.0 \%$ oo for al1. but one of the freshwater sediment samples measured here (Table I); this implies that higher land plants $\left(\mathrm{C}_{3}\right.$ pathway) and $10 \mathrm{w} 13^{\mathrm{C}} /{ }^{12} \mathrm{C}$ aquatic plants (44) dominate organic matter input to these sediments. For instance, an unidentified emergent aquatic macrophyte from Lake Dias ( $\$ 3$ ) yielded a $\delta^{13} \mathrm{C}$ of $-28.1 \%$. We determined a $\delta^{13} \mathrm{C}$ of $-22.5 \%$ oo for the SOM of Mirror Lake (Table I) which is substantially heavier than the other freshwater values. Possible explanations for this include a relatively greater contribution of isotopically heavy $\mathrm{C}_{4}$ pathway plant (44) material (i.e., domestic Bermuda grass), and ${ }^{4}$ utilization of isotopically heavier source carbon by the submerged aquatic plants (45). There is no obvious relationship between either $\delta 13 \mathrm{C}-\mathrm{SOM}$ or $\% \mathrm{C}-\mathrm{SOM}$ and $\delta 13 \mathrm{C}-\mathrm{CH}$ for the samples reported here (Table I). For example, while the $813 \mathrm{C}_{-} \mathrm{CH}_{4}$ of Crescent Lake \#2 is $8-12 \%$ lighter than the $\delta 13 \mathrm{C}-\mathrm{CH}_{4}$ of Crescent Lake \#1, there is no substantial difference between the two sites with respect to $\delta 13 \mathrm{C}-\mathrm{SOM}$ or \%C-SOM. Factors other than amount and $\delta{ }^{13} \mathrm{C}$ of the source organic matter, such as pathway selection (Figure 2), must also be involved in determining $\delta 13 \mathrm{C}-\mathrm{CH}_{4}$. Fractionation factors $\alpha \mathrm{C}\left(\alpha\left(\mathrm{CO}_{2} / \mathrm{CH}_{4}\right)\right)$ and $\alpha \mathrm{D}\left(\alpha\left(\mathrm{H}_{2} \mathrm{O} / \mathrm{CH}_{4}\right)\right)$ of the freshwater samples, calculated ${ }^{4}$ rom measured ${ }^{2}$ sotopic compositions, ranged from 1.042 to 1.073 and from 1.343 to 1.456 , respectively (Table I). These values are similar to those that were determined for German lake Wurmsee (22), although the ranges reported here are greater. The greater range (higher $\alpha \mathrm{C}$, lower $\alpha \mathrm{D}$ ) reflects the larger relative contribution of the $\mathrm{CO}_{2}$ reduction pathway in some of our samples (Figure 2). The fractionation factors calculated from typical deep-sea sediment isotopic compositions $(1,37,38)$ are significantly larger $(\alpha \mathrm{C} \sim 1.08)$ and smaller $(\alpha \mathrm{D} \sim 1.25)$ than the factors determined here; this further implies that both isotopes are affected by the methanogenic pathway and indicates the potential applicability of these parameters (particularly together) to the genetic characterization of biogenic methane deposits.

Atmospheric Methane Isotopic Composition

As discussed earlier, recent studies $(\underline{2}, \underline{3})$ inferred a doubling of atmospheric methane concentrations over the past few hundred years. Furthermore, during the last 3-4 years, atmospheric methane concentrations have increased at rates of $1-1.9 \%$ per year (46). Decomposition of organic matter in water-covered soils, intestinal fermentation in ruminants, biomass burning, and direct anthropogenic input (i.e., leakage of fossil fuels) are thought to be the major sources of methane to the atmosphere, contributing approximately $46,22,5$ and $7 \%$ of the total flux, respectively (46). The major sink of atmospheric methane is thought to be reaction with tropospheric on radicals (46). A recent study by Harriss et a1. (47) indicated that periodically inundated soils may also be a site of atmospheric methane removal during dry periods. 
Recent measurements (1980) indicate that the $\delta^{13} \mathrm{C}$ of atmospheric methane is about $-47.0 \pm 0.3 \%$ (48). The average isotopic fractionation associated with the sink process is $-2.5 \pm 1.5 \%$, and there is a $+0.3 \%$ isotope effect resulting from the nonsteady state increasing methane concentrations (48). This implies that the average $\delta^{13} \mathrm{C}-\mathrm{CH}_{4}$ for all sources $1 \mathrm{~s}$ about $-49 \pm 1.5 \%$; this is significantly less $13 \mathrm{C}$-depleted than most known biogenic sources (48), and is about $10 \%$ loo less negative than the average $\delta^{13} \mathrm{C}-\mathrm{CH}_{4}$ of all sources $(-61 \pm 3 \%$ oo $)$ calculated by Senum and Gaffney (49). ${ }^{4}$ Blomass burning and fossil fuels are the only known significant sources of methane more $13 \mathrm{C}$-enriched than $-49 / 00(48)$, and they apparently account for a relatively smal1 fraction of the total input. Bubble ebullition is the dominant mode of methane input to the atmosphere from some shallow

freshwater ( 50$)$ and marine (51) aquatic environments. All of the gas samples analyzed for this work were collected as bubbles from sediments covered by very shallow ( $1 \mathrm{~m}$ or less) water. Three of the freshwater lakes (Crescent Lake, Mirror Lake and Kilmer Pond) have been observed to release gas bubbles from their sediments, and it is very likely that active bubbling also occurs in the other environments studied here. There is a good deal of variation $\left(224^{\circ} / 00\right.$ ) in the $\delta^{13} \mathrm{C}-\mathrm{CH}_{4}$ data presented here (Table I); however, most of the samples are substantially lighter than $-49 \%$, in agreement. with other data from shallow aquatic environments $(48)$. Though limited in number, these data suggest that ebullition from these sediments is unlikely to provide an atmospheric input of methane as ${ }^{13} \mathrm{C}$-enriched as the estimated (48) source average. Based on the ${ }_{13}$ results of a study by Rust (52), which demonstrated that the $\delta{ }^{13} \mathrm{C}$ of methane produced by ruminants depends on the $\delta^{13} \mathrm{C}$ of the plants in their diet, Stevens and Rust (48) proposed that the anaerobic decomposition of isotopically heavy $C_{4}$ plant debris in large wetlands, such as the Sudd marshes and the Everglades, might be a significant source of isotopically heavy methane to the atmosphere. 13 s mentloned before, no such simple relationship between the $\delta^{13} \mathrm{C}-\mathrm{CH}_{4}$ and $\delta^{13} \mathrm{C}-\mathrm{SOM}$ of aquatic sediments is indicated by our data (Table I). According to Wolfe (7), four well-defined groups of bacterla are involved in the conversion of complex organic matter to methane in sediments, whereas in the rumen only two of the groups are involved and there is no significant production of methane from acetate. Also, substrate input, product output, and environmental conditions are more closely controlled in the rumen than in sediments where disorder is inherently greater (53). Thus, in addition to $\delta^{13} \mathrm{C}-\mathrm{SOM}$, other factors such as pathway selection and possibly kinetic effects are probably important in setting the $\delta^{13} \mathrm{C}-\mathrm{CH}_{4}$ of aquatic sediments. Escape of dissolved methane across the air-water interface, rather than ebullition, may be the more likely means of transferring 1sotopically heavy methane from shallow aquatic environments to the atmosphere. Dissolved methane should be more read1ly avallable for aerobic methane-oxidation (39) and 1sotopic fractionation (41); however, assessment of the potential contributions of ebullition and dissolved methane to atmospheric $\delta^{13} \mathrm{C}-\mathrm{CH}_{4}$ is hindered by a lack of relevant data. 
Using data obtained in 1960 and 1970 (54-56), Senum and Gaffney (49) noted an apparent decrease in atmospheric methane $\delta D$ with time that they extrapolated to the present to yleld an estimate of $-104 \pm 4 \%$ for the $S D$ of present-day atmospheric methane. The extrapolated $\delta D$ value was corrected for kinetic Isotop 1c fractionation resulting from the reaction of methane with hydroxyl radicals (the magnitude of the fractionation was attributed to Gorden and Mulac (57)) in the troposphere to yleld an estimate of $-322^{\circ} \%$ as the present-day average $\delta \mathrm{D}$ of all methane sources to the atmosphere (49). Analyses reported in (Table I) and by Woltemate et al. (22) Indicate that methane as deuterlum-depleted as $-322 \%$ is produced in some freshwater sediments. Organic matter decomposition in sewage sludge may also yleld methane as deuterium-depleted as $-322 \%$ (21). According to the genet1c characterization model of Schoell (38), which is based on approximately 500 natural gas analyses, thermogenic methane is generally less deuterlum-depleted than $-300 \%$. To our knowledge, there are no estimates of the $\delta \mathrm{D}$ of methane produced from elther the intestinal fermentation in ruminants or blomass burning. Although an important source of atmospheric methane with a $\delta D$ near the estimated source average (49) has been 1dentifled (freshwater sediments), there are presently too few measurements of the $\delta D$ of atmospheric methane and 1ts sources avallable to determine whether or not this apparent agreement has any real significance with regard to evaluating the role of shallow aquatic sediments in the atmospheric methane budget and in determining the $\delta D$ of atmospheric methane.

\section{Summary}

Stable hydrogen and carbon 1sotopic compositions of blogentc methane produced in the sediments of several freshwater and estuarine environments have been measured and interpreted using a previously published model. The results infer that acetate dissimilation is the dominant methanogenic pathway in these sediments, accounting for about 50 to $80 \%$ of the total methane production, with $\mathrm{CO}_{2}$ reduction responstble for the remainder. In general, $\delta \mathrm{D}-\mathrm{CH}_{4}$ and ${ }^{2} \delta^{13} \mathrm{C}-\mathrm{CH}_{4}$ are inversely correlated, Implying that methane oxidation alone can not explain the 1sotopic variations. The inverse relationsh1p also implies that both 1sotopes are affected by methanogenic pathway selection. Fractionation factors, $\alpha \mathrm{D}$ and $\alpha \mathrm{C}$, calculated from the 1sotop1c data presented here are significantly larger and smaller, respectively, than $\alpha D$ and $\alpha C$ typlcally found in deep-sea sediments. Measurements performed to date indicate that the $\delta^{13} \mathrm{C}-\mathrm{CH}_{4}$ of gas bubbles formed in shallow aquatic sediments is generally significantly more negative than the average of all sources to the atmosphere. There are presently too few measurements of the $\delta D$ of atmospheric methane and 1 ts sources avallable to allow evaluation of the role of shallow aquatic sediments in determining the $\delta D$ of atmospherfc methane. 


\section{Acknowledgments}

We would like to thank Dr. Paul Carlson of the Florlda Department of Natural Resources for providing samples from the Tampa Bay Estuary. Dr. James M. Brooks of Texas A\&M Untversity provided sh1ptime which enabled us to collect the Mississippl Delta samples. Dr. Willard S. Moore of the Untv. of South Carolina supplied the samples from Kllmer Pond. Mr. Roger A. Burke, Sr. of DeLand, FL provided the Lake Dlas samples. Th1s manuscrlpt was typed by Jod1 Gray. Th1s research was supported by NSF grants OCE-8308945 and OCE-8417321 (Marine Chem1stry Program) to W.M.S. and R.A.B.

\section{L1terature C1ted}

1. Rice, D. D.; Claypoo1, G. E. Bu11. AAPG 1981, 65, 5-25.

2. Cra1g, H.; Chou C. C. Geophys. Res, Lett. 1982, 9, 477-481.

3. Khal11, M. A. K.; Rasmussen, R. A. Chemosphere. 1982, 11 , 877-883. 4. Wang, W. C.; Yung, Y. L.; Lac1s, A. A.; Mo, T., Hansen, J. E. Sclence 1976, 194, 685-690.

5. Lac1s, A.; Hansen, J.; Lee, P.; Mitche11, T.; Lebedeff, S. Geophys. Res. Lett. 1981, 8, 1035-1038.

6. Mah, R. A. Phil. Trans. R. Soc. Lond. B 1982, 297, 599-616.

7. Wolfe, R. S. In "Microbial Blochemistry (International Review of Blochemistry, vol. 21)"; Quayle, J. R. Ed.; Untvers1ty Park Press: Baltimore, 1979; pp. 270-300.

8. Zehnder, A. J. B. In "Water Pollution Microblology"; Mitche11, R., Ed.; W1ley: New York, 1978; vo1. 2, pp. 349-376.

9. Jer1s, J. S.; McCarty, P. L. J. Wat. Pollut. Control Fed. $1965,37,178-192$.

10. Sm1th, P. N.; Mah, R. A. App1. Microb1ol. 1966, 14, 368-371.

11. Koyama, T. J. Geophys. Res. 1963, 68, 3971-3973.

12. Taka1, Y. Soil. Sc1. and P1an Nutr. 1970, 6, 238-244.

13. Cappenberg, Th. E.; Prins, R. A. Ant. van Leeuwenhoek, J. Microb1ol. Serol. 1974, 40, 457-469.

14. W1nfrey, M. R.; Zetkus, J. G. App1. Environ. M1croblol. $1979,37,244-253$.

15. Lovley, D. R.; Klug, M. J. Appl. Environ. M1crobtol. 1982, 43, 552-560.16. Belyaev, S. S.; F1nke1'shte1n, Z. I.; Ivanov, M. V. M1kroblolog1ya (Engl1sh translation) 1975, 44, 272-275.

17. Jones, J. G.; S1mon, B. M.; Gardener, S. J. Gen. M1croblol. $1982,128,1-11$.

18. Sansone, F. J.; Martens, C. S. Sclence 1981, 211, 707-709.

19. Oremland, R. S.; Marsh, L. M.; PolcIn, S. Nature (Lond.) $1982,296,143-145$.

20. King, G. M.; Klug, M. J.; Lovley, D. R. App1. Environ. M1croblo1. 1983, 45, 1848-1853.

21. Schoel1, M. Geoch1m. Cosmoch1m. Acta 1980, 44, 649-661.

22. Woltemate, I.; Whiticar, M. J., Schoe11, M. L1mnol. Oceanogr. 1984, 29, 985-992.

23. Coleman, M. L.; Shepherd, T. J.; Durham, J. J.; Rouse, J. E.; Moore, G. R. Ana1. Chem. 1982, 54, 993-995. 
24. McNa1r, H. M.; Bonelli, E. J. "Basic Gas Chromatography"; Varian: Palo Alto, CA., 1969, pp. 144-147.

25. Cra1g, H. Geoch1m. Cosmoch1m. Acta 1953, 3, 53-92.

26. Dantels, L.; Fulton, G.; Spencer R. W.; Orme-Johnson, W. H. J. Bacter1ol. 1980, 141, 694-698.

27. Pine, M. J.; Barker, H. A. J. Bacteriol. 1956, 71, 644-648.

28. Naka1, N.; Yashida, Y.; Ando, N. Ch1ku Kagaka 1974, 7/8, 87-98.

29. Lovley, D. R.; Klug, M. J. App1. Environ, Microb1o1. 1983, $45,1310-1315$.

30. King, G. M. Geomicrobiol. J. 1984, 3, 275-306.

31. King, G. M. Appl Environ. Microblol. 1984, 48, 719-725.

32. Yancey, P. H.; Clark, M. E.; Hand S. C.; Bowlus, R. D.; Somero, G. M. Sclence $1982,217,1214-1222$.

33. Cavalier1, A. J.; Huang, H. C. Oecologia 1981, 49, 224-228.

34. Blunden, G.; Gordon, S. M.; McLean, W. F. H.; Guiry, M. D. Bot. Mar. 1982, 25, 563-567.

35. Sackett W.; Brooks. G.; Conkright, M.; Doyle L.; Yarbro, L. 1985, In Press.

36. Mountfort, D. O.; Asher, R. A., Mays, E. L., Tiedfe, J. M. App1 Environ. Microbiol. 1980, 39, 686-694.

37. Claypool, G. E.; Kaplan, I. R. In "Natural Gases in Marine Sediments"; Kaplan, I. R., Ed.; Plenum Press: New York 1974; pp. 99-139.

38. Schoe11, M. Bu11. AAPG 1983, 67, 2225-2238.

39. Rudd, J. M. W.; Taylor, C. D. Adv. Aquat. Microblol. 1980, 2, 77-150.

40. Bernard, B.; Brooks, J.; Sackett W. Proc. Offshore Tech. Conf. 1977, OTC 2934, pp. 435-438.

41. Coleman, D. D.; Risatt1, J. B.; Schoel1, M. Geochim. Cosmoch1m. Acta $1981,45,1033-1037$.

42. Zehnder, A. J. B.; Brock, T. D. Appl. Environ, Microblol. $1980,39,194-204$.

43. Bernard, B. B.; Brooks, J. M.; Sackett, W. M. Earth Planet. Sc1. Lett. 1976, 31, 48-54.

44. Smith, B. N.; Epste1n, S. Plant Physiol. 1971, 47, 380-384.

45. Osmond, C. B.; Valaane, N.; Haslam, S. M.; Vot1la, P.; Roksandic, Z. Oecolog1a 1981, 50, 117-124.

46. Khal11, M. A. K.; Rasmussen, R. A. J. Geophys. Res. 1983, 88, 5131-5144.47. Harriss, R. C.; sebacher, D. I.; Day, F. P. Nature (Lond.) 1982, 297, 673-674.

48. Stevens, C. M.; Rust, F. E. J. Geophys. Res. 1982, 87, 4879-4882.

49. Senum, G. I.; Gaffney, J. S. In "The Carbon Cycle and Atmospheric $\mathrm{CO}_{2}$ : Natural Varlations Archean to Present"; Sundquist, E. T.; Broecker, W. S., Eds.; American Geophysical Union: Washington, D.C., 1985; Geophysical Monograph 32, pp. 61-69.

50. Cicerone, R. J.; Shetter, J. W. J. Geophys. Res. 1981, 86, 7203-7209.

51. Martens, C. S.; Klump, J. V. Geoch1m. Cosmochim. Acta 1980, 44, 471-490.

52. Rust, F. Sclence $1981,211,1044-1046$. 
53. Wolin, M. J. In "Microbiol. Interactions and Communities"; Bull, A.T.; Slater, J.H. Eds.; Academic: New York, 1982; vol.1, pp. 323-356.

54. Balnbridge, A. E.; Seuss, H. E.; Friedman, I. Nature (Lond.) $1961,192,648-649$.

55. Begemann, F.; Friedman, I. J. Geophys. Res, 1968, 73, 1149-1153.

56. Ehhalt, D. H. In "Carbon and the Biosphere"; Woodwell, G.M.; Pecan E.V. Eds.; Offlce of Information Service: Washington, D.C., 1973; pp. 144-158.

57. Gorden, S.; Mulac, W. A. Int. J. Chem. Kfnet. 1975, 7 (Symp.\#1), 289-299.

RECEIVED September 16, 1985 


\title{
Polybromomethanes
}

\section{A Year-Round Study of Their Release to Seawater from Ascophyllum nodosum and Fucus vesiculosis}

\author{
Philip M. Gschwend and John K. MacFarlane
}

Ralph M. Parsons Laboratory for Water Resources and Hydrodynamics, Department of Civil Engineering, Massachusetts Institute of Technology, Cambridge, MA 02139

\author{
Polybromome thanes $\left(\mathrm{CHBr}_{3}, \mathrm{CHBr}_{2} \mathrm{Cl}\right.$, and $\left.\mathrm{CH}_{2} \mathrm{Br}_{2}\right)$ were \\ released to seawater in laboratory lncubations by \\ Ascophyllum nodosum and Fucus vesiculosis at nanograms \\ to mlcrograms each compound per gram dry algae per day \\ throughout the year. Th1s biological source of \\ halogenated compounds was detectable in nearshore \\ seawater during h1gh t1des when these 11ttoral algae \\ were submerged. The weak seasonallty of \\ polybromome thane formation, together w1 th varlous \\ evidence from the 11 terature, suggest that these \\ brominated organic compounds may arise from fungal \\ eplphytes closely assoclated with these algae.
}

It has long been recognized that marine macroalgae contain halogenated metabolites $(1-3)$. A few investigations have provided evidence that certain of the volatile halogenated compounds are released from these algae into coastal seawater (4 - 7$)$. In particular, of all the volatile halogenated compounds observed, three polybromomethanes $\left(\mathrm{CHBr}_{3}, \mathrm{CHBr}_{2} \mathrm{Cl}\right.$, and $\mathrm{CH}_{2} \mathrm{Br}_{2}$ ) were released in the greatest quantitles in a survey of several temperate macroalgae (7). Th1s natural source of halogenated organ1c compounds to the marine environment is especially important in $11 \mathrm{ght}$ of our concern for emissions of halogenated solvents and haloforms in coastal discharges $(\underline{8}-\underline{9})$ and to the atmosphere (10). Such natural sources must be quantified to place man's 1mpact 1n perspective and to suggest natural sink mechanlsms which may have evolved in response to these sources.

In this report, we describe a seasonal study of polybromomethane releases from two common fucold algae, Ascophyllum nodosum and Fucus vesiculosis. We performed this investigation to evaluate the yearround varlations in algal impact on coastal seawater chemistry. Further, we hoped to observe seasonal correlations between polybromome thane releases and factors in the $11 \mathrm{fe}$ cycles of these algae to provide 1nsights as to the genesis and function of these natural products. 


\section{METHODS}

Algal Incubations. Our procedures for quantifying polybromomethane releases from macroalgae to seawater have been described previously (7). A brief description follows. Ascophyllum nodosum and Fucus vesiculosis specimens were collected approximately monthly from the rocky Intertidal shoreline of the Cape Cod Canal, Sagamore MA. Algae were collected by breaking of $f$ plece of the rock to which the plants were attached, thereby not causing any tissue lesions, and were held in a bucket of seawater until delivery to the laboratory w1thin 2 hours. Plants supporting visible ep1phytes were avolded, but it was not possible to exclude closely assoclated microscopic organisms. Seawater temperature and t1dal stage were recorded at the time of sampling and water samples were taken for nutrients and $s$ tored frozen until analysis. Nitrate-N was determined by the cadmium reduction method and phosphate-P was assesed by the ascorbic ac1d or 8 tannous chloride methods (11).

At the laboratory, the algae were placed in a 34-11ter aquarium, filled with seawater and maintained without headspace by a tightly f1tting glass 11d. The aquarium was kept in a temperature and light-controlled incubation refrigerator set to mimic the current environmental conditions. Water motion was malntained using a two-1nch magnetic stir bar. Algal incubations typically lasted one day. After Incubating, seawater was withdrawn from the aquarium, splked with a volatile halogenated organic internal standard, and analyzed for polybromomethane content.

Analysis of Polybromomethanes in Seawater. Polybromomethanes in aquarium water and Cape Cod Canal seawater samples were determined by a hybrid procedure of the "purge and trap" method (12) and the Grob closed-loop-strlpping analys1s (13). Briefly, headspace alr was bubbled through a 1.8 l1ter water sample at a rate of $650 \mathrm{~mL} / \mathrm{min}$ for 10 minutes. The effluent vapors pass through a condenser maintained at $10^{\circ} \mathrm{C}$ to reduce the water content of the gas stream, and then through a Tenax trap ( $65 \mathrm{~mm}$ long $\times 3 \mathrm{~mm} 1 . \mathrm{d}$., containing about $20 \mathrm{mg}$ Tenax solid adsorbent) where the nonpolar organic compounds are collected. The "cleansed" air stream then recycles via a metal bellows pump to the water sample.

Af ter 8 tripping the water, the Tenax trap was immediately transferred to the hot infection port of a Hewlett Packard 5995B benchtop gas chromatograph-mass spectrometer (GC-MS). The volatiles were then thermally desorbed from the Tenax and carried with the gas 8 tream on to the front of a glass cap1llary column (coated with SE54). The first loop of the capillary column was dipped in a Dewar containing liquid nitrogen and served to cryogenically focus the volatile concentrate at the column front. Af ter 5 minutes of thermal desorption and transfer, the liquid nitrogen Dewar was removed and chromatography was begun. Data from the GC-MS was corrected for instrument response factors and stripping efficiencies to ultimately derive the amounts of polybromomethanes present in the sample. Seawater held in the aquarium without macroalgae never showed any polybromomethane formation. 1-Chloropentane, added to the seawater as an internal standard to monitor stripping efficiency, was recovered with a precision of $74 \pm 18 \%(\mathrm{~N}=200)$. 1-Chlorobenzene added directly to the Tenax trap prior to thermal desorption was 
recovered w1th a prec1sion of $89 \pm 12 \%(N=120)$. Given the conditions of our algal incubations and analytical capabilities, our lower $11 \mathrm{mit}$ of detection for algal releases was about $50 \mathrm{ng}$ polybromomethane/g dry algae $d$. Polybromomethanes could be detected in Canal seawater down to approximately $10 \mathrm{ng} / \mathrm{L}$.

\section{RESULTS AND DISCUSSION}

The seasonal varlations in temperature and nutrient concentrations in the Canal where the algae were growing are shown in Table I. Water temperature varled by about $20^{\circ} \mathrm{C}$ belng lowest in January and highest In August. Nitrate and phosphate were detectable yearround, undoubtedly reflecting the influence of nutrient-rich Cape Cod Bay seawater. In light of the literature and given these environmental conditions, these fucolds grew optimally in the spring, summer, and fall, and in the winter grew slower due to decreased light and cooler temperatures $(14-17)$.

Polybromome thanes were released from both $A$. nodosum and $F$. vesiculosis to lab aquarium seawater throughout the year (Figure 1). Tribromomethane (or bromoform) was emitted by both algae at rates between 0.1 and $10 \mu \mathrm{CHBr}_{3} / \mathrm{g} \bullet \mathrm{d}$. Release was high in fall of 1983, but did not show any subsequent seasonality. Dibromochlorome thane was always observed from $A_{\text {. }}$ nodosum, but was undetectable in several F. vesiculosis incubations. Dibromomethane was only produced and released by $A_{0}$ nodosum, although not during the winter. This dihalo-compound was released at generally lower rates (note scale difference in Figure 1) than the two haloforms. Dibromochloromethane and dibromomethane appear to be released somewhat more extensively during the summer and fall.

Cape Cod Canal seawater samples collected at high tide (1.e., when both fucold populations would be submerged) always contained detectable bromoform, although no seasonal pattern could be seen (F1gure 2). Low tide water samples generally showed undetectable bromoform, except for a few spring and summer samples. Clearly these fucold populations imparted substantial bromoform to the surrounding seawater, and this polybromomethane typically had no other detectable sources as reflected by most low tide samples.

Dibromochloromethane and dibromomethane were only observed in

two Canal water samples each. Since dibromochloromethane is released by these algae at comparable rates to bromoform, it appears that some sink is relatively more important for this compound. Kaczmar et al. (18) report that $\mathrm{CHBr}_{2} \mathrm{Cl}$ volatilizes about $50 \%$ faster than $\mathrm{CHBr}_{3}$, and possibly it is this mechanism which maintalns $\mathrm{CHBr}_{2} \mathrm{Cl}$ concentrations below our detection 11mits in high tide Cape Cod Canal seawater. Dibromomethane was only released from $A$. nodosum and then at several times lower rates than bromoform, thus its nondetection in the Canal water is not surprising.

A simple calculation suggests that the algal incubation release rates we observed in the laboratory could readily account for the Canal water concentrations. If $A$. nodosum and $F$. vesiculosis blomasses are about $10^{3} \mathrm{~g}$ dry algae per m $\mathrm{m}^{2}(17)$, they w111 release about $100 \mu \mathrm{g}$ of bromoform $/ \mathrm{m}^{2} \cdot \mathrm{hr}$. Thus, a $20-50 \mathrm{~cm}$ deep layer of water covering the algae at high tide will take only several minutes to bulld up the concentrations we observe. Thus our fleld observations of 20-80 ng bromoform/L seem consistent w1 th the laboratory results. 
TABLE I. Temperature and nutrient data for Cape Cod Canal seawater (September 1983-December 1984).

\begin{tabular}{|c|c|c|c|}
\hline Date & Temp $\left({ }^{\circ} \mathrm{C}\right)$ & $\mathrm{NO}_{3}(\mu \mathrm{M})$ & $\mathrm{PO}_{4} \quad(\mu \mathrm{M})$ \\
\hline $\begin{array}{l}9.10 .83 \\
9.20 \\
9.25 \\
9.29 \\
10.05 \\
10.18 \\
10.26 \\
11.01 \\
11.08 \\
11.15 \\
11.22 \\
12.01 \\
12.06 \\
12.13 \\
12.22\end{array}$ & $\begin{array}{c}17.5 \\
15.0 \\
15.8 \\
15.0 \\
14.5 \\
14.5 \\
11.0 \\
10.0 \\
9.7 \\
9.2 \\
9.0 \\
8.5 \\
6.5 \\
7.0 \\
-\end{array}$ & $\begin{array}{c}- \\
- \\
- \\
- \\
- \\
- \\
3.5 \\
1.1 \\
11.2 \\
3.4 \\
- \\
2.4 \\
4.3 \\
4.5 \\
4.6 / 2.6\end{array}$ & $\begin{array}{c}- \\
- \\
- \\
- \\
- \\
- \\
0.16 * \\
0.99 t \\
1.00 t \\
0.93 t \\
- \\
0.95 t \\
0.93 t \\
1.12 t \\
0.79 t\end{array}$ \\
\hline $\begin{array}{l}1.04 .84 \\
3.01 \\
3.07 \\
3.15 \\
3.21 \\
4.03 \\
5.03 \\
5.10 \\
5.15 \\
5.22 \\
6.04 \\
6.18 \\
7.10 \\
7.24 \\
8.07 \\
8.22 \\
9.12 \\
10.04 \\
10.24 \\
11.15 \\
12.12\end{array}$ & $\begin{array}{r}1.5 \\
3.5 \\
3.7 \\
1.5 \\
3.8 \\
5.0 \\
8.0 \\
10.0 \\
9.2 \\
10.3 \\
12.0 \\
13.5 \\
16.5 \\
14.5 \\
21.0 \\
21.5 \\
14.3 \\
14.4 \\
14.1 \\
9.5 \\
7.2\end{array}$ & $\begin{array}{c}8.0 \\
- \\
2.4 \\
4.0 \\
3.7 \\
5.2 \\
3.2 \\
0.7 / 1.4 \\
3.5 \\
5.5 \\
4.9 \\
7.8 \\
2.2 \\
3.3 \\
1.4 \\
- \\
- \\
- \\
- \\
- \\
-\end{array}$ & $\begin{array}{c}1.68 \dagger \\
- \\
0.25^{\star} \\
0.22^{\star} \\
- \\
0.12^{\star} \\
0.16^{\star} \\
- \\
- \\
- \\
- \\
0.44 / 0.13 * \\
0.19 / 0.15 * \\
0.15 / 0.19 * \\
0.18 \pm 0.01 \star \\
0.19 / 0.34 * \\
- \\
- \\
0.34 / 0.35 \star \\
0.34 * \\
0.34 / 0.34 \star\end{array}$ \\
\hline
\end{tabular}

- no data avallable for this sample date.

* $\mathrm{PO}_{4}{ }^{3-}$ analyzed by the Stannous chloride method (Standard Methods, APHA, 1980).

t $\mathrm{PO}_{4}{ }^{3-}$ analyzed by the Ascorbic ac1d method (Standard Methods, APHA, 1980). 


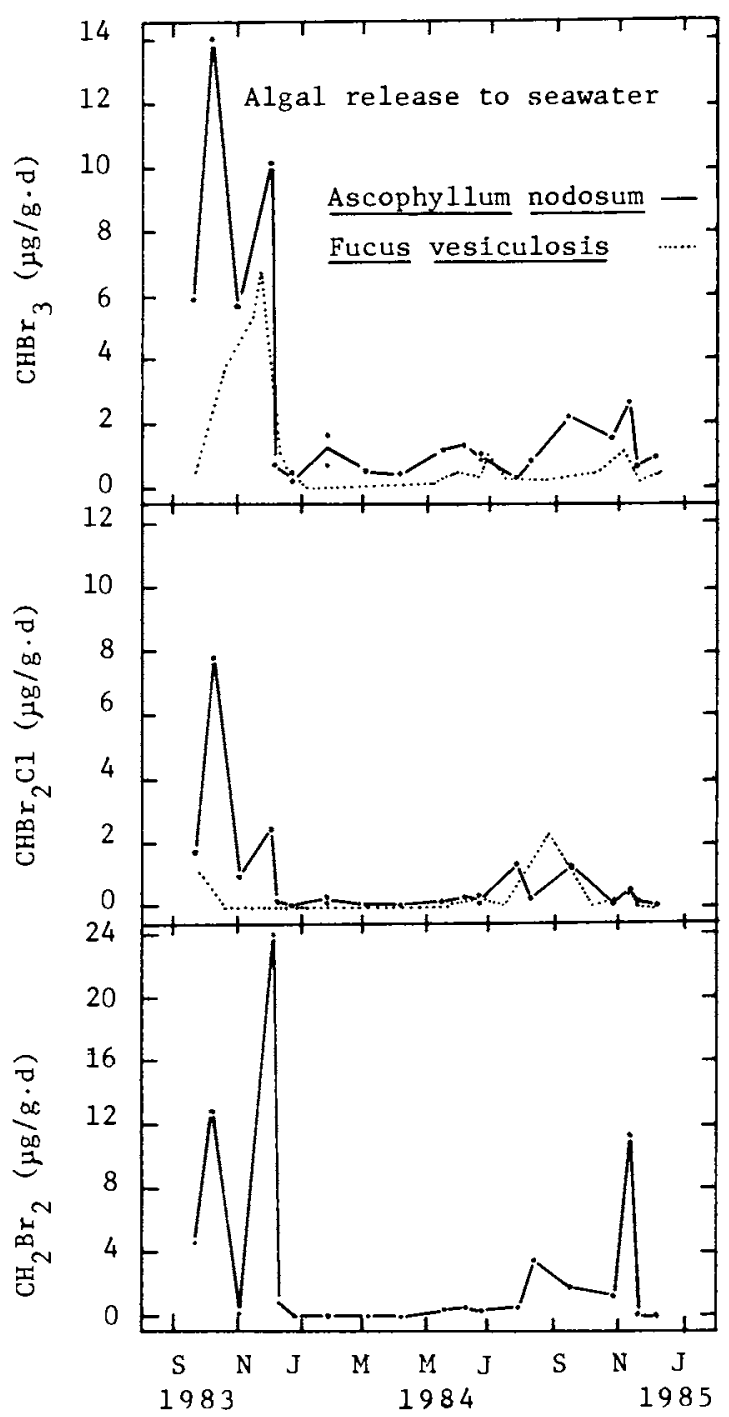

F1gure 1. Seasonal release rates of $\mathrm{CHBr}_{3}, \mathrm{CHBr}_{2} \mathrm{Cl}$, and $\mathrm{CH}_{2} \mathrm{Br}_{2}$ to seawater by the brown algae, Ascophyllum nodosum and Fucus vesiculosis. Open symbols indicate no detectable release.

In Organic Marine Geochemistry; Sohn, M.;

ACS Symposium Series; American Chemical Society: Washington, DC, 1986. 

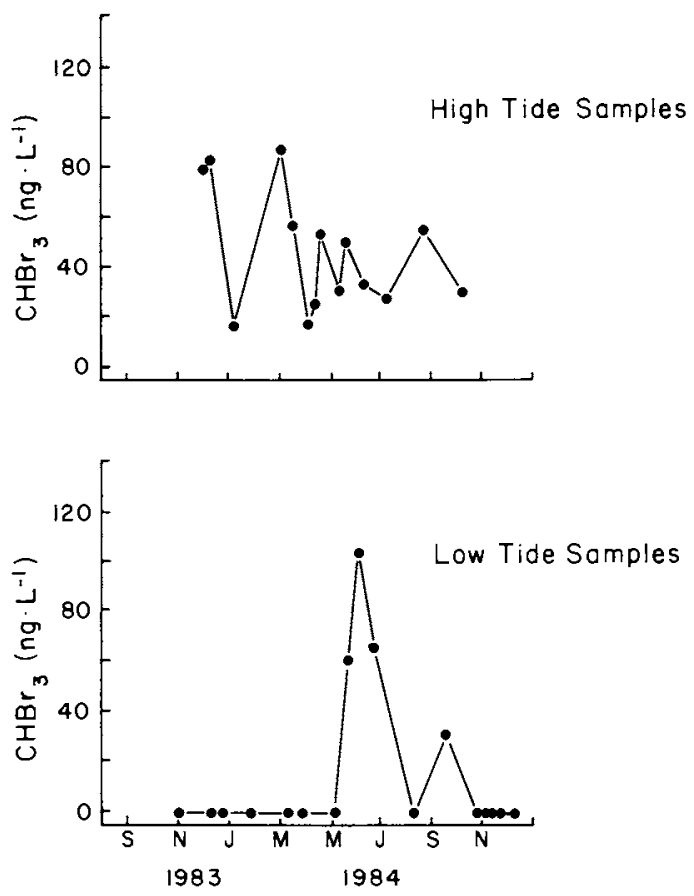

Figure 2. Seasonal $\mathrm{CHBr}_{3}$ concentrations $\left(\mathrm{ng} \cdot \mathrm{L}^{-1}\right)$ in nearshore seawater of the Cape Cod Canal, Sagamore, MA.

In Organic Marine Geochemistry; Sohn, M.; 
Algal versus Ep1phyt1c Source. Our observations may also provide some insight to the genesis of the polybromomethanes. Foremost in this regard is whether the algae or some attached microorganisms synthesize these halogenated compounds. Gschwend et al. (7) previously reasoned that algae were most $11 \mathrm{kely}$ responsible; however, the absence of a strong seasonality in the polybromomethane releases from $A$. nodosum and $F$. vesiculosis indicated that this conclusion may be wrong, since nearly every other process assoclated with these macrophytes does vary yearround. First, numerous studies of temperate fucold algae have demonstrated major changes in their growth rates and reproductive physlology throughout the year ( 15 , 17). Investigations of algal metabolites, including the halogen I, also show regular seasonality $(16,19,20)$. Further algal peroxidase enzymes, which could reasonably be proposed to oxidize halldes prior to their addition to organic substrates, have also been found to vary greatly in activity in both $A$. nodosum and $F$. vesiculosis (21). Both species exhibited the greatest activicy in the spring and summer; $A$. nodosum peroxidase activity diminished to one tenth maximal levels by September and $F$. vesiculosis showed more than fifty times decrease in this enzymatic activity by July-September. Clearly we did not see these magnitudes of changes in polybromomethane release on a seasonal bas1s. Further, Hewson and Hager ( 3 ) and Vilter (22) report that peroxidase preparations from $A$. nodosum and $F$. vesiculosis could not oxidize bromide (a prerequisite step to polybromomethane formation). Thus 1 t appears that these algae do not blosynthesize and release the polybromomethanes we observe.

We have atrempted to support this conclusion by inoculating seawater with surface materlal gently scraped of the surfaces of A. nodosum and $F$. vesiculosis plants and monitoring for polybromomethane formation. In both cases bromoform concentrations in the water were observed to increase (F1gure 3). Mercuric chloride polsoning, $0.2 \mu \mathrm{m}$ filtering, and autoclaving the inoculated seawater prevented this bromoform production. Thus, some component of the epiphytic commun1ty may be involved.

The ep 1phytic communites of $\mathrm{A}$. nodosum and $\mathrm{F}$. vesiculosis

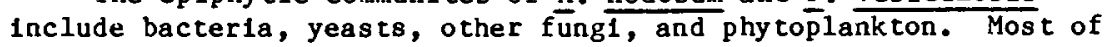
these microorganisms appear to undergo yearround varlations in their abundance. Using viable count techniques, Chan and McManus (23) found the fewest bacteria on $A$. nodosum during the summer months of July and August. Sieburth and Tootle (24) extended this result by examining both $A$. nodosum and $F$. vesiculosis with scanning electron microscopy (SEM). They found bacterial colonization of these algae was greatest in November and April and diminished to virtually clean In May to July. Seshadri and Sieburth (25) also enumerated the yeasts growing on these fucold algae and again discovered a strong seasonal varlation. Further, these same yeast species were most abundant on a red alga, Chondrus crispus, which exhibits 11 ttle or no polybromomethane production (7). Finally, some microalgae grow as eplphytes on fucolds (24); but no bromination capabilities have ever been demonstrated in a microalgae (7). Although culturing and SEM approaches to evaluating microorganisms on fucolds may be somewhat crude for our purpose, these assuys consistently demonstrate strong seasonal trends in the dominant micrublal subpopulations living on A. nodosum and $\mathrm{F}$. vesiculosis. Consequently, we suspect these microorgan 1 sms do not make the polybromomethanes. 
Finally, Vilter et al. (21) have suggested that an ascomycete, Mycosphaerella ascophyll1, growing symblotically on A. nodosum may be responsible for the bromoperoxidase activity attributed to that fucold. Th1s fungus is apparently always present on this brown alga (26), consistent with the continuous production of polybromome thanes. M. ascophyll1 has been isolated and cultured by Pederson and Fries $(\overline{2} 7)$ and production of brominated phenols by the culture was observed. Although the ascomycete is thought to be rare on $F$. vesiculosis (26), the same bromophenols are observed from that algäe (28), suggesting a similar source. Since bromoperoxidases capable of forming bromophenols would also be able to yleld bromoform from the approprlate organic precursors, $M$. ascophyll1 ubiquitous on A. nodosum, or similar fung 1 on other algae, appears to be the most Iikely source of the polybromomethanes. As we have noted previously (7), If these or other ep1phytes are involved, the microorganisms must be quite host-specific to account for the different combinations and rates of polybromomethane releases observed from between vartous algal species.

If ascomycetes living in mycophycoblotic relationships with fucolds (25) are lndeed the answer, it is tempting to speculate on the function of their bromoperoxidase activity. Such a strong oxidative enzymatic capability is common to fung (29), and it could be used by the ascomycete to brominate the plant surface chemicals (e.g., forming bromophenols such as lanosol). These metabolites may then protect the algae from herbivores and microbial colonization, in return for macrophyte supply of nutrition to the fungus.

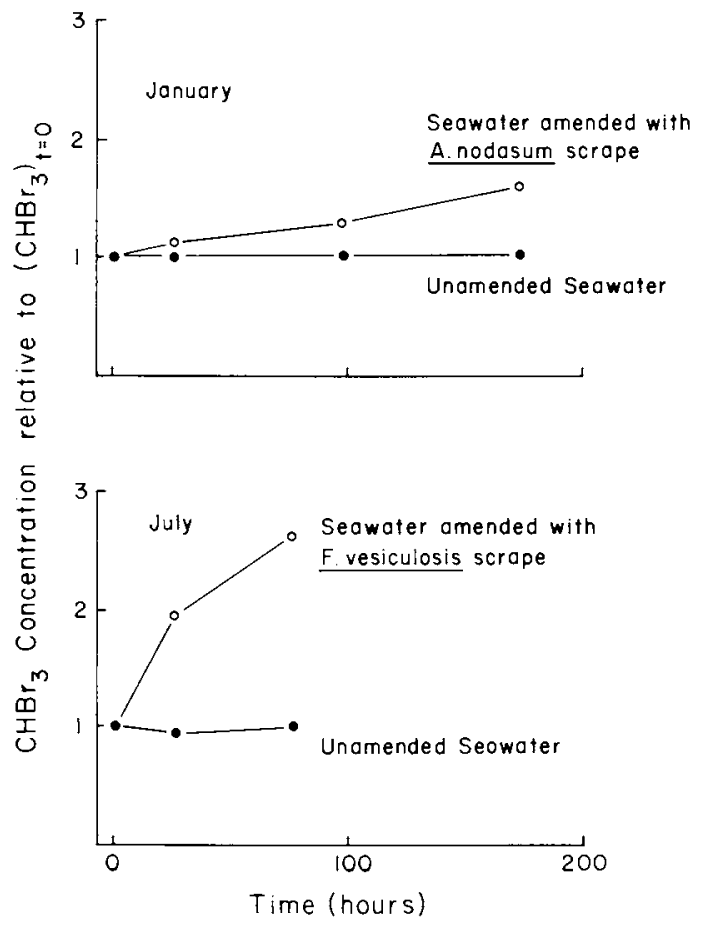

Figure 3. Production of $\mathrm{CHBr}_{3}$ in seawater with and w1thout macroalgae surface material added. 


\section{SUMMARY}

Polybromome thanes $\left(\mathrm{CHBr}_{3}, \mathrm{CHBr}_{2} \mathrm{Cl}, \mathrm{CH}_{2} \mathrm{Br}_{2}\right.$ ) were found to be released yearround from two common rockweeds, A. nodosum and $F$. vesiculosis, or their closely associated microflora. Th1s biologicalsource appears sufficient to support parts per trillion levels of these halogenated organic compounds in nearby seawater. Several ines of evidence Indicate that epiphytic fungl may actually accomplish the polybromome thane blosynthes18. Future research clarifying the genesis and functions of these volatile brominated compounds 18 surely warranted.

\section{L1 terature C1 ted}

1. Fenical, W. J. Phycol. 1975, 11, 245.

2. Moore, R.E. Acc. Chem. Res. 1977, 10, 40 .

3. Hewson, W.D.; L.P. Hager.J. Phycol. 1980, 16, 340.

4. Lovelock, J.E.; R.J. Magg8; R.J. Wade. Nature 1973, 256, 193.

5. Lovelock, J.E. Na ture $1975,256,193$.

6. Dryssen, D.; E. Fogelqu1st. Oceanol. Acta 1981, 4, 313.

7. Gschwend, P.M.; J.K. MacFarlane; K.A. Newman. Sclence 1985, $227,1033$.

8. Helz, G. In "Hydrocarbons and Halogenated Hydrocarbons in the Aquat1c Environment"; B.K. Afghan and D. Mackay, EdB.; Plenum Press: New Jersey, 1980; Pp. 435-444.

9. Fogelquist, E.; B. Josefsson; C. Roos. Environ. Sc1. Technol. $1982,16,479$.

10. C1cerone, R.J. Rev. Geophys. Space Phys. 1981, 19, 123.

11. "Standard Methods for the Examination of Water and Was tewater," American Public Health Association, 1980.

12. Bellar, T.A.; J.J. L1chtenberg. J. Amer. Water Works Assoc. $1974,66,739$.

13. Grob, K.; F. Zurcher. J. Chromatogr. 1976, 117, 285.

14. Conover, J.T. Publ. Inst. Mar.Sc1. 1958, 5, 97.

15. Math1eson, A.C. ; J.W. Sh1pman; J.R. O'Shea; R.C. Hasevlat. J. Exp. Mar. B101. Ecol. 1976, 25, 273.

16. Ragan, M.A.; A. Jensen. J. Exp. Mar. B1ol. Ecol. 1978, 34, 245.

17. Chock, J.S.; A.C. Mathieson. Bot. Mar1na 1983, 26, 87 .

18. Kaczmar, S.W.; F.M. D'Itr1; M.J. Zabik. Env1ron. Toxicol.

Chem. $1984,3,31$.

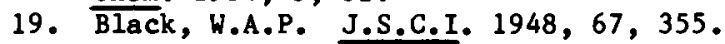

20. Black, W.A.P. J.S.C.I. 1949, 68, 183 .

21. V1lter, H.; K.-W. Glomb1tza; A. Grawe. Bot. Marina 1983, 26, 331.

22. V11ter, H. Bor. Mar1na 1983, 26, 429.

23. Chan, E.S.C.; E.A. McManus. Can. J. Microb1ol. 1969, 15, 409.

24. Sleburth, J. McN.; J.L. Tootle. J. Phycol. 1981, 17, 57.

25. Seshadr1, R.; J. McN. S1eburth. Mar. B10l. 1975, 30, 105.

26. Kohlmeyer, J.; E. Kohlmeyer. Bot. Mar1na 1972, 15, 109.

27. Pederson, M.; N. Fr1es. Z. Pflanzenphys101. 1977, 82, 363.

28. Pederson, M.; L. Fries. Z. Pflanzenphys101. 1972, 74, 272.

29. Sluda, J.F.; J.F. DeBernard18. Lloyd1a 1973, 36, 107.

RECEIVED September 16, 1985 


\title{
Biogeochemical Cycling of Sulfur
}

\author{
Thiols in Coastal Marine Sediments
}

\author{
Kenneth Mopper and Barrie F. Taylor \\ Division of Marine and Atmospheric Chemistry, Rosenstiel School of Marine and \\ Atmospheric Science, University of Miami, Miami, FL 33149-1098
}

\begin{abstract}
Thiols are major intermediates in the microbial cycling of sulfur and, because of their high reactivity, they may also play important roles in geochemical processes. Preliminary studies using a new, highly sensitfve HPLC assay revealed that thiols are present at concentrations up to $100 \mu \mathrm{M}$ in intertidal marine sediments from Biscayne Bay (FL). Methanethiol (MeS) and 3-mercaptopropionate (MP) were the major thiols found. The presence of the latter compound suggests that, in addition to protein degradation, anaerobic decomposition of dimethylpropiothetin (DMPT), a major sulfur compound of marine algae and higher plants, may be an important source of thiols and a significant degradation pathway for DMPT in the environment. Acrylic acid produced from this pathway readily adds HS across the double bond, via Michael addition, to form 3-mercaptopropionate. Alternatively, this thiol may be formed directly from DMPT by successive anaerobic demethylations; however the biochemical feasibility of this pathway is presently not known. Addition of a specific disulfide cleaving reagent to sediments revealed that thiols are dominantly present in bound forms. Binding of thiols to sediment particles may be an important mechanism for the incorporation of organic sulfur into geopolymers.
\end{abstract}

Diagenesis of organic matter in the water column and sediments results in the production of a wide variety of organosulfur compounds. Most studies involving these compounds in the marine environment have focussed on gaseous and hydrophobic species (1). In contrast, information regarding reduced, hydrophilic sulfur organics, in particular the thiols (general formula $\mathrm{R}-\mathrm{SH}$, where $\mathrm{R}$ is an organic group), is almost nonexistent.

0097-6156/86/0305-0324\$06.00/0

(c) 1986 American Chemical Society

In Organic Marine Geochemistry; Sohn, M.; 
Thiols, or sulfhydryl compounds, play important biochemical roles in maintaining macromolecular structures, binding metals at active sites of enzymes and electron transport components, capturing and detoxifying metals, and serving as coenzymes. In aquatic sediments these compounds arise during microbial processes of sulfate reduction and lithotrophic oxidation (oxic and anoxic), and from biodegradation of organic matter $(2,3)$. Abiotic sources of thiols include reactions of dissolved organic matter with $\mathrm{H}_{2} \mathrm{~S}$ and elemental sulfur present in pore water and on particle surfaces $(\underline{4,5,6)}$.

Functional group, spectrophotometric, electrochemical and elemental analyses have shown the presence of significant concentrations of thiols and other organo sulfur compounds in anoxic marine waters and sediments $(5,7-10)$. For example, using polarographic techniques, Luther et a1. (10) reported that thiols were the major reduced sulfur species, either inorganic or organic, in the porewaters of saltmarsh sediments (Great Marsh, Lewes, DE) with total concentrations up to $2.4 \mathrm{mM}$. The high concentrations and the high chemical reactivity of thiols strongly suggest that these compounds play a major role in the early diagenesis of organic matter in sediments, as well as in the incorporation of sulfur into organic geopolymers. For example, thiols readily react to form disulfide and polysulfide bridges (5), which may enhance the crosslinking and, hence, the molecular weight of organic matter in sediments. In addition, thiols form strong complexes with metal ions, especially transition metals (5), and may promote the mobilization of metals, e.g. arsenic (11). It is likely that through complexation with metals on particle surfaces that thiols also become strongly bound.

Despite the biogeochemical significance of thiols, relatively little is known about the nature and distribution of these species in sediments. Therefore, with the aid of a newly developed analytical method, a study was initiated to explore the role that thiols play in the marine sedimentary sulfur cycle. Some of the questions addressed were: (1) What thiols are present in sediments? (2) What are the possible formation pathways; that is, what is the relative importance of biological (e.g. microbial) versus nonbiological (e.g. chemical reactions) sources for thiols in sediments? (3) Are thiols bound to sediment particles and (4) What is the nature of the binding? The major findings and conclusions of this initial study are presented in this report.

\section{Experimental}

Thiols, as well as sulfide and sulfite, were determined in porewater samples by reversed phase high performance liquid chromatography (HPLC). The technique is based on precolumn derivatization with an o phthalaldehyde/amine reagent (Figure 1) followed by HPLC and fluorometric detection. Derivatized porewater samples were injected directly into the HPLC system; the detection 1 imit is $0.1 \mathrm{nM}$ (for 100 ul injection). Details of the method are given in Mopper and Delmas (12).

Intertidal Biscayne Bay (FL) sediments were periodically collected (using glass jars) during June through September of 1984 . A total of 27 samples were taken during this period. Slurries were 
prepared using two parts sediment and one part deaerated seawater $(\mathrm{V} / \mathrm{V})$. The slurries $(\sim 500 \mathrm{ml})$ were stored at $25^{\circ} \mathrm{C}$ under argon $1 \mathrm{n}$ glass jars. Background data for typical sediment samples are given in Table I.

Table I. Typical Background Data on Intertidal B1scayne Bay Sediments

\begin{tabular}{|c|c|c|c|c|c|}
\hline Date & $\begin{array}{c}\text { Porewater } \\
\mathrm{pH}\end{array}$ & $\begin{array}{c}\text { Size Fraction } \\
\mu \mathrm{m}\end{array}$ & $\begin{array}{l}\% \text { Dry } \\
\text { Sediment }\end{array}$ & $\underset{\%}{\mathrm{CaCO}_{3}}$ & $\underset{\%}{\operatorname{Organic}} \mathrm{C}$ \\
\hline Aug. 1, 1984 & 7.4 & $\begin{array}{l}\phi>300 \\
300<\phi>63 \\
63<\phi\end{array}$ & $\begin{array}{r}72.3 \\
20.1 \\
7.6\end{array}$ & $\begin{array}{l}64.8 \\
39.9\end{array}$ & $\begin{array}{l}\text { N.A. } \\
1.53\end{array}$ \\
\hline Aug. 8, 1984 & 7.4 & $\begin{array}{l}\phi>300 \\
300\langle\phi\rangle 63 \\
63\langle\phi\end{array}$ & $\begin{array}{r}74.1 \\
16.1 \\
9.8\end{array}$ & $\begin{array}{l}64.1 \\
37.7\end{array}$ & $\begin{array}{l}\text { N.A. } \\
1.34\end{array}$ \\
\hline Aug. 24,1984 & 7.5 & $\begin{array}{l}\phi>300 \\
300\langle\phi\rangle 63 \\
63\langle\phi\end{array}$ & $\begin{array}{r}69.7 \\
22.3 \\
8.0\end{array}$ & $\begin{array}{l}58.1 \\
41.7\end{array}$ & $\begin{array}{l}\text { N.A. } \\
1.76\end{array}$ \\
\hline
\end{tabular}

N.A. = not analyzed; $\phi=$ medium grain size .

Prior to thiol analysis, slurries were allowed to settle and a $2 \mathrm{ml}$ aliquot of the supernatant was filtered $(0.2 \mu \mathrm{m}$, Nucleopore) and derivatized. Some sediment slurries were treated with a specific $S-S$ cleaving reagent, tributylphosphine (13), in order to evaluate the degree to which thiols were bound via disulfide linkages. The reagent was added to a final concentration of $0.5-1.0 \mathrm{~m} 1$ per 11 ter slurry.

Results and Discussion

Identification of Thiols in Marine Sediment Porewaters. Thiols were present at significant levels (up to about $100 \mu \mathrm{M}$ ) in anoxic, intertidal Biscayne Bay sediments during the entire sampling period. The concentrations found were similar to those reported for other low molecular welght organics in sediment porewaters (Table II). More than 30 individual thiols were detected of which 13 were positively or tentatively identifled (Figure 2 and Table III). Peaks were 1dentified by co-1njection with authentic compounds under different chromatographic and derivatization conditions, as outlined in Figure 3. For example, altering the $\mathrm{pH}$ of the mobile phase was particularly effective for the identification of carboxylated thiols, such as 3 -mercaptopropionate, because protonation of the carboxy group selectively enhanced the retention of these compounds. 


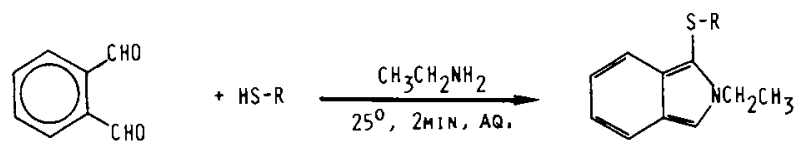

O-Phthalaldehyde Thiol Isoindole

F1gure 1. Fluorescence derivatization of thiols; the excitation and emission maxima of the fluorescent isolndole product are at $340 \mathrm{~nm}$ and $450 \mathrm{~nm}$ respectively (12).
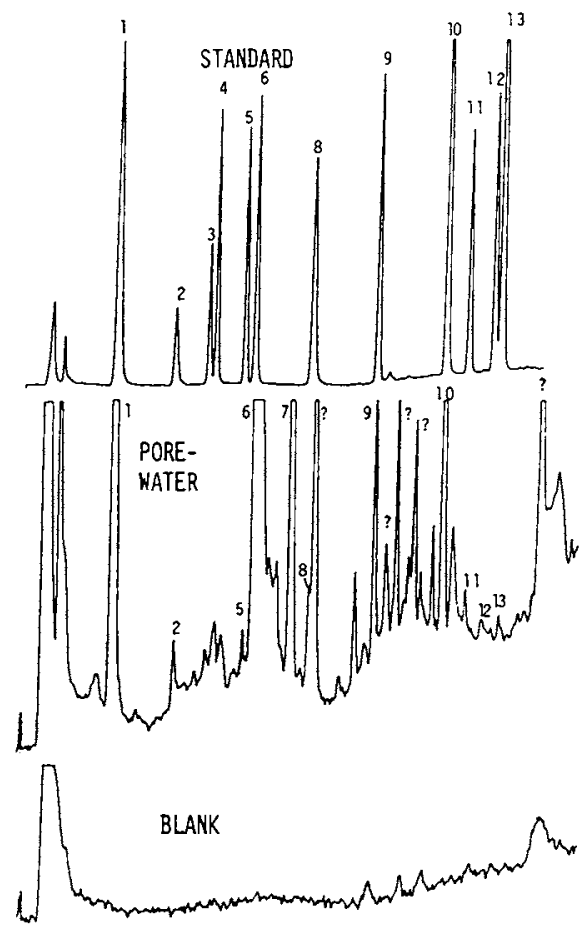

F1gure 2. Upper: Gradient separation of ophthalaldehyde derivatives of 11 thiols and sodium sulfite according to Mopper and Delmas (12). Peaks: (1) sodium sulfite (100 pmo1); (2) glutathlone (7 pmol); (3) thloglycollate (200 pmo1); (4) $\mathrm{N}$-acetylcyste1ne ( $7 \mathrm{pmol}$ ); (5) 2 -mercaptoethanesulfonate (Co-11) (10 pmol); (6) 3-mercaptopropionate (10 pmol); (8) monoth1oglycerol (10 pmol); (9) 2 mercaptoethanol (10 pmol); (10) methanethiol (15 pmol); (11) ethanethiol (10 pmol); (12) 2 propanethiol (15 pmol); (13) 1 propanethiol (15 pmol). Middle: Thiols in porewater in reducing sediment slurry from Biscayne Bay. Porewater water was filter-sterilized prior to derivatization. Peak 7: sulfide (Note: response factor is about 200 times lower than for thiols). Lower: reagent blank in porewater matrix.

In Organic Marine Geochemistry; Sohn, M.;

ACS Symposium Series; American Chemical Society: Washington, DC, 1986. 
Table II. Concentration Range of Thiols in Comparison to Other Low Molecular Weight Organics in Sediment Porewaters

\begin{tabular}{lll}
\hline Compounds & Typical Concentrations & Reference \\
\hline Thiols & $0.1-100 \mu \mathrm{M} ; 0.1-2.4 \mathrm{mM}$ & $\begin{array}{l}\text { This work and } \underline{10} \\
\text { respectively }\end{array}$ \\
Sugars & $0.2-2 \mu \mathrm{M}$ & $\underline{33}, \underline{34}$ \\
Amino Acids & $1-200 \mu \mathrm{M} \star$ & $\underline{35}, \underline{36}$ \\
F $_{\text {LMW Carboxylic }}$ & $1-30 \mu \mathrm{M}$ & $\underline{37}, \underline{38}$ \\
Acids & $0.1-5 \mu \mathrm{M}$ & $\begin{array}{l}\text { Mopper } \\
\text { (unpublished) }\end{array}$ \\
LMW Carbonyls & &
\end{tabular}

* Note: The highest value was measured in Thioploca mats underlying the Peru upwelling. Maximum amino actd concentrations found in typical marine sediments are $10-20 \mathrm{uM}$.

F LMW = Low molecular weight.

Table III. Thiols Identifled in Slurries of Marine Sediments

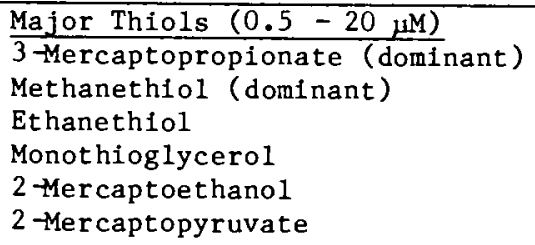

Minor Thiols $(<0.5 \mu \mathrm{M})$

Mercaptoacetate (thioglycollate)

Glutathione

Coenzyme M (2 mercaptoethanesulfonate)

1 -Propanethiol

2 Propanethiol

$\mathrm{N}$-Ace tylcysteine

2 -Mercaptopropionate

Unknowns

At least 20 unknown thiols, including 4 or 5 which are major.

Methanethiol (MeS) and 3 mercaptopropionate (MP) were by far the dominant thiols (Figure 2). Biochemical formation pathways are feasible for these thiols, although the importance of these pathways relative to abiotic pathways is presently unknown, especially for 3 -mercaptopropionate, as summarized in Figure 4. The relative importance of these pathways are discussed in the following sections. 
Change chemical structure of the fluorescent derivative:<smiles>[R]Sc1c2ccccc2cn1CCO</smiles>

ETHANOLAMINE DERIVATIVE<smiles>[R]Sc1c2ccccc2cn1C</smiles>

MethyLAMINE DERIVATIVE<smiles>[R]Sc1c2ccccc2cn1C(C)C(=O)O</smiles>

ALANINE DERIVATIVE

LOWER PH OF MOBILE PHASE RESULTING IN PROTONATION OF CARBOXY GROUP:

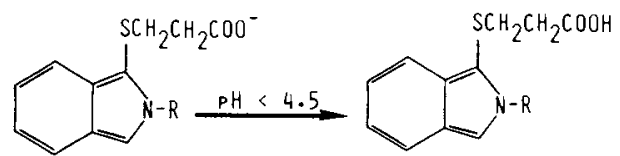

Figure 3. Identification of thiols in sediments by altering chromatographic selectivity.

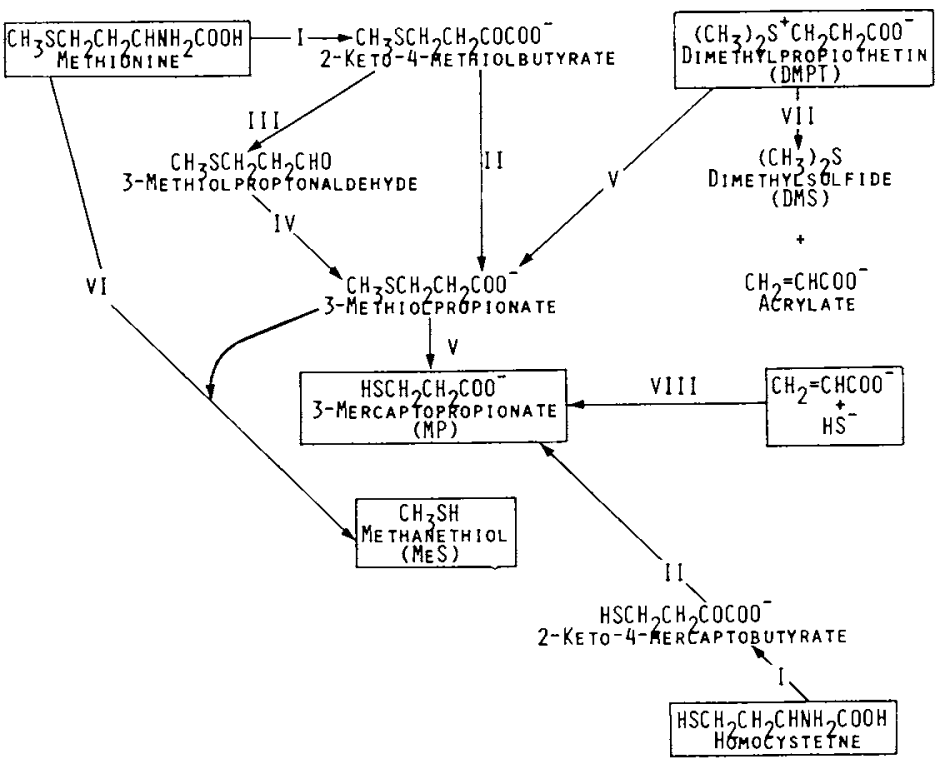

Figure 4. Possible routes for the formation of 3 -mercaptopropionate and methanethiol. $I=$ oxidative deamination or transamination; II. Oxidative decarboxylation; III. Nonoxidative decarboxylation; IV. Oxidation; V. Demethylation; VI. Demethiolation; VII. Aerobic/anaerobic catabolism; VIII. Michael addition.

In Organic Marine Geochemistry; Sohn, M.;

ACS Symposium Series; American Chemical Society: Washington, DC, 1986. 
Microblal Production of Thiols. Sulfur contalning amino acids have been shown to be 1mportant precursors of thiols in many environments, including sediments $(14-17)$. B1scayne Bay sediments are not likely to be an exception. Thus, methionine degradation might contribute to the production of methanethiol and 3 -mercaptoproplonate (the major thiols detected in the porewaters, Table III). Microbes in anoxic environments, specifically the rumen and lake sediments, convert methionine to methanethiol (14-17). Oxidative deamination or transamination of methionine, followed by oxidative decarboxylation, yields 2 -keto-4 methiolbutyrate and then 3 methiolpropionate (18); subsequent demethylation would produce 3 mercaptopropionate (F1gure 4). Sim1lar mechan1sms, but without the necessity for a final demethylation reaction, could convert homocysteine into 3 -mercaptoproplonate via 2 -keto-4th1olbutyrate (F1gure 4). The pathway from homocysteine would be analogous to that from cysteine to 2 -mercaptoacetate via 3 -mercaptopyruvate (18). Ethanethiol (Table III) might be derived from S-ethylcysteine or ethionine (19). Alkylated thiols, other than methanethiol and ethaneth1o1, could be derived from elther alkylated analogs of methionine or via mechanisms involving reductive deaminations and nonoxidative decarboxylations.

While amino acids are undoubtedly important precursors of thiols, in coastal marine habitats dimethylproplothetin (DMPT) is probably also an 1mportant precursor because of 1 ts high intracellular concentrations (up to $300 \mathrm{mM}$ ) in algae and seagrasses $(20,21)$. D1methylproplothetin is degraded under oxic conditions by bacterial and algal enzymes ylelding principally acryllc acid and dimethylsulfide (DMS) $(19,22,23)$ :

$$
\underset{\text { DMPT }}{\left(\mathrm{CH}_{3}\right)_{2} \mathrm{~S}^{+} \mathrm{CH}_{2} \mathrm{CH}_{2} \mathrm{COO}^{-} \longrightarrow \underset{3}{\longrightarrow} \underset{\text { DMS acrylic actd }}{\mathrm{CH}_{3} \mathrm{SCH}_{3}+\mathrm{CH}_{2}=\mathrm{CHCOOH}}}
$$

DMS is also generated during anaerobic fermentation of dimethylproplothetin (24) and was detected as the principal volatile sulfur compound evolved from salt marsh flats (25). Therefore, 1t 18 reasonable to hypothesize that DMPT, 1s also a major precursor for other organosulfur compounds, e.g. thiols, in anoxic marine sediments. However, no studies have been reported on the microbial production of thiols from this compound. Hypothetical formation pathways for methanethiol and 3 -mercaptopropionate from DMPT are given in Figure 4. Two successive demethylations of DMPT would yield 3-methiolpropionate and 3-mercaptopropionate. The first demethylation of dimethylpropiothetin 1s blochemically feasible; for example, homocysteine can accept a methyl-group from DMPT, in a reaction analogous to that involving dimethylthetin $(26)$, to yield methionine and 3-methiolpropionate (27). The second demethylation, that of 3 -meth1olpropionate, has not been demonstrated but it might be catalyzed by methanogenic and/or acetogenic bacteria. Methyl transfer reactions from methylated sulfur substrates could operate and involve cobalamine-containing enzymes as shown for methanol (28) and postulated for methylamines and methoxy-aromatic molecules $(29,30)$. Finally, 3-methlolpropionate $1 \mathrm{~s}$ a known precursor of methaneth1o1 (18). 
Ablotic Production of Thiols. While the formation pathway of 3 -mercaptopropionate from successive demethylations of DMPT remains to be proven, DMPT may nonetheless be an 1mportant precursor of this thiol by a less speculative pathway involving established reactions. The first reaction is the anaerobic cleavage of DMPT to DMS and acrylic acld (reaction VII, Figure 4). If this reaction occurs in the sulfate reducing zone, acrylic acld will then rapidly react with HS (a powerful nucleoph1le) by adding it across the double bond via the we11 known Michael addition reaction (31) (Figure 4). In the past, this reaction has been studied at high concentrations of reactants and in the absence of water (32). Therefore, the environmental relevance of this reaction $1 \mathrm{~s}$ questionable.

Several experiments were performed to examine this possible reaction. Acrylic acld and sodium sulfide were added to deaerated, aged Gulf Stream seawater to final concentrations of $0.1 \mathrm{mM}$ and 1.0 $\mathrm{mM}$, respectively. Controls consisted of seawater alone, seawater plus acrylic acid, and seawater plus sodium sulfide. The reaction was run at $\mathrm{pH} 8.2-8.4$ under argon at $25^{\circ} \mathrm{C}$ and $60^{\circ} \mathrm{C}$. After two hours, allquots were removed for thiol analysis by HPLC. On1y two thiols were detected, of which 3 mercaptopropionate, the expected product, was one. The 1dentity of the other thiol has not been established. Controls showed negligible th1ol production (Figure 5). The apparent yleld of the reaction (\% acrylic acid converted to 3 -mercaptoproplonate) was about $1-2 \%$ at $60^{\circ} \mathrm{C}$ and $0.3-0.4 \%$ at $25^{\circ} \mathrm{C}$. Addition of tributylphosphine, a disulfide cleaving reagent, to the reaction mixture efther before or after the 2 hour incubation, increased the thiol yleld by about a factor of two. These results suggest that abiotic reactions may indeed be responsible for the formation of some thiols in the environment and that thiols oxidize rapidly to form disulfide compounds even under reducing conditions. A kinetic study of the Michael reaction in seawater is currently being undertaken.

In order to provide additional evidence in support of the proposed Michael addition reaction, a sediment study was also performed. Acrylic acid was added directly to slurries of reducing sediments from Blscayne Bay and the formation of 3 -mercaptoproplonate in the porewater, relative to unsplked controls, was monitered by HPLC. The concentration of added acrylic acid was 0.1 mmol per liter slurry ( $0.2 \mathrm{mM}$ in the porewater) and the slurries were 1 ncubated under argon at $37^{\circ} \mathrm{C}$ for 2 hours prior to thiol analysis. Figure 6 clearly shows that addition of acrylic acid to reducing sediment gives rise to 3 mercaptopropionate, the main product expected from the Michael addition of HS to acryllc acid.

The addition of $\mathrm{H}_{2} \mathrm{~S}$, traces of which will be present at the $\mathrm{pH}$ of the porewater (Table I), to acryllc acld probably follows the Markownikoff addition rule to yleld 2 -mercaptopropionate:

$$
\mathrm{H}_{2} \mathrm{C}=\mathrm{CHCOO}^{-}+\mathrm{H}_{2} \mathrm{~S} \longrightarrow \mathrm{H}_{3} \mathrm{C}_{\mathrm{SH}}^{\mathrm{CHCOO}}{ }^{-}
$$

In fact, 2 -mercaptoproplonate was tentatively 1dentified (at trace concentrations) in some Biscayne Bay sediments (Table III).

It is tempting to conclude from these studies that ablotic reactions play a major role in the formation of thiols in sediments. 


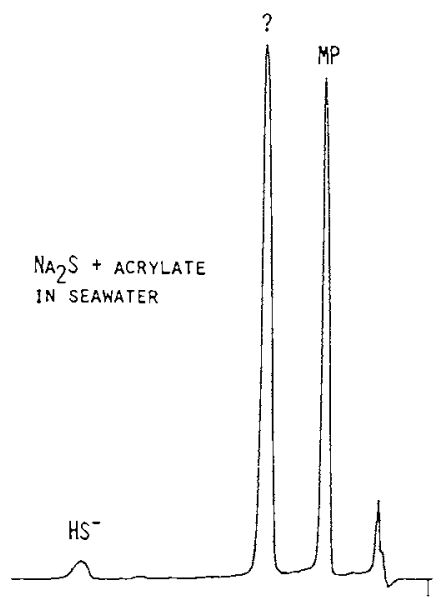

NA 2 S ALONE

IN SEAWATER

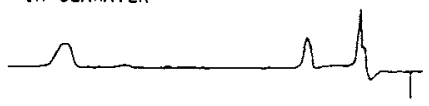

SEAWATER ALONE

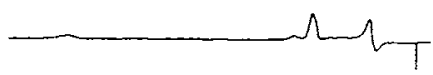

Figure 5. Upper: Abiotic production of 3 -mercaptopropionate (MP) and an unknown thiol (?) in deaerated seawater from reaction of acrylic acid $(0.1 \mathrm{mM})$ with sodium sulfide $(1.0 \mathrm{mM})$ at $60^{\circ} \mathrm{C}$ for 2 hours under argon; detection by fluorescence derivatization and HPLC. Middle: Control = sodium sulfide $(1.0 \mathrm{mM})$ alone in seawater under identical reaction conditions as above. Lower: Control = seawater alone under identical reaction conditions as above.

In Organic Marine Geochemistry; Sohn, M.; ACS Symposium Series; American Chemical Society: Washington, DC, 1986. 


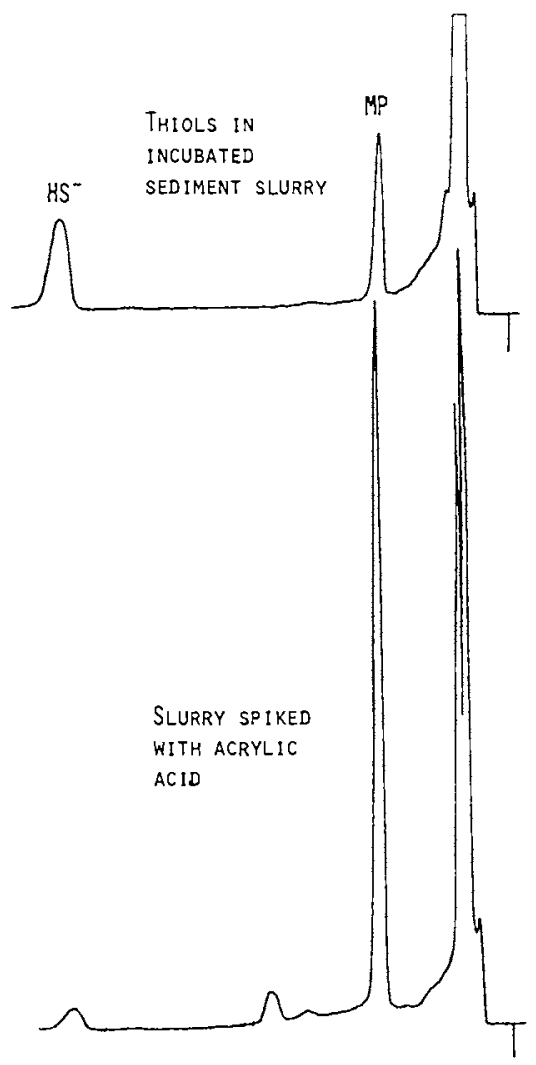

Figure 6. Upper: 3 -mercaptopropionate (MP) and hydrogen sulfide (HS) present in aqueous phase of Biscayne Bay sediment incubated at $37^{\circ} \mathrm{C}$ for 2 hours under argon; detection by fluorescence derivatization and HPLC; the large initial peaks are probably humic substances. Lower: Allquot of same sediment slurry sample incubated under the same conditions as above but with added acrylic acid ( 10 pmole per $100 \mathrm{ml}$ slurry); note increase in 3 -mercaptoproplonate and decrease in $\mathrm{HS}^{-}$.

In Organic Marine Geochemistry; Sohn, M.;

ACS Symposium Series; American Chemical Society: Washington, DC, 1986. 
While this may be true for 3-mercaptopropionate, the actual importance of these reactions relative to microblal production of thiols can only be properly assessed with tracer experiments using radiolabelled substrates and reactants.

Release of Bound Thiols. Tributylphosphine quantitatively and rapidiy reduces disulfides to thiols and, by maintaining reducing conditions, prevents their reoxidation (13):

$$
\mathrm{R}^{\prime}-\mathrm{S}-\mathrm{S}-\mathrm{R}+\left(\mathrm{C}_{4} \mathrm{H}_{9}\right)_{3} \mathrm{P}+\mathrm{H}_{2} \mathrm{O} \longrightarrow \mathrm{R}^{\prime} \mathrm{SH}+\mathrm{RSH}+\left(\mathrm{C}_{4} \mathrm{H}_{9}\right)_{3} \mathrm{P}=0
$$

Although this reagent had only been used in the past to preserve standard thiol solutions, it was felt that it could also be employed to quantify the relative amounts of $-s-s-$ bound thiols in sediments. However, since tributylphosphine had not been previously used in seawater media, a preliminary test was performed to evaluate its chemical behavior under these conditions. Dimethyldisulfide and oxidized glutathione were added to seawater to a final concentration of $1 \mu \mathrm{M}$ each. Tributylphosphine was added $(0.5 \mathrm{ml}$ per 11 ter seawater) and the samples were incubated at $25^{\circ} \mathrm{C}$ in the presence of a1r. Aliquots were perlodically removed for thiol analysis. After $20 \mathrm{~min}, 95 \%$ of the disulfides were reduced to thiols (Figure 7 ). The thiols were stable for three days even in the presence of air. After this period, reoxidation occurred probably due to loss of the excess and protective phosphine by reaction with oxygen. From these tests 1t was concluded that the phosphine reagent could be used to study the relative abundance of free versus $-s-s-$ bound thiols in reducing sediments.

Sediment slurries were incubated at $30^{\circ} \mathrm{C}$ (approximate in situ temperature) with and without tributylphosphine. Aliquots of porewater were perlodically removed for thiol analysis over the following 2-4 days. During the course of this study, a total of 7 such incubations were performed on freshly collected sediment. Results were similar in all cases and typically showed that tributylphosphine induced a dramatic and rapid release of bound (or oxidized) thiols (Table IV and Figure 8). Bound thiols were present at approximately 20 times greater concentrations than free thiols (1.e., $\sim 95 \%$ of all thiols released from sediment were initially bound). If air is not excluded during the incubation, released thiols become reoxidized after several days (Figure 8) probably due to the oxidation of the protective phosphine. Addition of fresh tributylphosphine regenerated the thiols.

Addition of tributylphosphine to extracted porewater (particle free) resulted in only a minor increase in thiol concentrations. This result indicates that the dramatic increases obtained with slurries (Table IV and Figure 8) are probably due to release of thiols bound to particle surfaces, as opposed to release from disulfides dissolved in the interstial water.

Surface binding is most 11kely through $-S-S-11$ nkages, but $1 t$ is also concelvable that some fraction of the released thiols may be due to displacement of thiols from metal complexes on particle surfaces by the phosphine nucleophile. However, when an equivalent amount of a strong metal complexing agent (EDTA) was substituted for the phosphine, only negligible releases of thlols were observed, suggesting that, for the sediments studied, binding by metal 
I M Glutathione (OX.)
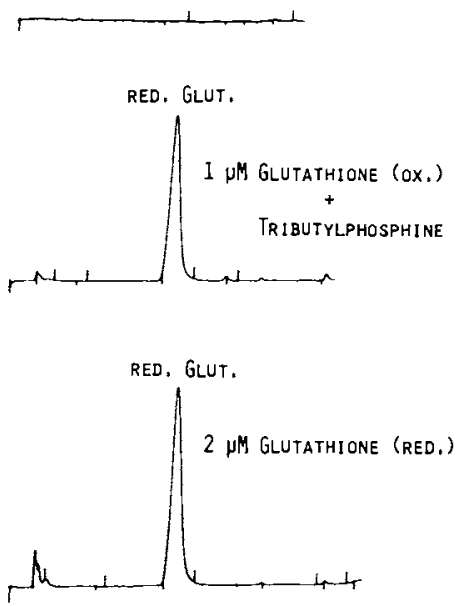

Figure 7. Cleavage of oxidized glutathione in seawater by tributylphosphine to yield reduced glutathione (red. Glut.); detection by fluorescence derivatization and HPLC. Upper: oxidized glutathione $(1 \mu \mathrm{M})$ alone. Middle: Oxidized glutathione $(1 \mu M)$ plus tributylphosphine $(50 \mu \overline{1 / 100 m i}$ seawater $)$ reacted for

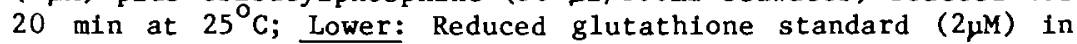
seawater.

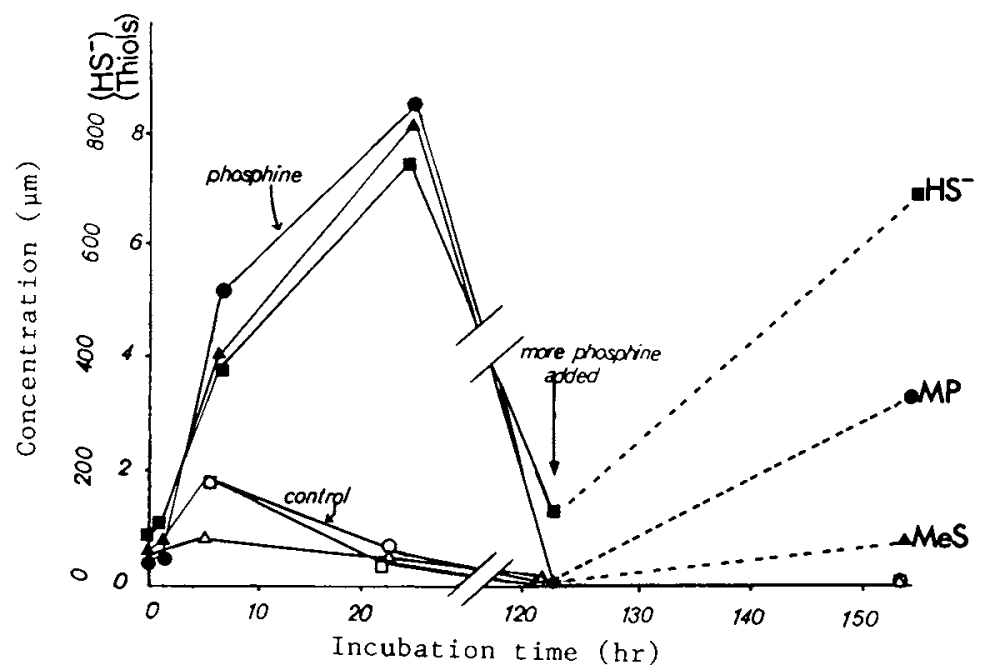

Figure 8. Release of thiols ( 3 -mercaptopropionate - MP and methanethiol - MeS) and HS upon addition of tributylphosphine $(50 \mu 1$ per $100 \mathrm{ml}$ slurry) to a Biscayne Bay sediment slurry; incubated at $25^{\circ} \mathrm{C}$; control slurries received no tributylphosphine.

In Organic Marine Geochemistry; Sohn, M.;

ACS Symposium Series; American Chemical Society: Washington, DC, 1986. 
complexation may not be as important as binding by -s-S- bond formation. Specific methods for releasing metal bound thiols are being explored.

Table IV. Release of Bound Thiols from Sediment

\begin{tabular}{|c|c|c|c|c|}
\hline Incubated Sediment* & $\begin{array}{c}3 \text {-Mercaptopropionate } \\
(\mu \mathrm{M})\end{array}$ & $\begin{array}{l}\text { Methanethiol } \\
\qquad(\mu M)\end{array}$ & $\begin{array}{l}\mathrm{HS}^{-} \\
(\mathrm{mM})\end{array}$ & $\begin{array}{l}\mathrm{SO}_{3}= \\
(\mathrm{mM})\end{array}$ \\
\hline Control Slurry* & 0.19 & 0.05 & 4.24 & 0.071 \\
\hline $\begin{array}{l}\text { Slurry with } \\
\text { Tributylphosphine* }\end{array}$ & 6.53 & 1.31 & 6.16 & 0.033 \\
\hline$\%$ Thiol Bound* & $97 \%$ & $96 \%$ & $31 \%$ & $0 \%$ \\
\hline \multicolumn{5}{|c|}{$\begin{array}{l}\text { * } 8 / 24 / 84 ; \text { Biscayne Bay intertidal sediment incubated for } 23 \mathrm{~h} \text { at } \\
25^{\circ} \mathrm{C} \text {; thiols detected in the "control slurry" (no tributylphosphine } \\
\text { added) are interpreted as belng in the unbound (or free) state; } \\
\text { thiols detected in "slurry with tributylphosphine" are interpreted } \\
\text { as free plus bound species; the "\% thiol bound" was calculated from: } \\
\text { [(thiols in tributylphosphine treated slurry) - (thiols in control)] } \\
x 100 \% / \text { (thiols in tributylphosphine treated slurry). }\end{array}$} \\
\hline
\end{tabular}

Summary and Conclusions

Thiols are present at significant levels in reducing, intertidal sediments and apparently arise as a result of interacting biotic (microbia1) processes and ablotic reactions (Figure 9). Over 30 thiols were detected, of which methanethiol and 3 mercaptopropionate were present in the highest concentrations throughout the entire 4 month sampling period. Methanethiol can readily arise through a number of known anaerobic pathways; however, no such pathways have been reported for the formation of 3 mercaptopropionate. It can be speculated that this compound is produced by successive anaerobic demethylations of dimethylpropiothetin (DMPT), a major sulfur compound of marine algae and plants. On the other hand, the known anaerobic breakdown pathway of DMPT is via enzymatic cleavage to yield dimethylsulfide and acrylic acid. Acrylic acid is a highly reactive species and, in zones of active sulfate reduction, it will readily undergo a Michael addition with HS to yleld 3 -mercaptopropionate (Figure 6). If this reaction is in fact occurring in sediments and in the water column of anoxic basins, a number of important geochemical implications can be inferred. For every mole of DMPT hydrolyzed, up to two moles of organosulfur compounds (dimethylsulfide and 3-mercaptopropionate) are produced. If direct blological sources are indeed negligible for the latter compound, then 1 ts concentration and turnover may be used to estimate that of acrylic acid and indirectly that of DMPT hydrolysis 


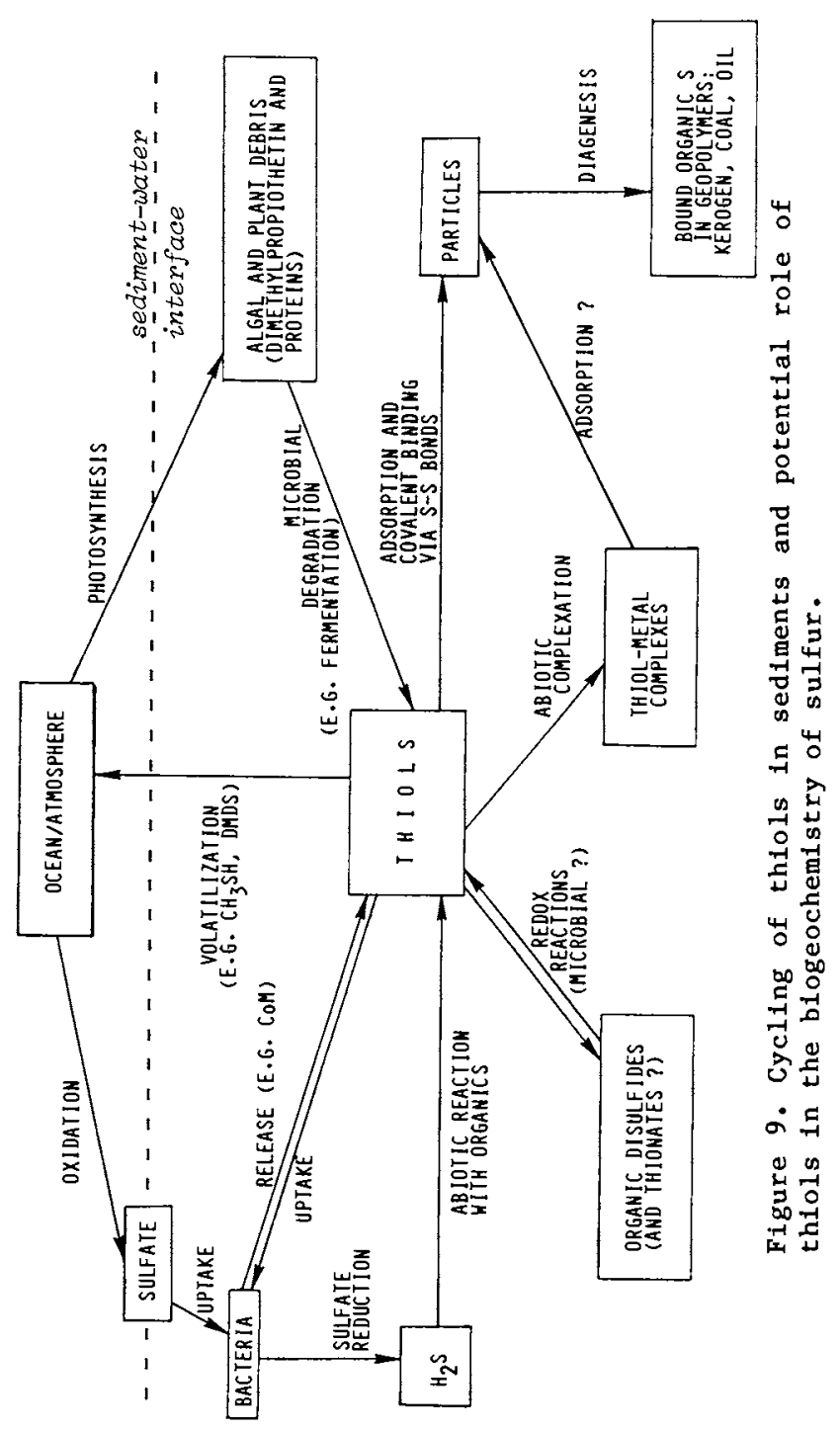

In Organic Marine Geochemistry; Sohn, M.; ACS Symposium Series; American Chemical Society: Washington, DC, 1986. 
in the environment. More generally, the results imply that a major chemical pathway for the incorporation of sulfur into organic geopolymers is by reaction of HS with reactive sites, e.g. olefinic double bonds, displaceable halogens (39), within sedimentary organic matter. The Michael addition reaction of $\mathrm{HS}^{-}$to acrylic acid may be used as a model case of such interactions.

Addition of a specific $\rightarrow-s-$ cleaving reagent, tributylphosphine, to reducing marine sediments resulted in a dramatic and rapid release of thiols into the porewater. The results showed that in the sediments studied bound thiols are present in at least 20 times greater concentration than freely dissolved thiols or disulfides. These results imply that another important route for the incorporation of sulfur into organic geopolymers may be binding of thiols to reactive sites (e.g., $\mathrm{R}-\mathrm{SH}$ groups and metal ions) on particles.

The results of this initial study indicate that thiols play an active role in the biogeochemical cycling of sulfur in marine sediments (Figure 9). Many questions remain to be addressed. In particular, how fast is the turnover of thiols in sediments and what organisms are involved? What fraction of sedimentary sulfur passes through the thiol pool? What are the precursors of the thiols? How do thiol-metal interactions affect the geochemistry (e.g. migration and binding) of heavy metals and thiols in sediments? How is biotic and ablotic production of thiols in porewaters related to the sulfur content and sulfur speciation within organic geopolymers?

\section{Acknowledgments}

We would like to thank R. Cuhel, G.R. Harvey, and G.E. Luther for valuable input regarding possible formation routes for thiols. Financlal support was provided in part by a grant from the National Institutes of Health (Blomedical Research Support Grant to K.M.) and from the National Science Foundation (OCE -8516020).

\section{Literature Cited}

1. Balzer, W. In "Marine Organic Chemistry"; Duursma, E.K.; Daws on, R., Eds.; Elsevier: Amsterdam, 1981; Chap. 13.

2. Trudinger, P.A. Phil. Trans. Roy. Soc. 1982, B298, 563-581.

3. Zinder, S.H.; Doeme1, W.N; Brock, T.D. App1. Environ. Microbiol. $1977,34,859-860$.

4. Altschuler, Z.S.; Schnepfe, M.M.; Silber, C.C.; Simon, F.0. Science $1983,221,221-227$.

5. Boulegue, J.; Lord, C.J.; Church, T.M. Geochim. Cosmochim. Acta $1982,46,453-464$.

6. Martin, T.H.; Hodgson, G.W. Chem. Geol. 1973, 12, 189-208.

7. Adams, D.D.; Richards, F.A. Deep-Sea Res. 1968, 15, $471-481$.

8. Nissenbaum, A.; Kaplan, I.R. L1mnol. Oceanogr. 1972, 17, $570-582$.

9. Dyrssen D.; Haraldsson, C.; Westerlund, S.; Aren, K. Mar. Chem., submitted.

10. Luther, G.W.; Church, T.M.; Giblin, A.E.; Howarth, R.W. In "Organic Marine Geochemistry"; Sohn, M., Ed.; ACS Symposium Series No. American Chemical Soclety: Washington, D.C., 1986; in press. 
11. Cullen, W.R.; McBride, B.C.; Reglinsk1, J. J. Inorg. Blochem. $1984,21,174-194$.

12. Mopper, K.; Delmas, D. Anal. Chem. 1984, 56, 2558-2560.

13. Humphrey, R.E.; Potter, J.L. Ana1. Chem. 1965, 37, 164-165.

14. Bird, R.P.; Moir, R.J. Aust. J.Biol. Sc1. 1972, 25, 835-848.

15. Salsbury, R.L.; Merricks, D.L. Plant Sol1 1975, 43, $191-209$.

16. Zikakis, J.P.; Salsbury, R.L. J. Dairy Sci. 1969, 52, 2014-2019.

17. Zinder, S.H.; Brock, T.D. Appl. Environ. Microbiol. 1978, 35, 344-352.

18. Cooper, A.J.L. Ann. Rev. Biochem. 1983, 52, 187-222.

19. Bremner, J.M.; Steele, C.G. Adv. Microblal Ecol. 1978, 2, $155-201$.

20. White, R.H. J. Mar Res. 1982, 40, 529-536.

21. Valravamurthy, A.; Andreae, M.0.; Iverson, R.L. Limnol. Oceanogr. 1985, 30, 59-70.

22. Canton1, G.L.; Anderson, D.G. J. Bio1. Chem. 1956, 222, $171-177$.

23. Kadota, H.; Ishida, Y. Ann. Rev. Microbiol. 1972, 26, 127-138.

24. Wagner, C; Stadtman, E.R. Arch. Blochem. Biophys. 1962, 98, $331-336$.

25. Aneja, V.P.; Overton, J.H., Jr.; Cupitt, J.T.; Durham, J.L.: Wilson, W.E. Tellus 1979, 31, 174-178.

26. Lehninger, A.L. "Biochemistry"; Worth: New York, 1975; 2nd Edition.

27. Maw, G.A.; du Vigneaud, V. J. Biol. Chem. 1948, 176, $1037-1045$.

28. Wood, J.M.: Moura, I.; Moura, J.G.G.; Santos, M.H.; Xavier, A.V.; LeGa11, J.; Scandellar1, M. Sclence 1982, 216, 303-305.

29. Naumann, E.; Fahlsbuch, K.; Gottscha1k, G. Arch. Microbiol. $1984,138,79-83$.

30. Tschech, A.; Pfennig, N. Arch. Microbiol. 1984, 137, 163-167.

31. Noller, C.R. In "Textbook of Organic Chemistry"; W.B. Saunders: Philadelphia, 1966; 3rd Edition; p. 619.

32. Dahlbom, R. Acta. Chem. Scand. 1951, 5, 690-698.

33. Mopper, K.; Dawson, R.; Llebezelt, G.; Ittekkot, V. Mar. Chem. $1980,10,55-66$.

34. King, G.M.; Klug, M.J. Appl. Environ. Microbiol. 1982, 44, $1308-1317$.

35. Henrichs, S.M.; Farrington, J.W.; Lee, C. Limnol. Oceanogr. $1984,29,20-34$.

36. Jorgensen, N.0.G.; Lindroth, P.; Mopper, K. Oceanolog. Acta $1981,4,465-474$.

37. Hordijk, K.A.; Cappenberg, T.E. App1. Environ. Microbiol. $1983,46,361-369$.

38. Ansbaek, J.; Blackburn, T.H. Microb. Ecol. 1980, 5, 253-264.

39. Schwarzenbach, R.P.; Giger, W.; Schaffner, C.; Wanner, 0. Environ. Sc1. Technol. 1985, 19, 322-327.

RECEIVED September 16, 1985 


\title{
Speciation of Dissolved Sulfur in Salt Marshes by Polarographic Methods
}

\author{
George W. Luther III ${ }^{1}$, Thomas M. Church ${ }^{2}$, Anne E. Giblin ${ }^{3}$, and Robert W. Howarth ${ }^{3}$ \\ ${ }^{I}$ Chemistry-Physics Department, Kean College of New Jersey, Union, NJ 07083 \\ ${ }^{2}$ College of Marine Studies, University of Delaware, Newark, DE 19716 \\ ${ }^{3}$ Ecosystems Center, Marine Biological Laboratory, Woods Hole, MA 02543
}

\begin{abstract}
Polarographic techniques are capable of measuring a variety of sulfur species. These species include thiosulfate, sulfite, polythionates, sulfide, organic sulphydryl groups and inorganic and organic polysulfides. All of these can be produced in salt marsh porewaters as a result of sulfate reduction and the consequent oxidation of sulfide and sulfide minerals. Other wet and instrumental methods generally are not capable of measuring all of these sulfur species or distingulshing between these species.

Sulfur speciation in the porewaters of two salt marshes (Great Marsh, Delaware and Great

Sippewissett, Cape Cod, Massachusetts) are presented. A major finding is that the porewaters from Great Sippewissett salt marsh are dominated by inorganic sulfur species throughout the depth profile. However, Great Marsh, Delaware porewaters are dominated by organic sulphydryl species at millimolar concentrations from the surface to $12 \mathrm{~cm}$ and by inorganic sulfur species below $12 \mathrm{~cm}$. Glutathione may be the thiol principally responsible for the field observations. The physical and geochemical characteristics of the two salt marshes differ widely and appear to be related to the differences in sulfur chemistry. There appears to be an interconversion between the Inorganic and organic forms of sulfur in Great Marsh. Pyrite oxidation may be important to the formation of thiols.
\end{abstract}

Sulfur can form a number of inorganic and organic species with oxidation states varying from -2 to +6 and as a result undergoes a variety of biogeochemical transformations in the estuarine environment. Target compounds or ions for study in the dissolved phase

$0097-6156 / 86 / 0305-0340 \$ 06.00 / 0$

๑ 1986 American Chemical Society 
are sulfate, sulfide, polysulfide $[S(-2)$ and $S(0)]$, thiosulfate, sulfite, polythionates and organic compounds such as thiols. Most research over the last several years has shown that sulfur species with intermediate oxidation states are present in porewaters in substantial quantities and are important to many biogeochemical processes $(\underline{1}-\underline{8})$.

In particular, the partially oxidized forms of sulfur may be produced by a variety of reactions including the oxidation of hydrogen sulfide $(\underline{1}, \underline{2})$, the reductive dissolution of goethite $(\underline{3})$, the oxidation of sulfide minerals(4) and microbial processes $(\underline{5})$. Inorganic polysulfides are important to metal cycling( 6 ) and to pyrite formation( 7 ). Thiosulfate as well as polysulfides have been linked to energy export in salt marsh ecosystems(

The formation of organic sulfur compounds in salt marsh porewaters is not as wel1 understood(11) as the inorganic moieties although progress has been made in coastal marine sediments(12). Their presence as thiols and alkyl sulfides has been determined but generally in trace amounts $(12-16)$. The importance of these trace organic sulfur compounds to atmospheric sulfur emissions is presently an area of intense research $(14,15)$. Less appears to be known about organic sulfur compounds in salt marsh porewaters.

Traditional techniques to measure dissolved sulfur in marine porewaters are iodometric titrations and colorimetric methods based on methylene blue color development. However, these methods(17-19) are not capable of measuring a wide variety of sulfur species or distinguishing between sulfur species. Major sulfur species are defined as those with concentrations typically greater than $10 \mathrm{uM}$. Iodometric titrations can determine sulfur in -1 and -2 oxidation states as shown in equations (1) through (4). However, these titrations cannot distinguish between all of the various forms.

$\begin{array}{rll}2 \mathrm{~S}_{2} \mathrm{O}_{3}^{2-}+\mathrm{I}_{2} \longrightarrow & 2 \mathrm{I}^{-}+\mathrm{S}_{4} \mathrm{O}_{6}^{2-} \\ \mathrm{s}^{2-}+\mathrm{I}_{2} \longrightarrow & 2 \mathrm{I}^{-}+\mathrm{S} \\ \mathrm{S}_{\mathrm{x}}^{2-}+\mathrm{I}_{2} \longrightarrow \mathrm{I}_{2} \longrightarrow & 2 \mathrm{I}^{-}+\mathrm{x} \mathrm{S} \\ 2 \mathrm{RSH}+\mathrm{RSSR}+2 \mathrm{H}^{+}\end{array}$

Thus, iodometric titrations are limfted to the analysis of pure standards. The popular methylene blue colorimetric techniques of C1ine(17) and Gilboa-Garber( 18$)$ only measure inorganic sulfide and not organic sulfur compounds. UV-VIS spectroscopy can measure a number of organic and inorganic sulfur compounds but many of these compounds have overlapping peaks and thus cannot be distinguished. Inorganic and organic sulfur can be determined by a Raney nickel reduction of many sulfur compounds followed by colorimetric 
measurement of the inorganic sulfide formed(19). However, this method cannot distinguish the forms of sulfur readily. Therefore, quantitative analysis of all major sulfur compounds is difficult at best with these methods.

To date only two methods have been able to give a rather complete speciation of major sulfur species in salt marsh porewaters. First, Boulegue et a1 $(\underline{20}, \underline{21})$ have used electrochemical titrations with UV-VIS spectrophotometry to determine organic and inorganic sulfur species in Great Marsh, Delaware. The titrations yield specific information on inorganic sulfide $S(-2)$, sulfite, thiosulfate and polysulfides and general information on organic compounds. The major drawback to these titrations is that they are tedious. The method also uses UV-VIS spectrophotometry to

determine thiols and polysulfides and to check on inorganic species which are better determined by electrochemical titrations. The analysis of inorganic and organic compounds by UV-VIS spectrophotometry is complicated by overlapping peaks and is less quantitative.

Secondly, Luther et al(22) have used polarographic techniques to measure inorganic sulfur speciation in a New England salt marsh. Thiosulfate, sulfite, inorganic $\mathrm{S}(-2)$ (as polysulfide and sulfide) and $S(0)$ polysulfides were measured. Polythionates and thiols were not determined although each react at the mercury electrode $(22,23)$. The objectives of this paper are (1) to show the usefulness of polarographic techniques in determining organic sulfur and its likely structure(s), (2) to show that polarographic techniques can provide routine field data and (3) to compare the chemistry of major sulfur species in salt marsh porewaters from two different salt marshes - Great Marsh, Delaware and the Great Sippewissett Marsh, Cape Cod, Massachusetts.

\section{Experimenta1}

Reagents. Iodine and thiosulfate standard solutions were purchased from Fisher Scientific Co.. Sodium sulfide was purchased from Alfa Products and was checked for purity by differential scanning calorimetry (DSC), X-ray diffraction (XRD) and polarographic methods. Final standardization was by iodometric methods. Pure sodium polysulfides were prepared and standardized as previously described(22). Glutathione(GSH), oxidized glutathione, L-cysteine * $\mathrm{HCl}, \mathrm{DL}-\mathrm{penicillamine,} \mathrm{L-cystine,} \mathrm{D-penicillamine} \mathrm{disulfide,}$ 2-mercaptoethylamine, 3-mercaptoproprionic acid and mercaptosuccinic acid were purchased from Sigma Chemical Co.. Methanethiol, ethanethiol, 1,2-ethanedithiol and 2-mercaptoethanol were purchased from Eastman Kodak Co.. The thiols were standardized by iodometric methods. In the case of mercaptosuccinic acid, iodometric titrations yielded 1.3 thiol groups per formula weight rather than the expected 1.0 indicating an impure sample. The disulfides were used without further purification. All solutions were prepared with deoxygenated and deionized water in a nitrogen filled glove bag or by using Schlenk type apparatus.

Apparatus. Polarograms were recorded with a Princeton Applied 
Research (PAR) mode1 $174 \mathrm{~A}$ or 364 system with a model 303 static mercury drop electrode (SDME). The SDME cell assemb1y was modified for a SCE reference electrode as described previously(22). Prepurified argon was used to purge the cell assembly. Linear Sweep Voltammetry (LSV) was performed at a 50 or $100 \mathrm{mV} / \mathrm{s}$ scan rate from 0 to $-1.5 \mathrm{~V}$ using the SDME in the hanging mercury drop electrode mode (HMDE). Differential pulse polarography (DPP) and sampled DC polarography (SDC) were performed with a 2 or $5 \mathrm{mV} / \mathrm{s}$ scan rate from 0 to $-1.5 \mathrm{~V}$ and a one $s$ drop time for the SDME in the dropping mercury electrode mode.

Fie1d sampling. Marsh cores from Great Sippewissett Marsh, Massachusetts were taken near the eastern most site and in the short Spartina zone as described in Giblin and Howarth(24). Cores were taken in August, 1984 at the beginning of senescence. Marsh cores from Great Marsh, Delaware were taken in June and August 1984 at the site described in Lord and Church(25). All cores were handled in a nitrogen filled glove box or glove bag. Sediment cores were sectioned in 3 to $5 \mathrm{~cm}$ intervals, pressed wih a Reeburgh squeezer and filtered as previously described $(10,25)$. The filtered samples were placed into gas tight syringes until ready for splitting and analysis. Measurements of $\mathrm{pH}$ were made on aliquots of these samples.

Sulfur analytical scheme. The polarographic analysis of many of the major sulfur species which are found in porewaters has been described in detail by Luther et a1(22). Tables I and II show the relevant reactions of sulfur species at the mercury electrode. Sulfur species are quantified by the method of standard additions. Briefly, the samples are split in the following manner.

The first subsample ( $5 \mathrm{~mL}$ ) is analyzed by LSV or DPP to determine thiosulfate, tetrathionate, and sulfite. All samples are acidified with $1 \mathrm{M} \mathrm{HCL}$ (degassed) to a $\mathrm{pH}$ of 5 and then purged to remove sulfide. This step is necessary to determine sulfite. Replicate measurements are always precise to $\pm 5 \%$ and are frequently precise to $\pm 1 \%$.

The second subsample ( 2 to $5 \mathrm{~mL}$ ) is placed in an ampoule and spiked with an excess of freshly prepared $0.01 \mathrm{M}$ sodium sulfite and covered with a septum. The ampoule is later sealed under nitrogen and heated to $60^{\circ} \mathrm{C}$ for 2 hours. Sulfite reacts with inorganic zerovalent polysulfide, $\mathrm{S}(0)$, to form thiosulfate. Thiosulfate is measured again by LSV or DPP. The difference between the values of thiosulfate in this subsample and the first subsample equals the total $S(0)$ from polysulfides.

A third subsample ( $25 \mathrm{uL}$ to $500 \mathrm{uL}$ ) is added to $5 \mathrm{~mL}$ of a $\mathrm{pH}$ 10 buffer of $0.2 \mathrm{M}$ nitrate/0.2 $\mathrm{M}$ bicarbonate as described previously $(22,23)$. This solution is analyzed by SDC for thiols, disulfides, inorganic $S(-2)$ and inorganic polysulfide $S(0)$. Figure 1 shows the anodic wave for a thiol and inorganic $\mathrm{S}(-2)$ (negative current) and the cathodic wave for inorganic polysulfide $S(0)$ (positive current) in two separate field samples from Great Marsh, Delaware. Figure 2 shows the anodic wave for glutathione and the cathodic wave for its disulfide in the $\mathrm{pH} 10$ buffer. 


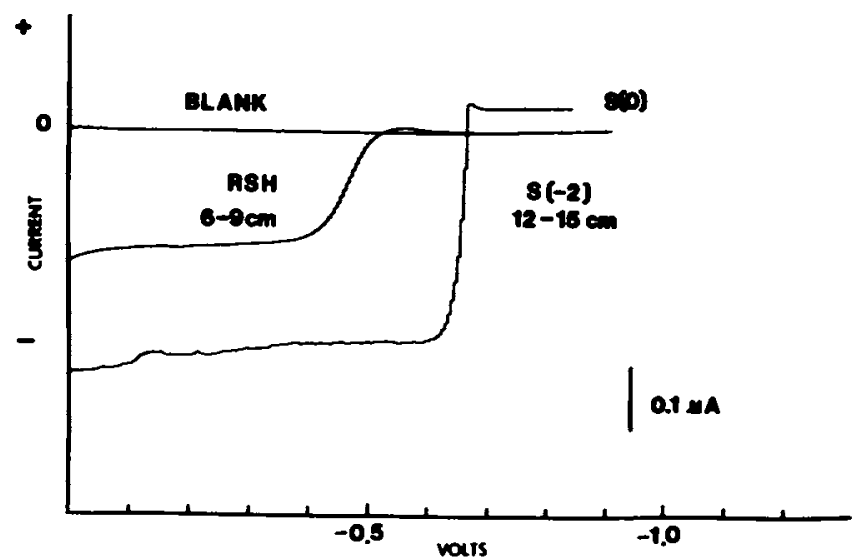

Figure 1. SDC polarographic waves for two field samples from Great Marsh, Delaware.

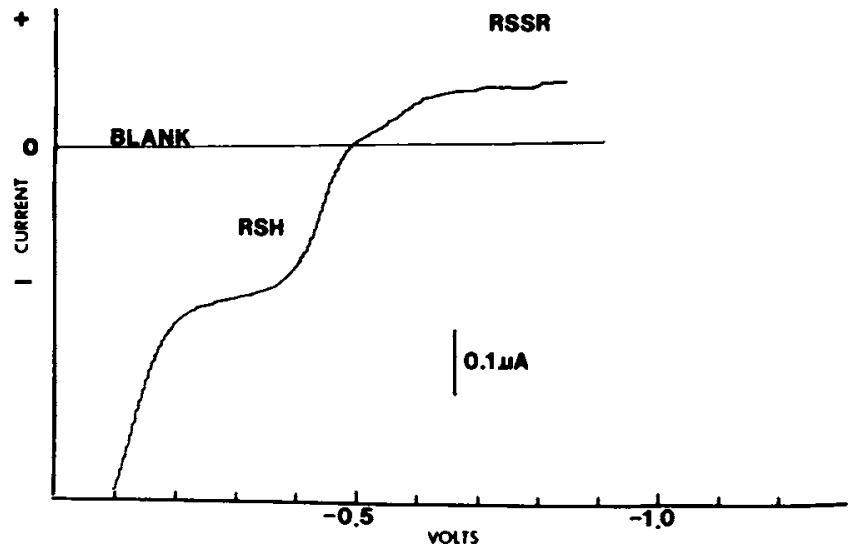

Figure 2. SDC polarogram of glutathione and oxidized glutathione prepared by adding iodine to glutathione.

In Organic Marine Geochemistry; Sohn, M.;

ACS Symposium Series; American Chemical Society: Washington, DC, 1986. 
Sulfate and chloride ion were measured by ion chromatography using a Dionex model $2010 \mathrm{I}$ system on samples from Great

Sippewissett Marsh. On samples from Great Marsh, sulfate ion was determined gravimetrically as $\mathrm{BaSO}_{4}$ and chloride ion was determined by an argentometric Mohr titration.

\section{Results and Discussion}

Methods. In a recent study(22), polarography was used to determine inorganic sulfur species in marine porewaters as in Tables $I$ and II. In that study, no thiols or organic polysulfides were detected

Table I. Oxidation reactions at the mercury electrode.

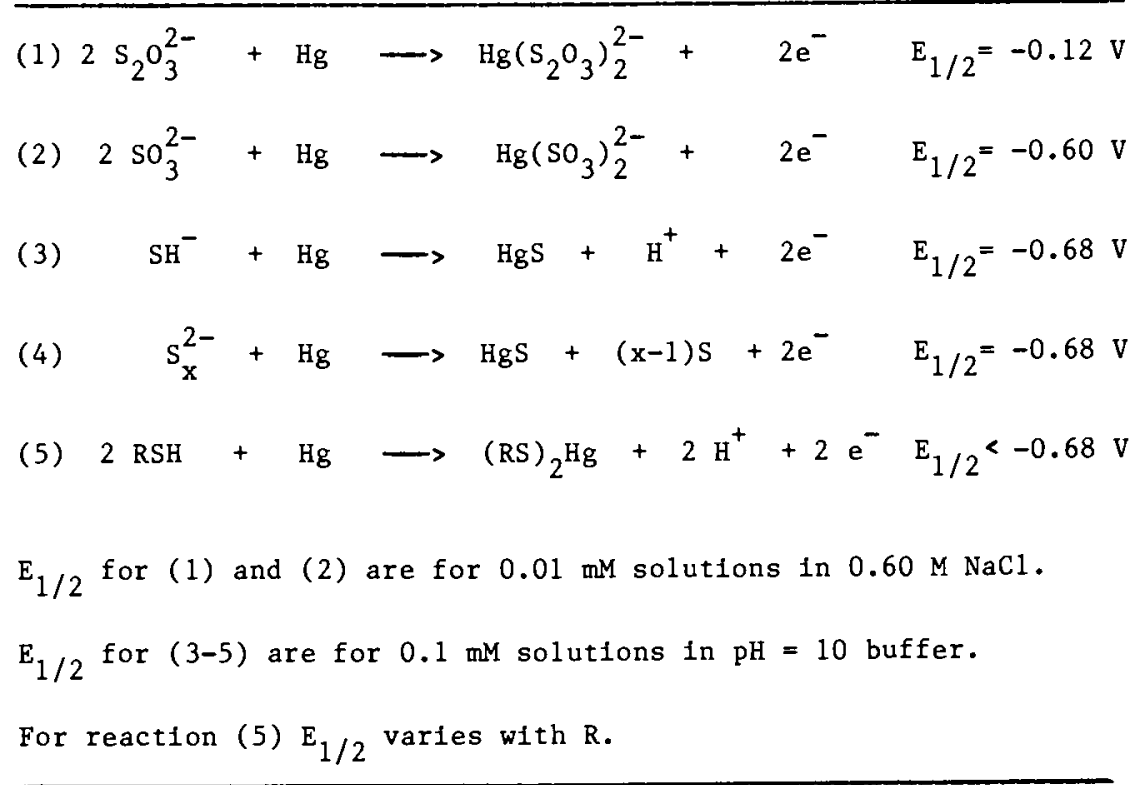

when the porewaters were prepared according to the third subsample described in the experimental section. In this study, a one electron reversible polarographic wave representing a thiol was observed in porewaters from the surface to $12 \mathrm{~cm}$ zone in Great Marsh, Delaware. This wave occurred at a half wave potential of $-0.45 \mathrm{~V}$ (Figure 1 ) with an $\mathrm{n}$ value for the electrode process of 0.997 . In addition, two samples $(0-3 \mathrm{~cm}$ and $3-6 \mathrm{~cm})$ from Great Marsh gave broad irreversible reduction waves at half wave 
potentials of $-0.59 \mathrm{~V}$ and $-0.75 \mathrm{~V}$. The wave at $-0.59 \mathrm{~V}$ is similar to organic disulfide standards (Figure 2). The wave at $-0.75 \mathrm{~V}$ has not yet been assigned but may be indicative of polysulfides of composition $\mathrm{RS}_{\bar{x}}^{-}$. Thus, we were not able to calculate the concentration of the species responsible for this latter wave.

Table II. Reduction reactions at the mercury electrode.

(1) $\mathrm{S}_{\mathrm{x}}^{2-}+2(\mathrm{x}-1) \mathrm{e}^{-}+\mathrm{x} \mathrm{H}_{2} \mathrm{O} \longrightarrow \mathrm{x} \mathrm{OH}^{-}+\mathrm{x} \mathrm{SH}^{-} \mathrm{E}_{1 / 2}=-0.68 \mathrm{~V}$
(2) $\mathrm{S}_{4} \mathrm{O}_{6}^{2-}+2 \mathrm{e}^{-} \rightarrow 2 \mathrm{~S}_{2} \mathrm{O}_{3}^{2-} \quad \mathrm{E}_{1 / 2}=-0.32 \mathrm{~V}$
(3) $\mathrm{RSSR}+2 \mathrm{e}^{-} \quad \mathrm{E}_{1 / 2}=-0.54 \mathrm{~V}$
$\mathrm{E}_{1 / 2}$ for (2) is for $0.01 \mathrm{mM}$ solutions in $0.60 \mathrm{M} \mathrm{NaCl}$.
$\mathrm{E}_{1 / 2}$ for (1) and (3) are for $0.1 \mathrm{mM}$ solutions in $\mathrm{pH}=10$ buffer.
$\mathrm{E}_{1 / 2}$ for (3) is for cystine. $\mathrm{E}_{1 / 2}$ and sensitivity vary with $\mathrm{R}$.

In previous studies of Great Marsh, Delaware(25), the Cline method was used to measure inorganic sulfide, and no dissolved sulfur was detected in the $0-12 \mathrm{~cm}$ zone. The Cline(17) and the Gilboa-Garber (18) methods depend upon methylene blue formation to determine free inorganic sulfide. Because thiols have strong $\mathrm{C}-\mathrm{S}$ bonds and no free sulfide, the colorimetric methods should not measure thiol compounds. This hypothesis was tested using cysteine and glutathione. Neither of these compounds reacted with the reagents to develop the methylene blue color used for inorganic sulfide analysis. Thus, these colorimetric methods are not useful for the study of thiols in porewaters from the marine environment. As part of this study, an intercalibration was performed using the colorimetric methods and the polarographic techniques for inorganic sulfide. The results were generally satisfactory. In seven samples from Great Sippewissett salt marsh, the colorimetric and polarographic methods agreed within $5 \%$. However, the polarographic technique has a wider linear range.

Polarography of thiols. In an effort to duplicate the field results, several thiols which are commercially available were studied. The compounds were prepared in the $\mathrm{pH} 10$ matrix which is used for the porewater analysis. The half-wave potentials are given for $0.1 \mathrm{mM}$ solutions of each compound in $\mathrm{pH} 10$ buffer. Our 
results for these compounds are listed in Table III. The compounds range from simple thiols and amino acids to the tripeptide glutathione, which is commonly found in plant and animal tissue at intercellular concentrations ranging from 0.1 to $10 \mathrm{mM}(\underline{26})$.

Table III. Polarographic data for selected sulfur species.

Compound $\quad \mathrm{E}_{1 / 2}$ (Vo1ts) $\quad \mu \mathrm{A} / \mathrm{M}$

\section{Thiols}

$\begin{array}{lll}\text { 1,2-Ethanedithiol } & -0.759 & 3490 \\ \text { Sodium sulfide } & -0.680 & 4960 \\ \text { 2-Mercaptoethanol } & -0.557 & 3327 \\ \text { Mercaptosuccinic Acid } & -0.533 & 1964 \\ \text { D-L Penicillamine } & -0.530 & 1743 \\ \text { 2-Mercaptoethylamine } & -0.526 & 2878 \\ \text { L-Cysteine } & -0.525 & 2000 \\ \text { 3-mercaptoproprionic acid } & -0.492 & 2800 \\ \text { Glutathione } & -0.462 & 1731\end{array}$

Disulfides

$\begin{array}{llr}\text { Cystine } & -0.540 & 800 \\ \text { Penicillamine disulfide } & -0.550 & 96 \\ \text { Oxidized glutathione } & -0.582 & 3615\end{array}$

The half wave potentials for each compound or class is indicative of its relative structure. The reaction of each of these thiols with the mercury electrode is generally a reversible one electron oxidation of the mercury electrode (anodic depolarization of the electrode). Large negative values of the half-wave potential indicate a stronger interaction between the thiol and the mercury electrode. The highest negative potential for the compounds studied is for 1,2-ethanedithiol and shows that both sulphydryl groups form a complex with the mercury electrode over a wide range of potentials. Inorganic sulfide which forms a stable HgS film at the electrode is the next highest. As reported before $(22,27)$, simple mercaptans with on $1 y$ the thiol functional group form stable mercury complexes and yield half-wave potentials near $-0.58 \mathrm{~V}$. Amino acids and low molecular weight thiols with at least one other functional group yield more positive half-wave potentials indicating overall weaker interactions with the mercury electrode. Glutathione yields the most positive half wave

potential and the value corresponds to that of the field data from

\section{American Chemical Society Library \\ 1155 16th St., N.W. \\ In OrganWashingtomchonestry $200796^{\mathrm{M}}$.}


Great Marsh, Delaware. The $n$ value for glutathione equals 0.965 . Because the $\mathrm{pK}$ values of the sulphydryl groups in cysteine, penicillamine and glutathione are similar(28), the large relative size of the tripeptide should make the mercury complex (RS) ${ }_{2} \mathrm{Hg}$ weak because of steric hindrance. Because glutathione is the only commonly found tripeptide containing SH groups in nature(26), it is likely that it is the thiol principally responsible for our field observations.

The relative slopes from current versus concentration plots (Table III) for these thiols show that they are analytically useful and similar in sensitivity. Figure 3 and Table III show that the slopes of most of these thiols is lower than that of inorganic sulfide. The principal reason for this difference in sensitivity is due to the $n$ value of the electrode process for inorganic sulfide versus thiols. The $n$ value for inorganic sulfide is 2.0 and the $n$ value for thiols is typically 1.0 per thiol group. As a result, thiols have broader polarographic waves than inorganic sulfide as shown in Figures 1 and 2 . Inorganic polysulfide, [S(-2) and $S(0)$ ], yields a similar slope per sulfur atom as that of inorganic sulfide, $\mathrm{S}(-2)$. The thiols show two distinct classes of sensitivity. The thiols with straight chain structures (e.g. mercaptoethanol) have higher sensitivities $(2800-3200 \mathrm{uA} / \mathrm{M})$ than amino acids with branched chain structures (1700 - $2000 \mathrm{uA} / \mathrm{M})$. Sterically hindered structures should have lower sensitivity because of poor electron transfer at the mercury electrode. This behavior has been noted for certain organic disulfides(29).

Minimum detectable limits (MDL) for these thiols using SDC are about 1-2 uM and were calculated according to the method of Turner et a1(30). MDL values for thiols can be lowered an order of magnitude if DPP is used. Because our field samples are diluted in a buffer matrix to a maximum of $500 \mathrm{uL}$ in $5 \mathrm{~mL}$ of buffer, the MDL for field samples is about 10 uM. The linear range for analysis of these thiols is from MDL to about $0.4 \mathrm{mM}$.

Polarography of organic disulfides. Organic disulfides are reduced but react irreversibly at the mercury electrode in a manner as per equation (3) in Table II. However, Hall(29) has shown that the $\mathrm{n}$ value for a number of disulfides is typically much less than 1.0 . Values for $n$ of 0.6 or less were found for cystine, penicillamine disulfide and oxidized glutathione. Only in the case of oxidized glutathione was the slope large enough to be suitable for analytical work (Table III). In fact, oxidized glutathione is the most soluble of these disulfides. This lowered sensitivity for penicillamine disulfide and cystine may be related to low solubility as well as steric hindrance(29). For penicillamine disulfide, which has the lowest sensitivity, each carbon bound to sulfur has two methyl groups rather than two protons, as cystine and oxidized glutathione have. These methy 1 groups would prevent electron transfer at the electrode. A better method to determine organic disulfides would be to reduce them chemically to form the more sensitive thiols and then to determine the increase in thiol concentration after the reduction. Unfortunately it was not 


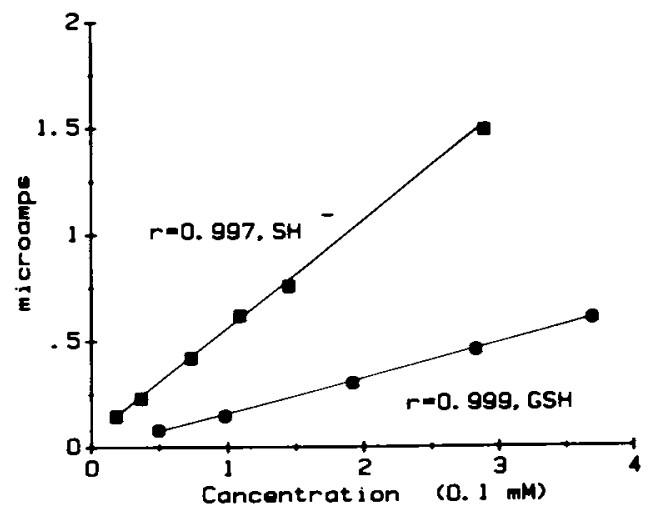

Figure 3. Current versus concentration plots from SDC polarographic data for bisulfide ion and glutathione in $\mathrm{pH} 10$ buffer solution.

In Organic Marine Geochemistry; Sohn, M.; 
possible to perform this experiment because of the small volumes obtained from the porewaters.

As shown in Figures 1 and 2 and Tables $I$ and II, polarographic methods can distinguish between many of the organic and inorganic sulfur species by the shape and the potential of each wave. However, they cannot measure organic sulphinic acids such as taurine and sulfides $\left(R_{2} S\right)$, which are likely to be present in porewaters.

\section{Field Results}

Organic sulfur species. Tables IV and $V$ show results for the field samplings from Great Marsh, Del aware and Great Sippewissett Marsh, Cape Cod, Massachusetts respectively. The major discovery is the presence of thiols in the surface to $12 \mathrm{~cm}$ zone of the Delaware marsh. In addition, organic disulfides are present from $0-6 \mathrm{~cm}$.

Table IV. Dissolved sulfur speciation in Great Marsh, Delaware, June 1984

\begin{tabular}{lcccccc}
\hline $\begin{array}{l}\text { Depth } \\
(\mathrm{cm})\end{array}$ & $\begin{array}{c}\mathrm{SO}_{4}^{2-} / \Delta \mathrm{SO}_{4}^{2-} \\
(\mathrm{mM})\end{array}$ & $\begin{array}{l}\mathrm{S}_{2} \mathrm{O}_{3}^{2-} \\
(\mu \mathrm{M})\end{array}$ & $\begin{array}{l}\mathrm{S}(0) \\
(\mu \mathrm{M})\end{array}$ & $\begin{array}{c}\mathrm{SH}^{-} \\
(\mu \mathrm{M})\end{array}$ & $\begin{array}{c}\mathrm{RSH} \\
(\mu \mathrm{M})\end{array}$ & $\mathrm{pH}$ \\
\hline $0-3$ & $35.3 /+4.63$ & 6.6 & $<1$ & $<5$ & 25 & 6.20 \\
$3-6$ & $42.0 /+12.0$ & $\mathrm{n} . \mathrm{m}$. & $<1$ & $<5$ & 336 & 5.04 \\
$6-9$ & $54.1 /+22.5$ & 18.6 & $<1$ & $<5$ & 2411 & 4.87 \\
$9-12$ & - & 30.6 & $<1$ & $<5$ & 209 & 6.66 \\
$12-15$ & $18.3 /-7.65$ & 37.4 & 326 & 948 & $<10$ & 6.80 \\
$18-21$ & $19.2 /-7.78$ & 104 & 243 & 1406 & $<10$ & 6.96 \\
$30-33$ & - & 16.0 & 162 & 3360 & $<10$ & 6.83 \\
\hline
\end{tabular}

Table V. Dissolved sulfur speciation in Great Sippewissett, Massachusetts, August 1984

\begin{tabular}{lcccccc}
\hline $\begin{array}{l}\text { Depth } \\
(\mathrm{cm})\end{array}$ & $\begin{array}{c}\mathrm{SO}_{4}^{2-} / \Delta \mathrm{SO}_{4}^{2-} \\
(\mathrm{mM})\end{array}$ & $\begin{array}{l}\mathrm{S}_{2} \mathrm{O}_{3}^{2-} \\
(\mu \mathrm{M})\end{array}$ & $\begin{array}{l}\mathrm{S}(0) \\
(\mu \mathrm{M})\end{array}$ & $\begin{array}{c}\mathrm{SH}^{-} \\
(\mu \mathrm{M})\end{array}$ & $\begin{array}{c}\mathrm{RSH} \\
(\mu \mathrm{M})\end{array}$ & $\mathrm{pH}$ \\
\hline $0-4$ & $21.0 /-1.10$ & 624 & $<1$ & $<5$ & $<10$ & 6.60 \\
$4-8$ & $17.0 /-0.75$ & 157 & 104 & 2220 & $<10$ & 7.10 \\
$8-13$ & $15.7 /-1.81$ & 186 & 83 & 3630 & $<10$ & 6.90 \\
$23-28$ & $14.7 /+0.26$ & 172 & 64 & 2610 & $<10$ & 7.00 \\
\hline
\end{tabular}

In Organic Marine Geochemistry; Sohn, M.; 
Assuming oxidized glutathione as the disulfide responsible for the polarographic wave at $-0.59 \mathrm{~V}$, the disulfide concentrations were calculated as $5 \mathrm{uM}$ and 139 uM for the $0-3$ and 3-6 cm depths respectively. Below $12 \mathrm{~cm}$, the pore water profile is dominated by inorganic sulfide. Inorganic sulfide is not present when thiols are present. The thiol concentration increases with depth until just above the onset of the inorganic sulfide zone which shows increased sulfide content with depth. The highest concentration of thiol corresponds to the $\mathrm{pH}$ minimum and to sulfate production as evidenced by the excess sulfate values relative to open ocean sulfate chloride ratios ( $\Delta \mathrm{SO}_{4}^{2-}$ in Tables IV and $\mathrm{V}$ ).

In the Massachusetts marsh, only inorganic sulfide and thiosulfate occur as the major reduced forms of sulfur over the depth profile. Although this could be related to a lack of sulfide oxidation, sulfate depletion is not very high in this core. Therefore, neither process is the more dominant biogeochemical process. Previous studies $(10,22)$ have not found evidence for thiols in this marsh even when sulfide oxidation was prevalent. In addition, cores were prepared from this marsh for controlled microcosm experiments. In cores in which oxidation was induced, thiols were not detected in the porewaters.

The formation of thiols appears related to the oxidaton of sulfide or sulfide minerals in Great Marsh, Delaware because of the high sulfate excesses whenever thiols are present. Conversely, the reaction of bisulfide ion with labile organic compounds such as halides and alcohols via nucleophilic displacement reactions is not likely because of the absence of bisulfide ion in the porewaters. A number of mechanisms for thiol formation using other sulfur species are plausible. Two nucleophilic displacement type mechanisms appear most promising. However, these mechanisms may not occur in each marsh because of differing physical and geochemical characteristics which are described later.

First, thiosulfate is capable of acting as a nucleophile to displace hydroxyl groups in labile compounds such as amino acids. This reaction forms thiols, hydrogen sulfate and leads to increased acidity(31). Although thiosulfate is pervasive in the Delaware core, it never reaches particularly high values in the thiol zone, indicating a possible steady state concentration. Thiosulfate could be produced when hydrogen sulfide diffuses upward into the oxidized zone $(0-12 \mathrm{~cm})$ where thiols are forming or by sulfide mineral oxidation. When diagenetically modeled(25), the rate of reoxidation of dissolved sulfides and sulfide minerals is greater than or equal to sulfate reduction rates in this zone. Therefore, any inorganic sulfide which is formed in, or which diffuses into this zone, should be readily oxidized.

Secondly, the zone of greatest thiol production occurs at 6-9 $\mathrm{cm}$ which is also the interval of optimal pyrite formation in that marsh during the winter season(25). Thus, pyrite is a possible starting material for thiol production because pyrite formation and its eventual oxidation during the growing season are important geochemical processes in most salt marshes $(25, \underline{25}, \underline{33})$. Pyrite formally contains zero and -2 valent sulfur. In the case of pyrite 
oxidation, the $S(-2)$ may be transformed to a thiol and the $S(0)$ to the fully oxidized sulfate ion. This process would be rapid if mediated by microbial catalysis(34). Roy and Trudinger(31) propose that glutathione or some other membrane bound thiol is the true enzymatic intermediate for sulfide and elemental sulfur oxidations to sulfate. Because inorganic sulfide concentrations were not detected in the $0-12 \mathrm{~cm}$ zone in Great Marsh, our data suggests that a thiol such as glutathione may serve as a link between the inorganic and organic sulfur pools in some salt marsh wetlands.

Inorganic sulfur spectes. Other differences in major sulfur species are evident between the two systems as shown in Tables IV and $V$. Thiosulfate concentrations in Great Sippewissett were higher by 5 to 100 times than those in Great Marsh, Delaware at similar depths. Polysulfide $S(0)$ sulfur concentrations in Great Marsh, Delaware were higher than those in Great Sippewissett. These sulfur species were present even in the strongly reducing zone. As described above, thiosulfate can form from dissolved sulfide $(\underline{1}, \underline{2})$ and sulfide mineral oxidation( 4$)$. Also, it can form from polysulfide decomposition( 1 ).

Polysulfides can be generated via two major pathways. First, polysulfides can be formed by the oxidation of dissolved sulfide and sulfide minerals $(\underline{1}, \underline{2})$. Second, they can be formed by the reaction of elemental sulfur with bisulfide ion(35). Polysulfide levels can be predicted for the second process as described in previous studies $(22,36-38)$. Equilibrium calculations as described in a previous study (22) were performed for the polysulfide levels in these samples. The ratio of $S(0)$ experimental to $S(0)$ calculated for all samples from Great Sippewissett were 0.145 (4-8 $\mathrm{cm}), 0.137(8-13 \mathrm{~cm})$ and $0.128(23-28 \mathrm{~cm})$. Because these ratios are less than 1.0 , these results indicate that polysulfides should form primarily from the reaction of bisulfide ion with elemental sulfur(5) rather than sulfide oxidation. This data set is

$$
\mathrm{SH}^{-}+\mathrm{x} \mathrm{S}^{\circ} \longrightarrow \mathrm{S}_{\mathrm{x}}^{2-}+\mathrm{H}^{+}
$$

different than that on which we reported previously(22). In the previous study, the ratios were much greater than $1 . \overline{0}$ demonstrating that polysulfides were forming primarily by sulfide oxidation reactions. The different results are attributed primarily to differences between sites in the Massachusetts marsh. The present results were observed in the eastern site where dissolved sulfide levels are typically above $1 \mathrm{mM}$ and $\mathrm{pH}$ values are near 7.0. Our previous results(22) were from the western site where dissolved sulfide levels are typically lower than $1 \mathrm{mM}$ and $\mathrm{pH}$ values are below 6.5 , further demonstrating a more oxidizing environment. For Great Marsh, Delaware the ratio was $2.74(12-15 \mathrm{~cm}), 1.02(18-21$ $\mathrm{cm})$ and $0.362(30-33 \mathrm{~cm})$. These results demonstrate that polysulfide formation via sulfide oxidation can occur at the 12-15 $\mathrm{cm}$ zone but at greater depths polysulfides likely form from elemental sulfur reacting with bisulfide ion.

Sulfite concentrations were observed only at depths of $20 \mathrm{~cm}$ 
or more in both systems. In samples from Great Marsh, Delaware, sulfite concentrations were $8.3 \mathrm{uM}$ at depths of $18-21 \mathrm{~cm}$ and $30-33$ $\mathrm{cm}$. In the core from Great Sippewissett, sulfite was determined only at the 23-28 cm depth (37.8 uM). Incomplete sulfate reduction may be responsible for the formation of sulfite with depth.

Marsh characteristics. In the upper zone, Great Marsh appears to act as an organic sulfur producing marsh which may be simflar to the production of organic sulfur compounds in paper pulp mil1s(27). The formation of thiols and organic disulfides in Great Marsh, Delaware but not in Great Sippewissett, Massachusetts may be a clue to any differences between biogeochemical processes in different salt marshes. These processes in turn may be related to a number of marsh characteristics. First, Great Marsh is inundated by tides only 3 days a month, creating dessicated sediments, whereas Great Sippewissett is flooded twice daily. There is significant groundwater Intrusion in Great Sippewissett but not in Great Marsh. Thus exchange of water and the removal of soluble labile materials is more likely in Great Sippewissett than in Great Marsh. Second, Great Marsh has higher salinity in the upper zone during the summer than Great Sippewissett. Third, solid material in cores from Great Sippewissett approaches $80 \%$ peat content and $20 \%$ inorganic content with very $11 t t 1$ e clay $(10)$. Great Marsh contains $20 \%$ organic and $80 \%$ inorganic content which is essentially all aluminosilicate clay(39). Clays are important natural catalysts for the synthesis of labile organic compounds because of their high surface area and reactive surfaces(40). Great Marsh appears to be a more saline, closed system with higher clay content and potentially important labile organic content. These conditions appear to be significant for the formation of organic sulfur compounds.

\section{Conclusions}

The half wave potentials, sign of the current for the electrode reactions and the shape of the polarographic waves allow inorganic and organic sulfur species to be distinguished readily. Thus, polarographic methods are capable of providing useful fleld data in a routine manner for many of the major inorganic and organic sulfur species present in salt marsh waters. The data derived from these methods show that differences between salt marshes can be substantial. We believe that the polarographic methods rather than the conventional colorimetric methods should be used to study major sulfur species in porewaters from other salt marshes as well. With their use, the overall importance of organic sulfur to the biogeochemistry of salt marshes should become better understood.

Acknowledgments

We thank M. Cosman, J. Ortega and R. Varsolona for polarographic measurements of organic sulfur standards. J. Scudlark and G. Banta assisted in fleld sampling, core sectioning 
and sulfate - chloride measurements. This work was funded by NSF grants DEB-8104701, DEB-8216376 and OCE-8201056. We also thank the Donors of the the Petroleum Research Fund, administered by the American Chemlcal Society, for partial support of this research.

\section{Literature Cited}

1. Chen, K.Y.; Morris. J.C. Environ. Sci. Techno1., 1972, 6, 529-537.

2. Hof fmann, M. R. Environ. Sci. Technol, 1977, 11, 61-66.

3. Pyzik, A.J.; Sommer, S.E. Geochim Cosmochim. Acta, 1981, 45, 687-698.

4. Goldhaber, M. B. Am. J. Sci., 1983, 283, 193-217.

5. Goldhaber, M. B.; KapIan, I. R. In "The Sea"; Goldberg, E. D., Ed. Wiley: New York, 1974; Vol. 5, p.569-655.

6. Gardner, L.R. Geochim. Cosmochim. Acta, 1974, 38, 1297-1302.

7. Rickard, D. T. Am. J. Sc1., 1975, 275, 636-652.

8. Howarth, R. W. Biogeochemistry, 1984, 1, 5-27.

9. Howarth, R. W.; Teal, J. M. Am. Nat.,1980, 116, 862-872.

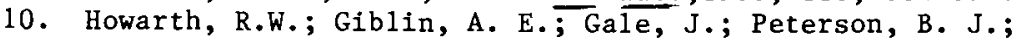
Luther, G. W. Environ. Biogeochem. Ecol. Bull. (Stockholm), $1983,35,135-\overline{152}$.

11. Balzer, W. In "Marine Organic Chemistry, Dursma, E. K.; Davison, R; Eds.; E1sevier Sci.: New York, 1983, p. 395-414

12. Mopper, K.; Taylor, B. In "Organic Marine Geochemistry", M. Sohn, Ed.; ACS SYMPOSIUM SERIES this volume, Amer. Chem. Soc.; Washington, D.C., 1986.

13. Wakeham, S. G.; Howes, B. L.; Dacey, J. W. H. Nature, 1984, $310,770-772$.

14. Steudler, P. A.; Petersen, B. J. Nature, 1985, 311, 455-457.

15. Adams, D. F.; Farwel11, S. 0.; Pack, M. R.; Robinson, E. APCA Journal, $1981,31,1083-1089$.

16. Mopper, K.; Delmas, D. Anal. Chem., 1984, 56, 2557-2560.

17. Cline, J. D. Limnol. Oceanogr., 1969, 14, 454-458.

18. Gilboa-Garber, N. Ana 1. Biochem., $197143,129-133$.

19. Kijowski, W.; Steudler, P.A. Limnol. Oceanogr., 1982, 27, 975-978.

20. Boulegue, J.; Ciabrini, J. P.; Foull1ac, C.; Michard, G.; Ouzounian, G. Chem. Geol., 1979, 25, 19-29.

21. Boulegue, J.; Lord, C. J.; Church, T. M. Geochim. Cosmochim. Acta, $1982,46,453-464$.

22. Luther III, G.W.; Giblin, A.E.; Varsolona, R. Limnol. Oceanogr., 1985, 30, 727-736.

23. Jordan,J.; Stahl, J.; Yakupkovic, J. E. "Instrumental methods of analysis of sulfur compounds in synfuel process streams". DOE/PC/40783-T9 and DOE/PC/40783-T10, NTIS, U.S. Department of Energy, 1983.

24. Giblin, A. E.; Howarth, R. W. Limnol. Oceanogr., 1984, 29, 47-63.

25. Lord III, C. J.; Church, T. M. Geochim. Cosmochim. Acta, 1983, 47, 1381-1391. 
26. Smith,E.; Hill, R. L.; Lehman, I. R.; Lefkowitz, R. J.; Handler, P.; White, A. "Principles of Biochemistry." McGraw-Hil1: New York, 1983, pp. 886.

27. Renard, J.J.; Kubes, G.; Bolker, H. I. Anal. Chem., 1975, $47,1347-1352$.

28. Friedman, M.; Cavins, J.F.; Wa11, J.S. J. Am. Chem. Soc., $1965,87,3672-3682$.

29. Ha11, M. E. Anal. Chem., 1953, 25, 556-561.

30. Turner, J.A.; Abe1, R.H. Osteryoung, R. A. Ana1. Chem., 1975, $47,1343-1347$.

31. Roy, A.B.; Trudinger, P.A. "The biochemistry of inorganic compounds of sulphur." Cambridge University Press: London, 1970 , pp. 400.

32. Howarth, R.W.; Teal, J. M. Limnol. Oceanogr., 1979, 24, 999-1013.

33. Luther III, G. W.; Giblin, A. E.; Howarth, R. W.; Ryans, R. A. Geochim. Cosmochim. Acta, 1982, 46, 2665-2669.

34. Ehrlich, H. L. "Geomicrobiology". Marcel Dekker, Inc.: New York, 1981 , pp. 393.

35. Giggenbach, W. Inorg. Chem., 1972, 11, 1201-1207.

36. Emerson, S.; Jacobs, L.; Tebo, B. In "Trace metals in sea water", Wong et a1, Ed.; Plenum: New York, 1983, p. 579-608.

37. Jacobs, L.; Emerson, S. Earth Planet. Sci. Lett., 1982, 60, 237-252.

38. Boulegue, J.; Michard, G. In "Chemical modeling in aqueous systems", E.A. Jenne, Ed.; ACS SYMPOSIUM SERIES No. 93, Amer. Chem. Soc.; Washington, D. C., 1979, p.25-50.

39. Lord III, C. Ph. D. Thesis, University of Delaware, 1980.

40. Pinnavaia, T.J. Science, 1983, 220, 365-371.

RECEIVED September 16, 1985

In Organic Marine Geochemistry; Sohn, M.; 


\title{
Chemical Speciation in High-Complexation Intensity Systems
}

\author{
Robert H. Byrne and William L. Miller \\ Department of Marine Science, University of South Florida, St. Petersburg, FL 33701
}

Theoretical and experimental developments indicate that mixed ligand complexes are 1mportant in mult1ligand systems. Consequently, the formation of ternary and higher order mixed complexes must be incorporated in the structure of multi-ligand metal speciation models. Our experimental investigation of $\mathrm{Cu}(\mathrm{II})$ complexation by oxalate and glycine is in accord with previous work in demonstrating that mixed-1igand stability constants can be reasonably assessed from theoretical considerations:

$$
\begin{aligned}
& \beta_{11} \text { (experimental) }=(5.0 \pm 0.5) \times 10^{12} \text { and } \\
& \beta_{11}(\text { theoretical })=2\left(\mathrm{G}_{2}{ }^{\circ} \cdot \mathrm{Ox}_{2}\right)^{\frac{1}{2}}=5.4 \times 10^{12} \text { where } \\
& \beta_{11}=[\mathrm{CuOxG}] /\left[\mathrm{Cu}^{2+}\right]\left[\mathrm{Ox}^{2}\right]\left[\mathrm{G}^{-}\right] \text {and } \\
& \mathrm{x}_{2}^{\beta_{2}}=\left[\mathrm{Cux}_{2}\right] /\left[\mathrm{Cu}^{2+}\right][\mathrm{X}]^{2} \text {. }
\end{aligned}
$$

Mixed ligand $\mathrm{Cu}$ (II) complexes of probable importance in natural systems include 11gand number two inorganic, organic and mixed organic/inorganic species. Due to the probable existence of ternary organic/inorganic metal species, trace metal complexation cannot be cleanly divided into organic and inorganic components.

Equilibrium models are widely used in assessments of trace metal bioavailability, toxicity, and transport through the environment. Properly applied, equilibrium models are powerful tools in such assessments. Due to a variety of factors, however, equilibrium modeling often falls short of its full potential. One problem, of special 1mportance in equilibrium characterizations, is simplistic modeling. The use of simplistic chemical models is particularly important because it affects not only the modeling of complex natural systems, but also modeling of relatively simple chemical media used to generate primary thermodynamic data.

A common starting point in metal speciation schemes is the construction of a model in the form:

$0097-6156 / 86 / 0305-0358 \$ 06.00 / 0$

(c) 1986 American Chemical Society 


$$
\frac{M_{T}}{[M]}=1+\Sigma_{j} \beta_{1}\left[L_{j}\right]+\Sigma_{j} \beta_{2}\left[L_{j}\right]^{2}+\Sigma_{j} \beta_{3}\left[L_{j}\right]^{3}+\ldots \cdot \cdot
$$

where $M_{T}$ is the total concentration of metal $M,[M]$ denotes the free concentration of metal, $\left[L_{j}\right]$ denotes the free concentration of each ligand $L_{j}$, and $\beta_{n}$ denotes the cumulative formation constant for each trace metal complex $M\left(L_{j}\right)_{n}$ :

$$
j_{n} \beta_{j}=\frac{\left[M\left(L_{j}\right)_{n}\right]}{[M]\left[L_{j}\right]^{n}}
$$

The chemical model embodied in equation 1 is flawed due to the omission of important chemical species. In chemical systems containing two or more ligand types, it is important to include the possibility of mixed ligand complex formation. As an example, appropriate descriptions of two ligand systems must include the following terms:

$$
\begin{gathered}
\frac{M_{T}}{[M]}=1+{ }_{x} \beta_{1}[X]+x_{2} \beta_{2}[X]^{2}+\beta_{11}[X][Y]+{ }_{Y} \beta_{1}[Y]+Y^{\beta_{2}}[Y]^{2}+\ldots(3) \\
\text { where } \beta_{11}=\frac{[M X Y]}{[M][X][Y]}
\end{gathered}
$$

and brackets denote the concentration of each chemical species. Since the existence of mixed complexes is well documented (1) and the potential significance of mixed ligand species increases greatly in high ligand variety systems (2), it is quite important that the potential significance of mixed complexes is explicitly acknowledged in quantitative modeling efforts.

Statistical considerations are widely used in predictions of mixed complex stabilities $(\underline{1}, \underline{3}, \underline{4})$. The formation of a ternary complex, $\mathrm{MXY}$, from the ligand number 2 complexes $\mathrm{MX}_{2}$ and $\mathrm{MY}{ }_{2}$ can be described using a stability constant of the form:

$$
\frac{[\mathrm{MXY}]^{2}}{\left[\mathrm{MX}_{2}\right]\left[\mathrm{MY}_{2}\right]}=X
$$
Since $M X Y$ is inherently twice as probable as $M X$ or $M Y$, statistical
considerations alone predict that $X=4(\underline{1}, \underline{3}, \underline{2}, \underline{5}) .{ }^{\text {Accordingly, }}$ the statistically modeled mixed ligand formation constant, $\beta_{11}$ is
given as $(1,3,5)$ :

$$
\beta_{11}=\frac{[\mathrm{MXY}]}{[\mathrm{M}][\mathrm{X}][\mathrm{Y}]}=2\left({ }_{\mathrm{X}} \beta_{2}{ }{ }^{\mathrm{B}} \mathrm{B}_{2}\right)^{\frac{1}{2}}
$$

Using statistical relationships, it can be shown that mixed ligand complexes are of great potential importance even in media containing only two ligand types ( $(5)$. In high ligand variety media, the vast number of possible mixed ligand complexes compels the incorporation 
of statistical assessments in the general framework of metal speciation models.

In high ligand variety systems, equation 1 can be replaced with an equation which implicitly accounts for the formation of ternary and higher order mixed complexes (2)).

$$
\frac{M_{T}}{[M]}=1+\sum_{j} B_{1}\left[L_{j}\right]+\left(\sum_{j} B_{2}^{\frac{1}{2}}\left[L_{j}\right]\right)^{2}+\cdots \cdot
$$

The important difference between equation 1 and equation 7 is seen in the treatment of ligand number two and higher order species found in high complexation intensity systems. Equation 1 provides an account of ligand number two complexes by obtaining a weighted summation of squared free ligand concentrations. Equation 7 provides an account of ligand number two complexes by obtaining a weighted summation of free ligand concentrations and subsequently squaring the result.

It is important to note that although equation 7 can provide much greater calculated $\mathrm{M}_{\mathrm{T}} /[\mathrm{M}]$ values than equation 1 , it is, nevertheless, expected that equation 7 will provide underestimates of the total to free metal ratio. This conclusion is based on the observation (1) that equation 6 , in the vast majority of cases, underestimates the magnitude of mixed ligand stability constants. In general, mixed ligand stability constants are larger, and often considerably larger, than predictions based on single ligand type stability constants, $B_{n}(\underline{1}, \underline{6})$. A simple example of this occurs when steric factors greatly diminish formation of the complex $\mathrm{MX}_{2}$ where $X$ is a high molecular weight ligand, but do not limit the formation of MXY where $Y$ is a low molecular weight ligand. In another example, for a four coordinated metal such as $\mathrm{Cu}^{2+}$, ligand number two $\mathrm{MX}$ complexes with tridentate ligands, $\mathrm{X}$, may be of little importance, while the significance of mixed complexes, MXY, involving monodentate and tridentate ligands, can be considerable. Due to these factors and others, experimentally determined values of $X$ are commonly observed between the statistically predicted value, 4 , and values of $10^{3}$ or more $(1,6)$. Accordingly, while equation 7 should be expected to provide speciation assessments which are superior to those provided by equation 1 , the assessments provided by equation 7 should consistently underestimate the complexation of metals as mixed ligand spectes.

\section{Trace Metal Complexation in Natural Systems}

Equation 7 can be used to provide insights about the nature of trace metal speciation in high complexation intensity systems. Using copper as an example, equation 8 provides speciation predictions in a system of inorganic ligands, $\mathrm{L}_{i}$, and organic ligands, $\mathrm{L}_{k}$.

$$
\frac{C u_{T}}{\left[\mathrm{Cu}^{2+}\right]}=1+\sum_{i} B_{1}\left[L_{i}\right]+\sum_{k} \beta_{1}\left[L_{k}\right]+\left(\sum_{i} B_{2}^{\frac{1}{2}}\left[L_{i}\right]+\sum_{k} B_{2}^{\frac{1}{2}}\left[L_{k}\right]\right)^{2}+\ldots
$$

Expanding this equation produces the result: 


$$
\begin{gathered}
\frac{\mathrm{Cu}_{\mathrm{T}}}{\left[\mathrm{Cu}^{2+}\right]}=1+\sum_{i} \beta_{1}\left[\mathrm{~L}_{i}\right]+\sum_{k} \beta_{1}\left[\mathrm{~L}_{k}\right]+ \\
\quad\left(\sum_{i} \beta_{2}^{\frac{1}{2}}\left[L_{i}\right]\right)^{2}+ \\
2\left(\sum_{i} \beta_{2}^{\frac{1}{2}}\left[L_{i}\right]\right)\left(\sum_{k} \beta_{2}^{\frac{1}{2}}\left[L_{k}\right]\right)+ \\
\left(\sum_{k} \beta_{2}^{\frac{1}{2}}\left[L_{k}\right]\right)^{2}
\end{gathered}
$$

The terms $\sum_{i} \beta_{1}\left[L_{i}\right]+\sum_{k} \beta_{1}\left[L_{k}\right]$ provide the sum contributions of ligand number one inorganic and organic complexes to the sum $\mathrm{Cu}_{\mathrm{T}} /$ $\left[\mathrm{Cu}^{2+}\right]$ ratio. The term $\left(\sum_{i} \beta_{2}^{\frac{1}{2}}\left[L_{i}\right]\right)^{2}$ provides the sum contribution of al1 inorganic 11gand number ${ }^{1}{ }^{2}$ wo complexes to the sum $\mathrm{Cu}_{\mathrm{T}} /\left[\mathrm{Cu}^{2+}\right]$ ratio. The term $\left(\sum \beta_{2} \beta_{2}^{\frac{2}{2}}\left[\mathrm{~L}_{k}\right]\right)^{2}$ provides the contribution of all organic ligand number two complexes. The expression $2\left(\Sigma_{i} \beta_{2}^{\frac{1}{3}}\left[L_{i}\right]\right)$ $\left(\sum_{k} \beta_{2}^{\frac{1}{2}}\left[L_{k}\right]\right)$ is the complexation contribution provided by ligand number two mixed, organic/1norganic complexes. In assessing the nature of this term it is noteworthy that the magnitude of the term can be increased by increasing either inorganic or organic ligand concentrations. Accordingly, it is possible to increase the contribution of organic complexation to the $\mathrm{Cu}_{\mathrm{T}} /\left[\mathrm{Cu}^{2+}\right]$ ratio by increasing only the concentration of inorganic ligands. The only exception to this conclusion should be obtained when ligand number one type species are of exclusive importance. In the general case where $\mathrm{Cu}\left(\mathrm{L}_{1}\right)_{2}$ and $\mathrm{Cu}\left(\mathrm{L}_{\mathrm{k}}\right)_{2}$ species are of some signiflcance, however slight, incregasing $\left[\mathrm{L}_{\mathrm{k}}\right]$ will increase the concentration ratio $\left[\mathrm{CuL}_{i} \mathrm{~L}_{\mathrm{k}}\right] /\left[\mathrm{Cu}^{2}\right]$, and will thereby increase the contribution of organic ligands to the $\mathrm{Cu}_{\mathrm{T}} /\left[\mathrm{Cu}^{2+}\right]$ ratio. In such a case, equation 9 indicates that the fraction of metal complexes involving organic ligands will decrease. However, in contrast to the predictions of equation 9 , when mixed ligand stability constants are much larger than those based on statistical arguments, increasing the concentration of inorganic ligands can increase both the fraction of metal complexes involving organic ligands as well as the contribution of organic complexes to the $\mathrm{Cu}_{\mathrm{T}} /\left[\mathrm{Cu}^{2+}\right]$ ratio.

Since the inorganic and organic chemistry of $\mathrm{Cu}(\mathrm{II})$ has been the object of considerable scrutiny, it is useful to consider in some detail the application of equation 9 to the chemistry of $\mathrm{Cu}$ (II) in organic rich systems. Recent work on inorganic $\mathrm{Cu}$ (II) speciation is sufficient to provide a reasonable assessment of the terms $\beta_{1}\left[L_{i}\right]$ and ${ }_{i} \beta_{2}^{\frac{1}{2}}\left[L_{i}\right]$. Our assessment of the inorganic speciation terms ${ }^{i}$ in equation 9 is based on the formation constant results of Byrne and Miller (7) and Paulson and Kester ( 8 ) and is appropriate to $35 \%$ seawater at $25^{\circ} \mathrm{C}$. Under these conditions the inorganic speciation scheme of $\mathrm{Cu}(\mathrm{II})$ in seawater at $\mathrm{pH} 8.2$ can be expressed as follows:

$$
\begin{aligned}
1+\sum_{i} \beta_{1}\left[\mathrm{~L}_{i}\right]= & 20.03=\left(\left[\mathrm{Cu}^{2+}\right]+\left[\mathrm{CuCl}^{+}\right]+\left[\mathrm{CuSO}_{4}^{\circ}\right]+\right. \\
& {\left.\left[\mathrm{CuOH}^{+}\right]+\left[\mathrm{CuHCO}_{3}^{+}\right]+\left[\mathrm{CuCO}_{3}^{\circ}\right]\right) /\left[\mathrm{Cu}^{2+}\right] }
\end{aligned}
$$




$$
\begin{aligned}
\left(\sum_{i} \beta_{2}^{\frac{1}{2}}\left[\mathrm{~L}_{i}\right]\right)^{2}= & 4.42=\left((1.95)^{\frac{1}{2}}+(0.5)^{\frac{1}{2}}\right)^{2}= \\
& \left(\left[\mathrm{Cu}\left(\mathrm{CO}_{3}\right)_{2}^{2-}\right]^{\frac{1}{2}}+\left[\mathrm{Cu}(\mathrm{OH})_{2}^{\mathrm{o}}\right]^{\frac{1}{2}}\right)^{2} /\left[\mathrm{Cu}^{2+}\right]
\end{aligned}
$$

The interactions of $\mathrm{Cu}$ (II) and dissolved organic matter are considerably more complex and consequently are less well defined. However, an assessment of the nature of organic copper complexation can be provided by treating organic complexation as, an independent variable. The two unknown terms $\Sigma_{k} \beta_{1}\left[L_{k}\right]$ and $\Sigma_{k} \beta_{2}^{\frac{1}{2}}\left[L_{k}\right]$ can be reduced to one by considering the behavior which typifies stepwise complex formation $(\underline{6}, \underline{9})$ :

$$
\begin{aligned}
& \frac{\mathrm{K}_{2}}{\mathrm{~K}_{1}}=\frac{\beta_{2}}{\beta_{1}^{2}}=\mathrm{R} \quad \text { and } \\
& 0.2 \leq \mathrm{R} \leq 0.3 \quad \text { monodentate ligands } \\
& 0.01 \leq \mathrm{R} \leq 0.1 \quad \text { bidentate ligands }
\end{aligned}
$$

We will take as a reasonable estimate, $R \simeq 0.03$. Using this estimate, it follows that $k^{\beta^{\frac{1}{2}}}=0.173{ }_{k} \beta_{1}$. Consequently, equation 9 can be written as:

$$
\frac{\mathrm{Cu}_{\mathrm{T}}}{\left[\mathrm{Cu}^{2+}\right]}=24.45+\sum_{k_{1}} \beta_{1}\left[L_{k}\right]+0.727 \sum_{k} \beta_{1}\left[L_{k}\right]+0.03\left(\sum_{k} \beta_{1}\left[L_{k}\right]\right)^{2}
$$

Equation 13 partitions the $\mathrm{Cu}_{\mathrm{T}} /\left[\mathrm{Cu}^{2+}\right]$ ratio into four components: (a) ligand number one and two inorganic complexes, (b) ligand number one organic complexes, (c) mixed inorganic-organic complexes, and

\begin{tabular}{|c|c|c|c|c|c|c|c|c|}
\hline $\mathrm{Cu}_{\mathrm{T}} /\left[\mathrm{Cu}^{2+}\right]$ & $=$ & $\begin{array}{l}\text { Inorganic } \\
(N=1, N=2)\end{array}$ & + & $\begin{array}{l}\text { Organic } \\
(\mathrm{N}=1)\end{array}$ & + & $\begin{array}{l}\text { Mixed } \\
(\mathrm{N}=2)\end{array}$ & + & $\begin{array}{l}\text { Organic } \\
(\mathrm{N}=2)\end{array}$ \\
\hline
\end{tabular}
(d) ligand number two organic complexes. The results of calculations using equation 13 and assumed values of $\sum_{k} \beta_{1}\left[L_{k}\right]$ between 0 and 50 are shown in Table $I$.

Table I. The influence of organtc ligands on $\mathrm{Cu}(\mathrm{II})$ speciation in seawater.

\begin{tabular}{lrrrr}
24.45 & 24.45 & 0 & 0 & 0 \\
44.8 & 24.45 & 10 & 7.3 & 3 \\
71.0 & 24.45 & 20 & 14.5 & 12 \\
103.3 & 24.45 & 30 & 21.8 & 27 \\
141.6 & 24.45 & 40 & 29.1 & 48 \\
185.9 & 24.45 & 50 & 36.4 & 75 \\
\hline
\end{tabular}

Examination of Table I shows that as organic $\mathrm{N}=1$ complexes become comparable in concentration to inorganic complexes, a large percentage of $\mathrm{Cu}$ (II) is present as ligand number two complexes. In addition, Table I shows that mixed organic/inorganic complexes are, 
under all conditions, comparable in concentration to $\mathrm{N}=1$ organic copper complexes. The latter result highlights the conclusion that, due to the formation of mixed ligand species, complexation by inorganic and organic ligands should be viewed as a cooperative rather than a competitive process.

The results shown in Table $I$ are contingent upon the statistical model embodied in equation 7 , and the assumption $\mathrm{K}_{2} / \mathrm{K}_{1} \cong$ Ifgands in natural aqueous systems have high molecular weights and, as a consequence of unfavorable steric effects, $\mathrm{K}_{2} / \mathrm{K}_{1}$ for complexation by such ligands may be very much less than the value assumed. As such, it is reasonable to view the term $\sum_{k} \beta_{1}\left[L_{k}\right]$ as a summation over a low molecular weight subset of the entire suite of organic ligands. The complexation properties of the remaining high molecular weight system may have an interesting characteristic which should be noted. While steric effects may greatly limit the formation of $\mathrm{N}=2$ organic complexes, such effects should be greatly reduced for mixed complexes involving a small inorganic ligand. Consequently, in systems of inorganic ligands and high molecular weight organic ligands, the relative importance of mfxed organic/inorganic complexes may actually be somewhat enhanced. Because of the substantial potential significiance of mixed Iigand species in trace metal complexation, it is important to evaluate the quality of theoretically predicted mixed-Iigand constants for a wide variety of ligand types. Toward this objective, we have examined the complexation characteristics of systems containing $\mathrm{Cu}$ (II), glycine and oxalate fons. Systems containing $\mathrm{Cu}$ (II) and bidentate ligands are particularly useful in investigations of mixed ligand complexation because the coordination chemistry of $\mathrm{Cu}$ (II) effectively precludes the formation of Iigand number three and higher order complexes. Glycine was used in this investigation because of the occasional importance of amino acids in natural systems $(\underline{10})$ and because of the high affinity of amino acids for $\mathrm{Cu}(\mathrm{II})$ (11). Oxalate was used as the second ligand type in our investigation because oxalate is a useful analog in assessments of the complexation properties of carbonate fons $(12,13)$, and because of the abundance and importance of oxalate in the environment (14, 15).

\section{Experimental Examination of Mixed Ligand Stability Constants}

Our formation constant determinations were conducted using a copper ion selective electrode and closely follow the potentiometric methods outlined by Byrne and Miller ( 7 ) in investigations of cupric carbonate complexation. The total copper concentration used in our work was $1 \times 10^{-4} \mathrm{M}$. Total glycine and oxalate concentrations were $0.02 \mathrm{M}$. The ionic strengths of our media were maintained at $1.0 \pm 0.02 \mathrm{M}$ or $0.7 \pm 0.02 \mathrm{M}$ using $\mathrm{NaClO}_{4}$ as a supporting electrolyte. Each experiment was conducted at $25^{\circ} \mathrm{C}$. Free copper concentrations were monitored using an orion model 942900 copper specific ton electrode, and a Ross type reference electrode (Orion No. 800500). Measurements of $\mathrm{pH}$ were conducted on the free hydrogen ion concentration scale $(\underline{16}, \underline{17}, \underline{18})$ using an Orion model 810200 combination $\mathrm{pH}$ electrode. Measurements in perchlorate solutions necessitated the use of 3 molar NaCl filling solutions rather than 
$\mathrm{KCl}$ in order to preclude $\mathrm{KClO}_{4}$ precipitates at the reference electrodes' liquid junctions. 'The use of two Corning model $130 \mathrm{pH}$ meters permitted simultaneous measurement of $\mathrm{pH}$ and free copper concentrations. Electrode calibrations demonstrated a Nernstian response (within $\pm 1 \%$ of theoretical) for both $\mathrm{pH}$ and copper electrodes. Free ligand concentrations were varfed by titrating our test solutions with $1 \mathrm{~N} \mathrm{HClO}_{4}$. All measurements were obtained under constant and subdued lighting conditions.

Free ligand concentrations in our experimental media were calculated using equations of the form:

$$
\begin{aligned}
(\mathrm{Ox})_{\mathrm{T}} & =\left[\mathrm{Ox}^{2-}\right]\left(1+\left(\mathrm{Ox}_{2}\right)^{-1}\left[\mathrm{H}^{+}\right]+\left(\mathrm{Ox}_{2} \mathrm{Ox}_{1}\right)^{-1}\left[\mathrm{H}^{+}\right]^{2}\right) \\
\mathrm{G}_{\mathrm{T}} & =\left[\mathrm{G}^{-}\right]\left(1+\left({ }_{\mathrm{G}} \mathrm{K}_{2}\right)^{-1}\left[\mathrm{H}^{+}\right]+\left({ }_{\mathrm{G}} \mathrm{K}_{2} \mathrm{G}_{\mathrm{K}}\right)^{-1}\left[\mathrm{H}^{+}\right]^{2}\right)
\end{aligned}
$$

where

$$
\begin{aligned}
& \mathrm{Ox}_{2} \mathrm{~K}_{2}=\frac{\left[\mathrm{Ox}^{2-}\right]\left[\mathrm{H}^{+}\right]}{\left[\mathrm{HOx}^{-}\right]} \text {and } \quad \mathrm{Ox}_{1}=\frac{[\mathrm{HO} \overline{\mathrm{x}}]\left[\mathrm{H}^{+}\right]}{\left[\mathrm{H}_{2} \mathrm{Ox}\right]} \\
& \mathrm{G}_{2} \mathrm{~K}_{2}=\frac{\left[\mathrm{G}^{-}\right]\left[\mathrm{H}^{+}\right]}{[\mathrm{HG}]} \quad \text { and } \quad \mathrm{G}_{1}=\frac{[\mathrm{HG}]\left[\mathrm{H}^{+}\right]}{\left[\mathrm{H}_{2} \mathrm{G}^{+}\right]}
\end{aligned}
$$

Oxalic actd dissociation constants were selected from the critical compllation of Martell and Smfth (19). At $25.0^{\circ} \mathrm{C}$ and 1 molar Ionfc strength the selected results are:

$$
\begin{aligned}
& -\log { }_{\mathrm{Ox}} \mathrm{K}_{2}=3.55 \pm 0.02 \mathrm{M} \\
& -\log _{\mathrm{Ox}_{1}} \mathrm{~K}_{1}=1.04 \pm 0.04 \mathrm{M}
\end{aligned}
$$

Aminoacetic acid dissoctation constants were directly determined through titrametric analysis. At $25.0^{\circ} \mathrm{C}$ we obtained the results shown in Table II.

Table II. Dissociation Constants of Amfnoacetic Acid at $25^{\circ} \mathrm{C}$

\begin{tabular}{ccc}
\hline Ionic Strength & $-\log _{\mathrm{G}} \mathrm{K}_{2}$ & $-\log _{\mathrm{G}} \mathrm{K}_{1}$ \\
\hline 1.0 & $9.68 \pm 0.01$ & $2.50 \pm 0.01$ \\
0.7 & $9.63 \pm 0.01$ & $2.49 \pm 0.01$ \\
\hline
\end{tabular}

Two types of glycine complexation experiments were performed in our study. Work at $0.70 \mathrm{M}$ lonic strength was performed at moderate complexation intensities within the $\mathrm{pH}$ range 4.6 to 2.5 . $\mathrm{Cu}$ (II) glycine complexation constants were determined by non-linear least squares fits using the equation: 


$$
\frac{\mathrm{Cu}(\mathrm{II})}{\left[\mathrm{Cu}^{2+}\right]}=1+{ }_{\mathrm{HG}}{ }^{\beta}[\mathrm{HG}]+{ }_{\mathrm{G}}{ }^{{ }_{1}}\left[\mathrm{G}^{-}\right]+{ }_{\mathrm{G}}{ }{ }_{2}\left[\mathrm{G}^{-}\right]^{2}
$$

where $\mathrm{Cu}(\mathrm{II})_{\mathrm{T}} /\left[\mathrm{Cu}^{2+}\right]$ is treated as the dependent variable, [HG] and $\left[\mathrm{G}^{-}\right]$are treâted as independent variables, and

$$
\begin{aligned}
\mathrm{HG}^{\beta} & =\frac{\left[\mathrm{CuHG}^{2+}\right]}{\left[\mathrm{Cu}^{2+}\right][\mathrm{HG}]} \\
\mathrm{G}^{\beta} 1 & =\frac{\left[\mathrm{CuG}^{+}\right]}{\left[\mathrm{Cu}^{2+}\right]\left[\mathrm{G}^{-}\right]} \\
\mathrm{G}^{\beta} 2 & =\frac{\left[\mathrm{CuG}_{2}^{\circ}\right]}{\left[\mathrm{Cu}^{2+}\right]\left[\mathrm{G}^{-}\right]^{2}}
\end{aligned}
$$

In a second set of experiments, results were obtained at one molar fonic strength and $\mathrm{pH}$ between 10.5 and 2.3. Free copper concentrations in these experiments were as low as $10^{-15} \mathrm{M}$. Due to the extreme range of copper complexation intensity in these experiments $\left(1 \leq \mathrm{Cu}_{\mathrm{T}} /\left[\mathrm{Cu}^{2+}\right] \leq 10^{1 \mathrm{I}}\right)$, use of equation 20 in our data analysis produced a very strong implicit weighting of our high $\mathrm{pH}$ data. Under these conditions the derived $\beta_{2}$ value was quite well defined while the derived constants ${ }_{\mathrm{HG}}{ }^{\beta}$ and ${ }^{2}{ }_{G}{ }^{\beta}$ were so poorly defined as to be useless. This problem was alteviated by analyzing our one molar ionic strength data using the equation

$$
\left(\mathrm{Cu}_{\mathrm{T}}\right)=\left[\mathrm{Cu}^{2+}\right]\left(1+{ }_{\mathrm{HG}}{ }^{\beta} 1[\mathrm{HG}]+{ }_{G^{\beta}}{ }_{1}\left[\mathrm{G}^{-}\right]+{ }_{G^{\beta}}{ }_{2}\left[\mathrm{G}^{-}\right]^{2}\right) .
$$

$\mathrm{Cu}_{\mathrm{T}}$ was thereby treated as the dependeht variable in our analysis and the independent variables were $\left[\mathrm{Cu}^{2 f}\right],[\mathrm{HG}]$, and $\left[\mathrm{G}^{-}\right]$. Analysis of our $0.7 \mathrm{M}$ Ionic strength data $\left(1.0 \leq \mathrm{Cu}_{\mathrm{T}} /\left[\mathrm{Cu}^{2+}\right] \leq 100\right)$ using equation 24 produced essentially the same $\mathrm{T}$ results as were obtained using equation 20 .

Cupric oxalate complexation experiments were analyzed using an equation identical in form to equation 24 :

$$
\begin{aligned}
& \mathrm{Cu}(\mathrm{II})_{\mathrm{T}}=\left[\mathrm{Cu}^{2+}\right]\left(1+{ }_{\mathrm{HOx}}{ }^{\beta}[\mathrm{HO} \bar{x}]+{ }_{\mathrm{Ox}} \beta_{1}\left[\mathrm{Ox}^{2-}\right]+{ }_{\mathrm{Ox}} \beta_{2}\left[\mathrm{Ox}{ }^{2-}\right]^{2}\right) \\
& \text { where } \\
& \mathrm{HOx}^{\beta}=\frac{\left[\mathrm{CuHOx}^{+}\right]}{\left[\mathrm{Cu}^{2+}\right]\left[\mathrm{HOx}^{-}\right]} \\
& { }_{\mathrm{Ox}}{ }^{\beta} 1=\frac{\left[\mathrm{CuOx}^{\circ}\right]}{\left[\mathrm{Cu}^{2+}\right]\left[\mathrm{Ox}^{2-}\right]} \quad \text { and } \\
& \mathrm{Ox}_{2}{ }^{\beta}=\frac{\left[\mathrm{Cu}(\mathrm{Ox})_{2}^{2-}\right]}{\left[\mathrm{Cu}^{2+}\right]\left[\mathrm{Ox}^{2-}\right]^{2}}
\end{aligned}
$$


Using equation 25 , our oxalate complexation data were analyzed within the range $1.3 \leq \mathrm{pH} \leq 4.8$. The results obtained in our analyses of $\mathrm{Cu}$ (II) complexation by oxalate and glycine are shown in Table III. The uncertainties provided with our $1.0 \mathrm{M}$ glycine and oxalate complexation results at $1.0 \mathrm{M}$ ionic strength reflect, in each case, the range of parameter estimates obtained in two experiments. The uncertainties provided with our $0.7 \mathrm{M}$ results reflect the range of parameter estimates obtained in six experiments.

Table III. Cu(II) - glycine and Cu(II) - oxalate stability constants at $25.0^{\circ} \mathrm{C}$.

Ionic Strength $\quad \log _{\mathrm{HG}} \beta \quad \log _{\mathrm{G}} \beta_{1} \quad \log _{\mathrm{G}} \beta_{2} \quad$ Source

$\begin{array}{lclll}1.0 \mathrm{M} & 1.4 \pm 0.1 & 8.4 \pm 0.1 & 15.36 \pm 0.01 & \text { this work } \\ 0.7 \mathrm{M} & 1.2 \pm 0.1 & 8.26 \pm 0.06 & 15.15 \pm 0.06 \text { this work } \\ 0.5 \mathrm{M} & - & 8.14 \pm 0.02 & 15.0 \pm 0.10 & \text { Martell and } \\ & & & & \\ & & & & \end{array}$

Ionfc Strength $\quad \log _{\mathrm{HOx}} \beta \quad \log _{0 \mathrm{x}} \beta_{1} \quad \log _{0 \mathrm{x}}{ }_{2} \quad$ Source

The $\beta$, results shown in Table III provide the following theoretically predicted mixed ligand stability constant:

$$
\beta_{11}\left(\text { theoretical) }=2\left({ }_{\mathrm{Ox}} \beta_{2}{ }_{\mathrm{G}} \beta_{2}\right)^{\frac{1}{2}}=5.4 \times 10^{12}\right.
$$

Our direct experimental determinations of this constant were conducted at $25^{\circ} \mathrm{C}$ and $1.0 \pm 0.02 \mathrm{M}$ lonic strength by methods nearly identical to those used in our oxalate and glycine stability constant determinations. The solutions used in our $\beta_{1}$ determinations were $0.02 \mathrm{M}$ in glycine plus $0.02 \mathrm{M}$ in oxalate. The results of our titrations between $\mathrm{pH} 10.4$ and 2.2 were analyzed using the equation

$$
\begin{aligned}
\left(\mathrm{Cu}_{\mathrm{T}}\right)= & {\left[\mathrm{Cu}^{2+}\right]\left(1+{ }_{\mathrm{HG}}{ }^{\beta[\mathrm{HG}]}+{ }_{\mathrm{G}^{\beta}} \beta_{1}\left[\mathrm{G}^{-}\right]+{ }_{\mathrm{G}_{2}}\left[\mathrm{G}^{-}\right]^{2}+\right.} \\
& \left.\beta_{11}\left[\mathrm{G}^{-}\right]\left[\mathrm{Ox}^{2-}\right]+{ }_{\mathrm{Ox}} \beta_{1}\left[\mathrm{Ox}^{2-}\right]+{ }_{\mathrm{Ox}}{ }^{\beta_{2}\left[\mathrm{Ox}^{2-}\right]}\right)
\end{aligned}
$$

The single ligand type formation constants in equation 30 were taken from our Table III results. The $\mathrm{CuOxG}^{-}$formation constant obtained using our methods is:

$$
\beta_{11}=(5.0 \pm 0.5) \times 10^{12}
$$


where the uncertainties provided encompass the $\beta_{11}$ results obtained in two analyses.

\section{Discussion}

Under proper conditions, $\mathrm{Cu}$ (II) Ion selective electrodes are well sulted to extreme complexation conditions. Our glycine complexation experiments at low $\mathrm{pH}$ and at high $\mathrm{pH}$ produced very similar results in spite of extremely different extents of $\mathrm{Cu}$ (II) complexation between the two types of experiments.

Our experimental design entalled the investigation of $\mathrm{Cu}$ (II) speciation under very intense complexation conditions. Investigation of mixed Iigand systems at high $\mathrm{pH}$ is potentially very complicated due to the probable significance of hydroxide complexes and mixed 11gand hydroxide complexes. According to our experimental design, oxalate and glycine concentrations were sufficiently high to render insignificant all species involving $\mathrm{OH}^{-}$. Consequently, the only significant complex species in our solutions were $\mathrm{CuOx}^{\circ}, \mathrm{Cu}(\mathrm{Ox})_{2}^{2}, \mathrm{CuG}^{+}, \mathrm{GuG}_{2}^{\circ}$ and $\mathrm{CuOxG}$. The relative simplicity of our experimental system was an important factor in our ability to sensitively examine the formation of the ternary complex. A second important factor was the substantial importance of CuOxG in our experimental system. In our titrations, performed over a wide range of $\mathrm{pH}$, conditions were obtained whereby $\mathrm{CuOxG}^{-}$was the dominant solution species.

Our mixed ligand formation constant result is in very good agreement with theoretical predictions. The value of $X$ obtained in our study is $X=3.5 \pm 0.7$. Spectrophotometric determinations of this constant at $30.0^{\circ} \mathrm{C}$ and $0.25 \mathrm{M}$ lonic strength (20), produced the est Imate $X=21.4$. Taken together, these studies are in good accord with the observation that experimentally determined mixed 1igand stability constants are as large or larger than theoretically predicted formation constants $(\underline{1}, \underline{6}, \underline{21})$. Our observations support the contention that mixed 1igand complexation should be included in the structure of trace metal speciation assessments (e.g. equation 7). Oxalate has been successfully used as a carbonate fon analog in assessments of trace metal-carbonate ion interactions $(\underline{12}, \underline{13})$. Consequently, our theoretical and experimental developments Indicate that carbonate may play a significant role in the interactions of metal lons and organic 1igands.

\section{Summary and Conclusions}

The results of our analyses reaffirm the importance of incorporating mixed ligand complexes in the structure of metal spectation models. Fallure to account for such complexes, even in the relatively simple solutions used in complexation analyses, can result in very large formation constant misestimations. In high ligand varlety media, fallure to consider mlxed complexes can result in substantial underestimation of a metal's degree of complexation. In natural media, fallure to consider mixed complex formation may produce a flawed assessment of trace metal bloavallability, toxicity, and interactions with organic matter.

Participation of organic ligands in trace metal complexation may be enhanced by cooperative complexation with inorganic ligands. 
Since high ligand number complexes involving hydroxide and carbonate are important in the marine speclation schemes of many metals, these ligands may be of particular importance in organic as well as inorganic complexation.

Few, If any, Investigations have produced useful mixed ligand complexation data involving carbonate ions. However, to the extent that oxalate serves as a useful carbonate fon analog, the results of this work Indicate that the formation of mixed carbonate complexes involving simple bidentate organic ligands is well predicted from statistical considerations.

Acknowledgments

This work was supported by the National Sclence Foundation (OCE-81-10162). The authors wish to thank Dr. Mark S. Shuman for his constructive criticism of this work.

\section{Literature C1ted}

1. MartIn, R.P.; Pet1t-Rame1, M.M.; Scharff, J.P. In "Metal Ions in Blological Systems"; Sige1, H., Ed.; Dekker: New York, 1973; Vol. II, Chap. 1.

2. Byrne, R.H. Mar. Chem. 1983, 12, 15-24.

3. Watters, J.I. ; Dewitt, R. J. Am. Chem. Soc. 1960, 82, 1333-9.

4. Dyrssen, D.; Jagner, D.; Wengelin, F. "Computer Calculation of Ionic Equilibria and Titration Procedures"; Almquist and WikselI Stockholm, 1968.

5. Byrne, R.H. Mar. Chem. 1980, 9, 75-80.

6. Sige1, H. In "Metal Ions in Blological Systems"; Sigel, H. Ed.; Dekker: New York, 1973; Vol. II, Chap. 2.

7. Byrne, R.H.; Miller, W.L. Geoch1m. Cosmoch1m. Acta 1985, $49,1837-44$.

8. Paulson, A.J., Kester, D.R. J. Sol. Chem. 1980, 9, 269-277.

9. Sillen, L.G.; Martell, A.E. "Stability Constants of Metal Ion Complexes"; Speclal Pub. No. 17, The Chemical Soclety; Burlington: London, 1964.

10. Henrichs, S.; Farrington J.W. Nature. 1979, 279, 319-21.

11. Martell, A.E.; Smith, R.M. "Cr $\overline{1 t 1 c a l}$ Stabllity Constants"; Plenum: New York, 1974; Vol. 1.

12. Langmulr, D. In "Chemical Modeling in Aqueous Systems; Jenne, E.A., Ed.; American Chemical Society: Washington, D.C., 1979; Chap. 18.

13. Turner, D.R.; Whitfleld, M.; Dickson, A.G. Geoch1m. Cosmochim. Acta $1981,45,855-881$.

14. Graustein, W.C. Science 1977, 198, 1252-54.

15. Zut1c, V; Stumm, W. Geoch1m. Cosmoch1m. Acta 1984, 48, 1493-1503.

16. McBryde, W.A.E. Analyst $1969,94,337-46$.

17. McBryde, W.A.E. Analyst $1971,96,739-40$.

18. Byrne, R.H.; Kester, D.R. J. Sol. Chem. 1978, 7, 373-83.

19. Marte11, A.E.; Sm1th, R.M. "Critical Stability Constants"; Plenum: New York, 1982; Vol. 5.

20. Ramanufam, V.V.; Krishnan,U. Ind. J. Chem., 1980, 19A, 779-82.

21. Byrne, R.H.; Young, R.W. J. Sol. Chem. 1982, 11, 127-36.

RECEIVED October 11, 1985

In Organic Marine Geochemistry; Sohn, M.; 


\title{
22
}

\section{The Adsorption of Organomercury Compounds from Seawater onto Sedimentary Phases}

\author{
Cristie Dalland, Eva Schumacher, and Mary L. Sohn
}

Department of Chemistry, Florida Institute of Technology, Melbourne, FL 32901

\begin{abstract}
Adsorption isotherms and conditional adsorption constants (Kads) were determined for the adsorption of diphenyl mercury and phenylmercuric ion (introduced as phenylmercuric acetate) from a seawater matrix onto several solid phases. Diphenyl mercury was found to adsorb onto humic acid, but no adsorption was detected onto bentonite, amorphous $\mathrm{Fe}(\mathrm{OH})_{3}$ or hydrous $\mathrm{MnO}_{2}$. The value of $\mathrm{Kads}$ was found to decrease with increasing ionic strength for the diphenyl mercury - humic acid system in seawater. As the concentraction of suspended humic acid increased, the nonlinearity of the diphenyl mercury - humic acid system became more pronounced at an increasingly lower diphenyl mercury concentration. Phenylmercuric ion adsorbed most strongly onto humic acid although adsorption onto $\mathrm{Fe}(\mathrm{OH})_{3}$ and $\mathrm{MnO}_{2}$ was detected and Kads values were determined. Kads values for PMA with humic acid, $\mathrm{MnO}_{2}$ and $\mathrm{Fe}(\mathrm{OH})_{3}$ were found to decrease with decreasing salinity.
\end{abstract}

The speciation, concentrations and residence times of dissolved substances in natural waters are dependent on many factors and processes. Important factors include temperature, $\mathrm{pH}$, redox potential, ionic strength and the concentrations of other dissolved species such as organic and inorganic ligands as well as the presence of suspended particulate and colloidal matter. Important processes in addition to rate of input, and biochemical cycling include precipitation, complexation, coagulation and adsorption onto suspended particulate matter.

The focus of this study is the process of adsorption. The adsorption of substances onto solid suspended phases is a primary mechanism for the removal of dissolved matter from the water column and the consequent accumulation of many substances in sediments. Of major concern is the value of the adsorption constant (Kads) which is a measure of the strength of the adsorption interaction. Knowledge of the variation in Kads with changes in experimental condi-

$0097-6156 / 86 / 0305-0369 \$ 06.00 / 0$

(c) 1986 American Chemical Society 
tions can provide valuable Insight into the mechanism of adsorption processes.

The majority of adsorption studies deal with the interactions between metal ions and either real or model sediment phases. Amorphous $\mathrm{Fe}(\mathrm{OH})_{3}$, hydrous $\mathrm{MnO}_{2}$, clays (bentonite, illite, kaolinite), $\mathrm{SiO}_{2}, \mathrm{Al}_{2} \mathrm{O}_{3}$ and organic matter (often humic substances) are the solid phases most frequently studied.

Equilibration of hydrous oxide solid phase adsorbents with a metal ion adsorbate is normally accomplished by mechanical shaking of the sample over a time period extending from several hours to several days when working with model solid phases which were prepared in the laboratory. An initial equilibration is usually reached within one or two hours and is followed by a period of much less extensive adsorption which may extend over a much longer time period $(1-3)$ However, sediments and suspended matter isolated from natural systems seem to require longer time periods of seven to twenty days before an accurate determination of Kads can be made $(4,5)$. In addition, when working with natural sediments, the major role played by adsorbed organic coatings on solid phases must be considered $(2,6)$.

The effect of $\mathrm{pH}$ on metal ion adsorption is usually quite dramatic with the percent of metal adsorbed onto a surface increasing from near zero to a maximum, over a range of several $\mathrm{pH}$ units $(1-4,7)$ as $\mathrm{pH}$ increases. Increased ionic strength of the supporting medium typically results in a decrease in Kads due to increased competition for available surface active sites $(7,8)$. However, the value of Kads for some metals with natural suspended sediments has been found to increase with increasing salinity (conditions similar to estuarine mixing), suggesting removal of metal ions from solution by coagulation $(9)$. Solid phase concentration is also a critical parameter affecting Kads values. The inverse relationship between the concentration of suspended adsorbing solids and Kads is most readily explained by a solid-solid interaction which decreases the availability of the strongest binding sites (9). The introduction of ligands into a metal ion-solid adsorbent equilibrium consideration can lead to either an increase or decrease in Kads. Ligands which are not adsorbed will decrease metal adsorption by competing with the adsorbent for the metal, while enhancement of metal adsorption can occur if the ligand is adsorbed and additional complexing functional groups are still available on the adsorbed ligand for metal ion interaction (2). The relative importance of the various solid phases to trace metal distributions in natural aquatic systems is dependent on the metal ion of interest. However, the fraction of metal adsorbed typically increases as the percentage of organic matter in the sediment increases $(9)$. The sorption behavior of metal ions onto solid surfaces is often described by a Langmuir isotherm. The value of Kads can be determined from the slope of the isotherm wich is usually linear in the range of low metal ion concentrations (3).

Studies involving the adsorption of organic substances onto solid phases have largely centered around organic pesticides because of the environmental significance of these toxic substances. The extent of adsorption of Bromacil onto freshwater 
sediments was found to correlate strongly with the percent of organic matter in the sediments while weaker adsorption onto clays and amorphous $\mathrm{Fe}(\mathrm{OH})$ s surfaces was indicated $(10,11,12)$. In many cases, the extent of adsorption of neutral organic compounds is inversely related to solubility (13). With respect to the effect of the concentration of solid phase on Kads, results seem to be similar to those obtained in metal ion solid interactions. Kads values for the partitioning of DDT, Kepone, Lindane, and Heptachlor decrease with increasing sediment concentration. The effect of $\mathrm{pH}$ on the adsorption of organic substances is dependent on the $\mathrm{pK}_{\mathrm{a}}$ of the substance considered $(14,15)$.

The sorptive behavior of organic substances is usually best described by a Freundlich isotherm $(10,13,14,16)$. The value of Kads can be determined from the $y$-intercept of a $\log -\log$ plot of the modified Freundlich equation:

$$
\mathrm{s}_{\mathrm{ads}}=\mathrm{K}_{\mathrm{ads}} \mathrm{C}^{1 / \mathrm{n}}
$$

$S$ represents the concentration of the adsorbate in the solid phase, while $C$ represents the equilibrium concentration in the bulk solution. The adsorption isotherm of diphenyl mercury and humic acid is illustrated in Figure 1.

Nature of This Study. The following represents preliminary results of an initial study on the adsorptive behavior of two organometallics. Numerous organometallics comprise the active ingredient of various pesticides. Examples include phenylmercuric salts, diphenyl mercury, triphenyl, tributyl, and tricyclohexyltin salts, as well as organoarsenic compounds (Table 1). Because of the toxicity of these substances their behavior and associations in natural water systems is a matter of concern.

Table I. Commercial and Agricultural Uses of Some Organomentallics

\begin{tabular}{ll}
\hline Compound & Use \\
\hline Diphenyl mercury & Fungicide \\
Phenylmercury acetate & Eradicant fungicide \\
Phenylmercury borate & Paint mildewstat \\
Phenylmercury chloride & Seed treatment fungicide \\
Phenylmercury hydroxide & Lumber treatment fungicide \\
Phenylmercury iodide & Fungicide \\
Ethylmercury chloride & Seed treatment fungicide \\
Methylmercury chloride & Seed treatment fungicide \\
Methylmercury iodide & Mercury analysis reagent \\
Fentin acetate & Fungicide \\
Fentin hydroxide & Fungicide \\
\hline
\end{tabular}

Materials and Methods. Laboratory glassware was soaked in $50 \%$ nitric acid overnight and then rinsed repeatedly with distilled water. All liquid solutions were stored in polyethylene containers. Stock solutions of diphenyl mercury and phenylmercuric acetate were prepared by dissolving weighed portions of the pure solids (obtained from the U.S. Environmental Protection Agency, Pesticides and Industrial Chemicals Repository) in distilled water and were 


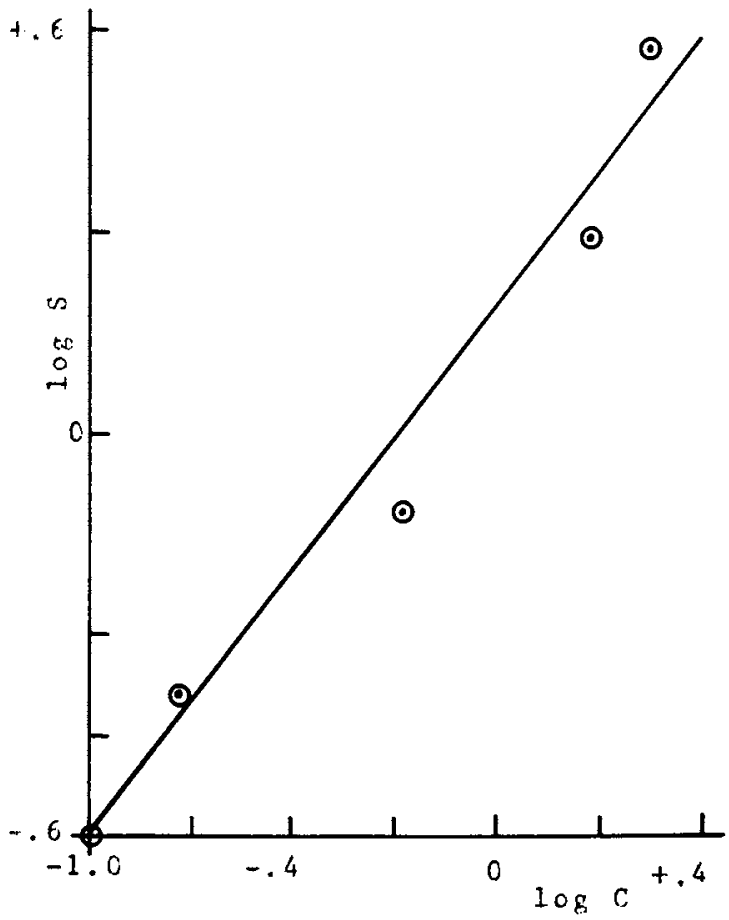

Figure 1. Freundlich isotherm for the adsorption of DPM onto $150 \mathrm{ppm}$ humic acid in $50 \%$ seawater.

In Organic Marine Geochemistry; Sohn, M.; ACS Symposium Series; American Chemical Society: Washington, DC, 1986. 
stored under refrigeration for a maximum of 100 days. Both diphenyl mercury (DPM) and phenyl mercuric acetate (PMA) are fungicides used in limited nonagricultural areas only $(17,18)$.

Hydrous manganese oxides and amorphous iron oxides were prepared in the laboratory according to the methods described by Oakley et al (3). The addition of manganese sulfate solution to a slightly basic potassium permanganate solution produces a suspension of hydrous $\mathrm{MnO}_{2}$. A suspension of $\mathrm{Fe}(\mathrm{OH}){ }_{3}$ is produced by simply adjusting a ferric nitrate solution to a $\mathrm{pH}$ of 8.0 with a dilute sodium hydroxide solution. Both suspensions were washed repeatedly with seawater and stored in seawater for several days.

Bentonite was obtained from Fischer Scientific. Humic acid was obtained from Aldrich. An additional humic acid sample (BV) which was extracted from Chesapeake Bay sediments, was used in one set of adsorption experiments. The extraction and purification of this sample has been described in detail elsewhere (19). Further characterization of BV humic acid is also presented elsewhere (20).

The adsorption of diphenylmercury (DPM) and phenylmercuric ion (PM) was studied on the solid phases described above (hydrous manganese oxides, amorphous iron oxides, humic acid and bentonite clay). The solid phase (5-15 mg) was added to $25-50 \mathrm{ml}$ of filtered seawater yielding solid phase concentrations of approximately 100 to $400 \mathrm{ppm}$ suspended matter. The concentration of seawater was also varied in order to study the variation of adsorptive behavior with changes in ionic strength. The suspension was then spiked with either DPM or PMA to yield concentrations of organometallic which varied from 0.10 to $3.5 \mathrm{ppm}$. The range in organometallic concentration used for this study was determined by the sensitivity of the detection method and the solubility of DPM and PMA in seawater.

The suspensions were then agitated on a shaker table for 48 hours. Adsorption constants which were measured after 10 days were identical to constants measured after a 48 hour equilibration period. Thus all adsorption measurements were made after a 48 hour equilibration period.

Samples were then removed from the shaker table and centrifuged. Initially, filtration was employed to separate liquid and solid phases, but the organometallics were strongly adsorbed onto the filter paper, so this procedure was abandoned and centrifugation was adopted. The concentration of DPM or PMA remaining in solution was measured on a Perkin-Elmer Model 460 atomic absorption spectrophotometer employing the Mercury-Hydride System (MHS-10). The reduction of phenylmercuric cations to elemental mercury has previously been reported $(21,22)$. The average relative precision of the method was $1.8 \%$. Linear calibration curves for DPM and PMA were obtained for almost the entire solubility ranges of these compounds in seawater (F1gure 2). The calibration curve for DPM became nonlinear near the solubility limit $(3.5 \mathrm{ppm}$ for DPM and $>5.0 \mathrm{ppm}$ for PMA). The detection limits for DPM and PMA were 0.10 $\mathrm{ppm}$ and $0.04 \mathrm{ppm}$ respectively, in seawater. Because of the relatively high detection limits for DPM and PMA, it was not possible to work in the ppb or lower concentration range which would be environmentally more relevant.

The amount of organometallic adsorbed by the solid phase was 


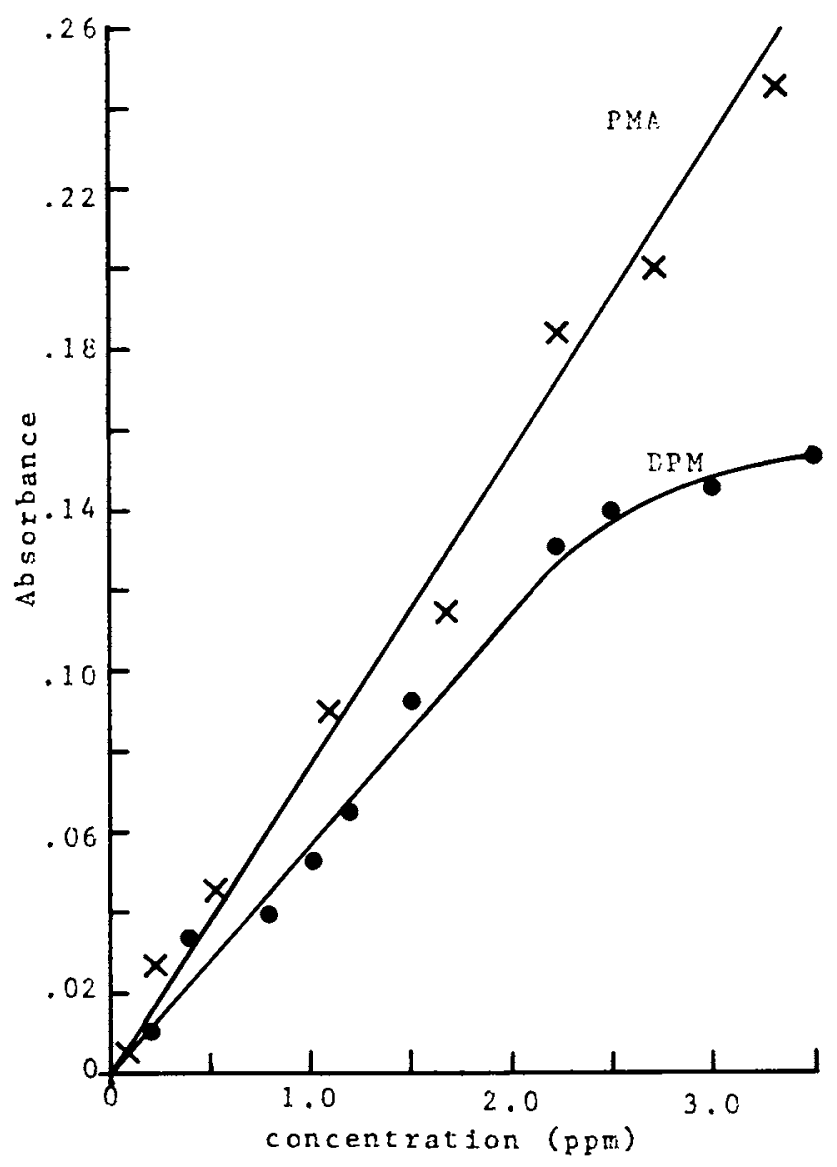

Figure 2. Calibration curves for PMA and DPM in seawater.

In Organic Marine Geochemistry; Sohn, M.;

ACS Symposium Series; American Chemical Society: Washington, DC, 1986. 
calculated as the difference between the spike and the amount remaining in solution after the equilibration period of 48 hours. Values of adsorption constants were determined graphically, as described below.

Results and Discussion

Diphenyl Mercury Adsorption. Adsorption of DPM from seawater onto amorphous iron hydroxide, manganese oxide and bentonite clay was not detected in this study. A comparison of standard dipheny 1 mercury solutions in seawater with identical solutions to which sediment phase had been added and shaken for 48 hours was routinely performed as part of the isotherm determination. There was no significant difference in the concentration of dissolved diphenyl mercury for standard versus standard plus solid phase for any of the suspensions of amorphous, $\mathrm{Fe}(\mathrm{OH})_{3}, \mathrm{MnO}_{2}$, or bentonite in seawater, implying no significant adsorption of DPM from seawater onto these phases under the concentrations studied. If lower concentrations of DPM could have been used ( $\mathrm{ppb}$ or lower) it is possible that adsorption might have been detected.

Adsorption of DPM from seawater by humic acid was recorded and the value of Kads was determined by a simple least squares analysis of the linear portion of the isotherm to be 1.11 for a $150 \mathrm{ppm}$ suspension of humic acid in seawater (Table II). This low value of Kads is not unexpected, since one would expect the interaction between the neutral nonpolar DPM molecule and the suspended humic acid to be due to a rather weak molecular attraction.

Table II. Values of Adsorption Constants for DPM onto Humic Acid (150 ppm) as a Function of Seawater Concentration

\begin{tabular}{lc}
\hline Kads $(L / G)$ & \% Seawater \\
\hline $1.11(1.07$, BV $)$ & 100 \\
1.25 & 50 \\
3.10 & 25 \\
1.28 & 0 \\
\hline
\end{tabular}

The effect of changing ionic strength on the value of Kads for the DPM - humic acid system was investigated by diluting seawater with distilled water. The $\mathrm{pH}$ of these systems varied from 7.0 to 7.6 and depended only on the relative amounts of seawater and freshwater. This small variation in $\mathrm{pH}$ should not significantly affect the adsorptive behavior of DPM. Schwartz (14) found no $\mathrm{pH}$ dependence for the sorptive behavior of organics when these substances are predominantly in their molecular forms. The slight decrease in $\mathrm{pH}$ with freshwater addition mirrors the changes which would occur in natural brackish systems where salt and fresh water mix. The effect of decreasing ionic strength on the value of Kads is shown in Table II. The progression from seawater to a mixture of $25 \%$ seawater ( $75 \%$ distilled water) led to an increase in Kads for the DPM-humic acid system. However, at $100 \%$ distilled water, the value of Kads decreased.

The trend of decreasing Kads with increasing ionic strength is 
the same trend typically seen when studying metal ion adsorption $(7,8)$. It is somewhat suprising that DPM, a neutral molecule, exhibits this same trend. It had been expected that increasing ionic strength would have had a salting out effect on the DPM, increasing the tendency of the DPM to associate with the organic humic phase. However, the trend from $100 \%$ to $25 \%$ seawater was just the opposite, and suggests that DPM and the ions of seawater may be competing for the same type of adsorption sites.

The reversal of this trend, or the decrease in Kads when one progresses from $25 \%$ seawater to distilled water can be explained if one considers the solubility behavior of the adsorbent, humic acid. Humic acid was found to be fairly insoluble in solutions varying from $25 \%$ to $100 \%$ seawater. These solutions are characterized by a faint coloration even after the humic acid has been centrifuged out. As mentioned earlier, filtration of these samples resulted in retention of DPM by the filter paper, probably due to adsorption. The coloration of the centrifugate was considerably darker for the distilled water experiments, suggesting that the humic acid was more soluble in this medium. Thus the increased concentration of dissolved humic acid in distilled water led to greater solubilization of DPM and its sorptive behavior was thus modified by the greater concentration of dissolved humic acid.

Table II lists two values for Kads at $100 \% \mathrm{SW}$. The bracketed value is that evaluated using a humic acid extracted from estuarine sediments. The sedimentary sample was obtained from the Chesapeake Bay near the town of Bivalve (BV). Because the values of Kads were so similar for the estuarine humic acid and the commercially prepared soil humic acid, use of the estuarine sample was discontinued and the soil humic acid was used consistently thoughout the study.

The effect of concentration of suspended adsorbent on sorptive behavior in a seawater matrix was studied by determining adsorption isotherms for DPM and 94,150,200,400, and $1000 \mathrm{ppm}$ humic acid. The corresponding values of Kads (Table III) show no definite trend with respect to increased adsorbent concentration. This is not totally unexpected in view of $0^{\prime}$ Connor and Connolly's observation that systems with low Kads values do not show dramatic changes of Kads with changes in suspended matter concentrations (9). Only systems with high Kads values typically show definite decreases in Kads with increases in adsorbent concentration.

Table III. Values of Adsorption Constants for DPM onto Humic Acid as a Function of Suspended Humic Acid Concentration

Kads $(\mathrm{L} / \mathrm{g})$ Concentration of Humic Acid $(\mathrm{ppm})$

$\begin{array}{rr}2.2 & 94 \\ 1.1 & 150 \\ 3.6 & 200 \\ 1.5 & 400 \\ 2.3 & 1000\end{array}$

Although least squares analysis of the linear portions of the 
adsorption isotherms do not indicate a systematic change in Kads with changes in suspended humic acid concentration, the corresponding isotherms (Figure 3) show a definite and meaningful pattern. As the concentration of suspended humic acid increases, the nonlinear behavior of the isotherm is initiated at a lower and lower DPM concentration. This suggests that as the concentration of adsorbent increases, nonideal (nonlinear) behavior is attained at a correspondingly lower concentration of adsorbate (DPM). This in turn implies fewer energetically favorable adsorption sites available at higher adsorbate concentration, implying solid-solid interaction resulting in the partial elimination of the availability of certain adsorption sites (9). Thus, inspection of the adsorption isotherms (Figure 3 ) demonstrates a trend consistent with that seen in other studies (9) although Kads values do not mirror this.

Phenylmercuric Adsorption. Phenylmercuric ion was chosen for this study primarily because of its structural similarity to DPM, the major difference, other than the loss of one benzene ring, being the charge. The presence of the $(+1)$ charge greatly modifies the adsorption behavior of the species with respect to DPM.

Phenylmercuric ion was introduced to the various solid phaseseawater suspensions as an aqueous solution of phenylmercuric acetate (PMA). Adsorption of phenylmercuric ion onto all solid phases studied, except bentonite clay, was noted at solid concentrations of $150 \mathrm{ppm}$ (suspended). Adsorption isotherms for humic acid, hydrous $\mathrm{MnO}_{2}$ and amorphous $\mathrm{Fe}(\mathrm{OH})_{3}$ are shown in Figure 4. Values of Kads for phenylmercuric ion and these solid phases are listed in Table IV.

Table IV. Values of Adsorption Constants for PMA in Seawater

\begin{tabular}{ll}
\hline Kads $(\mathrm{L} / \mathrm{g})$ & Solid Phase \\
\hline 4.5 & $\mathrm{MnO} 2 \mathrm{Fe}_{3}$ \\
5.3 & $\mathrm{HA}$ \\
50 & \\
\hline
\end{tabular}

Phenylmercuric ion showed a marked preference for humic acid ( Kads $=50)$ although adsorption onto two of the three inorganic phases was pronounced with respect to the behavior of DPM. The charge of the phenylmercuric ion allows interactions to occur with adsorption sites on $\mathrm{MnO}_{2}$ and $\mathrm{Fe}(\mathrm{OH})_{3}$, which were not reactive towards DPM.

The effect of changing ionic strength on the value of Kads for PMA adsorption was also investigated. Decreasing the salinity of the humic acid suspension, led to a very pronounced decrease in Kads. In $100 \%$ seawater, Kads was evaluated as $50 \mathrm{~L} / \mathrm{g}$ (Table IV) while at $25 \%$ seawater Kads dropped to a value of 1.2 . Decreasing salinity of the $\mathrm{MnO}_{2}$ and $\mathrm{Fe}(\mathrm{OH})_{3}$ systems yielded similar results. At $25 \%$ and $50 \%$ seawater, no adsorption of PMA onto either phase was detected. These results are similar to the results of $\mathrm{Li}$ et al. for mercuric ion adsorption (23). In that study, a decrease in the adsorption constant for mercuric ion onto sedimentary phases with 


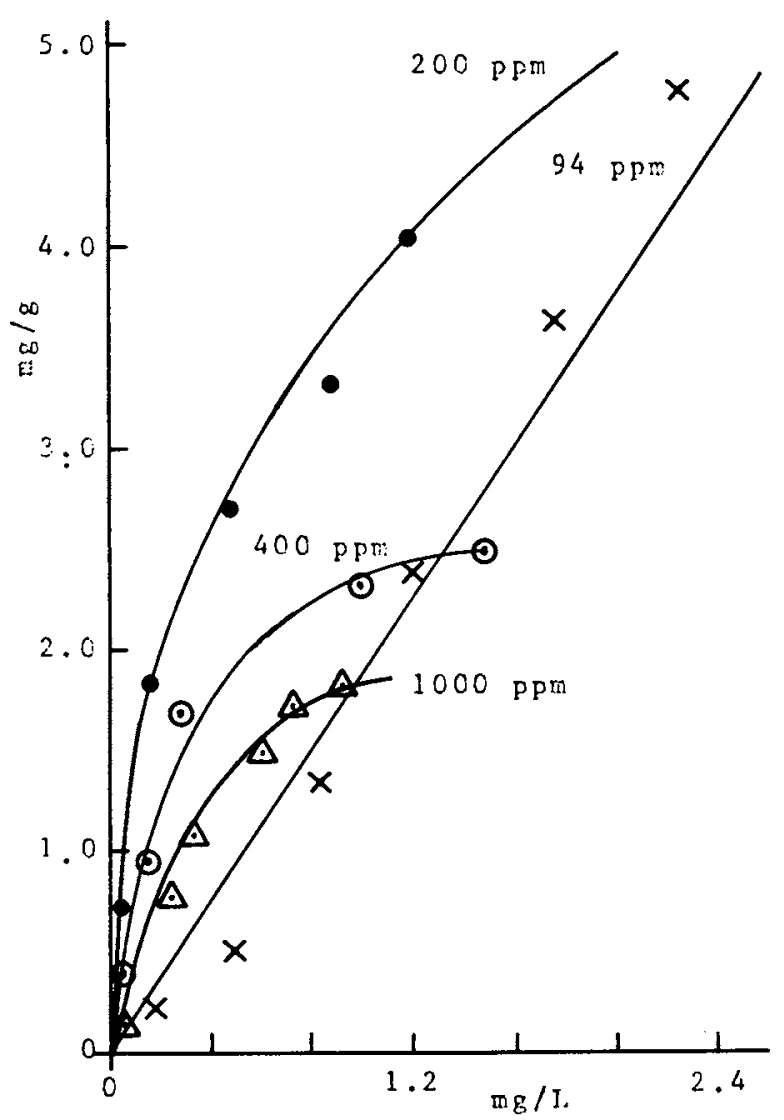

Figure 3. Adsorption isotherms for DPM and various concentrations of suspended humic acid in seawater.

In Organic Marine Geochemistry; Sohn, M.;

ACS Symposium Series; American Chemical Society: Washington, DC, 1986. 


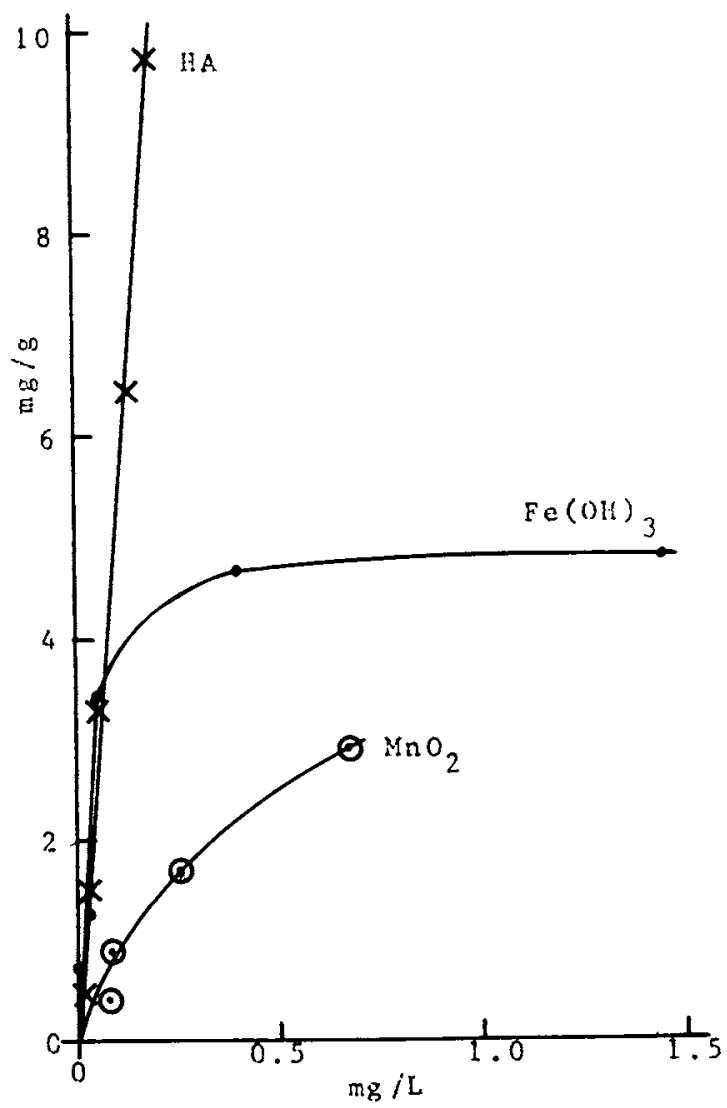

Figure 4. Adsorption isotherms of PMA and solid phases in seawater.

In Organic Marine Geochemistry; Sohn, M.;

ACS Symposium Series; American Chemical Society: Washington, DC, 1986. 
decreasing salinity was described. Thus the adsorptive behavior of PMA (a charged ionic species) with respect to salinity changes, was found to be somewhat similar to that of mercuric ion.

Conclusions. Diphenyl mercury, a neutral organometallic compound, which does not contain any markedly acidic or basic functional groups was found to adsorb only onto humic acid. No sorptive behavior could be detected with respect to bentonite, $\mathrm{MnO}_{2}$ or $\mathrm{Fe}(\mathrm{OH})_{3}$. The rather low value of Kads indicates a simple molecular attraction. However, the decrease in Kads with an increase in ionic strength indicates that DPM is competing with the metal ions in seawater for adsorption sites. The increasing nonlinearity of adsorption isotherms with increasing suspended humic acid concentration is also similar to results obtained for metal ion adsorption.

Phenylmercuric ion was found to associate most strongly with humic acid, although adsorption onto $\mathrm{MnO}_{2}$ and $\mathrm{Fe}(\mathrm{OH})_{3}$ was appreciciable. Adsorption onto bentonite was not detectable for either organometallic.

Although further studies are needed on the behavior of organometallic pesticides, the results of this study indicate that neutral organometallics can be expected to associate with organic phases such as humics. Charged organometallics, such as phenylmercuric ion associate most strongly with organic phases, although adsorption onto some inorganic phases does occur. Obviously, additional research is needed to generalize about the adsorptive behavior of organometallics other than organomercurials. Adsorption studies on organotin compounds are currently in progress.

\section{Acknowledgments}

Acknowledgement is made to the Donors of the Petroleum Research Fund, administered by the American Chemical Society, for the support of this research. The authors also wish to thank Rolf Sohn for preparation of figures.

\section{$\underline{\text { Literature Cited }}$}

1. Benjamin, M.M.; Leckie, J.0. J. Colloid Interface Sci 1981, 79, 209-221.

2. Davis, J.A.; Leckie, J.0. Environ. Sci. Technol. 1978, 12, 1309 1315 .

3. Oakley, S.M.; Nelson, P.0.; Williamson, K. J. Environ. Sci. Technol. 1981, 15, 474-480.

4. Balistrieri, L.S.; Murray, J. W. Geochim. Cosmochim. Acta $1984,48,921-929$.

5. Li, Y.; Burkhardt, L., Buchholtz, M.; O'Hara, P., Santschi, P.H. Geochim. Cosmochim. Acta 1984, 48, 2011-2019.

6. Balistrieri, L. S.; Brewer, P.G.; Murray, J.W. Deep-Sea Res. $1981,28 \mathrm{~A}, 101-121$.

7. Davies-Colley, R. J.; Nelson, P.0.,; Williamson, K.J. Environ. Sci. Technol. 1984, 18, 491-499.

8. Gaudette, H.E.; Grim, R.E.; Metzger, C. F. Amer.Mineral. 1966, $51,1649-1656$. 
9. O'Connor, D. J.; Connolly, J.P. Water Res. 1980, 14, 1517-1523.

10. Corwin, D. L.; Farmer, W. J. Environ. Sci. Technol. 1984, 18, 507-514.

11. Lambert, S.M.; Porter, P.E.; Schieferstein, R.H. Weeds 1965, $13,185-190$.

12. Lambert, S.M. J. Agr. Food Chem. 1968, 16, 340-343.

13. Hague, R.; Freed, V.H. Residue Rev. 1974, 52, 89-116.

14. Schwartz, H.G. Environ. Sci. Technol. 1967, 1 332-337.

15. Weber, J.B. Amer. Mineral. 1966, 51, 1657-1670.

16. Lotse, E.G.; Graetz, O.A.; Chesters G.; Lee, G.B.; Newland, L.W. Environ. Sc1. Technol. 1968, 2, 353-357.

17. "Analytical Reference Standards and Supplemental Data," Environmental Protection Agency, 1984.

18. Meister, T.T. "Farm Chemicals Handbook 1977"; Meister Publishing Co.; Willoughby, OH, 1977; p. D 212.

19. Sohn, M.L.; Hughes, M.C. Geochim.Cosmochim.Acta 1981, 45, 2393-2399.

20. Sohn, M.L. Org.Geochem. 1985, 8, 203-206.

21. Toffaletti, J; Savory, J. Anal. Chem. 1975, 47, 2091.

22. Braman, R.S. In "The Hydrolysis of Cations"; Baes, C.F., Jr.; Mesmer, R.E., Eds.; Wiley-Interscience: N.Y., 1976; p. 37.

23. Li,Y.; Burkhardt, L.; Teraoaka, H. Geochim.Cosmochim.Acta. $1984,48,1879-1884$.

RECEIVED September 23, 1985 


\title{
Effects of Humic Substances on Plutonium Speciation in Marine Systems
}

\author{
G. R. Choppin, R. A. Roberts ${ }^{\prime}$, and J. W. Morse ${ }^{2}$
}

Department of Chemistry, Florida State University, Tallahassee, FL 32306-3006

\begin{abstract}
The dominant oxidation state of plutonium in the dissolved phase of seawaters has been shown to be $\mathrm{Pu}(\mathrm{V})$. Data are presented that indicate a significant role by humic materials which cause rapid reduction of $\mathrm{Pu}(\mathrm{VI})$ to $\mathrm{Pu}(\mathrm{IV})$. The latter leaves the solution phase via hydrolysis. The humic material also seems to reduce $\mathrm{Pu}(\mathrm{V})$ but at a much slower rate and, in sunlight, this reduction may be negated by an oxidation process of unknown origin at this time. The role of humics sorbed on suspended particulate and sedimentary matter is discussed.
\end{abstract}

Sources and Amounts of Plutonium in the Environment. Since 1945 approximately $3300 \mathrm{~kg}$ of plutonium has been injected into the environment, mostly (>90\%) from atmospheric explosions of nuclear weapons. This corresponds to about $380 \mathrm{kCi}$ total alpha radioactivity. The addition to this amount by releases from nuclear power operations is much smaller; the major continuing addition is ca. 0.1 $\mathrm{kCi}$ per month released to the Irish Sea from the British nuclear reprocessing plant at Windscale. About $2 / 3$ of the plutonium from nuclear explosions would be formed into highfired oxides which would be rather inert chemically. However, 5 he remaindef5, createj during the explosion as single atoms via the ${ }^{238} \mathrm{U}(n, \gamma){ }^{239} \mathrm{U}\left(2 \beta^{-}\right)^{239} \mathrm{Pu}$ reaction sequence, should be more reactive and behave similarly to that released from reprocessing plants or nuclear waste repository sites.

Sampling of filtered water samples of the Pacific Ocean indicates a concentration of ca. $2 \times 10^{-1} /_{\mathrm{M}}$ (i.e. $10^{-3} \mathrm{dpm} \mathrm{L} \mathrm{L}^{-1}$ ) (1 $)$.

These values, however, are open to question as the plutonium associated with suspended particulates may be more than an order of magnitude greater than that in true solution. For example, for the

'Current address: Mallinckrodt Medical Products Research and Development, St. Louis, MO 63134.

${ }^{2}$ Current address: Department of Oceanography, Texas A\&M University, College Station, TX 77843.

0097-6156/86/0305-0382\$06.00/0

() 1986 American Chemical Society 
Mediterranean Sea, the plutonium activity in unfiltered water samples was twenty five times greater than that of filtered samples (2). In experiments in which plutonium was added to seawater, the solubility of ionic species after 30 days was found to be $5 \times 10^{-12} \mathrm{M}(3)$. Addition of relatively large quantities of humic material in these experiments increased the plutonium solubility sixfold.

Properties of Plutonium. As nuclear power utilization with its associated reprocessing and waste disposal operations expands, the fate of any released plutonium assumes greater importance. However, there is another rationale for studying the environmental behavior of plutonium. Because of its solution chemistry, it is an element with rather unique qualities as a probe of environmental properties. Plutonium has four oxidation states, VI, V, IV, and III, all of which can exist in aqueous solution within the $\mathrm{E}_{\mathrm{h}}$ and $\mathrm{pH}$ range found in nature. Under the proper conditions, all four states can coexist, although one or more of the states is usually favored. The III and IV oxidation states generally exist as hydrated or complexed cations. The $\mathrm{V}$ and $\mathrm{VI}$ states, on the other hand, exist as $\mathrm{PuO}_{2}^{+}$and $\mathrm{PuO}_{2}{ }^{+}{ }^{+}-$ the dioxo cations - also hydrated or complexed. Normally, acidic conditions stabilize the lower oxidation states while more basic conditions favor the higher states.

Distribution of plutonium between its different oxidation states is, of course, dependent not only on $\mathrm{pH}$. Complexation, for example, can change the relative stabilities of the different states. The various oxidation states differ in their ability to form complexes, with $\mathrm{Pu}(\mathrm{V})$ exhibiting the weakest complexation. $\mathrm{Pu}(\mathrm{VI})$ and $\mathrm{Pu}(\mathrm{III})$ are rather similar in complexation strength although $\mathrm{Pu}(\mathrm{VI})$ is usually stronger than $\mathrm{Pu}$ (III) for most ligands. $\mathrm{Pu}$ (IV) forms the strongest complexes. Hydrolysis, including hydrolytic polymerization, can also play an important role in stabilizing one oxidation state over another. The effects of redox potentials, complexation, hydrolysis, etc. can combine to give the possibility of more than one oxidation state coexisting under the same conditions which complicates the study of the environmental behavior of plutonium but also can serve to define the $E_{\text {, }}$, etc. of systems. The relative tendencies of various species of the different oxidation states to form colloids or to sorb to particulates add further dimensions to the chemical behavior of plutonium.

A topic which requires further study is the effect of organics on the behavior of plutonium in the marine environment. Based on a bioassay method, Fisher, et al. (4) have suggested that marine humic and fulvic acids produce no substantial complexation of transuranic elements in the oceans. However, Dahlman, et al. (ㅁ) support the idea of complexation by humic and fulvic acids and provide experimental evidence of reduction of $\mathrm{Pu}(\mathrm{VI})$ to $\mathrm{Pu}(\mathrm{IV})$ by fulvic acid. Complexation is also supported by the work of Pillai and Mathew (3), although the concentrations of organics used in their studies were unrealistically high. 
Previous Studies. Studies from the Irish Sea (6) and the Pacific Ocean (7) show that the soluble form of plutonium is predominanty in the oxidized forms ( $V$ and VI states) with evidence that $V$ is the more important state. However, modeling calculations with experimental complexation and redox data led Aston (8) to conclude that $\mathrm{Pu}(\mathrm{VI})$ is the dissolved form (no effect of organic material was included). In a recent extensive review of the geochemistry of plutonium in water environments, Sholkovitz (9) concluded the oxidation state distribution in waters requires more investigation. In this paper we report the result of studies designed to clarify the dominant oxidation state of plutonium in sea water and the role of humic material.

\section{Experimental}

The stability of $\mathrm{Pu}(\mathrm{VI})$ and $\mathrm{Pu}(\mathrm{V})$ was studied in solutions of standard artificial (same mineral constitution) seawater and of true seawater from the Gulf of Mexico (collected ca. 5 miles from the Florida coastline below Tallahassee). A11 solutions were buffered to $\mathrm{pH} 8.0$ by addition of trishydroxymethylaminomethane ("tris") and filtered by vacuum through 0.45 micron Millipore filters. The glassware, pipets, etc. used were treated to reduce adsorption losses of $\mathrm{Pu}$ at $\mathrm{pH} 8$ by a method developed in this laboratory (10).

The humic acid was recovered from Bahamian marine sediments obtained from sites in less than $5 \mathrm{~m}$ water depth and at least 0.5 miles from shore. The isolation and purification procedures have been described earlier (11).

$\mathrm{Pu}(\mathrm{VI})$ was prepared by oxidation of acidic stock ${ }^{238} \mathrm{Pu}$ or ${ }^{239} \mathrm{Pu}$ tracer solutions with $\mathrm{KMnO}_{4}$. The oxidized tracer solution was neutralized with $\mathrm{NaOH}$ prior to addition to the experimental solution.

$\mathrm{Pu}(\mathrm{V})$ was prepared by photolysis of a thenoyltrifluoracetone (TTA) solution as described previously (12). The Pu(V) was stripped from the organic-TTA solution directly into the experimental aqueous solution. The concentration of $239 \mathrm{Pu}$ was ca. $10^{-7} \mathrm{M}$ in a11 experiments while that of $238 \mathrm{Pu}$ was ca. $10^{-9} \mathrm{M}$.

Ten $\mathrm{m} 1$ of the test solutions were kept in treated screw cap glass vials and $0.500 \mathrm{ml}$ aliquots withdrawn periodically. Plutonium was separated by oxidation state by a solvent extraction method (13) and the alpha activity counted with a liquid scintillation counter using "Handifluor" (Mallinckrodt) as the cocktail.

\section{Results}

When $\mathrm{Pu}(\mathrm{V})$ was added to either artificial seawater or to real seawater, essentially no change in oxidation state was observed over the 120 hours of these experiments (Figure 1). Preliminary data from longer term experiments which have continued over 800 hours indicate a slow reduction of $\mathrm{Pu}(V)$ in seawater when kept in the dark but 1 ittle or no reduction when exposed to normal daily sunlight (14).

Figure 2 shows data for addition of $\mathrm{Pu}(\mathrm{VI})$ to artificial seawater with different amounts of humic acid. In all solutions, the $\mathrm{Pu}(\mathrm{VI})$ was reduced rapidly to $\mathrm{Pu}(\mathrm{V})+\mathrm{Pu}(\mathrm{IV})$ with the ratio of the $\mathrm{V} / \mathrm{IV}$ decreasing with humic acid concentration. The $\mathrm{Pu}$ (IV) is not found in solution but can be recovered quantitatively from the walls 


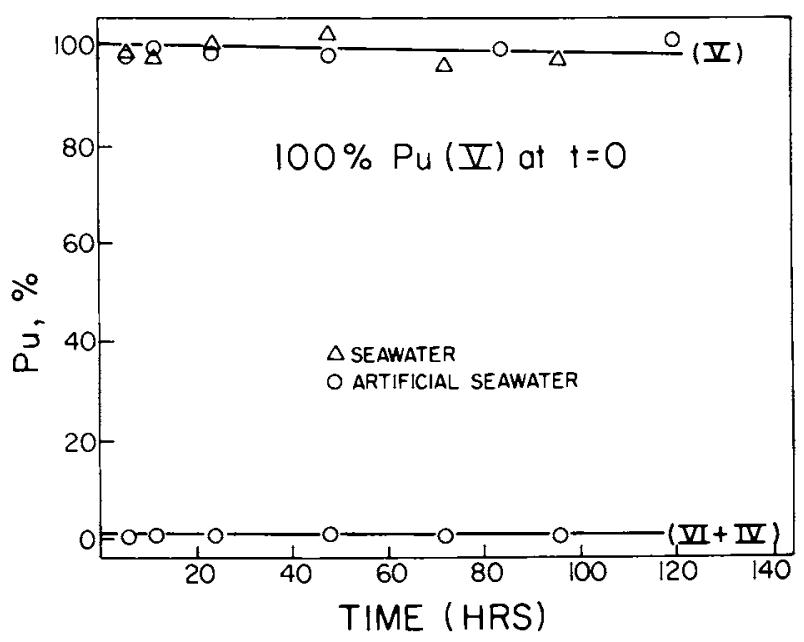

Figure 1. Variation of concentration of $\mathrm{Pu}(\mathrm{V})$ with $t$ ime in artificial and true seawater at $\mathrm{pH} 8.0$ and $25^{\circ} \mathrm{C}$; at $t=0$, $[\mathrm{Pu}(\mathrm{V})] \approx 10^{-7} \mathrm{M}$.

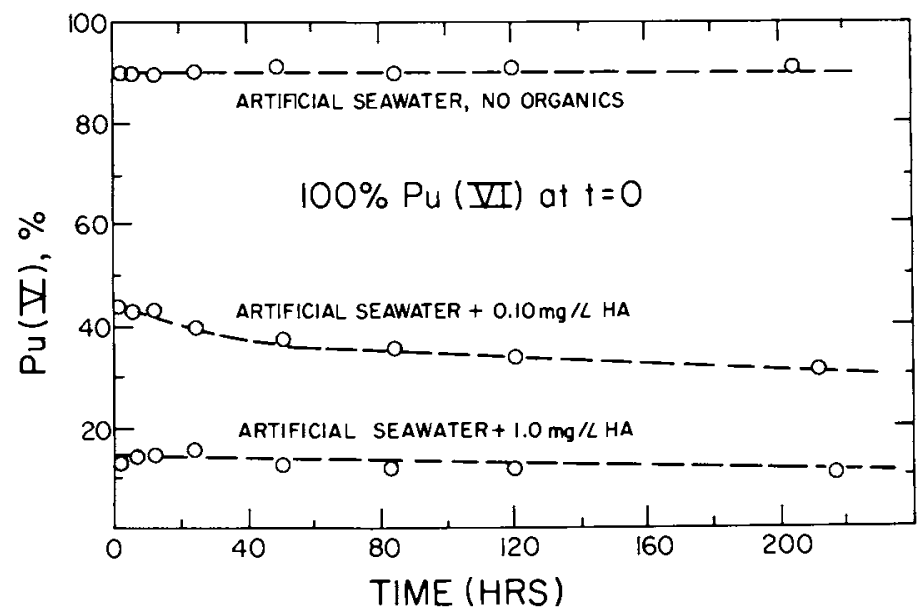

Figure 2. Percentage of $\mathrm{Pu}(\mathrm{V})$ of original ca. $10^{-7} \mathrm{M} \mathrm{Pu}(\mathrm{VI})$ added to artificial seawater with $0,0.1$ and $1.0 \mathrm{mg} / \mathrm{L}$ humic acid at $\mathrm{pH} 8.0$ and $25^{\circ} \mathrm{C}$.

In Organic Marine Geochemistry; Sohn, M.;

ACS Symposium Series; American Chemical Society: Washington, DC, 1986. 
by washing the empty vials with acid. Very similar results were obtained when $0 . \mathrm{M}$ NaCl solution at $\mathrm{pH}=8.0$ was used instead of artificial seawater. In true seawater, the $\mathrm{Pu}(\mathrm{VI})$ was reduced rapidly to $\mathrm{ca}$. $30 \% \mathrm{Pu}(\mathrm{V})$. Humic material is reported to be $6-30 \%$ of the DOC of seawater, (15), indicating a range of $0.1-1.0 \mathrm{mg} / \mathrm{L}$ as reasonable. The reduction to $30 \% \mathrm{Pu}(\mathrm{V})$ in seawater compares well with the reduction observed in artificial seawater for such a range of humic concentration.

\section{Discussion}

The data in Figures 1 and 2 are consistent with the existence of $\mathrm{Pu}(\mathrm{V})$ as the dominant oxidation state in solution in seawater. It is not possible to state whether this represents thermodynamic equilibrium or some balance of opposing redox conditions which results in a steady state concentration of $\mathrm{Pu}(\mathrm{V})$. $\mathrm{Pu}(\mathrm{VI})$ can be rapidly reduced to $\mathrm{Pu}(\mathrm{V})$. However, in the presence of humic materials a significant fraction of the $\mathrm{Pu}(\mathrm{VI})$ is reduced directly to $\mathrm{Pu}(\mathrm{IV})$ which hydrolyzes and sorbs to the walls and to particulate matter. Apparently there is competition between reduction of $\mathrm{Pu}(\mathrm{VI})$ to $\mathrm{Pu}(\mathrm{V})$ by seawater and complexation of $\mathrm{Pu}(\mathrm{VI})$ by humic acid (16). The latter results in rapid reduction of $\mathrm{Pu}(V I)$ to $\mathrm{Pu}$ (IV) with subsequent hydrolysis. Complexation of $\mathrm{Pu}(\mathrm{V})$ by humic acid should be much weaker and may account for the slow reduction of $\mathrm{Pu}(\mathrm{V})$ in the dark. Photolysis of the humic material apparently results in some oxidation of $\mathrm{Pu}(\mathrm{IV})$ to $\mathrm{Pu}(\mathrm{V})$, to provide a metastable $\mathrm{Pu}(\mathrm{V})$ concentration.

In an experiment with pore water ( $\mathrm{pH} 7.3$ ) squeezed from the Bahamian carbonate sediments from which the humic acid was extracted, we observed a significant reduction of $\mathrm{Pu}(\mathrm{V})$ with time. This observation would be consistent with a higher humic acid concentration in such pore water. It is in agreement with the observation that reduced forms (i.e. Pu(IV)) are predominant on particulate and sedimentary matter (5).

Observations that particulate organic matter has strong adsorption properties and that dissolved organic compounds often are adsorbed on inorganic phases to such an extent that they alter the surface properties of these phases have led to increased interest in the role played by organic matter on the sorption of dissolved compounds from seawater (17-29). Recently, interesting results have been reported for the sorptive properties of heterogeneous inorganicorganic solids (e.g., iron oxyhydroxide-humic acid) that may closely mimic natural particulate matter properties $(19,21,30-32)$. The influence of adsorbed organic compounds on the sorptive behavior of inorganic substrates is not the same for all sorbates (e.g., adsorption of copper is often strongly influenced, while cadmium adsorption is usually not significantly influenced) (19).

These new findings have added to the complexity of understanding and modeling the interaction of dissolved phases with particulate matter in marine waters, but the evidence is increasing that we are now capable of making reasonable quantitative predictions for the behavior of many trace metals in the deep ocean (21). To date, no direct studies have been made of the influences of organics, such 
as humic and fulvic acids, on the sorptive behavior of Pu on particles coated with these compounds. However, based on the strong interactions of $\mathrm{Pu}$ with dissolved humic acids, it is quite likely that they can also significantly influence both adsorption and surface redox reactions.

\section{Acknowledgments}

We acknowledge support of this research through a contract with the USDOE Office of Health and Environmental Research.

\section{Literature Cited}

1. Choppin, G. R. In "Environmental Inorganic Chemistry"; Martel1, A. E.; Irgolic, K. J., Eds.; VCH Publ. Inc.: Deerfield Beach, F1.; 1985; pp. 301-320.

2. Beasley, T. M.; Cross, F. A. In "Transuranium Elements in the Environment"; Hanson, W. C., Ed.; DOE/TIC-22800, National Tech. Inform. Serv.: Springfield, Va.; 1980; pp. 524-540.

3. Pillai, K. C.; Mathew, E. In "Transuranium Nuclides in the Environment"; Inter. At. Ener. Agency, STI/PUB/410: Vienna; 1976; pp. 25-44.

4. Fisher, N. D.; Bjerregaard, P.; Huynh-ngoe, L.; Harvey, G. R. Mar. Chem. 1983, 13, 45-56.

5. Dah1man, R. C.; Bondietti, E. A.; Eyman, E. D. In "Actinides in the Environment"; Friedman, A. M., Ed.; ACS SMMPOSIUM SERIES No. 35, American Chemical Society: Washington, D.C., 1976; pp. 47-80.

6. Nelson, D. M.; Lovett, M. B.; Nature 1978, 276, 599-601.

7. Nelson, D. M.; Carey, A. E.; Bowen, V. T. Earth Planet Sci. Lett. $1984,68,422-430$.

8. Aston, S. R. Mar. Chem. 1980, 8, 319-325.

9. Sholkovitz, E. R. Earth-Sci. Rev. 1983, 19, 95-161.

10. Caceci, M.; Choppin, G. R. Radiochem. Acta 1983, 33, 113-114.

11. Bertha, E. L.; Choppin, G. R. J. Inorg. Nuc1. Chem. 1978, 40, 655-658.

12. Saito, A; Roberts, R. A.; Choppin, G. R. Anal. Chem. 1985, $57,390-391$.

13. Bertrand, P. A.; Choppin, G. R. Radiochem. Acta 1982, $31,135-137$.

14. Kobashi, A.; Choppin, G. R., unpublished data.

15. Stumm, W. and Morgan, J. J. "Aquatic Chemistry" 2nd Ed.; John Wiley \& Sons, Inc.: New York, 1981, p. 514.

16. Shanbhag, P. M.; Choppin, G. R. J. Inorg. Nuc1. Chem. $1981,43,3369-3372$.

17. Davis, J. A. In "Contaminants and Sediments"; Ann Arbor Science: 1980; Vol. II.

18. Davis, J. A. Geochim. Cosmochim. Acta 1982, 46, 2381-2393. 
19. Davis, J. A. Geochim. Cosmochim. Acta 1984, 48, 679-691.

20. Hunter, K. A. Linno1. Oceanog. 1980, 25, 807-822.

21. Hunter, K. A. Deep-Sea Res. 1983, 30, 669-675.

22. Hunter, K. A.; Liss, P. S. Nature $1979,282,823-825$.

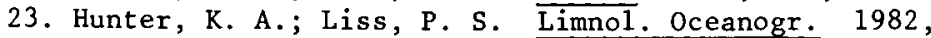
$27,322-335$.

24. Loeb, G. I.; Neihof, R. A. J. Mar. Res. 1977, 35, 283-291.

25. Neihof, R. A.; Loeb, G. I. Limno1. Oceanogr. 1972, $17,7-16$.

26. Neihof, R. A.; Loeb, G. I. Mar. Res. 1974, 32, 5-12.

27. Tipping, E. Chem. Geol. 1981a, 33, 81-89.

28. Tipping, E. Geochim. Cosmochim. Acta 1981b, 45, 191-199.

29. Tipping, E.; Cooke, D. Geochim. Cosmochim. Acta 1982, 46, 75-80.

30. Balistrieri, L. S.; Murray, J. W. Geochim. Cosmochim. Acta $1984,48,921-929$.

31. Davis, J. A.; Leckie, J. O. Environ. Sci. Techno1. $1978 \mathrm{~b}, 12,1309-1315$.

32. Tipping, E.; Griffith, J. R.; Hilton, J. Croatica Chem. Acta $1983,56,613-621$.

RECEIVED September 16, 1985 


\title{
The Interaction of Trace Metal Radionuclides with Humic Substances
}

\author{
Ljerka Musani-Marazovič ${ }^{\prime}$, Danielle Faguet ${ }^{2}$, and Zdenka Konrad ${ }^{t}$ \\ ${ }^{I}$ Center for Marine Research Zagreb, "Rudjer Boškovič” Institute, Zagreb, Yugoslavia \\ ${ }^{2}$ Centre de Recherches de Sedimentologie Marine de Perpignan, France
}

\begin{abstract}
The fate of trace metal radionuclides in the aquatic environment and their participation in the biogeochemical cycle depend strongly on the chemical and physico-chemical form in which radionuclides are introduced in natural waters. The abundance of natural humic substances and their ability to form metal complexes and to adsorb on suspended matter and sediment makes these substances especially important in transport, availability and accumulation of trace metal radionuclides in natural water environments. In that sense complexation of di- and tri-valent metal radionuclides with humic and fulvic acids of different origin was studied. The sorption properties of natural suspended matter and undissolved humic acid for the sorption of some radionuclides was also studied.
\end{abstract}

The toxicity and fate of metals in natural waters and their participation in biogeochemical cycles depend strongly on the physico-chemical forms of metals entering natural waters. Particularly important is the extent of organic complexation of trace metals. In recent years special interest has been paid to dissolved organic matter, a part of which consists of humic substances. Humic materials have been widely presumed to be important for organic complexation of metals. From that point of view it is of special importance to determine and characterize the species of metals actually present in aquatic systems. Dissolved and colloidal humic material enter the marine environment by river input into estuaries and are produced by biological and chemical processes occurring in the sea. According to Mantoura and Riley (1), humic substances are formed by random condensation of breakdown products of dead organisms and of extracellular metabolites of phytoplankton. Harvey et al. (2) propose that marine humic substances are formed from either Iight-induced oxidative cross-linking of two or more polyunsaturated fatty acids or from polyunsaturated glycerides.

Evidence of the formation of metal complexes with humic substances in natural waters has been reported by many authors (3-12). The same applied to the stability constants of the above complexes

0097-6156/86/0305-0389\$07.00/0

(c) 1986 American Chemical Society 
(13-18). Tremendous work has been done on the characterization of humic substances in the aquatic environment $(\underline{2}, 19,20)$ and much analytical data on the concentration of humic substances in natural waters is reported $(2,21-25)$. Special attention has been paid to the physico-chemical processes governing behaviour of metals and dissolved organic matter during estuarine mixing $(6,26-28)$.

In our work we concentrate on the interactions between di- and tri-valent metal radionuclides which enter estuarine and seawater in ionic forms and humic and fulvic acids of different origins. However, as humic substances react with metals, not only in dissolved but also in undissolved states, we report some data on the adsorption of trace metal radionuclides on suspended humic acids.

Materials and Methods

Electrophoretic experiments were performed with a high voltage device (Flat Plate Electrophoresis, Savant Instruments Inc., USA). Temperature was maintained at $20 \pm 0.1{ }^{\circ} \mathrm{C}$ with an ultrathermostat. The experimental conditions for high voltage paper electrophoresis were: basic electrolyte: 0.45 um filtered $10 \%$ seawater (sampled in Mid-Adriatic, original salinity $37.4 \%$ ) and estuarine water, the Krka estuary (salinity $2 \%$ ) with or without humic or fulvic acids; $\mathrm{pH}$ adjusted to 8.0; Whatman 3 MM filter paper with a free length and width of $85 \times 1.5 \mathrm{~cm}$; voltage $1000 \mathrm{~V}$; current per strip of paper: 2.0-3.9 mA (10\% seawater) and 1.3-1.5 mA (estuarine water); current per $1 \mathrm{~cm}$ width of the paper strip: $1.3-2.6 \mathrm{~mA}(10 \%$ seawater $)$ and 0.9-1 mA (estuarine water); specific electric effect on the paper strips: $0.016-0.031 \mathrm{VA} \mathrm{cm}-2$ (10\% seawater) and $0.010-0.012 \mathrm{VA} \mathrm{cm}^{-2}$ (estuarine water); duration of an experimental run: $102 \mathrm{~min}$. The radionculides ${ }^{54} \mathrm{Mn},{ }^{55} \mathrm{Fe}$ and ${ }^{51} \mathrm{Cr}$ were from N.E.N. (New Englapd, Nuclear), USA. The specific radioactivities were as follows: ${ }^{54} \mathrm{Mn}$ $10 \mathrm{mCi} \mathrm{ml}^{-1}$, concentration of $\mathrm{Mn}: 1527$ ug ml ${ }^{-1}$; 5 F : $10 \mathrm{mCi} \mathrm{ml}^{-1}$, concentration of $\mathrm{Fe}: 4.1 \mathrm{ug} \mathrm{ml}{ }^{-1}$; ${ }^{5 T} \mathrm{Cr}: 100 \mathrm{uCi} \mathrm{ml}^{-1}$, concentration of $\mathrm{Cr}: 0.62 \mathrm{ug} \mathrm{ml}{ }^{-1}$.

The samples for electrophoresis were prepared in the following way. An aliquot was evaporated to dryness. The residue was dissolved in estuarine or dilufed seawater adjusting 35 specific radioactivity of $0.45 \mathrm{uCi} / 20 \mathrm{ul}\left({ }^{\mathrm{Mn}}\right) ; 0.22 \mathrm{uCi} / 20 \mathrm{ul}\left(55_{\mathrm{Fe}}\right)$ and $2 \mathrm{uCi}-8 \mathrm{ul}$ $\left({ }^{51} \mathrm{Cr}\right)$. This corresponds to a Mn concentration of $5.3 \times 10^{-8} \mathrm{M}$, an $\mathrm{Fe}$ concentration of $7.9 \times 10^{-8} \mathrm{M}$, and a $\mathrm{Cr}$ concentration of $1.19 \times 10^{-5} \mathrm{M}$. Twenty microlitres of those solutions were applied to the starting point of the electrophoretic strips which were wetted previously with the respective solvent containing the respective humic/fulvic acid concentration. This caused a dilution of the respective trace metal concentration in the liquid phase on the electrophoretic paper strip by a factor of 3.355 . For experiments in the presence of humic/fulvic acid, the respective humic/fulvic acid concentration was adjusted in the test solution, and from the latter, after $30 \mathrm{~min}$, an aliquot of $20 \mathrm{ul}$ was subjected to electrophoresis. This measurement was termed 0 day. The measurements were extended for each adjusted humic/fulvic acid concentration over a period of 0 to at least 7 days (maximum 30 days) 789 detect $29 \delta_{s i b l e}$ aging effects. Experimental conditions for ${ }^{6} \mathrm{Zn},{ }^{189} \mathrm{Cd}$ and ${ }^{29}{ }_{\mathrm{Pb}}$ were described earlier $(\underline{8})$.

The humic and fulvic acids used in our experiments were from different sources. Humic acid (HAL sample) was isolated from sediment 
in the shallow waters of the Lim Channel (the Adriatic Sea) by a procedure reported in the literature $(\underline{3}, \underline{29})$. Humic acid was extracted from wet sediment with a mixture of $0.2 \mathrm{M} \mathrm{NaOH}$ and $0.2 \mathrm{M} \mathrm{Na}_{2} \mathrm{CO}_{3}$ at $80^{\circ} \mathrm{C}$ for $12 \mathrm{~h}$, purified by repeated precipitation with $\mathrm{HCl},{ }^{2}$ redissolved in $\mathrm{NaOH}$, dialysed and finally Chelex-100 was used to remove bound metals. Then it was again precipitated with $\mathrm{HCl}$, dried at $40^{\circ} \mathrm{C}$ and stored as crystalline powder in the acidic form. The HAN humic acid sirnple was isolated from the bottom sediment of the deep Norwegian Sea ( $1 \mathrm{~m}$ below the sediment surface). The HAM humic acid sample was isolated from the sediment of a tropical estuary at Mahakam (Borneo). The FAC and HAC samples of fulvic and humic acids were isolated from a Mediterranean lagoon (Canet, near Perpignan, France), and the HALR sample was isolated from deposit of Ruppia maritima, Linneaus from the same lagoon. The HAN, HAM, HAC, FAC and HALR samples were extracted from the sediment with a mixture of $0.1 \mathrm{M}$ $\mathrm{NaOH}$ and $0.1 \mathrm{M} \mathrm{Na}_{4} \mathrm{P}_{2} \mathrm{O}_{7}$ according to the procedure of Kononova and Balachirova (30). Those samples were purified by repeated precipitation with $\mathrm{HCl}$, redissolved in $\mathrm{NaOH}$ solution, dialysed and finally passed through the Dowex $50 \mathrm{~W}-\mathrm{X} 8$ resin.

Stock solutions of all samples were prepared in diluted $\mathrm{NaOH}$. The concentrations of humic and fulvic acids varied from 3 to $200 \mathrm{mg}$ $1^{-1}$ and the $\mathrm{pH}$ was adjusted to $\mathrm{pH} 8.0$ by the addition of $\mathrm{NaOH}$ or $\mathrm{HCl}$. The behaviour of radionuclides was followed up by measuring their electrophoretic mobility $(\mathrm{u})\left(\mathrm{cm}^{2} \mathrm{v}^{-1} \mathrm{~s}^{-7}\right)(31)$ and by evaluating the amount of the respective radionuclide in the three observable zones, i.e. cationic, anionic, and the immobile zone at the starting point. The electrophoretic zones could be detected conveniently by autoradiography exposing an X-ray film overnight to the electrophoretic strips. The respective zones were cui from the paper and counted in a $\beta$-liquid scintillation counter or in a $Y$-counter.

Some characteristics of humic and fulvic acid samples. Unfortunately, we were not able to perform some desired analyses of the samples; in the first place because of very small quantities in which some of the samples were available, and secondly, because some samples were not soluble enough to do molecular size distribution analyses.

The results of the elemental analyses of the humic substances are presented in Table $I$.

According to Nissenbaum and Kaplan (33) the $\mathrm{C} / \mathrm{N}$ ratios from most humic acids of marine origin fall into the range $9.4-14.2$. Our samples named HAL, HAN, HAC might be of marine origin.

In Table II total acidity and carboxyl groups analyses are given for some of the samples used.

For some of the samples adsorption spectra were recorded (11). The ratio between the optical densities at 465 and $665 \mathrm{~nm}$ has been used as an indicator of the condensation degree of humic substances (34). The lower the $E_{4} / E_{6}$ ratio the higher the condensation degree of the humic acids. According to this, the condensation degree of HAN is the highest $\left(E_{4} / E_{6}=3.7\right)$, followed by HAL $\left(E_{4} / E_{6}=6.7\right)$ and the lowest is HAM $\left(E_{4} / E_{6}=8.3\right)$. The optical densities of the UV spectra increase with decreasing wavelength. For the same weight concentrations the sequence of UV-light absorption is HAN > HAL > HAM at wavelengths below $240 \mathrm{~nm}$ (11). From the measured IR spectra Raspor et al. (11) concluded that of the three samples (HAL, HAN and HAM) the $\overline{H A N}$ sample showed the most pronounced aliphatic character followed by HAL. 
Table I. Elementary composition of investigated humic material and $\mathrm{C} / \mathrm{H}$ and $\mathrm{C} / \mathrm{N}$ ratios

\begin{tabular}{|c|c|c|c|c|c|c|c|c|c|}
\hline \multirow{2}{*}{ Humic substances } & \multicolumn{6}{|c|}{ Elementary composition (\%) } & \multirow{2}{*}{$\mathrm{C} / \mathrm{H}$} & \multirow{2}{*}{$\mathrm{C} / \mathrm{N}$} & \multirow{2}{*}{ Ref. } \\
\hline & $\mathrm{C}$ & $\mathrm{H}$ & $\mathrm{N}$ & S & $\mathrm{Cl}$ & 0 & & & \\
\hline $\begin{array}{l}\text { HAL-humic acid } \\
\text { from Lim Channel } \\
\text { (Adriatic Sea) }\end{array}$ & 54.1 & 5.5 & 4.2 & 1.4 & 3.4 & 31.4 & 9.8 & 12.8 & $(11)$ \\
\hline $\begin{array}{l}\text { HAN-humic acid } \\
\text { from Norwegian } \\
\text { sea sediments }\end{array}$ & 52.9 & 6.7 & 4.2 & 2.2 & 1.6 & 32.4 & 7.9 & 12.7 & $(\underline{11})$ \\
\hline $\begin{array}{l}\text { HAM-humic acid } \\
\text { from estuarine } \\
\text { sediments } \\
\text { (Mahakam, Borneo) }\end{array}$ & 50.7 & 4.8 & 1.7 & 1.2 & ND & 39.8 & 10.7 & 30.7 & (11) \\
\hline $\begin{array}{l}\text { HAC-humic acid } \\
\text { from lagoon sed. } \\
\text { (Canet, France) }\end{array}$ & 50.8 & 5.8 & 4.0 & 1.5 & ND & $37 \cdot 7$ & 8.8 & 12.7 & $(\underline{32})$ \\
\hline $\begin{array}{l}\text { FAC-fulvic acid } \\
\text { from lagoon sed. } \\
\text { (Canet, France) }\end{array}$ & 38.7 & 5.4 & 2.2 & 2.0 & ND & 51.6 & 7.2 & 17.2 & $(\underline{32})$ \\
\hline
\end{tabular}

$N D=$ not determined. Reproduced with permission from Ref. 11. Copyright 1984 Elsevier Sclence.

Table II. Total acidity and carboxyl groups for samples of some humic substances (32)

\begin{tabular}{|c|c|c|}
\hline Humic substance & $\begin{array}{c}\text { Total acidity } \\
\text { (meq } g^{\prime} \text { ) }\end{array}$ & $\begin{array}{l}\text { Carboxy l groups } \\
\left(\text { meq } g^{-1}\right)\end{array}$ \\
\hline $\begin{array}{l}\text { HAN (Norw. S. sed.) } \\
\text { HAM (Mahakam) } \\
\text { HAC (Canet) } \\
\text { FAC (Canet) }\end{array}$ & $\begin{array}{l}3.73 \\
6.78 \\
3.65 \\
5.82\end{array}$ & $\begin{array}{l}2.21 \\
3.25 \\
2.89 \\
4.62\end{array}$ \\
\hline
\end{tabular}

They also concluded that HAN and HAL samples have higher molecular weights than the HAM sample, and that HAN and HAL samples are of marine origin. This is also supported by the findings of Hatcher et al. (19) showing that humic acids from marine sediments are predominantly composed of highly branched, unsubstituted aliphatic structures.

For most of the samples the molecular size distribution was not measured owing to the samples' incomplete solubility, which shows their hydrophobic character. The molecular size distribution was determined (32) only for HALR humic acid sample (deposit of Ruppia maritima, Linnaeus) using size exclusion chromatography. The carbon content was measured by DOC and by a UV detector. Two peaks were

In Organic Marine Geochemistry; Sohn, M.;

ACS Symposium Series; American Chemical Society: Washington, DC, 1986. 
found. The dominant fraction has a molecular size corresponding to a molecular weight of approximately 50,000 , and the smaller fraction has an apparent molecular weight of approximately 18,000.

Some of the samples were analyzed for trace metal concentration and the results are presented in Table III.

Table III. Trace metal concentrations of the humic substances investigated

\begin{tabular}{|c|c|c|c|c|c|c|c|}
\hline \multirow{2}{*}{ Humic substance } & \multicolumn{6}{|c|}{ Concentrations of trace metals (ug $\mathrm{g}^{-1}$ ) } & \multirow{2}{*}{ Ref. } \\
\hline & Al & $\mathrm{Cu}$ & $\mathrm{Cd}$ & $\mathrm{Pb}$ & $\mathrm{Zn}$ & $\mathrm{Fe}$ & \\
\hline HAL (Lim Channel) & 170 & 166 & 0.3 & 3.9 & 56.4 & ND & (11) \\
\hline HAN (Nor. S. sed.) & 2000 & 433 & 2.9 & 12.2 & 101.5 & ND & $(\underline{11})$ \\
\hline HAM (Mahakam) & 3100 & 188 & 0.6 & 7.9 & 69.7 & 2500 & $(\overline{11})$ \\
\hline HAC (Canet) & 900 & 1041 & 8.3 & 113.0 & 113.0 & ND & $(\overline{32})$ \\
\hline FAC (Canet) & 140 & ND & ND & ND & ND & ND & $(\underline{32})$ \\
\hline
\end{tabular}

ND $=$ not determined. Reproduced with permission from Ref. 11. Copyright 1984 Elsevier Science.

Raspor et al. (11) have also measured the adsorption of HAN, HAL and HAM samples at the hanging mercury drop electrode applying out-of-phase ac-voltammetry. According to their results the molecular size and the hydrophobicity of the investigated sample increase in the order HAM $<$ HAL $<$ HAN.

Results

The electrophoretic results on the interaction of ${ }^{65} \mathrm{Zn},{ }^{109} \mathrm{Cd}$ and

$\mathrm{Pb}$ with humic acid (HAL sample) in different dilutions of seawater have been reported earlier $(8)$. All three trace metal radionuclides in $10 \%$ seawater (without the additig of humic acid 31 are mostly in the cationic form $\left({ }^{65} \mathrm{Zn}: 98.2 \%\right.$; ${ }^{89} \mathrm{Cd}: 99.5 \%$ and ${ }^{210} \mathrm{~Pb}$ : $61.8 \%)$.

The distribution of ${ }^{109} \mathrm{Cd}$ species in the $10 \%$ seawater ${ }^{2}$ umic acid (HAL) system is presented in Table IV, and the binding of ${ }^{65} \mathrm{Zn}$ and

$\mathrm{Pb}$ with HAL is presented in Figure 1. (The percentage of the metal humates was calculated from the decrease in the amount of the cationic form of metal ion).

${ }^{54}$ Manganese. In 5 diluted seawater $(10 \%, S=3.7 \% 0)$ and in estuarine water $(S=2 \% 0){ }^{54} \mathrm{Mn}$ pehaves as a fation with electrophoretic mobilities $u=4^{-3.03 \times 10^{-4}}\left(\mathrm{~cm}^{2} \mathrm{v}^{-1} \mathrm{~s}^{-1}\right)$ in diluted seawater and $u=$ $-3.22 \times 10^{-4}\left(\mathrm{~cm}^{2} \mathrm{v}^{-1} \mathrm{~s}^{-1}\right)$ in estuarine water, but shows also some cationic tailing, i.e. moves more slowly in the electric field than the cationic zone. The distribution of ${ }^{54} \mathrm{Mn}$ species in the estuarine and diluted seawater is shown in Table $\mathrm{V}$.

By the addition of humic agid to the diluted seawater $(10 \%)$, the amount of the cationic zone of ${ }^{54} \mathrm{Mn}$ decreases, while the cationic tailing and the immobile zone increase (Figure 2). One hundred percent represents the total amount of $54 \mathrm{Mn}$ in the system. The percentage of

In Organic Marine Geochemistry; Sohn, M.;

ACS Symposium Series; American Chemical Society: Washington, DC, 1986. 


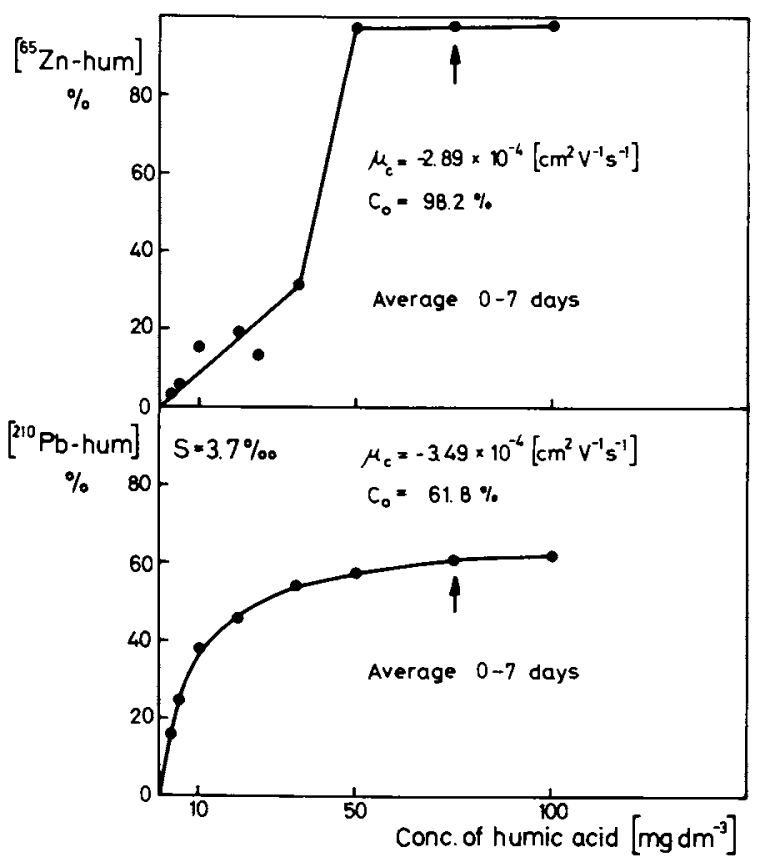

Figure 1. Dependence of $\mathrm{Zn}$ - and $\mathrm{Pb}$-humates formation on the concentration of humic acid (HAL) in 10\% seawater. (Reproduced with permission from Ref. 8. Copyright 1980 Academic Press, London.)

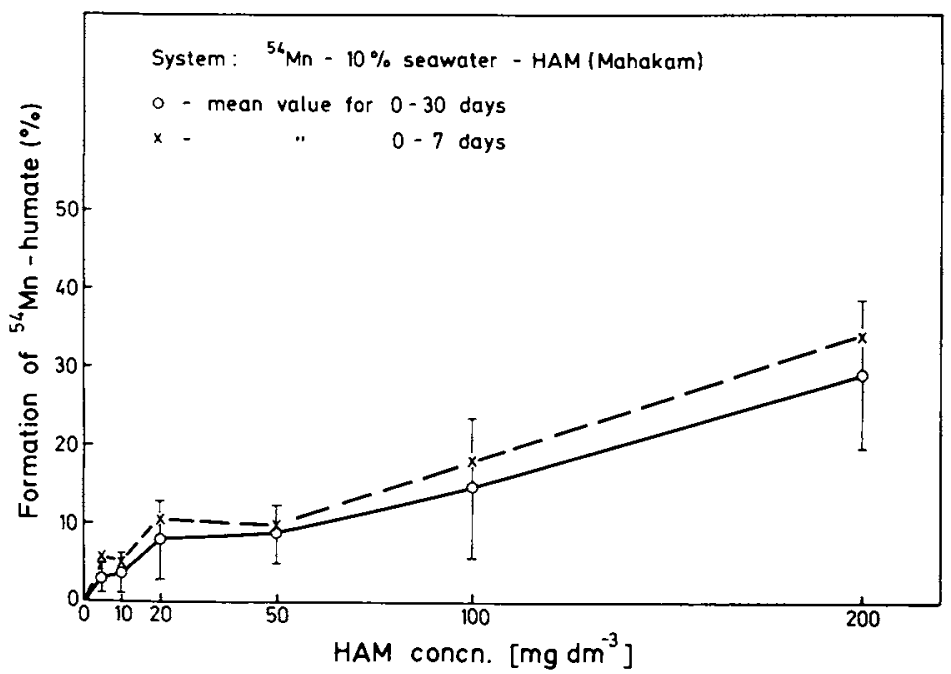

Figure 2. Dependence of Mn-humate formation on the concentration of humic acid (HAM) in $10 \%$ seawater.

In Organic Marine Geochemistry; Sohn, M.;

ACS Symposium Series; American Chemical Society: Washington, DC, 1986. 
Table IV. Distribution of ${ }^{109} \mathrm{Cd}$ species in the $10 \%$ seawater - humic acid system ( $\underline{8})$

\begin{tabular}{cccc}
\hline \multirow{2}{*}{$\begin{array}{c}\text { Concentration of } \\
\text { humic acid (mg dm }\end{array}$} & \multicolumn{3}{c}{ Distribution of ${ }^{109} \mathrm{Cd}$ species (\%) } \\
\cline { 2 - 4 } & $\mathrm{C}$ & $\mathrm{S}$ & $\mathrm{A}$ \\
\hline 0 & 99.5 & 0.5 & 0 \\
3 & 98.6 & 1.4 & 0 \\
5 & 98.3 & 1.7 & 0 \\
20 & 98.8 & 1.2 & 0 \\
150 & 4.2 & 95.2 & 0.6 \\
\hline
\end{tabular}

$C=$ cationic zone, $u=-2.03 \times 10^{-4}\left(\mathrm{~cm}^{2} \mathrm{~V}^{-1} \mathrm{~s}^{-1}\right) ; \mathrm{S}=$ zone at the starting point; $A=$ anionic tailing. Reproduced with permission from Ref. 8. Copyright 1980 Academic Press.

Table V. Distribution of ${ }^{54} \mathrm{Mn}$ species in $10 \%$ seawater and in estuarine water

\begin{tabular}{|c|c|c|c|c|c|}
\hline \multirow{2}{*}{ Electrolyte } & \multirow{2}{*}{$\begin{array}{l}\text { Aging of the } \\
\text { system (days) }\end{array}$} & \multicolumn{4}{|c|}{ Distribution of ${ }^{54} \mathrm{Mn}$ species $(\%)$} \\
\hline & & C zone & $c_{\text {tail }}$ & $S$ & A \\
\hline Estuarine water & $\begin{array}{r}0 \\
1 \\
7 \\
15\end{array}$ & $\begin{array}{l}93.5 \\
93.5 \\
92.3 \\
84.0\end{array}$ & $\begin{array}{l}5.8 \\
5.4 \\
6.9 \\
9.9\end{array}$ & $\begin{array}{l}0.7 \\
1.1 \\
0.7 \\
6.1\end{array}$ & $\begin{array}{l}0.0 \\
0.0 \\
0.1 \\
0.0\end{array}$ \\
\hline $10 \%$ seawater & $\begin{array}{r}0 \\
1 \\
7 \\
15 \\
30\end{array}$ & $\begin{array}{l}92.1 \\
95.6 \\
95.7 \\
93.7 \\
93.2\end{array}$ & $\begin{array}{l}7.9 \\
4.4 \\
3.6 \\
5.9 \\
6.5\end{array}$ & $\begin{array}{l}0.0 \\
0.0 \\
0.7 \\
0.3 \\
0.3\end{array}$ & $\begin{array}{l}0.0 \\
0.0 \\
0.0 \\
0.1 \\
0.0\end{array}$ \\
\hline
\end{tabular}

$\mathrm{C}=$ cationic zone; $\mathrm{C}_{\text {tail. }}$ = cationic tailing; $\mathrm{S}=$ starting point zone; $A=$ anionic zone.

${ }^{54} \mathrm{Mn}$ bound to the humic acid was calculated from the decrease of ${ }^{54} \mathrm{Mn}$ in the cationic zone, or, in other words, the ${ }^{54} \mathrm{Mn}$ bound to humic acid represents the sum of the increase in the cationic tailing, the immobile zone and in the anionic tailing.

of 54 The aging of the system plays an important role in the binding of ${ }^{4} \mathrm{Mn}$ to the humic acid. The maximum of binding was reached at $^{1-7}$ days of aging. For older systems the percentage of the bound ${ }^{54} \mathrm{Mn}$ to the humic subtances decreased, which is partially seen when the $0-30$ day and 0-15 day curves are compared (Figure 2).

Figure 3 shows the change in the distribution of the ${ }^{54} \mathrm{Mn}$ zones when $100 \mathrm{mg}$ of HAM (Mahakam humic acid) is added to the seawater. It is well demonstrated that the maximum of binding to the humic acid is seen in the 1 day old system; older systems show relatively smaller decreases of the cationic ${ }^{4}$ Mn zone.

In Organic Marine Geochemistry; Sohn, M.;

ACS Symposium Series; American Chemical Society: Washington, DC, 1986. 


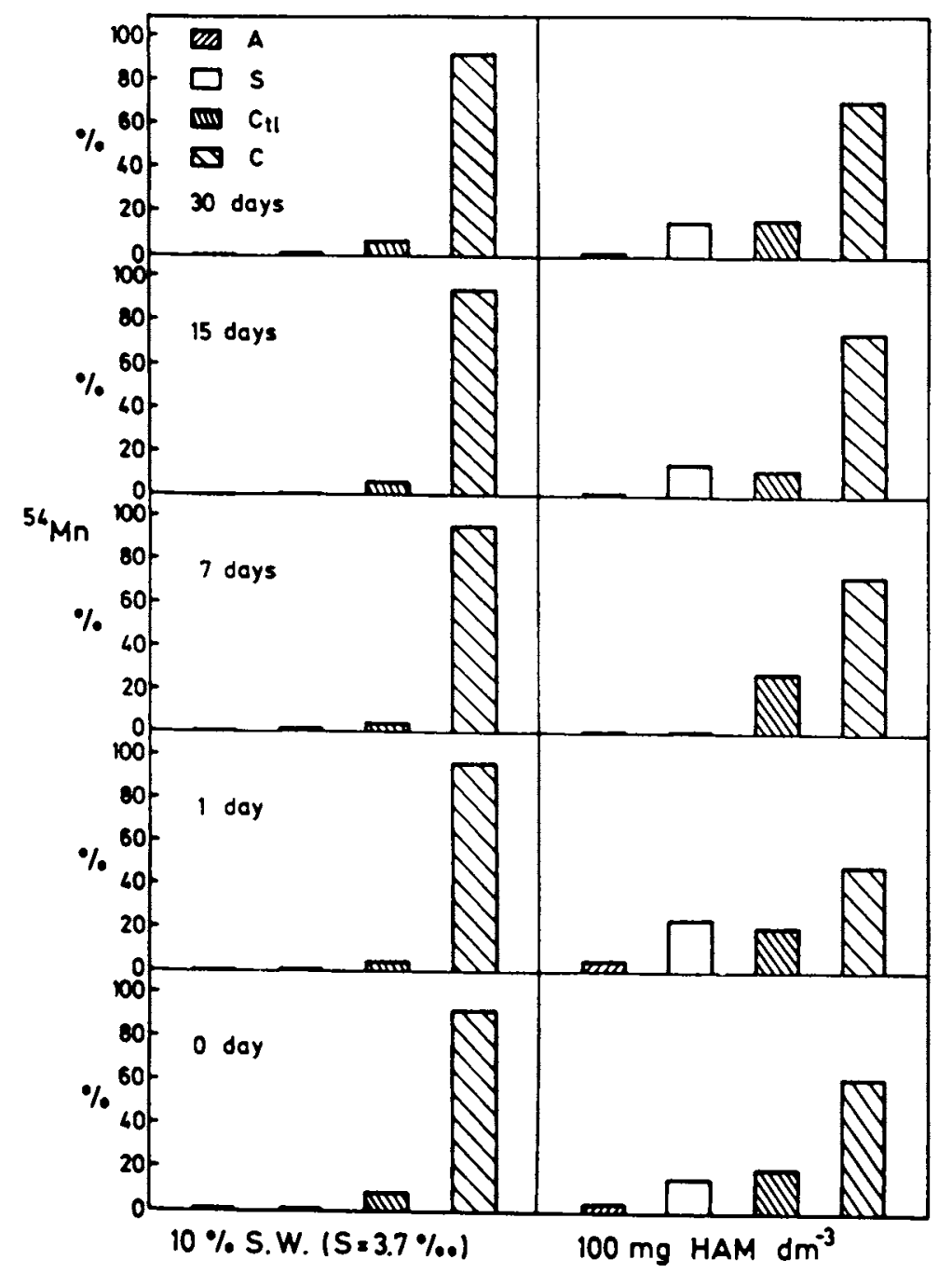

Figure 3. Distribution of ${ }^{54} \mathrm{Mn}$ zones in the $10 \%$ seawater -100 mg HAM system.

In Organic Marine Geochemistry; Sohn, M.;

ACS Symposium Series; American Chemical Society: Washington, DC, 1986. 
Figure 4 presents the distribution of ${ }^{54} \mathrm{Mn}$ zones in the presence of $100 \mathrm{mg}$ of different humic acids and fulvic acid samples in estuarine water. As seen in Figure 4, in older systems, the binding of $54 \mathrm{Mn}$ to humic substances is stronger. The maximum for HAL and FAC samples is reached in the 7 day old systems and for HAM at 1 day of aging. If we calculate the mean binding of ${ }^{54} \mathrm{Mn}$ to humic substances for all system aged from 0 to 15 days in the same way as demonstrated in Figure 2, the strongest binding of ${ }^{54} \mathrm{Mn}$ is with the HAM sample, followed by the FAC and HAL samples.

${ }^{55}$ Iron. In diluted seawater $(10 \%){ }^{55} \mathrm{Fe}$ introduced as $\mathrm{Fe}$ (III) is present almost completely in the immobile electrophoretic zone ( $98.7 \%)$, only a small part in the cationic tailing $(1.2 \%)$ and a negligible amount in the anionic tailing zones $(0.1 \%)$. However, the addition of humic substances to diluted seawater pegduces not only anionic but also cationic zones 95 the tailing of ${ }^{5} \mathrm{Fe}$. In Table VI, VII and VIII the distribution of ${ }^{55} \mathrm{Fe}$ zones in diluted seawater - humic acid systems (HAM, HAN and HAC samples) is presented.

As seen from the tables in addition to the concentration and the origin of humic acid, the aging of the system is also very important in the distribution of the ${ }^{35} \mathrm{Fe}$ zones.

Comparing these three tables it is obvious that the HAN sample produces more of the cationic ${ }^{55} \mathrm{Fe}$ zone/tailing than the other samples, and that HAC produces more of the anionic $55 \mathrm{Fe}$ zone, but that the highest amount of the anionic ${ }^{55} \mathrm{Fe}$ is found in the 24 day old HAM - $10 \%$ seawater system.

In Figure 5 we have tried to demonstrate the influence of both the concentration of fulvic acid and of the aging of the system on the distribution of electrophoretic zones of ${ }^{55} \mathrm{Fe}$ in diluted seawater. The concentration of $10 \mathrm{mg}$ of FAC in $10 \%$ seawater produces a tremendous increase in the cationic zone/tailing of ${ }^{55} \mathrm{Fe}$, amounting to $80.7 \%$ of the total ${ }^{55} \mathrm{Fe}$ present (without FAC only $1.2 \%$ of ${ }^{55} \mathrm{Fe}$ is in the cationic tailing zone). However, after aging 27 days, this zone dropped to only $0.4 \%$ in favgur of the anippic zone (48.4\%). At FAC concentrations of $100 \mathrm{mg} \mathrm{dm}$ the anionic $55 \mathrm{Fe}$ zone amounted to $9 \%$, and after 27 days it amounted to $79.6 \%$ of the total ${ }^{55} \mathrm{Fe}$.

Differences in the distribution of ${ }^{5} \mathrm{Fe}$ zones in the $10 \%$ seawater-humic substances systems, when the same concentrations of different humic substance samples are used, are presented in Figure 6 . There is no goubt that the FAC sample produces the highest amount of the anionic ${ }^{55} \mathrm{Fe}$ zone but all samples of the pumic substances significantly influence the distribution of the ${ }_{55}^{5} \mathrm{Fe}$ electrophoretic zones. Besides that, the distribution of the ${ }^{55} \mathrm{Fe}$ zones in very aged systems ( 24 days) is always significantly different than in the freshly prepared or in the 1 and 7 day old systems.

${ }^{51}$ Chromium. ${ }^{51} \mathrm{Cr}$ introduced into diluted seawater as $\mathrm{Cr}$ (III), is distributed between three electrophoretic zones: one immobile zone and both anionic and cationic tailing zones. The distribution of electrophoretic zones is given in Table IX.

By the agdition of humic substances to diluted seawater the dis5 tibution of ${ }^{5} \mathrm{Cr}$ species charged. In Figure 7 the distribution of $\mathrm{Cr}$ species in $10 \%$ seawater - fulvic acid (Canet) is presented as a function of both the concentration of FAC and the aging of the system. The influence of FAC on the distribution of $51 \mathrm{Cr}$ zones is especially 


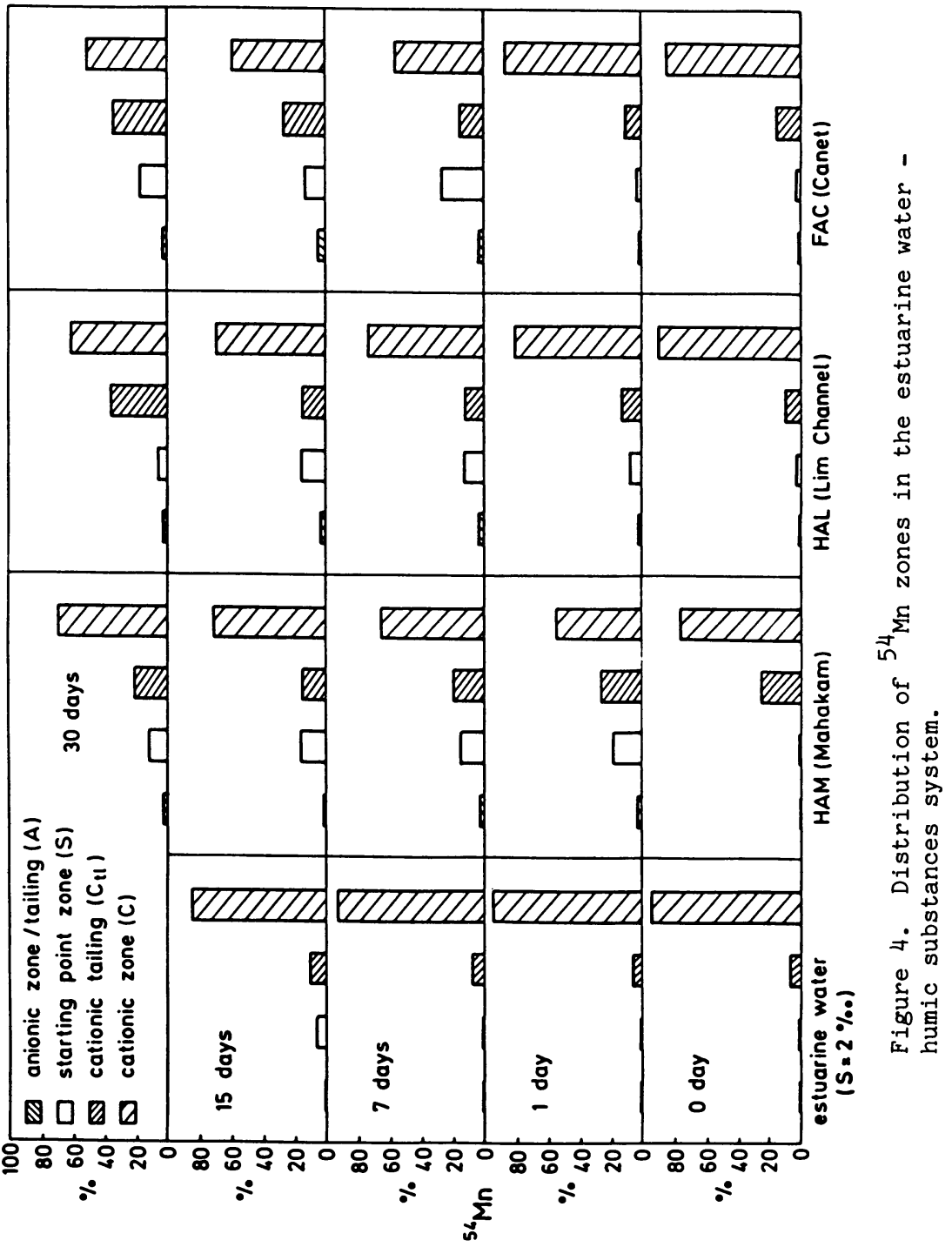

In Organic Marine Geochemistry; Sohn, M.; ACS Symposium Series; American Chemical Society: Washington, DC, 1986. 
Table VI. Distribution of electrophoretic zones of ${ }^{55} \mathrm{Fe}$ in $10 \%$ seawater-humic acid (HAM) systems (\%)

\begin{tabular}{|c|c|c|c|c|c|}
\hline $\begin{array}{l}\text { HA conc } \\
\left(\mathrm{mg} \mathrm{dm}^{-3}\right)\end{array}$ & $t$ (days) & A & $S$ & C & Total cpm \\
\hline 100 & $\begin{array}{r}0 \\
1 \\
7 \\
24\end{array}$ & $\begin{array}{r}1.5 \\
2.1 \\
2.0 \\
36.3\end{array}$ & $\begin{array}{l}21.6 \\
27.2 \\
36.0 \\
63.4\end{array}$ & $\begin{array}{r}76.9 \\
70.7 \\
52.0 \\
0.3\end{array}$ & $\begin{array}{l}16,000 \\
27,000 \\
41,000 \\
22,000\end{array}$ \\
\hline 50 & $\begin{array}{r}0 \\
1 \\
7 \\
24\end{array}$ & $\begin{array}{r}0.9 \\
0.6 \\
3.0 \\
23.7\end{array}$ & $\begin{array}{l}13.0 \\
16.2 \\
31.0 \\
75.8\end{array}$ & $\begin{array}{r}86.1 \\
83.2 \\
66.0 \\
0.5\end{array}$ & $\begin{array}{l}14,000 \\
40,000 \\
11,000 \\
15,000\end{array}$ \\
\hline 20 & $\begin{array}{r}0 \\
1 \\
7 \\
24\end{array}$ & $\begin{array}{r}0.7 \\
0.5 \\
0.8 \\
36.7\end{array}$ & $\begin{array}{l}17.3 \\
14.5 \\
27.0 \\
63.0\end{array}$ & $\begin{array}{r}82.0 \\
85.0 \\
72.2 \\
0.3\end{array}$ & $\begin{array}{r}36,000 \\
19,000 \\
28,000 \\
9,000\end{array}$ \\
\hline 10 & $\begin{array}{l}0 \\
1\end{array}$ & $\begin{array}{l}0.7 \\
1.0\end{array}$ & $\begin{array}{l}21.2 \\
18.8\end{array}$ & $\begin{array}{l}78.1 \\
80.2\end{array}$ & $\begin{array}{l}9,000 \\
9,000\end{array}$ \\
\hline
\end{tabular}

Table VII. Distribution of electrophoretic zones of ${ }^{55} \mathrm{Fe}$ in $10 \%$ seawater-humic acid (HAN) systems (\%)

\begin{tabular}{|c|c|c|c|c|c|}
\hline $\begin{array}{l}\text { HA conc } \\
(\mathrm{mg} \mathrm{dm}-3 \text { ) }\end{array}$ & $t$ (days) & A & $S$ & C & Total cpm \\
\hline 100 & $\begin{array}{r}0 \\
1 \\
7 \\
24\end{array}$ & $\begin{array}{l}2.8 \\
4.4 \\
4.3 \\
8.8\end{array}$ & $\begin{array}{l}28.5 \\
28.5 \\
37.9 \\
90.8\end{array}$ & $\begin{array}{r}68.7 \\
67.1 \\
57.8 \\
0.4\end{array}$ & $\begin{array}{r}6,000 \\
12,000 \\
15,000 \\
30,000\end{array}$ \\
\hline 50 & $\begin{array}{r}0 \\
1 \\
7 \\
24\end{array}$ & $\begin{array}{l}1.6 \\
1.6 \\
1.0 \\
6.4\end{array}$ & $\begin{array}{l}27.3 \\
17.2 \\
18.1 \\
86.1\end{array}$ & $\begin{array}{r}71.1 \\
81.2 \\
80.9 \\
7.5\end{array}$ & $\begin{array}{r}7,000 \\
13,000 \\
32,000 \\
22,000\end{array}$ \\
\hline 20 & $\begin{array}{r}0 \\
1 \\
7 \\
24\end{array}$ & $\begin{array}{l}2.7 \\
0.1 \\
0.4 \\
7.8\end{array}$ & $\begin{array}{l}63.2 \\
31.4 \\
18.4 \\
69.7\end{array}$ & $\begin{array}{l}34.1 \\
68.5 \\
81.2 \\
22.5\end{array}$ & $\begin{array}{r}4,000 \\
6,000 \\
23,000 \\
6,000\end{array}$ \\
\hline 10 & $\begin{array}{r}0 \\
1 \\
7 \\
24\end{array}$ & $\begin{array}{l}1.3 \\
0.7 \\
1.7 \\
5.8\end{array}$ & $\begin{array}{l}34.5 \\
13.2 \\
20.5 \\
85.9\end{array}$ & $\begin{array}{r}64.2 \\
86.1 \\
77.8 \\
8.3\end{array}$ & $\begin{array}{r}5,000 \\
14,000 \\
5,000 \\
4,000\end{array}$ \\
\hline
\end{tabular}

$\mathrm{A}=$ anionic zone and/or anionic tailing; $\mathrm{C}=$ cationic zone and/or cationic tailing; $S=$ zone at the starting point of the electrophoretic strip

In Organic Marine Geochemistry; Sohn, M.;

ACS Symposium Series; American Chemical Society: Washington, DC, 1986. 


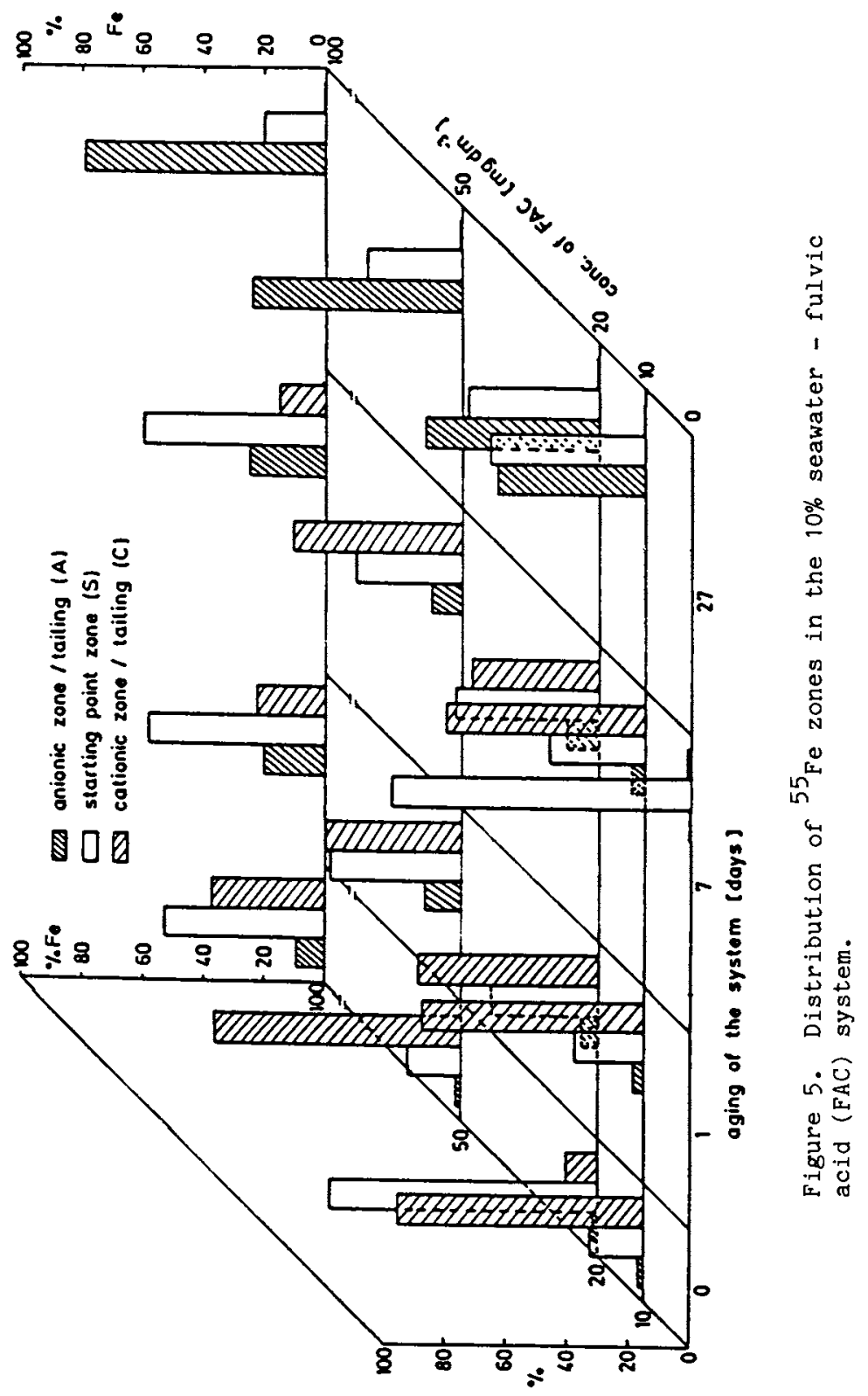

In Organic Marine Geochemistry; Sohn, M.;

ACS Symposium Series; American Chemical Society: Washington, DC, 1986. 


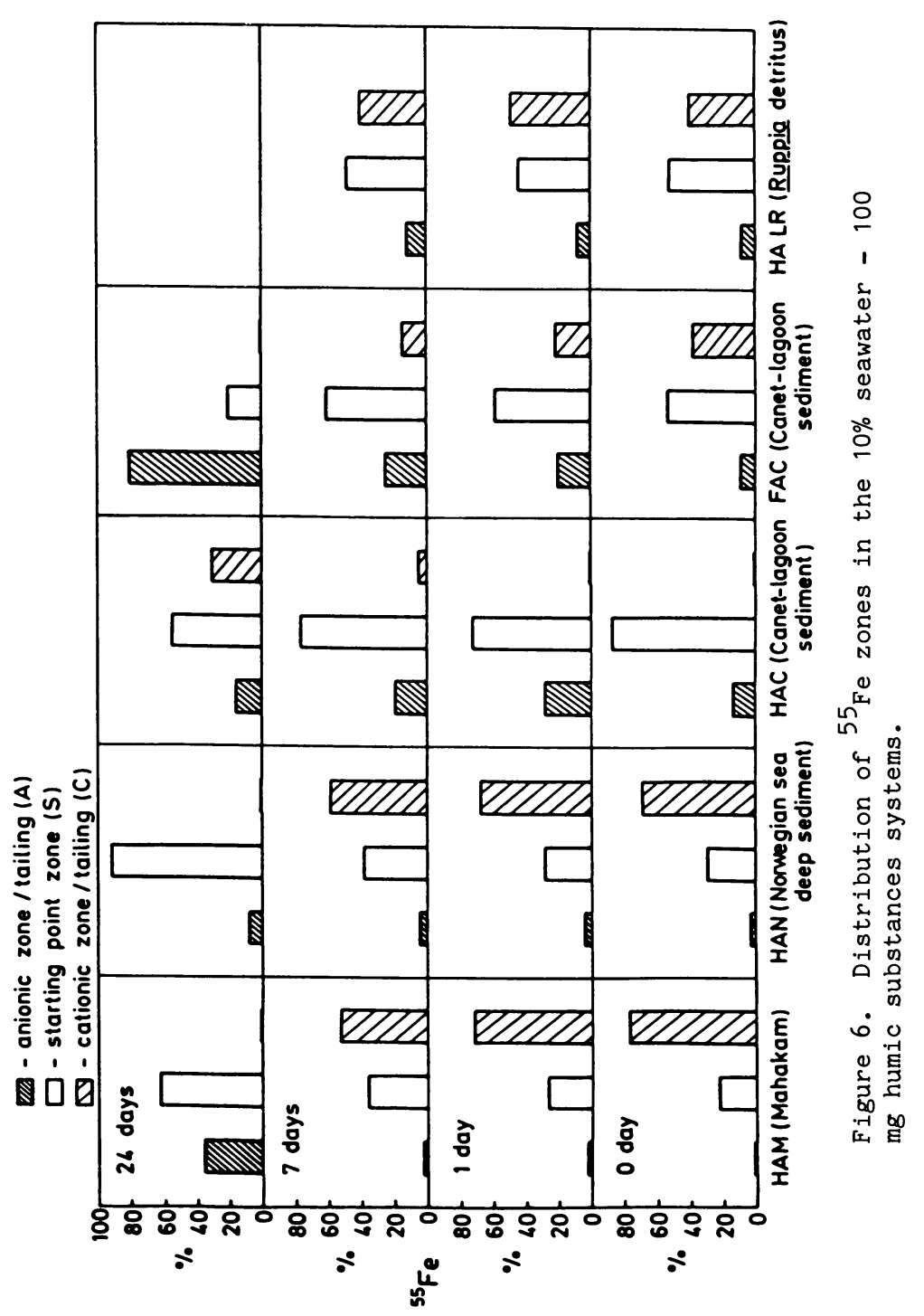

In Organic Marine Geochemistry; Sohn, M.;

ACS Symposium Series; American Chemical Society: Washington, DC, 1986. 


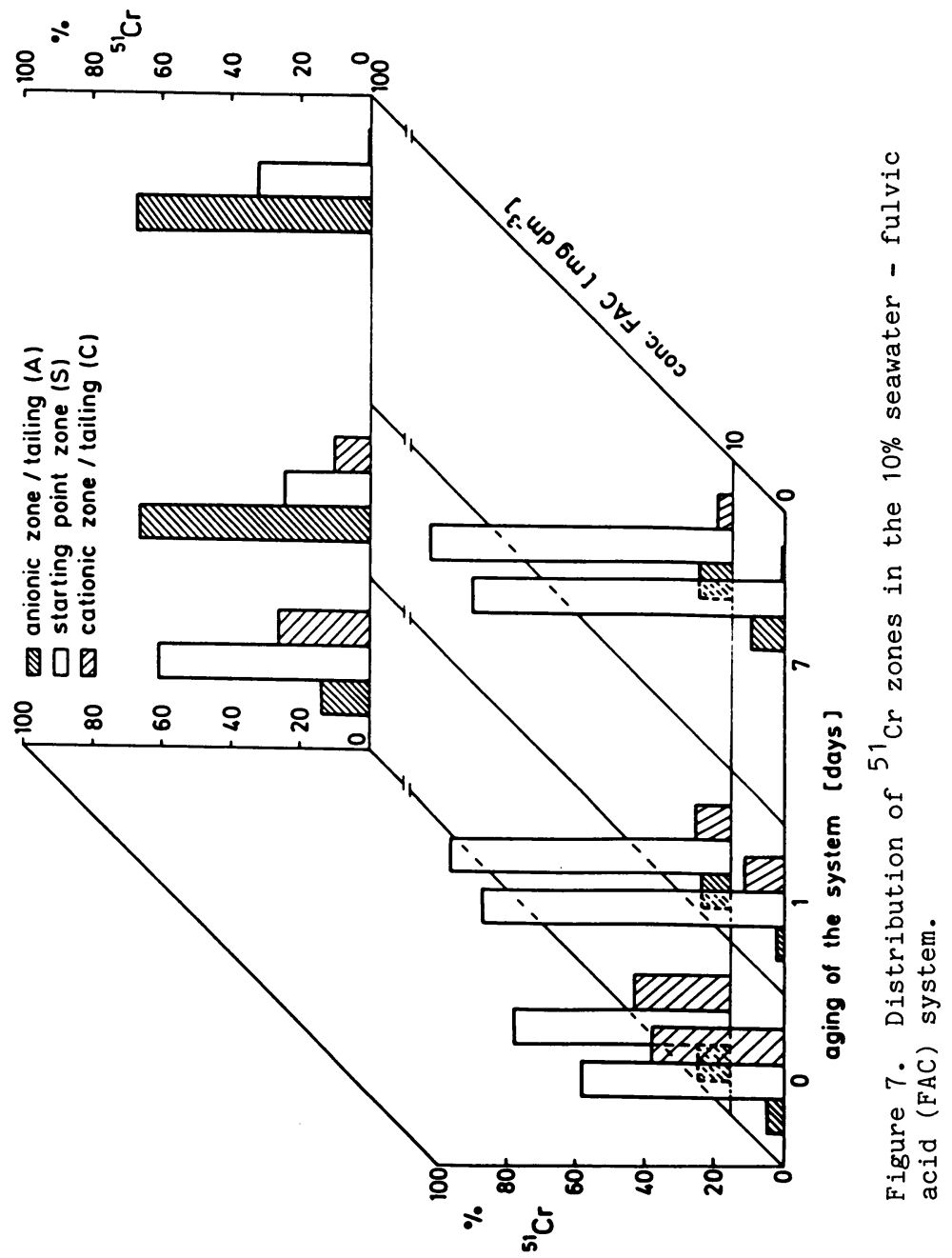

In Organic Marine Geochemistry; Sohn, M.;

ACS Symposium Series; American Chemical Society: Washington, DC, 1986. 
Table VIII. Distribution of electrophoretic zones of ${ }^{55} \mathrm{Fe}$ in $10 \%$ seawater-humic acid (HAC) systems (\%)

\begin{tabular}{|c|c|c|c|c|c|}
\hline $\begin{array}{l}\text { HA conc } \\
\left(\mathrm{mg} \mathrm{dm}^{-3}\right)\end{array}$ & $t$ (days) & A & $S$ & C & Total cpm \\
\hline 200 & $\begin{array}{r}0 \\
1 \\
7 \\
24\end{array}$ & $\begin{array}{r}13.9 \\
22.0 \\
29.2 \\
9.5\end{array}$ & $\begin{array}{l}77.8 \\
67.8 \\
60.1 \\
59.3\end{array}$ & $\begin{array}{r}8.3 \\
10.2 \\
10.7 \\
31.2\end{array}$ & $\begin{array}{r}82,000 \\
82,000 \\
74,000 \\
118,000\end{array}$ \\
\hline 100 & $\begin{array}{r}0 \\
1 \\
7 \\
24\end{array}$ & $\begin{array}{l}13.0 \\
28.0 \\
19.0 \\
15.6\end{array}$ & $\begin{array}{l}86.8 \\
71.8 \\
75.6 \\
54.5\end{array}$ & $\begin{array}{r}0.2 \\
0.2 \\
5.4 \\
29.9\end{array}$ & $\begin{array}{r}47,000 \\
63,000 \\
68,000 \\
101,000\end{array}$ \\
\hline 50 & $\begin{array}{r}0 \\
1 \\
7 \\
24\end{array}$ & $\begin{array}{r}9.3 \\
21.8 \\
15.9 \\
7.7\end{array}$ & $\begin{array}{l}88.8 \\
77.8 \\
78.7 \\
47.9\end{array}$ & $\begin{array}{r}1.8 \\
0.4 \\
5.4 \\
44.4\end{array}$ & $\begin{array}{r}4,000 \\
4,000 \\
5,000 \\
12,000\end{array}$ \\
\hline 20 & $\begin{array}{r}0 \\
1 \\
7 \\
24\end{array}$ & $\begin{array}{r}4.7 \\
14.2 \\
13.4 \\
6.1\end{array}$ & $\begin{array}{l}81.9 \\
81.2 \\
70.9 \\
51.6\end{array}$ & $\begin{array}{r}13.4 \\
4.6 \\
15.7 \\
42.3\end{array}$ & $\begin{array}{l}3,000 \\
2,000 \\
3,000 \\
5,000\end{array}$ \\
\hline 10 & $\begin{array}{l}1 \\
7\end{array}$ & $\begin{array}{r}15.6 \\
8.2\end{array}$ & $\begin{array}{l}81.2 \\
45.0\end{array}$ & $\begin{array}{r}3.2 \\
46.8\end{array}$ & $\begin{array}{l}2,000 \\
3,000\end{array}$ \\
\hline
\end{tabular}

Table IX. Distribution of ${ }^{51} \mathrm{Cr}$ species in $10 \%$ seawater

\begin{tabular}{ccccc}
\hline \multirow{2}{*}{$\begin{array}{c}\text { Aging } \\
\text { system (days) }\end{array}$} & \multicolumn{3}{c}{ Distribution of ${ }^{51} \mathrm{Cr}$ species $(\%)$} \\
\cline { 2 - 5 } & $\mathrm{C}$ & $\mathrm{S}$ & $\mathrm{A}$ \\
\hline 0 & 37.4 & 57.9 & 4.7 \\
1 & 11.4 & 87.1 & 1.6 \\
7 & 0.3 & 90.3 & 9.4 \\
\hline
\end{tabular}

$A=$ anionic zone and/or anionic tailing; $C=$ cationic zone and/or cationic tailing; $S=$ zone at the starting point of the electrophoretic strip

pronounced at higher fulvic acid concentrations and in older systems. The distribution of ${ }^{5} \mathrm{Cr}_{3}$ species in the $10 \%$ seawater - humic

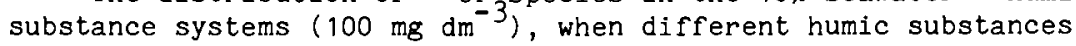
samples were used, is presented in Figure 8 . From all the humic substance samples used, $F A C$ had the strongest influence on the redistribution of ${ }^{5} \mathrm{Cr}$ species, producing the highest amount of anionic zone/ tailing.

In Organic Marine Geochemistry; Sohn, M.;

ACS Symposium Series; American Chemical Society: Washington, DC, 1986. 


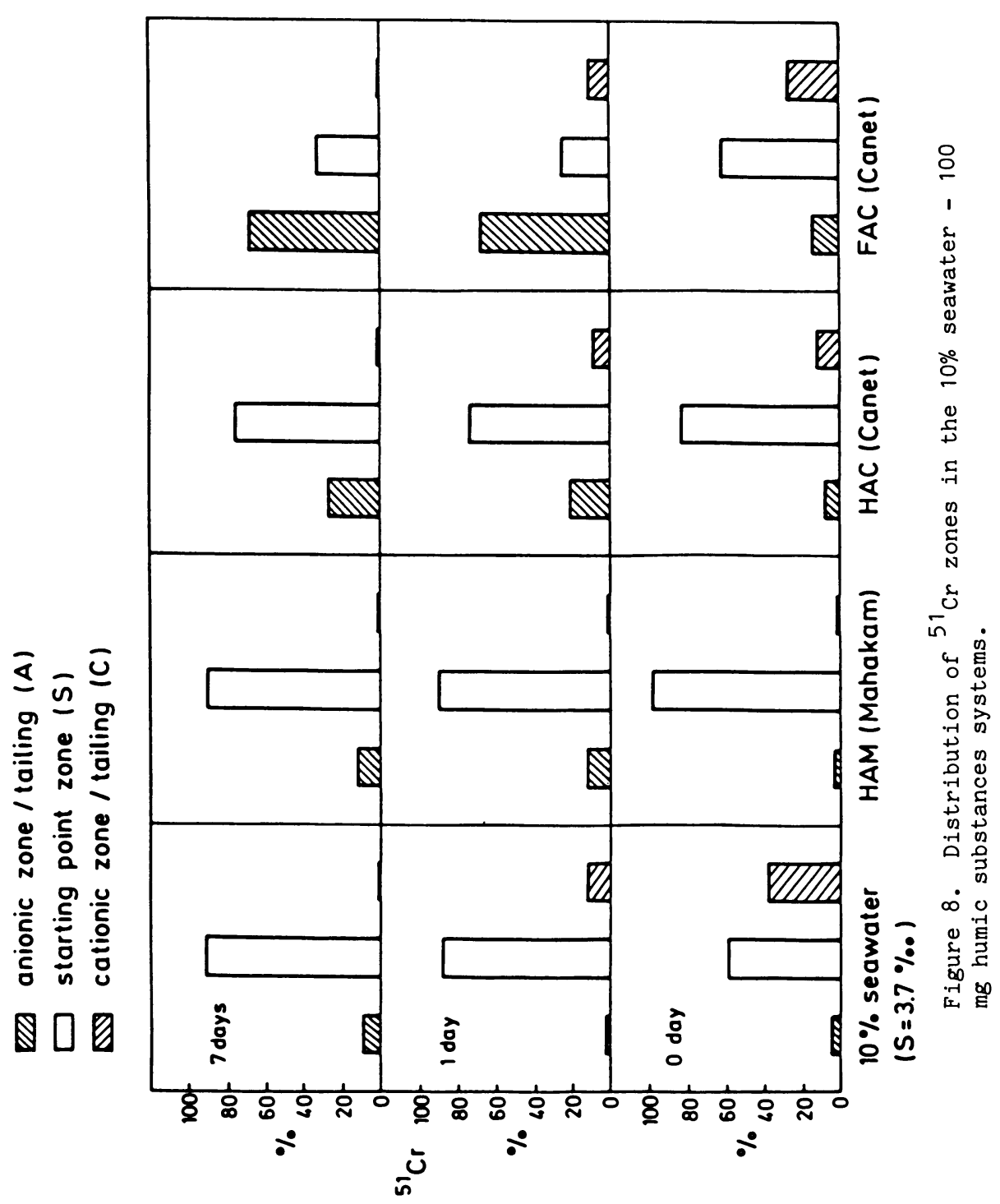

In Organic Marine Geochemistry; Sohn, M.;

ACS Symposium Series; American Chemical Society: Washington, DC, 1986. 
Adsorption of ${ }^{109} \mathrm{Cd}$ on suspended humic acids. Recognizing the property of humic acids as adsorbents for metal ions, suspensions of humic acid (HAt, HAM and commercial "Fluka" samples) were prepared at $35 \mathrm{mg} \mathrm{dm}^{-3}$. ${ }^{10 \mathrm{Cd}}$ was added to that suspension and the adsorption of $109 \mathrm{Cd}$ was measured. The results are expressed as $\mathrm{K}_{\mathrm{d}}$ values. $\mathrm{K}_{\mathrm{d}}$ value is the ratig of the cadmium concentration in solid and ligyid phase given in $\mathrm{cm}^{3} \mathrm{~g}^{-1}$. As seen in Figure 9 the adsorption of ${ }^{109} \mathrm{Cd}$ is rather strong on the humic acid. The $K_{d}$ values decrease as the solubility of the humic acid samples increase.

In Figure 10, some $\mathrm{K}_{\mathrm{d}}$ values for the adsorption of ${ }^{109} \mathrm{Cd}$ on smectite (pure inorganic support), natural river sediment and a mixture of the same sediment and HAL in the ratio $1: 1$ are presented. The presence of humic acid in the sediment suspension significantly increases the adsorption of ${ }^{1} \mathrm{Cd}$.

\section{Discussion}

Most of the divalent metals studied behave in diluted seawater as cations when introduced into seawater as petal (II) ions. According to our results in $10 \%$ seawater, $99.5 \%$ of ${ }^{109} \mathrm{Cd}, 98.2 \%$ of ${ }^{65} \mathrm{Zn}$, $92.1 \%$ of ${ }^{54} \mathrm{Mn}$ and $61.8 \%$ of ${ }^{210} \mathrm{~Pb}$ are in cationic forms giving defined electrophoretic zones. In estuarine water $(S=2 \% 0) 93.5 \%$ of ${ }^{34} \mathrm{Mn}$ is in the cationic form of defigfd electrophoretic mobility. In $10 \%$ seawater the cationic zone of ${ }^{2} \mathrm{Cd}$ is a mixture of the monochloro complex, free $\mathrm{Cd}^{2+}$ and the dichlgro complex (up to $7 \%$ ) (8). The cationic electrophoretic mobility of ${ }^{6} \mathrm{Zn}$ corresponds to the electrophoretic mobilities of free divalent cations $(35,36)$. The immobile zone could be related to a particulate $\{8 \mathrm{rm}$ of $\mathrm{Zn}$ or to $\mathrm{Zn}$ adsorbed on particles (37). The cationic zone of ${ }^{210} \mathrm{~Pb}$ might be a mixture of all cationic species of $\mathrm{Pb}$ present in seawater at $\mathrm{pH}$ values of $8.0\left(\mathrm{~Pb}^{2+}, \mathrm{PbCl}^{+}\right.$, $\mathrm{PbOH}^{+}$and $\mathrm{PbHCO}_{3}^{+}$) as reported in the literature $(38-44)$. The immobile zone of ${ }^{210} \mathrm{~Pb}$ should correspond to all uncharged lead species present $^{3}$ in seawater and to the precipitated $\mathrm{Pb}$. The cationic zone of ${ }^{54} \mathrm{Mn}$ might be attributed to the free $\mathrm{Mn}^{2+}(45)$, the cationic tailing to positively charged hydrolytic products of $M n$ (III) and the immobile zone to hydrolyzed products, especially in older systems (46).

The addition of humic substances to seawater generally produces an increase of the immobile zone and the formation of anionic tailing of the investigated divalent radionuclides $(\underline{8}, \underline{9})$. In diluted seawater, if the immobile zone does not exist, it appears when humic acid is added.

The effect of the HAL sample in $10 \%$ seawater on the distribution of particular metal-radigpuclide zones is demonstrated as follows:

1) disappearence of the ${ }^{6} \mathrm{Zn}$ cationic zone, increase of the immobile zone and formation of the anignjc talling up to $3 \%$; 2 ) disappearance of the cationic zone of ${ }^{210} \mathrm{~Pb}$, increase of the immobile zone and formation of the anionic tailing up to $4 \%$; 3) decrease of the cationic zone of ${ }^{109} \mathrm{Cd}$ and formation of the immobile zone and an almost negligible amount of anionic tailing $\left(\frac{8}{4}\right)$.

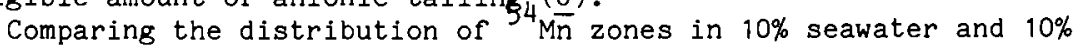
seawater-humic acid (HAM sample) it is evident that there is a decrease of the amount in the ${ }^{54} \mathrm{Mn}$ cationic zone, the cationic tailing increases (up to $20 \%$ at the HAM concentration of $200 \mathrm{mg} \mathrm{dm}^{-3}$ ) as well as the immobile zone (up to $20 \%$ ) and the anionic tailing zone (up to $5 \%)$. However, at higher pHs it is possible to get an anionic zone of 


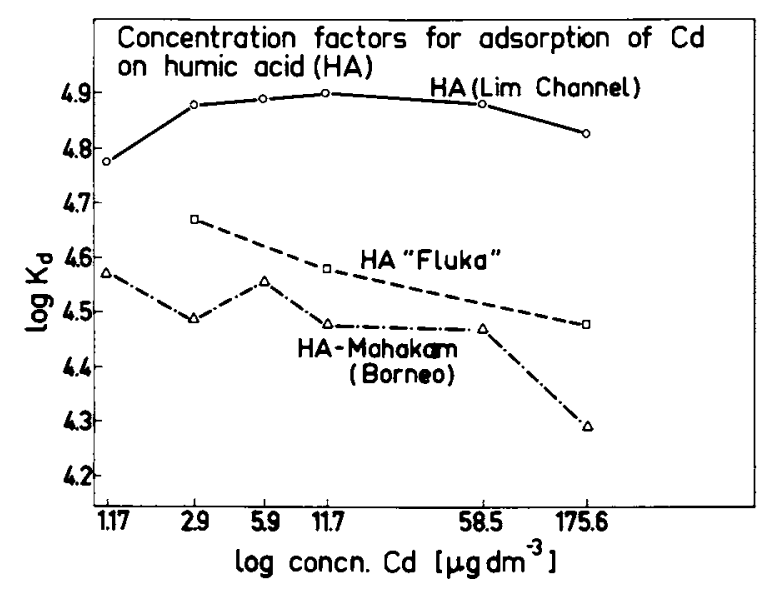

Figure 9. Concentration factors $\left(\log \mathrm{K}_{\mathrm{d}}\right.$ ) for the adsorption of $C d$ on different suspended humic acids in the river water. Concentration of humic acids: $35 \mathrm{mg} \mathrm{dm}{ }^{-3}$. Particle size between 0.45 and $32 \mathrm{um}$.

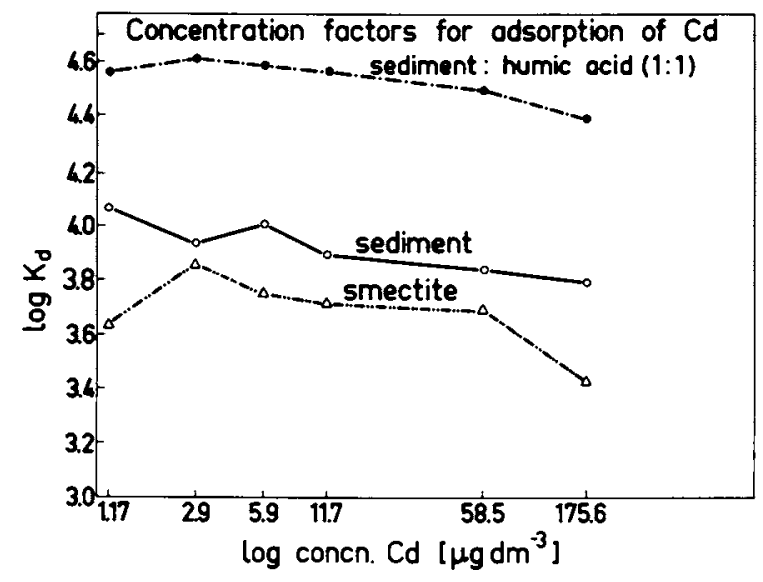

Figure 10. Concentration factors $\left(\log \mathrm{K}_{d}\right)$ for the adsorption of $\mathrm{Cd}$ on different supports in the river water. Concentration of suspended particles $35 \mathrm{mg} \mathrm{dm}^{-3}$. Particle size between 0.45 and 32 um.

In Organic Marine Geochemistry; Sohn, M.;

ACS Symposium Series; American Chemical Society: Washington, DC, 1986. 
the ${ }^{54}$ Mn-humic acid complex. This was experimentally confirmed when the HAM sample was added to river water; at the HAM concentration of $200 \mathrm{mg} \mathrm{dm}{ }^{-3}$ at $\mathrm{pH} 10.6$, approximately $30 \%$ of ${ }^{54} \mathrm{Mn}$ was in the anionic form and only $0.1 \%$ was cationic. At the same humig acid concentration in river water but at a pH of 8.0 , only $3.6 \%$ of ${ }^{54} \mathrm{Mn}$ was anionic and $55 \%$ remained in the cationic zone.

In estuarine water the interaction of ${ }^{54} \mathrm{Mn}$ and the three samples of humic substanges was examined: the strongest influence on the redistribution of ${ }^{54} \mathrm{Mn}$ species is by the HAM sample followed by FAC, while the HAL sample has the smallest influence. As said before, the HAL sample is the least soluble of all three humic substance samples. Therefore it seems that $M n$ is bound more to the dissolved part of humic substances (lower molecular weight fraction) and less to the undissolved and the immobile part. As seen in Figures 2, 3 and 4, the binding of ${ }^{54} \mathrm{Mn}$ to humic acid is stronger in the estuarine water than in seawater, owing to the lower content of other metals which can compete with manganese for binding sites on humic substances.

As demonstrated earlier (45) when ${ }^{54} \mathrm{Mn}$ was complexed with EDTA in seawater, the electrophoretic "picture" of the distribution of Mn zones showed the spread of the radioactivity from the cationic to the anionic values without any electrophoretic zone defined. In other words, at the intermediate EDTA concentrations, which were not high enough to complex all manganese present, both Mn-EDTA complexes and free $\mathrm{Mn}^{2+}$ were present at each position of the electrophoretic strip moving in opposite directions and resulting in the spread of $\mathrm{Mn}$ between the maximal cationic and anionic electrophoretic mobi54 ties. That finding supports the idea that the cationic tailing of $\mathrm{Mn}$ in estuarine or seawater-humic substance systems might be partly attributed to the formation of the Mn-humic substance complex (besides positively charged hydrolytic products of Mn(III) which are present to some extent in the estuarine or diluted seawater without the addition of humic substances).

Although we did not experiment with ${ }^{54} \mathrm{Mn}$ in the $10 \%$ seawater-HAL sample system, from the experiment performed in estuagine water, it can be predicted that the HAL sample would also bind ${ }^{54} \mathrm{Mn}$ less strongly than the HAM sample. Therefore the sequence of binding of divalent metals to the humic acid would be as follows: $\mathrm{Pb}>\mathrm{Zn}>\mathrm{Cd}>$ $\mathrm{Mn}$. These results are in agreement with published stability constants data $(16,17, \underline{47})$.

According to our results it appears that all investigated divalent radionuclides are bound more to higher molecular weight fractions of the humic substances used (except Mn, which forms positively charged species), forming either uncharged complexes or are adsorbed on undissolved fractions of humic substances, and less to lower molecular weight fractions of humic substances, which is demonstrated by the formation of negatively charged metal species.

In natural waters, iron concentrations are commonly several orders of magnitude greater than the equilibrium solubility of iron hydroxide (48). Two of the chemical species postulated to account for this phenomenon are: 1) fine colloidal particles of iron hydroxide (possibly associated with colloidal organic matter) and 2) dissolved complexes of iron with naturally occurring organic substances (49). During estuarine mixing processes, iron colloids or organic complexes are flocculated due to the increasing salinity. Sholkovitz and coworkers $(\underline{6}, \underline{26})$ demonstrated the close association of $\mathrm{Fe}, \mathrm{Mn}, \mathrm{Al}$ and $\mathrm{P}$ 
with both river-dissolved humic substances and seawater-flocculated humates. On the other side, Fox (28) found that dissolved humic acid and soluble iron appear to be chemically unassociated in estuagies despite their coincidental removal. According to our results, $55 \mathrm{Fe}$ in diluted seawater is almost completely present in the immobile electrophoretic zone, but the addition of humic substances forms the anionic species, which are specially abundant when fulvic acid is applied.

Another interesting influence of humic substances is recognized: in the presence of humic substances iron becomes solubilized. Hydrolytic species of ${ }^{5} \mathrm{Fe}$ are adsorbed on the walls of experimental vessels but by the addition of humic substances to the system, the number of cpm (counts per minute) tremendously increased in the same volume of solution applied for the electrophoretic experiment (see Tables VI-VIII). Exen at lower humic substance concentrations the cationic zone of ${ }^{5} \mathrm{Fe}$ was found, which amounted ${ }_{5}$ depending on the humic substance sample, up to $86 \%$ of the total $35 \mathrm{Fe}$ applied to the electrophoretic strip. The amount of these cationic ${ }^{5} \mathrm{Fe}$ zones decreases by increasing the humic substance concentration and by aging of the system (except for HAC humic acid sample) in favour of the anionic zone or the immobile zone. This zone might be attributed to the positively charged iron colloids, which were "available" for electrophoretic experiments when humic substances were added to seawater. Comparing these results with the resylts obtained for divalent metals, it segms that the immobile zone of $55 \mathrm{Fe}$ could be partly attributed to $55_{\mathrm{Fe}}$ bound to humic substances by any possible mechanism (complexation or adsorption) 55 In the electrophoretic experiments 5 we can not distinguish between $55 \mathrm{Fe}$ in the hydrolytic species and ${ }^{5 \mathrm{Fe}}$ bound to humic substances.

Hydrolytic species of iron are also able to adsorb humic substances on their surfaces and the negatively charged humic substances can adsorb additional $\mathrm{Fe}$ cations. From our results we can at least conclude that iron forms negatively charged complexes with humic substances and that humic substances solubilize iron when they are present in diluted seawater. If we compare the quantity of ${ }^{55} \mathrm{Fe}$ in the anionic zones depending on the humic substance used, we get the following sequence of the humic substances FAC $>$ HAC $>$ HAM $>$ HAN . This sequence corresponds to the solubility of the humic substance samples, and it seems that a fraction of humic substances having lower molecular weight is responsible for the formation of Fe-humic complexes.

Chromium(III) is present in seawater probably as $\mathrm{Cr}(\mathrm{OH})_{2}^{+}(50)$. Although the hexavalent state of chromium is thermodynamicaliy the most stable valent state of chromium in seawater, it can be reduced in marine organisms or by some reducible materials. $\mathrm{Cr}$ (III) is easily oxidized to $\mathrm{Cr}$ (VI) in the presence of manganese oxides, but organic complexes of $\mathrm{Cr}$ (III) are not oxidized and the trivalent state is stabilized (51). Thus chromium can be present in seawater as any form of inorganic 5 (III), $\mathrm{Cr}$ (VI), and as organic species. According to our results, ${ }^{51} \mathrm{Cr}$ (introduced to the diluted seawater as $\mathrm{Cr}$ (III)) is affected by the presence of humic substances forming anionic species. From the three humic substance sample studied, the FAC sample produces the most abundant anionic species followed by the HAC and the HAM sample.

Comparing the influence of different humic substances on the 
behavior of ${ }^{55} \mathrm{Fe}$ and ${ }^{51} \mathrm{Cr}$ in $10 \%$ seawater it is evident, that at the same humic substance concentration and aging of the system, the ${ }^{5} \mathrm{Cr}$ anionic species are more pronounced for all humic substance samples studied, although the concentration of chromium was for almost three orders of magnitude higher than that of iron. That is specially evident in the $10 \%$ seawatef ${ }_{1}$ fulvic acid system.

The immobile zone of ${ }^{5} \mathrm{Cr}$ is more abundant for the HAM sample, followed by the FAC. But for the HAC sample, the immobile zones of both radionuclides are equal. Consequently, the cationic zone is more abundant for ${ }^{55 e}$ although in $10 \%$ seawater, without addition of humic substances, the cationic zone of ${ }^{5} \mathrm{Cr}$ amounted to $37 \%$ at $t=0$ days, and for ${ }^{5} \mathrm{Fe}$ was negligible. Although from our results it seems that fulvic acid is more effective in the binding of ${ }^{51} \mathrm{Cr}$ than of ${ }^{55} \mathrm{Fe}$ there is still some doubt as to whether some chromate is also formed and since it is negatiyely charged, it could contribute to the anionic zone/tailing of ${ }^{5} \mathrm{Cr}$. However, results of Nakayama et al. (51) support the idea that most of the anionic chromium might be attributed to a $\mathrm{Cr}$ (III) complex with humic/fulvic acid, because the organic complexes of $\mathrm{Cr}$ (III) are not oxidized.

The adsorption experiments show that undissolved humic acid (the HAL sample) has a very high ability to adsorb ${ }^{109} \mathrm{Cd}$. Other humic acid samples, owing to their higher solubility, have lower abilities to adsorb $C d$. For the adsorption experiments which were performed in river water and in seawater or estuarine water, the $K_{d}$ values should be lower due to the presence of other macro- and microconstituents of seawater competing with $C d$ for adsorption sites on the negatively charged surface. These data are in agreement with the results of electrophoretic experiments showing that cadmium is adsorbed on undissolved or precipitated humic substances in seawater and that only small amounts of $C d$ is found in the anionic form as the Cd-humic substance complex.

By knowing the sequence in which metals are sorbed on humic acid (52) we could predict that on our humic substance samples, $\mathrm{Fe}, \mathrm{Pb}$ and $\mathrm{Cr}$ will be sorbed more than $\mathrm{Cd}$ and $\mathrm{Zn}$, and that $\mathrm{Mn}$ will be sorbed less than $\mathrm{Cd}$.

Our results show that the adsorption on suspended matter is increased in the presence of suspended humic acid (Figure 10). This is supported by the finding of other authors $(53,54)$ showing that organic flocculant coatings greatly affect the cation exchange capacities of sediment and suspended matter.

\section{Conclusions}

The interaction of divalent metal radionuclides with humic substances is particularly demonstrated by the formation of uncharged species and/or adsorption on undissolved or precipitated humic substances and less by the formation of negatively charged species. Nevertheless, the amount of cationic forms of all investigated divalent metals decrease in the presence of humic substances, while some other species are formed having different electrophoretic mobilities than particular metal ions in seawater or estuarine water. The concentrations of humic acid at which observable changes in speciation of trace metals occurred are rather high when comparing the humic substance concentrations in the open oceans. However, higher humic substance concentrations are possible in shallow waters, closed areas or estuaries with high biological activity.

In Organic Marine Geochemistry; Sohn, M.;

ACS Symposium Series; American Chemical Society: Washington, DC, 1986. 
For trivalent metals the influence of humic substances present in diluted seawater is shown by the formation of negatively charged species, which might be attributed to metal-humic substance complexes (especially pronounced for fulvic acid). The presence of humic substances, even at lower concentrations, solubilizes iron. This is partly evident by the formation of the cationic species, which are not found in estuarine or seawater unless humic substances are added. These effects might also be attributed to the stabilization of iron colloids in water rich in humic substances.

When present in undissolved states, humic substances act as adsorbants for trace metals. The presence of suspended humic substances increases the adsorption ability of suspended matter and sediment.

\section{Acknowledgments}

This work is devoted to the memory of Prof. H.W. Nürnberg, who unfortunately left us too early. The financial support by the Self-Managed Authority for Scientific Research, SR Croatia, Yugoslavia, is gratefully acknowledged. The authors are greatful to G. Cauwet for the supply of humic substances (HAC, FAC, HAN, HAM and HALR samples).

\section{Literature Cited}

1. Mantoura, R.F.C.; Riley, J.P. Anal. Chim. Acta 1975, 76, 97-106.

2. Harvey, G.R.; Boran, D.A.; Chesal, L.A.; Tokar, J.M. Mar. Chem. $1983,12,119-132$.

3. Huljev, D. M.Sc. Thesis, University of Zagreb, Zagreb, 1970.

4. Rashid, M.A. Soil. Sci. 1971, 111, 298-305.

5. Schnitzer, M.; Khan, S.U. "Humic Substances in the Environment", Marcel Dekker: New York, 1972.

6. Sholkovitz, E.R. Geochim. Cosmochim. Acta 1976, 40, 831-845.

7. Nriagu, J.0.; Coker, R.D. Environ. Sci. Technol. 1980, 14, 443-446.

8. Musani, Lj.; Valenta, P.; Nürnberg, H.W.; Konrad, Z.; Branica, M. Estuar. Coastal Mar. Sci. 1980, 11, 639-649.

9. Musani, Lj.; Nürnberg, H.W.; Valenta, P.; Konrad, Z.; Branica, M. Thalassia Jugosl. 1981, 17, 71-81.

10. Schnitzer, M.; Ghosh, K. Soil. Sci. 1982, 134, 354-363.

11. Raspor, B.; Nürnberg, H.W. ; Valenta, P.; Branica, M. Mar. Chem. $1984,15,217-230$.

12. Raspor, B.; Nürnberg, H.W.; Valenta, P.; Branica, M. Mar. Chem. $1984,15,231-249$.

13. Schnitzer, M.; Skinner, S.I.M. Soil Sci. 1966, 102, 361-365.

14. Schnitzer, M.; Hansen, E.H. Soil. Sci. 1970, 109, 333-340.

15. Buffle, J.; Greter, F.L.; Haerdi, W. Anal. Chem. 1977, 49, 216-222.

16. Mantoura, R.F.C.; Dickson, A.; Riley, J.P. Estuar. Coastal Mar. Sci. 1978, 6, 387-408.

17. Whitfield, M.; Turner, D.R. In "Proc. Int. Expert Discussion, Lead-Occurence, Fate and Pollution in the Marine Environment"; Branica, M.; Konrad, Z.; Eds.; Pergamon Press: Oxford, 1980.

18. Torres, R.A.; Choppin, G.R. Radiochim. Acta 1984, 35, 143-148.

19. Hatcher, P.G.; Rowan, R.; Mattingly, M.A. Org. Geochem. 1980, $2,77-85$. 
20. Wilson, M.A.; Barron, P.F.; Gillam, A.H. Geochim. Cosmochim. Acta $1981,45,1743-1750$.

21. Duursma, E.K. In "Chemical Oceanography"; Riley, J.P.; Skirrow, S.; Eds.; Academic Press: London, 1965; Vol. I, pp. 433-473.

22. Ogura, N. Mar. Biol. 1972, 13, 89-93.

23. Frimmel, F.H. Vom Wasser 1977, 49, 1-10.

24. Stuermer, D.H.; Harvey, G.R. Deep-Sea Res. 1977, 24, 303-309.

25. Tipping, E. Chem. Geol. 1981, 33, 81-89.

26. Skolkovitz, E.R.; Boyle, E.A.; Price, N.B. Earth Planet. Sci. Lett. 1978, 40, 130-136.

27. Moore, R.M.; Burton, J.D.; Williams, P.J.; Young, M.L. Geochim. Cosmochim. Acta $1979,43,919-926$.

28. Fox, L.E. Geochim. Cosmochim. Acta 1984, 48, 879-884.

29. Desai, M.V.; Ganguly, A.K. "Report Bhabha Atomic Research Center, B.A.R.C.-488"; Bombay, 1970.

30. Kononova, M.M.; Balachirova, N.P. Soviet Soil. Sci. 1960, 4, 1149-1155.

31. Pučar, Z. Anal. Chim. Acta 1957, 17, 476-484.

32. Faguet, D. Doctorat de Specialite Oceanologie, I'Universite de Perpignan, Perpignan, 1982.

33. Nissenbaum, A.; Kaplan, I.R. Limnol. Oceanogr. 1982, 17, $570-582$.

34. Schnitzer, M.; Skinner, S.I.M. Soil. Sci. 1969, 108, 383-390.

35. Marazović, Lj.; Pučar, Z. Rapp. Comm. Int. mer Medit. 1972, 20, 701-703.

36. Kozjak, B.; Marinić, Z.; Konrad, Z.; Musani-Marazović, Lj.; Pučar, Z. J. Chromatogr. 1977, 132, 323-334.

37. Piro, A.; Bernhard, M.; Branica, M.; Verži, M. In "Radioactive Contamination of the Marine Environment"; IAEA: Vienna, 1973; STI/PUB 313, pp. 29-44.

38. Zirino, A.; Yamamoto, S. Limnol. Oceanogr. 1972, 17, 661-671.

39. Dyrssen, D.; Wedborg, M. In "The Sea"; Goldberg, E.D., Ed.; Wiley-Interscience: New York, 1975; Vol. 5, pp. 181-195.

40. Stumm, W.; Brauner, D.A. In "Chemical Oceanography"; Riley, J. P.; Chester, R., Eds.; 2nd edn., Academic Press: London, 1975; Vol. 1, pp. 173-234.

41. Florence, T.M.; Batley, G.E. Talanta 1976, 23, 179-186.

42. Lu, J.C.S.; Chen, K.Y. Environ. Sci. Techn. 1977, 11, 174-182.

43. Sipos, L.; Raspor, B.; Nürnberg, H.W.; Pytkowicz, R.M. Mar. Chem. $1980,9,37-47$.

44. Sipos, L.; Valenta, P.; Nürnberg, H.W.; Branica, M. In "Proc. Int. Expert Discussion, Lead-Occurence, Fate and Pollution in the Marine Environment"; Branica, M.; Konrad, Z., Eds.; Pergamon Pres: Oxford, 1980.

45. Musani-Marazović, Lj.; Pučar, Z. Mar. Chem. 1977, 5, 229-242.

46. Beneš, P. J. Inorg. Nucl. Chem. 1967, 29, 2889-2898.

47. Pagenkopf, G.K. In "Organometals and Organometalloids. OCcurence and Fate in the Environment"; Brinckman, F.E.; Bellama, J.M., Eds.; ACS SYMPOSIUM SERIES No. 82, American Chemical Society: Washington, D.C., 1978; pp. 372-387.

48. Stumm, W.; Morgan, J.J. In "Aquatic Chemistry"; Wiley: New York, 1970; pp. 238-299.

49. Perdue, E.M.; Beck, K.C.; Reuter, J.H. Nature 1976, 260, 418-420 .

50. Elderfield, H. Earth Planet. Sci. Lett. 1970, 9, 10-16. 
51. Nakayama, E.; Kuwamoto, T.; Tokoro, H.; Fujinaga, T. Anal. Chim. Acta 1981, 131, 247-254.

52. Kerndorf, H.; Schnitzer, M. Genchim. Cosmochim. Acta 1980, 44, 1701-1708.

53. Rashid, M.A. Maritime Sediments 1969,5 , 44-50.

54. Pillai, T.N.V.; Desai, M.V.M.; Mathew, E.; Ganapathy, S.; Ganguly, A.K. Current Sci. 1971, 40,75-81.

RECEIVED October 31,1985

In Organic Marine Geochemistry; Sohn, M.;

ACS Symposium Series; American Chemical Society: Washington, DC, 1986. 


\section{Author Index}

\author{
Baker, Earl W., 107 \\ Beller, H. R., 198 \\ Boon, Jaap J., 76 \\ Brandt-de Boer, B., 76 \\ Brassell, S. C., 10 \\ Brown, Robert C., 229 \\ Brownawel1, Bruce J., 174 \\ Burke, Roger A., Jr., 297 \\ Byrne, Christian, 247 \\ Byrne, Robert H., 358 \\ Choppin, G. R., 382 \\ Church, Thomas M., 340 \\ Clifford, C. Hovey, 174 \\ Cline, Joel D., 272 \\ Cooper, W. T., 158 \\ Dalland, Cristie, 369 \\ Dallinga, Jan, 76 \\ Davis, Alan C., 174 \\ de Leeuw, J. W., 33 \\ Eglinton, G., 10 \\ Faguet, Danielle, 389 \\ Farrington, John W., 174 \\ Genuit, Wim, 76 \\ Giblin, Anne E., 340 \\ Gillam, Andrew H., 128 \\ Gschwend, Philip M., 314 \\ Hatcher, Patrick G., 142 \\ Heiman, A. S., 158 \\ Howarth, Robert W., 340 \\ Joyce, Rosanne M., 91,229 \\ Katz, Charles N., 272 \\ Kelly-Hansen, Kimberly, 272
}

\author{
Kennicutt, Mahlon C., II, 215 \\ Konrad, Zdenka, 389 \\ Livramento, Joaquim B., 174 \\ Louda, J. William, 107 \\ Luther, George W., III, 340 \\ MacFarlane, John K., 314 \\ Merrill, Elizabeth G., 215 \\ Miller, William L., 358 \\ Mopper, Kenneth, 324 \\ Morse, J. W., 382 \\ Musani-Marazovic, Ljerka, 389 \\ Orem, William H., 142 \\ Overton, Edward B., 247 \\ Pierce, Richard H., 229 \\ Roberts, R. A., 382 \\ Sackett, William M., 297 \\ Schumacher, Eva, 369 \\ Schurtz, Michael H., 247 \\ Sherr, Evelyn B., 62 \\ Simoneit, B. R. T., 198 \\ Sohn, Mary L., 1,369 \\ St. Pe, Kerry M., 247 \\ Tarafa, Martha E., 62 \\ Taylor, Barrie F., 324 \\ Tripp, Bruce $W ., 174$ \\ Turkstra, E., 76 \\ Van Vleet, Edward S., 91,229 \\ Wade, Terry L., 215 \\ Whelan, Jean K., 62 \\ Wilson, Michael A., 128 \\ Yates, R. R., 158
}

\section{Subject Index}

A

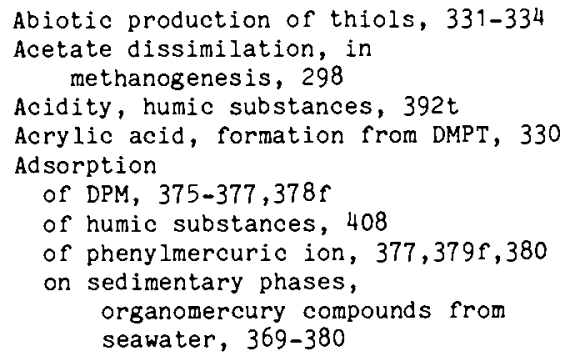

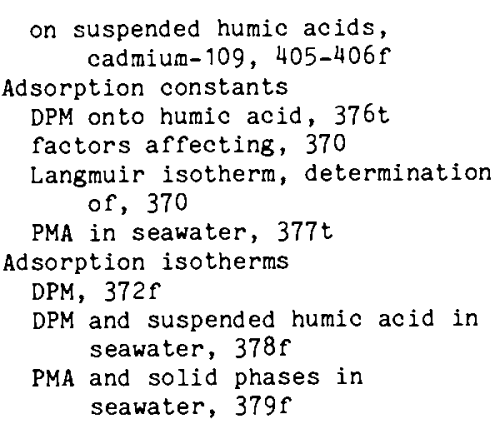

415

In Organic Marine Geochemistry; Sohn, M.;

ACS Symposium Series; American Chemical Society: Washington, DC, 1986. 


\section{Author Index}

\author{
Baker, Earl W., 107 \\ Beller, H. R., 198 \\ Boon, Jaap J., 76 \\ Brandt-de Boer, B., 76 \\ Brassell, S. C., 10 \\ Brown, Robert C., 229 \\ Brownawel1, Bruce J., 174 \\ Burke, Roger A., Jr., 297 \\ Byrne, Christian, 247 \\ Byrne, Robert H., 358 \\ Choppin, G. R., 382 \\ Church, Thomas M., 340 \\ Clifford, C. Hovey, 174 \\ Cline, Joel D., 272 \\ Cooper, W. T., 158 \\ Dalland, Cristie, 369 \\ Dallinga, Jan, 76 \\ Davis, Alan C., 174 \\ de Leeuw, J. W., 33 \\ Eglinton, G., 10 \\ Faguet, Danielle, 389 \\ Farrington, John W., 174 \\ Genuit, Wim, 76 \\ Giblin, Anne E., 340 \\ Gillam, Andrew H., 128 \\ Gschwend, Philip M., 314 \\ Hatcher, Patrick G., 142 \\ Heiman, A. S., 158 \\ Howarth, Robert W., 340 \\ Joyce, Rosanne M., 91,229 \\ Katz, Charles N., 272 \\ Kelly-Hansen, Kimberly, 272
}

\author{
Kennicutt, Mahlon C., II, 215 \\ Konrad, Zdenka, 389 \\ Livramento, Joaquim B., 174 \\ Louda, J. William, 107 \\ Luther, George W., III, 340 \\ MacFarlane, John K., 314 \\ Merrill, Elizabeth G., 215 \\ Miller, William L., 358 \\ Mopper, Kenneth, 324 \\ Morse, J. W., 382 \\ Musani-Marazovic, Ljerka, 389 \\ Orem, William H., 142 \\ Overton, Edward B., 247 \\ Pierce, Richard H., 229 \\ Roberts, R. A., 382 \\ Sackett, William M., 297 \\ Schumacher, Eva, 369 \\ Schurtz, Michael H., 247 \\ Sherr, Evelyn B., 62 \\ Simoneit, B. R. T., 198 \\ Sohn, Mary L., 1,369 \\ St. Pe, Kerry M., 247 \\ Tarafa, Martha E., 62 \\ Taylor, Barrie F., 324 \\ Tripp, Bruce $W ., 174$ \\ Turkstra, E., 76 \\ Van Vleet, Edward S., 91,229 \\ Wade, Terry L., 215 \\ Whelan, Jean K., 62 \\ Wilson, Michael A., 128 \\ Yates, R. R., 158
}

\section{Subject Index}

A

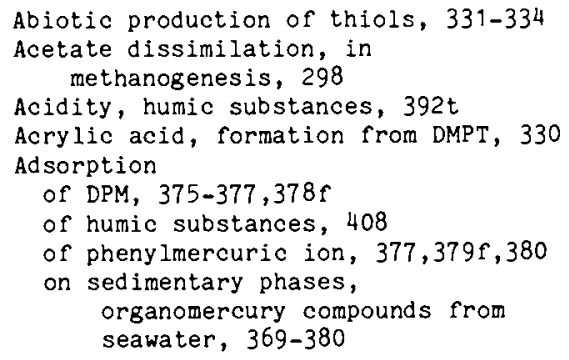

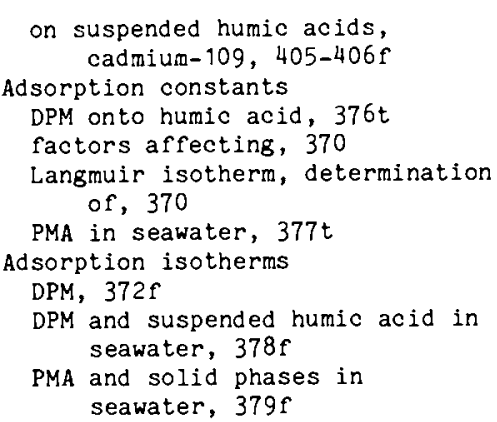

415

In Organic Marine Geochemistry; Sohn, M.;

ACS Symposium Series; American Chemical Society: Washington, DC, 1986. 
Aerobic oxidation of methane, 304

Aerobic soil from southern Georgia, humin from, $150,153 \mathrm{f}$

Alcohol fraction, distribution in sediments, $24,26-28$

Alcohol-like structures, as components of humin, 150

Alditolacetates obtained from Solar Lake sediment

GC trace, $44 \mathrm{f}$

polysaccharide analysis, $44 \mathrm{f}$

Algal incubations, for quantifying polybromomethane releases from macroalgae, 315

Algal indicators, in sediments, $13,15 \mathrm{f}, 16$

Algal versus epiphytic source of polybromomethanes in seawater, 320-321

Aliphatic hydrocarbons, in North American basin cretaceous black shales, 97-100

Aliphatic structures, humic acids from marine sediments, 391-392

Alkan-1,15-diols and alkan-15-one-1-ols, in sediments, 39-40

Alkanes, in North American basin cretaceous black shales, 97-100

Alky l- and alken-1-enyl-diacy lglycerides, in sediments, $41,42 \mathrm{f}$

Alkylated aromatic hydrocarbons, sediment concentrations in Lake Pontchartrain, 258-259f

N-Alkylthiolanes in Rozel Point oil, 57,59f

N-Alkylthiophenes in a Sarsina marl aromatic hydrocarbon fraction, $57,58 \mathrm{f}$

Aminoacetic acid dissociation constants, 364

Analysis concentration, dissolved methane in the southeastern Bering Sea, 273

Analytical methods, samples from Lake Pontchartrain, 250-251

Anionic tailing, trace metal radionuclides in seawater samples, 405

A-nor-steranes, in sediments, $46-48$

Anoxia

extent during specific intervals of the Upper Cretaceous, 92-102

photic zone, 115

Anthropogenic hydrocarbon indicators, in sediments, 21-22

Aroclor mixtures

chlorobiphenyl content, 202

glass capillary gas

chromatograms, $178 \mathrm{f}$
Aromatic carbon

humin, 150

marine and estuarine humic

acids, 148

Aromatic hydrocarbons

distributions in a marine environment, 226-227

polynuclear, general discussion, 215

Artificial seawater, changes in oxidation states of plutonium, 384-386

Ascophyllum nodosum, release of polybromomethanes to seawater, 314-321

Atmospheric exchange of methane, $282,286-291$

Atmospheric methane isotopic composition, 308-310

Bacteria, methanogenic, 304

Bacterial indicators, in sediments, $18-19,20 \mathrm{f}$

Bacteriopheophytin-a, electronic absorption spectra, $117 \mathrm{f}$

Barium, sediment concentrations in Lake Pontchartrain, 266-267f

Bering Sea, southeastern, seasonal cycles of dissolved methane, 272-294

Bioaccumulation concentration factors, chlorobiphenyls, 187,191-193

Biogenic hydrocarbons, description, 241,243

Biogenic methanes from aquatic environments, hydrogen and carbon isotopic composition, 297-310

Biogeochemical cycling of sulfur, role of thiols, 324-338

Biogeochemistry chlorophy 11, 107-124

PCBs in the Acushnet River estuary, Massachusetts, 174-195

Biological methane formation, 297 oxidation, 304

Biomarkers, general discussion, 1-2

Biomass burning, as a source of methane, 309

Biopolymers, degradation and rearrangement, 159

Biota compound class distributions, 21 relative contributions to sediments, 22

Biscayne Bay, thiol concentrations, 324-338

Bound $\mathrm{PCB}$ assemblages, estuarine sediments, sources, 205-206

In Organic Marine Geochemistry; Sohn, M.;

ACS Symposium Series; American Chemical Society: Washington, DC, 1986. 
Bound thiols, release, 334-336

Bristol Bay, location, 274-276

Bromoform, release to seawater from fucoid algae, 316,318-319f

Bubble ebullition, as a mode of methane input to the atmosphere, 309

Buzzards Bay, PCB and hydrocarbon analysis, 202-211

\section{C}

Cadmium, sediment concentrations in Lake Pontchartrain, 266-267f

Cadmium-109

adsorption on suspended humic acids, 405,406f

distribution in $10 \%$ seawater-humic acid system, $395 \mathrm{t}$

Calibration curves, DPM and PMA, $374 \mathrm{f}$

Caloosahatchee River at Fort Myers, hydrocarbon contamination from coastal development, 232-245

Cape Hatteras, area east of, origin of organic matter, 91-104

Capillary gas chromatograms, glass, Aroclor mixtures, $178 \mathrm{f}$

Capillary GC-ECD chromatograms

free lipid fractions of estuarine sediments, 203-205

humin fractions of estuarine sediments, 203-205

Capillary GC-FID traces, saturated hydrocarbons in estuarine sediments, 208-209

Captiva Island, hydrocarbon contamination from coastal development, 232-245

Carbohydrates

humic acid isolate, 148

humin isolates, 150

Carbon

effect on methane production in the southeastern Bering Sea, 293-294

sediments from the Peruvian Upwelling Zone, early diagenesis, 158-171

Carbon dioxide reduction, in methanogenesis, 298

Carbon isotopes

plant, seston, and sediment samples from a Georgia estuary, $64 t$ stable, analysis, 94

Carbon isotopic data, as a source indicator for mid-cretaceous inputs, $94-96$

Carbon number

distributions, hydrocarbons and fatty acids in cretaceous black shales, 97-104
Carbon number--Continued

sterols in surface sediments of the

Peruvian coast, 163-165

Carbon skeletons, methoxy-phenolic pyrolysis products, 70

Carbon-13 NMR, humic substance analysis, $3,130-137$

Carbon-14 labeling studies, methanogenesis, 298

Carbonized coal hydrocarbons, fate in a highly industrialized estuary, 215-227

Carboxyl groups, humic substances, $392 t$

Cationic zones, trace metal radionuclides in seawater, 405

Charlotte Harbor, hydrocarbon contamination from coastal development, 229-245

Chemical speciation, in high-complexation intensity systems, 358-368

Chlordane-nonachlor, sediment concentrations in Lake Ponchartrain, 262-263f

Chlorin, electronic absorption spectra, $121 \mathrm{f}$

Chlorin acid

generation, 120

surface sediments, 113

Chlorinated compounds, analysis by GC-ECD, 201

Chlorinated phenols, in estuarine sediments, $207,210-211$

Chlorobiphenyls

Acushnet River, general discussion, 175

chlorine substitution, $181 \mathrm{t}$

octanol-water partition coefficients, $187,191-193$

selected organisms, Acushnet River estuary, $184-186 t$

various species, metabolism, 194

water particulates and sediment, Acushnet River estuary, 182-183t

Chlorophyll derivatives, in near-surface marine sediments, $114 \mathrm{t}$

Chlorophyll-a derivatives, diagenesis, $123 \mathrm{f}$

Cholesterol, in cell membranes, 13

Chromatograms, pheophytin-a, $118 \mathrm{f}$

Chromatographic selectivity, alteration for identifying thiols in sediments, $329 \mathrm{f}$

Chromium, forms in seawater, 408

Chromium-51

distribution in $10 \%$ seawater, $403 t$

interaction with humic substances, 397,402-404

Cleavage of oxidized glutathione in seawater, $334,335 \mathrm{f}$

In Organic Marine Geochemistry; Sohn, M.;

ACS Symposium Series; American Chemical Society: Washington, DC, 1986. 
Coal and coal-like materials, in estuarine sediments, 154

Coal hydrocarbons, carbonized, fate in a highly industrialized estuary, 215-227

Coastal development, hydrocarbon contamination from, 229-245

Coastal marine sediments. thiols, $324-338$

Combustion of methanes, 299

Complex intensity systems, chemical speciation, 358-368

Complexation

copper(II) glycine, 364-365

copper(II) oxalate, 365

manganese -54 with edetic acid, 407

organic copper, 362-363

plutonium, 383,386

trace metals, 360-363

compound class distributions in biota, 21

Conductivity data, southeastern Bering Sea, 274

Copper(II), chemistry in organic-rich systems, $361-362$

Copper(II) glycine

complexation constants, $364-365$

stability constants, 366

Copper(II) oxalate

complexation analysis, 365

stability constants, 366

Crab, Acushnet River estuary

chlorobiphenyls, 185-186t

PCBs, $179,180 \mathrm{f}$

Crassostrea virginica, collection from Charlotte Harbor, 232

Creosote sample

fluorescence analysis, 223,224 f

GC analysis, 218,219 个, 222

Cretaceous black shales, North American basin, origin of organic matter, 91-104

Cross-polarization techniques, use in solid state NMR, 138-140

Cross-polarization/magic angle spinning (CP/MAS) carbon-13 NMR studies, sediments from the Peruvian Upwelling Zone, 158-171

Cross-shelf variations in water properties, influence on the distribution of methane, 279,280 f

cycling of sulfur, biogeochemical, role of thiols, $324-338$

D

De-A-steranes, in sediments, 46-48

Decarboxylated mesopyropheophorbides, electronic absorption spectra, $121 \mathrm{f}$
Decay constant for the signal intensity, carbon-13 NMR

spectroscopy, 133

Deoxomesopy ropheophorbide-a, 119

Deoxy sugars, in sediments, 43-44

Diagenesis

chlorophy 11, 107-124

chlorophyll-a derivatives, $123 f$

definition, 159

early, tetrapyrrole characteristic, 116

short term, sedimentary lipids and polysaccharides as indicators, 33-59

Diagenetic pathways for De-A-steroids and A-nor steroidal hydrocarbons, $46-48$

Dibenzothiophene, sediment concentrations in Lake Pontchartrain, 260-261

Dibromochloromethane, release to seawater from fucoid algae, $316,318 \mathrm{f}$

Dibromomethane, release to seawater from fucoid algae, $316,318 f$

Dichlorodiphenyldichloroethylene (DDE) distributions, estuarine sediments, 203

Dichlorodiphenyltrichloroethane (DDT) environmental degradation products, Lake Pontchartrain, 262-263f

Dihydroactinidiolide, in sediments, $46,47 \mathrm{f}$

Dimethylpropiothetin (DMPT), as a precursor of thiols, 330-331

Dimethylsulfide, formation from DMPT, 330

Dioxophorbide, electronic absorption spectra, $123 \mathrm{f}$

Diphenyl mercury (DPM)

adsorption isotherm, $372 \mathrm{f}$

adsorption onto sedimentary phases

from seawater, 369-380

calibration curves, $374 \mathrm{f}$

Dipolar dephased spectra

intact sediments, Peruvian Upwelling Zone, $171 \mathrm{f}$

sea loch sedimentary humic acid, $136 \mathrm{f}$

Dipolar dephasing, use in carbon-13 NMR spectroscopy, 133-137

Discriminant function score map of pyrolysis mass spectra, sediment samples, $78 \mathrm{f}$

Dissociation constants

aminoacetic acid, 364

oxalic acid, 364

Dissolved methane in the southeastern Bering Sea, seasonal cycles, 272-294

Dissolved sulfur in salt marshes, speciation, 340-353

In Organic Marine Geochemistry; Sohn, M.;

ACS Symposium Series; American Chemical Society: Washington, DC, 1986. 


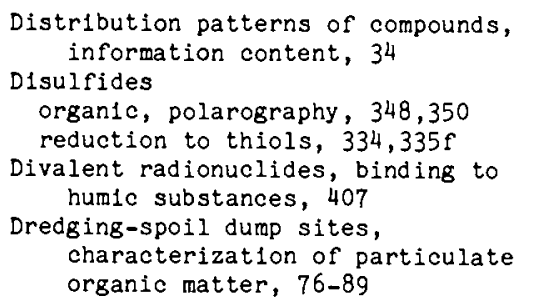

\section{E}

Early diagenesis of organic carbon in sediments from the Peruvian Upwelling Zone, 158-171

Ebullition, bubble, as a mode of methane input to the atmosphere, 309

Electronic absorption spectra bacteriopheophytin-a, $117 \mathrm{f}$

chlorin, $121 \mathrm{f}$

decarboxylated mesopy ropheophorbides, $121 \mathrm{f}$ pheophytin-a, $118 \mathrm{f}$

sapropel extract, $117 \mathrm{f}$

Synedra sp. extracts, $112 \mathrm{f}$

Electrophoresis

experimental conditions, 390

sample preparation, 390

Electrophoretic zones

iron-55 in 10\% seawater-humic acid systems, $399 t, 403 t$

trace metal radionuclides in seawater samples, 405

Elemental analyses

humic substances, $392 t$

sedimentary organic matter, 96-97

Epiphytic source, of polybromomethanes in seawater, 320-321

Equilibrium models, assessments of trace metals in the environment, 358

Estuarine sediments, lipid fractions, PCB and hydrocarbon distributions, 198-211

Estuarine water, interaction of manganese -54 and humic substances, 407

Estuary

highly industrialized, fate of

carbonized coal

hydrocarbons, 215-227

Rhine, sedimentation of particulate matter from fluvial and marine origin, 76

Exchange velocity of methane, in the southeastern Bering Sea, 288
Extraction

fulvic acids, 143

humic acids, 143

F

Fatty acids, in North American basin cretaceous black shales, 97,101-104

Flounder, Acushnet River estuary, PCBs, 179

Fiuoranthene-pyrene, sediment concentrations in Lake Pontchartrain, $260-261 \mathrm{f}$

Fluorescence analysis creosote sample, $223,224 f$

fuel oil, $223,224 \mathrm{f}$

sediment samples from the Elizabeth River, 223

Fluorescence derivatization of thiols, $325,327 f$

Flux of methane, in the southeastern Bering Sea, 287-291

Formation constant, mixed ligand, 359

Fossil fuels, as sources of methane, 309

Free ligand concentrations, calculations, 364

Free lipids of estuarine sediments capillary GC-ECD chromatograms, 203-205

PCB and DDE distributions, 203

PCB homolog compositions, 205

pentachlorophenol

distributions, 219

saturated hydrocarbon distributions, 206

Free PCB assemblages, estuarine sediments, sources, 205,206

Freundlich isotherm, sorptive behavior of organic substances, 371

Fucoxanthin as a possible precursor of loliolide, $47 \mathrm{f}$

Fucus vesiculosis, release of polybromomethanes to seawater, $314-321$

Fuel oil, fluorescence analysis, 223

Fulvic acid carbon-13 NMR spectra, $134 \mathrm{f}$

characteristics, 391-393

extraction, 143,391

solid state carbon-13 NMR studies, $145,146 \mathrm{f}$

G

Gas chromatograms, saturated fractions of Lake Pontchartrain sediment samples, $256 \mathrm{f}$

In Organic Marine Geochemistry; Sohn, M.;

ACS Symposium Series; American Chemical Society: Washington, DC, 1986. 
Gas chromatographic (GC) analys is

Charlotte Harbor samples, 234

creosote sample, $218,219 \mathrm{f}, 222$

dissolved methane in the southeastern Bering Sea, 273-274

Elizabeth River sediment sample, $218,221 \mathrm{f}, 222$

methane isotopes, 299-301

oil spill sample, $218,220,222$

PCBs in the Acushnet River estuary, 174-195

Gas chromatographic (GC) traces

alditolacetates obtained from Solar Lake sediment, $44 \mathrm{f}$

alkylglycerol fraction of Wadden Sea anaerobic tidal flat sediment, $42 f$

lipids fractions of Rhodobactor sulfidophilus, $5 \overline{0 f}$

Gas chromatography-electron capture detection (GC-ECD), analysis of chlorinated compounds, 201

Gas chromatography-flame ionization detection (GC-FID) chromatograms

reference petroleum products, $236 \mathrm{f}$

saturated hydrocarbon fractions marine and coastal flora, $237 \mathrm{f}$ sediments, 239-240f, $242 \mathrm{f}$

Gas chromatography-mass spectroscopy (GC-MS)

Charlotte Harbor samples, 234

estuarine sediments, 201

Geochemical indicators in sediments, molecular, 10-30

Geochemistry, organic marine, overview, 1-5

Geopolymers, formation from biopolymers, 159

Geoporphyrins, description, 107,109

Georgia estuary, phenolic and lignin pyrolysis products of plants, seston, and sediment, 62-74

Glass capillary gas chromatograms, Aroclor mixtures, $178 \mathrm{f}$

Global warming, contribution of atmospheric methane, 297

Glutathione

oxidized, cleavage, $334,335 \mathrm{f}$

polarography, $344 f, 347-348$

Great Marsh, Delaware, sulfur speciation in the porewaters, 340-353

Great Sippewissett, Cape Cod, sulfur speciation in the porewaters, 340-353

Gypsum extract of Sarsina sediment, GC traces, $55 f$

\section{$\mathrm{H}$}

Half-wave potentials, sulfur species, $347 t$

Heavy metals, distribution in Lake Pontchartrain, 247-269

Heptoses, in sediments, 43-44

Hexachlorophene, in estuarine sediments, 207,210-211

Hexadecanoic acid, in cell membranes, 13

High-complexation intensity systems, chemical speciation, $358-368$

Horizontal distributions of dissolved methane in the southeastern Bering Sea, 276

Hudson Canyon, humin, 150

Hudson River, PCB and hydrocarbon analysis, 203-211

Humic acid

adsorption isotherm, $372 \mathrm{f}$

adsorption of DPM from seawater by , $375-376$

carbon-13 NMR, $134 \mathrm{f}$

characteristics, 391-393

estuarine sediments

PCB and DDE distributions, 203

pentachlorophenol distributions, 211

saturated hydrocarbon distributions, 206

extraction, 143,391

solid state carbon-13 NMR studies, $145,147-149$

Humic substances

carbon-13 NMR spectra, $132 \mathrm{f}$

effects on plutonium speciation in marine systems, 382-387

extraction, 199

formation, 389

general discussion, 2-4

interaction with trace metal radionuclides, 389-410

relaxation data, $140 t$

Humin

comparison to humic acid, 154-155

definition, 149

estuarine sediments

capillary GC-ECD

chromatograms, 203-205

PCB and DDE distributions, 203

PCB homolog compositions, 205

pentachlorophenol distributions, 211

saturated hydrocarbon distributions, 206

solid state carbon-13 NMR studies, 149-154

In Organic Marine Geochemistry; Sohn, M.;

ACS Symposium Series; American Chemical Society: Washington, DC, 1986. 
Hydrocarbon(s)

carbonized coal, fate in a highly industrialized estuary, 215-227

Charlotte Harbor samples, 233-234

sediment concentrations in Lake

Pontchartrain, 258-259f

Hydrocarbon contamination from coastal development, 229-245

Hydrocarbon fractions

distribution in sediments, 22-24

extracts of Sarsina sediment, GC traces, 55-56f

Hydrocarbon indicators, anthropogenic, in sediments, 21-22

Hydrogen-1 NMR

analysis of aquatic humic

substances, $120,131 \mathrm{f}$

spectra of humic acid, $131 \mathrm{f}$

Hydrolytic species of iron, adsorption of humic substances, 408

Hydrous oxide solid-phase adsorbents, equilibration with a metal-ion adsorbate, 370

Hydroxyl radicals, reaction with methane, 310

Hypersaline depositional sedimentary environments, characteristics, $54 \mathrm{t}$

I

Ice coverage, effect on methane production in the southeastern Bering Sea, 293-294

Identifiable compounds, in sediment from Lake Pontchartrain, 258-259 f

Incubation, slurries of sediment, $334,335 \mathrm{f}$

Inorganic-organic interactions, general discussion, 5

Inorganic speciation scheme of copper(II), 361-362

Inorganic sulfur species, salt marshes, 352-353

Intensity systems, high complexation, chemical speciation, 358-368

Interannual variations of dissolved methane, 291-294

Ionic strength

DPM-humic acid system, effect on adsorption constant, 375-376

supporting medium, effect on adsorption constant, 370

Iron

concentrations in natural waters, 407-408

hydrolytic species, adsorption of humic substances, 408

Iron-55, interaction with humic substances, $397,399-403$
Isohalines, Lake Pontchartrain samples, $254,255 \mathrm{f}$

Isotope ratio mass spectrometer, methane isotopic analysis, 299-301

Isotopic analysis, to determine sources of organic matter in Georgia estuaries, 62-63

Isotopic composition, atmospheric methane, 308-310

\section{K}

Ketone-carboxylic acid fraction, distribution in sediments, $24,25 f$

L

Lake Pontchartrain description, 248

distribution of trace organics, heavy metals, and conventional pollutants, 247-269

Langmuir isotherm, determination of adsorption constant values, 370

Lead, sediment concentrations in Lake Pontchartrain, 266-267f

Lead-210, binding with humic substances, $394 \mathrm{f}$

Ligand(s), effect on adsorption constant values, 370

Ligand complexes, high-complexation intensity systems, 359-368

Lignin, definition, 3

Lignin parameters of Spartina alterniflora, comparison with those of an estuarine sediment sample, 73

Lipid(s)

Acushnet River estuary, 187,193

biomarkers, 159-160

biota, discrepancies and similarities 11-13

bound and unbound, purification, 92-94

cretaceous black shales, 94-95

definition, 159

discrimination by mode of occurrence, $48,49 \mathrm{r}$

estuarine sediments, $\mathrm{PCBs}$ and hydrocarbons, 198-211

fossil cuticle, total profile, $53 \mathrm{f}$

indicators for sources of input, microbial activity, and short-term diagenesis, 33-59

Mediterranean sapropel, 52-53

Lipopolysaccharide structure, schematic, $52 \mathrm{f}$

Lobster, Acushnet River estuary, PCBs, $179,180 f$

In Organic Marine Geochemistry; Sohn, M.;

ACS Symposium Series; American Chemical Society: Washington, DC, 1986. 
Loliolides, in sediments, 46,47f

Long-chain alkenones, as climatic indicators, $28,29 \mathrm{f}$

Los Angeles-Long Beach Harbor, PCB and hydrocarbon analysis, 203-211

\section{M}

Macroalgae surface material, possible role in the production of polybromomethanes, $320-321$

Manganese -54

distribution in $10 \%$ seawater and in estuarine water, $395 t$

interaction with humic substances, 393-397,398f

\section{Mangrove Lake}

humic acids from sediments, $147 f, 148$ humin from sediments, $150,151 \mathrm{f}$

Marine environment, organic pollutants, general discussion, 4

Marine geochemistry, organic, overview, 1-5

Marine sediments, distributions of marker compounds, 22-28

Marine systems, effects of humic substances on plutonium speciation, 382-387

Marines surface sediments, 113

Marker compounds, distributions in marine sediments, 22-28

Marl extract of Sarsina sediment, GC traces, $55-5 \overline{6 f}$

Marshes, salt, speciation of dissolved sulfur, 340-353

Mass spectral histograms

tetrapyrrole pigments, $110 \mathrm{f}$

vanadyl porphyrins, $112 \mathrm{f}$

Matanzas Pass, hydrocarbon contamination from coastal development, 232-245

2-Mercaptopropionate, in coastal marine sediments, 331

3-Mercaptopropionate, in coastal marine sediments, 324-338

Mesopheophorbides, 116,119,121f

Metabolism of chlorobiphenyls in various species, 194

Metal-ion adsorbate, equilibration with hydrous oxide solid-phase absorbents, 370

Metal-ion adsorption, effect of pH, 370

Metal-radionuclide zones, effect of humic substances on distribution, 405

Metal-speciation schemes, construction of models, 358-360

Metalloporphyrins, formation, 109

\section{Methane}

atmospher1c, 1sotop1c composition, 308-310

coastal waters, general discussion, 273

concentrations in the southeastern Bering Sea, $287 t$

dissolved in the southeastern Bering Sea

seasonal cycles, 272-294

seasonal distributions, 276-282

gas samples, preparation for 1sotopic analyses, $299,300 f$

model of formation, 301-302,305f

oxidation, 286,303-307

production, 282,286

Methanethiol, in coastal marine sediments, $324-338$

Methanogenesis, general discussion, 298

Methanogenic bacteria, 304

Methanogenic pathways, relative contributions, 303

Methanogenic substrates, alternate, importance, 302-303

Methionine degradation, role in production of thiols, 330

Methoxy phenols, possibly derived from lignin or higher plant material, proposed structures, $65,66 \mathrm{f}, 70-71$

Methoxy sugars, in sediments, 43-44

4-Methylsteroids, in sediments, 45

$4 \alpha-M e t h y l s t e r o l s$, link to dinoflagellates, 12

Microbial activity, sedimentary lipids and polysaccharides as indicators, 33-59

Microblal degradation, effect on chlorobiphenyl composition of Aroclors, 187

Microbial production of thiols, 330

Midchain ketones and sterol ethers, in sediments, $36,38 f, 39$

Mixed-function oxidase activity, effect on metabolism of biphenyls, 194

Mixed ligands

complexes, 359-360

formation constant, 359

stability constant, 363-367

Mode of occurrence of compounds, information content, 34-35

Models, metal speciation schemes, 358-360

Molecular geochemical indicators in sediments, 10-30

Molecular size distribution, humic substances, 392-393

Mussel, Acushnet River estuary

chlorobiphenyls, $184 t$

PCBs, $179,180 \mathrm{f}$

Mycosphaerella ascophylli, possible role in the production of polybromomethanes, 321

In Organic Marine Geochemistry; Sohn, M.;

ACS Symposium Series; American Chemical Society: Washington, DC, 1986. 
N

Natural systems, trace metal complexation, 360-363

Near-bottom distributions of dissolved methane in the southeastern Bering Sea, 278-285

New Bedford, Buzzard Bay, PCB and hydrocarion analys1s, 202-211

New York Bight humlc acids from sediments, $147 \mathrm{f}, 148-149$

humin from sediments, 150

NMR studies

aquatic humic substances, $128-140$

Intact sediments from the Peruvian Upwelling Zone, 165,167-171

sedimentary organ1c matter, 160-161

sediments from the Peruvian Upwelling Zone, 163

structural composition of humic substances, 142-156

Nonchlorinated hydrocarbons, analysis by GC-FID, 201

Nondiagnostic biological markers, in sediments, $13,14 \hat{1}$

Nutrient concentrations, Cape Cod Canal, seasonal variations, $316-318$

\section{0}

Octanol-water partition coefficients, chlorobiphenyls, 187,191-193

0il, fuel, fluorescence analysis, 223

Oil spill sample, GC analysis, $218,220 \mathrm{f}, 222$

Optical densities of UV spectra, humic substances, 391

Organic compounds dipolar dephasing behavior, 133 sedimentary, as information carriers, $37 \mathrm{f}$

Organic copper complexation, 362-363

Organic disulfides, polarography, 348,350

Organic geochemical data, North American basin cretaceous black shales, $94-95$

organic-inorganic interactions, general discussion, 5

Organic ligands, influence on copper(II) speciation in seawater, $362 t$

organic marine geochemistry, overview, 1-5

Organic matter

coastal water and sediments, determining the plant origins, 62-63

microbial decomposition to methane and carbon dioxide, 297-298
Organic matter--Continued

North American basin cretaceous black shales, origin, 91-104

transformations in aquatic sediments, 158

Organic pollutants in the marine environment, general discussion, 4

Organic substances

adsorption onto sediments, 370-371

effect on plutonium in the marine environment, 383

volatile, general discussion, 4-5

Organ1c sulfur species, salt marshes, 350-352

Organomercury compounds, adsorption from seawater on to sedimentary phases, 369-380

organometalics, commerclal and agricultural uses, $371 \mathrm{f}$

Overhauser effect, in solution NMR, 138

oxalic acid dissociation constants, 364

oxidase activity, mixed function, effect on metabolism of biphenyls, 194

Oxidation, methane, 286,303-307

oxidation reactions at the mercury electrode, sulfur species, $345 t$

oxidation states of plutonium, 383

oxydeoxomesopyropheophorbides, 119

Oxydeoxovinylphorbides, 119

Oxygen concentrations, Lake Pontchartrain samples, 251-254

Oysters, Charlotte Harbor

collection, 232

hydrocarbon analysis, 233

hydrocarbon patterns, 235-242

P

Packed-column gas chromatograms, PCBs, $181 \mathrm{f}$

Paraffinic structures

as components of humic acids, 145

as components of humin, 150

Particulate organic matter from sediments in the estuary of the Rhine and dump sites of dredging spoils, 76-89

Pathways, methanogenic, relative contributions, 303

Peace River, hydrocarbon contamination from coastal development, 232-245

Pentachlorophenol, in estuarine sediments, 207,210-211

Peruvian Upwelling Zone, organic carbon in sediments, early diagenesis, 158-171

Perylene, sediment concentrations in Lake Pontchartrain, 260-261f

Pesticides, organic, adsorption onto sediments, $370-371$

In Organic Marine Geochemistry; Sohn, M.;

ACS Symposium Series; American Chemical Society: Washington, DC, 1986. 
Petrogenic hydrocarbons, description, 243

Petroleum, description, 241,243

Petroleum hydrocarbon contamination from coastal development, 229-245

Petroleum sample, molecular nature of the aromatic hydrocarbon fraction, 243

$\mathrm{pH}$

effect on adsorption of organic substances, 371

effect on metal-ion absorption, 370

Phenanthrene, sediment concentrations in Lake Pontchartrain, 260-261

Phenolic and lignin pyrolysis products, in a Georgia estuary, 62-74

Phenolic and methoxy pyrolysis products, in a Georgia estuary, $69 f, 72-73$

Phenylmercuric acetate (PMA) calibration curves, $374 \mathrm{f}$

Phenylmercuric ion, adsorption from seawater, $377,379 f, 380$

Pheophorbides, in surface sediments, 113

Pheophytin, electronic absorption spectra, $118 \mathrm{f}$

Pheophytin-a, chromatograms, $118 \mathrm{f}$

Photic zone anoxia, 115

Phytoplankton cultures, $111,112 f$

Pigment (s), as a portion of total organic carbon, 115

Pigment yield index, definition, 115

Plant debris, as a source of atmospheric methane, 309

Plants, seston, and sediment in a Georgia estuary, phenolic and lignin pyrolysis products, 62-74

Plutonium

changes in oxidation states in seawater, 384-386

complexation by humic acid, 386

effects of humic substances on speciation in marine systems, $382-387$

preparation, 384

properties, 383

reduction in seawater, 386

sources and amounts in the environment, 382-383

Polarogram, glutathione, $344 \mathrm{f}$

Polarographic methods, to study speciation of dissolved sulfur in salt marshes, 340-353

Polarography organic disulfides, 348,350

salt marsh samples, 343-346

thiols, 346-348,349r

Pollutants, distribution in Lake Pontchartrain, 247-269
Polybromomethanes, release to seawater from two fucoid algae, 314-321

Polychlorinated biphenyls (PCBs) concentrations in the Acushnet River estuary, fluctuations, 193

distributions in estuarine sediments, 203

homolog compositions

free lipid fractions of estuarine sediments, 205

humin fractions of estuarine sediments, 205

lipid fractions of estuarine sediments, 198-211

mixtures environmental modification, 206

microbial activity modification, 206

packed-column gas chromatograms, $181 \mathrm{f}$ quantification, estuarine sediment, 201-202

sediment concentrations in Lake Ponchartrain, 262-263f

Polynuclear aromatic hydrocarbons (PAH) general discussion, 215

Lake Pontchartrain sediment, 247-269 marine environment, 226-227

uses, 243

Poly saccharides

alditolacetates obtained from solar Lake sediment, $44 \mathrm{f}$

indicators for sources of input, microbial activity, and short-term diagenesis, 33-59

substances like, as components of fulvic acids, 145

Polysulfides, generation, 352

Polyunsaturated methyl and ethyl ketones, in sediments, 41,43

Porewaters, identification of thiols, 326-329

Potomac River

humic acids, $147 f, 148-149$

humin, 150

Pressure data, southeastern Bering Sea, 274

Prist-1-ene, in sediments, 45-46, $47 \mathrm{f}$

Processes controlling the distribution of methane in the southeastern Bering Sea, 282,286-291

Pulse delays, effects on solution NMR, 135,138

Purpurin acid, generation, 120

Pyrite, as a starting material for thiol production, 351-352

Pyrolysis GC-photoionization-mass spectroscopy, particulate organic matter from sediments, $85-89$

Pyrolysis mass spectroscopy, chemical interpretation of data, $80-81$

In Organic Marine Geochemistry; Sohn, M.;

ACS Symposium Series; American Chemical Society: Washington, DC, 1986. 
Pyrolysis products, possibly derived from lignin or higher plant material, $65,66 f, 70-71$

\section{$Q$}

Quality assurance, hydrocarbon contamination studies, 234

Radionuclide zones, effect of humic substances on distribution, 405

Reconstructed mass spectra of pyrolysis mass spectral data, sediment samples, $83 f$

Reduction

disulfides to thiols, use of tributylphosphine, 334, $335 f$

plutonium in seawater, 386

Reduction reactions at the mercury electrode, sulfur species, $346 \mathrm{t}$

Relaxation data from humic materials, $140 \mathrm{t}$

Rhine estuary sediments, characterization of particulate organic matter, 76-89

\section{Salinity}

effect on adsorption constants, 370 Lake Pontchartrain samples, 251-254 southeastern Bering Sea, $276,277 \mathrm{f}, 287 \mathrm{t}$

Salt marshes, speciation of dissolved sulfur, 340-353

Sampled dc polarography, salt marsh samples, 343-346

Sampling

dissolved methane in the southeastern Bering Sea, 273

hydrocarbons in Charlotte Harbor, 232-233

$\mathrm{PAH}$ in Lake Pontchartrain, 248-250

particulate organic matter from sediments, $79-80$

PCBs in the Acushnet River estuary, 176-178

salt marshes, 343

sediments

Elizabeth River, 216-218

Peruvian Upwelling Zone, 161

Sanibel Island, hydrocarbon contamination from coastal development, 232-245

Saponified extracts, estuarine sediments, 199
Sapropel extract, electronic absorption spectra, $117 \mathrm{f}$

Sapropel from Mangrove Lake humic acids, $147 f, 148$ humin, 150,151

Saturated hydrocarbons, distributions in estuarine sediments, 206-209

Screening by automated pyrolysis mass spectroscopy, particulate organic matter from sediments, 80

Sea-to-air seasonal flux of methane, in the southeastern Bering Sea, 287-288

Seasonal cycles of dissolved methane, in the southeastern Bering Sea, 272-294

Seawater

changes in oxidation states of plutonium, $384-386$

organomercury compounds, adsorption

Sediment on to sedimentary phases, $369-380$

Acushnet River estuary, PCBs, $179,180 \mathrm{f}$

coastal marine, thiols, $324-338$

Elizabeth River

fluorescence analysis, 223

GC analysis, $218,221 \mathrm{f}, 222$

lipid fractions, PCB and hydrocarbon distributions, 198-211

marine, distributions of marker compounds, $22-28$

molecular geochemical indicators, 10-30

Peruvian Upwelling Zone analysis of chlorophyll derivatives, 111,113 early diagenesis of carbon, 158-171

Sedimentary chlorophyll derivatives, 113

Sedimentary lipids and polysaccharides, as indicators for sources of input, microbial activity, and short-term diagenesis, 33-59

Sedimentary organic compounds cretaceous black shales, provenance, 95-96

information carriers, $37 f$

Sedimentary phases, adsorption of organomercury compounds from seawater, 369-380

Sedimentary reactions of sterols, $162 \mathrm{f}$

Selective extraction

determination of PCBs and hydrocarbons, 198-211

flow diagram, $200 \mathrm{f}$

Shrimp, PCB concentrations, 194

Signal intensities

carbon-13 NMR spectroscopy, 133

various carbons, effect of dipolar dephasing, $137 \mathrm{f}$

In Organic Marine Geochemistry; Sohn, M.;

ACS Symposium Series; American Chemical Society: Washington, DC, 1986. 
Sinks of atmospheric methane, 308-309

Slurries of sediment

incubation, $334,335 \mathrm{f}$

thiols identified in, $328 \mathrm{t}$

Solar Lake sediment, alditolacetates GC trace, $44 \mathrm{f}$ polysaccharide analysis, $44 \mathrm{f}$

Solid phase concentration, effect on adsorption constant values, 370

Solid state carbon-13 NMR

humic substances, 143-156

sediments from the Peruvian Upwelling Zone, 158-171

Solid state NMR, humic substances, 138-140

Solution NMR

humic substances, 135,138

versus solid state NMR, 129-130

Sorption, effect on chlorobiphenyl composition of Aroclors, 187

Southeastern Bering Sea

location, $274-276$

seasonal cycles of dissolved methane, 272-294

Spartina

as a contributor of higher plant carbon to marsh creek-bank sediment, $71-72$

isotopic analysis, 62-63

Spartina alterniflora, lignin parameters, 73

Speciation, chemical

dissolved sulfur in salt marshes, 340,353

high-complexation intensity systems, $358-368$

inorganic, of copper(II), 361-362

Spin-lattice relaxation times, carbon in organic substances, 135,138

Spin-spin relaxation times, carbon in organic substances, 135,138

St. George Basin, seasonal cycles of dissolved methane, 272-294

stability, of plutonium, 384

Stability constants

copper(II) glycine, 366

copper(II) oxalate, 366

formation of a ternary complex, 359

mixed ligand, 363-367

Stable isotopic compositions

carbon of methane and carbon dioxide, 298

hydrogen of methane and water, 298

Stagnant-film boundary layer model, to quantify the transfer flux of methane to the atmosphere, 286

Stanols, definition, 165

Stenols, definition, 165

Sterols

distributions in sediments, $24,26-28$
Sterols--Continued

distributions in surface sediments of the Peruvian coast, $161,163-165$

general discussion, 160

isolated from Black Sea sediment extracts, GC traces, $40 \mathrm{f}$

Stratification, in the St. George basin, 287

Structural analysis of aquatic humic substances by NMR spectroscopy, 128-140

Structural interrelationships among humic substances in marine and estuarine sediments, 142-156

Structures of compounds, information content, 34

Substrates of methane, alternate, importance, 302-303

Sulfur

analytical scheme, 343-345

biogeochemical cycling, role of thiols, $324-338$

marine porewaters, techniques to measure, 341

partially oxidized forms, 341

salt marshes, speciation, 340-353

Sulfur species

organic, in salt marshes, 350-352

oxidation reactions at the mercury electrode, $345 t$

polarographic data, $347 \mathrm{t}$

salt marsh porewaters, methods to give a complete speciation, 342

Surface concentrations of dissolved methane in the southeastern Bering Sea, 276,278-285

Surface sediment, Charlotte Harbor collection, 232

hydrocarbon analysis, 233

hydrocarbon patterns, 235-242

Suspended humic acid concentration, effect on adsorption constants for DPM on to humic acid, $376 t$

Synedra sp. extracts, electronic absorption spectra, $117 \mathrm{f}$

$\mathrm{T}$

Tandem mass spectroscopy, particulate organic matter from sediments, $81,84 f, 85$

Temperature effect on methane production in the southeastern Bering Sea, 293-294 seasonal variations in the Cape Cod Canal, 316-318

southeastern Bering Sea, 274-277,287t

In Organic Marine Geochemistry; Sohn, M.;

ACS Symposium Series; American Chemical Society: Washington, DC, 1986. 
Terminal Island sewage outfall, PCB and hydrocarbon analysis, 203-211

Ternary and higher order mixed complexes, formation, 359-360

Terrigenous indicators, in sediments, $16-18$

Tetrapyrrole characteristic of early diagenesis, 116

Tetrapyrrole diagenetic continuum, 109

Tetrapyrrole pigments

mass spectral histograms, $110 \mathrm{f}$

structures, $110 \mathrm{f}$

Thiols

abiotic production, 331-334

biochemical role, 325

bound, release, $334-336$

coastal marine sediments, 324-338

formation, 351

identification in marine sediment porewaters, 326-329

microbial production, 330

polarography, $346-348,349 \mathrm{f}$ sources, 325

Tocopherols as precursors for pristene and pristane, $47 \mathrm{f}$

Total ion current trace, TLC fraction of Namibian Shelf diatomaceous ooze sediment extract, $38 \mathrm{f}$

Total lipid data, North America basin cretaceous black shales, 94-95

Total organic carbon, North America basin cretaceous black shales, 94-95

Total profiles of compounds, information content, 35

Trace metal complexation in natural systems, $360-363$

Trace metal concentrations of humic substances, $393 \mathrm{t}$

Trace metal radionuclides, interaction with humic substances, 389-410

Trace organics, distribution in Lake Pontchartrain, 247-269

Transfer flux of methane to the atmosphere, stagnant-film boundary layer model, 286

Transport of methane, in the southeastern Bering Sea, 288,290t

Tribromomethane, release to seawater from fucoid algae, $316,318 \mathrm{f}$
Tributylphosphine, reduction of disulfides to thiols, $334,335 \mathrm{f}$

\section{U}

Unknown indicators, in sediments, 19-21 Upper Cretaceous, description, 91-92 Uptake and metabolism of Aroclors by marine biota, effect on chlorobiphenyl composition, 187

\section{V}

Vanadyl porphyrins, mass spectral histogram, $112 f$

Vertical and horizontal distributions of dissolved methane in the southeastern Bering Sea, 276

Vinyl moiety of chlorophyll derivatives, 120

Volatile organic substances, general discussion, 4-5

Volatilization, effect on chlorobiphenyl composition of Aroclors, 184

W

Walvis Bay

humic acids, $147 f, 149$

humin, 150

Water samples, Charlotte Harbor collection, 232

hydrocarbon analysis, 233-234

hydrocarbon patterns, 235-242

$\mathrm{X}$

Xenobiotics, effect on mixed-function oxidase activity, 194

Z

2inc-65, binding with humic substances, $394 \mathrm{f}$

In Organic Marine Geochemistry; Sohn, M.;

ACS Symposium Series; American Chemical Society: Washington, DC, 1986. 